\title{
Interoperability
}

\section{Capability to interoperate in a shared work practice using information infrastructures - studies in ePrescribing}

\author{
Sten-Erik Öhlund
}

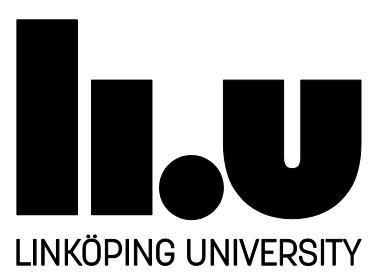

Linköping Studies in the Arts and Science No. 711

Faculty of Arts and Sciences

Linköping 2017 
Linköping Studies in the Arts and Science, Dissertation No. 711

At the Faculty of Arts and Science at Linköping University, research and doctoral studies are carried out within broad problem areas. Research is organized in interdisciplinary research environments and doctoral studies mainly in graduate schools. Jointly, they publish the series Linköping Studies in Arts and Science. This thesis comes from the Information Systems division at the Department of Management and Engineering.

Distributed by:

Department of Management and Engineering

Linköping University

SE - 58183 Linköping

Sweden

Sten-Erik Öhlund

Interoperability

Capability to interoperate in a shared work practice using information infrastructures - studies in ePrescribing

Edition: $1: 1$

ISBN: 978-91-7685-565-2

ISSN: 0282-9800

๑)Sten-Erik Öhlund, 2017

Front page cover painting: 'Optimisten' by Thomas Öhlund 2015

Photo reproduction of painting: Robert Bjervås

Back page cover photo, sailing @ekenäs: Sten-Erik Öhlund

Department of Management and Engineering

Information Systems Division

Printed by: LiU-Tryck 
"Just one more thing"

Columbo 


\section{Abstract}

The ability to interoperate between systems, people, and organizations is considered an important issue within eHealth in order to deliver patient centered care. The achieving and improving of interoperability is a complex undertaking involving the evolution of an information infrastructure, sharing of knowledge and resources, governance of the interoperation between organizations, people and work practices, and handling of economic and legal matters. However, there is a weak scientific basis for interoperability, and proposed initiatives to improve interoperability largely lacks empirical evidence of their utility.

This thesis contributes with practical knowledge on improving interoperability, based on active participation in and empirical studies of improving interoperability in ePrescribing. A case study is presented that describes and analyzes the evolution of ePrescribing in Sweden since the early pioneering years in 1980s, its growth and consolidation before the reregulation of the pharmacy market in 2009. The case study shows the importance of cooperation between the stakeholders for the growth and consolidation of ePrescribing, and identifies important events in the evolution of an advanced information infrastructure. To better understand the complexity of ePrescribing work practice, a practical theory on ePrescribing was developed. A unique field experimental study measuring improvement of interoperability in ePrescribing, before and after a major intervention to improve the quality of ePrescriptions between 2004 and 2009 is presented. The findings from the field experimental study showed that collective efforts to clarify and align the shared ePrescribing work practice and the ePrescription message contributed to substantially improve interoperability in ePrescribing.

Based on the findings and knowledge gathered in the situational inquiry into the evolution of ePrescribing in Sweden, the improvement of interoperability, and the application of theories about information systems actability, communication and organizational theories, a practical theory on interoperation and interoperability aiming both towards the practice and research community is presented. Interoperability is seen as the exercised capability of organizations through their agents to interoperate in a shared work practice in an effective, efficient, and satisfactory manner based on a common ground in a mediated, prescriptive, and nonpersonal communicative setting using an information infrastructure for mediating interoperation. The plausibility that the theory of interoperation and interoperability grounded in ePrescribing is generalizable to eHealth is analyzed. 


\section{Foreword}

Information Systems Development (ISD) is a research discipline within the Faculty of Arts and Sciences at Linköping University (LiU), Linköping Sweden. ISD is a discipline studying human work with developing and changing different kinds of IT systems in organizational and societal settings. The research discipline includes theories, strategies and policies, models, methods, co-working principles and artefacts related to information systems development. Different development/change situations can be studied as planning, governance, analysis, specification, design, implementation, deployment, evaluation, maintenance and redesign of information systems and its interplay with other forms of business development, processes of digitalization and innovation. The discipline also includes the study of prerequisites for and results from information systems development, as e.g. institutional settings, studies of usage and consequences of information systems.

The ISD research at $\mathrm{LiU}$ is conducted in collaboration with both private companies and public organizations. Collaboration also includes national and international research partners in the information systems research field. The research has a clear ambition to give distinct theoretical contributions within the information systems research field. Simultaneously, the research aims to contribute with practically needed and useful knowledge.

This work, Interoperability. Capability to interoperate in a shared work practice using information infrastructures - studies in ePrescribing, is written by Sten-Erik Öhlund, CGI and associated to Research Group VITS at Linköping University and eHealth Institute at Linnaeus University. He presents this work as his $\mathrm{PhD}$ dissertation in Information Systems Development, Information Systems Division, Department of Management and Engineering, Linköping University, Sweden.

Linköping, January, 2017

$\begin{array}{lll}\text { Göran Goldkuhl } & \text { Karin Axelsson } & \text { Ulf Melin } \\ \text { Professor emeritus } & \text { Professor } & \text { Associate Professor }\end{array}$




\section{Doctoral dissertations in information systems development}

1. Karin Axelsson (1998) Metodisk systemstrukturering - att skapa samstämmighet mellan informationssystemarkitektur och verksamhet

2. Stefan Cronholm (1998) Metodverktyg och användbarhet - en studie av datorstödd metodbaserad systemutveckling

3. Anders Avdic (1999) Användare och utvecklare - om anveckling med kalkylprogram

4. Owen Eriksson (2000) Kommunikationskvalitet hos informationssystem och affärsprocesser

5. Mikael Lind (2001) Från system till process - kriterier för processbestämning vid verksamhetsanalys

6. Ulf Melin (2002) Koordination och informationssystem i företag och nätverk

7. Pär J. Ågerfalk (2003) Information Systems Actability: Understanding Information Technology as a Tool for Business Action and Communication

8. Ulf Seigerroth (2003) Att förstå och förändra systemutvecklingsverksamheter - en taxonomi för metautveckling

9. Karin Hedström (2004) Spår av datoriseringens värden - effekter av IT i äldreomsorg

10. Ewa Braf (2004) Knowledge Demanded for Action - Studies of Knowledge Mediation in Organisations

11. Fredrik Karlsson (2005) Method Configuration - method and computerized tool support

12. Malin Nordström (2005) Styrbar systemförvaltning - Att organisera systemförvaltningsverksamhet med hjälp av effektiva förvaltningsobjekt

13. Stefan Holgersson (2005) Yrke: Polis - yrkeskunskaper, motivation, ITsystem och andra förutsättningar för polisarbete

14. Marie-Therese Christiansson \& Benneth Christiansson (2006) Mötet mellan process och komponent - mot ett ramverk för en verksamhetsnära kravspecifikation vid anskaffning av komponentbaserade informationssystem

15. Britt-Marie Johansson (2007) Kundkommunikation vid distanshandel. En studie om kommunikationsmediers möjligheter och hinder

16. Göran Hultgren (2007) eTjänster som social interaktion via användning av ITsystem - en praktisk teori

17. Björn Johansson (2007) Deciding on Sourcing Option for Hosting of Software Applications in Organisations

18. Per Oscarson (2007) Actual and perceived information systems security 
19. Hanna Broberg (2009) DEVIS: Design av verksamhetsstödjande IT-system - En designteori och metod

20. Anders Hjalmarsson (2009) Behovet av struktur och frihet - en avhandling om situationsanpassad facilitering vid samarbetsinriktad modellering

21. Jenny Lagsten (2009) Utvärdera informationssystem - Pragmatiskt perspektiv och metod

22. Ida Lindgren (2013) Public e-Service Stakeholders - On who matters for public e-service development and implementation

23. Malin Granath (2016) The Smart City - how smart can 'IT' be? Discourses on digitalisation in policy and planning of urban development

24. Fredrik Söderström (2016) Introducing public sector eIDs - the power of actors' translations and institutional barriers

25. Sten-Erik Öhlund (2017) Interoperability. Capability to interoperate in a shared work practice using information infrastructures - studies in ePrescribing

\section{Licentiate theses in information systems development}

1. Owen Eriksson (1994) Informationssystem med verksamhetskvalitet utvärdering baserat på ett verksamhetsinriktat och samskapande synsätt

2. Karin Pettersson (1994) Informationssystemstrukturering, ansvarsfördelning och användarinflytande - en komparativ studie med utgångspunkt i två informationssystemstrategier

3. Stefan Cronholm (1994) Varför CASE-verktyg i systemutveckling? - En motiv- och konsekvensstudie avseende arbetssätt och arbetsformer

4. Anders Avdic (1995) Arbetsintegrerad systemutveckling med kalkylprogram

5. Dan Fristedt (1995) Metoder i användning - mot förbättring av systemutveckling genom situationell metodkunskap och metodanalys

6. Malin Bergvall (1995) Systemförvaltning i praktiken - en kvalitativ studie avseende centrala begrepp, aktiviteter och ansvarsroller

7. Mikael Lind (1996) Affärsprocessinriktad förändringsanalys - utveckling och tillämpning av synsätt och metod

8. Carita Åbom (1997) Videomötesteknik i olika affärssituationer - möjligheter och hinder

9. Tommy Wedlund (1997) Att skapa en företagsanpassad systemutvecklingsmodell - genom rekonstruktion, värdering och vidareutveckling i T50-bolag inom $\mathrm{ABB}$

10. Boris Karlsson (1997) Metodanalys för förståelse och utveckling av systemutvecklingsverksamhet - analys och värdering av systemutvecklingsmodeller och dess användning 
11. Ulf Melin (1998) Informationssystem vid ökad affärs- och processorientering - egenskaper, strategier och utveckling

12. Marie-Therese Christiansson (1998) Inter-organisatorisk verksamhetsutveckling - metoder som stöd vid utveckling av partnerskap och informationssystem

13. Fredrik Öberg (1998) Object-oriented frameworks - a new strategy for CASE tool development

14. Ulf Seigerroth (1998) Integration av förändringsmetoder - en modell för välgrundad metodintegration

15. Bengt EW Andersson (1999) Samverkande informationssystem mellan aktörer i offentliga åtaganden - en teori om aktörsarenor i samverkan om utbyte av information

16. Pär J. Ågerfalk (1999) Pragmatization of information systems - a theoretical and methodological outline

17. Karin Hedström (2000) Kunskapsanvändning och kunskapsutveckling hos verksamhetskonsulter - erfarenheter från ett FoU-samarbete

18. Göran Hultgren (2000) Nätverksinriktad förändringsanalys - perspektiv och metoder som stöd för förståelse och utveckling av affärsrelationer och informationssystem

19. Ewa Braf (2000) Organisationers kunskapsverksamheter - en kritisk studie av "knowledge management"

20. Henrik Lindberg (2000) Webbaserade affärsprocesser - möjligheter och begränsningar

21. Benneth Christiansson (2000) Att komponentbasera informationssystem - Vad säger teori och praktik?

22. Per-Arne Segerkvist (2001) Webbaserade imaginära organisationers samverkansformer - Informationssystemarkitektur och aktörssamverkan som förutsättningar för affärsprocesser

23. Stefan Holgersson (2001) IT-system och filtrering av verksamhetskunskap kvalitetsproblem vid analyser och beslutsfattande som bygger på uppgifter hämtade från polisens IT-system

24. Per Oscarson (2001) Informationssäkerhet i verksamheter - begrepp och modeller som stöd för förståelse av informationssäkerhet och dess hantering i verksamheter

25. Johan Petersson (2002) Lokala elektroniska marknadsplatser informationssystem för platsbundna affärer

26. Fredrik Karlsson (2002) Meta-method for Method Configuration - A Rational Unified Process Case

27. Lennart Ljung (2003) Utveckling av en projektivitetsmodell - om organisationers förmåga att tillämpa projektarbetsformen 
28. Britt-Marie Johansson (2003) Kundkommunikation på distans - en studie om kommunikationsmediets betydelse $\mathrm{i}$ affärstransaktioner

29. Fredrik Ericsson (2003) Information Technology for Learning and Acquiring Work Knowledge among Production Workers

30. Emma Eliason (2003) Effektanalys av IT-systems handlingsutrymme

31. Anders Hjalmarsson (2004) Att etablera och vidmakthålla förbättringsverksamhet. Behovet av koordination och interaktion vid förändring av systemutvecklingsverksamheter

32. Björn Johansson (2004) Deciding on Using Application Service Provision in SMEs

33. Ulf Larsson (2004) Designarbete i dialog - karaktärisering av interaktionen mellan användare och utvecklare i en systemutvecklingsprocess

34. Anders Forsman (2005) Standardisering som grund för informationssamverkan och IT-tjänster - En fallstudie baserad på trafikinformationstjänsten RDS-TMC

35. Jenny Lagsten (2005) Verksamhetsutvecklande utvärdering i informationssystemprojekt

36. Jan Olausson (2005) Att modellera uppdrag - grunder för förståelse av processinriktade informationssystem i transaktionsintensiva verksamheter

37. Amra Halilovic (2006) Ett praktikperspektiv på hantering av mjukvarukomponenter

38. Hanna Broberg (2006) Verksamhetsanpassade IT-stöd - designteori och metod

39. Sandra Haraldson (2008) Designprinciper för handlingskvalitet i samverkan ett multiorganisatoriskt perspektiv på tredjepartslogistik

40. Jonas Sjöström (2008) Making Sense of the IT artefact - A socio-pragmatic inquiry into IS use qualities

41. Anders Persson (2009) Förutsättningar för sammanhållen kommunal eFörvaltning

42. Ann-Margreth Hammar (2011) Från projektorganisation till förvaltningsorganisation - en studie av överlämningsarenan

43. Eva Karlsson (2012) Systemutveckling för riskbaserad tillsyn - Hur verksamhetsanalys på praktikteoretisk grund kan användas för kravfångst

44. Hannes Göbel (2014) IT Service Management - Designprinciper för informationssystemsartefakter

45. Kayvan Yousefi Mojir (2016) New Forms of Collaboration in Emergency Response Systems: A framework for participatory design of information systems 


\section{Acknowledgements}

One lecture at Stockholm University in the 1990s, on my way to complete my licentiate degree, has a special place in my memory. It was a lecture aimed at us poor doctoral students. Held by a scientist specializing in formal logic, the subject of the lecture was contradictory or at least surprising. It was about the alchemist's experience of the research process. The message was that even though the alchemist was doomed to fail they never gave up and thus gained a deep knowledge of the difficulties in the research process that is valuable for any research student of today. A somewhat similar analogy is a famous theoretician in the art of acting when he explained why he was driven to reflect on acting in general. He explained that it was because he suffered from stage fright that he needed to cope and compensate for this stage fright. His method was to wonder what it was all about to be on stage and act. From this, he developed his famous theory of acting.

One lesson learned from the two examples is that a situation or a practice that is problematic will foster problem solving and new ideas.

I have had the luxury to be a practitioner deeply embedded in problematic situations, always reflecting on what was good and what was bad. The real privilege is to be able to have time to report and reflect on these situations and propose actions to improve them. I know there are many practitioners that have good suggestions and ideas but never get the opportunity to reflect and propose suggestions on how to improve a situation. Thus, I very much appreciate being able to do this based on my own experience and contribute to improving a problematic situation.

In completing this work, I would like to acknowledge those people and organizations that have made this possible. In the role as consultant, the focus is on customer's immediate needs, but there is always time for reflection about the work either directly or afterwards. To be a reflective practitioner has always been my approach in my work experience in the IT sector. I have always had one foot in research and the other foot in practical work. It was this mixture of theoretical and practical aspects of information systems that attracted me to work in the IT-sector.

Research is a long-term engagement and cannot rely on occasional reflections as a practitioner. It has to be based on a long-term commitment. Two factors made this thesis possible. One was that I had the opportunity to be engaged in an interesting journey of implementing ePrescribing in Sweden, as a consultant at the National Pharmacy Cooperation. Gunnel Bridell, the project manager for implementing ePrescribing in Sweden on the part of National Pharmacy Cooperation (NPC), and Bengt Åstrand, head of new eServices at NPC, gave me many challenging and interesting commitments during the 2000s. Bengt Åstrand, pioneer in Sweden in 
introducing ePrescribing, was a very important source of inspiration for the work in this thesis.

The National Pharmacy Corporation (Apoteket AB), CGI, the eHealth Institute at Linnaeus University and Linköping University have funded this research in different phases.

I thank especially the efforts of Bengt Åstrand (at that time at NPC), Jörgen Lindeborg (CGI), and Göran Petersson (eHealth Institute at Linnaeus University) who made this research possible.

Without my colleagues, with whom I have had many discussions and reflections in the different projects around ePrescribing, at NPC, the eHealth Agency, the eHealth Institute, the regional county councils of Stockholm, Gothenburg, Malmö, Västernorrland, Kronoberg, Blekinge and Kalmar, and at CGI, this work would not have been possible.

I would also like to thank researchers at the division of information systems at the Department of Management and Engineering at Linköping University for inspiration and opportunities to present experiences and ideas for discussion at seminars.

Many thanks to my supervisor, Göran Goldkuhl and my co-supervisors Owen Eriksson and Göran Petersson: Göran Goldkuhl for his vast knowledge, and his role both as a theoretical inspirer and "dissector"; He and Owen have been my Occam's razor, forcing me to sharpen my theoretical concepts; Owen Eriksson for his constant and never ebbing enthusiasm spanning many years about the subject matter, inspiring in me new lines of thought and helping me to structure and present the most essential, and not the least I would like to thank him for encouraging me to be more stringent in formulating the central concept of the theory. Göran Petersson, has my gratitude for his engagement and knowledge about eHealth and for giving me inspiration and support.

I also thank the support and encouragement of my wife, who has often had to cope with an absent-minded husband staring out into space, thinking of something that has to be written and changed in the thesis. From now on, there will be no turning back, no changes and no regrets; but I will still be staring into the sky now and then.

Finally, I dedicate this thesis to my parents. Both of them did well in school. However, at that time, their parents could not afford their further education, paying for proper clothes and books. Very early in their youth they contributed to the family income. 


\section{Content}

1 Introduction 1

1.1 Interoperability 1

1.2 Research problem 2

1.3 Knowledge gap 3

1.4 Research aim 5

1.5 Outline of thesis 6

2 Interoperability, information infrastructures, work practices, and standards 9

2.1 Interoperability concepts and frameworks 9

$\begin{array}{ll}2.1 .1 & \text { Interoperability in the military domain and public safety }\end{array}$

$\begin{array}{ll}\text { 2.1.2 Interoperability in computer and engineering sciences } & 11\end{array}$

\begin{tabular}{ll}
2.1 .3 & Interoperability in public services \\
\hline
\end{tabular}

$\begin{array}{ll}2.1 .4 & \text { Enterprise interoperability } 13\end{array}$

$\begin{array}{ll}2.1 .5 & \text { Interoperability in eHealth } \\ 14\end{array}$

$\begin{array}{ll}\text { 2.1.6 Interoperability and related concepts } & 16\end{array}$

$\begin{array}{lll}\text { 2.1.7 Designed and ad-hoc interoperability } & 17\end{array}$

$\begin{array}{lll}2.1 .8 & \text { From technical to a broader view on interoperability } & 17\end{array}$

2.2 Information infrastructure and interoperability 20

$\begin{array}{lll}2.2 .1 & \text { Classification of information infrastructures } & 20\end{array}$

2.2.2 Work practices, information systems, and information infrastructures 21

$\begin{array}{lll}2.2 .3 & \text { Features of information infrastructures } & 27\end{array}$

2.2.4 Evolution and design of information infrastructure 30

2.3 Standards and interoperability 34

2.3.1 Horizontal and vertical standard $\quad 35$

2.3.2 Predefined and emerging standards 36

2.3.3 Vertical standards for business processes, reflexive standardization, and standardized vocabularies $\quad 37$

2.4 Summary and conclusion 46 
3 Methods of inquiry 51

3.1 Insider research 52

3.2 Access, pre-understanding, and roles in relation to ePrescribing 55

3.2.1 Consultant with a research background 55

3.2.2 Researcher and consultant 57

3.2.3 Reflections on access, pre-understanding, and understanding as an inside researcher $\quad 58$

3.3 Research approach 59

3.3.1 Relation between action and practice research 59

$\begin{array}{lll}3.3 .2 & \text { Practice research } & 63\end{array}$

3.3.3 Practical theory 66

3.4 Grounding, warranted assertability, reliability, validity,
and evaluation of research

3.4.1 Grounding and warranted assertability 68

3.4.2 Reliability, validity, and evaluation of research 69

$\begin{array}{ll}\text { 3.4.3 Data generation in practice research } & 73\end{array}$

3.5 Generalizability in information systems and qualitative research $\quad 74$

3.6 Development of research interest, activities and results 79

3.6.1 Evolution of initial research interest in ePrescribing 81

3.6.2 Design and conduction of the field experimental study (NEF) 82

3.6.3 Analyzing the context of the ePrescribing process 83

3.6.4 Analyzing findings in the field experimental study NEF 84

3.6.5 Analysis of the context of improvement of interoperability and evolution of ePrescribing in Sweden $\quad 85$

3.6.6 Developing a theory on interoperation and interoperability 86

3.7 Practice research in interoperability and ePrescribing 88

3.7.1 Overview of research and contributions 88

3.7.2 Sources of evidence, data collection, literature reviews, and data analysis 91

3.7.3 Contributions and theory components 96

4 Implementing ePrescribing in Sweden - case study 101

$\begin{array}{lll}4.1 & \text { Research method } & 102\end{array}$

$\begin{array}{lll}\text { 4.1.1 Data collection and analysis } & 102\end{array}$

$\begin{array}{ll}4.2 & \text { Structure of the case study report } \\ & 103\end{array}$

$\begin{array}{ll}4.3 \text { Early pioneering phase } & 104\end{array}$

4.4 Evolution of an information infrastructure for ePrescribing 105 
4.5 The use of standards

4.6 Infrastructure for communication - from point-to-point to national repository of prescriptions

4.7 Institutional objects in ePrescribing

$\begin{array}{ll}\text { 4.7.1 Identifying prescribed medical drugs } & 115\end{array}$

$\begin{array}{ll}\text { 4.7.2 Identifying stakeholders in prescribing } & 117\end{array}$

4.8 The implementation process of ePrescribing 119

$\begin{array}{lll}\text { 4.8.1 From early experience to strategic initiatives } & 120\end{array}$

$\begin{array}{lll}\text { 4.8.2 From initial growth to consolidation } & 123\end{array}$

4.9 Economic, legal, and organizational issues

in implementing ePrescribing $\quad 126$

$\begin{array}{lll}4.9 .1 & \text { Economic challenges } & 126\end{array}$

$\begin{array}{lll}4.9 .2 & \text { Legal aspects } & 127\end{array}$

$\begin{array}{lll}4.9 .3 & \text { Organizational challenges } & 129\end{array}$

4.10 Success factors in the implementation process 129

4.11 Conclusion 131

5 Improving interoperability in ePrescribing - a field study 133

$\begin{array}{lll}5.1 \text { Background } & 135\end{array}$

5.1.1 The need to improve the quality of communication 135

$\begin{array}{ll}\text { 5.1.2 Stakeholders in ePrescribing } & 138\end{array}$

5.1.3 The ePrescribing process 139

5.2 Intervention - the combined efforts to design and implement NEF 139

5.2.1 Joint project to design a new ePrescription format 140

5.2.2 Joint project and coordination to implement a new
ePrescription format in ePrescribing

$\begin{array}{lll}\text { 5.2.3 'On-line' validation of ePrescription } & 141\end{array}$

$\begin{array}{lll}\text { 5.2.4 Enhanced test and approval process } & 141\end{array}$

$\begin{array}{ll}\text { 5.2.5 Managing interoperability errors } & 142\end{array}$

5.2.6 Common maintenance of the ePrescription process and format 142

5.3 Design of a new National ePrescription Format (NEF) 142

5.3.1 Pre-NEF existing standards and specifications 143

5.3.2 Clarification of ePrescription concepts 145

$\begin{array}{ll}\text { 5.3.3 Documentation and design considerations } & 149\end{array}$

5.4 Objective, research questions, and methods in
the field experimental study

$\begin{array}{lll}5.4 .1 & \text { Objective } & 159\end{array}$ 
$\begin{array}{lll}\text { 5.4.3 Methods } & 159\end{array}$

5.5 Design of measurement and data collection

5.5.1 Collection of data and development of a procedure for validating ePrescriptions

5.5.2 Definition of interoperability errors

5.5.3 Estimation of sample size

5.5.4 Sampling method

5.6 Analysis of interoperability problems in the ePrescription communication

5.7 Format and prescription rule errors

5.8 Findings in the field experimental study

5.8.1 Sampled prescriptions

$\begin{array}{lll}\text { 5.8.2 } & \text { Errors per prescription and prescription set } & 167\end{array}$

$\begin{array}{lll}5.8 .3 & \text { Format errors } & 169\end{array}$

$\begin{array}{lll}5.8 .4 & \text { Prescription rule errors } & 170\end{array}$

$\begin{array}{lll}\text { 5.8.5 Distribution of errors per prescribing system } & 171\end{array}$

$\begin{array}{lll}\text { 5.8.6 Duplicate prescriptions } & 172\end{array}$

$\begin{array}{ll}5.9 \text { Analyzing and situating the findings } & 173\end{array}$

5.9.1 ePrescribing and information systems actability theory 174

5.9.2 Stakeholders involvement and shared information services 179

$\begin{array}{ll}\text { 5.9.3 Interoperability levels to analyze interoperability errors } & 181\end{array}$

5.9.4 The characteristics of the joint intervention to implement NEF 185

5.9.5 Implementing the NEF - part of implementing ePrescribing information $\begin{array}{ll}\text { infrastructure } & 187\end{array}$

$\begin{array}{ll}5.10 \text { Conclusion } & 189\end{array}$

6 A practical theory on ePrescribing 191

6.1 Complexity of communication between organizations $\begin{array}{ll}\text { using information systems } & 191\end{array}$

6.2 ePrescribing-background 192

6.3 Research method 193

6.4 Analysis of ePrescribing work practice 194

6.4.1 The Generic Exchange Model 194

6.4.2 The Generic Regulation Model 195

6.4.3 Initial definition of ePrescription and ePrescribing 196

6.4.4 Health care market - the prescriber - patient exchange 201 
6.4.5 Pharmacy market - the pharmacy customer exchange 204

6.4.6 Model of exchange in ePrescribing - a regulatory perspective 205

6.5 Socio-pragmatic communication analysis of ePrescribing 206

6.5.1 Analysis framework: a socio-pragmatic $\begin{array}{ll}\text { conceptualization of communication } & 207\end{array}$

6.5.2 Analysis of ePrescription communication situations 208

6.5.3 Analysis of the prescriber - patient communication 209

6.5.4 Analysis of the Customer - Pharmacist Communication 212

6.6 Application of practical theories and elements of a $\begin{array}{ll}\text { practical theory on ePrescribing } & 215\end{array}$

6.6.1 Utility of practical theories analyzing ePrescribing 216

$\begin{array}{ll}\text { 6.6.2 Elements of a practical theory on ePrescribing } & 217\end{array}$

$\begin{array}{lll}6.6 .3 \text { Conclusion } & 224\end{array}$

7 Context of interoperation and interoperability 225

7.1 Interoperation and interoperability - initial analysis 227

7.2 Information systems and information infrastructure 228

7.3 Theories of meaning and views on interoperation and interoperability 231

7.3.1 Approaches to theories on meaning 232

7.3.2 What is intended, said and its use - summing up on perspectives on meaning $\quad 240$

7.3.3 Meaning theories and their implications on interoperability 242

7.4 Messages in the context of interoperation 244

7.4.1 Messages and information systems - and overview 245

7.4.2 Information is not contained in the messages or data 245

7.4.3 Communicating messages is also action and institutional facts 247

7.5 Communication and coordination in a work practice 248

7.5.1 Coordination through communication acts 248

7.5.2 Coordination and coordination mechanisms in a work practice 248

7.5.3 Communication acts and coordination mechanism 250

7.6 Common ground for interoperation 250

7.7 Communication acts and common ground 253

7.8 Communication settings for interoperation 255

$\begin{array}{lll}\text { 7.8.1 Basic settings of communication } & 255\end{array}$

7.8.2 Interoperation in a mediated, non-personal, prescriptive setting 256

7.9 Actability of information systems for interoperation and communication quality 
$\begin{array}{lll}\text { 7.9.2 Communication quality } & 261\end{array}$

7.10 Definition of interoperability 262

7.10.1 Interoperability as exercised capability to interoperate 262

7.10.2 Defining goals, criteria, and metrics for interoperability 264

8 Interoperation, governance, and collective action 269

8.1 Governance of ePrescribing in Sweden - some elements 270

$\begin{array}{lll}8.1 .1 & \text { Organizational } & 270\end{array}$

$\begin{array}{lll}8.1 .2 \text { Legal } & 271\end{array}$

$\begin{array}{lll}8.1 .3 \text { Economical } & 271\end{array}$

8.1.4 Standards and technologies 272

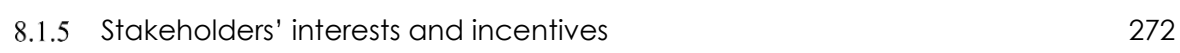

8.1.6 Social interaction and culture 272

8.2 Network governing, governance, and collective action 273

$\begin{array}{lll}\text { 8.2.1 Forms of network governing } & 273\end{array}$

8.2.2 Governing, governance and governance mechanisms 274

$\begin{array}{lll}8.2 .3 & \text { Collective action } & 276\end{array}$

8.2.4 Governing, governance and collective action - summing up 276

8.3 New National ePrescription Format - Vertical Information Systems standardization effort as collective action 278

8.4 Network governance, IT governance, and IT service management in the context of interoperation

8.4.1 Network governance in ePrescribing - comparison US - Sweden 281

8.4.2 IT governance for enterprises and governance of interoperation 286

8.4.3 IT service management and interoperation 288

9 A practical theory on interoperation and interoperability 293

9.1 Objectives 293

9.2 Overall guide to the theory 294

9.3 Interoperation and interoperability in a shared work practice 300

$\begin{array}{lll}9.3 .1 & \text { Shared work practice } & 301\end{array}$

9.3.2 Interoperation, interoperability, and the role of
the information infrastructure

9.4 Collective action and interoperation 316

$\begin{array}{ll}9.5 \text { Collective action and governance } & 319\end{array}$

$\begin{array}{lll}\text { 9.5.1 Strategic actions and governance } & 319\end{array}$ 
9.5.2 Tactical actions and governance

9.6 Interoperation and governance of shared information infrastructure and work practice

9.6.1 IT service operation in a shared work practice 323

9.6.2 Governance of shared work practice issues 325

9.7 Aspects of interoperation 326

9.7.1 "Levels" of interoperability tend to separate interdependent aspects of interoperation

9.7.2 Aspects of interoperation and its characteristics 327

9.7.3 Work practice action aspect 332

9.7.4 Communication action aspect 335

9.7.5 Mediating communication action aspect 337

10 Conclusion, contributions, generalizability, and future research

10.1 Conclusion 340

10.2 Contributions and their practical and theoretical implications 342

10.2.1 Local practice contributions and implications 342

10.2.2 General practice contributions and implications 343

10.2.3 Research contributions and their implications 343

10.3 Grounding 346

10.4 Generalizability of research findings 347

10.4.1 Assumptions about generalizability 349

10.4.2 Generalization of the theory on interoperation and interoperability to the health care sector

10.5 Support for the theory on interoperation interoperability in the original domain

10.6 Utility of the theory on interoperation and interoperability for practitioners

10.7 Future research 357

References 


\section{Introduction}

\subsection{Interoperability}

Interoperability is a popular catch phrase for the ability of information systems (IS) and organizations using information systems to interact.

Interoperability is sometimes defined as the ability of information systems to interact and exchange data (IEEE [1]) and sometimes as the ability of organizations to cooperate and exchange data using information systems. [2-4]

According to a report from the European Commission on eHealth, interoperable Electronic Health Record (EHR) systems [5] are the most important enabling tools for a patient centered care, for the continuity of care and for supporting patients mobility. The application of ePrescribing on an international level $[6,7]$ has focused on issues of interoperability on many levels, including application of ePrescribing on a local, national and international level respectively, involving professional, semantic, organizational and legal aspects. [8-10]

Interoperability is also considered to be one of the most important issues in eGovernment. There are many initiatives on a European level in order to promote interoperability in public services and in public eHealth. [4, 11-13] Interoperability has also been an important issue in various branches of industry and within the military domain for years.

There is a general understanding that to achieve and improve interoperability the use of technology is only one aspect, and that it is a complex undertaking involving among other things sharing of knowledge and resources, cooperation between organizations, and influence from policies and legal matters. Thus, interoperability is seen not only as the ability of information systems to interact and exchange data but also as the ability of organizations and individuals to interact in a meaningful way. $[4,5,11]$ 


\subsection{Research problem}

Standards of various kinds, controlled vocabularies, and ontologies of a domain containing assumed general knowledge, have been put forward as solutions to the complex problem of achieving interoperability. The success of applying technical standards in the telecommunication and computer industry, and particularly the application of standards making the Internet possible, have increased the hopes to master the interoperability challenge. The success in applying technical standards concerned with protocols for machine-to-machine interfaces has successively been applied to business transactions such as eCommerce applications for electronic ordering and invoicing, and the exchange of product data within various branches of industry. This approach has also been applied in recent years within the health care sector and in public services, where experience of achieving interoperability is still rare ${ }^{1}$.

Standards have enabled a significant progress in achieving interoperability on the technical level. Many standards primarily support machine-to-machine interoperability and enable the sharing and exchange of data. Achieving interoperability is a complex issue also in machine-to-machine communication ${ }^{2}$, where there is room for human errors and different interpretations.

However, in terms of the meaning of data and its use for action and the alignment of organizational processes, standards and other formal methods have showed limited progress in practice. The implementation of standardized vocabularies or ontologies often needs tailoring because of the specific use of terms in a subfield or even due to local usage. [19-21] [22-24] In order to understand a term it is necessary to understand its use, and therefore it is important to also focus on the workflows and the interacting organizational agents.

Thus, there are limits to the application of standards and formal methods in solving the problems of interoperability. The experience of achieving interoperability is that there is not one single solution to the challenges. [21, 25]

Additional complexity comes with the interaction between organizations using information systems.

\footnotetext{
${ }^{1}$ See for example a study [14] in US on the use of standard vocabularies in electronic laboratory reports in two states. This study showed that very few of the reports were using the mature and internationally recognized standard vocabularies LOINC and SNOMED CT. Instead local codes were used. See also a recent survey [15] in the StandIN project [16] in Sweden on the use of standards in the Swedish health care, which also show a low level of use of standards. Most integrations where not based on standards. [15]
}

${ }^{2}$ See for example the difficult process of achieving Bluetooth interoperability.[17, 18] 
A report from the Software Engineering Institute (SEI) [25] put forwards a number of factors, inspired by Frederick Brooks [26], as to why it is inherently difficult to achieve and maintain interoperability:

- complexity of the participating systems and the potential interaction between them;

- lack of conformity between the human institutions involved in the software development process, therefore resulting in a lack of consistency in the systems developed;

- changed expectations of the systems and the resulting volatility in the interactions;

- lack of visibility of the details between the interoperating systems.

Additional difficulties are funding and control issues that do not promote incentives for joint projects, as well as legal issues, particularly in eGovernment and the existence of different incentives and objectives of the stakeholders.

Moreover, the interaction is not only technical but also social, involving the establishment and change of relations, and the use of different types of social interactions such as business-to-business, business-to-customer, public-to-citizen, and social actions such as request, offers, commitments, demands, directions, authorizations, and decrees.

There are usually several stakeholders directly or indirectly involved or influenced by the interaction and there are often long chains of interdependencies between systems and actors. A change in one place could influence a process in another context, often with unforeseen consequences.

This complexity implies that to achieve and improve interoperability all these challenges must be considered concomitantly and one should not be tempted to think that there is one single solution, a 'silver bullet'. Instead of viewing interoperability from the point of departure of technology, it is necessary to start from the point of view of organizations and people involved using information systems.

Thus, standards and formalism should be seen as important instruments needed to achieve interoperability, not as the solution. To use the formulation of a report by McKinsey: "Global standards could be a critical enabler to improving the safety and quality of patient care in a cost effective way." [27] (our emphasis)

\subsection{Knowledge gap}

Interoperability has been addressed from many different perspectives and theories. In information system research the notion of interoperability has been addressed in for example research on information infrastructures [28] and inter-organizational information systems (IOS) [29, 30].

However, definitions of interoperability are numerous [31] and there is a weak scientific basis for interoperability. [32, 33] 
Another difficulty is that theoretical underpinnings and underlying assumptions are often not problematized and reflected upon. This has led to a fragmentation of research results and to difficulties to build on other researches results. [32, 34]

Underlying assumptions on the nature of the interaction will influence the way in which interoperability is viewed and thereby point in a certain direction to define problems and their solutions. Thus, there is a gap in the theorizing about interoperability and all the different challenges experienced by practitioners.

Although, there are many empirical studies on the adoption of inter-organizational systems and their consequences on the governance of economical transactions and interactions (see [30] for a review and summary of 51 empirical studies), there are few empirical studies [35-37] evaluating different approaches to information systems design, and methods and approaches for achieving, maintaining, and improving interoperability. There are many proposals for solutions, but there is still a lack of studies to probe their usefulness, adequacy and applicability.

For example, a report by the European Commission (EC), Enterprise interoperability roadmap for research, emphasized:

"Various technologies and tools resulting from research lack follow-up beyond (further) research. Large question marks remain as regards the 'value' and 'impact' of the myriad of initiatives undertaken within the research lab, promoted by technology providers, or organized around groupings of companies ... Organisations lack examples of successful cases, best practices, and guidelines about where most value is created through Enterprise Interoperability." [38]

That important initiatives are taken by different stakeholders without a solid ground for their utility and applicability has implications for the practice of interoperability. It has also implications for research into interoperability, in the sense that a better grasp of realworld interoperability problems and challenges could inform research about potential utility of different methods, approaches, and theories and need for research.

One approach to achieve and improve interoperability has been a vision of a "big-bang" radically changing technology and processes to a future state of "best-practice" with a focus on efficiency. This change was supposed to be designed by experts and managed top-down without involving the knowledge of the whole enterprise. Thus, interoperability was seen as a big one-time investment for a new structure that would last and that the investment would pay off later. [36]

However, research into the development of information infrastructures that are necessary for achieving interoperability, point to the need to consider the installed base and that development of information infrastructures are a long-term process. [39-41] 
According to the EC roadmap for research on enterprise interoperability [38] (cited above), this has implications for research which should a focus on:

- problem-solving to contribute with results that are more directly beneficial, applicable and easy to use;

- public infrastructures that many stakeholders can use.

There are efforts $[3,4,12,36]$ that aim to focus on other issues of interoperability than those of technical interoperability and data exchange, such as the communication of meaning and actions, the interoperability of processes, organizations, and the legal and political and financial questions related to interoperability. Although, these efforts are promising, conceptualizations are fragmented and ambiguous regarding how to relate different aspects of interoperability and how to define interoperability.

A major reason for the fragmented view on interoperability is a lack of understanding and agreement on the meaning and scope of interoperability. Interoperability is often described as the ability of systems and organizations to interact. However, the characteristics of the interaction between organizations are often undefined or less developed. For this interaction between organizations, $\mathrm{we}^{3}$ will use the term interoperation. Interoperation means that actors and organizations mutually perform and coordinate their actions. How one define and understand interoperation and its relation to interoperability, viewed as a quality of interoperation, will influence one's view of interoperability.

\subsection{Research aim}

The research presented in this thesis stems from practical involvement in design of information systems and problem solving related to interoperation in the context of work practices and inter-organizational cooperation. It is also influenced by reflections about the state of knowledge among practitioner and research communities.

This thesis aims at contributing with practical knowledge for improving interoperability. The contribution is based on knowledge gained from active participation in and empirical studies of improving interoperability in ePrescribing and on theoretical reflection and generalization of the experiential knowledge.

Research on interoperability has evolved from considering it mostly as a technical problem to be increasingly understood as a semantic and organizational problem. [4] Moreover, interoperability has evolved from improving business-to-business efficiency toward being an essential factor in innovation and change in a network economy with a greater focus towards evolution of information infrastructures.[37]

\footnotetext{
${ }^{3}$ In this thesis, we will use 'I' to reflect a personal engagement of the author in operational and research work. 'We' will be used as the voice of the author of this thesis. When 'we' means a specific group of people, such as me and my colleges, this will be noted. For the electronic reader, italicized links to chapters, sections, figures and tables are supposed to work as clickable links to that part of the document.
} 
This implies that the context of interoperation is complex and there is a need of integrating research results from several different research fields. There is a lack of theoretical $[32,33]$ understanding of the implications of this evolution for proposed approaches, methods and solutions to achieve and improve interoperability.

Thus, another aim with this thesis is to contribute with a practical theory on interoperation and interoperability, empirically grounded in the practice of improving interoperability in ePrescribing and theoretically grounded in theories about information systems, information infrastructures, work practices, network organizations and communication.

\subsection{Outline of thesis}

Chapter 2 Interoperability, information infrastructures, work practices, and standards introduces and discusses interoperability and related concepts. The chapter is a result of a literature review with a particular focus on different definitions of interoperability and related research fields.

One important research field relevant for interoperability concerns design theories on information infrastructures. Standards, which are key enablers for interoperability, will be briefly discussed. Standardized vocabularies and terminology research are reviewed. The aim of the chapter is to introduce some central concepts to facilitate the reading of the thesis.

Chapter 3 Methods of inquiry contains a discussion on the methods of inquiry used and considered in this thesis. An important aspect of the research has been the role of the researcher as an insider, actively participating in and contributing to the practice.

Chapter 4 Implementing ePrescribing in Sweden - case study contains a retrospective case study of the history of implementing ePrescribing in Sweden. The case study introduces ePrescribing for the following chapter's 5 and 6. The case study is based on interviews with key stakeholders in the implementation process and on internal project material, published accounts, reports and legislations. The case study findings are discussed from the point of view of influencing factors on the implementation process and the evolution of an information infrastructure for ePrescribing.

Chapter 5 Improving interoperability in ePrescribing - a field study is a summary of a field experimental study evaluating an intervention to improve interoperability in ePrescribing. This chapter is based on two published papers, Interoperability in Actionthe case of electronic prescribing [9] and Improving Interoperability in ePrescribing [8] with additional reflections on design decisions made and on the joint actions of the stakeholders to improve interoperability.

Chapter 6 A practical theory on ePrescribing analyze ePrescribing in more depth using practical theories to analyze and conceptualize the ePrescribing work practice. The multifunctionality of the ePrescription message is described using a socio-pragmatic theory. 
The ePrescribing process is viewed from a regulatory and communication exchange perspective using other practical theories. The result of this analysis is conceptualized in a practical theory on ePrescribing. The chapter is based on the published paper Towards a socio-pragmatic understanding of ePrescribing. [42]

Chapter 7 Context of interoperation and interoperability contributes with a theoretical background to the theory on interoperation and interoperability presented in chapter 9 . This chapter discusses different views on information systems, theories of language, meaning theories, communication quality, information infrastructures, the role of messages, and the settings of communication in interoperation. The chapter concludes with a definition of interoperation and interoperability.

Chapter 8 Interoperation, governance, and collective action analyze and defines central concepts such as the notion of governance, governance mechanism, and collective action. It includes an example of collective action in implementing a vertical standard (ePrescription in Sweden) and a short description of existing models of IT governance and IT service management and how they relate to and can contribute to a shared network governance.

Chapter 9 A practical theory on interoperation and interoperability presents the theory based on the previous chapters 4, 5, 6, 7 and 8 . The theory is grounded in the experience from improving interoperability in ePrescribing $(4,5,6$, ) and on a theoretical grounding in information systems and communications theories (7), and on theories of governance and collective action (8).

Chapter 10 Conclusion, contributions, generalizability, and future research summarizes the findings and contributions to research and practice, and discusses their generalizability to other cases and the utility of the practical theory on interoperation and interoperability. The chapter concludes with questions for future research. 


\section{Interoperability, information infrastructures, work practices, and standards}

This chapter will introduce and discuss the concept of interoperability and related fields. An important research field relevant for interoperability is that of design theories on information infrastructures. Research on work practices and the link to information infrastructures are reviewed. Then, standards, standardized vocabularies and terminologies, key enabler for interoperability, are reviewed. This chapter is a result of a literature review (see section 3.7.2).

\subsection{Interoperability concepts and frameworks}

In section 1.3 Knowledge gap, we noted that there are many definitions of interoperability. In this section, we will give an overview of different definitions of interoperability. How you view and define interoperability will imply how interoperability problems are conceived and how they could be approached and be resolved. [43] The definition will influence what solutions or remedies to propose, who and what resources are to be involved, what goals to be met, and how systems are to be designed, implemented, used and maintained.

Interoperability is a concept that has been defined and used in many different ways. Some studies have found more than 30 different definitions of interoperability. [31] Interoperability has been the focus of many different application contexts. Interoperability appears to have been first used in the military domain in the 1970s, and later used in 
application of information and communication technology $\left(\mathrm{ICT}^{4}\right)$, and lately in applications in domains like public services, eHealth and enterprise interaction. This section analyzes the concept of interoperability and different interoperability frameworks are presented.

\subsubsection{Interoperability in the military domain and public safety}

Public safety, related to events of natural catastrophes like flooding, tsunamis, fires et cetera, has put more focus on interoperability:

“... effective interoperability can save lives, improve response capabilities and save billions of dollars." [44]

Warfare has become more complex with the introduction of new weapon systems and ICT, but also a result of war being conducted with forces far away. This has stressed both the need for technical ability to exchange data and the need to handle the social aspects and processes involved in conducting military operations. [45]

Since about the late $1960 \mathrm{~s}$, interoperability has been used as a concept to deal with particular problems in the military domain. In 1977, the Department of Defense (DoD) in the United States published a directive which provided the definition of interoperability that has become the most accepted in the military domain and which probably dates back to 1967 [1], when the first version for the DoD Directive 4630.5 was published:

"E2.1.14. Interoperability. The ability of systems, units, or forces to provide data, information, materiel, and services to and accept the same from other systems, units, or forces and to use the data, information, materiel, and services so exchanged to enable them to operate effectively together. IT and NSS interoperability include both the technical exchange of information and the end-to-end operational effectiveness of that exchange of information as required for mission accomplishment. Interoperability is more than just information exchange. It includes systems, processes, procedures, organizations, and missions over the life cycle and must be balanced with information assurance." (our emphasis) [2]

This definition is broad in the sense that it includes systems and materials as well as people, processes, and organizations that interoperate to achieve a certain goal effectively.

\footnotetext{
${ }^{4}$ The term ICT is often used to emphasize the role of information technology (IT) as an instrument for communication between people, organizations and within the society in general. The term is a reflection of the evolution since the $90 \mathrm{~s}$ of a closer link between the computer and telecommunication industry, particularly with the diffusion of the Internet and mobile telecommunication. In this thesis, ICT and IT is used as synonyms as it has become obvious that IT no longer only has its traditional interpretation of storing and processing information within an organization, but is increasingly is about communication between people and organizations.
} 
Interoperability is seen within a context of end-to-end operational effectiveness in a broader context of actions to accomplish certain objectives.

Therefore, in this domain, we see a clear focus taken on social and organizational aspects on interoperability in which technical considerations are included.

\subsubsection{Interoperability in computer and engineering sciences}

The Institute of Electrical and Electronics Engineers (IEEE) defines interoperability as:

"The ability of two or more systems or components to exchange information and to use the information that has been exchanged." [1]

The IEEE definition [1] reflects a view of interoperability which limits the scope of interoperability to information systems and the exchange and use of information.

There are slightly different interpretations within the software engineering community:

"From software engineering point of view, interoperability means that two co-operating software systems can easily work together without a particular interfacing effort." [46]

This definition is somewhat broader in the sense that it does not limit itself to exchanging information only but includes also the interaction of services. The focus in the definition is still however, on interaction between systems.

From the point of view of software engineering, it could be useful to limit interoperability to systems interaction. Interoperability is then used to denote a quality of an existing state of affairs in systems interaction. Of course, there are particular problems with this limited scope as it only addresses the technical issues in interaction between information systems and does not consider or refer to the information exchange ${ }^{5}$, as part of a communication between people with a certain purpose.

The definition does not consider the pre-conditions and effects of system interaction, and therefore does not give any guidance as to whether the exchange of data is meaningful in some respect or what it means that the systems easily work together.

However, the definition is useful if we do not include the meaningful sharing of information in the definition, and focus instead on technical interoperability as defined by the European Interoperability Framework [4]:

\footnotetext{
${ }^{5}$ When the term information is used in this context, it seems to be synonymous with data. However, it is unclear what actually is meant by information. See chapter 7 for a discussion of the concept of information and meaning.
} 
"... covers the technical aspects of linking information systems. It includes aspects such as interface specifications, interconnection services, data integration services, data presentation and exchange, etc."

Note that in this quotation the term information is not used, instead the term data is used to denote what is exchanged. It is not clear what the definition by the IEEE mean by information and information exchange. If information denotes the meaning of data, the definition seems to assume that information is contained in what is exchanged and not something that belongs to the intention and interpretation of the participants.

Even at this technical level of interoperability, there are legal, organizational and semantic issues involved. For example, the interface specification must include a formal description of the data format exchanged, and this must be based on a mutual agreement between the communicating parties about the content of the communicated messages or services. Furthermore, the type of processes and objectives of the communication has a strong influence on for example the choice of communication protocols or service level agreements.

\subsubsection{Interoperability in public services}

One important source of a definition of interoperability in public services is the European Interoperability Framework (EIF) [4]. In version 2.0 of the EIF, interoperability is defined:

"Interoperability, within the context of European public service delivery, is the ability of disparate and diverse organizations to interact towards mutually beneficial and agreed common goals, involving the sharing of information and knowledge between the organizations, through the business processes they support, by means of the exchange of data between their respective ICT systems."

This definition has evolved since the EIF version 1 [3]. In a draft document published for public comments to the EIF 2.0, referring to an earlier version [47], it is stated:

"Since that time, the appreciation of additional aspects of interoperability, encompassing more than just the ability of ICT systems to exchange data leads us to consider a more general view of interoperability as the ability of disparate and diverse organizations and systems to work together efficiently towards mutually beneficial common goals."

Furthermore, in the draft to the EIF 2.0, the following reflection was made (although it did not become part of the final EIF 2.0 [4]):

"It is also worth noting that interoperability is neither ad-hoc, nor unilateral (nor even bilateral) in nature. Rather, it is best understood as a shared value of a community."'[47] (our emphasis in italics)

There is an explicit move from a technical focus on interaction and interoperability towards communication between people and processes. However, what this 'shared value of a community' means is not developed further. 


\subsubsection{Enterprise interoperability}

Enterprise interoperability is another concept and view of interoperability that focus on the interaction between enterprises. This approach to interoperability stems from industrial engineering and management research. An enterprise is defined as "one or more organizations sharing a definite mission, goals and objective to offer an output such as a product or a service." (Quoted from [48] referring to ISO 15704)

This focus on enterprise interoperability is influenced by interoperability frameworks develop in EU projects such as IDEAS ${ }^{6}$, ATHENA $^{7}$ and INTEROP ${ }^{8}$. These frameworks are developed in research sponsored by the European Commission fifth and sixth framework program. (confer Chen et al [48] for an overview of the historic background. See also [32])

IDEAS interoperability framework has three layers [48]:

Business layer interoperability is the organizational and operational ability of an enterprise to interoperate with other enterprises.

Knowledge layer interoperability is the compatibility of skills, competencies and knowledge assets of an enterprise in relation to other enterprises.

Information and Communication Technology (ICT) systems layer interoperability is the ability of the enterprise's ICT systems to cooperate with external organization ICT's.

The ATHENA interoperability framework [48], seen as a complementary to the IDEAS framework, is about structuring different sources of results (research, applications and techniques)

The INTEROP [48] framework has the purpose to define research domains of enterprise interoperability.

One paper addressing the scientific basis for enterprise interoperability defined enterprise interoperability as:

" ... the capability of two or more enterprises, including all the systems within their boundaries and the external systems that they utilize or are affected by, in order to cooperate seamlessly, over a sustained period of time to pursue a common objective." [33].

${ }^{6}$ IDEAS (Interoperability Developments for Enterprise Application and Software - roadmaps): http://cordis.europa.eu/project/rcn/63037_en.html

${ }^{7}$ ATHENA (Advanced Technologies for Interoperability of Heterogeneous Enterprise Networks and their Applications): http://cordis.europa.eu/pub/ist/docs/directorate_d/ebusiness/athena.pdf

8 INTROP (Interoperability research for networked enterprises applications and software): http://cordis.europa.eu/project/rcn/71148_en.html 
This definition is close to the view of the EIF framework (see above).

\subsubsection{Interoperability in eHealth}

Definitions of interoperability within the eHealth field are in most cases developed from the IEEE definition. [1] An ISO standard in Health Informatics, defines interoperability in the following way:

"Interoperability refers to the ability of two or more systems (computers, communication devices, networks, software, and other information technology components) to interact with one another and exchange information according to a prescribed method in order to achieve predictable results." [49]

In a report from the $\mathrm{CEN}^{9} / \mathrm{ISSS}$ eHealth Standardization Focus Group [50], referring to other CEN reports, interoperability is defined as:

"... a state which exists between two application entities when, with regard to a specific task, one application entity can accept data from the other and perform that task in an appropriate and satisfactory manner without the need for extra operator intervention."

One interpretation of this CEN-definition is that interoperability is all about data exchange between systems and performing predefined operations in the system on that data in a formally correct way, irrespective of the organizations and people using the systems. It is common to use this definition of interoperability between systems or applications in the eHealth domain, rather than viewing information systems as an instrument for interaction between people and organizations.

Much of the focus in the eHealth area is on the adoption of standards as key enablers for interoperability and the adoption of standardized vocabularies and ontologies. Much focus is on 'semantic' interoperability, which has a technical flavor and is limited to systems interaction:

"Semantic interoperability: the ability for information shared by systems to be understood at the level of formally defined domain concepts." [51]

The concept of interoperability in eHealth, viewed as interoperability of systems, is also mirrored in the definition of semantic interoperability with is a view of "semantics" between systems, or rather semantics as a relation between "shared information" of systems and a formal ontology.

In the EIF 2.0 version, the focus is much more on 'meaning' and 'understanding' by the 'communicating parties', while meaning and understanding in the definitions of semantic interoperability in eHealth tend to apply 'meaning' and 'understanding' to machines and

\footnotetext{
${ }^{9}$ European Committee for Standardization
} 
formal semantics. It is obvious that the concept of semantic interoperability is ambiguous and not well defined.

We will later return to semantic issues related to the concept of semantic interoperability in chapter 7.

The HL $7^{10}$ Interoperability Work Group [52] put forward a framework of three points; technical, semantic and process interoperability:

"Technical interoperability moves data from system A to system B, neutralizing the effect of distance. It is domain-independent. It does not know or care about the meaning. One of the foundations of technical interoperability is Claude Shannon's information theory. ...

Semantic interoperability ensures that system A and system B understand the data in the same way. It allows computers to understand, interpret, and use data without ambiguity. This is specific to domain and context, and usually involves the use of codes and identifiers. Semantic interoperability is at the core of what we usually mean by health care interoperability.

Process interoperability coordinates work processes, enabling the business processes at the organizations that house system A and system B to work together. Process interoperability is achieved when human beings share a common understanding, so that business systems interoperate and work processes are coordinated." [52].

In a report from the HL7 EHR Interoperability Work Group [43], the different points of view of interoperability (above) is discussed in depth. It summarizes the three different views as follows:

- technical interoperability neutralizes the effects of distance;

- semantic interoperability communicates meaning;

- process interoperability coordinates work processes.

The definition above defines different aspects of interoperability. It is clear from this definition that semantic interoperability is viewed in a narrower sense as computers 'understanding' each other and that it could be separated from the actors understanding and work context. Interestingly, human shared understanding is on the level of work process coordination. Thus, this definition seems ambiguous on how it defines and relate semantics and understanding.

\footnotetext{
${ }^{10}$ Health Level Seven: http://www.hl7.org/
} 


\subsubsection{Interoperability and related concepts}

The concept of integration is often distinguished from interoperability [13, 47, 48, 53].

Integration refers to a stronger cohesion of the different units of a system or organization where parts of systems or organizations work as a coherent unit. Interoperability, on the other hand, refers to a relation between different independent systems, processes and organizational units, often, but not necessarily, managed by different corporations or authorities. Another view of the distinction between interoperability and integration is that this distinction depends on the point of view. Viewing the systems at a distance, they seem to be integrated but on a closer inspection, they are considered distinct interacting systems. [25]

According to the IEC TC65/290/DC [54], interoperability is defined as a degree of compatibility. Compatibility is defined as:

"The application data, their semantic and application related functionality of each device is so defined that, should any device be replaced with a similar one of different manufacturer, all distributed applications involving the replaced device will continue to operate as before the replacement, but with possible different dynamic responses" ${ }^{11}$ (Cited in [46]).

Interoperability is then defined as being:

" ... achieved only if the interaction between two systems can, at least, take place at the three levels: data, resource and business process with the semantics defined in a business context." [46]

This means that the aspect of interchangeability (replacing a device) is linked to compatibility but not directly to interoperability, which must be seen within a "business context".

Other definitions of compatibility concern the "technical" aspect of interoperability. [55]

Closely related to compatibility is interconnectivity. Researchers in the transport sector define interconnectivity as being:

" ... achieved when different transport systems, of either the same or different modes, are physically and operationally linked to facilitate transfers across the boundaries between different systems.'"[56]

\footnotetext{
${ }^{11}$ An interesting idea is the concept of "organizational compatibility". If you use a standard as a basis for interaction (which also includes a certain standardized business process), it is much easier to change organizations in a changed business condition. This concept has been adapted in Sweden in opening up for competition in the pharmacy market towards hospitals and health care centers. See the adoption of SFTI (Single Face to Industry) (http://www.sfti.se/) by Sveriges Kommuner och Landsting (SKL) (or in English: Swedish Association of Local Authorities and Regions, SALAR).
} 
and

"Achieving interconnectivity is a necessary preliminary step towards interoperability." [56]

In the EIF 2.0 draft [47], interoperability is distinguished from adaptability in the following way:

"Interoperability is not Adaptability, which is a means of changing a tool, adding additional capabilities as needed even on an ad-hoc basis, whereas interoperability refers to inherent capabilities."

\subsubsection{Designed and ad-hoc interoperability}

There is also a distinction made between design-in and ad-hoc interoperability, where the last means that systems are expected to adapt to changing circumstances, which are close to the concept of adaptability described above, and where design-in interoperability means that the interoperability is fixed in design and has less flexibility concerning changes [57].

This raises several questions. One is how to maintain interoperability in a changing environment, a question that will be discussed later, while others concern the degree of interdependence and flexibility in interoperability.

One way to view the degree of interdependence in interaction and which is related to the concept of ad-hoc or adaptable interoperability and design-in interoperability, is the concept of loosely or tightly coupled interaction. One can view tightly coupled systems (and processes) as an integration, while loosely coupled systems (and processes) can be regarded as an interaction rather than integration [48].

It is important to address which is the optimal degree of interdependence in interaction because there is a tradeoff between flexibility and rigidity, cost, and efficiency. See section 2.3.3 on reflexive standardization, where standardization in a complex and heterogeneous environment is discussed.

\subsubsection{From technical to a broader view on interoperability}

With the growing importance of using information technology (IT) for communication between organizations and people, a natural focus in the early days was on the technical issues of the communication. The development has been towards a better mastering of technology and the number of standards in the IT sector have grown. This has simplified communication, particularly with the advent of the internet and their accompanying communication protocols and data exchange standards. Accordingly, focus has become increasingly on the challenge to interact between organizations and people, centered on 
the requirements and changes needed (legal, organizational, semantics) to make the interaction work according to the actor's purpose. [58]

This means that the scope of interoperability has widened in order to include the purpose of the interaction, to involve people, work processes, and organizations, as well as communication technology.

With this change to widen the scope, it seemed necessary to develop concepts to handle the different aspects of interoperability. First, it is possible to distinguish technical interoperability from other aspects of interoperability. The pioneer of Information Theory, C. E. Shannon, made clear that the communication problems he focused on did not include any semantics: [59]

"The fundamental problem of communication is that of reproducing at one point either exactly or approximately a message selected at another point."

This means that channel capacity, the encoding and decoding of messages and sources of noise are interesting topics which can be analyzed mathematically. Other aspects of technical interoperability are linked to technical communication protocols, the reliability of communication, protection against data loss and corruption of data, recovery operations, modes and speed of communication, and type of data communicated.

Thus, technical interoperability is an important issue in itself with ongoing international work to agree on new standards in protocols, formats and type of media in communication. This work has established processes to achieve interoperability. See for example the work and processes defined within telecommunication and within the $\mathrm{W} 3 \mathrm{C}$ consortium.

There is, of course, an interdependence between technical interoperability and the purpose and type of communication needed to achieve overall interoperability. [8]

The interoperability frameworks presented below express the concern to address other aspects of interoperability. As interoperation is a complex phenomenon, it is not surprising that we see a number of concepts that analyze different aspects of interoperability. The frameworks discussed has evolved to handle the complexity involved in achieving interoperability in public administration, particularly in the European Union.

The European Interoperability Framework (version 2.0) define an interoperability framework as:

“... an agreed approach to interoperability for organizations that wish to work together towards the joint delivery of public services. Within its scope of applicability, it specifies a set of common elements such as vocabulary, concepts, principles, policies, guidelines, recommendations, standards, specifications and practices." [4] (Our emphasis)

The EIF aims to supplement national interoperability frameworks. Here we see another view of the definition of interoperability that focuses on issues addressing how to achieve interoperability and different approaches in this achievement process. The EIF interoperability framework can be viewed as a framework for agreeing on governance and 
governance mechanisms for interoperability in the long term and with a varying scope of applicability. See further chapter 8 Interoperation, governance, and collective action for an elaboration of these aspects.

Here, we will not further discuss the details of the general frameworks for achieving interoperability but instead focus on EIF's four different levels of interoperability: legal, organizational, semantic, and technical (see Table 1).

Table 1 Levels of interoperability in the EIF [4].

\section{Level of Description \\ interoperability}

\begin{tabular}{ll}
\hline Legal & $\begin{array}{l}\text { Alignment of legislation concerning the interaction between } \\
\text { different organizations, which affects how and what can be } \\
\text { communicated }\end{array}$ \\
Organizational & $\begin{array}{l}\text { How different organizational processes are integrated and how } \\
\text { information exchange is managed }\end{array}$ \\
Semantic & $\begin{array}{l}\text { Processing information in a meaningful way, ensuring that } \\
\text { information in the communicated message is precisely defined, } \\
\text { agreed and understood by all the stakeholders involved }\end{array}$ \\
Technical & $\begin{array}{l}\text { Technical prerequisites linking different systems, such as } \\
\text { communication protocols, message format, services, interface } \\
\text { specification. }\end{array}$
\end{tabular}

These levels of interoperability are seen as areas that must be dealt with in order to achieve interoperability. These levels seem not to be intended to describe a quality, but rather problem areas that have to be dealt with to achieve interoperability. Some scholars interpret these levels of interoperability as a kind of a maturity ladder. See for example the HL7 report [43] which discusses the full semantic interoperability as the "Holy Grail".

However, there is little mention of maintaining or improving interoperability in the literature. It is as if interoperability is something fixed and stable. This indicates that there is a lack of operational perspective on interoperability.

We consider that the levels of interoperability presented in the EIF, and which are interpreted as problem areas to focus on in order to implement, maintain, and improve interoperability, make a useful starting point in analyzing different problems of interoperability. What is missing though is a clear definition of semantic interoperability and a theoretical basis for the different aspects of interoperability and how these are related. 


\subsection{Information infrastructure and interoperability}

To engage in interoperation, i.e. to mutually perform and control work between actors, and to use information systems in this interoperation, requires development and sharing of an information infrastructure. Hence, one very important factor in achieving and facilitating interoperability, which is a quality of interoperation, is the evolution of information infrastructures.

Information infrastructures are networks or webs that enable locally controlled and maintained systems to interact, which in turn enable people and organizations to interoperate. They constitute a shared community of interoperation, particularly with many-to-many interoperations in a business sector. Hanseth and Lyytinen [60] define Information infrastructure as:

"a shared, open (and unbounded), heterogeneous and evolving socio-technical system (which we call installed base) consisting of a set of IT capabilities and their user, operations and design communities."

Hanseth and Lyytinen categorize information infrastructures according to their scope of application and function. See section 2.2.1 for a summary of this categorization with examples from eHealth and ePrescribing in Sweden.

In section 2.2.2, we analyze the relation between work practices, information systems and information infrastructures.

In section 2.2.3, we briefly describe some features of an information infrastructure, such as IT capabilities, the role of institutional objects for communication and inscribed behavior.

Finally, in section 2.2.4, we present some design considerations for building information infrastructures and discuss some of their limitations.

\subsubsection{Classification of information infrastructures}

Hanseth and Lyytinen [60] propose a classification of information infrastructures based on their function and scope of application.

In terms of functionality, they make a distinction between business functionality (application infrastructure) and infrastructure services (support infrastructure). The support infrastructure can be further divided into service and transport infrastructures. Examples of transport infrastructure are standard methods for transferring messages (TCP/IP, et cetera) and service infrastructure as services for addressing or accessing services such as Domain Name Service (DNS) or Universal Description, Discovery and Integration (UDDI) [61], which is a mechanism to register and locate Web services. 
Hanseth and Lyytinen (ibid) identify three types of 'vertical' information infrastructures, based on the criteria of their scope of application or use:

a) universal service infrastructure;

b) business sector infrastructure;

c) corporate information infrastructure.

One example of a universal service infrastructure is the Internet, which is used in all sectors and by many types of users in the society. An example of a business sector infrastructure could be within the health care sector in Sweden ${ }^{12}$, which share an infrastructure for identifying actors (people and organizations) within health care, and which share of a separate communication network, and a service infrastructure for communication between regional health centers.

A business sector infrastructure could enable electronic markets and collaborative information sharing within a business sector or among larger business communities. These structures typically evolve in an incremental fashion when previously unconnected applications are integrated. One example of this is the evolution of the information infrastructure for ePrescribing in Sweden (see Chapter 4 Implementing ePrescribing in Sweden-case study).

Applications are viewed as a set of IT capabilities. Thus, we consider that the IT capabilities of an information infrastructure comprise all designed and installed application artefacts and their support infrastructure. We here assume that the "user" uses the IT capabilities to perform some work with a certain purpose within a context of an organization or a network of organizations.

\subsubsection{Work practices, information systems, and information infrastructures}

In this section, we will describe the assumptions made in this thesis about work practices and their relations to information systems and information infrastructures.

\section{Work practice and information systems}

One important view in this thesis on information systems is that they exist and are used for communication in a work context. [62] In analyzing this context, information systems researchers [63] have been influenced by the notion of practice in social theory. One

\footnotetext{
${ }^{12}$ See Cehis 2014-02-25. URL:http://www.cehis.se/infrastruktur/. Accessed: 2014-02-25. (Archived by WebCite ${ }^{\circledR}$ at http://www.webcitation.org/6Ne9iLugk) for a description of this infrastructure (in Swedish). Cehis (2014) is a center for coordinating the health care regions efforts to develop and implement shared eHealth services, technical infrastructure, regulations and standards. Cehis has been merged (February 2014) with Inera which develops and maintains eHealth services for the county councils in Sweden.
} 
important argument by Orlikowski [64] for adopting a practice 'lens' is that it focuses on the actual use of information systems in the daily practice and how this use is structured by rules and resources implicated in the ongoing action. Thus, the focus is not first on the technologies (as artefacts) in themselves but how they are used in practice, in Orlikowski's words, technologies in practice. [65]

Schatzki et al [66] develop their view of practice (from point of view of philosophy and sociology) in their anthology, the "The practice turn in contemporary theory". In the introduction to the anthology Schatzki [67] defines a practice as:

“... embodied, materially mediated arrays of human activity centrally organized around shared practical understanding."

In the same anthology [68] in Practice as collective action, Barnes develops the notion of a shared practice (which is of interest in interoperation). These shared practices are not a simple addition of individual practices or habits, but:

“... the accomplishments of competent members of collectives. They are accomplishments readily achieved by, and routinely to be expected of members acting together ..." [68]

Practices are both shaped by individuals acting and by institutional norms and structures:

"Practices are engaged in by individuals as part of the ongoing structuring processes through which institutions and organizations are produced and reproduced. They are thus both individual (because performed by actors in their everyday action) and institutional (because they shape and are shaped by organizational norms and structures)" [69]

In social theory, practice is a very general term that could include different kinds of practices. To be useful for information systems research, it needs to be related to information systems as an artifact and to those kinds of practices in which information systems are mostly used, i.e. work practices.

Goldkuhl and Röstlinger [63] add the dimension of work to their definition a work practice:

"A work practice means that some actors make something in favor of some actors, and sometimes against some actors: ..." [63]

Work practices are a habitual, recurring pattern of action to produce a certain result for a client. Thus, there are expectations of results that are shared or agreed upon by the producer and the client, which implies that there is a shared purpose (explicit or implicit) for the work practice. In addition, producers do not create results out of nothing and there are certain conditions. Thus, the acting in a work practice is:

“... initiated by assignments from some actors, and is performed at some time and place and in some manner, and is based on material, immaterial and financial conditions of 
transactional and infrastructural character and work practice capability which is established and can continuously be changed." [63]

A work practice includes both transactional and infrastructural conditions for actions. Work practice theory has evolved as a suggestion for a theoretical foundation for information systems research to analyze the context of use and development of information systems [62] Work practice theory therefore provides a context for information systems, which is illustrated in Figure 1.

Knowing how to act in a work practice and to learn from experiences is an important element of a work practice capability. A work practice is performed by individuals, usually or at least partly in an institutionalized manner. This institutionalized manner is also part of a work practice capability, which could either be inscribed in an information infrastructure behavior [70] or in the form of manual guidelines and routine descriptions. [63]

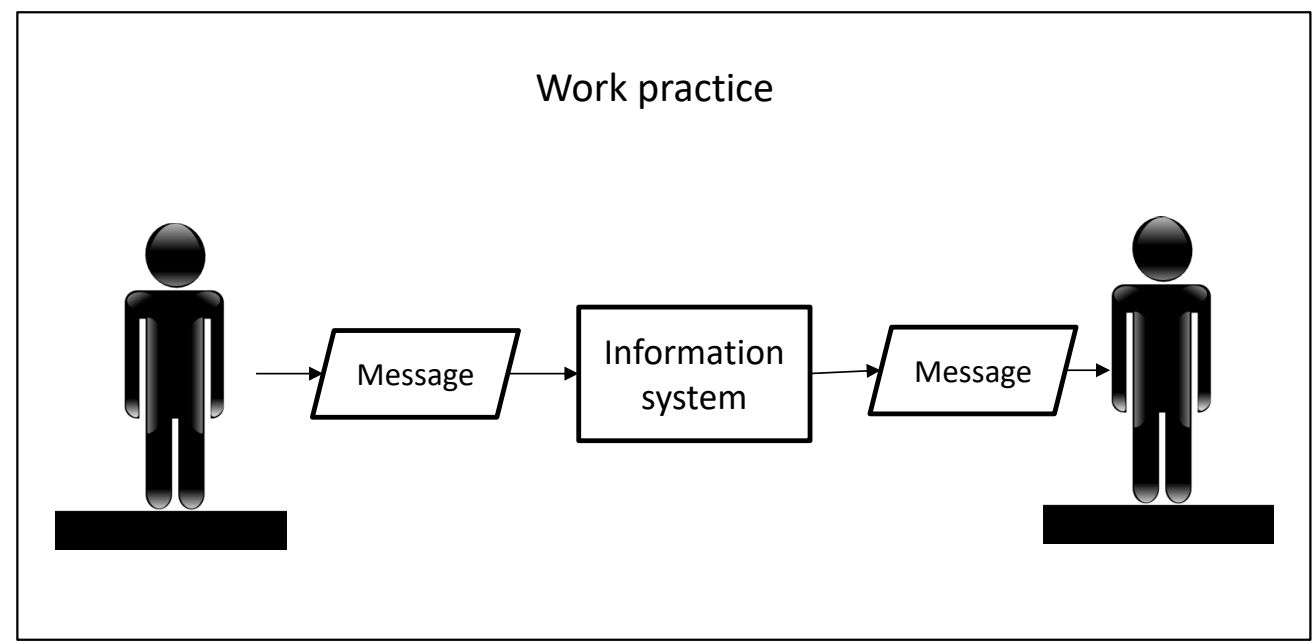

Figure 1 The work practice context of an information system use, adapted from Goldkuhl [62].

In analyzing the context of work practices, Goldkuhl and Röstlinger [63] make a distinction between transactional conditions, such as product assignments and substances (material or informational), and infrastructure conditions, such as guidelines, norms, instruments, judgments, and descriptions. Goldkuhl and Röstlinger [63] add transactional and infrastructure concepts to their work practice theory.

What interests us here is the relation between the transactional aspect of a work practice and the infrastructural conditions for its achievement. From a work practice perspective, it is natural to view an infrastructure as a condition, a foundation and a basis for the work practice, both for the short-term perspective on a transactional and operational level and 
for its ability to perform consistently in the long term. According to Goldkuhl and Röstlinger infrastructure is:

“... what is used for recurrent transactions, both for support and governance." [63]

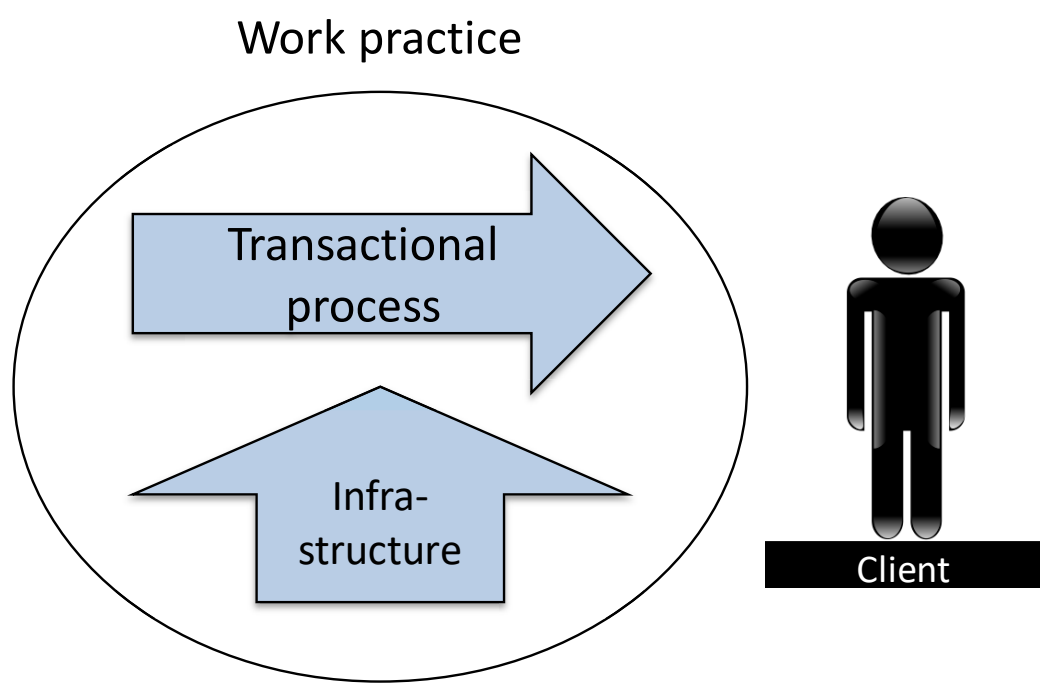

Figure 2 The relation between work practice, transactions and infrastructure inspired by Goldkuhl and Röstlinger. [63]

Figure 2 illustrates the relation between work practice, transactional process, and infrastructure. Seen from this perspective, an infrastructure constitutes an element or instrument of work practice. Note that infrastructure here [63] explicitly includes financial and resource assignments, which is obvious ${ }^{13}$ from a work practice perspective. The infrastructure supports the recurrent transaction process within the work practice.

Thus, a transaction is the horizontal coordination and transformation activity in a process while infrastructure is the underlying framework, which is used for recurrent transactions ${ }^{14}$. [63] It is important to note that information systems are involved in both the transaction process and the infrastructure.

Work practice theory focuses on the conditions for producing a product or service for a client. In a context of interoperation, the focus is on coordination of actions. In order to account for the interaction between the producer and the client, additional models have

\footnotetext{
${ }^{13}$ It is also essential for information infrastructures, for its development and sustainability.

${ }^{14} \mathrm{We}$ will return to the question about the relation between process/work practice and infrastructure below.
} 
been developed in the language action tradition, which sees the communication of messages not only as information or material processing but also as social acts. Such models are the Action Workflow [71], Business Action Theory (BAT) [72], Generic Exchange Model (GEM) [73], and Generic Regulation Model (GRM) [74, 75]. These models identify different generic phases of exchange in the dyadic interaction between the supplier and customer, producer and client, government and citizen, et cetera. These generic exchange models give an interactional perspective at the boundaries of work practices. See chapter 6 A practical theory on ePrescribing for an application of GEM and GRM to the ePrescribing process.

Work practice theory focus implicitly on the production of value localized within an enterprise or organization towards external or internal clients. It does not explicitly deal with interoperation between distributed (across time and place) work practices. In order to make it a useful concept for describing context of interoperation it has to be extended and developed to a concept and theory of interoperation between work practices, which are distributed in time and place and across sector, organizational, professional, and geographical borders.

\section{Work practices and information infrastructures}

Information systems have gradually grown from being mainly isolated local systems to becoming one component of an information infrastructure. [76] The evolution of internet and use of the internet technologies have become important factors in the development of commerce, governance, and social life in general. The need to understand the evolution of information infrastructures as well as Inter-Organizational Information Systems (IOS) [30] and their relationship to the existing work practices and the installed base of information systems has prompted the development of new research agendas. [28, 30, 76]

In discussing how research into the design and evolution of information infrastructures can be used to improve the design of information infrastructures in organizations, Pipek and Wulf define work infrastructure in the following way:

" ... the work infrastructure of a worker or organization is the entirety of devices, tools, technologies, standards, conventions, and protocols on which the individual worker or the collective rely to carry out the tasks and achieve the goals assigned to them." [77]

Pipek and Wulf consider information systems as the most important and major part of the work infrastructure. This definition refers to an infrastructure that supports a local work practice or the totality of work practices of an organization.

Hanseth and Lundberg developed a similar notion of work-oriented infrastructures and state that:

“... such infrastructures are developed to support specific work tasks and practices as opposed to the simple and universal services provided by traditional infrastructures ... (i.e. 
electric power at a certain voltage, access to telephone networks, water in a pipe, et cetera).“ [78]

Edwards et al [76] note in their introduction to a special issue on infrastructure studies in the Journal of the Association for Information Systems (JAIS), the tension between local communities and their work practices and the large scale universal infrastructures:

"Following, describing, and mapping these bridges among various scales of infrastructure demand techniques of analysis that penetrate deeply into the work lives of organizations and individuals, rather than uncritically accepting the largest scales of infrastructure as the most important ones.“ [76]

The nature and resolving of this tension will influence design considerations and the evolution of the information infrastructure, see below.

In their definition of information infrastructures, Hanseth and Lyytinen do not explicitly deal with the relation between work practice and information infrastructure although they define an information infrastructure as an " ... evolving socio-technical system”. [60]

Bowker and Star [79] developed the concept of a boundary infrastructure, which serves multiple communities of practice, inside or across organizations. Different communities of practice use boundary objects to communicate. Bowker and Star have thus a somewhat different view of an information infrastructure that focus more on the relation between communities of practice than on a traditional unitary view of infrastructure that focus on the tension between the local and the universal.

Within information infrastructure research, interoperation between work practices is not in the foreground ${ }^{15}$. When work practices are treated, they are mostly considered as a local or specific phenomena. The focus is usually not on the relational aspects of the interoperation between work practices ${ }^{16}$, but on the tension between local work practices and universal infrastructure. However, the notion of the installed base in information infrastructure research as a sociotechnical and practice oriented concept, which includes work context, existing routines, skills and beliefs [39] implies a link between work practices and information infrastructures. See also Hanseth and Monteiro in an early paper [40] discussing the close relation between infrastructure and institutionalized practices.

\footnotetext{
${ }^{15}$ With the exception of Bowker and Star [79] that use the term communities of practice from Wenger [80].

16 With exceptions of scholars that have a relational and process oriented view of information infrastructures with focus in "when is an infrastructure" rather than "what is an infrastructure": "... infrastructures is something that emerges for people in practice, connected to activities and structures." [81]
} 


\subsubsection{Features of information infrastructures}

In this section, we will outline some features of an information infrastructure that have been identified as important by different scholars. In the definition above by Hanseth and Lyytinen [82], an information infrastructure was seen as a "socio-technical system ... consisting of a set of IT capabilities and their user, operations and design communities". Thus, from the perspective of a socio-technical system [83] an information infrastructure consists of an interplay between a technical and a human system.

\section{Infrastructure IT capabilities}

IT capability is defined as "the possibility and/or right of the user or a user community to perform a set of actions on a computational object or process" [82].

We have already described Hanseth and Lyytinen's [60] classification of the functional aspects of an information infrastructure in application and support infrastructure. In addition, we highlighted some key elements of this application and support infrastructure.

In an information infrastructure, gateways are used to connect several heterogeneous applications and system-to-system services. [82] Edwards et al [28] claim that there is a need for gateways to bridge between applications with different properties in order to enable such applications to interoperate. Gateways permit information and functionality from multiple applications to be integrated. From a user or application point of view, gateways can be viewed as an IT capability, connecting various dispersed applications and work practices. Even if these gateways are developed using internet technology, their actual use is dependent upon and linked with, local workflows and communities of practice. Gateways are thus not only technology but also a choice of an agreement on standards for interconnection and exchange formats. Gateways are usually also linked to a service provider, which provide several gateway services to different customers. An example of this is the so called Value-added Network (VAN) ${ }^{17}$ providers that interconnect business partners. These types of services manage, communicate and transform business transaction between business parties engaged in a shared workflow.

Thus, these types of IT-capabilities can also be viewed from work practice, organizational (inter or intra), and macro social level. For example, gateways or systemto-systems services are part of a work practice interoperation between or within an organization or part of a larger community. These services may rely (most often) on internet infrastructures, based on organizational agreements between parties.

\footnotetext{
${ }^{17} \mathrm{~A}$ VAN is a network provider that provides network services to facilitate communication between companies. Initially they came into being to facilitate EDI and mail communication before the internet became generally available. Nowadays VAN does not only provide a technological bridge but also other services such as EDI mapping from applications in-house formats to business standard formats and vice versa, encryption, addressing services, network surveillance, backup, and reports.
} 


\section{Institutional objects for communication}

One important feature of information infrastructures is that they contain and produce standardized (by institutions, organizations, communities) information objects and their identifiers.

These objects have been referred by Eriksson and Ågerfalk [84] as "institutional objects". Eriksson and Ågerfalk [84] remark that identifiers in the information infrastructures are crucial to design. One can assume that they are also essential in the interoperation between work practices. In eHealth, institutional objects may include (c.f. Hanseth and Lyytinen [60]), disease, anatomical and drug classifications, identifiers of licensed prescribers, general practitioners, hospital departments, clinics, pharmacies, medical drug identifiers, dosage schemes, patient identifiers, and work place code. Registers of such identifiers must be available to information infrastructure users and must be administrated and up to date to avoid mistakes and errors.

They can also be viewed as "boundary objects" for communication and cooperation, in the sense that they share common properties to enable communication between communities and at the same time can be adapted to the specific needs of the participants. However, they need to be stable enough to maintain a common identity cross multiple contexts [85]. They are important in regulating and stabilizing the interoperation between applications, organizations and people. According to Bowker and Star [85], boundary objects emerges as a result of a sustained cooperation between different communities of practice. Bowker and Star view the creation and management of these boundary objects as key activities to develop and maintain coherence between different communities that cooperate.

Star and Griesemer [86] make an analytical classification of different types of boundary objects: repositories; ideal type; coincident boundaries; and standardized form. Cooper [87] analyzes the prescription as an example of a standardized form ${ }^{18}$ kind of boundary object.

Standardized forms are a kind of 'boundary' object that are used as a method for shared communication across dispersed work practices. In the prescribing process, the standardized form is a prescription, whether in paper or electronic form. Standardized form as a method could be viewed as the agreed rules that regulate the content and form of the communicated object. The communicated object in the actual transaction will be part of the dynamic and evolving information infrastructure.

\footnotetext{
${ }^{18}$ Cooper [87] concludes the analysis of the role of the paper prescription as a boundary object in relation to the move to implement ePrescription in UK, by stating that “... it is suggested that technological change should reflect on the value of previous systems fully, including recognition of insight offered by theoretical insights such as boundary object status."
} 
Repositories, another type of boundary object, are typically information repositories containing identities for reference to information, which is an important part of the information infrastructure crucial for communication.

Boundary objects enable different communities to work together without having consensus. They emerge for "doing things together" [88]. Thus, boundary objects are also linked to the requirement of different practices.

\section{Inscribed behavior of information infrastructure}

Different types of communication standards, from low-level machine-to-machine interface standards, internet standards, to Vertical Information Systems (VIS) standards, regulating business transactions within a business sector, are an important part of an information infrastructure. Hanseth and Monteiro [70] suggest that the design and implementation of these standards inscribe a certain a pattern of use and behavior of the information infrastructure.

Based on concepts in Actor Network Theory (ATN), inscriptions refer to the way technological artefacts embody a pattern of use. The design of a technological artefact builds on an anticipation and restriction of future patterns of use, which are often described in scenarios of intended use. These scenarios of use are designed into applied standards and systems used. These designs therefore create a repertoire of behavior by the user and the system.

The inscriptions designed and implemented in standards and system may be weak or strong. Weak inscriptions can be used in many different ways and may thus be regarded as flexible. Strong inscriptions restrict patterns of use and are thus regarded as inflexible. For example, a weak inscription in a system could demand a manual routine to regulate the use of the system as it is not inscribed in the technical artifact system or standard. In this way, inscriptions could be either technical or non-technical, depending of the division of the task between the user and the system. An inscription in the information infrastructure could be strong in some areas and weak in others and be complemented with manual routines. The inscription of behavior from a work practice point of view is particularly obvious in VIS standards. In these standards, usage scenarios and rules for restricting the content of communicated messages are usually defined. Other more technically oriented or general standards have also inscribed behavior, for instance identifiers like Global Localization Numbers (GLN) provided by GS1, have explicit rules for the assigning and changing of localization. [89]

Inscribed patterns of behavior in technical artefacts may not be successful in actual use. Translation, another ANT concept, is the ability of the diverse actors with different interests to appropriate other actor's interests. Therefore, the translation of the designer's intent with the information infrastructure towards its intended users as well as the translation of different user's intended usage of the infrastructure to other users is essential for a stable and predictable usage of the information infrastructure. Thus, it is possible that 
actors use the information infrastructure in heterogeneous and unpredicted ways not foreseen by the designer and users. This becomes even more complex in the sense that an information infrastructure is designed over a long period by designers with different interests, processes and traditions. Furthermore, the interoperation between actors from different business sectors, having different roles, traditions, knowledge, processes, and interests, adds to the complexity of translation.

Thus, an information infrastructure encompassing actors with different functional roles within a business sector will be a heterogeneous assemblage of different inscribed patterns of behaviors. These inscriptions may be technical in the sense that they are embedded in the technical infrastructure and thus directly inscribed in the information infrastructure, or non-technical ${ }^{19}$ when embedded in the work practice and the organizations in the form of routine descriptions, guidelines or undocumented habitual patterns of behavior by the actors.

Inscribed patterns of behavior could also be categorized in specific ${ }^{20}$ patterns and shared patterns (cross-functional) of behavior. It is the shared pattern of behavior that are in focus here, although specific patterns of behavior also influence the shared patterns.

\subsubsection{Evolution and design of information infrastructure}

In this section, we describe some aspects of the evolution and design of an information infrastructure. The first part describes the different phases in the evolution of an infrastructure, which can be seen as a socio-cultural evolutionary process. The later refers to a design theory developed by Hanseth and Lyytinen [60, 82], which focuses on design guidelines that will promote growth and adaptability of the evolving information infrastructure.

We will conclude this section by discussing the limitations of design in relation to infrastructure growth and consolidation.

\footnotetext{
${ }^{19}$ Also referred as "manual" as they are performed or administered by human actors.

${ }^{20}$ With specific pattern, we mean a pattern of behavior of one part of an organization or information system involved in interaction with another organization/information system. This specific pattern is dependent on the shared pattern of behavior as well as the specific behavior of the interacting agents or systems.
} 


\section{Phases of infrastructural evolution}

In a general sense, technological change, as well as evolution of information infrastructures, can be viewed as a socio-cultural evolutionary ${ }^{21}$ process with periods of variation, selection, and retention. According to Anderson and Tushman [90], three major phases in technological change can by identified:

1. ferment activities where new technologies or other changes create an increased competitive activity between different solutions, challenging the existing technology;

2. selection of a dominant design paradigm or standard;

3. retention, where incremental development of the dominant design continues until a new discontinuity occurs.

Phase 2 and 3 correspond roughly to Hanseth and Lyytinen's [60] bootstrap or growth phase and to Edwards et al [28] consolidation phase.

In the growth or retention phase, according to Anderson and Tushman, a process of consolidation emerges in which:

"Social structures arise that reinforce this stable state; standard operating procedures are predicated on the reigning technical order, organizational power structures reflect dependencies that are partly governed by technology, and institutional networks with powerful norms arise whose shape is partly determined by an industry's technical regime." [90]

Edwards et al [28] conclude that "the careful nurturance of infrastructural change, and attending to the tensions that emerge from it, is a managerial and political skill of the highest order."

Although the borrowing of an evolutionary metaphor for information infrastructure development put forward by Hanseth and Lyytinen has its merits, it would be a mistake to rule out the possibility of any human control (unlike in evolutionary biology) in this evolution.

Therefore, with the growth and consolidation of information infrastructure operating procedures, organizational structures to govern and manage the infrastructure, implementation guidelines as well as legal and financial conditions will emerge in order to support growth and maintain the evolving information infrastructure.

21 Hanseth and Lyytinen [82] adopt a theory of Complex Adaptive Systems (CAS), which have similarities with evolutionary theories in biology, in order to better understand the evolution and design of information infrastructures. 
Eriksson and Goldkuhl [91] identify the following pre-conditions for developing an einfrastructure in the public sector: legal, economical, organizational, and e-infrastructure precondition (technical, informational, and contractual).

\section{Design theory for information infrastructure design}

Hanseth and Lyytinen [60] claim that a basic assumption in information systems design theory is that the design can be made from scratch by identifying and matching specific user requirements into a design. This implicitly assumes that a majority of the requirements can be specified beforehand and that the final design is a stand-alone and closed artefact that follows a specific life cycle. From this point of view, design theories do not regard relations to other designed (past or future) artefacts or design communities in the environment as critical. These assumptions are particularly untenable in relation to the design problems of information infrastructures. Information infrastructures evolve in space and time and have a scope and longevity beyond designers' own control and timeframe. Design boundaries for an information infrastructure and its elements are only partially known and controlled by the designer, and there can be multiple designers and designer communities. Design almost never starts in a greenfield situation, and therefore design requirements cannot be defined unambiguously or acquired in isolation. In contrast, the installed base imposes its own requirements.

The evolution of infrastructures is both enabled and hampered by the installed base, comprising the existing configuration of IT capabilities (Hanseth and Lyytinen [82]). Newly developed IT capabilities need to be integrated into the installed base. This imposes constraints on what can be designed and make the design more complex. The design theory of Hanseth and Lyytinen [82] focuses upon how the installed base could be used as an enabler for promoting the bootstrapping and further development of the information infrastructure. The bootstrap problem is oriented towards the first stage of information infrastructure design. The purpose of this stage is to create a momentum of growth, and it includes three design principles:

- design initially for usefulness, which guides the designers to develop a simple IT capability that is directly useful for a small user group;

- build on the installed base, which guides the designers to use the installed base, especially the existing universal service infrastructures, as an enabler for einfrastructural growth;

- expand the installed base with persuasive enrollment tactics. This means that after the first small user group has started to use it and find it useful, the designers have to focus on sustained growth. To achieve this, designers have to continuously persuade users to adopt the IT capability, and not add functionality that complicates its implementation.

When the information infrastructure gains momentum, the designers need to guarantee that the information infrastructure will grow, adapt, and re-organize itself constantly. Ad 
hoc designs, originally created for early users will now threaten to create technology traps. If designers continue to generate interdependent and local IT capabilities, the whole infrastructure will be inflexible. In contrast, if IT capabilities are organized in a modular fashion through loosely coupled 'layers,' which can change independently, this will generate higher component variation for successful adaptation.

This defines the adaptation problem of information infrastructure design and the following two design principles offer guidance to promote modularity:

- make the organization of capabilities simple;

- modularize the information infrastructure.

In the growth phase, which Edwards et al. [28] refer to as the consolidation phase, Hanseth and Lyytinen [82] recognize that the installed base can be an obstacle for the development process due to lock-in effects or technology traps, because information infrastructures that face early lock-in and obstacles will not scale up. Early design decisions based on the requirements of a small user group may later constrain expansion of the information infrastructure.

Edwards et al ([28] p. 17-18) describe how the as-is infrastructure can serve as both an enabler and obstacle, because technological change is path dependent. Path dependency means that a change constraints or opens up for new possibilities.

The installed base can be an enabler if it promotes so-called network effects, which means that the value of certain kinds of IT capability increases exponentially with widespread adoption.

\section{Limits of information infrastructure design}

Although Hanseth and Lyytinen adopt a socio-technical approach to information infrastructures (II), according to Nielsen [92], their design theory in practice tends to undertheorize the influence of human agency, in "portraying technology as autonomous by leaving developers simply with the ability to cultivate." [92]

Nielsen aim at "extending the evolutionary perspective on II development to also take into account interests, values and institutions and thus opposition, conflicts and contradictory forces at play in II building." [92]

Nielsen adopts the perspective of building information infrastructures as "evolution and construction" (our emphasis). Information infrastructure builders bring their own sociotechnical frameworks, nurture their assets, and bring their own process of building. Institutions such as "practices, organisations, authorities, laws and regulations influence not only the individual builders, but also the structures (and the formation of these structures) between the different II builders". (ibid) 
The perspective of construction brings with it a certain control and plan to implement changes. Outputs are bound to be controversial and disputed, influenced by other builders, politics, power structures, and institutions, as well as by the installed base. [92]

Aanestad [93] use the metaphor cultivation to balance the role of humans and technology. The evolution of the information infrastructure cannot be completly controlled, but human actors have an influence in the change process.

Anderson and Tushman argued that:

"Because no technology dominates all dimensions of merit, we argued that the closing on an industry standard is an inherently political and organizational phenomenon constrained by technical possibilities. The passage of an industry from ferment to order is not an engineering issue as much as a sociological one. Since stakes are substantial, a complicated array of organizational and collective forces bear on the emergence of a single standard." [90]

Pipek and Wulf [77] develop another perspective on the design of information infrastructures (they prefer the term 'infrastructuring' instead of design) to Hanseth and Lyytinen [60]. Pipek and Wulf do not emphasize the designer's perspective, but instead view the designer as one of many roles in a process that is not mainly design driven. The development of infrastructure is driven by infrastructure breakdowns and user innovations. They argue that an infrastructure oriented view of information systems design needs to "focus on mapping actors and activities, to acknowledge their contributions to infrastructure development ". [77]

Aanestad and Jensen [39] focus on implementation strategies for building nation-wide information infrastructures in health care. They contribute with a discussion on different implementation strategies and on the challenges in involving multiple independent stakeholders in infrastructure development, based on a comparison of two different cases in Denmark. They give interesting examples how initial approaches for realization of visions shapes implementation strategies. For a related topic see our discussion in section 8.4.1 on how chosen "operational models" may influence implementation and rate of adoption of infrastructure for ePrescribing in US and Sweden.

The evolution and design of information infrastructures is complex with evolutionary traits, in the sense that there is no overriding goal and complete rational control of the evolution of information infrastructures. Design strategies, the installed base and implementation tactics, as well as economical, commercial, institutional, political, and legal factors will influence the evolution.

\subsection{Standards and interoperability}

Standards are considered key enablers for interoperable systems and information infrastructure development [94]. Hanseth and Lyytinen [82] define standards as shared and agreed upon infrastructure specifications among a set of communities. ICT-standards 
can be divided into technical (horizontal) and semantic (vertical) standards, or named Vertical Information Systems standards [95].

\subsubsection{Horizontal and vertical standard}

Horizontal standards, like internet related standards, convey technical specifications that dictate how IT capabilities should work together. These standards are important in that they allow for the design of interoperable modular systems. Horizontal standards can thus be viewed as standards that apply cross business domains or applications valid for a large community and wide application. Vertical Information Systems (VIS) standards, in contrast, prescribe information and data structures and their definitions, document formats, and business processes for particular domains or industries [95].

VIS standardization is part of the effort by different parties to enable interoperable business processes. Usually these parties have different roles in the business process such as Buyer - Supplier, or in the case of ePrescribing: Prescriber - Dispenser. This means also that they usually have different structures and conditions on their market [95].

VIS standardization vs. horizontal standardization differs. While horizontal standardization is often characterized by a race and competition between rival homogeneous groups, VIS standardization is rather characterized by collective actions among heterogeneous groups. Consequently, a successful development of a VIS standard of small homogeneous groups could meet unsurmountable difficulties in diffusion of the standard. Therefore, the development of VIS standards is likely to be different from the development of horizontal standards, in that the characteristic of their development to much higher degree will influence their adoption and diffusion. A fragmentation of competing rival efforts, something that is common with horizontal standardization, will probably not work in VIS standardization. Markus et al [95] make some interesting propositions for successful VIS standardization derived from their case study on U.S. Residential Mortgage Industry:

- ensure the participation of all structurally different groups in order to meet the needs and demands of the interoperating processes;

- key players in diffusing the VIS standards should be part of the standardization work;

- deploy successful tactics in developing standards, that do not jeopardize prospects of diffusion;

- develop simpler solution that promotes diffusion better than a technically complicated one.

VIS standardization is a long-term process in which sustainability is important in the development, diffusion, and maintenance of a standard. Zhao et al [96] studied factors that contributed to the sustainability of Vertical standardization efforts in Vertical Standards Consortia (VSC). They propose a multi-level framework to explain characteristics that 
affect VSC sustainability on the level of member participation, characteristics of the consortia, and the industry sector.

The key role of standards as the enabler for information infrastructure design have also been acknowledged in the eGovernment literature. It is common that so-called interoperability frameworks (in a certain domain such as eGovernment and their geographical/regional context) refer to their own technical standards catalogue. These frameworks refer to basic technical and "semantic" specifications that all agencies relevant to the eGovernment strategy implementation should adopt $[4,97]$. This could include both horizontal and vertical standards.

\subsubsection{Predefined and emerging standards}

Standards can be divided into "De jure" (predefined) and "De facto" (emerging) standards. De jure standards are those developed by standardization bodies, and de facto standards are emerging industry standards [28]. Standards could also contribute to bootstrapping the infrastructure and initiating growth [82]. Standards are considered to be a very important mechanism for information infrastructure growth because they can produce positive network effects. The value of a standard depends on the number of users (organizations, people) that have adopted it, and the more users there are the more valuable the standard becomes, which in turn leads to increased adoption that further increases its installed base.

The important role of standards as a key enabler for information infrastructure development also explains why standards research constitutes a major part of information infrastructure research (c.f. $[28,79,95,98])$. Problems and obstacles related to vertical standards implementation have however been recognized. See for example Hanseth and Monteiro [41, 70] and Markus [95].

A quote from Libicki [99] can illustrate the difficulty of implementing standards: "Information technology standards have been touted as a means to interoperability and software portability, but they are more easily lauded than built or followed". In particular, the development and implementation of predefined vertical standards have proven to be a tedious, costly and failure prone process. Damsgaard and Truex [100] claim that predefined semantic standards with their enforced grammar could be seen as "procrustean beds" 22 , and thus incapable of resolving the trade-offs between global and local requirements.

Lyytinen and Damsgaard [101] have criticized the diffusion of innovation theory (DOI) in missing important factors in the diffusion of complex networked IT solutions. Vertical standards can be viewed as complex networked IT solutions. These standards are interorganizational in nature and require considerable alignment of procedures and policies. Their implementation and operation requires considerable skills and expertise and they

\footnotetext{
${ }^{22}$ According to Greek mythology, Procrustes, a son of Poseidon, was a rough smith that cut peoples' legs in order for them to fit an iron bed.
} 
rely on a complex network technology and on VAN providers. The standards also need an institutional regulation. Therefore, a diffusion of innovation theory must take into account the complex nature of this technology and its standards, and focus on the roles of institutional bodies and key players, as well as process features in the diffusion. Lyytinen and Damsgaard [101] calls for a diffusion of innovation theory that has multiple perspectives.

\subsubsection{Vertical standards for business processes, reflexive standardization, and standardized vocabularies}

Developing and implementing message standards for business processes (Vertical standards) and of standardized vocabularies are very important for achieving interoperability. In this section, we will discuss some challenges in the development and application of standards and standard vocabularies, taking examples from the eHealth sector.

\section{Message standards for business processes}

Within the area of eHealth, a number of standards are available for Electronic Health Records or Electronic prescriptions, although they do not seem to be used very much in implementing eHealth solutions. However, ePrescribing in Sweden is an example of how a UN standard and European pre-standard have been used to implement ePrescription messages. Here, we will briefly describe how the standard was used to arrive at an agreement between the parties exchanging ePrescriptions in Sweden. (See further chapter 5)

As with all standards, particularly with VIS, there is a trade-off between general applicability and precision. This is particularly striking when it concerns heterogeneous domains with different sets of legal rules and work practices. One dimension of this heterogeneity is its scope of applicability, i.e. different levels of application: international, national, and business communities. This wide and varying scope of applicability has different characteristics in terms of the legal and political context, and the characteristics and culture of the business sector. Another dimension of heterogeneous domains is that inter-organizational interoperation is usually between different domains, and therefore we assume that interoperation is taking place in a shared heterogeneous domain.

If we take, for example, a traditional eCommerce situation, there is a relative stability in the sequence of ordering, order response, dispatch notice and to some extent invoicing. However, note that when it comes to defining the content of the invoice or how to handle its attestation, this usually differs from country to country due to legislation on minimum requirements of what an invoice must contain and how attestation of an invoice should be done according to laws on accounting. eCommerce communication is usually an 
interoperation between different domains, and there could be different rules in each company about how to handle invoices and what they should contain. Another typical difference in the application of this type of standard is the fact that the definition and identification of the product to be provisioned and procured is different in each sector and market (national/regional/international). The development and the use of global standards for identifying actors and products, such as Global Localization Number (GLN) ${ }^{23}$ and Global Trade Item Number (GTIN) are very important, and so is the development of business sector standards.

In any case, it is possible to define the content of such eCommerce transaction relatively generally and with good precision regarding the structure and format of data. These standards are however huge and it is only a minor part of the standard that is agreed upon in the exchange agreements of the communicating parties. Furthermore, a specific interpretation and application of a standard is made in designing an implementation for a particular region or business sector.

Thus, there is usually a need to have guidelines and restrictions in one country, region or branches of industry, to limit the number of options available and make it economically feasible to develop information systems that could comply with a certain limited subset of the standards, which could be adapted to a particular exchange between the parties. eCommerce standards are developed over many years and imply a certain business process, with the intention to achieve certain common business goals. These standards are not simply there to enable electronic eCommerce transaction; they are also used to improve the work practices of the participants, for example by getting a better control of pricing, of what is ordered and the automatic attestation of invoices. Most of these eCommerce standards have been developed to a mature field with successive improvements.

Another aspect of vertical standards is that the specification of a standard is not enough to completely define the standard. For example, the national standard of ePrescription in Sweden is a totality of specifications, implementation guidelines, implementation and test procedures, and application certification.

The point here is that a standard for a message is a very useful tool on which to base the implementation of interoperability. In this sense, there is a gradual difference between a standard that is prescriptive in detail and is mandatory, and a standard that is more a guide for implementation. In the case of a vertical standard, it is not realistic to have a detailed prescriptive standard on a generic level of application, as there are so many contextual dependencies on a specific level of application in a business sector community. Therefore, these types of standards are usually developed in consortia in a business sector either regionally/nationally and sometimes internationally.

Even regarding those highly technical standards (horizontal standards) that are applicable for a more universal use, it is common knowledge that a standard is not only a

\footnotetext{
${ }^{23}$ See www.gs1.com
} 
specification but also an implementation [102]. See for example the notion used by the World Wide Web Consortium (W3C) to have both specifications and "running code". We recall the Architectural Principles of the Internet were the internet's evolution:

“... depends on rough consensus about technical proposals, and on running code.” [103]

This is even more valid when complex vertical standards are to be implemented in cooperation between several organizations with different roles and work practices.

Thus, in the case of a more mature standard that has evolved over many years in a consortium, it is more likely that the domain is more stable and better understood and that the shared process is better defined and linked to the different transactions. Moreover, the objectives for the different stakeholders are probably clearer. Focus is less on technology and more on the implementation of shared and internal processes. This is analogous to a consolidation phase of an information infrastructure for interoperability.

In a novel process, combined with a greater heterogeneity across a domain, the implementation of standards becomes more complex as it involves a learning process and alignment of work practices, objectives and the installed base of information systems. This is analogous to the bootstrap phase of information infrastructure development.

In any case, it is important to understand that developing standards is not the end of the story, but the beginning of implementing them as a common agreement between bi-lateral or community parties.

\section{Reflexive standardization and socio-technical complexity of standardization}

In this section, we will describe research on standardization which highlights the sociotechnical complexity and the unexpected side effects of standardization. Hanseth et al [104] address the question of what historical factors or events will influence the making of IS standards. They base their work on a three-year case study of the process of standardization of an electronic patient record system $\left(\mathrm{EPR}^{24}\right)$ in Norwegian hospitals. Hanseth et al [104] adopt the concept of reflexivity from theories of reflexive modernization. They use the concept to highlight the fact that new actions can cause unexpected effects, which in turn trigger new actions with new side effects, et cetera. In the end, these side effects will affect the initial action; hence the term reflexivity. Applying

\footnotetext{
${ }^{24}$ Hanseth et al uses the term EPR, which is similar to EHR, which is an abbreviation of Electronic Health Record. EPR has its origin in UK and is defined by NHS (National Health Service) as the "record of periodic care provided mainly by an institution. Typically, this will relate to the healthcare provided to a patient by an acute hospital." EHR is defined as “... the concept of a longitudinal record of patient's health and healthcare - from cradle to grave. It combines both the information about patient contacts with primary healthcare as well as subsets of information associated with the outcomes of periodic care held in the EPRs. " [105]
} 
this to standardization, which they see as a kind of constructing of a new order, may very well result in the opposite effect, undermining the initial aim with standardization.

Hanseth et al [104] show the socio-technical complexity of IS standards and standardization efforts. One aspect of the complexity is the network externalities, which are the benefit of the increased use of standards and technologies. This can have a negative effect making it difficult to change in the future, as the installed base grows and many actors become dependent. Other aspects of this complexity are variation in the interconnected local work practices and organizational structures, and the heterogeneity of the actors involved in standardization (see above on vertical standards efforts and further in section 8.3 New National ePrescription Format - Vertical Information Systems standardization effort as collective action). To these aspects of complexity, Hanseth et al add the concept of reflexivity to call attention to the risk of creating disorder instead of order - the initial aim with standardization - particularly when standardization is applied in complex areas that are difficult to control.

Standards are the products of a standardization. Hanseth et al [104] use the well-argued definition of standardization by de Vries, which is:

“... the activity of establishing and recording of a limited set of solutions to actual or potential matching problems directed at benefits for the party or parties involved balancing their needs and intending and expecting that these solutions will be repeatedly or continuously used during a certain period by a substantial number of the parties for whom they are meant." [106]

In line with this definition, they view the work to create an EPR system to be used by several regional university hospitals in Norway as an effort of standardization. One aim with this work was that all information about the patient should be gathered in the EPR system and that the system should be one shared and integrated system for all the departments at a hospital. However, the joint project at the hospitals was terminated without achieving the initial goal. What started as a project to create an EPR system for university hospitals grew to a Norwegian standard, to a European and then to an international standard, and in the end the needs and demands of the Norwegian hospitals was marginalized. Thus, the scope of standardization grows with the number of parties involved.

The case study also highlighted the implementation process inside the hospitals. The aim was to have an EPR system that would make information available anywhere and at any time without duplication and inconsistencies of data. The catchword was "One Patient One record". However, this ambition resulted in an increase in the fragmentation of the medical records that were kept in different departments. One reason for this was that some users felt that their local systems gave better support for their work practices and refused to abandon their existing systems. It was considered too complex to integrate all the different demands from different departments. This led to double entries of information and, "cut and paste" of information between systems. 
Hanseth et al [104] view EPR standards as a complex system, which contain a large number of standards on very different objects. These standards embed different work practices $^{25}$ and standardization work involves different user groups and experts. Furthermore, there are many links between the different elements of such a standard, which interact in a dynamic way, with a history, and with no clear-cut border to other systems.

Considering other aspects such as project management and use of methods, Hanseth et al [104] claim that the main reason for the failure of the EPR standardization was "... poor understanding of complexity and standardization within software engineering, information systems, and standardization field." [104]

Hanseth et al [104] claim that their case represents a general class of problem that involves a complex interaction of information infrastructures, information processing and work practices. This class of problem is characterized by a high degree of heterogeneity and many actors involved. To this is coupled a need to coordinate and standardize the actor's interdependent behaviors.

Hanseth et al [104] do not provide any final answer for how to handle this type of complexity, although they do give some tentative answers. One is to avoid creating complex systems, as it may not be possible to manage the inherit complexity. Efforts to achieve "perfect order" may instead lead to increased chaos.

They claim that there is a risk that traditional software engineering methods tend to underestimate complexity and overestimate the uniformity of multiple work practices, and thus tend to meet real complexity with simplification and abstraction. See for example the design metaphor ${ }^{26}$ "One patient, One Record", which tends to focus on completeness and non-redundancy of information and underestimate complexity.

Hanseth et al [104] point to the need to understand that in complex areas there is a multitude of "sub worlds" that are inconsistent, and that we need to be able to deal with these. One way is to identify these "sub worlds". In our context, we view these as work practices in different communities.

In order to deal with this complexity Hanseth et al [104] suggest that:

"Maintaining loose coupling between the social and the technical is perhaps the most important strategic element. What should be avoided is embedding specific working practices into the standards. To do so, one needs to be well aware of the local specificity

\footnotetext{
${ }^{25} \mathrm{We}$ assume different professional communities.

${ }^{26}$ This metaphor focuses on information processing in general and tends to view information systems as systems for storing, processing, retrieving and presenting information and underestimates the action aspects of information systems and thereby the complexity of multiple interdependent work practices. See chapter 7.2 Information systems and information infrastructure for our view of information systems as vehicle for communication and action.
} 
of work practices, and the fact that the practices are embedded into the technology." (Our emphasis [104])

One can interpret this statement as aiming to separate the technical and the social. However, this would only move the existing complexity to the local work practices and their adaptive use of the technical artifact and not much would be gained in managing complexity. We agree that it is important not to build in specific local work practices into standards. The dichotomy of general and local practices assumes that the practices are of similar kind and that differences can be subsumed or abstracted away in a general case. Standardization of work practices of similar kind, which over time have developed their own local idiosyncratic specificities is a precondition for standardization of information systems. However, we see another kind of complexity in the interoperation between work practices of different kind in different "sub worlds" and organizations.

Instead of separating the technical and the social, we think that one way to deal with the complexity is to make a loose coupling between work practices. This coupling is made using shared boundary objects and shared work practices. The challenge is to find the correct balance of what is shared and what is specific, i.e. what is to be shared and what is controlled by each agent's work practice. We think the concept of a boundary infrastructure that Bowker and Star [85] develop describes this complexity well:

"Any working infrastructure serves multiple communities of practices simultaneously be these with a single organization or distributed across multiple organizations." [85]

They use the example of a hospital system that has to consider both separate and combined needs by different professional communities at a hospital and related external stakeholders. To manage this situation boundary objects is used by different communities of practice to communicate with other practices through the information system. These boundary infrastructures are not perfect, they are always based on compromises and concessions made by different communities, but they "keep things moving along". [85]

The concept of a boundary infrastructure developed by Bowker and Star has advantages compared to a unitary view in that it considers the complexity of the interaction and the differences that exist between communities of practice. Star and Ruhleder [81] argue for a relational and process oriented view of an infrastructure. [107]: "It becomes infrastructure in relation to organized practices." [81].

A limited focus on the tension between the specific and the generic can lead to an underestimation of the complexity of the interoperation of heterogeneous work practices. This complexity may thus be overlooked in efforts to construct unitary systems. 
See further our conception of shared work practices and boundary objects in section 9.3 Interoperation and interoperability in a shared work practice to analyze and identify this balanced loose coupling ${ }^{27}$ of work practices.

According to Hanseth et al [104] another way to handle the socio-technical complexity is to limit the reach and range of the standard. Instead of a tightly coupled universal standard, one can reduce the complexity with several simpler loosely coupled standards. One way to do this is to identify the important institutional objects in an area that are used as boundary objects in communication between different work practices. These objects could then be standardized in such a way that they work as elements of coordinating and connecting work practices and in addition enable a certain independence of each work practice. See further section 9.3 .

An alternative method to reduce complexity in information systems standardization, not mentioned by Hanseth et al [104], is the standardization of work practices. For example, why have slightly different work practices for the same type of care, a work practice of the same kind, in one hospital and a different one in another? Differences in work practices may be due to individual, historical and occasional circumstances and have no rational motivation. Furthermore, in the situation of inter-organizational interoperation and the interaction between different kinds of work practices, one option to reduce complexity is to standardize the shared work practice into a generic work practice. See chapter $6 \mathrm{~A}$ practical theory on ePrescribing for an example of a generic work practice.

\section{Standardized vocabularies}

An important type of standards is standardized, controlled vocabularies or other coding systems within a particular domain, for example in health care and life sciences.

One important standardized nomenclature within health care is the Systemized Nomenclature of Medicine (SNOMED) and SNOMED-CT, where CT stands for Clinical Terms. CT is a conceptually based terminology for clinical health care terminology. It consists of " 311,000 active concepts with unique meanings and formal logic-based definitions organized into hierarchies.“ [109]

Such huge vocabularies in a professional domain must imply a complex process of introduction, acceptance, assimilation, feedback and use in daily work practice by practitioners. However, reported evaluation of experience of using SNOMED CT is rare, as are studies of its use. There is a lack of knowledge as to whether these terminologies can be applied consistently. [20] Some studies of use indicate that there is great

\footnotetext{
${ }^{27}$ Hugoson et al [108] discuss different interoperability strategies for the agile business enterprise: Uniform, Intersection, Interlinking. They show that the same type of difficulties in the standardization of EHR systems exist in Sweden as in Norway. They suggest that the strategy on interlinking is one viable strategy. By interlinking they mean that interaction: “ ... between different systems is carried out through the exchange of messages which are based on business demands."
} 
heterogeneity among coders of the same controlled terminology and concludes that this is due to "complexities inherent in language usage" [19] and that there is a need for a discussion on how to better enable users of the terminology to use it in an efficient way. [20]

Terminologies are important elements of standards and play an important role in interoperability to facilitate communication between people and systems. There is a discipline called Terminology, which deals with vocabulary in a specialized discourse.

Therefore, the terminology field can be interesting and valuable to study from the point of view of interoperability, as interoperability between organizations, people, and systems occurs within a certain domain of knowledge and practice, which uses a specialized language.

Another related concept is 'corporate vocabulary' or 'professional vocabulary', which develops within a certain profession, work or business process. Often interoperability between organizations also involves a cross-domain communication between communities which have different specialized languages and there is a need to create a common specialized language to facilitate communication.

Specialized languages communities can be viewed from at least two standpoints; normative or descriptive. A normative view prescribes the proper use by idealized language users of terms in specialized languages and the descriptive view describes how terms are actually used ${ }^{28}$ by real users within a language community.

Terminologies have traditionally been normative or prescriptive. In the traditional school of terminology, there was a strong belief in standardization in order to facilitate special language communication.

The traditional school of terminology is based on a number of premises. In the Vienna school of terminology which has been one of the dominating schools, terminology always begins with the concept. This is called an onomasiological perspective. In Lexicology, two different perspectives for analyzing the relationship between a word and its semantic value are defined. A semasiological perspective starts from the word and the onomasiological perspective from the so-called content aspect of the sign, which is considered to be its meaning. However, traditional terminology sees the concept not as the subjective or intersubjective meaning, but view the concept as somewhat independent of language and context. [23] This perspective assumes that concepts exist before words and thereby downplaying the role of language in the process of conceptualization. Other tenets of the traditional school of Terminology are:

\footnotetext{
${ }^{28}$ This actual use of a language by real speakers is of course based on conventions and norms how to use the language in a community.
} 
- Concepts are clear-cut and can be defined on the basis of necessary and sufficient conditions

- Univocity of terms is essential for unambiguous, effective and efficient communication

- Figurative language and change of meaning is a concern for terminology, but these are relegated to linguistics. [23]

The theoretical basis for these assumptions is influenced by Saussurian structuralist linguistics and 'objectivist' philosophy. [23]

Criticism of this approach have emerged within the terminology research community expressed in different branches such as 'Social and communicative terminology theories' influenced by linguistics and particularly sociolinguistics and 'Cognitive-based theories of Terminology' influenced by cognitive semantics and cognitive linguistics.[110]

Here, we will present some of the critiques from the so called socio-cognitive approach [22] to terminology, developed by Rita Temmerman.

Behind the premise that concepts are clear-cut, lies the idea of a concept field where relations between concepts are logically and ontologically structured according to a number of relations.

Underlying this, there is an assumption that it is possible to delineate a concept by a number of common characteristics. This idea has been criticized by many scholars, such as Wittgenstein, with his notion of family resemblance and language games [111], and for example by the prototype theory (See Lakoff for a discussion on this topic [112]). Some scholars believe that the flexibility of categories is useful in communication for the evolution of understanding. [22]

The univocity of terms means that each concept should only be designated by one term, which excludes synonymy and polysemy. The assignment of terms to concepts is a deliberate act of specialists and committees, which shows the strong link between standardization and terminology work or what Gärdenfors [113] would have considered a oligarchic linguistic power structure.

It is our view that with regard to the publication of standards and terminology, the primarily value is not in the standards or terminologies in themselves, but their application. However, this is the most difficult and important step. The problem of the traditional approach towards terminology is that it downplays much of knowledge of how concepts and language actually evolve in human communication, especially by treating concepts as if they were independent from language and language use. For example, when studying a corpus of text in a specialist field such as life science, it is a fact that polysemy and synonymy have an important function to play in terminology. Different terms allow for shifting perspectives.

The use of figurative language such as metaphors has been shown to be an important part of human conceptualization, and not as an exception. [114] 
Traditional terminology has a synchronic view of terms and concept systems. However, meaning changes over time as do the terms. Studying terminology diachronically, over time, is part of understanding the concepts and terms themselves.

Rita Temmerman [23] summarizes her critique of traditional terminology in a table (see Table 2).

Table 2 Temmerman's [23] comparison between traditional terminology and the reality of terminology in special language in the life-sciences.

\section{Principles of traditional terminology \\ Temmerman's observations}

Terminology starts from concept without considering language

A concept is clear-cut and can be assigned a place in a logically or ontological structured concept system

A concept is ideally defined in an intensional definition

Language plays a role in the conception and communication of categories Many categories are fuzzy and cannot be absolutely classified by logical and ontological means

An intensional definition is often neither possible or desirable

A concept is referred to by one term only, Polysemy, synonymy and figurative which designates one concept language are frequent and functional in special languages

The assignment term/concept is permanent

Categories evolve, terms change in meaning, understanding develops

If the premises of terminology creation are not in line with the reality of terminologies in a special language, the application of such a terminology will be problematic. What is needed is a terminology that is based on the use of terminologies in specialist languages. With this approach, it will be possible to base terminology work on findings from linguistics and cognitive psychology, such as cognitive linguistics and cognitive semantics.

Such an understanding of terminology work will focus on the application and use of terminologies, rather than on their creation.

\subsection{Summary and conclusion}

There is no agreed definition of interoperability. The definitions vary from a narrow technical system-to-system focus to a broader view incorporating actors, processes, organizations, and legal issues. However, there is an increased understanding that 
interoperability is not primarily a technical question; the challenge is the ability to interoperate between organizations and their agents.

Interoperation between organizations is dependent on an information infrastructure. Information infrastructures enable people and organizations to use their locally controlled information systems to interoperate. Information infrastructures are open heterogeneous socio-technical systems consisting of application and supporting infrastructures and communities of operation and design. From a perspective of interoperation, information infrastructures are instruments for interoperation between work practices.

A work practice is habitual recurring patterns of action to produce a certain result for a client. These actions are based on transactional and infrastructure conditions. A transaction is the horizontal coordination and transformation activity in a work practice were the infrastructure supports the recurring transactions. The information infrastructure supports both transactions and the underlying infrastructure of the work practice.

We have identified three important features of an information infrastructure that have relevance for interoperation:

- IT capabilities of an information infrastructure;

- institutional objects that are essential in an information infrastructure, enabling communication between different communities;

- inscribed behavior of the information infrastructure that influence the interoperation between work practices.

The evolution and design of an information infrastructure can be considered as a sociocultural evolutionary process with three phases: (i) initial situation with challenges and opportunities to change, (ii) growth, and (iii) consolidation. In the growth and consolidation phase organizational structures and governance mechanisms emerges to manage the development and operation of the information infrastructure.

The evolution of information infrastructures is different from traditional information systems in at least two major respects. Information infrastructures are always built on an existing installed base, and evolve during a longer time, with a wider scope, escaping the control of single projects, organizations, and design communities.

Design theories for information infrastructures aim at understanding the consequences of these differences and at developing design principles to facilitate the growth of infrastructures. Some scholars tend to undertheorize the role of the human agency in the evolution while others claim that there is also an aspect of construction and building of infrastructure, and that the evolution is not only driven by technology but is also influenced by the actors and their contribution to infrastructure development.

Standards are considered key enablers for interoperation between organizations and for the development of information infrastructures. Standards can be viewed as shared and agreed infrastructure specifications among a set of communities. Standard can be divided 
into horizontal and vertical standards; horizontal standards are applied cross domains while vertical standards are valid for a particular domain. Standards can be developed by standardization bodies and or can emerge as de facto industry standards. Although key enabler for interoperation, it is well recognized that implementation of standards is difficult and costly.

Vertical standards for a domain are developed by heterogeneous groups through collective action. Development of vertical standards is also a matter of standardization of processes and identifiers of institutional objects, and the developed standards have to be adapted to specific situations of interoperation. Standards can range from being prescriptive to giving guidelines for implementation.

Standardization can lead to unexpected results. Initially aiming at bringing order, standardization could instead lead to the opposite. This is called reflexive standardization, which means that the initial effort of standardization has unwanted side effects that bounces back on the initial aim. This phenomenon is due to the social-technical complexity of standards.

Standardized vocabularies or terminologies play an important role for communication in a professional domain. The terminology research field studies the creation and use of specialist languages in scientific or professional communities. Efforts have been made to implement standardized vocabularies to improve interoperability. However, there is a lack of knowledge on how these vocabularies are actually used by real language users. Some studies indicate that there are inconsistencies in the use of such vocabularies. Research on terminologies has traditionally focused on the construction of vocabularies and the prescribed use by idealized users. There are new trends within this research field to focus more on the use of vocabularies by real language users.

We have reviewed research areas related to interoperation and interoperability such as definitions of interoperability, information infrastructures, work practices, standards, and vocabularies. These research areas, except those that explicitly deals with definition and frameworks of interoperability, does not have interoperation and interoperability in the foreground. Interoperation is the implicit background to the study of information infrastructures, standards, and vocabularies. Some approaches to interoperability study the use of standards and vocabularies as enabler or solutions to interoperability. Most research on work practices does not take into account interoperation between work practices and the emergence of a shared practice.

To conclude, we adhere to a broader view of interoperability which sees the interoperation between organizations and work practices as the major challenge in improving interoperability. We have highlighted the emergence of cross functional, shared work practices as the context of interoperation to which research on standards, vocabularies, information infrastructures and interoperability frameworks could be related. A theory on interoperation and interoperability should be able to integrate and relate to these research areas. 
These research areas, except those that explicitly deals with definition and frameworks of interoperability, do not have interoperation and interoperability in the foreground. Interorganizational interoperation is the implicit background to the study of information infrastructures, standards, and vocabularies as such. Some approaches to interoperability study the use of standards and vocabularies as enabler or solutions to interoperability. Most research on work practices does not take into account inter-organizational interoperation and the emergence of a shared work practice. 


\section{Methods of inquiry}

This chapter contains a discussion of methods of inquiry which has been used and considered in this thesis. The aim with this thesis is to contribute with practical knowledge of improving interoperability and to make a contribution to a theory on interoperation and interoperability. As a consequence, this thesis contains both empirical and theoretical work.

One part of the empirical work has been made in the role as an insider who actively participated in and contributed to the work to improve interoperability in ePrescribing. The role of the researcher as an insider is described in section 3.1 and 3.2. The section 3.1 Insider research, contains a more general discussion and the section 3.2 Access, preunderstanding, and roles in relation to ePrescribing, describes the specific role and participation of the researcher in the operational practice of ePrescribing.

The research approach in this study is action research and specifically practice research. In section 3.3 Research approach, we describe the relation between theoretical and empirical work and the work in an operational practice.

In section 3.4 Grounding, warranted assertability, reliability, validity, and evaluation of research, different methods for grounding, assuring, and assessing quality of research is discussed.

An important topic in information systems and qualitative research is the degree of generalizability of research results. In section 3.5 Generalizability in information systems and qualitative research, a brief review of different scholar's view of generalizability is made. In the concluding chapter 10 , the review is used for a discussion about the generalizability of the contributions made in this thesis.

Research interests and research questions have evolved over time. This process is described in 3.6 Development of research interest, activities, and results.

The section 3.7 Practice research in interoperability and ePrescribing contains a description of the domain of the inquiry, sources of evidence, and contributions made. 


\subsection{Insider research}

An early research interest I had was how to improve the process of information systems development. In the 1990s, I became interested in what characterized successful development processes. I began to study best practices and empirical studies of product development within the industry, particularly in the automotive industry. My licentiate thesis [115] included a synthesis of factors characterizing successful product development. These factors were integrated into an evaluation model in order to support the selfassessment of information systems development processes.

In contrast to research on the product development process, which contained many empirical studies, I reflected on why there were relatively few studies ${ }^{29}$, which really describe from the inside how information systems development actually is performed ${ }^{30}$. One reason could be difficulties to get access to and follow real development projects over time. Larger information systems development projects normally extend several years from the initial idea to real implementation.

When starting a research endeavor, academic researchers are equipped with general methods knowledge. However, it is not common to have what Gummesson [120] calls institutional knowledge, i.e. knowledge of the formal and informal structure and processes of the company, its markets and competitors, and its history and culture. For most academic researchers, the opportunities to apply their methods and general knowledge in a realistic setting, are few. It is important that the researchers can gain good access to the object of study and quickly acquire knowledge of the existing practices and culture. However, it may be the case that this will take months and even years. It is sometimes necessary to be involved in several projects before the researcher has a good insight and understanding of the situation. In particular, this is true when studying the evolution of information infrastructures which are stretched out in time. This is coined as the "The Long Now" of infrastructure evolution. [76, 121] A collaboration between researchers and practitioners can speed up the process of knowledge acquisition for the researcher as well as contribute to opportunities for reflection for the practitioner.

Thus, one important aspect of research is the access, pre-understanding and understanding of the problem domain. These aspects can be defined as follows:

\footnotetext{
${ }^{29}$ See for example a systematic review of empirical studies in agile software development where 36 out of 1996 papers were regarded as empirical studies. [116] See also a recent empirical study which shows that very few developers actually use design models, promoted and evaluated in research, before coding. [117]

${ }^{30}$ There are a number of exceptions of course. See for example studies in participatory design [118] and studies in a related area to information systems developed - product development - where there are many empirical studies of development projects like Lean Design, Concurrent Engineering, et cetera. [115] Within information systems development, the situation has changed. See for example the increase of empirical studies in requirements engineering since 2005 [119]
} 
- access is the ability of and opportunities for the researcher to come close to the object of study and to gain access to what is really happening;

- pre-understanding is knowledge and insights by the researcher before the research or study is taking place;

- understanding is the knowledge and insights gained by the researcher in a project or assignment. [120]

Traditional research methods, which assume an outside 'objective' and 'neutral' observer, usually have difficulties to come close to the object of study and access the underlying reality. Interviews and questionnaires can easily survey an official, idealized reality, presented to the researchers, what Gummesson calls the 'top of the iceberg'. [120]

A different approach is to be interactively engaged with the studied practice to gain closer access to the object of study. This approach is typical of action or practice research. In this sense, the researcher becomes temporarily, more or less part of the object of study and is no longer only an outside observer.

One strength of such an approach in information systems development research is that the researcher obtains experiential data (personal experience) through direct social interaction with other actors, for example in the process of collaboration with different actors in the design. Another strength of such an approach is that the actual construction of an IT artifact provides a direct experience and understanding of the materiality of the IT artifact and of the real-world conditions under which the design and construction is made. This type of access and experience is not possible to attain only by observing or interviewing someone. Such an experience is also helpful in order to understand what is important and what is irrelevant in the research. [91]

It is not always possible for a researcher to invest much time and engagement in a research project. Researchers that are insiders or consultants with a long assignment in a company might have spent many years in different projects, and some consultants have experiences from several companies in the same branch of industry. The advantage of being an insider is that the researcher already has a good understanding of and most often good access to different parts of a company or to different work practices through their built-up network.

There has been some critique of insider research within qualitative research, implying that the dual role of an investigator and an employee is incompatible and may put the researcher in a conflict of interest. However, others like Brannick \& Coghlan make a case for insider academic research. [122]

One critique mentioned by Brannick \& Coghlan [122] is the risk of a lack of intellectual rigor due to the fact that inside researchers have personal stakes and have made emotional investments in the setting. Another argument against insider research is that the assumed benefit of being close to the setting also has a disadvantage in a lack of distance and objectivity. For Brannick \& Coghlan (ibid), inside researchers are employees of the 
company. However, we think it is useful to also include certain 'inside' consultants, while not being employees, in many cases, have made the same investment in knowledge and understating of the company's practices. Consultants are somewhat less dependent on the company investigated, while it is not unusual that consultants change company for different personal or professional reason now and then.

Two different types of inquiries are described by Brannick \& Coghlan [122]: inquiry from the outside and inquiry from the inside.

Inquiry from the outside means that the researcher is more detached from and neutral to the object of study. In this type of inquiry, the researcher applies some categories before the study and tries to generate general context-free knowledge.

Inquiry from the inside means that the researcher is involved in the local situation and generates knowledge that is emerging from experience in the local context. Usually in action research, the generated knowledge remains situated to the particular practice and not generalized, or at least there is no demand for creating generalized knowledge, as is made in practice research (See Goldkuhl [123]).

Brannick \& Coghlan [122] attributes different views of insider research to different research traditions. In the positivist tradition, insider research is not addressed at all. Within qualitative research, in the hermeneutic tradition or interpretative tradition, it is often considered as a problem to be very close to the data, while in action research, insider research is not seen as problematic.

The main advantage of insider research is the direct access to the field and a developed pre-understanding. There are also disadvantages. Insider research can lead to making premature or hasty assumptions when taking more for given than an outsider would. A developed pre-understanding can blind the researcher for certain interpretations and facts.

One way to manage such risks is to have regular communication with 'outside' researchers or practitioners, who could make alternative interpretations and point in directions that were not obvious for the participant in the practice.

The ability of the researcher to shift focus from near to distance and back, and being able to reflect on the data from other points of view, is very important to mitigate the risk of assuming too much and being blind due to a pre-understanding that is based on a longtime involvement in the practice. To understand what you are actually doing when doing, is not only a typical question for a reflective practitioner [124] but also for the inside researcher.

Another challenge is the dual burden of being an active participant and at the same time involved in research. This can be managed by planning the research in such a way that the participation/practitioner role in certain moments is downplayed and the research role is in the foreground. 
Another issue is whether the research is overt or covert, which could influence the gathering of data and pose ethical problems. One research process could consist of both covert and overt research as discussed by Holgersson [125] who acted as an inside researcher and at the same time being a police.

One of the most difficult aspects of insider research is managing organizational politics and their influence on both the studied object and the research. This is also an issue indirectly influencing outside researchers, usually the ability to get access to the reality as it actually is - not as presented or prepared to suite political objectives. It has an important influence on both consultant insiders as well as employee insiders, were employee insider confronts this issue more upfront, because what they do can influence their career more directly.

Brannick \& Coghlan [122] conclude that the critique of insider research does not invalidate it as serious and rigorous research approach and is not problematic in itself.

It is necessary to consider the strength and limits of the pre-understanding and use the experience and theoretical knowledge to reframe insider's research understanding, and to consider the double role as researcher and practitioner, handle organizational politics, and be aware of the personal stakes and emotions of being an insider, whether employed or consultant.

Considering these aspects, an insider researcher role has many advantages in a closer access to and pre-understanding of the problem domain.

\subsection{Access, pre-understanding, and roles in relation to ePrescribing}

The aim with this section is to describe my access to the practice studied, my preunderstanding, and my participation in the operational practice of ePrescribing ${ }^{31}$ and my contributions to this practice.

\subsubsection{Consultant with a research background}

Before being employed as a consultant at CGI (at that time WM-data) in the year 2000, I worked 12 years in an industrial research institute, SISU (Swedish Institute for Systems Development). My research was in information systems development and process improvement. As a consultant, I brought with me a researcher's background.

The consultant role meant initially a shift of focus; from being able to reflect and act on matters that were not of immediate importance for a particular client, the attention and energy were devoted to the client's needs. This did not mean that the reflection stopped,

${ }^{31}$ For a definition of ePrescribing see 6 A practical theory on ePrescribing. 
but it was no longer the principal task. The shift of focus meant that as a consultant you should act first in the interest of the client. This implies to judge whether your knowledge or proposed actions, even if generally consider good or useful, might be too advanced or premature for the client for the moment. It is necessary to be very attentive to the clients' understanding, needs, and objectives. This is a consultancy role which is process oriented in comparison with a more traditional role of being expert oriented ${ }^{32}$. For action and practice research, it is my view that the process role for consultants is better suited, in addition to its benefits for the clients.

In 2003, I got my first assignment as a consultant in the pharmacy market. I was appointed to work as a service leader for ePrescriptions at the National Pharmacy Corporation (NPC, Apoteket AB), at that time a state-owned monopoly. An additional task was to make a pre-study of how to change the ePrescription format to accommodate demands for improvements from different stakeholders.

I was also involved with staff activities at NPC to promote ePrescribing both within the pharmacy company and externally. The NPC needed to consolidate ePrescribing after the pioneering years and to prepare for an increase in volume from $30 \%$ to a targeted $80 \%$.

This involvement posed a lot of technical questions, such as upgrading of the technical platform for communication of ePrescriptions both externally and internally, a new central repository for ePrescriptions, and of developing a new national format for ePrescriptions.

There were also many organizational questions posed, such as managing the ePrescription format together with the stakeholders, and external and internal operational governance of the ePrescription service.

One outcome of all these questions and strivings was a joint project initiated by a number of regional county councils and the NPC. I was in charge, among other things, of documenting and defining the new national format for ePrescriptions.

All the time, I worked as representative for the NPC in relation to the regional county councils. In this phase, I learned all the details of the ePrescription and the technical infrastructure, the support process and the internal maintenance process in relation to the prescription dispensing system. I was also involved in other projects at the NPC regarding the development of the information infrastructure for ePrescribing. In 2004, I was responsible for a feasibility study on implementing a national ePrescription mailbox. Later, I was involved in projects deliveries: requirements specifications for the national prescription repository and for the drug register of dispensed medical drugs (National Pharmacy Register [126]); formalization of prescription rules for the dispensing systems and control of incoming ePrescription and feasibility studies of drug-drug interaction services. I was also engaged in the project which transferred the information infrastructure from the NPC to the state-owned infrastructure company as one step in the process of

\footnotetext{
${ }^{32}$ See Gummesson [120] for a discussion of different consultancy roles.
} 
deregulating the pharmacy market in Sweden. In this project, I was responsible for writing the handbook for the pharmacy dispensing process aimed at the new pharmacy chains.

\subsubsection{Researcher and consultant}

In 2007, I got the opportunity, before the first implementation of the new ePrescription format in 2008, to get a research project funded by the NPC and my employer, with the aim to study the experience of implementing a new ePrescription format. I had put forward the idea of comparing the quality of ePrescriptions before and after the implementation of the new ePrescription format.

I started to design the sampling procedure of ePrescriptions to evaluate the effects on the quality of ePrescriptions. In May 2008, I finally got access to one-month sample of ePrescriptions from production. In May 2008, I also got a research paper [42] analyzing the ePrescribing practice published based on an analysis made in the end of 2007. After I got access to the sample in 2008, I wrote the software to analyze the ePrescriptions in relation to the format specification and prescription rules. The analysis of this sample was summarized in a paper that was published in 2011. [9]

In 2009, when the new format was implemented in production, I could order a sample from May 2009 to compare the results. The result from this analysis was published in paper in 2012. [8] This meant that the actual research started when the specification phase of the new ePrescription format ended in 2006, and the implementation project started, although reflection and a development of a research interest occurred earlier.

ePrescribing is not only about the ePrescription message. It is a process involving prescribers, patients and pharmacists. After the specification of the new format was finished, I had the opportunity to be involved in several other parts of the ePrescribing process with new assignments particularly regarding the ePrescribing process at the pharmacy side (see above). I had at this time gathered extensive knowledge of the technical aspects as well as the content of the prescription and prescription rules, their use in the dispensing system, legal aspects, and all the organizational aspect involved in the ePrescribing process. I had the privilege of working with those experts at the NPC who had the best knowledge of ePrescribing in Sweden and I became one of the experts in ePrescribing. In this sense, I became a consultant insider, who had access to many primary sources of information, with a developed understanding of different aspects of the ePrescribing process.

After my work at the NPC and for the infrastructure company responsible for the deregulation of the Swedish pharmacy market, I got the opportunity to work for a new private pharmacy corporation in the takeover of pharmacies from the state own pharmacy company NPC. I became responsible for the implementation of the IT infrastructure and was acting $\mathrm{CIO}$ until a $\mathrm{CIO}$ was employed. 


\subsubsection{Reflections on access, pre-understanding, and understanding as an inside researcher}

From 2003 until 2012, when I was engaged in different projects in ePrescribing, I had very good opportunities to get a deep understanding as well as a good access to both primary and secondary resources (documents, policies, et cetera). I acquired knowledge which would not have been possible to access from the outside.

The researcher's personal involvement in the object of study may bias the research. Personal stakes and emotional investment could influence the research in a certain direction. It was obvious that I had to be very observant on the risk of being biased in assessing an improvement work oneself has been involved in. There were never any pressures or expectations on me from the NPC on the results of the evaluation of the improvement project. When completing the studies of the improvement project, I was no longer immediately engaged in the continuation of the project.

A second possible disadvantage of being an inside researcher is that your developed understanding could lead to making unreflected assumptions, obvious for an insider, but that could be questioned from an outside perspective. An advantage of a consultant insider compared to an employee insider, is that the consultant sometimes could take the role of questioning the old ways of working.

Apart from trying to be as open minded as possible, I had the opportunity to get input from the outside during my research and also from people from the inside. In addition, writing research papers together with others gives valuable input and adjustment of personal views. I had also the opportunity to present my ongoing research at a number of research seminars in the VITS research group (www.vits.org). I have several times revised my understanding of ePrescribing in dialogue with my supervisors, other researchers, and former colleagues and co-writers of different papers.

Another important influence, both challenging my understanding and opening up new views not reflected upon, was the use of practical theories in making a socio-pragmatic analysis of the ePrescribing practice. Thus, practical theories can help to question certain assumed beliefs, confirm and make more clearly tacit knowledge, but also point in new directions, gaining new knowledge.

Thus, I have found theories very practical in analyzing a practice. Perhaps it is more useful for inside researchers, who have a more developed pre-understanding and more tacit knowledge of the practice to use practical theories to guide the analysis. The use of theories has contributed to deepen my understanding of the ePrescribing practice.

Regarding the influence of organizational politics and its influence on the object of study and the research, although they have been present in the improvement project as always in such projects, I have never felt any pressure explicit or implicit to produce a certain result or on how to present a certain result. 


\subsection{Research approach}

The research in this thesis is a combination of action research (AR) [127] and practice research [128] where action research can be seen as a special kind of practice research. This section reviews the practice of practice research.

\subsubsection{Relation between action and practice research}

Goldkuhl [128] points to some unresolved issues in action research. One is that there is a lack of focus on contribution of knowledge to the general practice community. Focus is on contributing to the local practice and to inform general theory. Another issue is that the problem-solving cycle proposed - diagnosis, action planning, action taking, evaluation, and learning - describes the researcher's problem solving, not the problem owner's problem solving. The latter should be more relevant. The consequence of this is an unclear relation between the activities of the researchers and the practitioners respectively. Goldkuhl proposes another view to clarify this by defining two different cycles: research process and problem solving cycle. The research process cycle is an iteration between theoretical and empirical work and the problem-solving cycle is an iteration between development and operational work. These are integrated in a graphical model, see Figure 3.

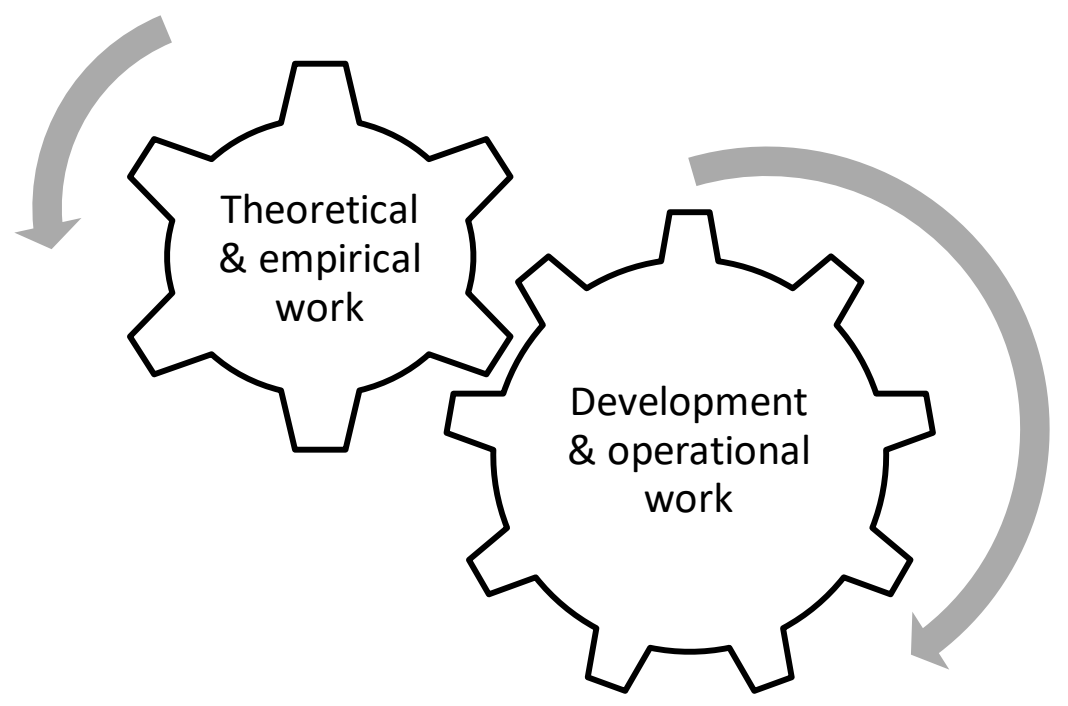

Figure 3 Integration of researchers and problem owners cycles inspired by Goldkuhl [128]. 
Development work is about a purposeful change of a situation. In the context of information systems development, this could be a new or changed information system and work practice.

Operational work is about keeping a desired situation in a controlled and stable state. In this context, it is about the daily operation and management of information systems and related work practices, which does not involve any major changes. This operational work can be characterized as the daily problems solving in a work practice.

Empirical work is about collecting and organizing data for the purpose of research. It could be collecting and organizing data for later analysis and research, such as field notes, memoranda, designed or diagnosed artifacts, collecting and organizing of documents, minutes, et cetera. This empirical work is related to a research interest in a situation and not necessarily to a particular research question formulated. Empirical work could also be gathering and organizing of data in direct connection to a research question and specific inquiry.

The empirical work is done by the researches. Both researchers and practitioners can do developmental and operational work. If the researcher is an insider and is involved in the development or operational activities, the empirical work can be done in parallel or in different phases of the developments or operational work, for example before, during and after development or operational work.

One important part of theoretical work is about developing research interest and research questions. This development is not necessarily a linear process but can include multiple inputs from the research community or be derived from practical needs and problems in the situation in which the researcher is involved.

Another essential part of theoretical work is the use and creation of abstract knowledge. Extant theories can be used in a situational inquiry to direct the attention towards specific phenomena in the situation studied or contribute to possible or alternative interpretations. These extant theories can thus influence the empirical work and they can be applied in a new situation in order to evaluate its generalizability to a situation in which it has not been tested before. New theories can be developed based on new empirical material and by incorporating parts of extant theories. Theoretical work is also about analyzing and improving the internal consistency of a theory.

Within practice research, there is an interaction between empirical work and theoretical work. An inside researcher could for example make empirical notes and at the same time do a theoretical reflection related to experienced phenomena. Donald Schön develops in his work The reflective practitioner [124] the notion of reflection in action, where the practitioner simultaneously reflects and adjust in action. For a researcher, this reflection does not only involve reflection about practical knowledge but also a reflection in action around theoretical knowledge. Closely linked to reflection in action is experimentation $[124]$ in the sense of doing certain action in a practice, in order to explore or arrive at a 
certain results. This experimentation can also provide empirical material for theoretical work.

Empirical work is also guided by the pre-understanding the researcher has when entering a situation. The experiential knowledge gained through the engagement in the situation will influence the researcher when making judgments about what is essential and important to note and gather in the empirical work. The pre-understanding will also influence the selection of extant theories that might be relevant to use in order to understand and explore the situation.

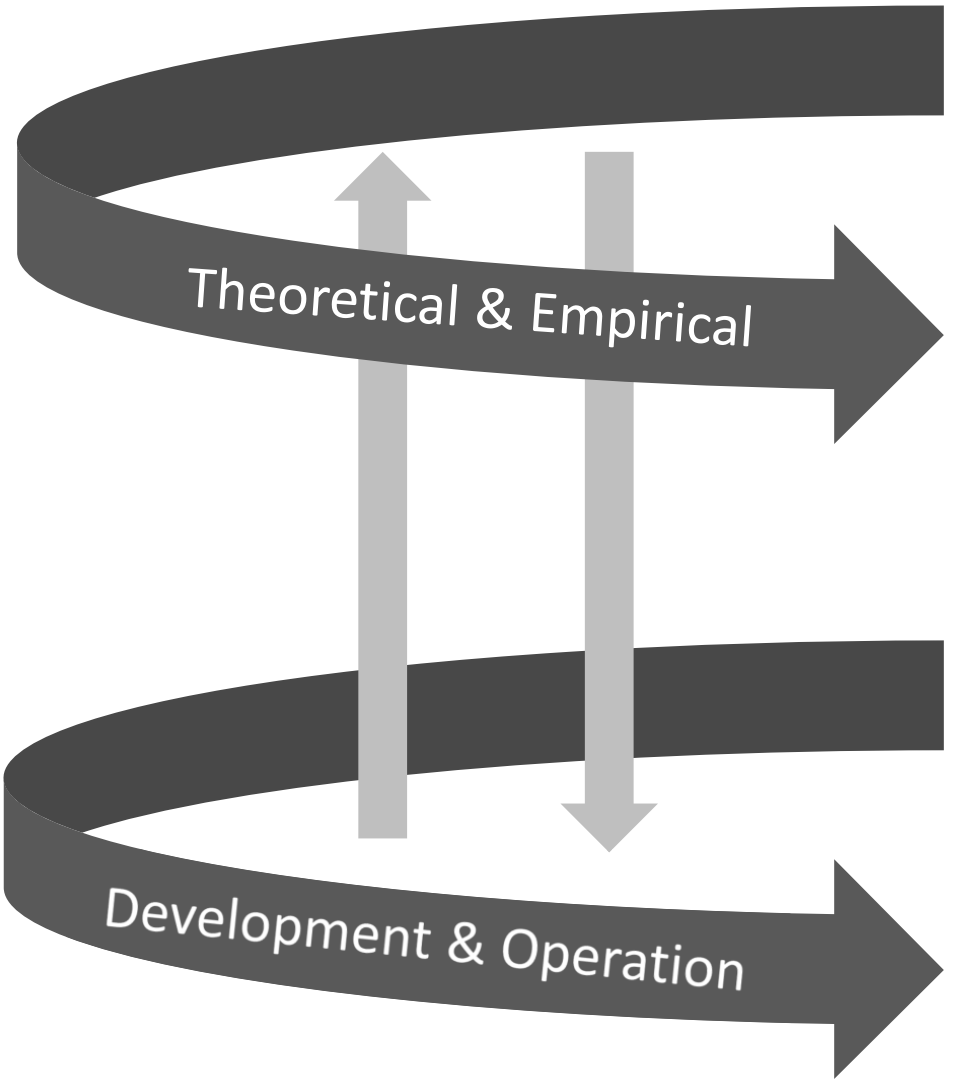

Figure 4 Interaction between different perspectives of research and operational work as an inside researcher and practitioner.

Argyris and Schön $[129,130]$ develops a concept of single- and double-loop learning. Briefly, single-loop learning is about choosing different actions within a view of a framed problem, and second-loop learning is about questioning the framing or the setting of the problem to find alternative actions. A researcher, which at the same time is a practitioner involved in these types of organizational learning, will most likely have a 'meta' view of this learning, by Argyris and Schön named 'deutero-learning', which is a kind of secondorder learning reflecting on single- and double loop learning. [131] 


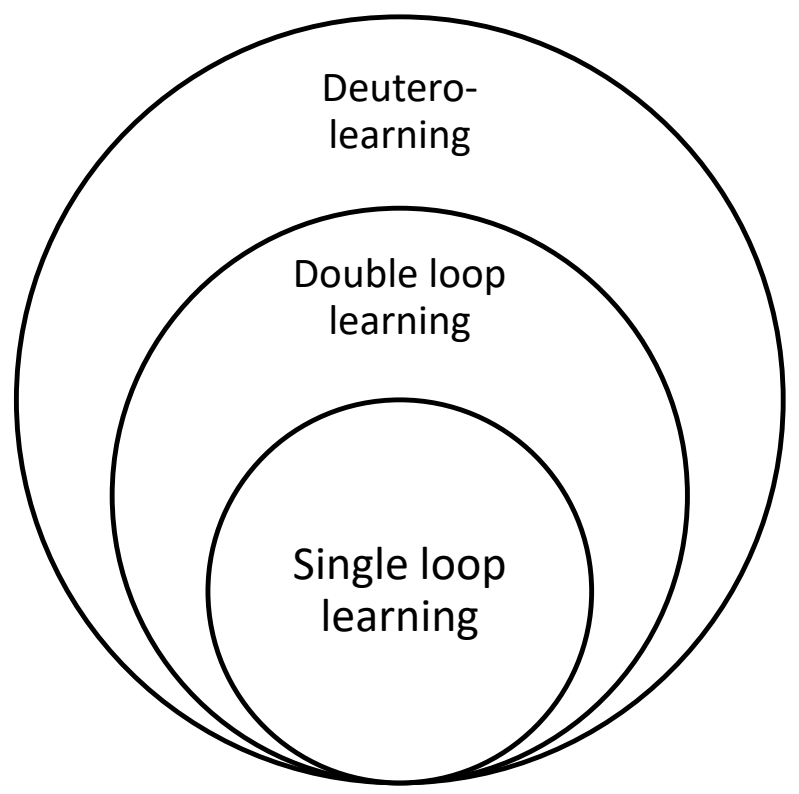

Figure 5 Relationship between different modes of learning.

Goldkuhl emphasizes the distinction between research work and operational work. Depending of the relation between the researcher and the research object, there is different degrees of proximity between research and operational work. For an inside researcher, these types of work are often intertwined. See Figure 6 for an illustration of the relation between the research practice and the work practice.

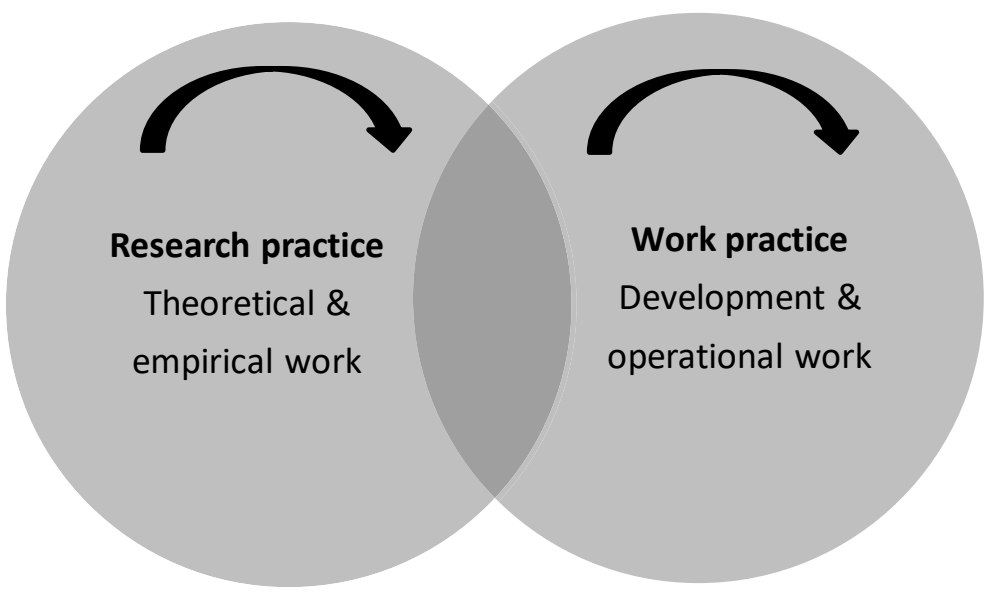

Figure 6 Interdependence of research and practical work 
The experience gained in operational work confronted with problematic situations is for an inside researcher the major influence for both the developmental work and for developing a research interest and defining explicit research questions.

If empirical work is the more purposeful gathering of empirical data, whether it be linked to an explicit research question or linked to a developing research interest, there is a parallel process of gathering experiential knowledge and understanding of the problematic situation and the work practice that will influence both the theoretical and empirical work. This experiential knowledge and understanding of the work practice which is accumulated with the engagement in the situation, has a different focus for a reflective practitioner who is not engaged in a research practice and a reflective practitioner who is engaged in a research practice. The mode of reflection for an inside researcher is both directed towards solving a problematic situation and at the same time reflecting about the problem-solving activity as such.

\subsubsection{Practice research}

Practice research is closely linked with Dewey's pragmatism. For Dewey, meaningful and useful research should start from problems grown out of a real situation. Thus, to set up problem,

"... that does not grow out of an actual situation is to start on a course of dead work, nonetheless dead because the work is 'busy work'. Problems that are self-set are mere excuses for seeming to do something intellectual, something that has the semblance but not the substance of scientific activity." [132]

For practice research, this implies a research on practices, for their improvement and often made in the practice. [128].

Goldkuhl defines a practice as follows:

"A practice is seen as meaningful and coherent assemblage of human actors, actions, utterances and documents and material artifacts. Practices are often arranged with purposes to serve other actors outside of the practice itself. A practice is shaped by humans as an organized, artificial and continually evolving arrangement, enabled and restricted by human knowledge and financial, semiotic and material conditions." [128]

Practice research, which in itself is a practice, $[123,132]$ is divided into two subpractices: theorizing and situational inquiry. 


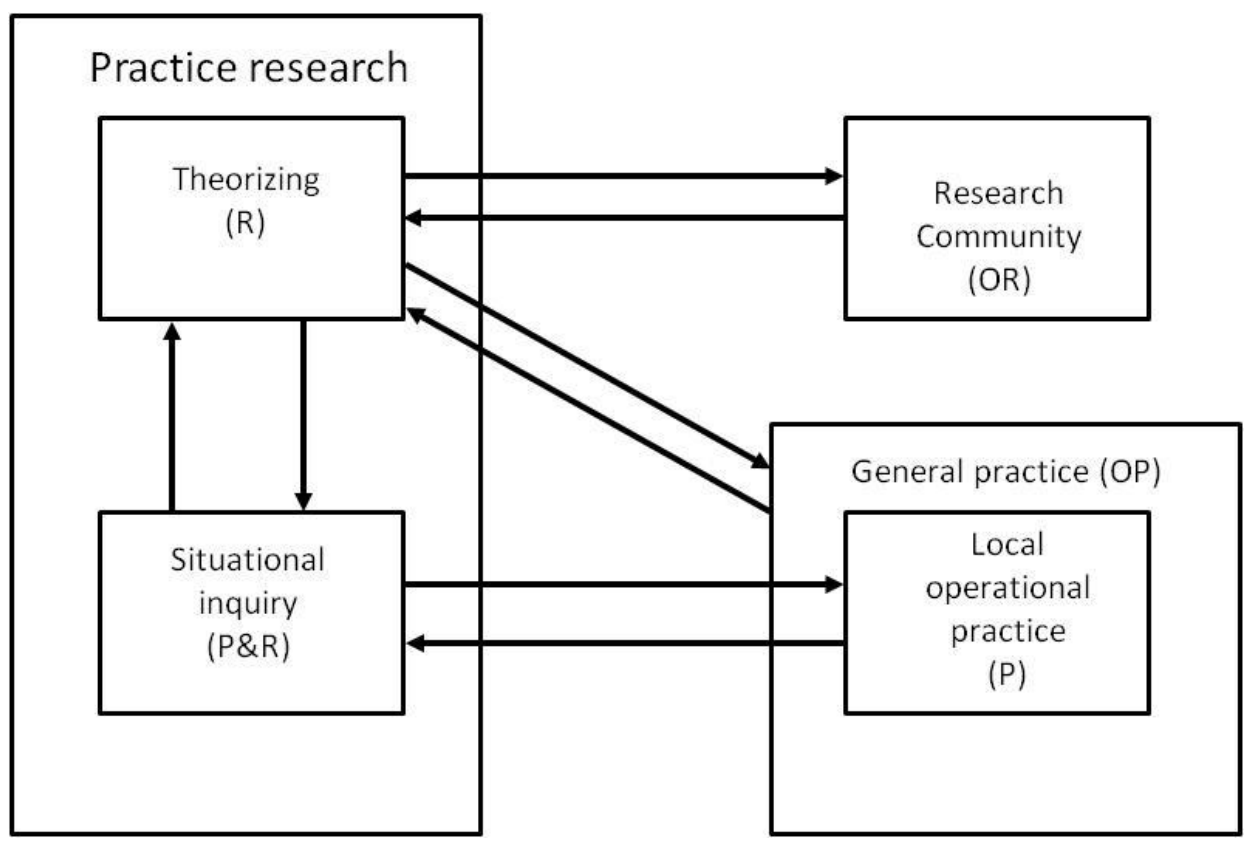

Figure 7 Practices research and its relation to practices and communities, from [123]. ( $R=$ Researcher, $\mathrm{OR}=$ Other researcher, $\mathrm{P}=$ Practitioner, $\mathrm{OP}=$ Other practitioner).

In Figure 7 the different practices and communities are depicted. Research in a local practice is a situational inquiry. [123] A situational inquiry is concerned with a problematic situation in a local practice, usually in change and development (se Figure 3, where empirical and developmental work are joined in an action research context); it could also be in a diagnostic phase. A situational inquiry aims to contribute with knowledge to improve a local practice. It also aims at contributing with experience and findings, providing material for further theorizing to develop theories that could be a general practice contribution to the general practice community, and an abstract scientific knowledge contribution aimed at the research community. If it does not aim at a general practice contribution or a general research contribution, it cannot be qualified as a part of a practice research, but rather as a part of a change process, driven by internal or external change agents, without a scientific purpose.

A situational inquiry is conducted by the researcher and could be a collaboration between practitioners and researchers. Here, we assume that a researcher also can be a practitioner, which is the case with an insider researcher. A situational inquiry from the practice point of view is an arena for practical problem solving and could generate situated knowledge for the improvement and change of the local practice.

A situational inquiry can be guided by theories in order to focus the attention on certain phenomena [133] or to provide suggestions to explain phenomena in the local practice. It is also possible to evaluate the adequacy, usefulness and applicability of a theory in a 
situational inquiry. A situational inquiry could also contribute with material to generate and improve practical theories.

Theorizing activities within practice research involves the evolution of research interest and the generation of abstract knowledge towards different communities. The evolution of research interest could have several sources.

There is a dialectical relationship between theorizing and situational inquiry in the sense that they mutually serve, influence and develop each other. Theories can serve to improve situational inquiry and the local practice as well as the situational inquiry can serve the theorizing in providing data for validation and revision of existing theories, and generation of new theories. The usefulness of abstract theories will and must be continuously tested and developed in situational inquiries involving researchers and practitioners.

In Figure 3 there is a separation between theoretical, empirical, developmental and operational work.

Developmental and operational work is part of a problem solving and changing activity in a particular situation, a work made by actors in the role of practitioners. In a situational inquiry conducted by a researcher, in which the researcher also is involved as a practitioner, the researcher as person can also have the role of a practitioner and thus conduct development and operational work. This work is not part of research activities although it can be studied from a research point of view in gathering data and developing understanding of a situation.

Empirical work is data collection for theorizing work and is part of practice research in a situational inquiry.

Theoretical work is generalization of findings in a situational inquiry or synthetizing and combining elements from other extant theories into an emergent theory, which can be tested in a situational inquiry.

\section{Type of knowledge contributions in practice research}

Practice research should aim at contributing useful knowledge to develop and improve practice. There are different types of knowledge contributions from practice research: conceptualization, explanatory, normative, diagnostic (critical or appreciative), prescriptive, and prospective. $[123,134]$ See Table 3 for a description of these knowledge contributions. 


\section{Type of knowledge Description contribution}

Conceptualization

Explanatory $^{33}$

Normative

Diagnostic

Prescriptive

Prospective
Description of important actors, actions, artifacts, et cetera, within a practice and their relationship. The conceptualization helps to direct the attention towards important aspects of a practice, that is fundamental for developing knowledge of the practice.

Description of reasons, conditions, contexts explaining certain facts, circumstances or state of affairs in a practice.

Description of desired values, norms and objectives in a practice.

Description of critical or appreciative aspects of the practice.

Description of suggestions for change and actions to improve or achieve a work practice that meet the normative values.

Description of future alternative or possible variants of a work practice.

\subsubsection{Practical theory}

The concept of a practical theory as developed by Cronen [133, 135] is influenced by pragmatism and its view of knowledge, knowing, and inquiry. Dewey's Logic - The theory of Inquiry, has influenced Cronen's concept of a practical theory. [132]

The concept of a practical theory is based on a view of knowledge and knowing that does not separate theory and practice. According to Cronen, practical theories rejects the

\footnotetext{
${ }^{33}$ In this thesis, we have made use of a retrospective analysis in explaining and describing the evolution of ePrescribing in Sweden, see chapter 4. Even if practice research aims at developing and improving practice, an historical account of the evolution of a practice is a valuable knowledge contribution in order to understand the mechanism of change and thus contribute with knowledge valuable for improving and change of a situation. We categorize this type of knowledge contribution as explanatory.
} 
dualism of practitioner and theorist as well between professional and participant ${ }^{34}$. This view is shared by many other scholars such as Donald Schön [124] and Bengt Molander. [136]

A practical theory should inform a 'grammar of practice'. A 'grammar of practice' is rules for action and utterances that make sense in a situation. This elucidation of the 'grammar of practice' enables the joining of grammars of others to explore new patterns of action. Practical theories should provide guidance to explore and explain a situation but also provide alternative interpretations. A practical theory should direct attention to "possibilities of phenomena and relationships among phenomena that might be missed." [133]

A practical theory is a generalization from one or several situational inquiries, in the sense that it makes general statements, grounded or warranted in a particular situation. If the situations or cases is representative of a kind of situation, the generalization, is plausible to hold for and organize a situation of a similar kind. Dewey formulates it in the following way in Logic: Theory of inquiry:

"We arrive again at the conclusion that 'induction' is a name for the complex of methods by which a given case is determined to be representative, a function that is expressed in its being a specimen or sample case." [132]

and, "The outcome is generalization in the form of a nonexistential law or principle, which through execution of the operations it formulates, organizes existential material." [132]

A practical theory is thus "nonexistential" with instrumentalities that can formulate and organize "existential material" in the form of a grammar of practice.

Thus, a practical theory is applicable for or useful in a semblance of practices of a particular type. Thus, it is important that a practical theory make statement on what family of practices it is useful to use the practical theory. [132]

A practical theory has instrumentalities, that can be statements about principles, definitions, models, or methods. These instrumentalities of the theory have to prove their value and usefulness in the process of making judgments and the actions proposed or derived from the judgments and the consequences of the actions.

According to Cronen, practical theories should lead to new possibilities and constraints and not deal with old, past situations. This is in line with the view of pragmatism that research should be made to change and make life better.

\footnotetext{
${ }^{34}$ This last point is important in the field of interpersonal communication and family therapy, where Cronen's own Practical Theory, Coordinated Management of Meaning (CMM) is mostly used.
} 
Cronen has put forward four primary criteria to evaluate practical theories whether they are useful for,

“... (1) identifying a situation-in-view, (2) constructing judgments (systemic hypothesis) about the situation that (3) implicate actions leading to (4) the consequence of improving the situation." [133]

Goldkuhl [137] has contributed with a specification of the constituents of a practical theory. These are summarized in Table 4.

Table 4 Constituents of a practical theory from Goldkuhl. [137]

\section{Constituent Description}

Conceptualizations What phenomena exist and their properties and relations in the practice.

Patterns How things may or may not work. Actions and descriptions of patterns of action play a central role.

Normative criteria Goodness of things. Normative criteria can be used to evaluate and to design a practice.

Design principles Ways to create good things, i.e. ways to achieve goals and normative criteria of the practice.

Models Illustrative crystallization of a practical theory.

A practical theory can contain all the constituent elements described. Conceptualization is the minimum constituent element of a practical theory. The constituents or instrumentalities, to use Cronen's term, can have different forms (text, graphical, multimedia, et cetera), preferably accompanied with case examples to guide their use.

\subsection{Grounding, warranted assertability, reliability, validity, and evaluation of research}

In this section, we discuss some methodological concepts considered in this thesis for the evaluation of the quality of research results.

\subsubsection{Grounding and warranted assertability}

Grounding in this thesis is justification and presenting good reasons for statements and theories. Goldkuhl \& Cronholm has developed a multi grounded theory [138] with three grounding processes: 
- empirical grounding of theories using empirical data. This grounding could include both to generate new theories and to ground existing theories in a new empirical setting;

- theoretical grounding of a theory is a process to assess the coherence in relation to other relevant theories;

- internal grounding of a theory is to assess the coherence within the theory itself, between its different constituent elements.

How grounding is applied in this thesis is described in section 3.7 Practice research in interoperability and ePrescribing.

In his Logic - The theory of Inquiry [132] Dewey put forward some conditions for grounding of theories. Theories must,

a) be verifiable in some domain. They cannot originate from the void and they cannot be extended ad hoc;

b) take account of argument, pros and cons, of other theories;

c) be able to order and account for different statements and concepts in relation to one another.

These conditions are very similar to those advanced by Goldkuhl \& Cronholm in their multi grounded theory [138], i.e. (a) empirical grounding in some domain, (b) theoretical grounding in relating to other relevant theories and finally (c) internal grounding in the coherence of theoretical concepts.

A very similar concept to grounding is Dewey's notion of warranted assertability.

For Dewey, knowledge is not something finite, not an ultimate end, but always, 'end-in view'. This means that knowledge is always a product of and a closure of an inquiry and is never complete and is always possible to revise and refine. It has the quality that it can be developed, tested and possibly falsified in the next inquiry. Knowledge is thus a term that Dewey uses for the objective of an inquiry. For Dewey, knowledge abstracted away from inquiry is an empty concept. Thus, absolute objectivity or truth is not possible to achieve.

For Dewey, a warranted assertion is an assertion that is linked to an inquiry, that warrants its assertion. Warranted assertability is as a general term for ascertained knowledge. Dewey prefers the term warranted assertability instead of belief or knowledge.

\subsubsection{Reliability, validity, and evaluation of research}

This thesis has mixed quantitative and qualitative research methods for gathering and analyzing empirical data.

Quantitative research methods use concepts such as reliability and validity in order to evaluate the quality of the results and their generalizability. 
Qualitative research methods have sometimes borrowed concepts from quantitative research. Some researchers claim these borrowed concepts are not applicable to qualitative research methods. [139] Others claim that it is possible to combine methods and that there are important advantages of mixed methods research. [140-144]

A mixed method research can be viewed as a broad form of triangulation. It allows to combine research styles whose strength and weaknesses are counterbalanced.[144]

Another advantage put forward is that mixed method research can contribute with meta inferences; combining quantitative and qualitative data analysis could contribute to an understanding, that would not be possible from point of view of one method alone. [145] Other possible gains of mixed methods research are described by Venkatesh et al. [146]

In this section, we will briefly discuss issues of reliability and validity and criteria for evaluation of the quality of research, that are applicable to the research in this thesis.

\section{Reliability and validity using quantitative methods}

Reliability of a measurement or observation is often defined as the consistency and reproducibility of a method of measure, when it is repeatedly used measuring or observing different sets of data. $[147,148]$ Reliability is not saying anything about the nature what is measured, only that whatever it measures is consistent and reproducible.

Validity can be divided in three categories ${ }^{35}$ :

- measurement validity;

- internal validity;

- external validity.

\section{Measurement validity}

A textbook in basic and clinical biostatistics defines validity as follows:

"Validity is a property of a measurement which indicates how well it measures the characteristics." [148]

Validity is not a quality of an measuring instrument as such but the measuring instrument in relation to the purpose for which it is being used.[147]

Some important types of validity in social research are: [147]

- criterion or predictive validity is about how well a measurement will predict some behavior that is external to the measuring instrument itself;

\footnotetext{
${ }^{35}$ If there is any consensus on the concept of validity in the field of psychological test is questioned by scholars in the American Psychological Association. Because there is no real consensus on validity and there is a constant invention of new "modifying" labels of validity, some scholars suggest that it is more useful to talk about quality instead of validity. [149]
} 
- content validity is the extent to which a measurement reflects the content of a domain;

- construct validity is the extent to which a measure, based on a theoretically derived prediction, can predict an outcome using another measure.

To make a judgment of the validity of a measure is to find an indication to what extent a measure actually measures an existing phenomenon. In social science as well as in information systems research, the qualities investigated usually are complex objects that are not directly tangible or observable. Even when judging the validity that a thermometer is actually measuring temperature, there is a need to compare the measurement of a thermometer with some other measure of temperature. In this sense, validity is usually connected with some method of triangulation.

\section{Internal validity}

Internal validity is the confidence of the inference that a covariance between independent and dependent variables reflects a causal relation. This means that the changes in the dependent variable are inferred to be caused by the independent variables.

Internal validity can be weakened by so called confounding (hidden, not accounted for) variables that could have influence on the dependent variable. There can also be historical changes in an experiment that can influence the dependent variable. Another factor that can weaken the internal validity is selection bias, i.e., those different samples are not alike on characteristics that can influence the independent variable and therefore could explain some of the changes in the dependent variable.

\section{External validity}

External validity is the extent to which results can be generalized to other situations than those from which the results were generated.

External validity is not treated further here. See section 3.5 for a treatment of generalizability of research results.

\section{Reliability and validity of practical theories}

Even if the concepts of reliability and validity have their origin in quantitative methods, they could have some relevance when discussing quality of practical theories, although with a different meaning.

Cronen discusses these concepts [133] in terms of pragmatism and practical theories. Practical theories, most often, do not develop measures that can be consistently used over time on new sets of data. Practical theories rather deal with heuristic knowledge in order to make judgments of different situations that are useful for further actions. This does not preclude the use of quantitative measures in practical theories. In this study, we have used quantitative measures to inform practical theories. Glaser and Strauss view qualitative and quantitative data as complement, useful for mutual verification. They also give examples how theories can be generated using quantitative data. [150] 
Cronen develops the term inclusiveness of practical theories as an analogue to reliability. Inclusiveness of a practical theory means that it should be able to include new data without major changes.

Dewey describes validity in the following way:

"Validity of the principals is determined by the coherency of the consequences produced by the habits they articulate. If the habit in question is such as generally produces conclusions that are sustained and developed in further inquiry, then it is valid even if in an occasional case it yields a conclusion that turns out invalid." (Our emphasis) [132]

In this quote, Dewey seems to argue for inductive reasoning in general as a suitable approach and seeing validity as part of an ongoing process of inquiries. See 3.5 for a treatment of inductive reasoning and its relation to generalizability.

Cronen [133] develops on the validity of practical theories in line with Dewey, in emphasizing the correspondence between judgments, actions implicated and the consequences of the actions. Cronen compares this validity with predictive validity in quantitative methods. In an inquiry, there is an emphasis of continually testing our understanding in action and evaluate the consequences.

\section{Quality of qualitative research}

Within the qualitative research community, the concepts of reliability and validity are viewed differently. Some reject these concepts altogether with the argument that they are based on a completely different view of knowledge and even consider quantitative methods incompatible with qualitative research. Quantitative purists, on the other hand claim that an inquiry in social science should be objective and detached from the object of study. [142]

There are several efforts to redefine and define corresponding concepts to reliability and validity within qualitative research.

Venkatesh et al [146] summaries examples of criteria for validity in qualitative research:

- descriptive validity is the accuracy of what is reported;

- credibility of the results means that they are believable from the point of view of the participants in the research and that alternative explanations are ruled out;

- transferability is the degree to which the results are applicable or possible to generalize to other context of settings;

- theoretical validity is the degree to which the theory fits the data;

- dependability is about how the changes in the setting affected the way the researcher approached the study;

- consistency is about logic in the process of analysis from raw data to findings;

- plausibility is concerned about whether the findings, results or theory fits the data from which they are derived; 
- interpretive validity is the degree of accuracy of the interpretation of the beliefs, views, thoughts, feelings, and intentions of the participants by the researcher;

- confirmability is the degree to which the results could be confirmed or corroborated by others.

Some of these criteria will be used in section 10.5 to discuss the quality of the research in this thesis.

\subsubsection{Data generation in practice research}

Goldkuhl [151] puts forward pragmatism as an alternative to interpretivism in qualitative information systems research. In the interpretivism tradition, as the label suggest, the actors achieve understanding through interpretation of the actor's beliefs, intentions, and the social process of creating meaning. In this process, the researcher can be part of this meaning construction but can also be an observer.

The focus in the interpretivism tradition is often on the context of the information system and its relation to the context. The information system in itself, as a designed reality, is usually not considered. Empirical data generation is seen as part of a socially constructed meaning in the interaction between the participants and the researcher. Thus, the empirical focus is cognitive and on the participant's beliefs. This type of research is typically used in field studies during a certain period. The role of the researcher is to be engaged in understanding. Data collection methods are focused on recording the observations in different ways and their interpretation using different data analysis methods. This methodology is well developed in for example grounded theory. [150]

In the tradition of pragmatism, the focus is on change and actions. An inquiry is a controlled transformation of a problematic situation with the aim to improve the situation. Knowledge creation is thus in the interest of change and improvement, not merely of understanding, although understanding is an important part in improvement and change. The focus is not only on "what is" but also on "what should or might be". Knowledge is an instrument for action and purposeful change. The researcher plays an active role in how knowledge is created where experimentation and interventions in the world is essential. The researcher participates in the practice studied and observes the results of different actions taken. The empirical focus is on actions and changes, looking for useful knowledge to improve a situation. Data is generated through pre-assessments of the situation, intervention and post-assessment of the effect of actions. The researcher is engaged in the change of the situation, and sometimes contributes actively to the change.

Pragmatism applied to information systems research has a focus on the designed and used information system artifact itself, as well as the context, in which it is designed and used. The information system artifact is part of a change of a situation. The design and use of the artifact will also influence the beliefs of the participants, particularly when it is an instrument for communication between people and organizations. 
Data generation in the tradition of pragmatism in information systems research is focused on recording change, actions, effects and consequences, and the nature and characteristics of the artifact.

\subsection{Generalizability in information systems and qualitative research}

This section summarizes some contributions to improve the understanding of generalization in information systems and qualitative research. These contributions about different types of generalizations and criteria for reasoning about and evaluation of plausible generalizations will later be used to discuss the possible generalizations of the results in this thesis, see 10.4 Generalizability of research findings.

The generalization of research findings and theories grounded in particular cases or settings to other cases and settings is of central concern for research. Dewey's concept of warranted assertability of practical theories mentioned earlier is related to concepts of generalizations and justifications for generalizations.

Within information systems research, as well as in qualitative research, there is a need to improve the understanding of generalization in order to make a critical judgment of the validity and usefulness of different theories and claims made for a particular domain of application.

Within information systems research, Lee and Baskerville [152] have outlined different types of generalizations. They claim that statistical generalization is often seen as the model for generalization, even in qualitative research. This has led to a misapplication of generalization in information systems research. Lee and Baskerville define generalization as a process to "form general notions by abstraction from particular instances".

Lee and Baskerville refer to a distinction originally made by Yin [153], between level one and level two inferences. A level one inference is a statistical generalization from a sample to a population and a level two inference is made from population characteristics, case study findings or experimental findings to a theory. Yin name this last level analytical generalization $^{36}$. Thus, Lee and Baskerville, in line with Yin, argue that in discussing generalizability of case studies, they should not be seen as samples, but rather be compared to experimental findings or population characteristics. Therefore, the analogy to sample size in statistical generalization is not adequate. Lee and Baskerville give examples from

\footnotetext{
${ }^{36}$ For Yin [153] is analytical generalization not only a one-directional activity but a part of a process were theory can be used in data collection and analytical generalization could be used to generate theories, and a theory could be compared with empirical result in another case study. Thus, analytical generalization is bi-directional between empirical findings and theoretical constructs.
} 
several information systems research studies, where discussions about generalizability of case studies, incorrectly borrows arguments about "sample size".

Generalization is seen by Lee and Baskerville as synonymous to induction. They refer to Hume's problem of induction, that implies that there is no logical justification for induction or for that matter generalization. In order to make inductive inferences one must always assume something that is outside the inference. When generalizing to general natural laws one must make the assumption about the uniformity or invariance of nature. For example, that the law of gravity will hold over time. Lee and Baskerville then make a general critique of statistical generalization based on Hume's problem of induction, and claim that it cannot be a general model for generalization and therefore it is necessary to investigate other forms of generalizations.

Lee and Baskerville propose a framework for categorization of different kinds of generalizations. [152]

Lee and Baskervilles influential article from 2003 has been met with a critique by Tsang and Williams [154] with suggestions for corrections and adjustments. They agree with Lee and Baskerville that statistical generalization is not the general model for generalization. However, they disagree with the grounds that Lee and Baskerville put forward, i.e. the insolvability of the Hume's problem of induction, which they suggest could lead to disprove generalization altogether. Tsang and Williams think that there can be a solution to Hume's problem of induction, even if they do not know yet which solution. They take as an example the attempts made by Strawson and Reicenbach (see their appendix A of the paper).

One line of argument is that there is an essential difference between deduction and induction, where deduction is truth preserving and induction is "... in Peirce's phrase ... ampliative. Induction can amplify and generalize our experience, broaden and deepen our empirical knowledge. Deduction on the other hand is explicative. Deduction orders and rearranges our knowledge without adding to its content." [155] (our emphasis in italics)

Thus, they conclude; induction should not be measured by the standards of deduction. Rather induction is not about true or false statements but of justification of beliefs based on evidence available.

Tsang and Williams definition of induction differs from Lee and Baskerville's definition. The former sees induction as an "inference from matter of facts that we have observed to those we have not." [154]

For Lee and Baskerville generalization (and induction) is a "reasoning process that begins with statements of particulars and ends in a general statement." [152] Tsang and Williams give examples of inductive inferences that are not generalizations but produce conclusions about particular conditions. Thus, they do not equate generalization with induction. [154] 
Tsang and Williams distinguishes two levels of research activities. On the empirical level, the researcher collects data through observation and on the theoretical level, the researcher develops theories based on observations and/or conjectures. They propose five types of generalizations:

- theoretical;

- within-population;

- cross-population;

- contextual;

- temporal.

Theoretical generalization is similar to Yin's analytical generalization.

- within-population generalizations are similar to statistical generalization, from a sample to population characteristics;

- cross-population generalization is a generalization from a sample in one population to another population in a similar context and period of time;

- contextual generalization is a generalization from a sample to another population in a different context but in a similar period of time;

- temporal generalization is a generalization from a sample to a same or different population in a different period of time while the context remains similar.

These different types of generalizations are often combined in a research situation.

Other scholars such as Smaling [156] agree that statistical generalization is not the only form of generalization. For Smaling there are at least two forms of inductive generalization - theory-carried and variation-based generalization.

In discussing Yin's concept of analytical generalization, Smaling empathize the role of formulated theories as vehicles for generalization to other cases that have not been studied $^{37}$. Smaling put forward the term theory-carried generalization.

Theory-carried generalization could be viewed as two different phases of research. One phase consists of developing and affirming a theory by several iterations between theoretical and empirical work. The other phase consists of using a sufficiently affirmed theory as a vehicle to generalize beyond the case or setting in which the theory has been developed and affirmed. This assumes that other cases or settings are assumed to be within the scope or domain of the theory.

Another form of generalization put forward by Smaling is variation-based generalization. In variation-based generalization, the researcher looks intentionally for variations, searching for deviating cases and even extreme cases. This process continues until the researcher judge that there is no new information to be collected and the collection

\footnotetext{
${ }^{37}$ Smaling has a similar view of induction as Tsang and Williams.
} 
of empirical data has reached a situation of saturation. This does not provide a sample that is statistical representative, but rather a sample that represents the variation.

The tree types of generalizations, statistical, theory-carried and variation-based generalization, are considered as generalizations based on inductive reasoning:

"Each is concerned with drawing conclusions pertaining to (a class of) subject, cases, situations, et cetera, that have not been researched, based on a limited number of persons, cases, situations, et cetera, that have been researched."[156]

These types of generalizations have no explicit criteria for comparing similarities and differences in situations and settings, i.e. there are no explicit criteria for good analogies that could assist in evaluating inductive generalizations. Hence, Smaling put forward six quality criteria to improve analogical reasoning and to avoid false analogies (comparing apples and pears) in comparing cases or in arguing for a theory to be plausible to hold for cases not yet researched. Table 5 Six quality criteria for analogical reasoning summarized from Smaling [156] summarize these criteria.

Table 5 Six quality criteria for analogical reasoning summarized from Smaling [156].

\section{Criteria Description}

Relative degree of similarity

If there are more similarities than differences analogical reasoning is more plausible.

The relevance for the conclusion If the similarities between cases are more relevant to the conclusion, it is more plausible to hold. In addition, if the differences are less relevant to the conclusion it is more plausible.

Support by other, similar cases

If there is support for a theory or finding by other similar cases, there is a stronger support for analogical reasoning that they will apply in other similar cases.

Support by means of variation

If there is support for a theory or findings in cases that have large differences, it is more plausible that it will also hold in other cases even if there are differences.

The relative plausibility of the conclusion on its own

If a theory or finding has a strong support in its original domain, it is more acceptable to use analogical reasoning.

Empirical and theoretical support

If the similarities and differences between cases and their relevance have been supported empirically and theoretically, the analogical reasoning is more plausible.

These six quality criteria for analogical reasoning can be used to evaluate and criticize the reasoning behind claims about the plausibility of generalizing findings or theories, generated in one setting, to hold in other settings. They can also be used to provide stronger 
arguments for generalization cross settings. In section 10.4.2, we will use three of Smalling's quality criteria to discuss the plausibility that the theory presented in this thesis would hold in another domain outside the original domain.

Whether research results and conclusions are generalizable is seen from the point of view of the researcher and the reader of the research. This social aspect of generalization called communicative generalization is divided into receptive and responsive generalization. In receptive generalization, there is not a direct interaction between the researcher and the reader and thus the reader has to rely on the clues given in the research reported. Responsive generalization is interactive in the sense that the potential user of the results is interacting before the final research is reported.

For receptive generalization, it is important that the readers be given sufficient information to be able to make judgments on the degree of relevance of the research for the reader. One form of communicative generalization is transferability, which is seen from the point of view the reader. Transferability of research is the plausibility that the conclusions of the research should hold in a situation that is of interest for the reader. To facilitate the reader's judgement of transferability, the researcher should provide information about the role of the researcher in the research situation, the context of the research project, informants, chosen methods, theoretical orientations, description of choices made and a 'thick description'. A 'thick description' refers to an extensive description of all relevant phenomena and alternative points of view.

The six criteria for good analogical reasoning would also be helpful for the reader to assess the transferability of the research result to setting relevant for the reader.

Another aspect of research linked to transferability put forward by Smaling is its utilization value. The utilization value of a research project is influenced by:

- accessibility of the language for the intended users;

- detailed information about research conclusions and context of what is researched;

- information about similar situations in which the research result has been used;

- research should start off from a real-life situation;

- potential users should participate in setup and conducting of the research;

- explication of methodological issues.

In general, good analogical reasoning contributes to utilization value.

The utility of the theory presented in this thesis will be discussed in section 10.6. 


\subsection{Development of research interest, activities, and results}

In this section, I will describe the evolution of my understanding of the ePrescribing practice and the successive evolution of research interests related to the engagement in different problems and situations in this practice. The research presented in this thesis has taken different directions with new insights and research questions have been posed underway. The research activities, data collection, and analysis methods chosen will be briefly described. The aim with this section is to give the reader information about the role of the researcher in the research, the context of the research and different orientations and choices made in order to facilitate a judgement of the quality and transferability of the research (see above).

My research journey is illustrated in Figure 8 using terms from practice research. The aim is to provide a roadmap for the research process, that consists of a number of overlapping research activities. In the top of the figure, the research activities (empirical and theoretical work) are ordered in a timeline with reported contributions to the research community. Research activities are yellow/light grey boxes and results are illustrated with white boxes.

At the bottom line of Figure 8, Development and operational work are illustrated with a summary of the contribution to the practice and the general practice contributions are shown in blue/grey boxes. The arrows between the boxes illustrates the influence between activities and contributions. See further section 3.3 Research approach for a definition of the concept empirical and theoretical work and developmental and operational work within practice research. In this section (3.3), the influence of the developmental and operational activities on the research activities (not illustrated in the figure) is also described.

In Figure 8, the period of engagement in the ePrescribing situation as well as the evolution of initial research interest in ePrescribing and engagement as a $\mathrm{Ph}$. D student is illustrated by dotted white boxes.

We will now continue to describe how interactions between the engagement in the situation of ePrescribing, the research activities, and contributions have evolved. 

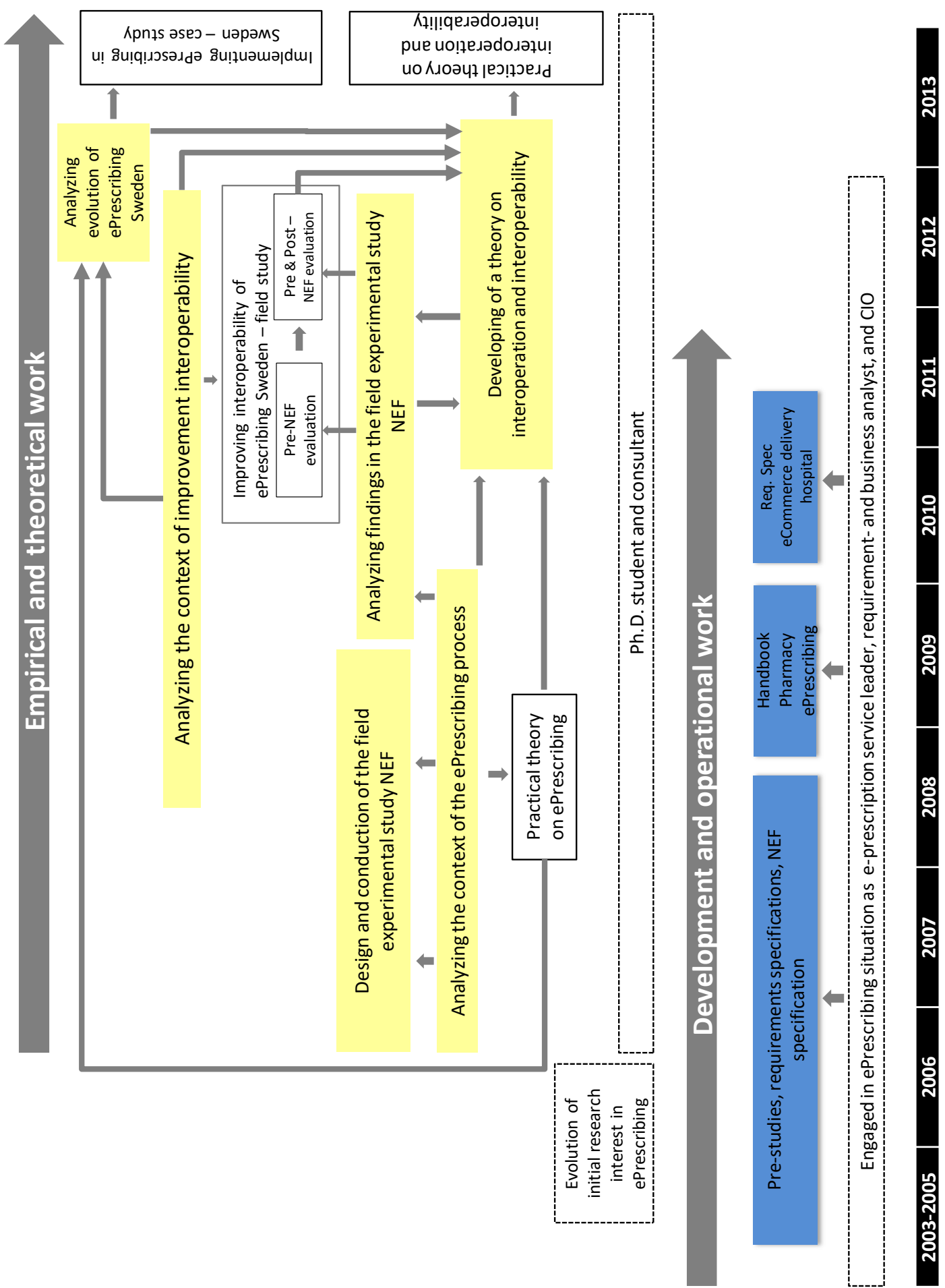

Figure 8 Relations between research activities and results. 


\subsubsection{Evolution of initial research interest in ePrescribing}

My first engagement in ePrescribing in Sweden was a consultant in 2003 at the National Pharmacy Corporation, NPC (Apoteket AB). I was involved in operational work as a "service leader" for the ePrescription service. The ePrescription service was provided by NPC for receiving ePrescriptions from hospitals and health care centers in the county councils. At that time (2003), the ePrescriptions were received centrally by the NPC and was then transferred to the local pharmacies. This operational work included solving problems that occurred in the production flow of ePrescriptions, making incidence reports, organize and participate in regular meetings dealing with emerging issues, externally with the health care regions and internally at the NPC. My consulting assignment also included to make a pre-study how to improve the situation. Experience from the operational work and reflection on how to improve the process gave rise to a need to improve the:

- quality of the incoming ePrescription message;

- robustness and capacity of the communication both externally and internally;

- process of maintenance both externally and internally of the ePrescribing process;

- process of change of functionality in ePrescribing.

Thus, problems in the operational work provided impetus to both development work and a research interest and subsequent research activities.

When in 2004, the NPC decided to initiate a work to change the ePrescription format, I made a review ${ }^{38}$ of articles and papers on the content of message specifications. I was specifically interested in the relation between syntax and semantics. This reflection resulted in an idea to make a distinction between static form and dynamic content; the latter dependent on the changing context of ePrescribing. Also my earlier work on expert systems and business rules [157] influenced me, together with the needs of the pharmacists, to develop a documentation of prescription rules as an addition to specifying rules for the dynamic content. The outcome of this was that there in the specification was a distinction made between minimum accepted form of a prescription and the dynamic contextual content defined by prescription rules. The prescription rules defined the regulated content of the prescription in different prescribing situations, for example when prescribing controlled medical drugs. This was the result of an approach of a reflective practitioner using theories to improve the practical work. See further chapter 5 Improving interoperability in ePrescribing - a field study for details on this work.

In 2006, in the end phase of my part of the work with the new ePrescription format NEF, my research interest developed around the needs put forward by the client at the NPC. This research interest can be summarized in the following questions:

${ }^{38}$ As a consultant with a research background. 
Question 1: How could the result of the efforts made in the project and the final implementation of the new ePrescription format in all county councils in Sweden be evaluated?

My initial focus was on the ePrescription message and the improvement of its quality, linked to design changes of the format and actions made in the implementation of the new ePrescription format.

Question 2: What methods could be used to measure the improvement made with the introduction of the new format?

Question 3: What was the relation between design changes, actions to implement the new format and the expected improvements?

\subsubsection{Design and conduction of the field experimental study (NEF)}

The design and implementation of a new national ePrescription format (NEF) was not just a technical implementation of a new format but was part of a whole range of actions that effected the quality of the ePrescription message. There were both actions of improvements of the prescribing systems and their use, but also actions to actually validate the adherence to the agreed format specification. The automatic validation of incoming ePrescriptions in the production flow was a strong incentive to improve the quality already when issuing an ePrescription.

To formulate it in quantitative research terms: there were a number of independent variables that influenced the dependent variable: the quality of the ePrescription message. Thus, a method emerged that was based on measuring the quality of the ePrescription message before and after the implementation of the new ePrescription format. Thus, the design and implementation was seen as an intervention affecting the ePrescribing work practice. The method developed to measure the quality of the ePrescription message was to compare the adherence of ePrescriptions to agreed message specifications and prescriptions rules. Some of these prescription rules became documented together with the new format. In another project at NPC, I documented and formalized the prescription rules in a requirements specification for the national repository of prescriptions. Data collection using a quantitative method of consecutive sampling was considered the best choice.

Thus, my research started with a focus on assessing the quality of the transferred message, the ePrescription. These types of assessments, in terms of formal or operationalized quality measures, are well suited for a quantitative analysis. The assessment was made before and after the implementation of NEF. Two papers, based on the pre (2008) and post (2009) NEF samples, were published as a result of this research. $[8,9]$ They have been published in the context of medical informatics, where a quantitative analysis is an important research approach. This research contribution is named 
"Improving interoperability in ePrescribing Sweden - field study" in Figure 8. See 5 Improving interoperability in ePrescribing - a field study.

\subsubsection{Analyzing the context of the ePrescribing process}

In 2007, I asked my current supervisor if he could accept me as a PhD-student at Linköping University. I was interested in his research approach, both theoretically concerning information system theories and the research methodology that combined theoretical work with practical contributions.

In the process of coming to grips with the quality of the transferred message, I started already in $2006^{39}$ and more systematically in 2007 to pose the question:

Question 4: Why was a seemingly simple message prone to errors ${ }^{40}$ and misunderstandings?

In 2007, I started to read about theories of communication with special interest in theories about language and the aspect of language as a social process ${ }^{41}$. I was interested in how the context of the message influenced the complexity, quality and interpretation of the message. One important context was the use of information systems in issuing and transferring prescriptions. When designing the test cases for qualifying EHR-systems that were allowed to issue and send ePrescriptions in the new format, I posed the question how the user interface and prescriptions rules implemented in the system would influence the quality of the ePrescription message. Thus, the practical question was how far into these systems should the test cases reach.

Question 5: How to evaluate and put demands on the user interface and the EHR-systems in order to improve the quality of the ePrescription message?

In the operational work, we (me and my colleagues) observed that some recurrent errors were due to design of user interfaces in the EHR-systems However, evaluating the user interface were considered outside the realm of project, even if we recognized that it had

${ }^{39}$ In 2006 I made a presentation at a conference in Slovenia on the implementation of ePrescribing in Sweden. In the presentation, I posed the question of the complexity of the prescription. See Figure 13 in this thesis for a slide in the presentation that illustrates the external complexity of the prescription. [158]

${ }^{40}$ Note that for ePrescriptions, there are very high demands on the quality, because there are patients involved that could be affected by errors. There is also a strong culture among pharmacists to be rigorous in controlling the prescription. Much of the quality assurance in ePrescribing is pushed towards the endpoint of the process, towards the last gateway, the pharmacist. This is also reflected in the legislation on prescriptions.

${ }^{41}$ At the research institute SISU (Svenska Institutet för SystemUtveckling - Swedish Institute for Systems Development), I had already in the 1990s knowledge about speech act theory and the theories of Winograd and Flores. [159] 
influence on the quality of the message. Thus, even if this was considered out of scope in the development work, it became nevertheless for me an important research question.

Question 4 and Question 5 lead me in the research activities to focus more on the context of the ePrescription message, the process of ePrescribing, as well as the quality of the systems used in the process. Thus, in 2007, I made an analysis using practical theories to get a better grasp of the multiple functions of an ePrescription message. This resulted in a paper presented in May 2008, contributing to a practical theory on ePrescribing. [42]

General practice and research contribution: Practical theory on ePrescribing (see Figure 8).

During this time, I was also engaged in requirement analysis projects involving the pharmacy side of the ePrescribing process. One important part of this was the documentation of the ePrescribing process at the pharmacy side in the form of a handbook $^{42}$ that was directed towards the new pharmacy chains.

Local practice ${ }^{43}$ contribution: A handbook for ePrescribing at pharmacies (named 'Handbook Pharmacy ePrescribing" in Figure 8).

In this document, I included results from the paper published in 2008, particularly on the link between the prescriber practice and the pharmacy practice and the regulatory perspective.

\subsubsection{Analyzing findings in the field experimental study NEF}

After gathering and analyzing the first results from the pre-NEF and post-NEF studies in 2010 , there was a need to place the findings in a wider context of ePrescribing, information systems theories and interoperability. I returned to the earlier analysis of the ePrescribing process and theories of interoperability and posed the following questions:

Question 6: How could the findings be understood in terms of theories of interoperability?

\footnotetext{
${ }^{42}$ Handbok för apoteksaktörer version 4.0, Apotekens Service AB.

${ }^{43}$ This is considered a local practice contribution in the sense that it was not a result of a deliberate theorizing, but was based on experiential knowledge. Thus, even if it was directed towards a wider community of practitioners outside the NPC pharmacy chain, it is still considered as a local practice contribution. This point to a difficulty to talk about a 'local' practice, which is reasonable within an organization. In the context of interoperation, there is always a community both inside and outside of the organizations involved, and in this sense, address the general practice. However, the other criteria about deliberate theorizing is not fulfilled to make it a general practice contribution. May be a better term would be situated practice instead of local.
} 
Question 7: How could the findings be understood in terms of the practice of ePrescribing?

Question 8: How could the findings be understood in terms of theories of quality criteria for information systems?

Question 9: How could the findings be understood in terms of other experiences of vertical information standards design and implementation?

In the two papers published [8,9] about the design and implementation of the new ePrescription format, the findings were analyzed and discussed using theories of interoperability and quality criteria for information systems. This analysis of the findings from the experimental study showed that the standardization of the ePrescribing work practice and the ePrescription message when implementing the new format improved the quality of ePrescribing. Therefore, it was of interest to develop a theory based on these findings that could better explain and amplify our knowledge about improving interoperability. Thus, the field experimental study contributed to the generation of a practical theory on interoperation and interoperability (see section below).

\subsubsection{Analysis of the context of improvement of interoperability and evolution of ePrescribing in Sweden}

Since 2009, the findings showing the improvement of interoperability in ePrescribing in Sweden led me to reflect more on the factors that had made it possible to develop a new digitalized work practice in ePrescribing based on interoperable information systems between different organizations.

The following questions were posed:

Question 10: What were the factors making the implementation of ePrescribing so successful in Sweden?

Question 11: What part played the project for the new national ePrescription format $(\mathrm{NEF})$ in this implementation process?

In order to explain the factors that contributed to the improvement of interoperability in ePrescribing, it was necessary to place this improvement within the overall evolution of ePrescribing in Sweden. The improvement project spanned over a period with intense growth and development and later a consolidation of the implementation of ePrescribing in Sweden.

Data about the implementation of ePrescribing in Sweden from the pioneering years in the 1980s up to the years of consolidation in the end of the first decade of 2000 was collected and analyzed, complemented with interviews of key informants of the implementation process. This work resulted in a case study of the implementation of 
ePrescribing in Sweden (see Figure 8 'Implementing ePrescribing in Sweden - case study').

The case study illustrates the importance of the evolution of information infrastructures in achieving interoperability and of a structured cooperation between stakeholders in the design and implementation process.

This study also contributed to the theory on interoperation and interoperability. See chapter 4 Implementing ePrescribing in Sweden - case study for a report of this case study.

\subsubsection{Developing a theory on interoperation and interoperability}

In the work with the first results of the field experimental study in 2010, I started to develop a theoretical framework influenced by different frameworks of interoperability, that emphasized technical, semantical, organizational and legal aspects. In this process, a number of questions were raised:

Question 12: What is the relationship between syntax and semantics?

Question 13: How is organizational and work practice aspects linked to semantics?

Question 14: How is semantics related to the content of the message and the participants understanding in the ePrescribing process?

These were the central questions in my mind. In the literature review, I found that there were few papers linking the different layers of interoperability in an elaborate way ${ }^{44}$.

When writing the second paper on the results of the NEF implementation, I returned to the impact (user behavior, education, work situation, incitements, et cetera) that the user interface of the Prescribing systems had on quality of the ePrescription message. The insight from 2007, that the context influences the content of the message, lead to a new insight:

Insight 1: An ePrescription is an instrument or vehicle for communication of different social acts, such as authorizing, directing and making commitments.

Thus, in preparing the papers of the quantitative analysis of ePrescription errors, I looked into the theory of actability of information systems to see if it could give some insights into the relation between context and message. Particularly the idea of communication, interaction and process quality was very useful in analyzing the ePrescribing process, and to analyze the measurement of quality I reported in the paper. $[8,9]$

\footnotetext{
${ }^{44}$ An exception was a paper by Stamper et al [160] who linked the different layers: physical, empiric, syntactic, semantic, pragmatic and social. This paper inspired me to go further in trying to elaborate on different the aspects of communication.
} 
The next phase in the development of my understanding of interoperability and interorganizational communication was triggered by the need to synthesize the work done so far and make it accessible and useful for practitioners and researchers - in writing this thesis. In this work, I made a literature review of theories, concepts and frameworks of interoperability (presented in 2 Interoperability, information infrastructures, work practices, and standards).

Most of the reviewed papers had a technical and formal approach to interoperability problems and its solutions. I felt that there was a weak and fragmented theoretical basis within the field of interoperability to understand the communication and its context. Many papers proposed formal methods that either focused on the technical aspects of the communication, or when dealing with semantic issues were based on formal semantic theories devoid of social aspects of communication. There were also few papers on interoperability that involved legacy systems. The approaches and solutions proposed were not in line with my experience of dealing with interoperability problems. However, I found many insightful papers reporting on interoperability in the military domain that reflected a more realistic approach. They insisted on organizational and process aspects of interoperability instead of promoting formal or technical solutions.

This reflection prompted me to look for a theoretical basis of communication. This direction lead to a review of literature in linguistic and communication theories. I was looking for a theoretical basis that could link the message content as part of a social process of communication between humans using an information system as an instrument for communication. The questions that emerged were:

Question 15: How is the message communicated part of a wider context of cooperation in a work process?

Question 16: Is it possible to define a theory that integrates different aspects of interoperation and interoperability such as technical, semantic, organizational and cooperative action? How could one describe their interdependence within a communication context where communication is mediated by information systems?

Another problem with the reviewed frameworks of interoperability was difficulties to apply them to my experience in a precise way. I felt that there was a confusion between different aspects of governance, development, implementation, and operation. In discussing this with my supervisor, I came to the following insight:

Insight 2: Make a distinction between the operational and governance aspect of interoperation.

This gave me the impetus to integrate operational and governance aspects into a theory on interoperation and interoperability.

One aim with this thesis is to contribute with a theory on interoperation and interoperability. The development of the theory has been the result of an interaction between different research activities and contributions related to ePrescribing and 
theorizing activities. The presented theory is a result of an effort to answer the different research questions posed and to integrate contributions from other extant theories on interoperation, interoperability, information systems, and communication. See Figure 8 'Practical theory on interoperation and interoperability' and chapter 9 A practical theory on interoperation and interoperability.

\subsection{Practice research in interoperability and ePrescribing}

In this section, we will first introduce the subject matter and contributions in this thesis. Then, we will describe our sources of evidence and methods to collect and analyze data. Finally, we describe different kind of knowledge contributions made and theory components in terms of practice research concepts presented earlier in this chapter.

\subsubsection{Overview of research and contributions}

In this thesis, we are studying and theorizing about the practice of ePrescribing, which is a shared practice of two other practices of medical treatment and pharmaceutical care.

The practical theory on interoperation and interoperability is a generalization of findings from the situational inquiry in the practice of ePrescribing. Thus, ePrescribing is viewed as a case of interoperation between organizations and actors to achieve a certain objective for a client. The theory is a generalization of interoperation and interoperability beyond the case of ePrescribing with the aim to be used in other contexts of interoperation.

Figure 9 illustrates the relationship between the general work practice of interoperation and the specific work practice of ePrescribing.

- The specific work practice of ePrescribing can briefly be described as the interoperation between health care and pharmacies, and of the prescribers and the pharmacists involving the prescription of medical drugs to a patient, the whole life cycle of the prescription and the follow up of compliance and consumption, using information systems for this cooperation and interaction.

- The general work practice of interoperation can briefly be described as the practice of organizations and actors to interoperate and manage a shared work practice for a certain objective and client using information systems.

The case of ePrescribing practice is contributing with findings to the general case of interoperation and is also informed by the general case.

The practical theory on ePrescribing is a generalization of the findings in a situational inquiry of ePrescribing in Sweden. This generalization to a practical theory is a general 
practice contribution aimed at the general practice community (see 3.3.2), with the aim to be used by the general practice community in Sweden and in other countries.

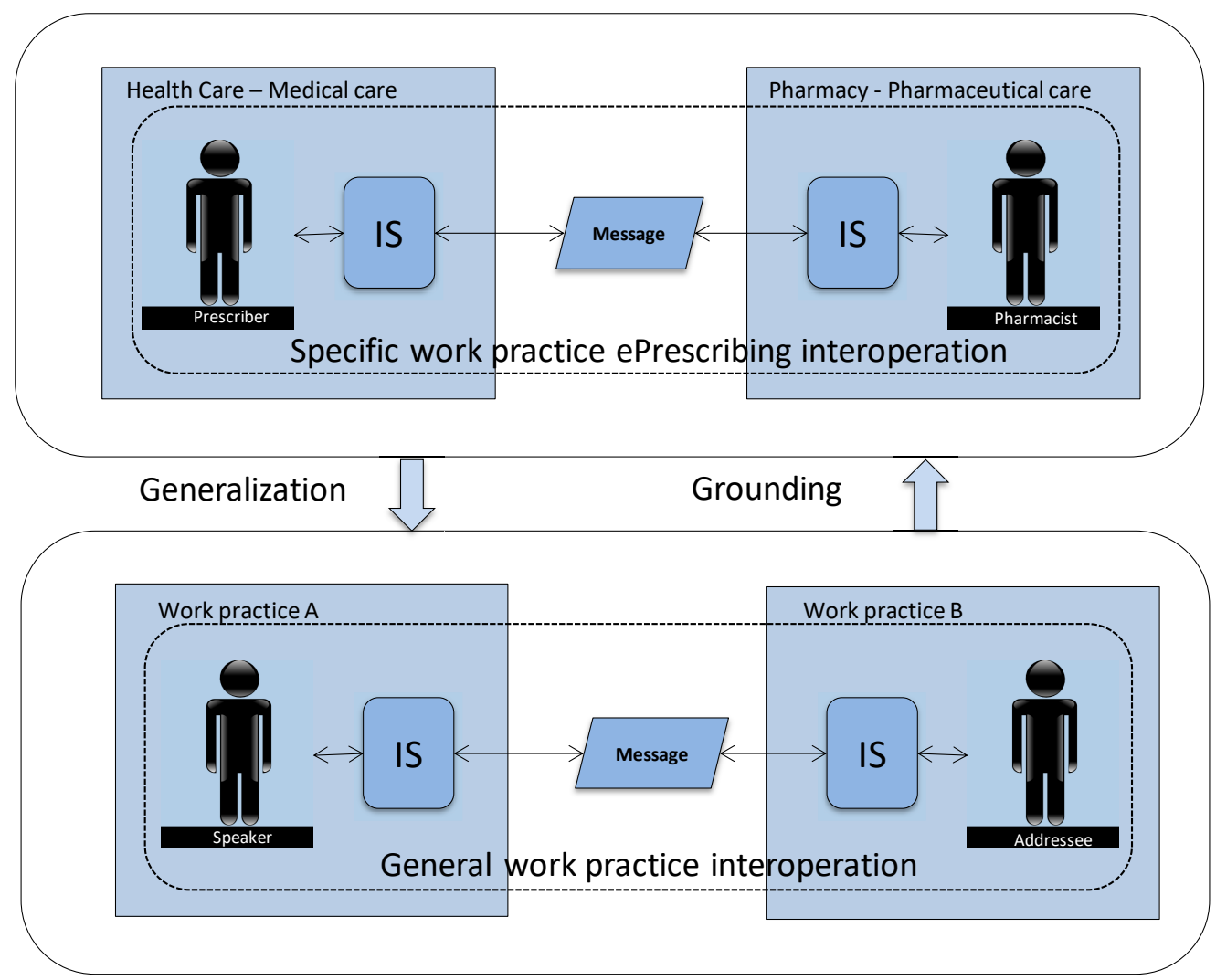

Figure 9 Illustration of the relationship between the specific case of ePrescribing and the general case of work practice interoperation using information systems.

In the following, we will briefly describe (see Figure 10) the relationship between theorizing activities and activities related to the situational inquiry of ePrescribing.

Theorizing activities, as well as the rendering and collection of the findings in the inquiry, were informed by extant theories about interoperability, information systems, information infrastructure, human communication, language, and semantics.

The situational inquiry into ePrescribing contributed with empirical data, preunderstanding, and understanding of the subject matter. This formed the material for the generalization into emergent theories about ePrescribing and interoperability. The situational inquiry was informed by theorizing activities and development of research interests and research questions. The case study on implementing ePrescribing in Sweden was important in order to place the improvements from the field experimental study within 
the overall evolution of ePrescribing in Sweden and to better understand the conditions for the evolution of the information infrastructure for ePrescribing.

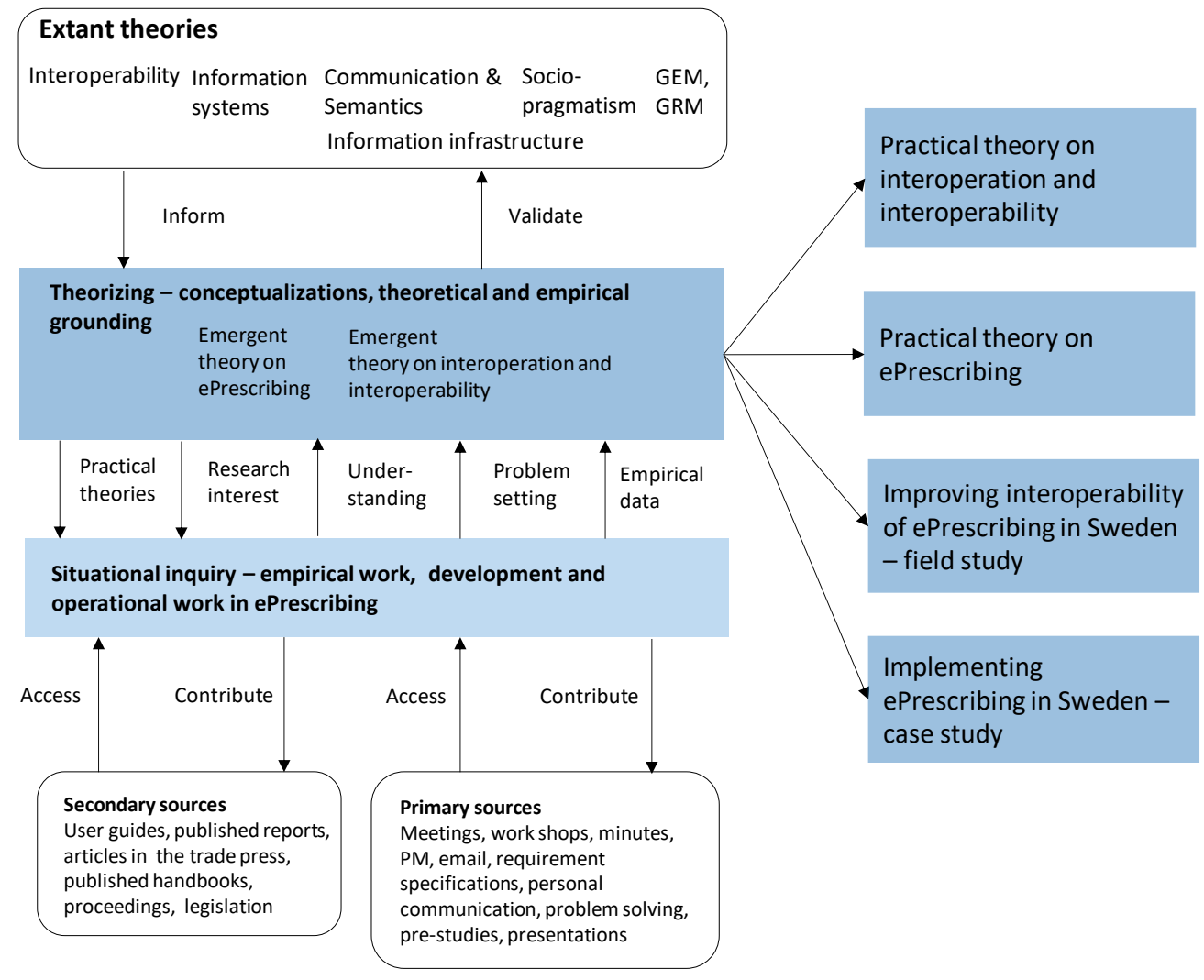

Figure 10 Relationship between theorizing, situational inquiry, and research contributions.

The practical theory on ePrescribing (6) has been used to analyze the findings from the field experimental study of improving interoperability of ePrescribing in Sweden (Chapter 5). Other extant theories such as IS actability theory and theories on interoperability have informed the analysis (Chapter 7).

The practical theory on ePrescribing has been theoretically grounded in socio-pragmatic communication theory, Generic Regulation Model (GRM) and Generic Exchange Model (GEM).

The practical theory on interoperation and interoperability (Chapter 9) has been theoretically grounded in extant theories on information systems, information systems actability theory, theories about human communication from a cognitive, language, and social perspective and theories about interoperability of information systems, processes and organizations. In summary, the theory on interoperation and interoperability presented in chapter 9 is grounded on the following empirical and theoretical contributions: 
- Implementing ePrescribing in Sweden - case study (Chapter 4);

- Improving interoperability of ePrescribing in Sweden - a field experimental study (Chapter 5);

- Practical theory on ePrescribing (6).

The practical theory on interoperation and interoperability and the practical theory on ePrescribing have been internally grounded by analyzing their internal consistency, clarity of concepts and completeness. In this process, supervisors and research colleagues have contributed by showing inconsistencies and the need to clarify concepts and definitions.

\subsubsection{Sources of evidence, data collection, literature reviews, and data analysis}

The researcher's role in the situational inquiry as an insider (see section 3.2 for a description of the role) has contributed to the empirical work with a close access to primary and secondary sources of evidence.

The role as an inside researcher has helped to develop a deep understanding of the design context and work practice of ePrescribing. This understanding contributes to what Donald Schön calls an understanding of the problem setting. [124]

A problem setting is the,

"... process by which we define the decision to be made, the ends to be achieved, the means which may be chosen."

and

"When we set the problem, we select what we will treat as the 'things' of the situation, we set the boundaries of our attention to it, and we impose upon it a coherence which allows us to say what is wrong and in what direction the situation needs to be changed. Problem setting is a process, interactively, we name the things to which we will attend and frame the context in which we will attend to them." [124] (Chapter: From technical rationality to reflection in action)

This understanding of the problem setting has an influence on what data to collect and how to analyze the collected data, and on the focus on what is essential and of importance for the situation. This kind of understanding is best learnt in an engagement with a practice involving many problem-solving activities with an attitude of constant reflection on what one is doing while doing, what Schön would call reflection in and on action. This reflection in and on action is part of a learning process in which the practitioner learns how to frame problems and find characteristics in a situation thst are important to attend to and consider. 
Taking this as a point of departure, which foremost has an influence on the qualitative data collection and analysis, we describe in the following our sources of evidence and data collection methods.

\section{Sources of evidence}

\section{Primary Sources}

The access to first hand sources have first been the involvement in different projects, meetings, workshops, communication with colleagues and with different technical, business, pharmaceutical and legal experts. In the role as an insider, I was also responsible at times for preparing and hosting meeting and workshop for analysis of the processes, concepts and objectives of the NPC regarding dispensing and requisition of medical drugs. I also participated in joint meetings between the county councils and NPC, that dealt with different issues in ePrescribing.

Field notes, that have not been part of taking minutes for meetings, have been taken at occasions to note some significant observation. Some of these reflections have been communicated by email to colleagues or have resulted in idea outlines made in Power point or in written PMs.

In the situational inquiry, I have contributed with different documents, such as minutes, pre-studies, requirements specifications, handbooks, process models of the dispensing and requisition process, conceptual models of ePrescribing, and models of project objectives.

I have also had access to other primary sources such as emails, memoranda, minutes, requirements specifications, pre-studies, user guides, process and routine descriptions, policies, legislation, and decrees. The sources that were regarded as important have been saved for later use.

\section{Secondary sources}

Secondary sources have been articles in the trade press, texts in published handbooks, presentation at conferences, papers published in conference proceedings and journals concerning ePrescribing in Sweden and in other countries.

\section{Data collection methods}

In the following section, we describe briefly the data collection methods used in this study.

\section{Quantitative data collection}

Consecutive sampling of ePrescriptions has been made before and after the intervention of a new NEF. Consecutive sampling was chosen as data collection method instead of random sampling, in order to better handle the change of historic data regarding medical drugs. The sample size was estimated and calculated in order to detect small significant changes between the two samples. See further Öhlund et al [9] and chapter 5 for a 
discussion on methods for calculation of sample size and reasons for the choice of consecutive sampling.

\section{Collection of documents}

The collection of documents that have been gathered in the situational inquiry, mentioned above as secondary sources, have been saved and organized electronically. Documents from external sources related to ePrescribing such as technical or status reports, legislation, policy documents, articles in trade press, presentations at meetings and conferences have been stored. This can be seen as part of creating what Yin [153] would call a case study database.

\section{Interviews}

Interviews have been used in order to gather the views of the participants in implementing ePrescribing in Sweden. The interviews were open-ended thematic interviews. The interviews were either face to face or by telephone. All interviews were recorded. Notes were taken during the interview and parts of the interviews were transcribed.

The informants in the interviews were given the opportunity to review a draft of the case study report to add comments and corrections. See chapter 4 and below on qualitative data analysis.

\section{Literature review}

The review of the literature for this thesis has been conducted in a structured way using certain keyword search ${ }^{45}$ to sample relevant documents. This initial literature search has been complemented during the whole research endeavor, with an interactive search using key words based on an increased understanding of the subject matter. A key word search was used in the initial phases for the review of concepts and frameworks of interoperability. Certain key words such as interoperability, ePrescribing, ePrescription, health, eHealth, definition, framework, interoperability problems, implementation interoperability, improving interoperability, information quality, information infrastructure, standard, standardization, terminologies, et cetera, were used separately and in combinations.

The collected articles were read and interesting references were searched and read and so on, until it was judged that more search would not yield more information that were relevant.

The review of the literature on communication theories from a philosophical, linguistic, logic, social or cognitive point of view was made in the same manner. In this case, it was

\footnotetext{
${ }^{45}$ Search for research paper has mainly been made using the 'OneSeach' service at Linnaeus University which contains the majority of their available databases for research publications and their library catalogue. Google Scholar has also been used to search for research publications. Google has been used to find articles in trade journals or in the daily press.
} 
necessary to limit the search because the search space is so huge. One method used to limit the search space was to identify certain important contributions, that represented different lines of thought and then focus on those that were the most promising in answering the research questions and contributing to the theorizing activities.

To find work that were made outside the academic world, search engines on internet was used to gather work, projects and reports that were not published in academic journals and conferences.

Papers that were possible to save electronically were saved.

\section{Quantitative data analysis}

The quantitative data analysis was made of the two consecutive samples collected before and after the introduction of the new NEF.

Descriptive statistics were used to compare some characteristics of the two different samples, such as number of prescription messages, average number of prescriptions per prescription message, average number of iterations, proportion of reimbursement medical drugs, number of prescriptions per prescribing systems, et cetera.

The other major data analysis consisted in analyzing all the detected errors in relation to agreed message specification and prescription rules. These errors where classified in two main categories, format and prescription errors. They were coded within each category to cluster the error in subcategories related to the content of the prescription.

The errors were also classified in relation to an interoperability framework with different aspects: technical, semantical organizational and judicial.

The descriptive statistics of the samples and of the errors were produced using SQL queries, due to the large amount of data, with more than 5 million error records.

Pearson chi-square was calculated to test that if no change in interoperability errors occurred. A high number of Pearson chi-square indicate a significant improvement in interoperability in the post-NEF sample. $P<.05$ was regarded to be significant.

See chapter 5 Improving interoperability in ePrescribing for at description of the data analysis.

\section{Qualitative data analysis}

The qualitative data analysis focused mostly on identification, gathering and ordering of sources for important changes and interventions made in the situational inquiry. The interviews with key participants in implementing ePrescribing in Sweden were focused on their understanding of the most important events in the history of implementing ePrescribing in Sweden and factors that influenced the implementation process. In other 
cases, most of the data collected and analyzed were about important events and results judged to be the most important data about the situation as it evolved.

The data analysis focused on identifying the essential changes and interventions. The analysis was iteratively going back to historic data sources. These sources were both inside and external sources, such as written accounts, research papers, legislations, and policy documents.

\section{Improving interoperability of ePrescribing in Sweden - field study}

In the pre- and post-NEF field experimental study on improving interoperability in Sweden, data was collected to describe the context and content of the intervention. This data was analyzed and ordered into different themes:

- experienced initial problematic situations;

- factors that drove the initiative for a change;

- action's initiated and description of the designed change and their motivation.

The co-authors of the papers, a pharmacist, researcher and pioneer in ePrescribing in Sweden, and a medical doctor and researcher in eHealth contributed in corroborating the qualitative data analysis of the contextual factors in the improvement project. [8,9]

\section{Practical theory on ePrescribing}

In the work with developing a practical theory on ePrescribing, the characteristics described and organized in the theory were successively verified against available data sources. It was possible to corroborate the statements in the practical theory using external sources and through consultation with experienced practitioners in the field. The validity of the interpretations of data using the practical theories was verified with the co-author of the paper, who also was one of the instigators of the practical theories used. Some ambiguities in using the practical theories to analyze the reality of ePrescribing, was identified and reported in the paper. [42]

\section{Implementing ePrescribing in Sweden - case study}

The empirical sources for the case study on implementing ePrescribing in Sweden were interviews; previously collected external and internal sources that were revisited and new sources gathered. These sources were used to verify and develop statements in the case study. The data was first analyzed in chronological order, starting from an idea of an initial pioneering phase. The data for this phase was gathered in the interview with the pioneer in ePrescribing, who also contributed with additional relevant references and documents. Initially, I had not a very clear idea about different phases. These phases became more apparent in the course of analysis. As an insider, I was part of the phase of growth and consolidation.

The chronological organization of the events in three phases were marked by important events or initiatives. The interview with one of the informants who had worked with managing the information about medical drugs draw attention to the development of the 
infrastructure. Another influence was from the research by one of my supervisors on the importance of identifiers for the evolution of information infrastructures. This influence made me to return to a reflection on information infrastructures I already had in 2006, in a presentation to a conference in Slovenia on implementing ePrescribing in Sweden. [158] The importance of identifying the actors in ePrescribing was also informed by the practical theory on ePrescribing, that clearly highlighted the different actors and the reference to important objects.

\section{Practical theory on interoperation and interoperability}

Building the theory on interoperation and interoperability was mainly based on findings presented in the different contributions, but also from several practice contributions such as the handbook on pharmacy ePrescribing process and the specification of the new national ePrescription format. The development of the theory on interoperation and interoperability is grounded in an analysis of data collected in nine years of involvement in ePrescribing and in implementing eCommerce processes and information systems for the distribution of medical drugs to hospitals.

\subsubsection{Contributions and theory components}

In this section, we will summarize the major contributions in this thesis in terms of practice research concepts. Within practice research, contributions could aim at different communities and situations. Within a situational inquiry, a researcher can contribute to the local operational practice targeted towards the participants in the local practice ${ }^{46}$. These are called local practice contributions. Theorizing activities in practice research could aim at contributing with knowledge to both the research community and the general practice. The general practice community can be the general practice in which the local practice takes place. It can also be a generalization of results towards other general practices considered plausible candidates for generalization of results. See further section 10.4 for a discussion on generalization of results to other practices outside ePrescribing.

The contributions are summarized and categorized in types of knowledge contributions and when relevant in different types of theory components (see section 3.3.2 and 3.3.3 on these concepts). In section 10.2, we summarize the contributions with a focus on their specific contributions to different research fields.

\section{Local practice contributions}

Within the situational inquiry into improving the interoperation and development of ePrescribing in Sweden, the inside researcher has contributed in operational and

\footnotetext{
${ }^{46}$ Regarding the term local practice and how it should be interpreted in an inter-organizational setting, see our previous note 43 in this chapter.
} 
developmental work with several local practice contributions in the form of documents summarized as follows:

- specification of the new national ePrescription format (NEF) with a focus on definitions of terms and valid content of the ePrescription, prescriptions rules, and feedback mechanism to the prescriber;

- handbook on implementing ePrescriptions as a reference document aimed at software providers and clients;

- requirements specifications and pre-studies about the national repository of ePrescriptions;

- requirements specifications and pre-studies about the National Pharmacy Register; [161]

- conceptual domain model of ePrescribing within the NPC;

- handbooks for the pharmacy ePrescribing process aimed at the new pharmacy actors in the new deregulated pharmacy market.

These documented contributions are not publicly available. They were available to restricted communities involving different organizations.

\section{General practice and research contributions}

\section{Implementing ePrescribing in Sweden - case study}

Chapter 4 contains a retrospective case study describing the implementation of ePrescribing in Sweden from the pioneering years in the 1980s up to the years of consolidation in the end of the first decade of 2000.

Firstly, the case study contributes to the understanding of the importance of the evolution of information infrastructures in achieving interoperability.

Secondly, it contributes with experience of the implementation process with a focus on structured cooperation between different stakeholders in the ePrescribing process.

Thirdly, the empirical material on which the case study was based and the findings in written case study report, contributed with material for generalization to a practical theory on interoperation and interoperability, particularly concerning governance of interoperation and the evolution of information infrastructures.

The knowledge contributions ${ }^{47}$ of this study are categorized as:

- conceptualization of different factors that influenced the development of ePrescribing in Sweden, regarding incentives, evolution of information infrastructure, economical, legal, and organizational factors;

\footnotetext{
${ }^{47}$ For a categorization and explanation of different knowledge contributions see section 3.3.2 Practice research and the subsection Type of knowledge contributions in practice research.
} 
- explanatory in describing and collecting the historical factors and events that influenced the pace and evolution of ePrescribing in Sweden.

- prescriptive, in the sense that it reports success factors in implementing ePrescribing in Sweden, that could be a useful example for other similar practices.

Thus, this study is a general practice contribution to ePrescribing and contributed with findings to the theory on interoperation and interoperability.

\section{Improving interoperability in ePrescribing - field study}

Chapter 5 reports a situational inquiry into improving interoperability in ePrescribing including empirical, development and operational work inside the practice. In the beginning of the inquiry, there was mainly operational and developmental work contributing to the local practice (see above). Closely related to this work, a research interest developed in evaluating the effects of the implementation, seen as an intervention in the ePrescribing practice. This research interest developed into a field experimental study measuring interoperability errors before and after the intervention.

The study is a general practice contribution, providing an evaluation of the outcome of the change process, showing the utility of the actions taken and thereby contribute with an experience to the general practice knowledge in ePrescribing interoperability. This knowledge contribution is both diagnostic and normative; normative in the sense that there were set up criteria for good quality of ePrescriptions messages, criteria if generalized, should be useful also for other practices. See section 10.2.2 General practice contributions for examples on how the contributions in this study have influenced the ePrescribing practice today after the deregulation of the pharmacy market.

The study is also a research contribution giving additional methods to assess interoperability. To our knowledge is the field experimental study evaluating an effort to improve interoperability unique, in the sense that it was possible to compare the situation before the intervention and after the implementation using a real-world field experiment. Thus, it is both an empirical and methodological contribution to the research field.

For a detailed description of the results from the situational inquiry on interoperability in ePrescribing confer $[8,9]$. Confer also chapter 5 Improving interoperability in ePrescribing - a field study in this thesis for a summary of these contributions. The situational inquiry has also contributed to highlight the operational aspect of interoperation in the theory on interoperation and interoperability.

\section{Practical theory on ePrescribing}

The inquiry into the ePrescribing practice and the daily encounter with this practice as an insider practitioner, called for a better understanding of the complexity of ePrescribing. The practice of ePrescribing was analyzed using practical theories for analysis of the ePrescription message, the regulatory aspects of ePrescribing, and the exchange between actors in the health care and pharmacy markets. The result was a contribution to a general practice theory on ePrescribing with a focus on conceptualization. It was also a 
contribution to an empirical grounding of the practical theories applied regarding their adequacy, usefulness, and applicability in this domain and thus also a research contribution.

For a detailed description of the result from this study on ePrescribing confer [42] and chapter 6 A practical theory on ePrescribing in this thesis.

Theory components

The practical theory on ePrescribing contains the following elements or instrumentalities ${ }^{48}$ :

- conceptualizations of actors, communicative actions, infrastructures, work practices, domains and artifacts in the practice of ePrescribing;

- patterns of the ePrescribing work practices and their interconnections;

- models to illustrate the communicative actions, actors and the context of the practice of ePrescribing.

\section{Knowledge contributions}

The knowledge contribution is a conceptualization of ePrescribing, useful to understand the complexity of the process and give attention to different aspects in ePrescribing that have influence on the work practice.

It is also prescriptive in the sense that it demonstrates the utility of applying practical theories, such as socio-pragmatic communication analysis and General Regulation Model, which contributed to highlight issues in the work practice that can be improved.

\section{Practical theory on interoperation and interoperability}

Based on the findings in the case study, the situational inquiry and the practical theory on ePrescribing, a further generalization has been made into a practical theory on interoperation and interoperability. The theory is empirically grounded in the situational inquiry in the operational practice of ePrescribing and in the history of implementing ePrescribing in Sweden. It is theoretically grounded in information systems theories, theories and framework for interoperability, work practice theory and communication theories.

Theory components

The practical theory on interoperation and interoperability has the following elements or instrumentalities:

- conceptualizations of the interdependencies in interoperation, general communicative context of interoperation, work practice context of interoperation, different aspects of interoperation in shared work practices, governance

${ }^{48}$ Confer Table 4 Constituents of a practical theory from Goldkuhl. [137], for a definition of these elements. 
mechanisms for collective action and interoperation, and the use of information infrastructures to communicate acts in interoperation;

- patterns of action in the interoperation of a shared work practice and in its governance and of collective actions;

- normative criteria are expressed in a definition of interoperability giving guidance for defining overall criteria for the capability to interoperate, and in criteria for information systems actability for judging interaction, communication and process quality;

- models are used to illustrate the main components of the theory on interoperation and interoperability.

The practical theory on interoperation and interoperability is targeting both the general practitioner working with developing, improving and governing interoperation, as well as the research community to inform about relevant research areas, theoretical refinement and further situational inquiries. For details about the practical theory on interoperation and interoperability, confer the chapter 9 A practical theory on interoperation and interoperability.

\section{Knowledge contributions}

The knowledge contributions with the practical theory on interoperation and interoperability are:

- conceptualization of different aspects of interoperability based on theories and findings from the situational inquiry in ePrescribing;

- normative in the sense that it provides concepts to define and evaluate quality of interoperation;

- prescriptive in the sense that the theory on interoperation and interoperability contains elements to be used in developing, improving and sustaining the ability to interoperate. 


\section{Implementing ePrescribing in Sweden - case study}

This chapter reports the result of a retrospective case study of the implementation of ePrescribing in Sweden, with particular focus on matters that influence the development of interoperability.

The context of this study and the research questions posed are developed in section 3.6.5 Analysis of the context of improvement of interoperability and evolution of ePrescribing in Sweden.

The research questions can be summarized as:

- Which were the factors that made the implementation of ePrescribing so successful in Sweden?

- What part did the improvement project (NEF) play in this implementation process?

The evolution of ePrescribing in Sweden could be viewed as a successive improvement of interoperability in ePrescribing between the health care and the pharmacy sector. Thus, a better understanding of the events and factors that influenced the successful evolution of ePrescribing in Sweden provide an empirical basis on which to build a theory on interoperation and interoperability, which in turn could be used to improve and maintain interoperability.

The second question was aimed to better understand the specific role of the improvement project (NEF) within the context of implementing ePrescribing in Sweden. This improvement project has been studied in a field experimental study reported in chapter 5 Improving interoperability in ePrescribing - a field study. 


\subsection{Research method}

In this section, we present the methods used in the case study and the different sources of evidence.

\subsubsection{Data collection and analysis}

From 2003 until 2009, the author was involved as a consultant in projects developing ePrescribing in Sweden and as an inside researcher. See chapter 3 Methods of inquiry, regarding the role of an inside researcher and practitioner. This gave direct access to inside information about the project through participative observation and action. Other sources of information were collected project documentation such as feasibility studies, requirements specifications, mail conversations, presentations at conferences and minutes from internal meetings between stakeholders in ePrescribing. Public sources have also been analyzed, such as legislation, project reviews, reports, research papers, and news in the trade press about implementing ePrescribing in Sweden. See also section 3.7.2 Sources of evidence, data collection, literature reviews, and data analysis.

In order to understand the whole history of the evolution of ePrescribing in Sweden, four interviews with key informants were made during 2013. The criteria for selecting informants were that they had played a central role in different phases of ePrescribing from the pharmacy or health care sector side. Another criterion was to find an expert in medical drug registers and their evolution, a central infrastructure component in ePrescribing.

One interview was made with one of the pioneers of ePrescribing. This informant came from NPC and had experience of ePrescribing in cooperation with local medical clinics from the beginning of the 1980s. He had also a key role as a project leader for implementing the national pharmacy register [161] and the national repository of ePrescriptions in 2005 and 2006. During a major part of the first decade of 2000, he had also been a manager of a department at the NPC that was responsible for the development of ePrescribing.

The second interview was made with the project manager appointed in 2000 with the responsibility for implementing ePrescribing from the point of view of the NPC.

The third interview was made with the project manager for implementing ePrescribing at a major county council, also appointed in 2000.

These last two informants (second and third) were chosen, because they were directly involved in and could describe the developed and successful cooperation between the pharmacy side (NPC) and the health care sector (major county council) that paved the way for implementing ePrescribing.

A fourth interview was made with an expert on medical drug registers who had worked in the $80 \mathrm{~s}$ and $90 \mathrm{~s}$ at pharmacies, and from the end of the $90 \mathrm{~s}$ with the central medical drug register (ACA - Apoteket Centrala Artikelregister) at the NPC. 
The interviews were open thematic interviews, that focused on how the informant viewed the evolution of ePrescribing in Sweden with respect to their personal role in the process as well as the role of their organization. The interviews centered on themes such as important events, factors, and pre-conditions that influenced the development of ePrescribing in Sweden. This concerned aspect such as organizational challenges, incentives, cooperation, and legal aspects, as well as technology and infrastructure. Two interviews were face-to-face and two were made on telephone. All interviews were recorded and notes were taken during the interview. The interviews lasted from one to two hours.

The interviews included both the recalling of important events and the informants' beliefs about important factors influencing the implementation process. When recalling facts, the informants were relying on their memories. This made it necessary to return to documents and search for new sources to verify the events mentioned in the interviews. Statements in the interviews also required a further investigation and analysis of certain events using additional sources of evidence.

The interviews were synthesized and analyzed based on notes taken and from repeated listening to the recordings of the interviews. The informants were given the opportunity to review a draft of this case study description. Two of the informants responded with confirmation and with minor corrections, clarifications, and further contributions.

\subsection{Structure of the case study report}

The first part contains a chronological presentation of major events and the second part is a thematic presentation of important aspects and their evolution over time. Finally, the third part describes the implementation process of ePrescribing with an analysis of preconditions and success factors. The chronological presentation begins with the early pioneering years in the 1980s (4.3 Early pioneering phase) in order to give a background, and is followed by a history of important events in the evolution of ePrescribing (4.4 Evolution of an information infrastructure for ePrescribing). These events are linked to different phases of growth: pioneering, growth and consolidation. The second thematic presentation describes important aspects of an information infrastructure and their evolution:

- 4.5 The use of standards. Standards are important enablers for interoperability (see 2.3 on standards). How they were used and evolved in ePrescribing is described in this section. See chapter 5 Improving interoperability in ePrescribing - a field study for further details on the use of standards.

- 4.6 Infrastructure for communication - from point-to-point to national repository of prescriptions. The mode of communication has evolved considerably since the early years from point-to-point to centralized communication (see also 2.2.3 on gateways and IT-capabilities of an information infrastructure). 
- 4.7 Institutional objects in ePrescribing. Institutional objects are essential for successful communication (see 2.2.3 on institutional objects). How identifiers and register of these objects was created and evolved is described in this section.

The third part is focused on the implementation process. Section:

- 4.8 The implementation process describes events and factors that influenced the implementation process of ePrescribing in Sweden.

- 4.9 Economic, legal, and organizational issues in implementing ePrescribing, describes how different economic, legal, and organizational challenges were managed.

- 4.10 Success factors in the implementation process summarizes the key informants view on success factors in implementing ePrescribing in Sweden.

The chronological format of the case study report helped the process of writing and organizing events, to find and fill gaps, and reflect on what happened in different phases of the evolution. The chronological organization of events highlighted the long-term gradual evolution of conditions and events. The three phases presented - pioneering, growth, and consolidation - were not assumed a priori but were found to be a natural way of organizing the material in the final written form.

The thematic organization of the case study findings is based on a characterization of the successive events. It has also been influenced by the experiential knowledge accumulated as an insider researcher, with knowledge about the context in which certain events took place. The theory on ePrescribing (see 6 A practical theory on ePrescribing) and the findings from the field study of the improvement project (NEF) (see 5 Improving interoperability in ePrescribing - a field study) also influenced the thematic analysis. To some extent, extant theories about infrastructure development influenced the decision to emphasize the evolution of the information infrastructure and its governance.

\subsection{Early pioneering phase}

The early years of ePrescribing in Sweden, described in the $\mathrm{PhD}$ thesis [162] by one of the pioneers, Bengt Åstrand (see also [163, 164] for a short historical account of development of electronic prescriptions in Sweden), goes as far back as 1983 when the world's first electronically transferred prescription was sent from a medical doctor's office to an outpatient pharmacy. This early development was a result of a cooperation between local medical clinics and local pharmacies. The initial ideas generated in this cooperation were not primarily to make electronic prescriptions but to find out the best support for medical doctors in their daily practice. There was a strong focus on decision support functions such as drug-drug interaction controls, warnings about medical drugs influence in certain 
conditions such as pregnancy, et cetera. The focus was on doctor's workplace systems, 'LTS' (Läkarnas Terminal System - Doctors' Terminal Systems).

In addition, the first introduction of personal computers (PCs) at that time made it possible to test and pilot new ideas, such as for medical doctors to use desktop computers for prescribing and handling patient health records. [165-168] The early initiatives had for the time very advanced functions such as a touch screen and recommended prescriptions for different diagnoses. These early initiatives were followed by different pilot projects including experiments with handheld computers. These pilot projects were collaborations between regional health care organizations and the NPC. The projects were always locally implemented. The NPC developed an information system for dispensing prescriptions, ATS (Apotekens Terminal System - Pharmacy Terminal System). By 1985, all the Swedish pharmacies were using this information system. The system was mainly for logistics, for writing prescription container labels ${ }^{49}$ to be placed on the medical drug packages, for collecting information for reimbursement, and for national statistics on dispensed medical drugs.

During the 90s different local projects continued, but there was no real increase in volume of ePrescriptions. One factor that could explain why the regional county councils, which organized health care, did not focus on ePrescription in the 90s, were efforts to develop and implement Electronic Health Record (EHR) systems in different county councils during the 90 s. By $1994,85 \%$ of the primary care centers had implemented EHRsystems and there were 27 different products available on the market, many of them developed by small software companies in close liaison with clinicians. Still, the use of EHR-systems in hospitals was low and the development much slower, to reach $85 \%$ in 2009. [171]

\subsection{Evolution of an information infrastructure for ePrescribing}

The implementation of ePrescribing in Sweden has been a long process since 1983, including the development of a complex infrastructure for ePrescribing. It is necessary to understand that the precondition for developing ePrescribing, in which the mere transfer of a prescription is only one part, is the evolution of a whole infrastructure to manage the prescription in the different stages of ePrescribing. ePrescribing includes the whole process from meeting with the patient, making and communicate a prescription, requesting and dispensing a medical drug to a patient, and the follow up of the medical treatment by

\footnotetext{
${ }^{49}$ According to legislation in Sweden [169], the name and birth date of the patient, the prescribers name, the dispensing pharmacy name, the date of dispensing, the number of packages dispensed, and instructions of use (dosage instructions) must be shown on the prescription container label that is glued on the medical package by the pharmacist. See also [170] for a definition and use of the term prescription container label in an international context.
} 
the health care both individually and in general. It is a continuous workflow in and between the health care provider and the pharmacies. $[8,162]$ 


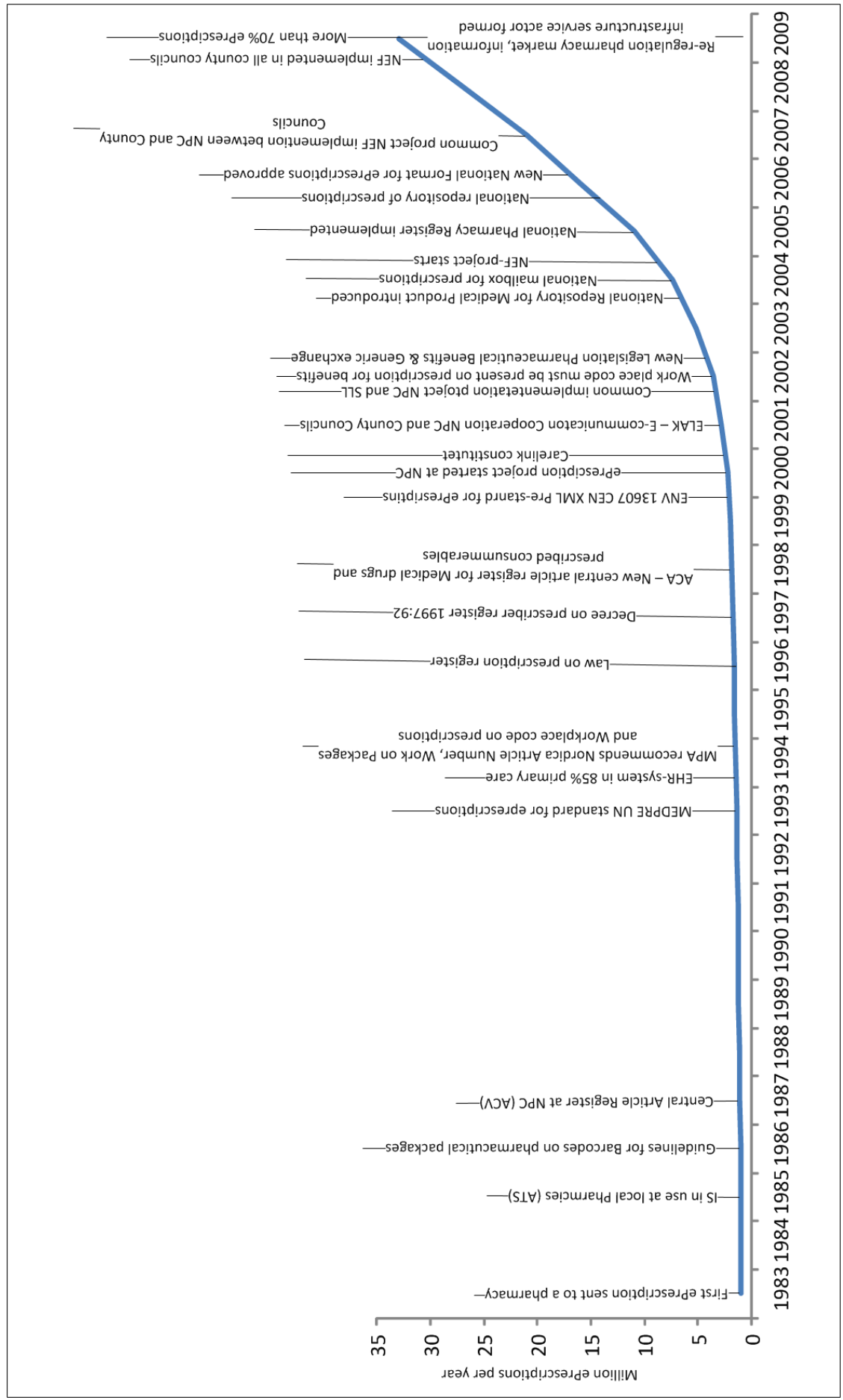

Figure 11 Number of prescriptions per year (million) from Bengt Åstrand [162] with the addition of major events that influenced the implementation of ePrescribing in Sweden. 
In this section, we describe the major events in the evolution of ePrescribing in Sweden. For an illustration of the pace of growth of ePrescribing in Sweden, see Figure 11. In the figure, we have added major events that influenced the implementation of ePrescribing in Sweden.

To make the figure easier to read, we summarize the major events in Table 6 Summary of major events that influence the implementation of ePrescription in Sweden.

Table 6 Summary of major events that influence the implementation of ePrescription in Sweden.

\begin{tabular}{|c|c|}
\hline Year & Event \\
\hline 1983 & First ePrescription sent to a local pharmacy. \\
\hline 1983 & First national regulation on ePrescriptions and pharmacist's responsibilities. \\
\hline 1985 & IS for dispensing prescriptions implemented at NPC (ATS). \\
\hline 1986 & $\begin{array}{l}\text { Use of barcodes on pharmaceutical packages included in guidelines for Nordic } \\
\text { article numbers [172]. }\end{array}$ \\
\hline 1987 & Central Article Register at NPC (ACV). \\
\hline 1993 & MEDPRE - UN standard (EDIFACT ${ }^{50}$ ) for Medical prescriptions published. \\
\hline 1994 & EHR-system used in $85 \%$ of primary care. \\
\hline 1994 & $\begin{array}{l}\text { Medical Products Agency (MPA) recommends the use of Nordic article } \\
\text { number on pharmaceutical packages and the use of the workplace code in } \\
\text { prescriptions. }\end{array}$ \\
\hline 1996 & $\begin{array}{l}\text { Law on prescription register, allowing the NPC to store information about } \\
\text { dispensed prescriptions for the invoicing of medical benefits and to follow up } \\
\text { prescribing patterns. }\end{array}$ \\
\hline 1997 & $\begin{array}{l}\text { Decree about prescriber register allowing The National Board of Health and } \\
\text { Welfare (Socialstyrelsen) to administer a register for registered prescribers. }\end{array}$ \\
\hline 1998 & $\begin{array}{l}\text { ACA - a new central register for medical drugs and prescribed consumables at } \\
\text { the NPC, replacing the old main frame based ACV. }\end{array}$ \\
\hline 2000 & ePrescription implementation project started at NPC. \\
\hline 2000 & $\begin{array}{l}\text { ENV } 13607 \text { - CEN pre-standard for medical prescriptions using XML } \\
\text { published. }\end{array}$ \\
\hline
\end{tabular}

${ }^{50}$ Electronic Data Interchange For Administration, Commerce and Transport 


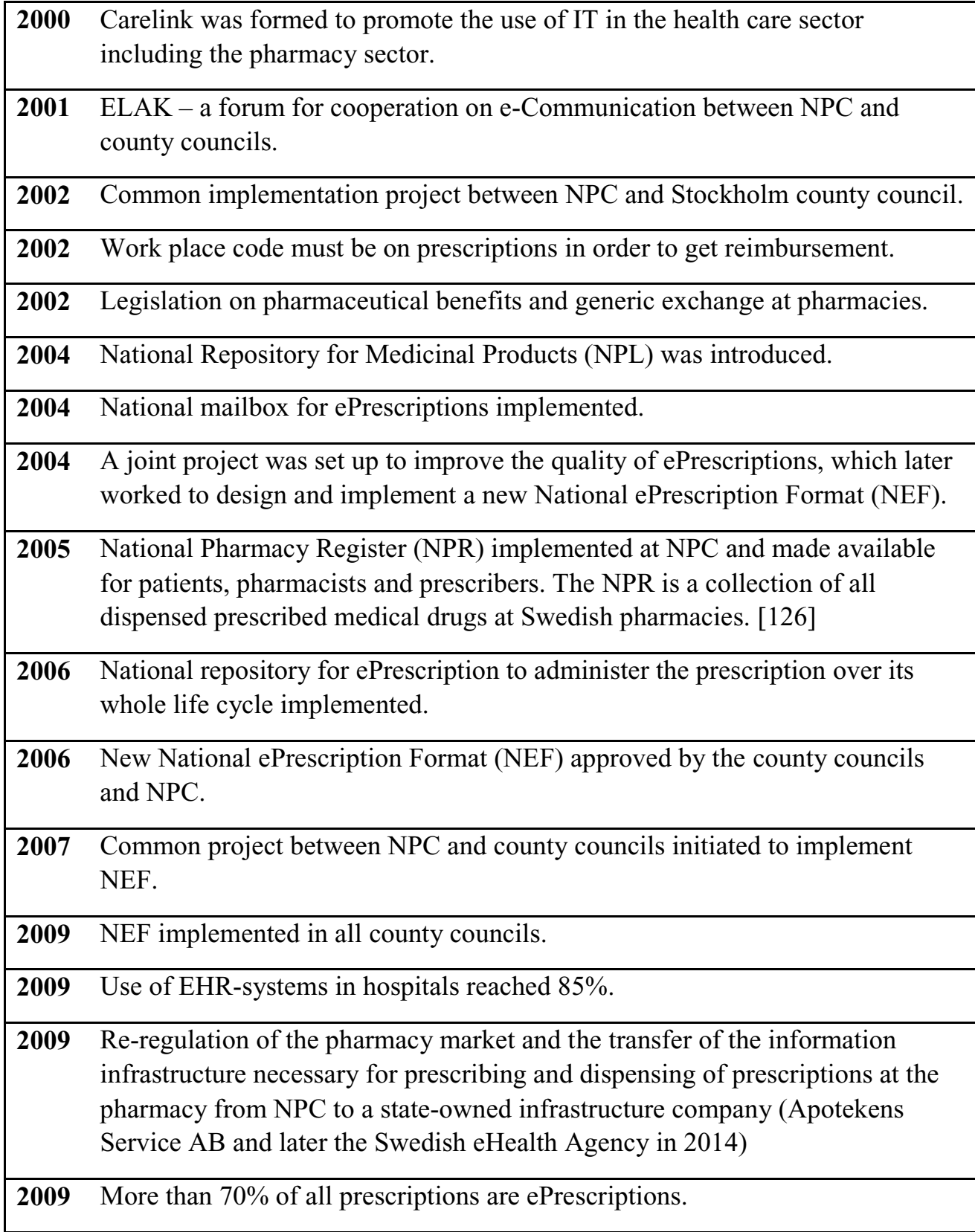

From the initial pilot project in the 80 s, the development was slow and local and by 2000 , only six percent of all prescriptions were ePrescriptions.

The implementation of ePrescribing can be divided into three major phases: 
- early pioneering phase from 1983 to 2000 characterized by cooperation between the NPC and local medical clinics. In this phase, the possibilities of ePrescribing were tested and evaluated in a larger context of a decision support for the prescribing process, and different system solutions and techniques were investigated;

- beginning of a growth phase from 2000 to 2006 based on a small but existing praxis of electronic transfer of ePrescriptions. Focus was on cooperation between different stakeholders leading to the creation of different forums for cooperation, which were missing on a national level. This phase also faced new demands and needs with the integration of larger county councils in urban regions. The stakeholders confronted a number of economic, organizational and legal issues. This led to major changes in legislation, new organizations for cooperation, and new services based on the electronically transferred prescriptions;

- consolidation phase from 2006 where stability, quality and confidence in the ePrescribing services became an important concern. In this phase, the ePrescribing process developed from the electronic transfer of prescriptions to an infrastructure for the ePrescribing process.

One interesting aspect of the implementation of ePrescribing in Sweden is the parallel development of a common infrastructure for a long period even before they were actually used in the ePrescribing process. This made the implementation more efficient with greater benefits for all the actors in the ePrescribing process. The common infrastructure was based on the use of standards, a technical communication infrastructure, common identifiers, repositories of actors, and institutional objects. This common infrastructure contained both technical and institutional/organizational structures. The basic infrastructure was needed to identify the medical drug in a safe and efficient way, and to identify the actors in the ePrescribing process - prescriber, patient, pharmacy, and work place. This was very important in order to fulfill the demands of the ePrescribing process.

The ePrescription is a means to coordinate a process between different stakeholders that are involved in a shared process. In this sense, the ePrescription coordinates the ePrescribing process both in being an act in itself, by making commitments, giving directives and authorizations to actors in the ePrescribing process and in referring and identifying actors and medical drugs within the context of the technical, legal, institutional, and organizational infrastructure. [42]

\subsection{The use of standards}

In 1993, there was already an international standard for electronic prescription messages, MEDPRE [70]. This was an UN/EDIFACT standard. Later, CEN developed a prestandard for XML prescriptions, ENV13607, at the end of the 90s, published in 2000 (ENV13607:2000) [173], at a time when XML was increasingly used with the rise in the 
use of internet technology. Since 1997, Sweden had been managing the secretariat for CEN/TC 251 Technical Committee on Health Informatics. SIS (Swedish Standards Institute) developed a Swedish implementation guide for ENV13607.

However, even in the late 90s the volume of ePrescriptions was very low, with the exception of the small county councils in the south (Blekinge) and the very north of Sweden (Norrbotten) which had a higher proportion of ePrescriptions but still at very moderate levels.

Communications during the $90 \mathrm{~s}$ used X.400 ${ }^{51}$ for the EDIFACT/MEDPRE based prescriptions or some other communication protocol with modem communication direct to the local pharmacy. After 2000, SMTP ${ }^{52}$ and later web services $\left(\mathrm{SOAP}^{53}\right)$ came into use. The use of web services meant that the communication developed from being an asynchronous communication with a relative long response time towards a more synchronous communication with a shorter response time. Before, a patient could arrive at the pharmacy earlier than the prescription, if the pharmacy was close to the hospital or primary care unit, because the electronic transfer of a prescription could take longer than five minutes. The long response time also meant that the prescriber had already taken on another patient before, theoretically at least, getting a receipt of a successful communication to the pharmacy. Thus, in the beginning there was a lack of feedback to the prescriber. See Figure 12 for an illustration of the methods of communication in 2006.

\footnotetext{
${ }^{51} \mathrm{X} .400$ is a messaging standard specified by the ITU-TS (International Telecommunications Union Telecommunication Standard Sector).

${ }^{52}$ Simple Mail Transfer Protocol (SMTP), protocol for delivering email.

${ }^{53}$ Simple Object Access Protocol (SOAP).
} 


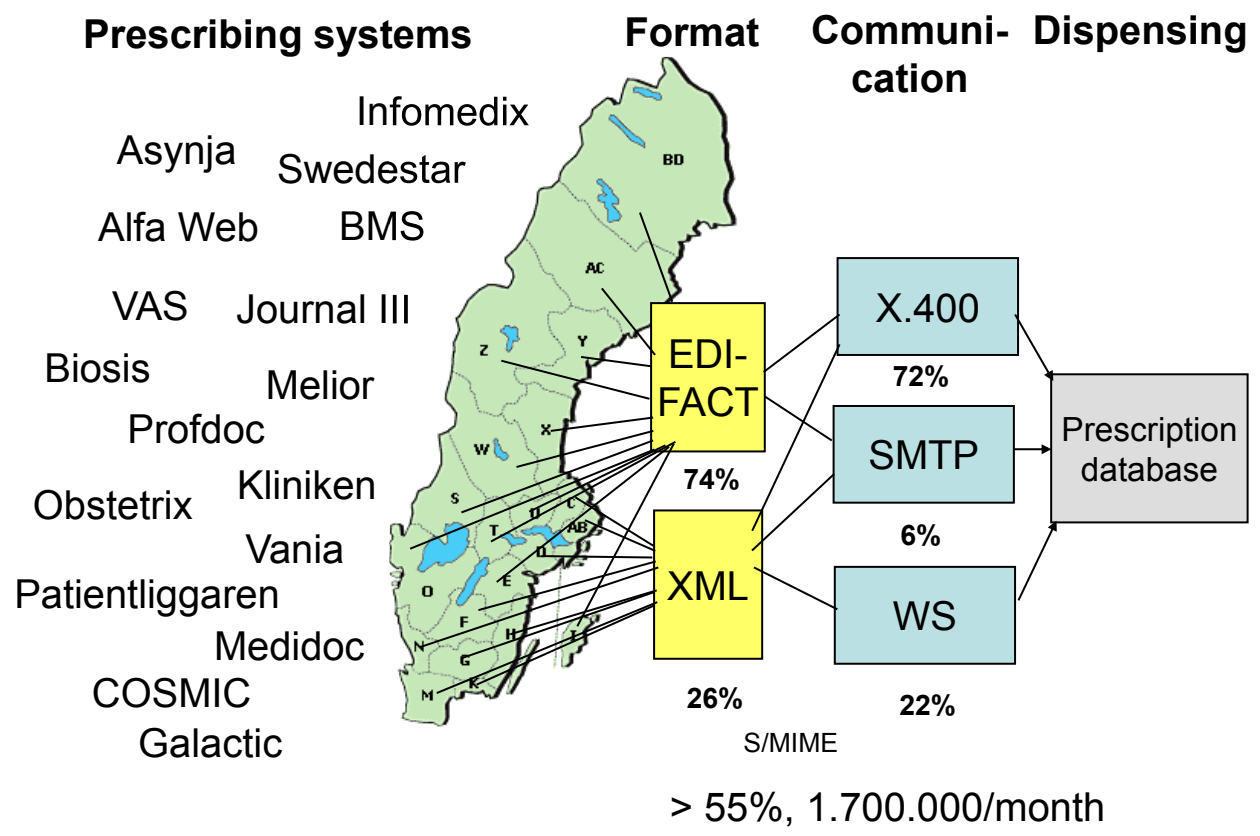

ePrescribing Implementation in Sweden, Sten-Erik Öhlund, sten-erik.ohlund@wmdata.com

Figure 12 Illustration of the technical communication infrastructure from a presentation by the author at ePrescribing \& Medication Management - International EHTEL Conference in Slovenia in 2006 [158].

\subsection{Infrastructure for communication - from point-to-point to national repository of prescriptions}

Early in the 1980s and late 1990s, there was only point-to-point communication between local medical clinics and local pharmacies. The prescriptions were only visible at the local pharmacy in their incoming 'post', a kind of local mailbox for prescriptions. Electronic prescriptions were regulated as a kind of prescription, which only differed in how it was communicated. There were also 'telephone' and 'fax' prescriptions that were regulated and used for emergencies. In the first years after 2000, there was still only point-to-point communication. However, in larger cities there arose a need to be able to address not only a specific local pharmacy but also a whole region. In the larger cities, it was considered inconvenient that the doctor had to assign a specific local pharmacy to dispense a prescription. In Stockholm, a pilot project started for a regional 'mailbox'. The legal 
experts at the NPC were concerned about issues of privacy that arose from prescriptions being collected at one central point.

Legal expertise interpreted the law of prescription register. [174] The first interpretation was that collecting prescriptions in one central repository was not allowed, but the second interpretation claimed that it was not allowed to save a prescription with refills (iterations). If there were iterations (the most common iteration for a continual treatment is four iterations per year), a paper prescription had to be printed on a specific prescription form for the remaining fills.

The pilot project continued in Stockholm and was called "Stockholmsbrevlådan" ("The Stockholm Mailbox"). This meant that a prescription could be picked up in any pharmacy in the Stockholm area. [175] This project was much appreciated by both prescribers and customers/patients. Later in 2004, this developed into a national mailbox of prescriptions. [176]

In the larger county councils, there were many EHR-systems sending ePrescriptions to the NPC. This fragmented situation called for a centralization of communications on the county council side. Particular efforts in this direction were made in Stockholm county council, where a common prescription server (GRS - Gemensam Recept Server) through which all prescriptions should pass and be verified before they were delivered to the NPC, was implemented. This also meant that, in pace with the increase of electronic prescriptions, the county councils had better control of issued prescriptions.

The next step in the evolution of communication was the creation of the national repository of prescriptions. This was sanctioned through a change in the law of prescription register in 2005. [177] It meant that the prescription could be stored, with the patient's consent, through its whole life cycle, and could be refilled as long as it was valid at any pharmacy in Sweden. This improved the situation for patients and minimized the risk of losing prescriptions. It also meant that the prescribers did not need to renew a prescription that was lost. The risk of double medication due to duplicate prescriptions was also minimized.

During the first decade of the century 2000, XML-based prescriptions (based on ENV13607 [173] began to increase in volume and EDIFACT based prescriptions (MEDPRE, [178]) were finally phased out in 2009 with the implementation of the new National ePrescription Format (NEF). See chapter $5[8,9]$ for more details.

In addition to the original communication protocols such as X.400 and telephone modem communication, SMTP (mail) was used as a reserve routine. Later Web services were used with a more synchronous mode of communication. This contributed to improve performance (throughput and faster response time) and lower communication costs.

Initially, there was no real feedback communication from the NPC to confirm that a prescription had arrived successfully. With X.400 and the introduction of an acknowledge receipt, at least a technical receipt could be communicated using the X.400 standard for 
receipts from the Message Transfer Agent (MTA) and on the application level using the acknowledge receipt message. However, there were still errors in the final internal communication between the central servers at the NPC and the local pharmacies, which could mean that the prescription had failed to reach the local pharmacy when the patient arrived at the pharmacy.

However, it was not until the introduction of the NEF that acknowledge receipts were used for more advanced receipts, signaling the acceptance or rejection of a prescription, and therefore also a responsibility for further processing according to agreements between the parties.

With the centralization of the prescription repository, communication failures between the MTA and the pharmacy were minimized. Still, the communication relied very much on the robustness of the central mailbox or repository. This led to an increased effort to secure the continuity of the central mailbox, and later the national repository of prescriptions. With the growth of volume, the consequences of a problem with the central system would influence all the pharmacies and would make it very difficult to dispense any prescription if there was a total stop in services.

With growth in volume, other issues also become more important, such as the quality of the prescription content, and the protection against intended and unintended corruption of prescription information or violation of the personal integrity with sensitive information about prescribed drugs and diagnoses. In the beginning, there was no encryption of the communication of prescriptions. Later, the communication was made through an extranet common to all health care providers, called Sjunet, but still no encryption of information. Encryption was later implemented using S/MIME ${ }^{54}$. In the project to implement NEF, quality issues of the prescription were addressed by improving the formal alignment of the prescription to the format and prescription rules.

\subsection{Institutional objects in ePrescribing}

This section describes the evolution of an information infrastructure (see section 2.1.8 for a definition) focusing on institutional objects (see section 2.2.3). Registers of such institutional objects must be available and up to date for information infrastructure users in order to avoid mistakes and errors. The institutional objects and their identifiers are essential for communication and are referred to in the prescription.

A prescriber issues a prescription to a patient in a context of a particular medical treatment. A prescription is a communication act that involves legal rights, directives, and commitments. This communication act has many functions. [42] The prescription has multiple references. The most important are the references to the actors involved in ePrescribing and reference to prescribed medical drugs. For ePrescription, as well for

\footnotetext{
54 Secure/Multipurpose Internet Mail Extensions
} 
interoperation in general, standardized and common identifiers are very important and are in many respects a precondition for implementation on a large scale.

See Figure 13 for an illustration of the complexity of the ePrescription message and its links to many identifiers of stakeholders and objects.

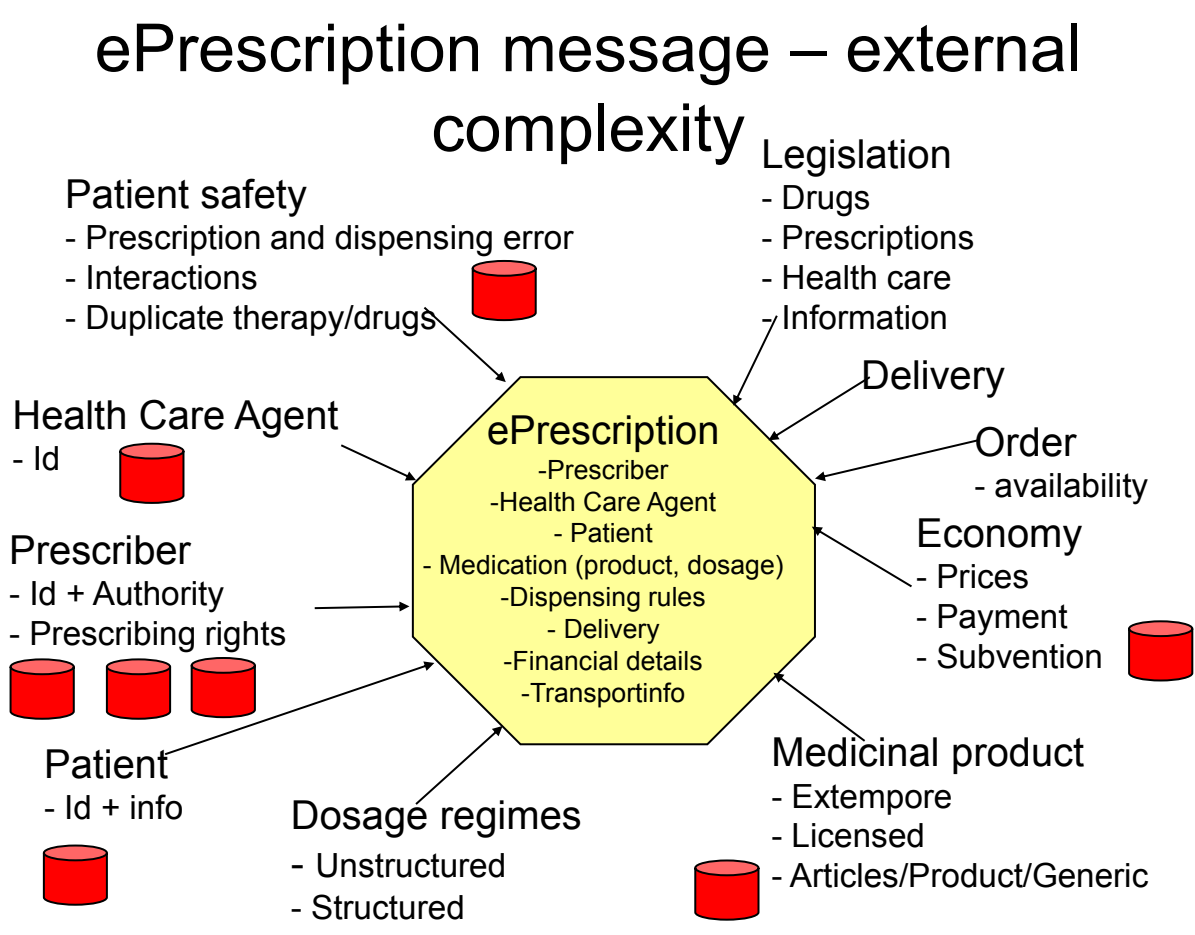

ePrescribing Implementation in Sweden, Sten-Erik Öhlund, sten-erik.ohlund@wmdata.com

Figure 13 Illustration of the complexity of the ePrescriptions message involving many identifiers of stakeholders and objects and with different external demands. From a presentation in 2006 by the author at a conference in Slovenia on ePrescribing. [158]

\subsubsection{Identifying prescribed medical drugs}

One important part of the evolution of ePrescribing in Sweden was the ability to identify the prescribed medical drug uniquely. In order to have traceability of prescribed medical drugs across the ePrescribing process, it was necessary to be able to identify the medical drug package. A cooperation among the Nordic countries made possible a common identifier of medical drugs packages using Nordic article number. This dates back to 1977 when there was an agreement between the Nordic countries on how to place article numbers on pharmaceutical packages, and in 1986 guidelines included how to use barcodes on pharmaceutical packages [172]. In a piece of legislation [179] on the marking of packages in 1994, the Medical Products Agency in Sweden referred to the Nordic article number as one identifier of the medical drug to be marketed and recommended that it 
should be printed on the package. The Nordic article number consists of six digits grouped in pairs of two digits to be more easily readable by human beings. Today, a Nordic article number is mandatory on all marked medical drugs packages ${ }^{55}$.

By the $80 \mathrm{~s}$, a barcode was printed on the medical drug packages. At this time, it was decided that the article number should be part of the barcode. The Nordic article number is administrated by the Nordic Number Centre and is today located at the Pharmaceutical Information Centre (PIC) $)^{56}$ in Finland.

By the second half of the 80s, the NPC already had a central register of all sold medical drugs. This central register, called ACV, was held in a mainframe computer and distributed to the health care services and pharmacies using a floppy disk. This register was to be replaced in the end of the 90 s by ACA (Apotekets Centrala Artikelregister), which was implemented in 1998 at the NPC. This register was distributed daily to ATS (the dispensing system at the local pharmacies) and available daily as a file, called JACA ${ }^{57}$, which was produced to be imported into the EHR-systems at the county councils.

The NPC was responsible for managing this register. From the Medical Products Agency, the administrators of ACA received letters reporting decisions about those drugs that were accepted to be sold on the Swedish market. The Nordic number center was contacted for an identifier for the drug package to be sold; while the distributor in Sweden was contacted for complementary information. The information was gathered from different sources for the medical drug package to be sold, to form the final information to make it available for sales, prescription, statistics, and procurement.

Because the Nordic article number could be reused for another medical drug, internal identities were created at NPC to keep record of each medical drug, describing its active substance, strength and form. There are also other identifiers of medical drugs that are being created in the approval process at the Medical Products Agency. These include, NPL Id and NPL Packid. NPL Id denotes the product (form, strength and substance) and NPL Packid denotes the actual package of a certain item quantity to be sold, for example 100 tablets $^{58}$.

\footnotetext{
${ }^{55}$ Already before the state monopolization of the pharmacies in Sweden in 1970, the Swedish Academy of Pharmaceutical Sciences (SAPS), at that time a trade organization for the pharmacies in Sweden had a list or card-catalogue of medical drugs that were sold in the different pharmacies, at that time privately owned by pharmacists.

${ }^{56}$ PIC acts on behalf of Dansk Lægemiddel Information A/S in Denmark, Pharmaceutical Information Centre Ltd in Finland, Lyfjastofnun in Iceland, Legemiddelindustriforeningen in Norway, and Läkemedelsindustriföreningen, LIF, in Sweden.

57 'J' refers to 'Journalsystem' - i.e. the EHR-systems.

58 The Swedish eHealth Agency proposed using NPL Id and NPL PackId as the future identifiers for prescribing medical drugs, and this was implemented in 2014.
} 
The manual process of administrating the content of the central article register (ACA) at Apoteket was to be replaced in 2005 . The new process was supported by a system in which the different actors in the process of approving a medical drug could assign its sales and procurement prices, its status for reimbursement, et cetera, and could provide their information to NPL (Nationellt Produktregister för Läkemedel - National Repository for Medicinal Products) [180]. NPL is a national repository for all the medical products available on the Swedish market. The project of creating the NPL was initiated in the late 90 s, probably in connection at that time with studies and suggestions of deregulating the pharmacy market, particularly after the entry of Sweden into the European Union in 1994.

After the deregulation of the pharmacy market in 2009, the responsibility for the information infrastructure for the pharmacy market was transferred from NPC to Apotekens Service AB, a state own company, which later became a state authority in 2014, the Swedish eHealth Agency.

\subsubsection{Identifying stakeholders in prescribing}

It is also important to identify the different stakeholders in the prescribing process such as the patient, prescriber, work place from which the prescriptions are issued, and the pharmacies that have the authority to dispense prescription drugs. Linked to the stakeholders' identifiers, are rights and responsibilities in relation to the prescription. For example, prescriber rights to prescribe certain drugs are linked both to the type of prescriber: doctor, dentist, nurse, midwife, et cetera, as well as individually to a specific doctor or clinic in the case of special drugs (although individual rights are not yet regulated in an available register).

A prescription is always issued to a particular patient for a particular purpose. Thus, the identification of the patient ${ }^{59}$ is very important for a number of reasons such as medical, privacy, and security reasons (to avoid frauds and the counterfeit of prescriptions). In Sweden, the personal identification number ('personnummer') was used from the very start as the identifier of the patient. This identifier is useful for identifying all Swedish residents. For those who do not have a 'personnummer', the health care regions used and created different 'reservnummer' (reserve numbers) to be able to deal with those patients that were not permanent Swedish residents. Unfortunately, these are not standardized on a national level and the health care regions have different administrations and different formats. This made it impossible to use 'reservnummer' to identify a patient (who did not have 'personnummer') outside the health care region that had issued the 'reservnummer'.

\footnotetext{
${ }^{59}$ It is also import to have an account at the pharmacies of family relations, when dispensing prescriptions to children in order to manage the children's reimbursement account. Who has the right to ask dispensing of a prescription on behalf of a child is complicated, sometimes by the fact that both parents have the right to do this after a divorce. Family relations are not considered when issuing a prescription but are useful when dispensing. Another issue is who has the mandate to request for dispensing a prescription on behalf of a patient in for example the home care services.
} 
Instead, the birth date was used, and a regulation was put into place that all such prescriptions had to be sent to and be filled at a specific local pharmacy, to ensure the correct identification of the patient. The Swedish Taxation Authority issues the 'personnummer'.

Prescribers are identified by a prescriber code, which the prescriber is assigned when approved a license to practice as a doctor, nurse or dentist. The National Board of Health and Welfare (Socialstyrelsen) administer a register of prescriber codes. For those doctors in medical internship (AT), who have not yet received their license to practice, but still need to be able to prescribe, a so-called group number is used.

The workplace code on the prescription identifies the work place where the prescriber issued the prescription. Since 1 October 2002 [181], according to a new law on Pharmaceutical Benefits, there must be a work place code on a prescription to get it reimbursed. As long ago as 1994, the work place code was recommended to be on the prescription according to prescription rules [179]. It was then mainly used for reporting sales statistics per work place to the health care regions. Thus, this identifier has evolved to be used for different purposes.

The development of the prescriber code and work place code is closely related to the shift of the responsibility for financing the reimbursement of medical drugs in 1998 from a state authority (RFV - Riksförsäkringsverket) to each regional county council. This meant that the NPC should invoice reimbursement benefits to the regional county councils instead of the state authority. For this reason, a new law regulating a prescription register [174] was passed. The law allowed the NPC to register all dispensed medical drugs with information such as dosage, diagnosis, price, reimbursement, patient, prescriber, and workplace in order to invoice and report to the workplace. This meant that the regional county councils also became interested in knowing what had been prescribed, not only for quality assurance but also for reduction of costs. In some county councils, there was a demand that all prescriptions (on paper) should have a barcode. At first, this was a glued etiquette with a barcode containing the prescriber and workplace code, and later this became preprinted barcodes on the prescription form. This caused some protest among prescribers and a number of solutions for administering this was put forward. [182-184] Interestingly, in one comment on this, it was foreseen that ePrescriptions would solve the problem and there was a strong optimism that in a few years there would be no more paper prescriptions $^{60}$. [184]

The pharmacies were identified by a Pharmacy id which at the beginning was an id issued by the NPC. An EAN-location number later complemented this, and today, a Pharmacy is identified by a GLN (Global Localization Number - earlier called the EAN-location

\footnotetext{
${ }^{60}$ In the interview with the pioneer in ePrescribing, the interviewed referred to Steve Job's biography, saying "we always overestimate in the short term and underestimate in the long term" when commenting on the somewhat optimistic expectations of the 1980s.
} 
number). This GLN identification is used when addressing a prescription to a local pharmacy. This means that the EHR-systems needed to have a register of all approved pharmacies in Sweden. This register was first administered by the NPC and was called 'apotekslistan' (the Pharmacy list). Today, the Swedish eHealth Agency, administrates this register.

Thus, in the 90s there were already a number of identifiers available for use in an electronic prescription. On a paper prescription, the article number for the medical drug was not used. Instead, the name of the drug had to be written as well as its strength, form and the duration of treatment or total quantity of the medication. At the pharmacy, this was then transformed into actual packages. Thus, the article number was first used at the pharmacy for managing the different packages for dispensing, pricing, and logistic purposes. When the article number was to be used on electronic prescriptions to safely identify a medical drug, there were some demands from the prescribers to go back to a "yellow prescription" (the paper prescription form was yellow) even for electronic prescriptions. Although there have been many suggestions about how to prescribe in a more "generic" way, the electronic prescription is still a prescription on the package level. To be able to prescribe on a more generic level, generic substance or product level identifiers have to be defined and administrated.

For the extempore prescription of (medical drugs to be manufactured 'for the moment' for a particular purpose or adapted to a patient), and licensed medical products (when the identification number is not published in the NPL for products that need a specific license from the Medical Products Agency to be prescribed and dispensed), two different 'pseudo' article numbers are used. Instructions to the pharmacy are written in the field for instructions for use, where dosage instructions normally are given in an electronic prescription.

\subsection{The implementation process of ePrescribing}

In this section, we will describe some important events and factors that influenced the implementation process of ePrescribing in Sweden. With implementation process we mean implementation from point of view of the work practice, the organizations and stakeholders involved. The focus is not on the technical implementation of the IT artifacts, even if they were a necessary part, but on the initiation, adoption, adaptation, and acceptance of ePrescribing by the organizations and stakeholders.

The description is based on interviews with some of the main participants as well as documents reporting the implementation process. The description begins with the perspective of the NPC and then from the perspective of a major county council. 


\subsubsection{From early experience to strategic initiatives}

In the pioneering phase during the $80 \mathrm{~s}$ and $90 \mathrm{~s}$, the activities continued but were on a low level. In this phase, experience was gained and expectations of the different stakeholders were created. See section 4.3 Early pioneering phase. The NPC never stopped assigning resources for its continuation during these years, even if on a low level. This situation changed at the end of the 90 s and the coming years, which saw a number of strategic initiatives evolve.

\section{Initiatives from the National Pharmacy Corporation}

At the end of the 90s, there were a number of strategic workshops ('Rådslag') at the NPC. One strategic goal decided was to start a project to implement ePrescribing on a larger scale in Sweden.

A project manager was assigned in 2000. At that time, the NPC had the tradition of engaging project managers with an understanding of the subject matter rather than professional project managers with administrative skills. The small project team that was set up were familiar with the work practice of prescribing and dispensing. The project was therefore not an IT project.

The situation was that ePrescription existed as a technology, which was used in some smaller county councils in the very north and south of Sweden. The task of the project group was to implement ePrescribing nationwide in Sweden. Thus, the focus was not so much on introducing new technology but on implementing an already existing solution.

The main benefits of ePrescriptions expected by the NPC were to be able to prepare prescriptions in advance, in order to be ready when the customer arrived at the pharmacy. This failed to be realized; particularly when new legislation was passed in 2002 [181, 185] that demanded that the Pharmacies should change the prescribed drug to a less expensive, equivalent generic medical drug.

This meant that it was not a very good idea to prepare the prescription in advance, as it was not known beforehand which medical drug would be dispensed. Viewing an ePrescription as an $\operatorname{order}^{61}$ to a pharmacy did not work out well.

In the $80 \mathrm{~s}$, one of the main benefits expected from ePrescriptions, from the health professional's point of view, was to minimize the work to rewrite lost and renew old prescriptions. For the pharmacy, the benefits of ePrescriptions were that the pharmacist did not need to reregister the prescription and interpret doctor's handwriting regarding the

\footnotetext{
${ }^{61}$ In fact, a prescription is rather a right for the holder of a prescription to get a prescription filled and a mandate for a pharmacy to dispense a prescription. See chapter 6.5 Socio-pragmatic communication analysis of ePrescribing for an analysis of a prescription and its different functions.
} 
medical drugs and instruction for use. This was also seen as way to improve patient safety, as it was often difficult to interpret the handwritten instructions from the prescriber. This could require direct contact with the prescriber when dispensing a prescription while the customer was at the desk. Another expected benefit was that ePrescriptions would be more difficult to counterfeit.

One early initiative of the project was at first a failure, but later opened the way for the successful implementation of the project. The project team contacted software vendors of different EHR-systems on the market to discuss the implementation of ePrescribing in Sweden. The reaction from the county councils was negative; arguing that is was not the business of the NPC to contact the software vendors, who were actually software providers to the county councils. This initial failure turned into a long and fruitful period of cooperation between the regional county councils and the NPC to implement ePrescribing in Sweden.

To foster the cooperation a common forum for discussion and cooperation was formed in 2001, ELAK (E-kommunikation mellan Landsting, Apotek och Kommuner, in English: e-Communication between county councils, pharmacies and municipalities). An additional organization that played a role in implementing ePrescribing in Sweden was Carelink, an organization that provided a forum for cooperation. Carelink was formed in 2000 by the Federation of County Councils, the Association of Local Authorities, the Private Health and Social Care Employers' Association and the NPC. The aim of Carelink was to promote and coordinate the use of IT in the health sector. Although Carelink was not the driving force in the implementation of ePrescribing in Sweden, it played an important role in convincing the directors of the county councils that ePrescribing was a good idea.

Fairly soon after the strategic initiative taken in 2000 , the most important county councils around the major cities joined with NPC to implement ePrescription. However, in the beginning, the pace was rather low in terms of ePrescription volumes. Some of the smaller county councils were faster in implementing ePrescription. The county council in Norrbotten (very north of Sweden) topped the list with about $90 \%$ of all prescriptions in 2003 , while in one major county council the same year only $1 \%$ of all prescriptions were ePrescriptions.

The NPC soon established common projects of implementation with the different county councils. Some county councils had well prepared implementation plans, while in others, plans were more ad hoc. The cooperation between NPC and the county councils for implementing ePrescribing involved important activities such as creating awareness, joint preparation and education of prescribers and pharmacists at the local level. In addition to newsletters, visits and seminars, nationally and locally, the NPC published a chart comparing the state of implementation of ePrescription in different county councils. This worked as a kind of contest between different county councils and according to the informants influenced the decision makers as "no one wanted to be the last". 
There seems to have been no major difficulty to explain the benefits of ePrescribing and motivate prescribers, pharmacists, or patients to use ePrescriptions. ${ }^{62}$ What seems to have influenced the pace of implementation was the ability to convince management on both sides to invest enough resources and prioritize implementing ePrescribing.

In 2002, there were four EHR-systems that could send ePrescriptions while six other systems were underway in developing and implementing ePrescriptions. [189]

There were very optimistic expectations on the part of NPC that $80 \%$ of all first-time prescriptions from primary care ${ }^{63}$ should be ePrescriptions by 2003. From 2003 to 2004, the share of ePrescriptions from primary care increased from $17 \%$ to $32 \%$. In Norrbotten, $95 \%$ of all first-time prescriptions were ePrescriptions in 2004. One major county council, Stockholm, finally increasing their volume after a longer period of preparation, explains the increase in volume. Furthermore, the fact that more EHR-systems could send ePrescriptions fueled the increase. A major county council like Stockholm confronted a greater complexity because they had a larger number of different EHR-systems that had to be integrated to their ePrescription server, with more demanding testing and approval that this required. $[190,191]$

Thus, from 2002 to 2004, there was an important increase in the number of ePrescriptions. After this initial growth, the development of ePrescriptions entered a phase of continued growth with a new focus of maintenance, quality, stability, security, et cetera.

\section{Strategic initiative from a major county council}

At the end of the $90 \mathrm{~s}$ and beginning of 2000 , the major county councils considered ePrescribing as an important part of their overall medicine strategy. There were some visionary ideas for ePrescribing. One idea was that the patient could fill the prescription anywhere in Sweden. Concepts were also developed which focused on different knowledge services ${ }^{64}$, such as drug-drug interaction control, warnings in relation to pregnancy, allergy, weak kidneys, et cetera. There were also visions about the actual use of information in ePrescribing, rather than a focus on the prescription form.

In 2001, the Stockholm county council made a strategic decision to use a common prescription server (GRS). All ePrescriptions from EHR-systems in Stockholm county council should pass through this server. This meant that the county council could control of the communication and assure its quality and reliability. This was seen as a necessary

\footnotetext{
${ }^{62}$ See [186-188] for studies about the attitude of physicians, pharmacists and patients towards ePrescribing.

${ }^{63}$ As mentioned earlier EHR-systems were not implemented to the same degree in the hospitals compared to primacy care.

${ }^{64}$ Similar to the views already discussed in the early 80 s.
} 
step to assure the trust in ePrescribing. Trust was seen as a very important factor in implementing ePrescribing.

A project manager in Stockholm county council was assigned in 2000. The project's approach was to be very systematic in building an organization, develop, and deploy a structured implementation process. In 2002, a common project between Stockholm's county council and the NPC, 'ePrescriptions Stockholm', started. The purpose of the project was to introduce ePrescribing in a safe and effective manner. During this project, an implementation model was developed and used. In addition, the stakeholder's attitudes towards ePrescribing, their expected benefits and the use of the implementation model were evaluated in the project. [192]

One objective of the implementation model was to support a structured and wellprepared introduction of ePrescribing at the health care units, in order to create conditions for a fast and smooth implementation. Other objectives were that all the participants should have the same information and to strengthen the cooperation between the local pharmacy and the health care units. This to achieve a high quality and volume of ePrescribing. In addition to the implementation process, the model also contained preparatory work and maintenance after the implementation of ePrescription.

Before the introduction of the common project with NPC, there had been a history of the county council being unsuccessful in their cooperation with the NPC. However, the ePrescribing project implied that new ways of cooperating were developed, which proved to be successful and influenced cooperation in other areas.

\subsubsection{From initial growth to consolidation}

With the initial growth in the first half of the first decade of 2000, new needs and problem arose. One issue concerned capacity. Both the county council and the NPC informants stated that trust in the technology was very important for the implementation of ePrescribing. As one informant worded it, "you get only one chance."

The informants gave some interesting examples of benefits of the inter-organizational cooperation, which could make it easier to argue internally for funding of the IT resources in respective organization. Demands from an outside partner are sometimes a better "argument" than from insiders that compete with other insiders for more resources. In this sense, ePrescribing is a commitment to the outside, to prescriber organizations, pharmacies, and to patients and customers. This is a new situation for the organization and the IT-department. In the same way, the maintenance of the software becomes part of an integrated environment, where decisions for one system have effects on systems and processes geared towards the outside. This is also true for the support process, which also has to involve inter-organizational aspects. 
One example of how to cope with this increased interdependence was the cooperation between the Stockholm county councils and NPC on the level of handling technical, work practice, and medical care quality, linked to ePrescribing ${ }^{65}$.

Inter-organizationally, there were also new challenges in the interaction with the external demands and the function of ePrescribing, where changes in the internal infrastructure and dispensing systems could affect ePrescribing. This also influenced the support process and problem solving. Incidents reports were required to be directed both internally and externally and new ways to communicate and handle incidents inter-organizationally had to be established. In case of serious incidents, other parts of the organization from marketing to the media department could be involved.

ePrescribing incidents are very serious, not only from a patient safety perspective, but also from the demands of the patient to immediately get access to the ePrescription at any pharmacy in Sweden. Serious incidents can also affect the confidence in the organization. Queues build up very quickly and even if in most cases the need for medication is not acute, it cannot wait too long. A worst-case scenario that was discussed between county council and the NPC was a stop in the ePrescribing systems for a period of half an hour to one hour, something that would quickly affect tens of thousands of customers all over Sweden. The effect of such a worst-case scenario was analyzed and used in arguments to improve the robustness of the ePrescribing systems, both on the prescriber and the pharmacy side. With an established growth in ePrescriptions these issues became more and more pressing.

To manage these issues, organizational structures and processes need to be created both intra- and inter-organizationally. One important step in this direction was the work of discussing and approving an eCommunication agreement with an additional support agreement. This agreement did not only regulate the exchanged ePrescription messages, but it regulated also how support as well as incidents should be handled. In discussing the e-communication agreement between each county council and the NPC, there was an opportunity to discuss the different responsibilities of the involved parties, and where the responsibilities started and ended.

Another issue that arose with the growth in volume was related to the content of the prescription. At one level, there is a question of adherence to an agreed form and structure of a prescription. This is usually defined in an exchange agreement of the message format, which regulates for example mandatory information, data types, and the minimum and maximum lengths of different fields.

\footnotetext{
${ }^{65}$ The author was involved in this activity representing the National Pharmacy Corporation as a service leader for ePrescription.
} 
Another side of this exchange agreement concerns the agreed meaning of the different terms used. This agreed meaning is based on a process of achieving a mutual understanding and which result is documented in an agreement on definition of terms.

A third aspect concerns regulating the valid content of a prescription according to prescription rules, which are regulated by legislation and in some cases by agreed praxis. With a growth in volume, even a small amount of error will cause problems for the ePrescribing process. It can make the process costlier in terms of cost for corrections, and increased direct contact between the pharmacist and the prescriber to clarify the content of the prescription, and to agree on a correction. This will lead to delays in term of queues and frustrated customers.

To meet these challenges a common project $^{66}$ was set up with a number of county councils to improve the quality of ePrescription content in terms of agreements to format and prescription rules. Carelink later coordinated this project. A technical group was set up with participants from the NPC and some county councils to work out a new proposal for a National ePrescription Format (NEF). The county councils and the NPC approved this proposal. It also contained a new process for the approval of EHR-systems.

This development pointed to a need to set up a process and organizational structure for the management of this new format. It was decided that Carelink should host this process. Later a common NEF maintenance group responsible for maintaining the NEF format was created and hosted by Apotekens Service AB. Before this, there was no common administration and maintenance of the rules and format of exchange of ePrescriptions between the county councils and NPC.

After approval in 2006, it took three years before all ePrescriptions complied with the NEF format. The implementation process consisted of making an implementation plan for each county council and EHR-system. To succeed with these plans (the deadline had to be changed several times), it was necessary to convince all county councils of the necessity and need to order a change to their EHR-system or to upgrade to a specific version. This meant many meetings, seminars, and telephone conferences. The cooperation between the county councils and the NPC established in the initial growth phase of ePrescriptions was expanded to all the 21 county councils in Sweden. In the summer of 2009, all ePrescriptions in Sweden from all the approved 16 EHR-systems, followed the new national format.

For further details about the improvement of interoperability in ePrescribing due to the intervention to improve the quality of the ePrescription, see chapter 5 , which contains a field experimental study of the situation before and after the intervention.

${ }^{66}$ At first it was called ELF - Elektronisk LäkemedelsFörskrivning - Electronic Prescription of Pharmaceutical, and then later became NEF - National ePrescription Format. 


\subsection{Economic, legal, and organizational issues in implementing ePrescribing}

From 2000 onwards, there arose a number of economic, legal, and organizational challenges that had to be faced in implementing ePrescribing in Sweden.

\subsubsection{Economic challenges}

The economic challenges were linked to financing the implementation of ePrescribing. The county councils suggested that the NPC, as they were considered to benefit the most from implementing ePrescription, should pay a fee for each ePrescription. In addition, a commercial company offered to build a web application for ePrescriptions and suggested that the NPC should pay a fee for each ePrescription transferred. These proposals were not accepted by the NPC and there was an agreement that each party should cover its own costs. There was, however, a common financing of the forums for cooperation like Carelink.

With no common financing, the challenge was to face the problem of the different priorities of the different county councils and of the NPC. This meant that one important activity of the major stakeholders and the common forums like Carelink was to convince different decision makers about the need to prioritize and make resources available to implement ePrescribing. Swedish state authorities supported the implementation of ePrescription in policy documents, although not through direct financing. Although the NPC was state-owned, it made its own priorities and there was no "ear-marked" funding. Thus, different levels of stakeholders, project leader, steering groups, et cetera, needed to work by themselves for internal financing and engage other stakeholders. Given the character of an inter-organizational project, the major stakeholders could use pressure and demands from the "outside" to their own advantage to gain support and financing in their own organization. This was an effect of viewing the "outside" as important partners and the project as part of building confidence and a relationship. In fact, the ePrescribing project was one important step in improving relations and cooperation among the stakeholders. From a situation where at the beginning most of the benefits were attributed to the NPC, there evolved an understanding of mutual benefits.

The informants stated that there was a need for a clear vision of the benefits for all stakeholders and a constant need to convince internal and external decisions makers to get the necessary funding. The stakeholders who were directly involved - prescribers, pharmacists, and patients - quickly accepted the use of ePrescription. The challenge was to convince the decision makers to provide funding and make prioritization of resources. In the NEF project, it was very important to be able to phase out the old format and get all the county councils to pay for an upgrade of their EHR-systems at all health care centers in all the 21 county councils. To achieve this, the common implementation project between the county councils and NPC agreed on a deadline after which the old format would no 
longer be possible to use. Even if this deadline had to be moved, it was a good incitement for change.

\subsubsection{Legal aspects}

Legal aspects are very important in implementing ePrescribing, as it is a highly-regulated process. The challenges are many. One is that legislation differs between the health care sector and the pharmacy sector. In Sweden, there are also different authorities that regulate the different sectors. The National Board of Health and Welfare (Socialstyrelsen) regulates the health care sector, while the Medical Products Agency (Läkemedelsverket) regulates the pharmacies and the manufacturing and marketing of medical drugs in Sweden. The Dental and Pharmaceutical Benefits Agency (TLV), regulates prices and medical benefits and the Data Inspection Board (Datainspektionen) is an authority that influences matters of security and privacy in the ePrescribing process. Thus, different laws and regulations regulate different aspects of ePrescribing.

These regulations influence all levels of implementation both at the pharmacies and in the health care sector. Here, we will mention some important issues that have been dealt with in the implementation of ePrescribing:

- recognition of ePrescription as a legally accepted type of prescription;

- central storing and access to ePrescriptions;

- management of the ePrescription during its whole life cycle;

- rules for change of ePrescriptions.

The first issue, the recognition of the ePrescription as a legally accepted phenomenon was early legally defined as the electronic transfer of a prescription. It was essentially a phenomenon of a mode of communication. It was then assumed that it was not allowed to store a prescription electronically, although this was not explicitly forbidden. This meant that the mailbox metaphor was used to describe the communication infrastructure for ePrescriptions. The Medical Products Agency together with the NPC defined a paper format for the ePrescriptions. The Medical Products Agency was not involved in the definition of the format for an electronic prescription, only its reprint on paper.

There was a regulation that there must exist an agreement between the prescriber and the NPC regulating the electronic transfer of a prescription. However, it was very impractical to have an agreement with every prescriber and the NPC interpreted this to be an agreement with the prescriber's health care organization on the county council level or with some other principal representative in the case of a private health care agent.

It seems that the early legislation reflected the local character of transferring ePrescriptions in the $80 \mathrm{~s}$ and $90 \mathrm{~s}$. This had to be changed due to the demands from larger county councils in the urban areas and with the growth in the volume of ePrescriptions. This led to attempts to change the legislation to allow central storing of the ePrescription 
with the patients consent at the pharmacy ${ }^{67}$. The change in legislation meant also that changes made to the prescription, for example a correction of instructions for use, could be recorded and saved for future dispensing. It was also possible to convert a paper prescription into an ePrescription and vice versa. This meant that an ePrescription became an original object in its own right with its own life cycle.

Another legal matter considered was who had the right to annul a prescription. Initially it was interpreted that it was only the pharmacy that could annul a prescription at the request of the patient or in case of emergency. However, the prescribers claimed a need to be able to annul the prescription in their system with the effect that it was annulled in the national repository of prescriptions. This was a difficult issue and included matters such as which prescriber had the right to annul a prescription and under which conditions. Today, it is possible to annul a prescription on the request of a prescriber or of a patient under certain conditions.

In sum, the legal challenges were approached in a number of ways. With the development of ePrescribing, new demands and needs arose which could conflict with the existing legislation. In some cases, the legislation was fast to adapt, such as in the case of accepting ePrescription as a mode of communication, but slower to codify the status of an electronic prescription as such. The need to view an ePrescription as having at least the same status as a paper prescription as an original, with a life cycle and history (all the dispensing history was recorded with labels on the front and back of the prescription form) evolved early in the visions of stakeholders in ePrescribing, particularly from the NPC. There was a long-term cooperation between the NPC and the authorities around prescription rules and new laws concerning registers. The fact that there were several reforms during the first decade of the century, demanding major revisions and changes in the regulation of the pharmacy market, were also opportunities to include changes to the legislation, which were beneficial for the ePrescribing process. Moreover, the fact that the county councils also benefitted from a more integrated ePrescribing process was probably a positive factor. Also, the fact that there was no breach of patient privacy reported in relation to ePrescriptions contributed. The relatively few incidents with ePrescriptions have mostly been attributed to technical failures of an arbitrary nature. This has contributed to trust, confidence and acceptance of the ePrescribing process. This taken together could have had a positive influence on the legalization process, as ePrescription was viewed by the public, stakeholders, and policy makers as a positive phenomenon. The common project between the county councils and NPC gave also the opportunity for the stakeholders to arrive at a common interpretation of the application of the legislation, which helped to overcome certain legal barriers on the project level.

\footnotetext{
${ }^{67}$ It was not considered necessary that the prescriber had the consent from the patient when issuing the prescription, but it was decided that it would be the task of the pharmacy when the patient requested the prescription for the first time.
} 


\subsubsection{Organizational challenges}

The organizational aspects have been dealt with in section 4.8.1 and 4.8.2. One thing to note is that the cooperation, which evolved between the health care sector and the NPC, was essential for the success of the implementation of ePrescribing. Different types of organizational mechanisms were included:

- project organizations, which could be multilateral between the NPC and different county councils or between local pharmacies and local medical clinics in the early years, as well as common projects involving all the county councils and the NPC, for example in the implementation project of NEF. This organizational mechanism was used for major changes;

- service operation organizations, which have been multilateral for managing the communication of ePrescriptions using e-communication and support agreements as governance mechanisms. This organizational mechanism ensures the operational continuity of services;

- long-term forums for cooperation and management between the health care sector and the pharmacies such as Carelink, and sub groups like ELAK and the NEF maintenance group. Their long-term work facilitated the creation of an information infrastructure in terms of identifying the actors and objects in the ePrescribing process, together with the creation of an organizational control of these information resources. These types of organizational mechanisms are a basis for establishing trust and cooperation in the long term, which influence the economic, legal, and organizational aspects related to ePrescribing. They ensure the long-term management of the ePrescription service;

- promoting policies, providing directions on standards, methods and technologies. The Swedish Standards Institute (SIS) contributed in the national implementations guideline of ENV 13607. Carelink also played a role in promoting policies and standards on encryption of ePrescription, and the authentication of prescribers. The Data Inspection Board had a governing influence on integrity and privacy matters in ePrescribing.

The implementation process of ePrescribing was characterized by the evolution of organizational mechanisms as the need arose, fostered by the existence and creation of long term forums for cooperation, a combination which probably was a success factor.

\subsection{Success factors in the implementation process}

In the interviews with the representatives from NPC and the Stockholm county council, one focus was on factors and events that influenced the implementation of ePrescribing in Sweden. The successful implementation of ePrescribing in Sweden, and the role of the 
informants, has been publicly recognized through different achievement awards. Based on the interviews, we have summed up and synthesized the major success factors.

From the point of view of the informants from the NPC, some success factors for the early and continued growth were:

- a driving actor that was consistently and constantly pushing for ePrescription in the early years by keeping resources even at a low level and later taking a strategic initiative to push for the development. In Sweden, the driving actor was a state-owned pharmacy corporation, but in Denmark, which had a deregulated pharmacy market, it was initiatives from the county councils and central government authorities that played the role of driving actors;

- common implementation projects with the county councils and common forums to solve problems;

- a pragmatic attitude and a will to solve problems or overcome obstacles when they occurred in the cooperation between the NPC and the county councils;

- acceptance of ePrescribing by the actors involved in the work practice, such as the patients, prescribers [193], and pharmacists. The patients accepted it immediately. The prescribers and pharmacists adapted quickly and changed their work practices to use ePrescribing instead of paper prescription;

- ability to convince decision makers with arguments about the benefits;

- create and maintain trust in the process and technology that must be robust and safe;

- implementation strategy adapted to the county councils and the local needs for education and awareness. For example, technical awareness that problems manifest themselves in another way with ePrescriptions.

Success factors, from the perspective of the county council, in the implementation of ePrescribing, can be summarized as follows:

- trust and confidence between the county council and the NPC;

- an active and competent steering group with participation from the major stakeholders;

- openness, i.e. no hiding of technical or organizational problems;

- clear chain of responsibilities in the ePrescribing process, between the county councils and the NPC. This was one of the main benefits of using the ecommunication and support agreements to discuss and understand where responsibilities start and ends;

- the involvement of all aspects and issues regarding work practice, technology and quality of medical care;

- understanding that there are different professional languages spoken in the different domains;

- a respect for legal matters. There are different legislations and they are not always compatible. It is necessary to try to reach a common approach and 
interpretation of the legal matters and find practical solutions to the problems that arises;

- a common dialogue, coordinated by the county councils, with the software vendors to give clear information and clarify the legal framework;

- structured forms of cooperation for dealing with daily problems;

- competition between the county councils regarding the level of implementation had a positive influence;

- an understanding of work practice on both sides of the ePrescribing process;

- use the implementation of ePrescribing as an opportunity to improve the work practice in prescribing;

- a clear vision and understanding of the benefits for all participants in the process.

\subsection{Conclusion}

This case study of the implementation of ePrescribing in Sweden has identified three important phases: pioneering, growth and consolidation. The early pioneering phase of the 1980s and 1990s (see 4.3) was characterized by visionary work regarding decisions support systems for medical practitioners and small scale local pilot projects based on cooperation between the health care sector and the NPC. These local pilot projects demonstrated the feasibility and usefulness of ePrescribing. However, it was not until a major county councils and the NPC decided to view ePrescribing as a strategic opportunity that a phase of growth was initiated in the beginning of the year 2000 (see 4.4 and 4.8). This growth was based on tight cooperation on many levels between the county councils and the NPC. With the increase in volume of ePrescriptions, a need for a consolidation with a focus on quality and sustainability spurred this development further from the mid of the first decade of 2000. 
This development, spanning about 30 years, has a shown a number of important characteristic. These include a:

- variety of organizational mechanisms to manage the increased need for cooperation between the actors in the health care sector and pharmacy sector, such as common development and implementations projects, processes for service operation and long-term development of ePrescribing. One important milestone in this development was the creation of an information infrastructure organization for ePrescribing, the Swedish eHealth Agency. (see 4.8 and 4.9.3);

- culture of cooperation and trust ${ }^{68}$ between the actors involved in ePrescribing. (see 4.10);

- complex information infrastructure to manage the ePrescribing process, such as repositories of shared institutional objects (medical drugs, prescriptions, pharmacies, prescribers register, et cetera), gateways for communication and an installed base of applications to support prescribing, communicating, and dispensing prescriptions. (see $4.44 .5,4.7$ );

- legal and financial framework reflecting and promoting the growth and consolidation of ePrescribing. (see 4.9).

\footnotetext{
${ }^{68}$ Different aspects of trust have been reported by the informants as one important success factor in implementing ePrescribing in Sweden. However, these aspects of trust have not been analyzed in detail. Söderström et al [194] have developed a trust matrix which they have used to identify trust issues related to electronic health records. The trust matrix contains three trust levels: organization, person and technology and different aspects of trusting beliefs: ability, benevolence and integrity.
} 


\section{Improving interoperability in ePrescribing - a field study}

This chapter contains a summary of a field experimental study in improving interoperability in ePrescribing. The summary is based on two published research contributions, which analyze interoperability error before and after an intervention. [8,9] We have added a background to and characterization of the intervention, an overview of design decisions made, and further reflections on the findings.

The study here presented can be viewed as an experimental study. In biostatistics, an experimental study is defined as:

"A comparative study involving an intervention or manipulation", where intervention is "the maneuver used in an experimental study." [148] (Glossary)

This study is a field experimental study [195], which means that it is taking place in a realistic setting, in a real inter-organizational context.

The intervention in this experimental study is all the actions taken together to design and implement a new National ePrescription Format (NEF) from 2004 to 2009. The completion of the implementation of NEF in the ePrescribing process in 2009 provided a unique opportunity to study the effects of this intervention by comparing the situation before and after its completion. This intervention occurred in the transition from a growth phase (from about 2002) to a consolidation phase (from about 2008 and onwards) within the context of the evolution of ePrescribing in Sweden. The intervention formed an important part of this consolidation process together with other important events. Se Figure 14. 


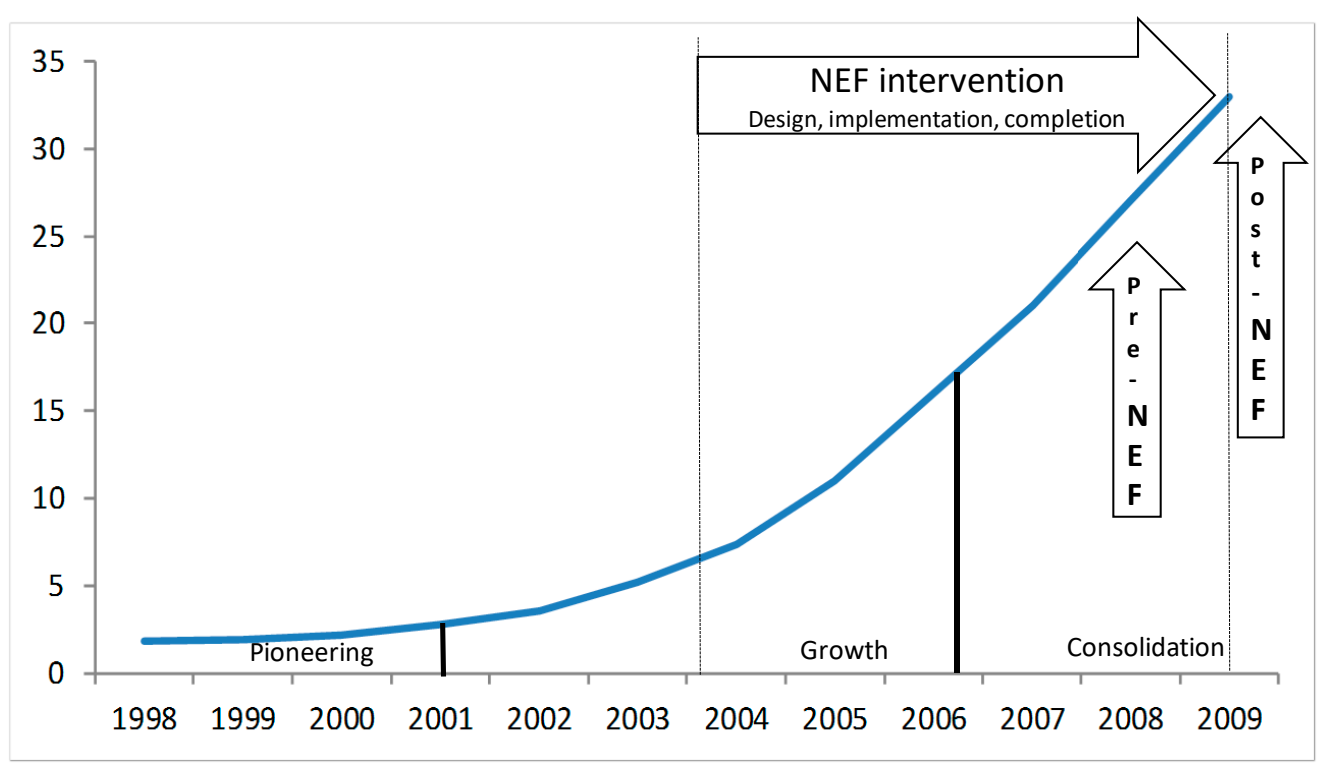

Figure 14 Placing the NEF intervention within the overall evolution or ePrescribing. Pre-NEF is the period of sampling ePrescription before the completion of NEF intervention and Post-NEF is the period of sampling of the ePrescriptions after the completion.

The field experimental study is an in-depth analysis of the NEF intervention. Confer the case study report in chapter 4 and section 4.8.2 to situate the intervention analyzed in this chapter.

Section 5.1 presents a background to the intervention made, in terms of needs to improve the quality of communication, the involved stakeholder and the ePrescribing practice.

The characteristics of the intervention are summarized in section 5.2.

Design decisions and considerations are described in section 5.3.

In section 5.4 to 5.8 , the objectives, methods, design of the pre- and post-NEF measurement and data collection, analysis of observations, and summary of findings are presented.

In section 5.9, we conclude and discuss how the results can be analyzed applying different theories and frameworks, such as Information Systems Actability Theory, and European Interoperability Framework. The characteristics of the intervention is analyzed in section 5.9.4 and in the following section (5.9.5) the implementation of NEF is placed in phases of growth and consolidation of the ePrescribing information infrastructure in Sweden. 


\subsection{Background}

In this section, we describe the background to the initiative to improve interoperability in ePrescribing in Sweden with the design and implementation of a new national format for ePrescriptions between 2004 and 2009.

This background is based on experiential knowledge as an active participant in this intervention for improving interoperability, on internal project documents, and other published documents.

Section 5.1.1 describes the emerging need to improve the quality of the ePrescription communication. In sections 5.1.2 and 5.1.3, we briefly describe the involved stakeholders, and the ePrescribing process to illustrate some of the complexity in ePrescribing which will influence interoperability in ePrescribing.

\subsubsection{The need to improve the quality of communication}

Several factors influenced the need to improve the quality of communication in ePrescribing in Sweden. The ePrescription communication became successively more complex with new systems and actors involved and more critical with the growth of volume. This motivated a move towards a more rigorous regulation and control of the process both technically and organizationally.

\section{Evolution of the ePrescription communication}

The communication of ePrescription messages from health care organizations to pharmacies in Sweden has evolved during three decades (see further chapter 4).

Varying communication standards and different message specifications have been introduced and applied. The infrastructure has constantly evolved, from point-to-point message communication of the prescriptions from local health care organizations to local pharmacies, towards a centralized communication on both sides. (see section 4.5 and 4.6)

The practice of ePrescribing has evolved from a mere electronic transfer of a message to the management of the prescription during its entire life cycle. A growing number of health care regions have been involved and the number of prescription systems have increased. In 2009, there were 16 Electronic Health Record (EHR) systems with ePrescription modules and one web based prescription system, sending ePrescriptions from 21 health care regions in Sweden. 


\section{eCommunication contract - a step forward}

According to the prescription regulation in Sweden, there must be a contract between the parties regulating the secure and trustful communication of ePrescriptions.

Therefore, already from the beginning of the first decade of 2000, NPC started to implement eCommunication contracts regulating the communication of ePrescriptions (and other messages) between organizations. The NPC started a negotiation with the 21 regional county councils to sign a more elaborated eCommunication contract. The eCommunication contract is an overall agreement between the parties with a focus on legal matters and organizational responsibilities. Thus, already before the development of the new national ePrescription format, a contractual agreement was used to regulate the responsibilities of the communicating parties. The structure of the eCommunication contract is illustrated in Figure 15.

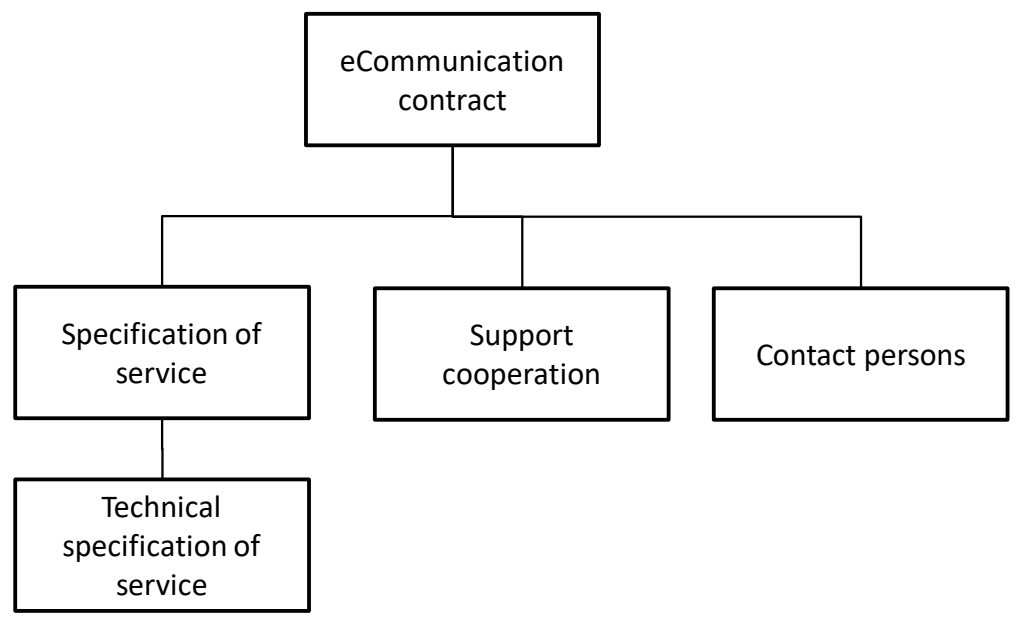

Figure 15 The eCommunication Contract structure.

The eCommunication contract contains ${ }^{69}$ briefly the following:

- assurance by

- each party the proper authentication and authority of the users for respective systems;

$\circ$ the prescriber's organization to provide the correct workplace and prescriber code;

○ the pharmacies to apply the rules of prescription rights;

- agreement on:

\footnotetext{
${ }^{69}$ The eCommunication contract referred to is from 2005 signed with a regional county council.
} 
o that all communication must follow the agreed technical specification and that the integration tests are approved by the parties;

o that all changes effecting the communication must be communicated to the other party and a consultation should be made how to handle this change;

$\circ$ the process of support and cooperation in handling incidents and problems including both information systems and medical issues;

O the specification of IT-services such as service levels, and exchange contracts defining the structure and content of messages, including additional document to guide the implementation of the integration.

Thus, there were already insights concerning the importance to regulate the ePrescription communication in order to secure the quality of communication and the interoperability between the health care providers and the pharmacies.

With the growth of volume, the ability to handle incidents and problems became an important concern and the eCommunication contracts became an important instrument to create governance mechanism to improve this ability cross organizational borders.

Initially the focus was on managing the ePrescriptions from a technical point of view in order to ensure an undisturbed data communication. However, with the increase in volume, the quality of the content of the ePrescription became an important issue to improve and regulate.

\section{Growth of volume highlights interoperability problems}

The ePrescription support team at the NPC observed an increasing number of issues regarding the quality of the content of ePrescriptions in the production flow. In 2004, NPC forecasted an increase of ePrescriptions from 30\% to 80\% (of new prescriptions) in 2007. With this expected increase of volume, the handling cost of poor quality were expected to increase considerably. There was no automated control of incoming prescriptions other than a failure to store the ePrescription in the database, which resulted in a negative acknowledge receipt; the system did not report any information about the possible cause. The procedures for test and approval of EHR systems to allow for sending ePrescriptions were rudimentary. The inter-organizational aspects of this was unclear, as was the process for maintenance and development of the ePrescribing process. Focus was on managing the technical communication between and within the organizations. The managing of errors regarding content of the ePrescriptions was pushed down to the pharmacist at the end of the process.

This situation expressed the fact that the communication of ePrescriptions in the beginning was first concerned with the reliability and stability of the technical communication. The focus on the quality of the content of ePrescriptions would involve much more of the ePrescribing work practice. However, based on the expected growth in volume, the quality of the content of the ePrescription message became a more obvious issue to address. 


\subsubsection{Stakeholders in ePrescribing}

The ePrescribing process involves a large number of stakeholders having interests in, being influenced by, and influencing the ePrescribing process and the content of the ePrescription (Figure 16).

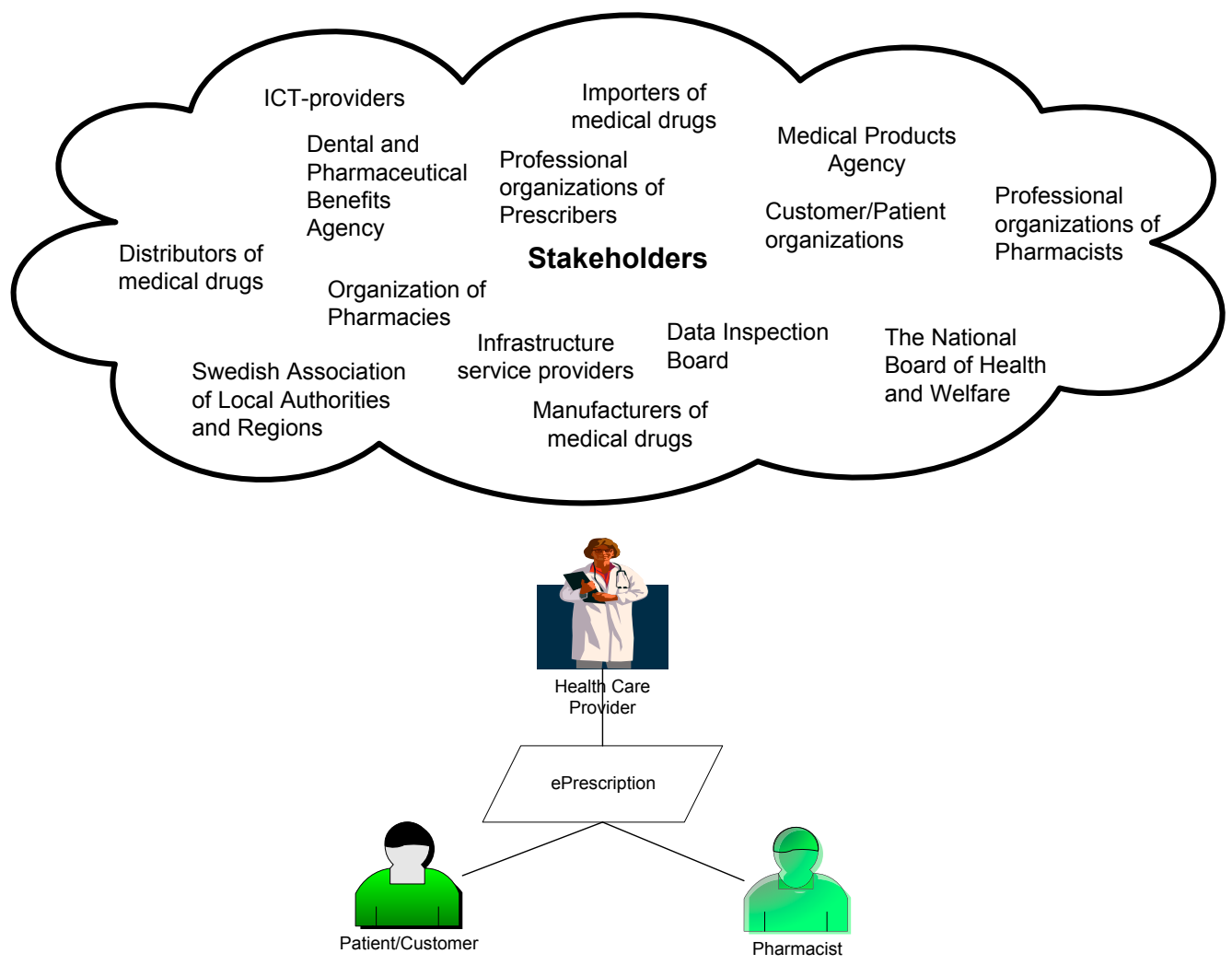

Figure 16 Stakeholders in ePrescribing.

The multiple functions ${ }^{70}$ inherent in the prescription and the number of stakeholders involved make the communication of ePrescriptions complex. The following provides an illustration of this complexity:

- the Medical Products Agency approves the medical drugs to be sold on the Swedish market, determines which drugs are to be considered to comprise generic exchangeable drugs, and acts as the statutory authority as regards the prescription regulations;

- the Dental and Pharmaceutical Benefits Agency decides which medical drugs are to be reimbursed, and determines their procurement and sales prices;

\footnotetext{
${ }^{70}$ See chapter 6 A practical theory on ePrescribing for an in-depth analysis of the multiple functions.
} 
- the National Board of Health and Welfare regulates the health care sector and provides information about prescribers and their prescription rights, as well as granting practitioner licenses to prescribers and pharmacists;

- the basic information about the medical drugs to be prescribed is provided by the Medical Products Agency, and by the manufacturers and importers of medical drugs.

There is a complex information flow to the prescriber organizations and to their Electronic Health Record (EHR) systems, and to the pharmacies and their dispensing systems via a state-owned infrastructure service provider. This service provider (in the beginning the NPC, today the Swedish eHealth Agency) also provides e-services for ePrescriptions, dispensing, reimbursement of prescriptions, and statistics. See further section 5.9.2 Stakeholders involvement and shared information services .

\subsubsection{The ePrescribing process}

ePrescribing is regarded as a process which starts with a communication between a prescriber and patient related to medical treatment. This process also includes communication between a patient and a pharmacy, a prescriber and a pharmacist regarding any clarification on the prescription, and followed by the completion phase with the aim to evaluate the result of the medical treatment. The ePrescribing process is also a communication between the health care market and the pharmacy market. The prescription is regulating the market for prescribed medical drugs. See chapter 6 A practical theory on ePrescribing for a more developed description of the ePrescribing practice.

\subsection{Intervention - the combined efforts to design and implement NEF}

In this section, we will describe the intervention - the combined efforts and activities to design and implement a new National ePrescription Format (NEF) in Sweden.

To improve the quality of the ePrescriptions message, a joint project between NPC and the regional health care providers was initiated in 2004, with the overall purpose to improve patient safety and to decrease the cost of deficient quality in ePrescribing.

The first part of the joint project concerned the design (from 2004 to 2006) of a new national ePrescription format (5.2.1). The project subsequently (from 2006 to 2009) implemented the new NEF-format [196] (5.2.2). Some important features of the NEF intervention is further described:

- the implementation of automatic control of the NEF format and prescription rules (5.2.3); 
- an enhanced test and approval procedure of EHR systems for the new NEF format (5.2.4);

- an enhanced process for management of interoperability error linked to new capabilities of the NEF format (5.2.5);

- a shared maintenance of the new format (5.2.6).

\subsubsection{Joint project to design a new ePrescription format}

A joint project started, initially with some major county councils and the NPC, to work on a new ePrescription format. A smaller group of participants from the county councils and the NPC developed the first definition of the new format. There was early a decision to phase out the UN standard for Medical Prescriptions, MEDPRE, which was using the EDIFACT format. The new format was based on the pre-standard ENV 13607, the SIS XML guide, and the existing exchange agreement between the parties. The guiding principle for the new format was to do as few changes as possible and focus on quality with the aim to create a stable base for new functionality. The new design of the message format was thus guided by demands to improve the quality of the ePrescriptions message and to adjust the format to legal demands that were not fulfilled.

An important step in this direction was to make explicit the explanation of certain terms used in the ePrescription message, to guide their interpretation and usage to avoid misunderstandings. Another major step in improving the quality of the ePrescription message was to supplement the format specification with a definition of the ePrescription message form and content in terms of legal and work practice rules. At an early stage the idea $^{71}$ was not only to define the formal syntax of a prescription but also its formal accepted and expected content. Thus, the focus was also on how the ePrescription message could be used in different prescription cases. One example is how to regulate the valid content of the prescription in the case when prescribing controlled medical drugs, and another is rules for co-occurrence ${ }^{72}$ of values in a prescription. The enhanced format specification (formally defined in a restrictive XML-schema) was supplemented with prescription rules, definitions and explanations. Thus, there was both a work practice and a technical focus on interoperability.

\footnotetext{
${ }^{71}$ See chapter 3 on the development of research interests and the insights gained in the research process for a description on the origins of this idea.

${ }^{72}$ Rules for co-occurrence of values means that if a certain value in a field occurs in a prescription certain values or occurrences of values in other fields must or are allowed to exist.
} 


\subsubsection{Joint project and coordination to implement a new ePrescription format in ePrescribing}

At the end of the design phase, additional stakeholders were involved and this involvement was strengthened when the format was approved and the implementation phase started. Many common national and regional meetings were organized, including a referral and revision procedure of the NEF documentation and the new format specification.

A joint project with more active involvement from the health care providers in the regional county councils and the NPC was created for implementing the ePrescription format. The joint project was centered on the cooperation of the health care providers in the 21 regional county councils and the NPC. The software vendors were consulted regarding the content of the new format and test procedures. However, the responsibility for the business relation between the software vendors and the health care providers and their respective implementations plans for the EHR-systems was placed on these different parties. The NPC had the responsibility for the changes to the infrastructure eService for ePrescriptions and for its own dispensing system (at that time there was only one dispensing system for prescriptions).

One major challenge in the implementation project was to manage all the 16 EHRsystems (with different versions and adaptations at the regional county councils). There was a need to have these systems to be changed, tested, and approved for the new format. The NPC and the health care regions made a common effort to put pressure on the software vendors and on the health care regions to provide implementation plans to be able to implement NEF in time. The implementation plans were coordinated and followed up in the joint implementation project.

\subsection{3 'On-line' validation of ePrescription}

The next important decision was to apply the definition of the ePrescription format and content to each ePrescription message in the actual production flow. The format rules were validated using an XML-schema. The prescription rules were validated using different registers and implemented in program code in the ePrescription service. In order to communicate this 'on-line' validation of ePrescriptions to the sending part a more advanced feedback mechanism was developed in an enhanced Application Acknowledgement Message. See further section 5.3 Design of a new National ePrescription Format (NEF) for some design considerations for the new ePrescription format.

\subsubsection{Enhanced test and approval process}

The existing test and approval process was rudimentary and informal, implying in practice that NPC got all the responsibility. To improve the quality of ePrescriptions, a more elaborated test and approval process certifying the EHR-systems for communication of 
ePrescription was developed. This process included a self-test phase using a provided extensive test protocol. It did also contain several milestones for different communication tests and a final approval to be a certified system for ePrescriptions for the new national ePrescription format. The scope of the testing of the EHR-systems was limited to the communicated message and included demands for quality controls in the EHR-systems of the prescription before it was approved and sent.

\subsubsection{Managing interoperability errors}

An important question arose on how to manage the identified errors between the various stakeholders. Another issue addressed was the manner in which the health care regions should handle and communicate the rejection of an ePrescription to the prescriber. A third question regarded which appropriate and legal actions to should be taken by the pharmacist in handling ePrescriptions with errors that were accepted with warning. The clear text messages linked to each error status code were also discussed extensively and were revised to be sufficiently clear to be directly communicated to the prescriber. On the operational level - a multilateral incident management process was developed to manage interoperability errors and other incidents. This process could handle both technical and medical errors. On a long-term basis - from a process management perspective - there were forums (like $\mathrm{ELAK}^{73}$ ) that worked for improving the quality.

\subsubsection{Common maintenance of the ePrescription process and format}

One difficult issue was which organization should be responsible for administration and coordinating the development of the ePrescribing process and the ePrescription format. At first, it was managed through a common network organization (Carelink) and later by a state-owned infrastructure company, finally (2014) by a state authority (the Swedish eHealth Agency).

\subsection{Design of a new National ePrescription Format (NEF)}

This section describes some design considerations made in defining the new national ePrescription format (NEF). The author was early involved in designing and documenting this new format before the implementation phase, which was later coordinated by Carelink together with the county councils and the NPC (for the role of Carelink see section 4.8 and 4.9).

${ }^{73}$ See section 4.8.1 for the role of ELAK. 


\subsubsection{Pre-NEF existing standards and specifications}

Before the new ePrescription format, there were two standards used for ePrescriptions: (i) the UN MEDPRE standard using EDIFACT message syntax and (ii) ENV 13607 using XML message syntax.

Both the MEDPRE and the ENV 13607 XML ePrescription message specifications (their adaptation to the actual exchange between the parties) were agreed upon between the county councils and the NPC in the form of an exchange agreement (see Figure 17).

Concerning the ENV 13607, the Swedish Standards Institute (SIS) had earlier developed a Swedish implementation guide for adapting the ENV 13607 to XML. [197] This implementation guide was a subset of the ENV 13607 messages $^{74}$.

The work made by SIS was an adaption to the needs in Sweden and functioned as a guide for implementing ENV 13607 for XML. At that time, in the beginning of 2000, XML was gaining some influence as a language for EDI-communication, even if EDIFACT still was predominant.

The final format specification that was agreed between the parties was furthermore a subset of the Swedish implementation guide to be used for the prescription message. The only message that was used from the ENV 13607 and the subset from SIS was the prescription message. In addition to the ENV 13607, a message 'envelope' was added that was used by the EDI distributors (VAN-providers) to communicate the message to its correct destination. An 'application error and acknowledges message' (APERAK ${ }^{75}$ ) was also developed, which was not included in the ENV 13607. Figure 17 illustrates this process of selecting useful parts of a general standard to a national level and finally to the level of the community.

\footnotetext{
${ }^{74}$ In the ENV 13607, there were two types of "subject of care": Animals and humans. This opened up for the use of the ENV 13607 for ePrescriptions for animals. The ePrescription for animals was developed in cooperation between the National Pharmacy Corporation, Swedish Board of Agriculture and their district veterinaries. CGI developed the ePrescription service and it was piloted in the beginning of 2008 and in production since May 2008. ePrescriptions for animals could use much of the material and experiences made in the implementation of the NEF. This was, to the knowledge of the author, the first implementation of ePrescriptions for animals in the world. The author participated together with other colleagues at CGI in the design of this ePrescription format that was based on the NEF.

${ }^{75}$ See the definition of an APERAK by EANCOM: "APERAK is a message from the party who received an original message, to the party who issued the original message, to acknowledge to the message issuer the receipt of the original message by the recipient's application and to acknowledge errors made during the processing within the application."[198]
} 


\section{Application level}

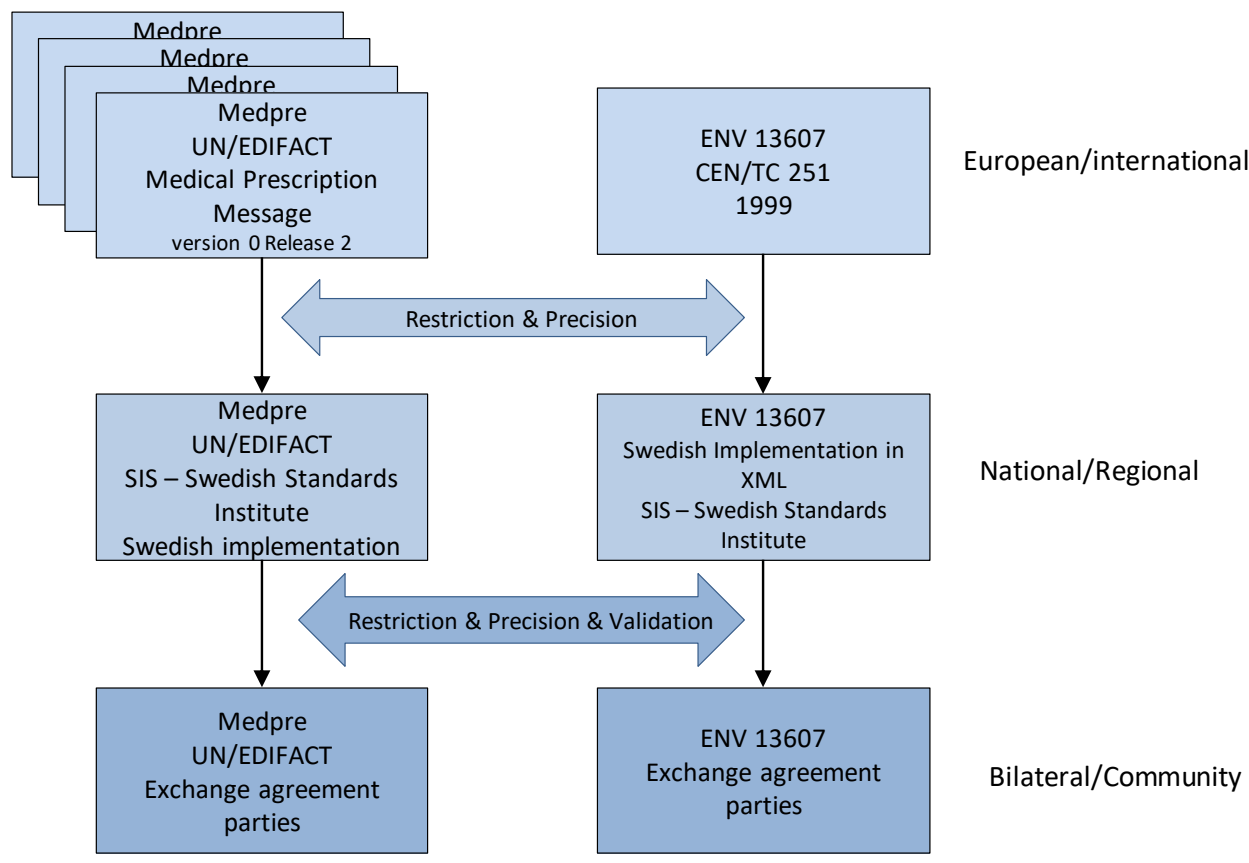

Figure 17 Adaptation of standards at different levels of application.

One reason for doing this transformation of a general standard to a specific implementation for a community is that, there are different legislations on the national level, such as what is a prescription, different rules for reimbursement, different means to identify a pharmacy, prescriber, patient, and the prescribed drug.

This transformation involved a number of design decisions in order to construct the final useful and used message specification. There is in this process a number of interpretations made of the more high-level constructs in a standard. This is more obvious with a standard that involves a shared work practice, which may vary to a higher degree than a technically oriented standard. A standard that involves a shared work practice will have the role as a guide for implementation rather than containing detailed prescriptive rules.

It may also be the case that a standard ambiguously or inconsistently define the conceptual structure of objects which will lead to difficulties to apply the standard to a national or local level. One example of this is the ambiguity in ENV 13607 how to define and identify a prescribed medical drug. This is a very central issue in an ePrescription, and will lead to ambiguities on how and on what level a prescribed medical drug should be identified and described, whether on substance, product or package level, and how this is linked to the amount of drugs prescribed. 


\subsubsection{Clarification of ePrescription concepts}

An international standard or specification has to be interpreted in the context of a national or local work practice. These work practices have their own work practice languages, which have to correspond to and be interpreted in terms of the vocabulary of the international standard. With the implementation of the NEF, the ePrescription concepts were elaborated and made more precise in the context of the ePrescribing practice, with aim was to improve interoperability through limiting ambiguities and diverging interpretations.

The work practice language reflects legal, economical, professional, organizational, and processual aspects of the practice. This work practice language need to be handled in the ePrescription message and thus be present in both the format specification and in all additional documentations guiding the interpretation and implementation of this message format. For that purpose, an ePrescription handbook was developed already before the implementation of the NEF. This handbook contained guidelines for implementing and using ePrescriptions. It was further developed and changed for the new ePrescription format.

The format specification contains the formal definition of terms used in the message with focus on their syntactical aspects, such as sequence order, data format, acceptable values, and presence (optional, mandatory). To facilitate the understanding of these terms and their expected and proper use, the format specification must be further explained with explicit definitions and examples of use. The context of the work practice, with its different aspects which previously were implicit, was made explicit in the new format, with definition of concepts that could be misinterpreted. Of special importance was that the prescription rules were made explicit in the new documentation. Thus, an essential feature of the new format was to make explicit the work practice language and its rules.

In the following, we will describe some important concepts of an ePrescription and how they have been implemented and refined in the new format. Explaining these concepts will also help the understanding of the findings in the experimental field study presented later in this chapter. Figure 18 illustrates some important ePrescription terms. 


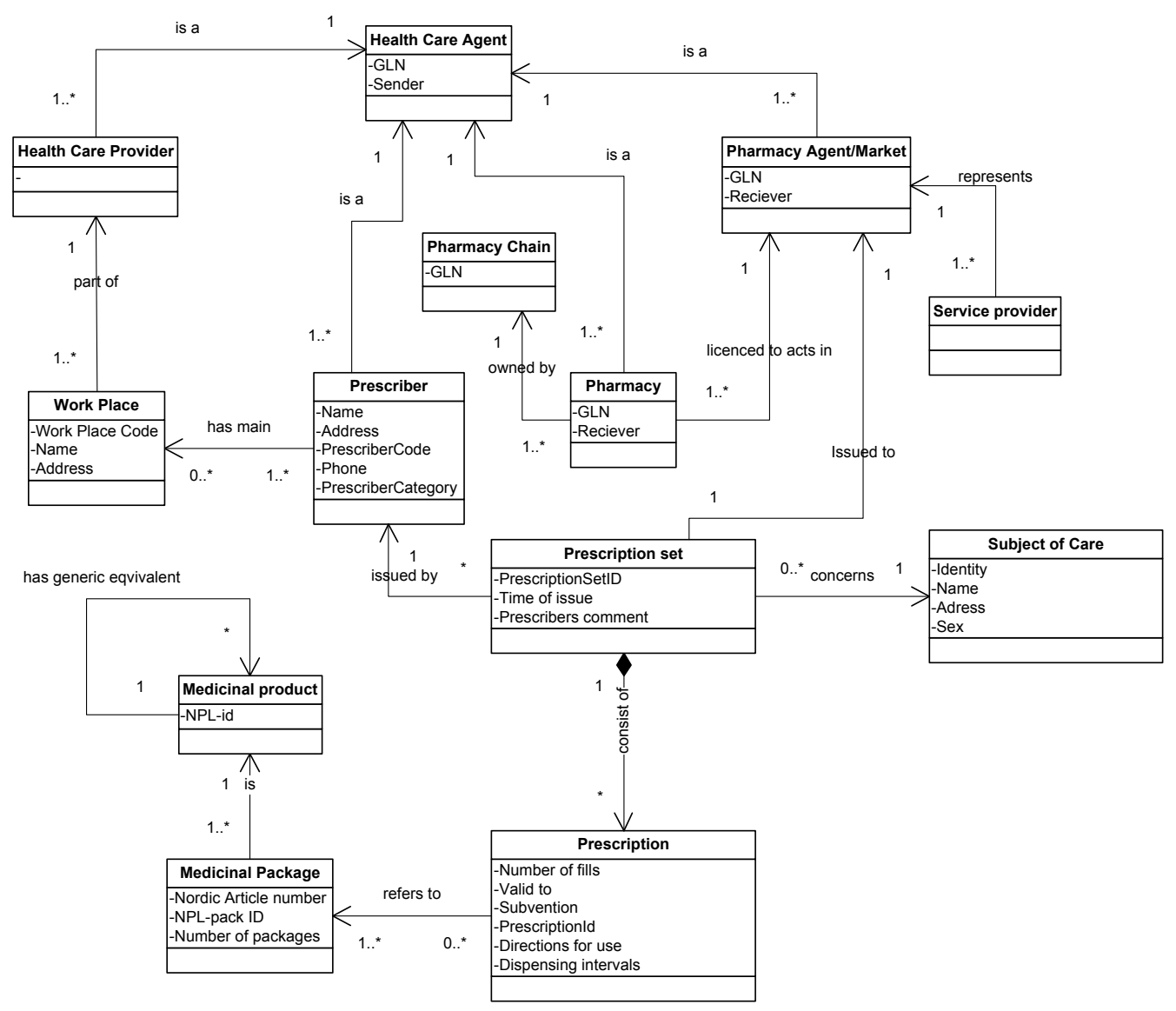

Figure 18 Simplified conceptual model of an ePrescription message.

An ePrescription message is defined as a structured electronic message in alignment with a predefined message specification and prescription rules. The ePrescription is issued by a prescriber and communicated to or made accessible to a pharmacy.

An ePrescription message refers to one prescription set.

A prescription set is a collection of prescriptions. A prescription set is issued by one prescriber concerning one patient at a specific moment for a specific medical treatment. An ePrescription is issued by a Health Care Agent, which is a Prescriber to a receiving Health Care Agent, which in Sweden is a Pharmacy Agent, which could either be the national service provider - the Swedish eHealth Agency ${ }^{76}$ or a local pharmacy in the case of a direct destination of a prescription to a specific pharmacy. In any case, the prescription

\footnotetext{
${ }^{76}$ A more proper role would be a Relaying Agent, a role which exists in the pre-standard but was not used in the SIS XML guide. The concept of the pharmacy market is missing in the pre-standard probably due to the messaging perspective held at that time.
} 
is issued towards the whole pharmacy market and not exclusively to a pharmacy or a pharmacy chain.

At the time of the implementation of the new ePrescription format, a national repository for ePrescription was already existing. This meant that all ePrescriptions were available in one central point to all pharmacies. With the new format, all ePrescriptions were assumed to be issued to all pharmacies in Sweden. Thus, it could be addressed to the NPC if no particular pharmacy was needed to be addressed (see below). In this sense, a Pharmacy Agent could now represent a whole pharmacy market (this was before the deregulation of the pharmacy market when there was a market monopoly with only one Pharmacy Agent, the NPC), in which pharmacies have license to dispense prescriptions. With the deregulation of the pharmacy market, the Pharmacy Agent naturally became the new service provider, now the Swedish eHealth Agency.

In some cases, a prescription must (according to prescription rules defined in the new format) be issued to one specifically destined local pharmacy in cases where the patient needs to be identified by other means than personal id.

A prescriber belongs to a main work place and is connected to a Health Care Provider, which is a kind of Health Care Agent.

A prescriber has a certain Qualification (PrescriberCategory in the figure), such as doctor, nurse, midwife, and dentist. A prescriber has also a unique Health Care Agent Id, which in Sweden is the identifier, which is issued, by the National Board of Health and Welfare when it has granted a license to practice. A prescriber is also a Health Care Person, which is the issuer of the prescription. The role of the issuer is not an explicit concept in the pre-standard.

Health Care Agents, which can be a Health Care Provider, Pharmacy agent or Pharmacy, are all identified by a Global Localization Number (GLN).

A prescription is a prescription of one medical $\operatorname{drug}^{77}$. A medical drug is defined as a marketed medical product with a specific substance(s), dosage form, and strength. A medical drug can be marketed with various packages.

A prescribed drug in ePrescriptions is currently made with reference to packages (i.e. articles and not medical products). A prescription row contains a reference to a package. Thus, a prescription can contain several rows referring to different packages and thus different article numbers, if it is necessary for prescribing a specific amount of the medical drug. In these cases, the packages must be of the same medical product, i.e. have the same product identity (NPL-id). This is regulated in prescription rules. Thus, if the prescriber needs to combine different packages of the prescribed drug to match the intended drug

\footnotetext{
${ }^{77}$ A prescription can also contain other items than medicinal drugs such as dietary foodstuff or equipment for administration of medicinal drugs.
} 
consumption for one fill or subsequent refills, this is defined as a multiple choice. A multiple choice consists of several prescription rows.

A prescription can be a renewal of an earlier prescription in the context of the prescriber and patient relation. However, a renewal is not a particular type of ePrescription, but always a new prescription and may be created on the request from a patient by phone or email. A patient fee is usually charged in the prescription to be paid by the patient when filling the prescription for the first time. This was possible to manage at the time of state monopoly but has been removed in the ePrescription after the deregulation of the pharmacy market.

A prescription is by default valid one year and have one fill and may have a number of refills defined. A prescriber can put a limit on the validity of a prescription or define the latest day for dispensing.

The patient can only have a prescription filled or refilled with a reimbursement for a three-month period ahead according the regulation in Sweden. Therefore, a dispensing (re)fill of four times on a prescription would indicate that it is a prescribed treatment for one year with four three-month (re)fills. A prescriber can also define formal dispensing intervals, which are not related to reimbursement rules, but regulate the dispensing of for example controlled drugs.

The prescriber has to actively assert that the prescribed drug is valid for reimbursement for the intended use/diagnosis. To allow a pharmacy to dispense a prescribed drug for reimbursement, it has to be approved for reimbursement by the Dental and Pharmaceutical Benefits Agency (TLV). The TLV also defines the rules for generic substitution to the rules for reimbursement and pricing. The pharmacist, with the support of their dispensing system (which include register on drugs which are approved for subvention, rules for application of generic substitution, pricing, et cetera), takes the ultimate decision.

Each prescriber has a workplace code denoting the work place from where the prescription is issued. The workplace code on the prescription is mandatory for reimbursement.

There are certain prescription rules that apply for controlled substances.

Directions for use for the patient are mandatory for prescribed drugs. If a prescriber prescribes for example foodstuff, it is not mandatory. 


\subsubsection{Documentation and design considerations}

In this section, we describe some aspects of the documentation and consideration made in the design of the new ePrescription format.

\section{Detailed specification with prescription rules}

The format specification for the NEF, which contained the formal syntactic rules for the various messages in the ePrescription communication, was refined and detailed compared to the previous specification. In addition to this, there was additional information included in the final definition of the new national ePrescription format:

- XML schemas, which closely followed the format specification (see section below);

- certain terms in the ePrescription was explained in more detail such as the:

$\circ$ use of unique identifies in different parts of the prescription;

o identification of prescribed medical drugs;

o dispensing intervals;

- destination of a prescription to a specific pharmacy;

- limited validity of a prescription;

o handling rules of a prescription with birth date and name as identifier of a patient;

- all prescription rules were documented and described how they could be implemented in a prescribing system;

- all prescription rule errors were documented with an explanation text and corresponding status and error code;

- document describing the set of valid character codes to be used and the use of ISO language $\operatorname{codes}^{78}$ in a prescription;

- a collection of "questions and answers" addressing many detailed questions about implementing the new NEF.

\section{Phasing out of EDIFACT}

An early design decision was to propose to phase out the MEDPRE prescription standard, which used the EDIFACT message syntax. The reason for this was:

- less complex design process with one standard ${ }^{79}$;

- lower cost in maintenance and support with only one standard;

${ }^{78}$ ISO Language codes can be used to inform the pharmacist which foreign language should be used to instruct the patient. There are a language guides in several languages how to interpret and explain instructions for use.

${ }^{79}$ The two standards were mapped by the NPC to a common in-house format for the internal dispensing system, which made it more complicated to handle changes in the format. 
- EDIFACT technology did not provide a simple and advanced mechanism for validating messages compared to using XML-schemas;

- XML-schemas could be used early in the process for validating a prescription created in XML;

- XML is a more flexible and general-purpose language compared to EDIFACT, and could provide easier and thus cheaper integration with smaller actors that have not invested in EDIFACT technology.

\section{Strict XML-schema for validation}

For the XML message, there existed a Document Type Definition (DTD) and an XMLschema ${ }^{80}$. These were not restrictive. They accepted all the XML tags that were described in the SIS XML implementation guide without any structural restrictions, of which the actual agreement between the parties was a subset. It became obvious that the potential of using XML was not realized. In line with the general requirements on the new ePrescription format to be more precise and with the effort to control both the structure and content of the ePrescription message, the design approach was to create a strict XMLschema that reflected, as much as it was technically possible ${ }^{81}$, the written format specification. Some examples were:

- all mandatory elements should also contain meaningful data and optional elements should not be used if they contained no information;

- data must apply to the data types specified;

- the string data type was restricted to contain only printable signs and a subset of the UTF-8 coding scheme was defined in a separate document and was implemented using regular expressions in the XML-schema. The reasons for this were that there were many problems with for example 'Carriage Return' and other non-printable character codes in the instructions for use ${ }^{82}$ at the pharmacies;

${ }^{80}$ XML (eXtensible Markup Language) was recommended by W3C in 1998 and the first XML-schema version (1.0) was recommended in 2001. This means that it was not surprising from a technical point of view that the full potentiality of the XML-schema was not used.

${ }^{81}$ In XML schema version 1.0, it was not possible to express so-called co-occurrence constrains which means that the value or presence of an attribute is dependent on the values or presence of other attributes. These types of constraints had to be implemented in program code. With the new XML Schema version 1.1 recommended by W3C in 2012 this is made possible. With this version, it is possible to use the XMLschema to define valid applications of a message, in a sense define pragmatics rules of a message.

${ }^{82}$ There must be labels glued on the package with the name of the patient and instructions for use. Thus, there is not only a limit on the number of characters to be used but it is also necessary that the target media for the instructions of use has control of the editing of the instructions. Any editing in an EHR-system could obscure the possibility to present instructions correctly on a glued label on the package. The requirement to be able to transfer an electronic prescription to a paper prescription must lead to the same type of consideration when designing rules for ePrescriptions. This is an example how rules and content of a transferred message must consider the use of other applications and media in the whole process. 
- all enumerated code must apply to a specified set. For example, only those categories of prescribers that were specified in the format specification were accepted.

\section{Structure of XML-schemas}

XML schemas were developed for each written message format specification. The XMLschemas contained as closely as possible the syntactical rules for that message.

There were three messages implemented:

- MessageRoutingAddress

- This message is an 'envelope' for all other messages, containing general information about the transition such as sender, receiver, systems used, et cetera. This 'envelope' could be read by a relaying agent in order to process the distribution of the message without reading the content of the prescription.

- NewPrescriptionMessage

- This message contains the ePrescription.

- ApplicationAcknowledgeMessage

○ This message contains the application error acknowledge receipt (commonly named APERAK).

All data types were defined in a separate XML schema file.

\section{Preparation for use of other types of product identifiers}

In the pre-NEF format, a prescribed medical product was identified by a Nordic article number which designates a package ${ }^{83}$.

A product id was accompanied with an IdType $=$ NVN (Nordiskt VaruNummer - Nordic article number)

A medical product can be defined on various levels:

- as a generic product, which is of no particular brand with an active substance, specific strength of this substance and of a particular form, thus:

○ with a substance register, defined strength groups and form it is possible to create an id for such a generic medical product;

- as a marketed approved product of substance, strength and form with a brand name. For this product level, if it is approved, an NPLId is assigned by the Medical Products Agency in Sweden;

${ }^{83}$ To be more precise: it could be the case that a Nordic Article Number could refer to the same type of package but manufactured and imported from a different country. This is not the case with GTIN which refers to a manufactured package and thus has a higher precision. 
- as a marketed approved product package of a substance, strength and form with a brand name and amount, for example 100 pcs of tablets, $500 \mathrm{ml}$. For this product level, if it is approved, an NPLPackId is assigned by the Medical Products Agency in Sweden.

In Sweden, it is not allowed to prescribe a generic medical product and it is not possible at the moment to prescribe on the marketed product level, only on package level. This means that the prescribed medical drug also implies a certain amount.

There were demands in 2005 to prepare for a future use of NPLId and NPLPackId for ePrescribing. Thus, the decision was to make an exception from ENV 13607, which demanded that the product id only could be of one type. As a consequence, it was made possible, in the future, to use either NVN for Nordic article number or NPLId and NPLPackId at the same time to define a prescribed medical product.

See Figure 19 for an illustration of the fact that the ManufacturedProductId in the NEF has minimum occurrence of 1 and max occurrence of 2 in order to handle this feature in the future. This is an example of a good foresight, because today (2016) all the prescribing systems must use this feature. [199]

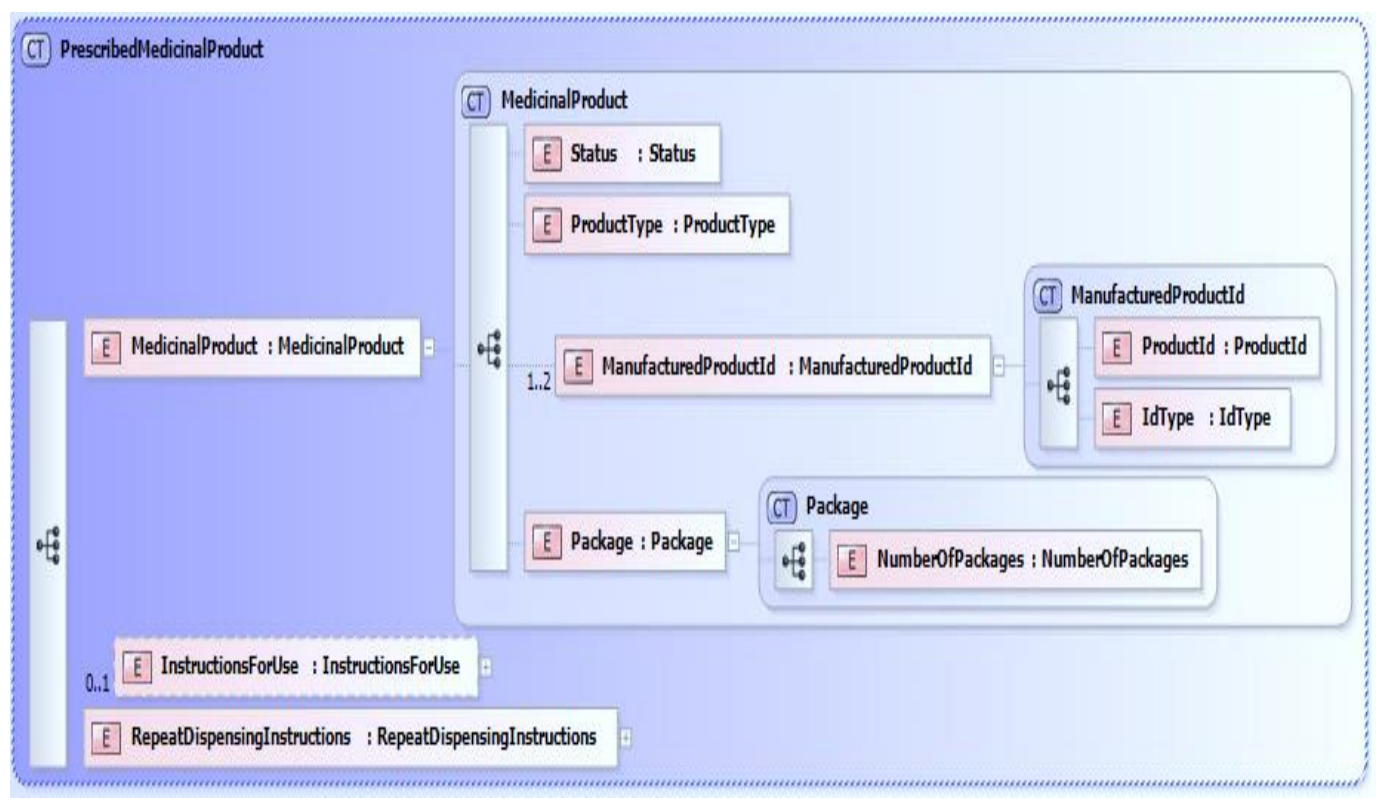

Figure 19 Graphical view of the structure for Medical Product in the NEF, generated from the XMLschema for the NEF. CT means Complex Type and E means Element. 


\section{Unique identifier of the interchange and the prescription set}

To be able to detect duplicate prescriptions, it was decided to use unique identifiers (UUID) on the interchange envelope and the prescription set. Duplicate prescriptions could occur for example when repeated sending occurred due to a communication failure and thereby creating duplicate prescriptions. This could be a danger if the patient requested medical drugs from several duplicate prescriptions of the same drug at different pharmacies. Rules were defined how to handle the situation if there were different UUID at the interchange and prescription level.

\section{Information about sending systems in the 'envelope' for message routing}

To be able to control that only certified systems was creating and sending ePrescriptions, information about the systems creating the prescription was decided to be in the 'envelope' of the message. In addition, this made it possible to have an alert and to be able to intervene in situations with serious errors that were due to certain systems deficiency and for follow up purposes for improving quality. The 'envelope' is named MessageRoutingAddress, se Figure 20. 


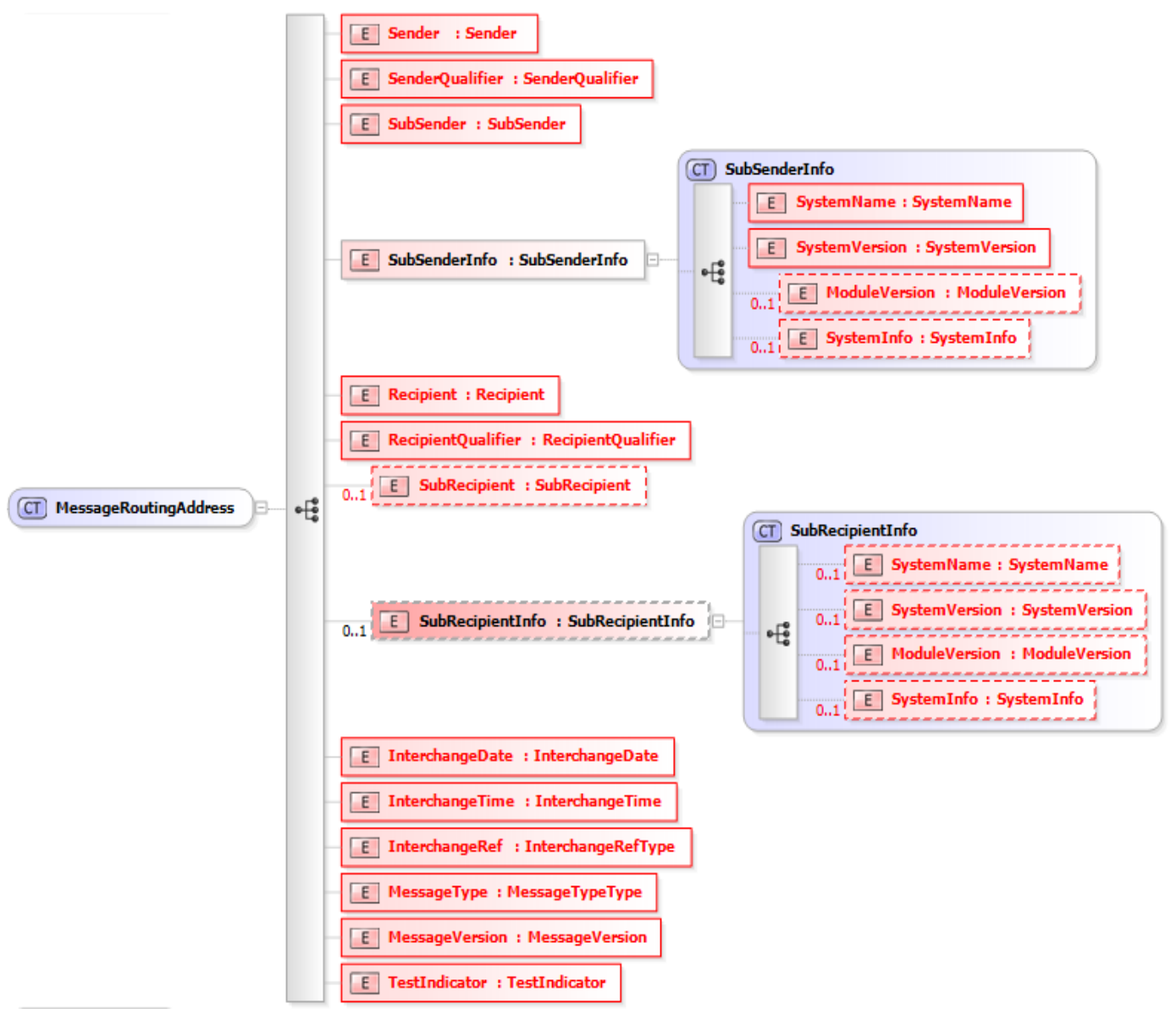

Figure 20 Graphical view of MessageRoutingAddress generated from the NEF XML-schema.

The tag SubSenderInfo (see Figure 20) contained information about sending system, its version and possibly information about modules. The MessageRoutingAddress was used both as envelope for a new ePrescription message and the Application Error Acknowledge Message. If the Application Acknowledge Receipt Message is a response to an ePrescription message, the SubSenderInfo system in the prescription envelope is sent back as SubRecipientInfo. This SubRecipient can be used by the recipient to further route the message to a particular system or server.

Sender and recipient are usually representing an organization or part of an organization using a Global Localization Number (GLN). These GLNs are used to route the message correctly if using a Value-Added Network (VAN) service.

\section{Extension of the application acknowledge receipt message}

The decision to use a strict XML-schema and implementing prescription rules for online validation of incoming prescriptions prompted for a need to communicate various types 
of error to the sender and ultimately to the prescriber. Some errors could be due to systems deficiencies and some errors could be due to user errors. Thus, there was also a need to code the errors in such a way that it could be sorted out by the sending organization: some errors could be handled by maintenance and support teams, other errors could be communicated to the prescriber directly, and some could be handled by the responsible for prescription medical care. The idea was to provide this possibility. It was also important that the prescriber could get a positive Application Error Acknowledge Message (APERAK) that the prescription could be handled by the pharmacies. Before the NEF, it was optional to have an APERAK, which essentially, when used, signaled that the prescription was technically accepted by the NPC. Some county councils relied instead on the technical acknowledges in the X.400 protocol.

With the NEF, an Application Error Acknowledge Message (se Figure 21) was always sent back.

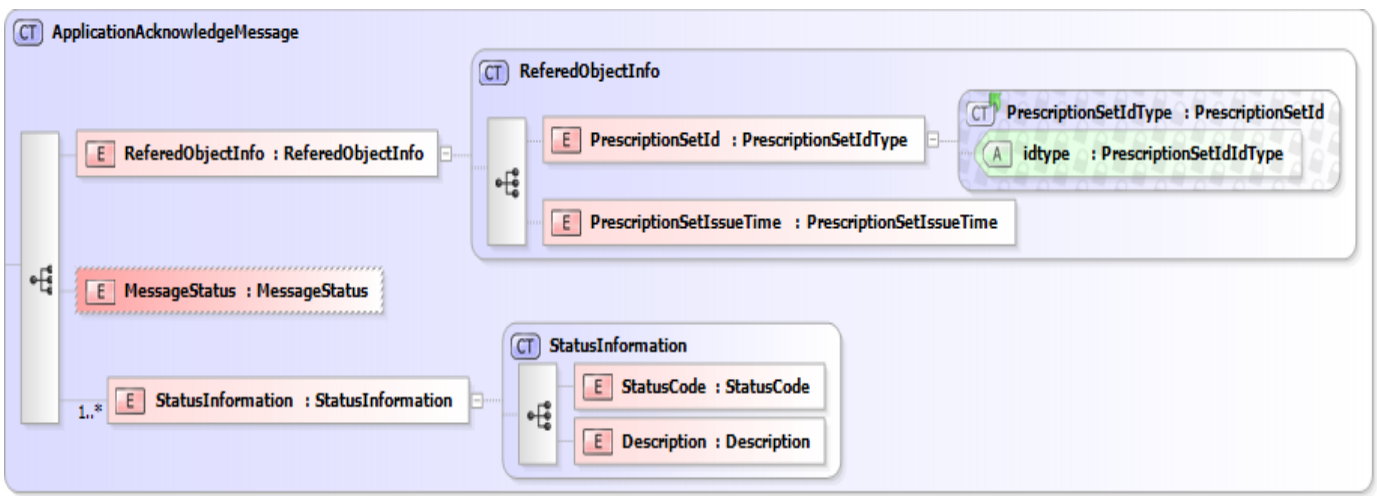

Figure 21 A graphical view of the ApplicationAcknowledgeMessage (APERAK) based on the XML schema for NEF.

The information about the referred object was changed to include a reference to the ePrescription using the unique id that was provided in the prescription message. Also, the time of issue of the prescription was added; usually the time the prescription was approved and created in the prescriber system.

An overall MessageStatus was provided indicating three different statuses:

- accepted;

- accepted with warning;

- rejected.

Accepted meant that the ePrescription was accepted to be handled by the pharmacies without any specific amendments needed and that is was in accordance with the format and prescriptions rules.

Accepted with warning meant that the ePrescription was accepted to be handled by the pharmacies but that there was a need for special handling or restrictions to dispense the 
prescription. This could give an indication to the prescriber to take some action or to make some improvements in the ePrescribing process.

Rejected meant that the ePrescription violated one or several format or prescription rule that made it unfeasible for the pharmacies to dispense the prescription.

The tag StatusInformation contained further information about possible errors. The StatusInformation contained a status code and a description of the errors. There could be several errors found on a prescription. If one of these errors meant a rejection, the overall status code, the MessageStatus was a rejection.

All these status codes and descriptions (as they were intended to be communicated to the prescriber in some cases) were discussed and agreed upon by the parties.

\section{Design changes due to legal demands}

There were some design changes made in order to align to existing legal demands.

There were some legal demands on a prescription form from the Medical Products Agency that were not fulfilled in ePrescriptions before the NEF. The two examples described here concerns the ability of the prescriber to set a date for latest dispensing of a medical drug and to set an earlier validity end date for the prescription ${ }^{84}$. The medical reasons for these demands were to be able to set a limited period of validity for a prescription in order to avoid that prescriptions were dispensed at a later stage when it was inappropriate. One example is prescription of antibiotics that should be consumed close to the prescription issue date and not a half year later. Thus, there were two design changes made in NEF: LatestRequestedTimeForDispensing and PrescriptionItemAuthTime were added as optional for a prescribed package (PrescriptionItemDetails).

${ }^{84}$ The default for a prescription is one-year validity. 


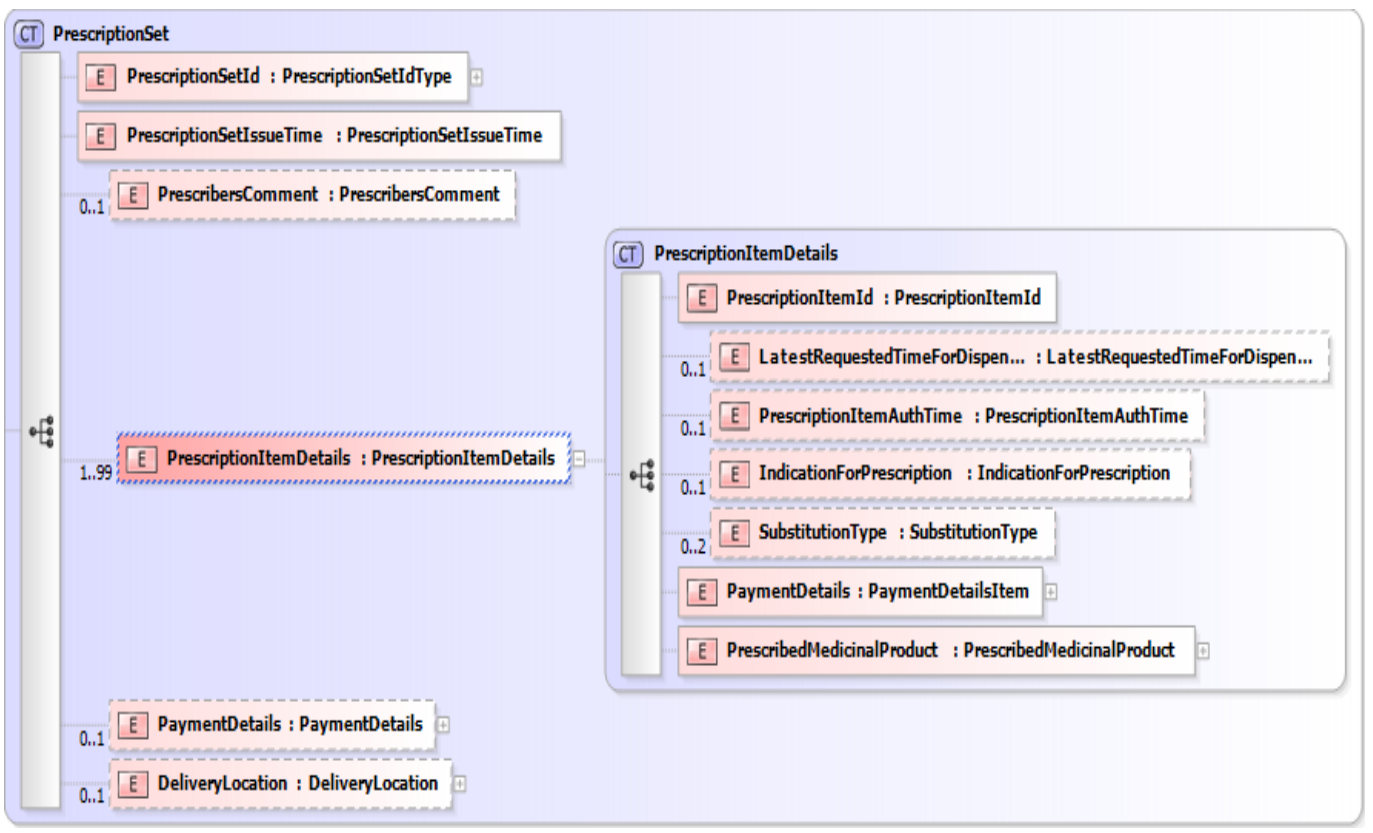

Figure 22 Addition of two new fields LatestRequestedTimeForDispensing and

PrescriptionItemAuthTime for the Prescription Item level in NEF. Graphical view generated from the XML-schema.

Before the NEF, it was only possible on the PrescriptionSet level, which could include several prescriptions of different medical drugs. An earlier ad hoc way to limit the validity time of a prescription was to use the prescriber's comment field.

The LatestRequestedTimeForDispensing was not included in the Swedish subset of SIS $X M L$ guide but was included in ENV 13607 but only on the prescription set level. Thus, the NEF borrowed the fieldname from ENV 13607 but placed it on the Prescription Item level.

PrescriptionItemAuthTime was a new field that did not exist in ENV13607 or in SIS XML guide. In ENV 13607, a corresponding field was 'prescription set authorization date and time', which was translated to PrescriptionSetAuthTime in SIS XML guide but was not included in the Swedish subset. Thus, the design decision was to use a similar naming for the new field on the Prescription Item level.

These two examples illustrate the need to adapt to national legal issues in the implementation of an international standard. It also illustrates that it is sometimes necessary to use a subset of a standard but also to add new features not anticipated in the international standard or in the national subset. 


\section{Design considerations in implementing prescription rules}

Most of the prescription rules concerned pragmatic ${ }^{85}$ rules for using the ePrescription format in different cases or in different combinations of attribute values. At the time of the $\mathrm{NEF}$, it was not possible to use an XML schema for this and it had to be implemented in program code. Other types of prescription rules concerned the use of valid identifiers, such as prescriber codes, drug identifier, work place code, and valid patient identifiers. There was a two-step process in the control of these identifiers; first a check digit control; secondly a check against various registers if the identifier referred to a valid and existing identity. There were two concerns posed in this design situation:

- Would the number of errors seriously interrupt the ePrescription flow if the erroneous prescriptions were rejected? Would it be wise as a first step just to register errors and then gradually reject erroneous prescriptions?

- Would the controls seriously affect the response time from receiving a prescription to generating an acknowledge receipt? The response time had become an issue because it became more common to use a synchronous communication method in which a long response time would keep the communication connected for a longer time and at the same time the sender was expecting a short response time when using this mode of communication.

The first question was resolved together with the county councils and it was agreed to implement the entire format and prescription rule with a rejection, if the prescription has such errors that they could not be dispensed. Thus, the cooperation in defining the rules and their consequences contributed to this solution. This fact was probably a good incentive to avoid that erroneous prescription was sent from the prescribing systems.

The second question, if the performance would seriously degrade with implementing the on-line controls, was solved by making load testing. The result was that, given the assumed technology to be implemented, the performance would not be seriously affected by implementing the on-line controls.

85 'Pragmatic' is used here in the sense of different usage situations in ePrescribing. 


\subsection{Objective, research questions, and methods in the field experimental study}

In this section, we summarize the objective with the field experimental study, initial research questions and methods considered and used.

\subsubsection{Objective}

The objective of the presented field experimental study was to analyze the manner in which the all the combined efforts in improving interoperability with the introduction of the NEF (NEF intervention) affected interoperability in the ePrescribing process. One way to measure this influence is to measure the possible improvement of the quality of the ePrescription message.

\subsubsection{Research questions}

One initial research question was how the outcome of the efforts made in the NEF intervention in all county councils in Sweden could be evaluated.

A related question was which methods could be used to measure the expected improvements in interoperability.

Furthermore, how were the activities and actions in the intervention (implementation of the NEF) related to a change in interoperability? The following questions were raised:

- What characterized the activities and actions in the design and implementation of NEF?

- How was the implementation of NEF situated within the overall context of implementing ePrescribing in Sweden?

- How could the results be analyzed using theories on interoperability and information systems actability theory?

- What knowledge contributions could the findings in the field experimental study give to a general knowledge in improving interoperability?

\subsubsection{Methods}

The answer to the initial research question, how to evaluate the effort of design and implementation of the NEF, was to develop a quantitative measure of interoperability problems prior to and after the intervention: pre-NEF and post-NEF.

A method considered as a complement to a quantitative measure of interoperability problems, was to assess the utility of the improvement at the pharmacies, using Process 
FMEA $^{86}$ (Failure Mode and Effect Analysis) and getting the estimates from selected group of pharmacists on effects and their estimates of possible cost reduction due to process improvements. This idea was not pursued on the grounds that it probably only would give some good guesses by the participants, and not any reliable measure of effects and improvements. Furthermore, it would be more suitable to use this method in the beginning of an improvement effort rather than to be used to assess the effects afterwards. Here, other measures could have been used, such the number of Help desk cases. However, this was considered unreliable, because many errors were probably not reported if they were dealt with and solved locally at the pharmacies.

The chosen approach was to measure the quality of the ePrescriptions message, operationalized as a quantitative measure (see below on the definition of interoperability errors), which was used to collect two measurements; before (pre-NEF) and after (postNEF) the completion of the NEF intervention in 2009.

In the pre-NEF measurement period, the pre-NEF prescriptions were validated using the format specification and prescriptions rules valid for the pre-NEF prescriptions.

In the post-NEF measurement period, the post-NEF prescriptions were validated using the format specification and prescription rules valid for the post-NEF prescriptions (the NEF-format). The prescription rules that was used in the validation was the same for the two the measurement periods.

Thus, in the two measurement periods, we compared changes in adherence to the agreed format specification and prescription rules based on legislation and agreed praxis. Consequently, the focus was on the communication quality between the health care and pharmacy using ePrescription as an instrument for communication for the medical treatment of a patient. The assessment of the communication quality was limited to the formal and documented requirements on the ePrescription message.

The hypothesis was that adherence would be improved with the introduction of NEF, resulting in fewer interoperability errors in the post-NEF period. Se Figure 23.

\footnotetext{
${ }^{86}$ FMEA is a method commonly used in the industry to assess failures in function of a product or process with respect to detection of failures, their probability for occurrence and their severity, i.e. consequences for people, process and organization.
} 


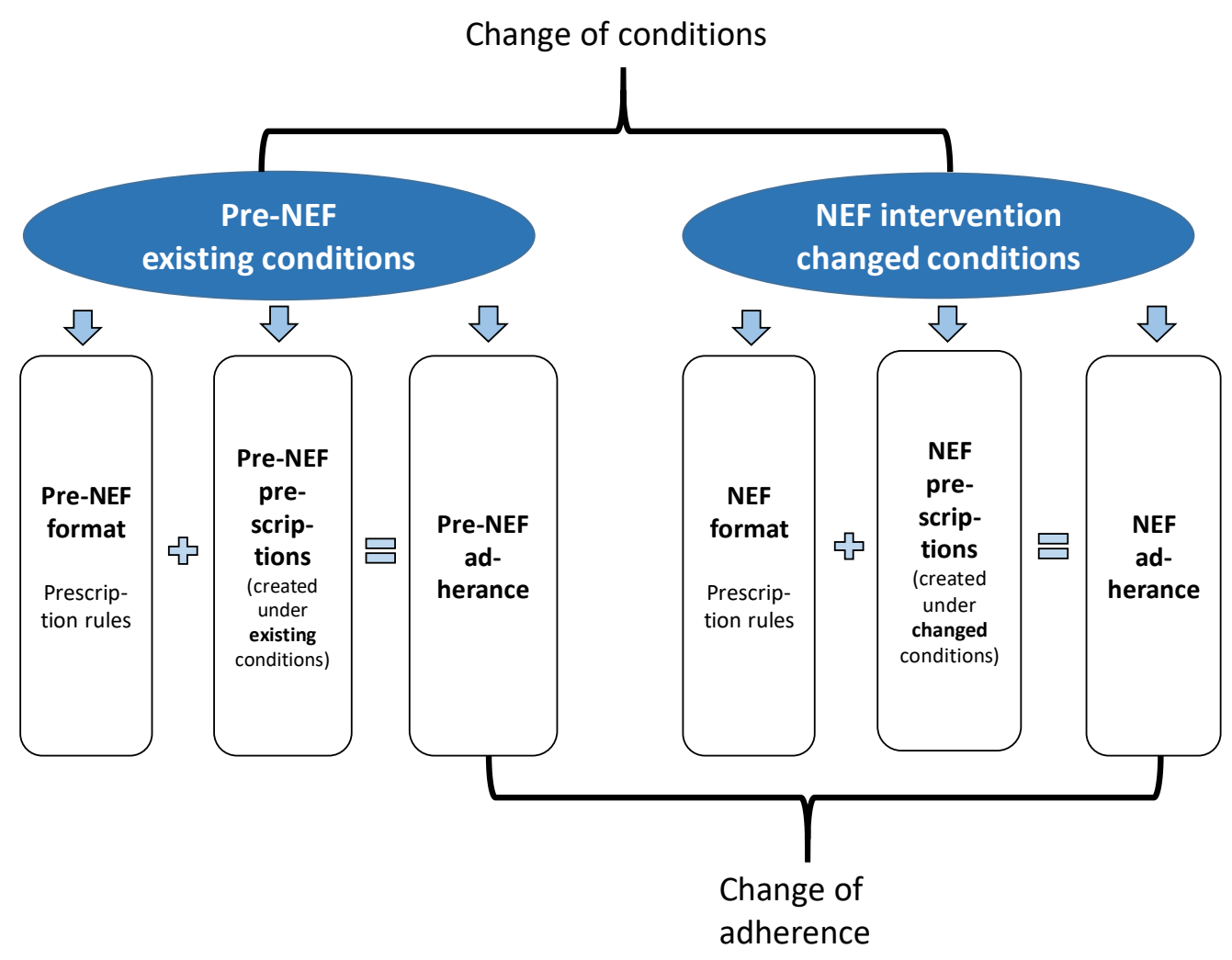

Figure 23 Illustration of the relation between the change of conditions (before and after the NEF intervention) for creating ePrescriptions and the hypothesized change of adherence of ePrescriptions in relation to format and prescription rules.

To answer the research question about the relationship between actions and activities contained in the NEF intervention in relation to the expected improvements, the findings were analyzed and discussed in relation the characterization made of these actions and activities. The findings were also related to theories of interoperability, information systems actability theory, and the development of ePrescribing in Sweden. Finally, the knowledge contributions to a theory on interoperation and interoperability were also discussed. See section 5.9 Analyzing and situating the findings. 


\subsection{Design of measurement and data collection}

In this section, we will describe data collection methods chosen for the measurement, definition of interoperability errors, methods for validating ePrescription messages and sampling methods considered and chosen.

\subsubsection{Collection of data and development of a procedure for validating ePrescriptions}

A test procedure was set up accessing all incoming ePrescriptions to the NPC in the former XML-format (Pre-NEF). The collected electronic prescriptions in the Pre-NEF format were validated with a constructed Pre-NEF XML-schema that agreed with the Pre-NEF format specification. When there were ambiguities in the format specification, the designed Pre-NEF XML-schema accepted all the possible interpretations. When parts of the Pre-NEF format specification were the same as the new national format specification (NEF), the new NEF XML-schema construct was used for that part of information.

The prescription rules were derived from either legislation or agreed praxis between the parties of the exchange. Pharmacists and judicial experts at NPC validated the prescription rules. The same prescription rules were applied to both Pre-NEF and NEF prescriptions.

The prescribed drugs in the ePrescriptions were controlled using a drug database to check availability of the drugs on the Swedish market at the time of prescription. For this purpose, a historical drug database was built for the selected test period of approved and marketed drugs in Sweden.

No information about patients or prescribers, or any information that could be traced back to an individual were collected from the prescriptions.

\subsubsection{Definition of interoperability errors}

The estimated frequency of errors in the ePrescription messages was assumed to be $1 \%$ of all ePrescriptions.

In this study, errors do not include a medical error in a prescription. An error in an electronic prescription is defined as a discrepancy in relation to the specification of the electronic prescription message and the prescription rules. The prescription rules were derived either from the legislation made by the Swedish Medical Products Agency and the National Board on Health and Welfare or praxis and interpretations of the legislation jointly agreed with the regional health care providers and NPC. 
No controls were made regarding the medical content or adequacy of the prescription. Other studies have addressed prescription errors from a pharmaceutical or medical point of view [200-202].

Two major classes of errors were defined, format error and prescription rule errors. Format errors consist of data type errors, enumeration code errors, and structural errors (sequence, mandatory information, cardinality). In the study design, no distinction was made between different categories of format errors.

Prescription rule errors can be divided in five categories of incomplete or erroneous information about the (i) patient, (ii) prescriber, (iii) prescribed drug, iv) administrative and technical information, and $\mathrm{v}$ ) other prescriptions rules such as reimbursement.

\subsubsection{Estimation of sample size}

With an even distribution of errors in all six subcategories, and assuming $1 \%$ errors after discussion with software engineers developing the services for electronic prescriptions at NPC, errors were expected to be approximately $0.17 \%$ in each subcategory, not taking into account ePrescriptions with multiple errors.

It was decided that it was desirable to be able to detect a significant difference in error frequency in the subcategories of more than $10 \%$ between two independent samples. The level of significance was determined to be $p<0.05$. The power of the study was planned to be $95 \%$. This implies a sample size of at least $1,450,000$ ePrescriptions. The calculation was made by using a sample size calculator developed by Rollin F. Brant [24].

\subsubsection{Sampling method}

Consecutive sampling was used for all ePrescriptions during a period until the sample size was expected to be reached.

Consecutive sampling was used to avoid a discrepancy in actuality of the various information resources. A historical record of the drug database was build up and maintained for a period of one month during the chosen sampling periods. Consecutive sampling meant that we could shorten the sampling period to one month to reach a sufficient sample size.

Only XML-prescriptions were included in the study. MEDPRE prescriptions were excluded because the format validation was made using an XML-schema and because it would be difficult to compare the result with the new NEF-format. MEDPRE prescriptions constituted approximately $1 / 5$ (23\% in June 2007) of the total number of ePrescriptions in the study period.

The intention with the choice of the study period was to include a change of month when most of the changes of availability and prices of drugs take place. 
In the two study periods, all of the prescribing systems that were being used would be represented with a fair amount of ePrescriptions.

\subsection{Analysis of interoperability problems in the ePrescription communication}

The analysis of the ePrescription messages was made applying specifically developed software (see below), which analyzed all collected ePrescriptions sent to the NPC in Sweden during the two study periods.

$\mathrm{A} \mathrm{C} \#^{87}$ program was developed to make all the validations of prescriptions using XMLschemas and prescriptions rules. All detected errors were stored in a database for statistical calculations. All validation rules were classified with an overall message status (accepted, accepted with errors and rejected). XML-schema validation errors were classified with the overall message status rejected and the prescription rule errors were classified according to the classification made in the NEF-specification for similar prescription rules.

A status code was assigned to each validation rule. For XML-schema validation errors the same status code was applied. To distinguish between different format errors, string matches were made of the XML-validation error messages.

To validate the correctness of the $\mathrm{C \#}$ program test cases was run to test that format and prescription errors were recorded correctly. Each error collected had a reference to a prescription id. A sample of errors was followed up to check that for each category of errors, recorded errors could be traced back to and found in the prescription message.

All descriptive statistics were generated using SQL-queries due to large amount of data.

No information about patients or prescribers, or any information that could be traced back to an individual was collected from the prescriptions. No controls were made of the medical content or adequacy of the prescription.

\subsection{Format and prescription rule errors}

As described above, two major classes that were defined: format errors and prescription rule errors.

The format errors were more precisely defined as a deviation from the XML-schema reflecting the message specification. Different types of format errors captured in the study are summarized in Table 7.

${ }^{87} \mathrm{C} \#$ (C-sharp) is an object-oriented program language developed by Microsoft. 
Table 7 Summary of format errors captured in ePrescriptions.

\section{Format errors Description}

Incorrect code enumeration

Incorrect qualification code according to format specification

Element not defined in the specification

Incorrect sign or format

Override of maximum length

Incomplete structure

Invalid data type or missing values
XML-tags not defined in the specification

Violating pattern constraints, such as using forbidden characters or wrong date-format

Excessive number of characters in a given field

Missing mandatory fields in a structure

Incorrect data type or missing values in field (minimum length, minimum value, missing value)

Prescription rule errors were defined as deviation from legislative rules for a correct and complete prescription and rules for agreed praxis for handling reimbursement, rules for communicating to the pharmacy in special cases of identification of the patient, correct references to drug identity, and valid packages for prescribed drug. Prescription rule errors refer to a deviation from the semantically defined content ${ }^{88}$ of the prescription. The prescription rules together with format rules define what a legal prescription is.

It has not been possible to implement all the prescription rules that are regulated in legislation and praxis. For example, in order to verify that the prescriber has valid prescriptions rights, we must have access to the prescriber register and to possible restriction in prescription rights - which has not been possible in this study.

${ }^{88}$ Even if it is not possible to find a sharp and exact difference between syntax and semantics, as well as between form/structure and content, they are nonetheless useful to distinguish when defining different types of interoperability errors. See cognitive linguistics that state "Grammar is conceptualization", which means that choice of grammatical form is used to conceptualize experience and thus not independent of semantics which is assumed in formal semantic theories. [203, 204] It is also possible to view the prescription rules as rules for the usage and handling of a prescription and in this sense can be considered as pragmatic rules. It is however, the position of the author that pragmatics is about semantics, i.e. that meaning is in the use, and that the separation of semantics and pragmatics which traditionally has been done in formal semantics and linguistics is false, following Dewey. [205] However, it could be useful to use pragmatics as a term to highlight the importance of rules for use and action in defining meaning. 
In all, 24 prescription rules were implemented and used in the validation. Prescription rule errors captured in the study are summarized in Table 8. Certain prescription rules are aggregated into one rule or collection of rules to improve readability.

Table 8 Summary of prescription rule errors captured in ePrescriptions.

\section{Prescription rule errors Description}

Incomplete prescriber Missing name, address or telephone number
information

Invalid prescriber code Incorrect format on the prescriber code

Missing workplace code Without workplace code. The prescription can only be dispensed if the customer pays the full price for the medical drug.

Invalid reimbursement The prescriber (or the system by default) has affirmed status for prescribed drug that the prescribed drug is valid for reimbursement, when the drug in question is not a reimbursement drug.

Incomplete or erroneous patient information For example, that the personal identification number is incorrect, or the name is missing.

Invalid drug identity

The drug identity in the prescription is not found in the database of approved and marketed drugs in Sweden at the point of issue of the prescription.

Prescription not valid for controlled substances The prescription does not follow the specific prescription rules for these types of drugs.

Invalid combination of packages

The packages combined in the prescription for a multiple choice of a prescribed medical drug is not of the same medical product according to the drug database.

Missing directions for patient use Text is missing when a medical drug is present in the prescription. 


\subsection{Findings in the field experimental study}

In this section, we present some of the results from the field experimental study. For a more detailed description of the result see $[8,9]$.

\subsubsection{Sampled prescriptions}

Consecutive sampling was used to collect all incoming XML ePrescriptions during two periods: April 3, 2008 - May 3, 2008 (Pre-NEF) and April 3, 2009 - May 3, 2009 (Post$\mathrm{NEF}$ ). For details on the sampling confer $[8,9]$.

The pre-NEF sample comprised 1,270,399 prescription sets. The number of prescriptions (prescribed drugs) was $1,910,982$. The mean number of prescribed drugs in each prescription set was 1.50 .

The post-NEF sample comprised of 1,479,588 prescription sets. The number of prescriptions (prescribed drugs) was $2,204,444$. The mean number of prescribed drugs in each prescription set was 1.49 .

Table 9 Sampled prescriptions - pre-NEF and post-NEF. EDIFACT prescriptions were excluded.

\begin{tabular}{lrr}
\hline Prescriptions & pre-NEF & post-NEF \\
\hline Prescription sets & $1,270,339$ & $1,479,588$ \\
Prescriptions & $1,910,982$ & $2,204,444$ \\
$\begin{array}{l}\text { Mean prescribed number of } \\
\text { prescriptions per prescription set }\end{array}$ & 1.5 & 1.5 \\
\hline
\end{tabular}

\subsubsection{Errors per prescription and prescription set}

The total number of errors found in pre-NEF prescriptions was 5,970,737. The number of pre-NEF prescription sets that had at least one error was $1,253,134$. The percentage of preNEF prescription sets with at least one error was $98.6 \%$.

The mean of pre-NEF prescription errors was 3.1.

The mean of pre-NEF prescription set errors was 4.7.

The total number of errors found in post-NEF prescriptions was 13,735. The number of post-NEF prescription sets that had at least one error was 13,735 .

The percentage of post-NEF prescription sets with at least one error was $0.9 \%$. 
The mean number of errors for post-NEF prescription sets with errors was 1.0. No errors were found in $1,465,853$ post-NEF prescriptions sets. No post-NEF prescription sets that had more one error.

The mean of post-NEF prescription errors was 0.006 .

The mean of post-NEF prescription set errors was 0.009 .

Table 10 Summary of pre-NEF and post-NEF prescription and prescription set errors.

\begin{tabular}{lrr}
\hline & pre-NEF & post-NEF \\
\hline Total prescription sets & $1,270,399$ & $1,479,588$ \\
Prescription sets with error & $1,253,134$ & 13,735 \\
Prescription sets with no error & 17,205 & $1,465,853$ \\
Prescription sets with error \% & 98.6 & 0.9 \\
Mean error prescription & 4.7 & 0.006 \\
Mean error prescriptions sets & 3.1 & 0.009 \\
\hline
\end{tabular}

Table 11 Distribution of format and prescription rule errors and mean per prescription set.

\begin{tabular}{lrrrrrrr}
\hline & \multicolumn{3}{c}{ pre-NEF } & \multicolumn{3}{c}{ post-NEF } \\
Error type & $\begin{array}{c}\text { No. of } \\
\text { errors }\end{array}$ & $\begin{array}{c}\text { Mean error } \\
\text { prescription } \\
\text { set }\end{array}$ & $\begin{array}{r}\text { No. of } \\
\text { errors }\end{array}$ & $\begin{array}{c}\text { Mean error } \\
\text { prescription } \\
\text { set }\end{array}$ \\
\hline Format error & $5,824,675$ & 97.6 & 4.6 & 1,273 & 9.3 & 0.0009 \\
$\begin{array}{l}\text { Prescription } \\
\text { rule error }\end{array}$ & 146,062 & 2.4 & 0.1 & 12,462 & 90.7 & 0.0084 \\
Total & $5,970,737$ & 100.0 & 4.7 & 13,735 & 100.0 & 0.0093 \\
\hline
\end{tabular}

The most common error $(5,824,675)$ for the pre-NEF prescriptions were format errors. Prescription rule errors in the pre-NEF sample were also common in absolute terms with 146,062 prescriptions rule errors, but relatively few compared to format errors.

Format errors in the post-NEF prescriptions were much less frequent compared to preNEF prescriptions with only 1,273 errors. Format errors were relatively fewer in post-NEF compared to the pre-NEF sample. Prescription rule errors had decreased considerably to 12,462 errors in the post-NEF sample, although they had not decreased in the same 
proportion as format errors. Prescription rule errors have in the post-NEF sample become the most common error.

\subsubsection{Format errors}

The distribution of format errors in the two samples were compared (see Table 12).

Table 12 Number of format errors (XML-Schema validation errors) in pre-NEF and post- NEF prescriptions grouped by type of error.

\begin{tabular}{lrr}
\hline Format Error Type & pre-NEF & post-NEF \\
\hline Incorrect code enumeration & $1,704,100$ & 26 \\
Element not defined in the & $1,175,861$ & 20 \\
specification & & \\
Incorrect sign or format & $1,131,238$ & 522 \\
Override of maximum length & 904,278 & 61 \\
Incomplete structure & 311,871 & 524 \\
Invalid data type (not integer) & 240,432 & 9 \\
Override of minimum length & 204,447 & 108 \\
Override of minimum value & 149,962 & 0 \\
No amount in patient fee & 2,486 & 3 \\
\hline Total & $5,824,675$ & 1,273 \\
\hline
\end{tabular}




\subsubsection{Prescription rule errors}

The distribution of prescriptions rule errors is compared in Table 13.

Table 13 Number of prescription rule errors grouped by type and the pre-NEF and the post-NEF sample.

\begin{tabular}{lrrrr}
\hline & \multicolumn{2}{c}{ pre-NEF } & \multicolumn{2}{c}{ post-NEF } \\
Prescription rule error type & \multicolumn{1}{c}{ No. } & \multicolumn{1}{c}{$\%$} & No. & \multicolumn{1}{c}{$\%$} \\
\hline $\begin{array}{l}\text { Incorrect account number for the } \\
\text { patient fee }\end{array}$ & 125,471 & 85.9 & 138 & 1.1 \\
Incomplete prescriber information & 10,829 & 7.4 & 0 & 0.0 \\
Invalid prescriber code & 6,279 & 4.3 & 425 & 3.4 \\
Missing workplace code & 1,184 & 0.8 & 132 & 1.1 \\
Invalid reimbursement status for & 1,007 & 0.7 & 7,589 & 60.9 \\
prescribed drug & & & & \\
Incomplete or erroneous patient & 895 & 0.6 & 7 & 0.0 \\
information & & & & \\
Invalid drug identity & 366 & 0.3 & 3,735 & 30.0 \\
Prescription not valid for controlled & 16 & 0.0 & 5 & 0.0 \\
substances & & & & \\
Invalid multiple choice & 14 & 0.0 & 273 & 2.2 \\
Missing directions for patient use & 1 & 0.0 & 2 & 0.0 \\
Local pharmacy destination required & 0 & 0.0 & 156 & 1.3 \\
\hline Total & 146,062 & 100.0 & 12,462 & 100.0 \\
\hline
\end{tabular}

The largest improvement in the post-NEF sample was a decrease of Incorrect account number for patient fee, from 125471 to 138 . The second largest prescriptions rule error in the pre-NEF sample decreased from 10,829 to zero in the post-NEF sample. Errors that increased in the post-NEF sample were Invalid reimbursement status for prescribed drug, Invalid drug identity, Invalid multiple choices, Missing direction for patients use and Local pharmacy destination required. However, overall the prescription rule errors decreased. 


\subsubsection{Distribution of errors per prescribing system}

With the introduction of the NEF, it was possible to trace each message to a prescribing system. This was a new feature and this do not have any comparison between the study periods. With this new feature, it was possible to measure each system's amount of ePrescriptions (Figure 24) and their contribution to interoperability errors (Figure 25).

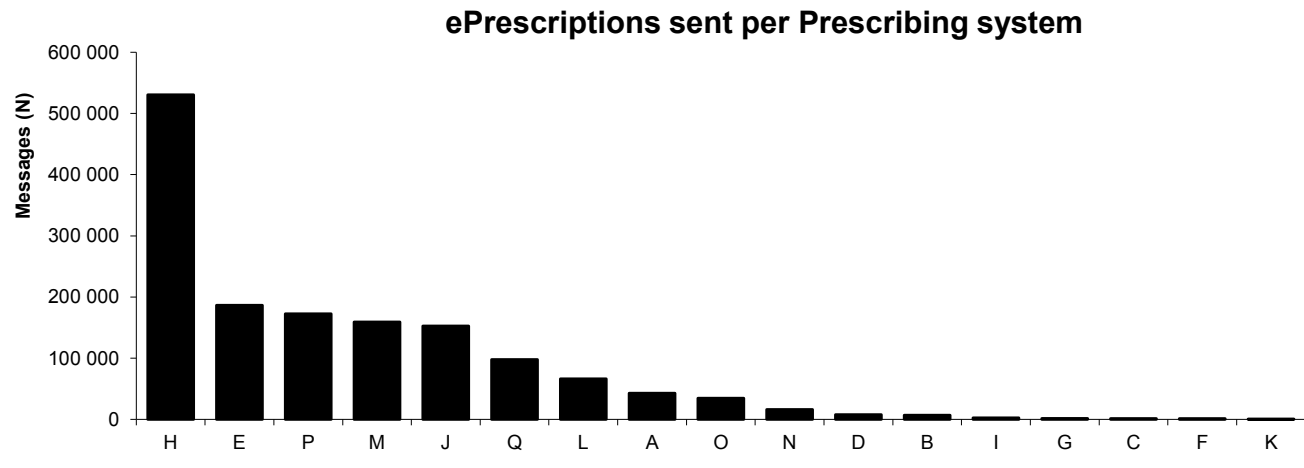

Prescribing system

Figure 24 Number of ePrescription messages (post-NEF) sent per prescribing system.

Mean prescription set errors per Prescribing system

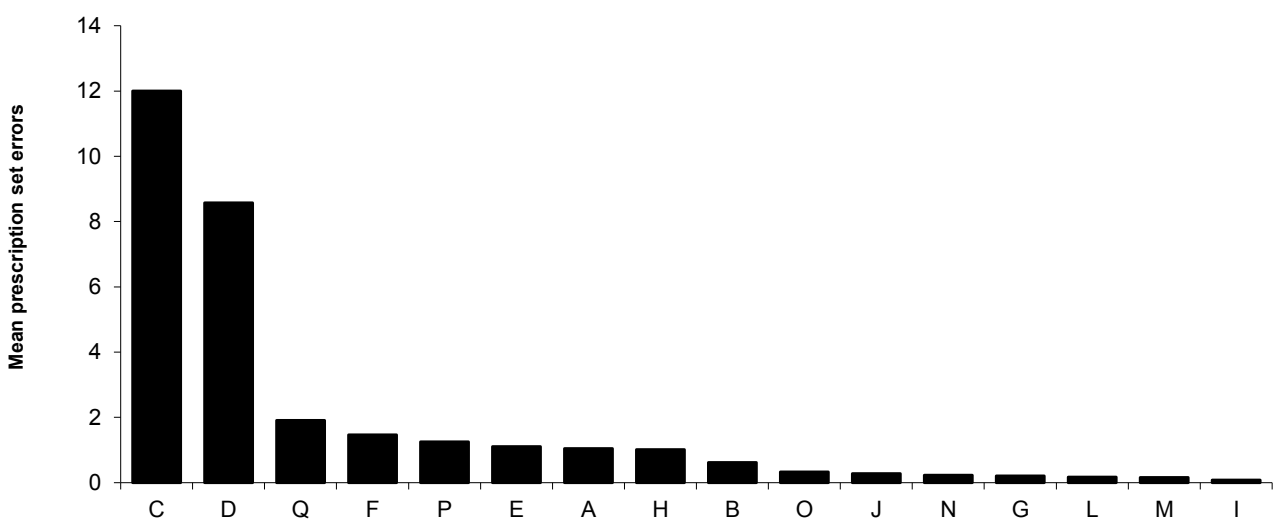

Prescribing system

Figure 25 Mean prescription set errors (post-NEF) per prescribing system. 
Fortunately, the prescription systems that had the highest mean of prescription errors had a low proportion of the total amount of ePrescriptions sent (Prescribing system C and D).

\subsubsection{Duplicate prescriptions}

With the introduction of NEF, a unique identification (UUID) was introduced for each prescription, allowing rejection of so-called technical duplicates. A technical duplicate can occur when for example prescriptions are resent in the case of communication failures or delays. In the post-NEF, this made it possible to measure the mean number of duplicated prescriptions from various prescribing system (Figure 26).

Technical duplicates of prescription sets per Prescribing System

(\%)

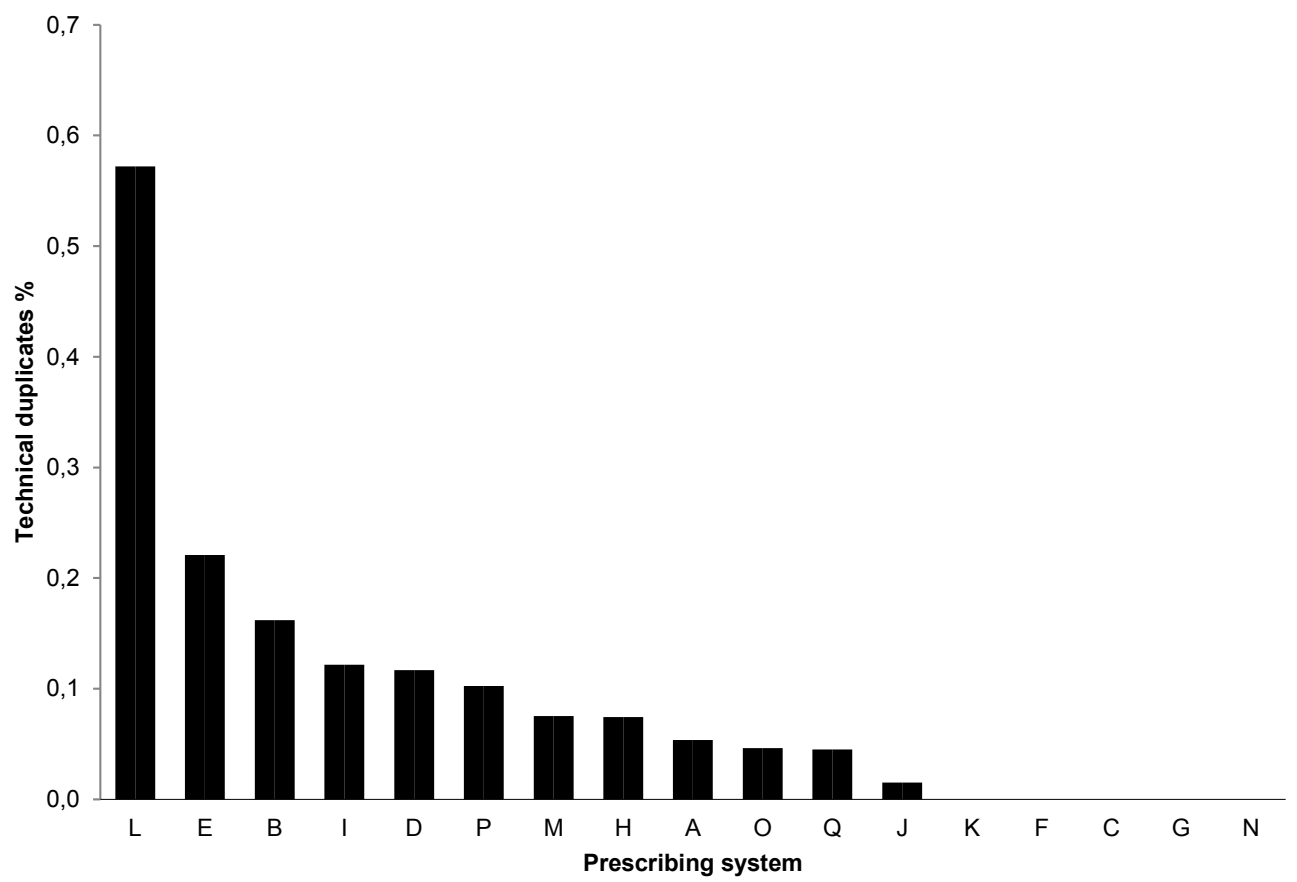

Figure 26 Technical duplicates of post-NEF prescription sets per prescribing system. 


\subsection{Analyzing and situating the findings}

From the findings presented of the measurement of adherence to format specification and prescriptions rule of ePrescribing, within this field experimental study of the NEF intervention, it is clear that all the actions and activities of this intervention contributed to substantially improve the interoperability in ePrescribing through improving the quality of the ePrescription message. The improvement in interoperability was expressed in an overall improved adherence to format specification and prescriptions rules ${ }^{89}$.

We think it is valuable to analyze the findings and the characteristics of the NEF intervention in order to highlight various aspects of such a complex intervention.

In the section, 5.9.1 ePrescribing and information systems actability theory, we analyze the finding within a context of information systems actability theory (see also 7.9.1). The stakeholder's involvement in the shared information services and their influence on the interoperability in ePrescribing is described in section 5.9.2 Stakeholders involvement and shared information services. The findings are further discussed in relation to the European Interoperability Framework (EIF) in section 5.9.3 Interoperability levels to analyze interoperability errors. [4]

We will then discuss the relation between the characteristics of the intervention and the improved interoperability in section 5.9.4 The characteristics of the joint intervention to implement $N E F$, and situate the intervention in the context of implementing ePrescribing Sweden in section 5.9.5 Implementing the NEF - part of implementing ePrescribing information infrastructure (see also chapter 4.8.2 From initial growth to consolidation).

Information systems actability theory have been found to be a valuable perspective in highlighting information systems as an instrument for communication and action. The theory provides a framework for analyzing various aspects of communication quality that seems well suited for analyzing interoperation in ePrescribing.

The European Interoperability Framework has been chosen as an analysis framework because it is a synthesis of several other interoperability frameworks.

The NEF implementation is part of the overall evolution of ePrescribing in Sweden, and thus it is valuable to situate this intervention in a historical context, in order to evaluate this contribution to the overall evolution.

${ }^{89}$ While the prescription rule errors decreased substantially in the NEF prescriptions, there was an increase in certain errors such as Invalid reimbursement status for prescribed drug, Invalid drug identity, Invalid multiple choices, Missing direction for patients use and Local pharmacy destination required. This increase may be explained by a more frequent change of marketed drugs, less frequent import of drug register into EHR-system during the measurement period and due to some new functions introduced in the EHR-systems. Possible causes for this has not been followed up. For a discussion on these matters, confer the published paper Improving Interoperability in ePrescribing [8]. 


\subsection{1 ePrescribing and information systems actability theory}

Information systems actability theory [206] considers an information system as an instrument for technology-mediated work communication. In addition to the technical aspects, user interaction, communication between users using information systems as an instrument for communication, and the overall influence of information and actions involved in the process, influence the ePrescribing process. In the first section, we will apply actability criteria for design and evaluation of information systems to ePrescribing. In a second part, we will focus on the communicated message using speech act theory and actability criteria.

\section{Actability criteria for design an evaluation}

Goldkuhl has developed a number of actability criteria for design and evaluation based on the information systems actability theory. [206] The actability criteria are related to three layers of quality: interaction, communication and process quality (Figure 27). The ability to interoperate in ePrescribing is closely related to interaction, communication, and process quality.

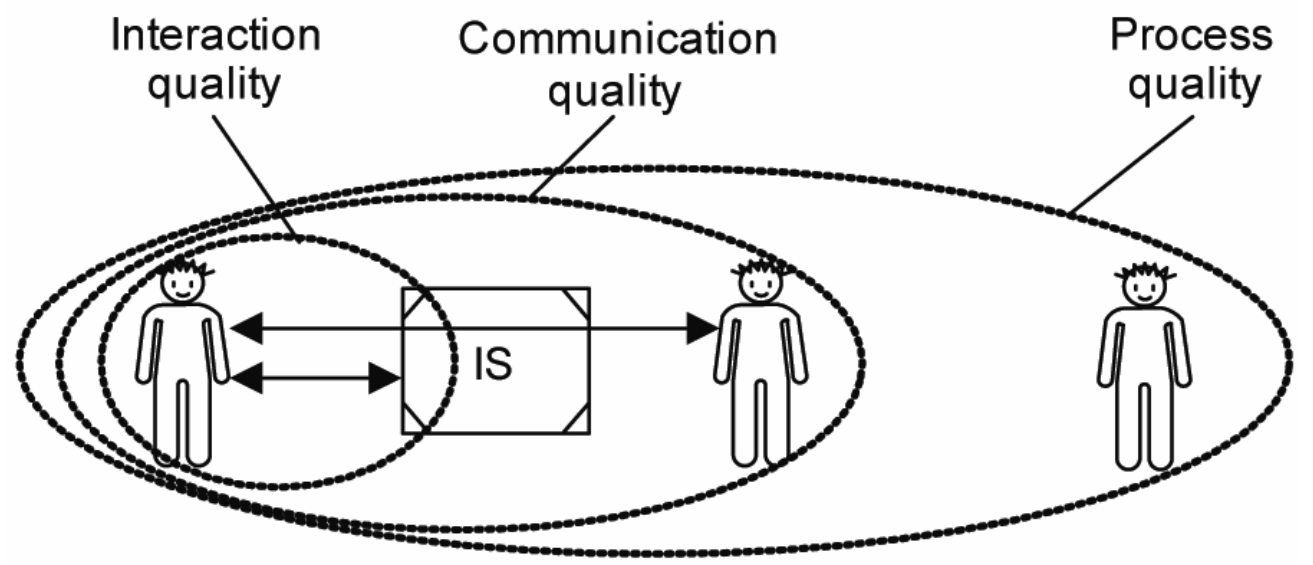

Figure 27 Layers of quality according to the Information systems actability theory. [206]

A sender interacts with an IS to communicate something to a receiver which, in turn, interacts with an IS to read and interpret a message. Quality criteria can be defined for this interaction, i.e. what the users are doing with the system. In this process, there is also a communication between the sender and the receiver about what the users are doing through the system. Communication quality criteria refer to the formulation and communication of messages by a sender, as well as the reading and interpreting of 
messages by a receiver. Process quality is concerned with what the users do outside the system, i.e. the effects of the IS usage on work practice.

Interaction quality criteria for an EHR system, which influences communication and process quality, for a prescriber might imply that the vocabulary of the system is intelligible and in line with terminology of the profession or regulated practice; that it is obvious what the user can do in the system and that consequences of different actions are transparent. For a prescriber, this could imply that the consequences of approving or cancelling a prescription are clear, and that navigation between the various parts of the system is easy and transparent.

For a pharmacist, communication quality criteria might refer to relevant prescription information being easily available for dispensing, that the information is relevant, authentic, accurate and trustworthy, that it is obvious who the sender is, and that the intention of the prescriber in the prescription is unambiguous.

In general, process quality criteria refer to the requirement that the information from the system is useful for its users; i.e. that the information has a meaningful use. In the ePrescribing process, the system should for example support process objectives, such as patient safety, correct reimbursement processes, clear instructions for the patients, but should also support the objectives of other stakeholders, such as achieving correct statistics for researchers and authorities.

The quality of the communication between prescriber and pharmacist is dependent on many factors, among them the quality of the communicated message. The quality of the communicated message is dependent on the quality of formulating an ePrescription (part of communication quality) and by interaction quality of the EHR system. Finally, how the communicated message is presented and made available to the pharmacists in their dispensing systems affects the overall communication quality. 


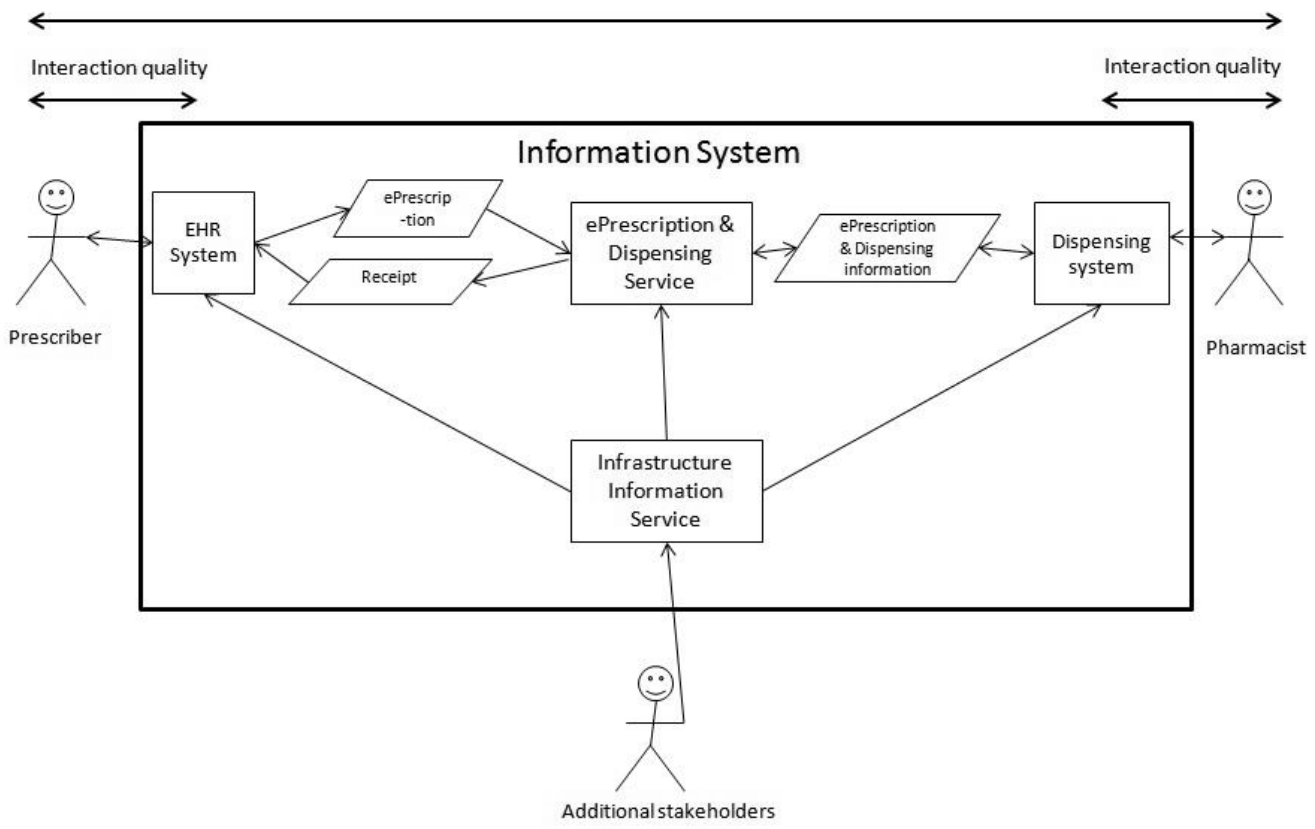

Figure 28 Overview of IS and stakeholders involved in ePrescribing communication.

In this field experimental study, we have elucidated the communication of ePrescription messages between the EHR systems prescription modules, the ePrescription service system and the quality of this message (box marked Information system) with regard to the requirements that have been established for this communication (Figure 28).

In this study, interaction and communication quality aspects in the EHR and dispensing systems are not directly considered, although they affect the quality of the communicated message. Some aspects of the Infrastructure information service ${ }^{90}$ such as the quality of the medical drug register have been taken into account (see below 5.9.2 about the influence of Infrastructure information). Thus, the quality of the communicated message by itself is an essential part of the overall communication quality. In the NEF project, aspect of interaction quality was not directly addressed and demanded, although there were some recommendations made regarding interaction in the EHR-systems.

Information systems actability theory and the quality criteria developed by Goldkuhl [206] for design an evaluation helps to sort out different aspects of the IS that influence the communication quality and thus the ability to interoperate. It does also contribute with

\footnotetext{
${ }^{90}$ Infrastructure information services refers here to shared information services such as repositories for medical drugs, prescribers, pharmacies, work places, et cetera. It should not be confused with an Information Infrastructure; of which it is a part. See 2.1.8 for a definition of Information Infrastructure and it components.
} 
quality criteria to consider in design an evaluation of IS used in inter-organizational interoperation.

As Figure 28 illustrates the IS part in the actability theory, when applied to interorganizational communication and interoperation is extended to involve a complex information infrastructure with several applications, shared information services and a communication infrastructure, involving many stakeholders.

\section{ePrescription - a focal point in the ePrescribing process}

The ePrescription, as mentioned above, is the focal point, which is regulating the whole pharmacy market for prescribed drugs. This documented act is at the center of all activities in the ePrescribing process. It refers to and directs various aspects of the ePrescribing process: the medical treatment, dispensing rules and reimbursement. The content of the ePrescription refers to or is closely related to all the information infrastructure services (see below 5.9.2 Stakeholders involvement and shared information services).

In this field experimental study, we have measured the degree of alignment of the ePrescription message to the prescribed and expected content and structure in terms of format and prescription rules.

The quality of the content of a ePrescription is an essential ground for a successful communication in the ePrescribing process, particularly when actors communicate separated in time and space and are using a formal message to communicate. The format and prescription rules define the minimum requirement for a prescription to count as a prescription and to be useful as a prescription for a medical treatment in the ePrescribing process.

Thus, communication of an ePrescription is not just communication of a message; it is aimed at a medical treatment of a patient in outpatient care. The prescription is an instrument in this medical treatment, which is a cooperation between a prescriber, pharmacist, and patient. See chapter 6 A practical theory on ePrescribing for a more detailed analysis.

\section{Communicating ePrescription - a speech act}

An ePrescription message can be viewed as a speech act. According to speech act theory an ePrescription message can viewed as an utterance of a Speaker (S) with the intention to communicate to a hearer $(\mathrm{H})$ (or a community of hearers). [207]

We assume that the intention of $\mathrm{S}$ with the prescription have been correctly expressed in the ePrescription message according to the formal rules for a prescription. This represented "propositional content" of the prescription is validated in relation to prescription rules and the result of this validation is acknowledged by an Application acknowledge receipt (APEREK). 
The prescriber communicates to pharmacies the intention of a medical treatment of a patient, through issuing a prescription. If accepted the prescriptions is counted as ${ }^{91}$ issued and the responsibility for its management is taken over by the pharmacies.

Following speech act theory, this is a successful illocutionary act: a sender (Speaker) has communicated a message with certain intent (issuing a prescription of a medical treatment for a subject of care) and the message and its intent have been received and understood by the receiver (Hearer).

With the introduction of NEF, this acknowledge has developed substantially compared to pre-NEF when the acknowledge was only a technical receipt, accepting the technical reception of the communicated message.

With the NEF, the pharmacies not only accepted it technically but also acknowledge it as a legal, appropriate, and readable prescription that can be dispensed according to prescription rules and praxis. Thus, the NEF contributed also to develop substantially the work practice rules and responsibilities of the parties, for example regulating the condition under which a pharmacist can take responsibility for dispensing a prescription or not.

At the pharmacies, the prescriptions are accessed and read using the dispensing system when a patient request for purchase of a medical drug on the basis of referring to a prescription. The interaction quality of the dispensing system will influence the take up by the pharmacist of the prescription communication act. The pharmacist is able to dispense a prescription with the perlocutionary $\operatorname{effect}^{92}$ (a specific medical treatment for a patient) intended by the prescriber.

The dispensing system contains support for the further actions in the process of dispensing the prescription. It can contain support for generic exchange of medical drugs, drug-drug interaction detection functions, and support for further explanations of instructions of use to the patient. These criteria are called subsequent actions support and is part of process quality in the IS actability theory.

\footnotetext{
${ }^{91}$ These can be seen as constitutive rules to follow Searle. [208, 209] An example of a constitutive rule is: an ePrescription Message counts as a Prescription if: a) it is issued by an identifiable licensed prescriber with valid prescription rights; b) the patient is an identifiable person; c) the prescribed drug is identifiable; d) it has directions for use. A regulative rule, defines according to Searle rights, duties and rules for action. One example of a regulative rule is: a prescription can only be dispensed with reimbursement if: a) the prescription has a valid workplace code; b) the patient has a resident status in Sweden or has the right according to European regulation 883/2004 regarding the coordination of social security rights; c) the prescribed medicinal drug is valid for reimbursement; d) the prescriber has approved that the purpose of the prescribed drug is a valid one for reimbursement.

92 Perlocutionary effects or acts are consequences outside of the linguistics communication. An illocutionary act may intend to produce an effect or consequence outside the utterance. In our case, the prescription is issued with the intention to produce consequences in term of dispensing a medical drug to a patient at a pharmacy.
} 
The result of the dispensing act is available to be communicated to the prescriber using the pharmacy register, which contains all dispensed prescribed medical drugs at the Swedish pharmacies identifying date, dispensed medical package, prescriber and patient. In this sense, it is possible for the prescriber to verify that the intent with the prescription for a particular treatment have been complied by the pharmacist and the patient. If and how the patient actually consumes the prescribed medical drug (the adherence to medical treatment ${ }^{93}$ ) is another matter (process) which is outside the control of the prescriber and pharmacist.

These acts are the effects of the ePrescription, which is outside, and following the communication act. This aspect is referred to as process quality in IS actability theory and concerns the quality of the shared work practice of ePrescribing as medical treatment. Process quality if affected by the communication quality, but rest first on the knowledge or prescriber and the pharmacist and their informed decisions.

The conclusion from this subsection is that the communication of an ePrescription is not only an information exchange but also a communication act that have multiple functions. See further our analysis of ePrescribing in chapter 6 .

\subsubsection{Stakeholders involvement and shared information services}

There are many stakeholders involved in providing shared information ${ }^{94}$ to ePrescribing. Examples of shared information are population and medical drugs register, prices, reimbursement rules, prescribers and pharmacist rights. This information is provided through various infrastructure services, which can be grouped into infrastructure information services, and ePrescription and dispensing services. These services are provided to the prescriber and pharmacy dispensing systems, and have an important influence on the communication quality. The interaction quality of the EHR and dispensing systems are also important to consider in assessing communication quality. [188]

Thus, the quality and content of the ePrescription message is dependent on stakeholder involvement both in the infrastructure services and in the actual formulation and interpretation of the prescription message by prescriber, pharmacist, and systems involved.

${ }^{93}$ In an WHO Adherence meeting 2001, adherence was defined as "the extent to which the patient follows medical instructions" quoted from [210].

${ }^{94}$ The information infrastructure for ePrescribing has developed since the beginning of 2000. See chapter 4 Implementing ePrescribing in Sweden - case study for a historical account of their development. 
An error or omission by for example the information providers, failures to deliver services correctly, or failures to incorporate information from the information infrastructure will influence the interoperability of the ePrescribing process. Therefore, it is valuable to get a grasp of the information flow in the information infrastructure (see Figure 29).

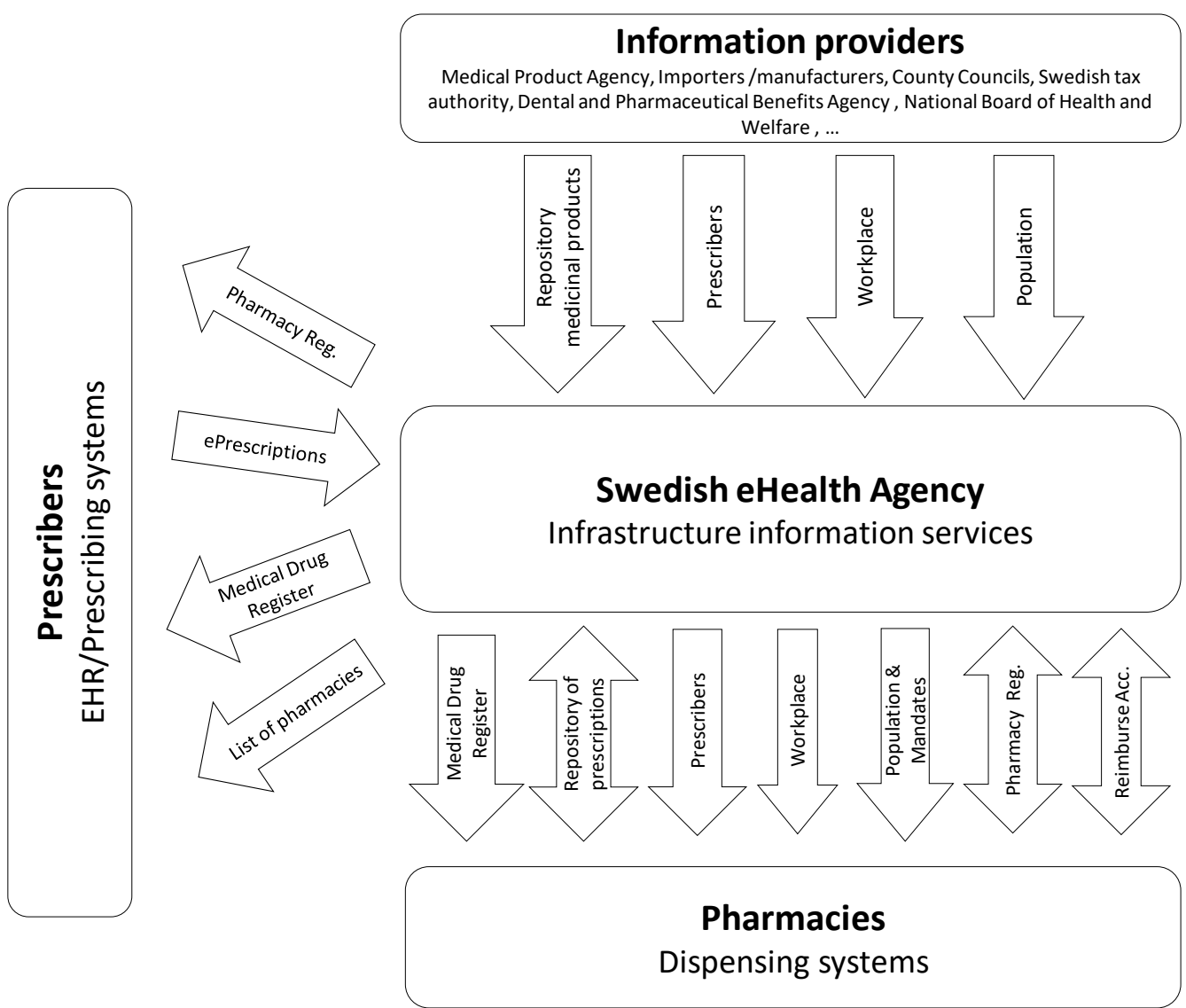

Figure 29 Information flow and infrastructure services for ePrescribing.

Figure 29 illustrates that there are many infrastructure information services used in the ePrescribing process in Sweden ${ }^{95}$. ePrescriptions issued by prescribers in Sweden are sent to and provided through the Swedish eHealth Agency (since 2014) to all the pharmacies belonging to different pharmacy chains in Sweden.

\footnotetext{
${ }^{95}$ The economical transactions linked to reimbursement benefits between the pharmacies and the county councils are omitted for the sake of clarity.
} 
Information providers are several authorities:

- the Medical Products Agency (MPA) is "responsible for regulation and surveillance of the development, manufacturing and marketing of drugs and other medical products." ${ }^{96}$ MPA contributes with information about approved medical drugs and generic substitution groups through the National Repository for Medicinal Product (NPL);

- importers and manufacturers of medical drugs provides information about their medical products through the National Repository for Medicinal Product (NPL);

- the Regional county councils provides information about their workplaces through the Workplace register;

- the Swedish tax authority (Skatteverket) provides a population register;

- the Dental and Pharmaceutical Benefits Agency (TLV) provides information about sales and procurement prices for reimbursement medical drugs through the National Repository for Medicinal Product (NPL);

- the National Board of Health and Welfare provides information about prescriber's license's through the Prescribers Register.

Swedish eHealth Agency provides information services to:

- pharmacies: Prescriber Register, National Repository of Prescriptions, Medical Drug Register, Population and Mandate Register, National Pharmacy Register, Reimbursement Account ${ }^{97}$ and Work Place Register;

- county councils and the prescribers: List of Pharmacies; Medical Drugs Register for prescription, National Pharmacy Register, Sale Statistics ${ }^{98}$;

- authorities: Sales Statistics.

The Pharmacies read and updates the National Repository of Prescriptions, National Pharmacy Register, Reimbursement Account and provides Sales Statistics to Swedish eHealth Agency.

\subsubsection{Interoperability levels to analyze interoperability errors}

Definitions of interoperability have different perspectives on interoperation. Some definitions focus on the ability of systems to interoperate [1], and others focus on the

\footnotetext{
${ }^{96}$ See http://www.lakemedelsverket.se/english/

${ }^{97}$ Reimbursement Account is an account for each citizen. The account keeps track of the level of reimbursement benefits that can be claimed, related to earlier historical payments of medical drugs.

${ }^{98}$ Sales Statistics are omitted from Figure 29 for readability.
} 
ability of people to interoperate (individual, organizational) by using systems to achieve a certain goal. [2, 4]

Based on the field experimental study, we regard interoperability as the ability of the entire process, involving people, systems, procedures and organizations; to interoperate using IS in order to achieve its objectives. This view of interoperability is similar to the definition of interoperability (see also section 2.1.3) made in the European Interoperability Framework (EIF) [4]:

"Interoperability, within the context of European public service delivery, is the ability of disparate and diverse organizations to interact towards mutually beneficial and agreed common goals, involving the sharing of information and knowledge between the organizations, through the business processes they support, by means of the exchange of data between their respective ICT systems."

European Interoperability Framework (EIF) defines four levels of interoperability: legal, organizational, semantic, and technical interoperability. These are summarized in Table 14.

Table 14 Levels of interoperability. [4]

\section{Level of Description \\ interoperability}

\begin{tabular}{ll}
\hline Legal & $\begin{array}{l}\text { Alignment of legislation concerning the interoperation } \\
\text { between different organizations, which affects how and } \\
\text { what can be communicated }\end{array}$
\end{tabular}

Organizational How different organizational processes are integrated and how information exchange is managed between the organizations

Semantic Processing of information in a meaningful way, providing that information in the communicated message is precisely defined, agreed and understood by all the stakeholders involved

Technical Technical prerequisites linking different systems, such as communication protocols, message format language, services, interface specification, et cetera.

These interoperability levels are aspects to consider in implementing interoperability. EIF does not explicitly refer to different perspectives of implementation when describing the interoperability levels. We think it is necessary to have at least two perspectives in mind: 
- operational perspective which concerns the flow of cooperative transactions and its immediate, short term governance;

- collaboration for the maintenance and development of future interoperation in the long and medium term, creating conditions for interoperation.

We will sometimes refer to the operational perspective and sometimes to the long and medium term perspective. The improvement of interoperability with the implementation of the NEF will now be analyzed in terms of the EIF interoperability levels.

Regarding legal interoperability, the implementation of NEF decreased in operational terms the number of ePrescriptions that were not in alignment with the legislation on prescriptions. The majority of the prescription rules errors captured concerned legal rules. The collaboration in the NEF project contributed with an explicit and formalized ${ }^{99}$ definition and interpretation of legislation, applied to ePrescriptions, defining the minimum requirements for a prescription to be counted as a prescription in line with legislation. During the implementation of the NEF, there were no major changes in legislation that affected the content of the ePrescription message. See chapter 4 Implementing ePrescribing in Sweden - case study for a description of the influence of change of legislation on ePrescribing.

Organizational interoperability in the EIF is concerned with how organizations "cooperate to achieve their mutually agreed goals". Two aspects are put forward in the EIF:

- business process alignment which is about alignment of existing or creation of new business processes;

- organizational relationships which is about finding instruments to formalize "mutual assistance, joint action interconnected business processes".

Organizational interoperability was also improved. The joint NEF project contributed with implementing new shared processes such as test and approval for certifying prescribing systems. It also contributed with a clarification of organizational responsibilities in the shared management of the prescription format, which was not at hand before. In the EIF vocabulary, this could be regarded as development of organizational relationships for the governance of interoperation in the medium term.

Agreement on how to handle errors on single prescriptions in the production flow, had a more direct effect on the operational level. This agreement became necessary with the implementation of controls in the production flow and the outcome returned in the application acknowledge receipt. With the NEF it was clarified which type of error should lead to a rejection and thus should be the responsibility of the prescriber organization to handle, and other types of errors that could be handled by the pharmacies and therefore

\footnotetext{
${ }^{99}$ For paper prescriptions, Medical Product Agency and the NPC had agreed on format for a printed form.
} 
could be accepted with a warning message. Thus, the NEF project changed the responsibilities in the process of error handling in both the prescribers and pharmacy organizations. In the EIF vocabulary, this could be regarded as development of business process alignment for the operational governance of interoperation.

Moreover, the NEF made it possible to identify the EHR system sending a prescription allowing for a more systematic follow up of errors to improve the ePrescribing process in the long term.

Semantic interoperability in terms of EIF improved most by the introduction of the NEF. This was most striking regarding syntactic interoperability, which in the EIF framework is part of semantic interoperability. This improvement had a clear effect on the operational level as an ePrescription with a syntactic error was immediately rejected. The actions in the NEF project, which contributed with a common and clearer definition of terms used in the message, explains the improvement in the semantic interoperability. Testing and approval procedures are assumed to have contributed to improve semantic interoperability.

The improvement might be explained by a greater effort by the EHR-vendors and by the health care regions to provide prescriptions with more complete and correct information in order to avoid a rejection of prescriptions. In the pre-NEF situation, corrections of this kind of information were done by personnel at the pharmacies.

Semantic interoperability depends also on information sources external to the prescription and the EHR and dispensing system. Some prescription rule errors related to shared information increased in proportion in the NEF-sample such as invalid drug identity. Thus, managing shared information is critical in achieving and maintaining interoperability.

Technical interoperability also improved, with the phasing out the EDIFACT format and with the use of XML-schema validation to support format controls early in the ePrescribing process, when creating the prescription and later when receiving the ePrescription to the pharmacy system. This change of technology in using XML and XMLschema validation simplified and supported the implementation of format and prescription rule controls in the ePrescribing process, particularly at the receiving end, helped to improve the interoperability of the EHR systems. The XML-schema validation also makes the controls more transparent, closely linked to the format specification of the ePrescription message.

Furthermore, the control and feedback process, which was implemented with the NEF, required a faster response from the receiving services and thus made it more beneficial to use a synchronous mode of communication, like Web Services. In the pre-NEF period with asynchronous communication, long response time was not a problem on the same level as there were no feedback. However, with the NEF new challenges arises to provide a faster response to the prescriber, which will involve not only the ePrescription services but also the technical infrastructure for message routing in the health care organization. 
The new feature with unique identifiers made it possible to measure the number of (and reject) technical duplicate prescriptions for the first time. Technical duplicates are a medical risk, which could lead to drug overuse. Thus, improvements in the technical interoperability have important effects on the overall interoperability, and vice versa, the overall requirements of semantic, organizational, and legal interoperability will influence the requirements for technical interoperability.

\section{Limits and usefulness of EIF}

The EIF interoperability levels aim at classifying interoperability concerns to focus attention on certain areas that are important to consider when implementing interoperation. They do not provide guidelines, nor are they precisely defined or grounded in any theory. Nevertheless, they provide a focus on important aspects to consider. To serve as a more practical guide in implementing interoperation the framework must be more precise and grounded in a theory. With this in mind, it was still valuable to use the "levels" (with are not really levels but aspects) to analyze the finding in the field experimental study. The use of the EIF interoperability levels contributed with valuable insights that prompted for a development of a theory on interoperation and interoperability. Some of these insights can summarized as a need for:

- various perspectives on interoperation regarding scope and time;

- developing an understanding of the interdependencies between the various "levels" because they are not actually separated;

- more precise definitions of the various aspects of interoperability;

- a theoretical grounding on how to view interoperability.

We also find it useful to take the definition on interoperability proposed by the EIF (see above) as an input to our theoretical elaboration of a new definition of interoperability.

Thus, the experience in using EIF as an analytical framework for analyzing interoperability errors have contributed to the theory on interoperation and interoperability, see further chapter 9 A practical theory on interoperation and interoperability.

\subsubsection{The characteristics of the joint intervention to implement NEF}

One research question posed in this study was the relationship between the expected results in improving interoperability and the various actions and activities conducted in the joint intervention of the stakeholders to implement the new ePrescription format.

From this field experimental study, it is reasonable to assume that the actions and activities carried out in the joint intervention to implement the new national ePrescription format contributed to improve the interoperability in ePrescribing. First, in substantially less errors in ePrescriptions, but also in improvement of other aspects of interoperability 
related to legal and organizational aspects. It is therefore of interest to characterize the activities and actions made in intervention that contributed to this improvement of interoperability. Although, it is not possible to give a causal explanation between specific actions and certain types of improvement of interoperability because of confounding factors, it can be assumed that taken all those things together, the intervention was a decisive factor for the improvement of interoperability. Thus, it is important to make an overall characterization of the various aspects of the intervention, because they point to actions and activities that might be important in achieving, improving and maintaining interoperability.

These characteristics contributes in this sense with an empirical grounding of a theory on interoperation and interoperability. The intervention to implement NEF can be characterized as follows:

- creating joint projects and shared implementation plans between the main stakeholders to implement the new ePrescription format in the work practices of medical care and the pharmaceutical care;

- creating between the stakeholders an agreed feedback mechanism in electronic communication and establishment of clearer responsibilities how to handle interoperability errors;

- creating a joint approval process and enhanced methods and procedures for testing of interoperability and for certifying used systems;

- organizing a joint management of the ePrescription format;

- national forums for cooperation between the county councils and the NPC around deviations and improvement of quality in ePrescribing, from a technical, organizational and medical perspective;

As mentioned above, the EIF framework used to analyze improvement of interoperability makes no distinction between different aspects of interoperability in terms of their relation to the actual operation of the communication and its long-term maintenance and development.

We have further categorized the improvements in two main perspectives on interoperability:

- The operational perspective on interoperability is the ability to operate and govern the ongoing interoperation. It is about managing the operational process in terms of controlling and measuring the operational flow and handling incidents and error in the short term:

○ 'on-line' control of structure and content of ePrescriptions in production flow;

$\circ$ 'on-line' measuring quality of ePrescription message. This is one source of evidence to improve quality;

- established support functions that are both internal and inter-organizational, to handle incidents and feedback. 
- The maintenance and development perspective on interoperability is the ability to achieve and change the operational interoperability for the future (medium or long term):

- maintenance and development of structure and content of exchanged format;

- maintenance and development of methods and procedures for certification of systems to be connected to the ePrescribing service;

- collection and analysis of interoperability errors to improve the ePrescribing process in the long term;

○ joint project for the development of ePrescription services.

Another maintenance and development aspect of interoperability was the governance and managing of different standards for exchange such as domain specific messages (ENV 13607, SIS XML Guide), choice of technical standards for communicating messages (XML, UDDI, WSDL ${ }^{100}$, SOAP) and security standards (S/MIME, SSL ${ }^{101}$, SITHS ${ }^{102}$ ).

These characteristics of the joint intervention to implement a new national ePrescription format have contributed with empirical grounding of the theory on interoperation and interoperability presented in chapter 9 A practical theory on interoperation and interoperability.

\subsubsection{Implementing the NEF - part of implementing ePrescribing information infrastructure}

The joint intervention for implementing the NEF has contributed to the consolidation of the ePrescribing process in the sense that it substantially improved the interoperability with fewer errors in ePrescribing and that it provided an organized framework for interoperation in the short and long term in ePrescribing.

It is plausible to assume that this improvement also was important for the process that followed of deregulation of the pharmacy market in 2009, through providing an ePrescribing process that were much more stable and less error prone.

The implementation of NEF was not an isolated phenomenon but was part of a larger process of implementing ePrescribing in Sweden. This joint intervention could benefit from earlier achievements, but also contribute to the further development of ePrescribing in Sweden.

\footnotetext{
${ }^{100}$ Web Services Description Language

${ }^{101}$ Secure Sockets Layer

${ }^{102}$ Säker IT för Hälso- och Sjukvården
} 
When the NEF project started in 2004, 30\% all prescriptions were ePrescriptions. Two factors were prompting for defining a new format:

- an expected growth in volume from $30 \%$ to $80 \%$ in few years;

- new demands for changes of the ePrescription format;

New stakeholders from major county councils were committed to engage in the growth in volume of ePrescriptions. These stakeholders also brought new demands for changes in the ePrescription service.

Parallel to the NEF project, there were a number of projects ${ }^{103}$ developing a:

- national prescription mailbox;

- national repository for prescriptions managing the whole life cycle of the prescription;

- national pharmacy register for all dispensed medical drugs at the pharmacies made available to the patient and the prescriber;

- a new national medical product register (NPL).

There were also projects aimed at upgrading communication services and databases by several stakeholders in the ePrescribing process, in order to cope with demands of increased volume and stability. Connected to these efforts contingency plans and service level agreements were updated.

These initiatives taken together, satisfying new demands from the stakeholders for new functionality in ePrescription services, in addition to the efforts of implementing the NEF, contributed to a higher degree of stability, to the high rate of growth during this period, and to a trust among stakeholders in the ePrescribing process. This trust in and satisfaction with the ePrescription service, both among the public [186] and the prescribers, [188] was essential to sustain in order to continue the growth in volume.

One can characterize this phase of implementing ePrescribing in Sweden as a transition from growth to a consolidation phase with a development from a system-to-system interoperation towards an evolution of a whole infrastructure for ePrescribing, with many systems and actors interoperating in ePrescribing. [28] Thus, from now on, interoperability cannot solely be seen from a multilateral point of view between systems and their actors, but must consider the whole information infrastructure. The NEF project started in an initial growth phase and was finally in 2009 part of a consolidation phase, just in time for the deregulation of the pharmacy market.

The developed ePrescribing information infrastructure was considered such an important asset, that when deregulating the pharmacy market from a state monopoly, it was legislated to create a state-owned infrastructure company for providing this ePrescribing information infrastructure to the new pharmacy company actors and to keep the link to the health care

${ }^{103}$ See chapter 4 Implementing ePrescribing in Sweden - case study for situating of these events, 
sector. This state owned infrastructure company, Apotekens Service AB, became a state authority for pharmacy and health care infrastructure in 2014, the Swedish eHealth Agency. [211, 212]

\subsection{Conclusion}

This field experimental study focused on measuring the improvement of interoperability in ePrescribing with a focus on the quality of communicated ePrescription. This improvement was due to the intervention to introduce a new ePrescription format. The background to this intervention was the increased complexity of the infrastructure in ePrescribing and the growth in ePrescription volumes. The ePrescribing process has developed from a system-to-system, prescriber to pharmacy interoperation towards a complex information infrastructure for ePrescribing involving many stakeholders.

The expected rapid growth of volumes led to a focus on quality and stability in the communication of ePrescriptions. The intervention to meet these challenges was to initiate at joint project to design and implement a new National ePrescription Format (NEF). The design aimed at improving the quality of the content of the ePrescriptions, while in the past the focus had been on the transfer of ePrescriptions. The design included a clarification and formalization of the content and prescription rules to validate and handle the prescription, including a validation of each ePrescription transaction according to these rules. The governance of the ePrescribing process was improved with enhanced test and approval procedures for EHR-systems, enhanced incident and problem management and a common maintenance of the changes to the ePrescribing process. The field experimental study was designed to measure the quality of the ePrescription message before and after the intervention. The findings in the field experimental study showed a dramatic increase in the quality of the ePrescription message.

These findings have been situated in the evolution of ePrescribing and have been analyzed using theories and frameworks. The IS actability theory and actability criteria was used to relate the findings in the field experimental study to various aspects of interaction, communication, and process quality. The communicated message was analyzed using speech act theory. The role of the stakeholders in providing shared information services in the ePrescribing process was described. The findings in the study was analyzed using the European Interoperability Framework (EIF) in order to analyze the improvements in an established and well-known interoperability framework and to draw some lessons in using such a framework.

The characteristic of the joint intervention of the NEF was summarized and related to the EIF framework. The intervention was further put in a historical context of implementing ePrescribing in Sweden.

From this field experimental study in improving interoperability in ePrescribing and the analysis of its findings, it is clear that improving interoperability is a complex endeavor, which includes political, legal, economical, organizational, cultural, semantical, and 
technical issues. These issues do not only concern the communicated messages between organizations, but also the related information systems, the whole information infrastructure, the interoperating processes and their context. Many stakeholders are involved in providing shared information that is necessary for the interoperation and will thus influence the interoperability.

This study focused first on the quality of the communicated message. Still, it was able to illustrate the complexity of the communicated messages and how it crystalizes various aspects of the overall process. This study shows the need for a theoretical framework that can structure this complexity in order to accumulate experience, research results, and be a guide to practitioners working with improving interoperability.

In this study, we have investigated the communication quality with regard to documented requirements on the ePrescription message before and after an intervention. Other studies have addressed prescription errors from a pharmaceutical point of view. [161, 200-202, 213-215]

This study has contributed with empirical finding and insights, which are contributions to a theory on interoperation and interoperability. See further chapter 9 A practical theory on interoperation and interoperability. 


\section{A practical theory on ePrescribing}

In this chapter, we will summarize a practical theory on ePrescribing. The chapter is based on the paper Towards a socio-pragmatic understanding of ePrescribing [42]. Confer the paper for a more detailed account.

This paper was written and accepted in 2008. Since then, there has been a major reregulation of the pharmacy market in Sweden, which has changed some aspects of ePrescribing, mainly in the form of a new constellation of actors. The presentation here is adapted to these changes, although they did not alter the fundamental elements of the practical theory.

An additional aim of this chapter, with its rather extensive summary, is to introduce (see also chapter 4 and 5) the reader to the domain of ePrescribing.

\subsection{Complexity of communication between organizations using information systems}

One important part of ePrescribing is communication of prescriptions between different organizations using information systems. Communication between organizations using information systems is considered a complex undertaking because in addition to exchanging data without errors in a secure and reliable way, there is also a need for a coordination of activities and resources between the different organizations. At first sight, the exchange of data does not seem complex. However, it is often the case that a single simple message represents many views and usages, in many cases a crystallization of a 
coordination of activities and resources that are actually (many times implicit) made in using the message. Thus, the message has multiple functions. [216]

A too narrow view of the informational aspect of a message could miss other aspects of the communication and thus lead to an underestimation of the complexity of communication. A more comprehensive approach is to view information exchange as a social act of communication, which put a particular focus on the coordination of actions between the participants in the communication. Frameworks have been suggested to analyze this communication. [140, 159, 160, 217, 218]

A contribution to an improved understanding of the nature of communication between organizations using information systems could be to:

- employ theories and methods in order to direct attention to various aspects of the communication;

- evaluate the utility of such theories and methods in a practical setting;

- develop practical theories of inter-organizational communication in various work contexts.

The purpose with this chapter is to make such a contribution in the ePrescribing work context. For this purpose, we have used a number of extant practical theories in order to analyze the communication between different parties in ePrescribing. In applying these theories on the practice of ePrescribing, we have gained experience in the utility of these theories. We have also used this work to develop a practical theory on ePrescribing, which could provide practitioners a reference model in the work to develop and improve ePrescribing.

\section{2 ePrescribing-background}

ePrescribing is a complex process involving various professions (Physicians, Nurses, Dentists, Veterinaries and Pharmacists), actors (Prescriber, Patient, Pharmacist, and Authorities), and relations (Prescriber - Patient, Prescriber - Pharmacist, Pharmacist Customer, Citizen - Authorities, et cetera). The outcome of a prescribing activity, the prescription, is not just a piece of information; it is an authorization to the pharmacist to dispense drugs at the request of the customer.

ePrescribing is technically complex, involving many different systems and system interfaces from an ordination made by a physician in the EHR (Electronic Health Record) system, via a prescription sent to the pharmacy, an order from the customer (either through an e-commerce system or at a pharmacy), to the dispensing process and the life cycle of the electronic prescription. ePrescribing in Sweden is no longer only an electronic transfer of a prescription; it has become the original artifact whose history is encoded in the information systems as it was yesterday noted on the paper prescription. 
The development of a new format for ePrescription in Sweden [219] (see chapter 5 for a detailed account) has demonstrated a need for handling the real communication complexity. Syntactic and semantic controls as well as the control of legal prescriptions and business regulations have been implemented to increase the quality of ePrescription with the focus on patient safety and reducing the costs of deficiencies in information quality. Studies have shown the importance of working with improving the quality of information in ePrescribing. [162, 200]

The tremendous growth of ePrescribing in Sweden, where more than $95 \%$ of all prescriptions are electronic, together with the growth of new public e-services, points to a need to develop and use models for conceptualization and guidance in analyzing and developing e-services. [73]

\subsection{Research method}

The initial research question posed for this study was to better understand why the seemingly simple message - the ePrescription - was much more complex than it first seemed. The first approach to answer this question was to assume that the complexity derived not from the message itself but from its role in a complex and regulated process.

To analyze the context of the ePrescription message, it was necessary to analyze its role in the ePrescribing process. Three theoretical models have been selected and applied in the analysis of ePrescribing:

- socio-pragmatic communication analysis; [216]

- Generic Exchange Model (GEM); [73]

- Generic Regulation Model (GRM). [74]

The main criteria for the selection of these models are that they contained elements that could highlight the action perspective in the communication as well as the aspect of social relations established in the communication.

The reason to use three models was an increased understanding during the initial analysis that the three models contributed with different perspectives of the prescribing process. First, a general point of view as a regulative process between markets or forums, then, an analysis of the overall interaction between parties or actors, and finally, a more detailed view of the communicated message.

Thus, there are three levels in this communication:

i. markets/forums in which actions takes place;

ii. actors making communication acts as part of a work practice;

iii. communication action made.

The Generic Regulation Model (GRM) [74] was used to analyze ePrescribing from a regulatory perspective - the relation between (i) market/forums. GRM is in turn based on 
Generic Exchange Model (GEM) [73], which was used to analyze the exchange in the work practice (ii).

The analysis of the different aspects of the communicated message between the actors (iii and ii) used a framework for socio-pragmatic communication analysis and the dyadic communication in GEM [216].

The main benefit expected from this application of extant theories is the conceptualization of various phenomena, properties, and relations that exist in the ePrescribing practice. Although, the focus is on ePrescribing, we think that most of the analysis result can also be applicable to other forms of prescribing such as using phone, fax, or paper as a medium. See section 6.4 .3 on the relation between ePrescribing and Prescribing in general.

The collected empirical material consisted of relevant parts of the existing documentation from the work with defining the new national ePrescription format (NEF), requirement specifications for developing the Swedish National Pharmacy Register [126], the Prescription Register, and the eCommerce system for ordering on prescriptions at NPC, laws and decrees regulating the prescribing process (from ordination to dispensing and consumptions of drugs), process and routine descriptions of the dispensing process, together with interviews and personal communications with requirement engineers, developers, pharmacists, prescribers, and other experts (for example a legal experts) in the field.

The researcher had also extensive knowledge and understanding of the field as an inside researcher and practitioner in ePrescribing. See chapter 3 Methods of inquiry for more details. This experience benefited the empirical work allowing access to internal sources and access to first-hand knowledge. The challenges have been to master and understand the extant theories and applying them correctly to the ePrescribing domain.

The contributions are twofold:

- empirical grounding of the extant theories in ePrescribing and assessment of their utility to analyze an inter-organizational work practice;

- generalizing experiential practical knowledge and other facts of ePrescribing using extant theories into a general practice theory on ePrescribing.

\subsection{Analysis of ePrescribing work practice}

In this section, we will analyze the overall context for the work practice of ePrescribing. We will summarize the theories used and then apply them to analyze ePrescribing.

\subsubsection{The Generic Exchange Model}

The Generic Exchange Model [73] has been developed specifically to analyze the government - citizen exchange and for a business setting with an interaction between 
supplier and customer (Figure 30). The model consists of two levels, the forum or market level, which is a place where actors can meet for exposure and search, and the dyadic level where communication between producer/supplier and client/customer takes place.

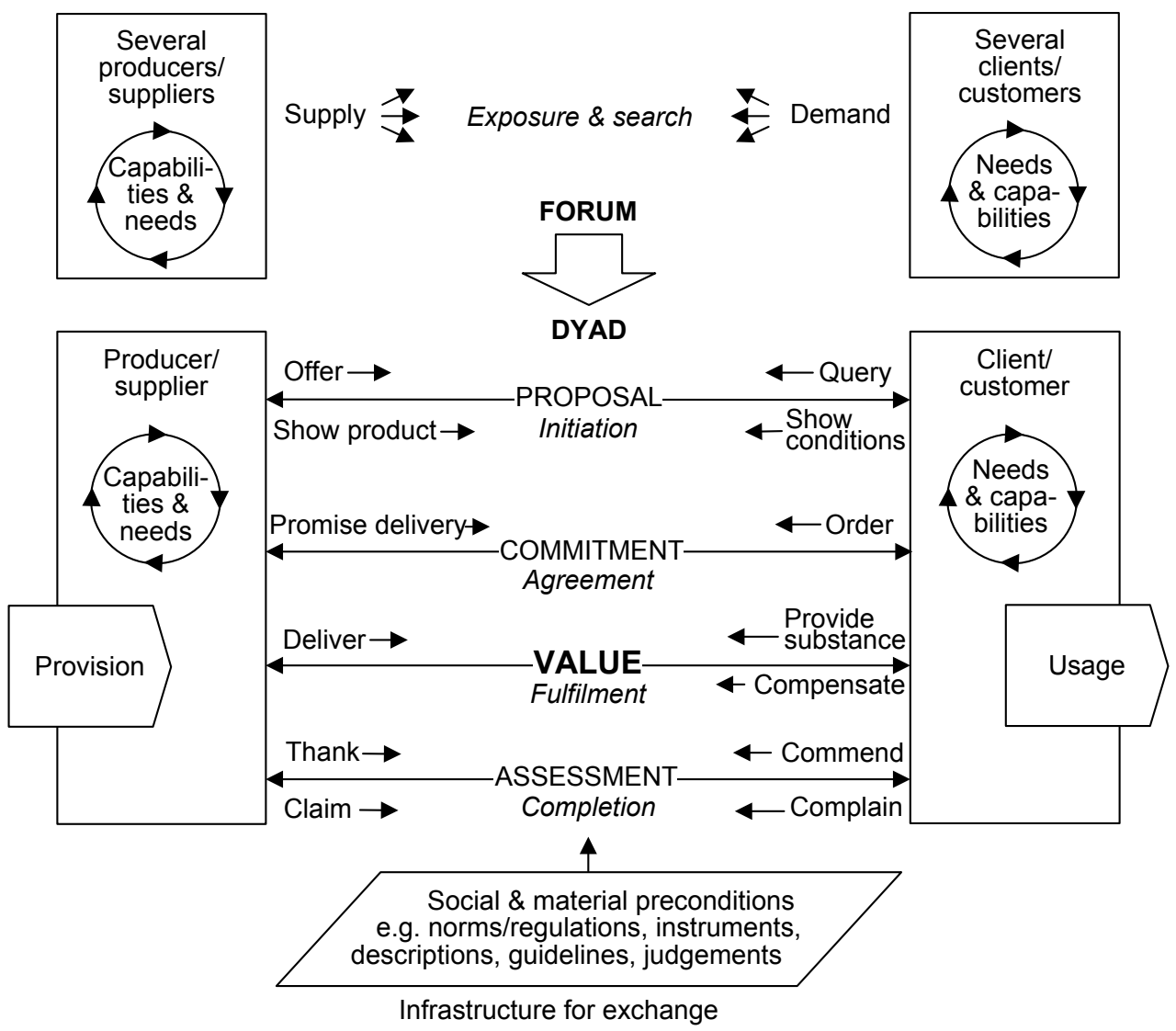

Figure 30 Generic Exchange Model (GEM).

The dyadic interaction consists of four generic phases: initiation, agreement, fulfillment and completion. Connected corresponding types of exchange objects to these phases are: proposal, commitment, value, and assessment. The actors perform different actions in each phase. Another important concept in the model is the infrastructure for exchange, which consists of social and material preconditions, such as norms and regulations, instruments, guidelines, descriptions, et cetera.

\subsubsection{The Generic Regulation Model}

The Generic Regulation Model was based on experiences in using GEM for developing eservices in the public sector [74]. E-services in this sector are usually highly regulated. The Generic Regulation Model, which builds on the GEM model, highlights regulatory aspects between public agencies and citizens. Regulation is seen as a regulation between 
different practices. One practice is considered the regulating practice that is regulating the other practice.

Regulation is also put in the context of application of laws regulating different practices. The regulating practice is concerned with transactions which end with a product in the form of a decision. This decision, an outcome of regulating practice, which in turn is regulated by laws, acts as a specific rule for transactions in the regulated practice. Specific laws also govern this regulated practice.

\subsubsection{Initial definition of ePrescription and ePrescribing}

In this section, we will put forward some initial definitions of ePrescription and ePrescribing. Then, we will discuss the relation between ePrescribing and Prescribing in general.

\section{What is ePrescribing?}

What is meant by ePrescribing? The National Council for Prescription Programs in the United States (US) makes the following definition:

"two way [electronic] communication between physicians and pharmacies involving new prescriptions, refill authorizations, change requests, cancel prescriptions and prescription fill messages to track patient compliance."

This definition of ePrescribing goes beyond the definition of an electronic prescription made by the Swedish Medical Products Agency in their directives on prescriptions:

"electronically transferred ordination of medical drugs ... for individual user issued by a qualified prescriber" (own translation from Swedish) [169]

This definition focus on the media ("electronically transferred") and the medical content ("ordination") and context ("user" and "prescriber") of the prescription.

Another definition, which focuses on the exchange of documents, taken from the Swedish National Board of Health and Welfare:

“... [a] document, issued by a prescriber, which means an authorization for a pharmacy to dispense a certain medicinal product... to a certain person." (own translation from Swedish, Socialstyrelsens Termbank 2007 - the Swedish National Board of Health and Welfare - Terminology)

This definition adds a legal aspect to the prescription in describing it as an "authorization for a pharmacy".

The definitions made above by the authorities in Sweden do not focus on the process of Prescribing but on the outcome of this process. The definitions focus on the exchanged objects. 
In ePrescribing - Studies in Pharmacoinformatics [162] a process perspective is presented which also involves the citizen/patient. In this view, ePrescribing

"... may be seen as an essential part of the continuous workflow in health care and pharmacy. In the same way, patients need to have updated and correct information on their drug therapy, both current and past. ... Furthermore, the patient demand for fast and reliable health care services and modern patients' claims for empowerment also need to fit into a good definition."

This perspective on ePrescribing is not limited to issuing the prescription document but also involves dispensing by the pharmacy and the consumption of the drug by the patient. We need to take into account the difference between Prescribed, Dispensed, and Consumed drugs [162].

One aspect that is missing in these definitions of ePrescription and ePrescribing is the economic aspects. These are regulated in an Act on Pharmaceutical Benefits [181]. The issuing of a prescription can thus be an act of commissioning a pharmaceutical benefit ("provisions" below) under certain conditions:

"The provisions ... shall be applied to a drug included on the Pharmaceutical Benefits Scheme if prescribed for human use by a doctor, dentist, nurse, midwife, or licensed dental hygienist for the purpose of preventing, identifying, alleviating or curing disease or symptoms of disease, or for a similar purpose, and provided that the prescription is labelled with a code which identifies the prescriber's place of work (workplace code). " (Section 6, [181] translated to English by Dental and Pharmaceutical Benefits Agency [220])

\section{Relation between ePrescribing and other forms of prescribing}

What is the relationship between ePrescribing and other forms of prescribing? First, we assume that the difference between ePrescribing and other forms of prescribing is a difference in media, which implies a different content, form and mode of communication of prescriptions and their related information. In Sweden, there have existed and exist at least four different ways of issuing a prescription:

- electronic prescription (ePrescription) which has the information content in a digital form stored on an electromagnetic media and is communicated to the pharmacy using some electronic communication technology. In Sweden, ${ }^{104}$ the only mode of communication for an electronic prescription is a structured digital synchronous or asynchronous system-to-system communication using some standardized communication protocol;

${ }^{104}$ Another possibility could be to store a prescription on an electromagnetic media, like smartcard, and let a human agent, in this case the patient or a representative hereof, carry the prescription to a pharmacy, as an intermediate agent. 
- paper prescription has the information content in an analog form printed on a paper. Its mode of communication is carried through a human agent who brings the prescription to a pharmacy;

- fax prescription is based on an existing paper prescription form (information content analog form) and its mode of communication is only partially system-tosystem, as it does not arrive in the pharmacy system. A fax prescription is only used in special situations and has only one month of validity and is not allowed to be stored in the national repository for prescriptions; [221]

- telephone prescriptions have the information content in analog form (speech and notes) communicated to a pharmacist taking notes of the prescription. It is communicated using telephone human agent to human agent. A telephone prescription is only used in emergency, have only one month of validity, and is not allowed to be stored in the national repository for prescriptions. [221]

For the analysis, we will not consider fax and telephone prescription further as they are used for special situations and are not very common.

Thus, the two main differences between ePrescriptions and paper prescriptions are digital vs analog form of information content and system-to-system vs human agent for the communication of the prescription. This has several implications:

- digital storing and communicating of a structured information content demands an information infrastructure to identify the content and the referred agents or objects and a communication infrastructure to distribute the prescription from system to system, from the prescriber system to the dispensing system at the pharmacies;

- analog storing of written content on paper do not need new information infrastructures $^{105}$ or new communication infrastructure to distribute the prescription, but can rely on the established writing sign system and the work practice language between prescribers and pharmacists including conventions for referring to medical drugs names, strength and from et cetera, and existing communication infrastructure to carry the prescription.

Thus, the evolution of an information infrastructure is both a precondition and an enabler for the prescribing process. It will affect the prescribing process in many ways, enabling new possibilities and restricting others. What aspects will be the same and what will change in the prescribing process? If we apply, IS actability theory (see 7.9), we have at least three main aspects that will be influenced:

- how to formulate the prescription;

- how to communicate the prescription;

\footnotetext{
${ }^{105}$ This does not mean that information infrastructure does not develop with the paper media. See in this section for example the evolution of information from the pharmaceutical industry from separate information to centralized information to the prescriber and the pharmacist in form of a printed book, FASS.
} 
- how to access and read the prescription.

The way a prescription is formulated will change with ePrescribing. A paper prescription was formulated with a pencil on a printed papers prescription form with the support of a huge book of product resumes on pharmaceuticals sold in Sweden (now in two bands) published by LIF (the trade association for the research-based pharmaceutical industry in Sweden) each year. This book had also a section on possible drug-drug interaction. LIF has also this information on product resume's on internet, which today are easily accessible from the EHR-systems and the dispensing systems used at the pharmacies. Before 1966, when this book (FASS) first was published, each pharmaceutical company published their own product resume's in 50 different publications [222].

With the use of EHR-systems to formulate a prescription, the prescriber has available all approved medical drugs, their prices, if they were in the pharmaceutical benefits scheme or not. Recall also (see 4.3 Early pioneering phase) that the initial focus in the pioneering phase of ePrescribing was to create a decision support tools for the prescriber in formulating the prescription, choosing the appropriate medication for a specific treatment, calculating dosage regimes, check for drug-drug interaction, et cetera. Today, the EHRsystems contain many of the functions that were envisaged and prototyped in the beginning of 1980s. In this sense, ePrescribing have contributed with a huge improvement for the prescriber in formulating the prescription.

One way to reflect on how it affects the mode of communication is to recall the evolution of ePrescribing in Sweden (for details see chapter 4). ePrescribing has had a long history in Sweden and existed parallel to prescription on paper. The regulation of ePrescriptions has followed and used similar rules as for paper prescriptions. In the beginning, an ePrescription was from a legal point of view only considered a mode of communication, an "electronic transfer", of a prescription (see above). If there were more fills left on the prescription it was printed out on paper at the pharmacy. An ePrescription was not yet completely accepted as a "real" prescription. This view on ePrescriptions as a mode of communication restricted in fact what you could do with the prescription from the point of view of the pharmacies and patient. It was regulated that the prescription should be sent to a specific pharmacy and that it had to be picked up at that pharmacy. ${ }^{106}$ Today, ePrescribing means that a patient can choose and approach any pharmacy in Sweden, physically or by using internet, to get an ePrescription filled.

How the pharmacies get access to and read the content of prescription was influenced by ePrescribing. With a paper prescription, a patient could go to any local pharmacy on the pharmacy market ${ }^{107}$. Thus, the paper prescription was not issued to a specific pharmacy

\footnotetext{
${ }^{106}$ It was then implemented in the dispensing systems at the pharmacies that it could be sent to another pharmacy on request.

${ }^{107}$ Even if was a pharmacy market with only one national pharmacy corporation, it was possible to go to any pharmacy in Sweden with a paper prescription.
} 
but to any pharmacy in Sweden that have the authority to sell prescribed medical drugs on the retail market.

ePrescribing evolved in two important aspects from its initially more restricted functioning:

- ePrescription got the same status as a paper prescription as the original artefact, i.e. no more a mere "transfer" of a prescription. It became possible to change the media of the prescription from ePrescription to paper and vice versa;

- ePrescription could be addressed to the whole pharmacy market, in the same manner as a paper prescription, using the national repository for prescriptions.

In this sense, ePrescription has regained some of the functionally which the paper prescription already had. Another important difference which was brought about with ePrescribing was the fact that the pharmacist no longer needed to interpret and transcribe the sometimes difficult to read paper prescription. The paper prescriptions had to be transcribed and registered in the dispensing system in order to be dispensed. In 1989, all the pharmacies in Sweden had a dispensing system with a medical drug register. Thus, the pharmacist had to translate the medical drug prescribed into packages delivered to the customer. The pharmacist was in this sense a filter, or rather a gatekeeper, between the prescriber's paper prescription and the final dispensed prescription, correcting misspellings or ambiguities. With ePrescribing, this filter was removed and all the errors created in the formulation phase in the prescription were transferred directly to the pharmacy dispensing systems. While some errors declined with ePrescriptions such as the identification of the medical drug, still pharmacists have to correct many instructions for use before they can be communicated to the patient $[200,223]$.

Another aspect to consider is the fact when more than $95 \%$ of all prescriptions are ePrescriptions, ePrescribing have become the new the role model for Prescribing.

Hence, it is plausible to assume that ePrescribing as analyzed here in its evolution, now encompasses and had become the role model for the prescribing process in general. Thus, in the final analysis, ePrescribing and Prescribing can be used interchangeable in a theory on ePrescribing. It is also the case that the prefix ' $e$ ' before a phenomenon usually first begins as a reference to something new. When it becomes the general mode of operation, the 'e' tends to disappear. This does not mean that ePrescribing and paper prescribing were all the same in the beginning. They have both evolved historically and merged into one process of ePrescribing. ePrescribing transforms the prescribing mode of operation and its manifestations. It creates new restrictions and new opportunities for the prescribing practice.

\section{Intermediary Conclusion}

The initial analysis of an ePrescription in the context of the ePrescribing work practice has highlighted the following aspects of a prescription: 
- media form and communication of the prescription;

- medical content and context of the prescription;

- judicial authorizations linked to a prescription;

- economical commissions linked to a prescription.

These aspects are important in defining the scope of ePrescribing. We need to consider the whole cycle from initiation in the interaction between the prescriber and the patient, through dispensing and consuming the drug, and finally the completion phase with its relation to both the pharmacy and the prescriber.

This approach is useful to understand the complexity of ePrescribing and helps us to highlight important issues such as quality, safety, and effectiveness, i.e. in the end contribute to a better drug utilization to the benefit for various stakeholders. Information technology plays an important role in contributing to this goal.

There are two exchange situations in ePrescribing:

- the health care market

○ prescriber - patient exchange with pharmacy as an indirect party;

- the pharmacy market

$\circ$ pharmacy - customer exchange.

The Generic Exchange Model (GEM) model will be used to analyses the two exchange situations and the relation between the health care market and the pharmacy market will be analyzed from a regulatory perspective using the Generic Regulation Modell (GRM).

\subsubsection{Health care market - the prescriber - patient exchange}

The forum/market place for the patient is usually the regional health care providers publicly or privately owned. It is possible for the patient to choose between several prescribers offering their services to the citizens.

The product offered in this forum has a generic meaning: something is produced with the intent to be used by someone. This means that what is produced can be a service like giving health care and, in the context of ePrescribing, result in an outcome of a prescribed medical treatment for outpatient care ${ }^{108}$ in the form of a prescription. Other outcomes of

${ }^{108}$ Within the context of ePrescribing, we are considering the situation that the patient is either not hospitalized more than 24 hours or is going to leave a hospital, i.e. inpatient care, and therefore is moving towards an outpatient care situation. In Sweden, prescriptions are issued for outpatient care only. Medical treatment at hospitals and other institutions are administered by the institutions themselves, who procure and store the medical drugs for later administration to patients from distributors via so-called hospital "pharmacies". Medical treatment at hospitals does not require a prescription but is documented as a medical "ordination". 
the health care service could be a doctor's certificate, treatment, advice, or a referral to another actor in the health care sector. Thus, in the health market place, health care services are supplied to meet the demands of the citizens. In the outpatient care, the most common outcome is a medical treatment ${ }^{109}$.

At the dyadic level, where the actual exchange takes place, there is an interaction between a producer and a client. In this context, the producer is the prescriber and the client is the patient.

The interaction starts with an initiation phase. Actions by the customer can be an earlier request for an appointment with a doctor, a presentation or description of a health-related problem. The response by the doctor in this phase could be an investigation, a diagnosis and a presentation of some alternative treatment. A proposal ${ }^{110}$ for medical treatment with medical drugs could be made to the client, represented in the model as an exchange object of the Proposal type.

The next phase is called the agreement phase. In this phase, the prescriber and the patient agree on the prescription of a medical drug to alleviate, cure, or prevent a disease or a health-related problem. The prescriber makes a promise to issue a prescription to the patient. The prescriber also promises (implicitly), on behalf of the public health care, to pay the reimbursement for the prescribed medical if that is applicable to the disease. The exchange object is a Commitment from both parties.

The next phase is called the fulfillment. The exchange object is of the Value type. From the point of view of the prescriber, it is an ePrescription, which is a " $\ldots$ document, issued by a prescriber, which means an authorization for a pharmacy to dispense a certain medicinal product ..." (see above). The prescriber gives instructions of use to the patient.

The exchange object from the patient is either the patient fee, or in case of the renewal of the prescription by phone, a corresponding patient fee paid later. Note that the compensation for the delivered prescription is not directly linked to the prescription, but is a payment for the appointment. In a way, the issuing of a prescription is free of charge except in the case of a renewal by phone, email or eService.

The completion phase may consist of various types of assessment actions. This phase could be viewed in two ways. First, as a completion of the appointment and, in this context, an assessment of the immediate outcome. Another, as an assessment of the intent behind

\footnotetext{
${ }^{109}$ In 2012, the total cost for prescribed pharmaceuticals was 25,315 million SEK. [224] In 2009, the number of doctors' visits at primary care per 1000 inhabitants was 1460 and prescribed pharmaceuticals was $9.1 \%$ of the health care cost in 2009. [225]

${ }^{110}$ With this action one can say that ePrescribing is initiated, the other type of initiations belongs to the medical treatment in general, not yet necessarily resulting in a proposal for at treatment involving a medical drug. In any case, they are a prelude to ePrescribing practice. For an analysis of boundaries of ePrescribing see 9.3.1.
} 
the prescription which is the completion of the medical treatment. This second view highlights one of discontinuities that exist today in the ePrescribing process. The prescriber often has no knowledge, apart from the information given directly by the patient, of what is dispensed and then presumably consumed by the patient.

Ideally, the completion phase seen as an assessment of the effects of the treatment with medical drugs would benefit from a "prescription fill message to track the patient's compliance" (see above) and its incorporation into the medical treatment ${ }^{111}$ of the patient. Part of this feedback can be achieved by using information in the Swedish National Pharmacy Register [126], which contains dispensed prescribed drugs at pharmacies. This information can influence further decisions of the prescriber together with data from the patient.

The connection between the different exchanges in ePrescribing, i.e. the Prescriber Patient exchange and the Pharmacy - Customer exchange, can be described as linked communication loops, see Figure 31.

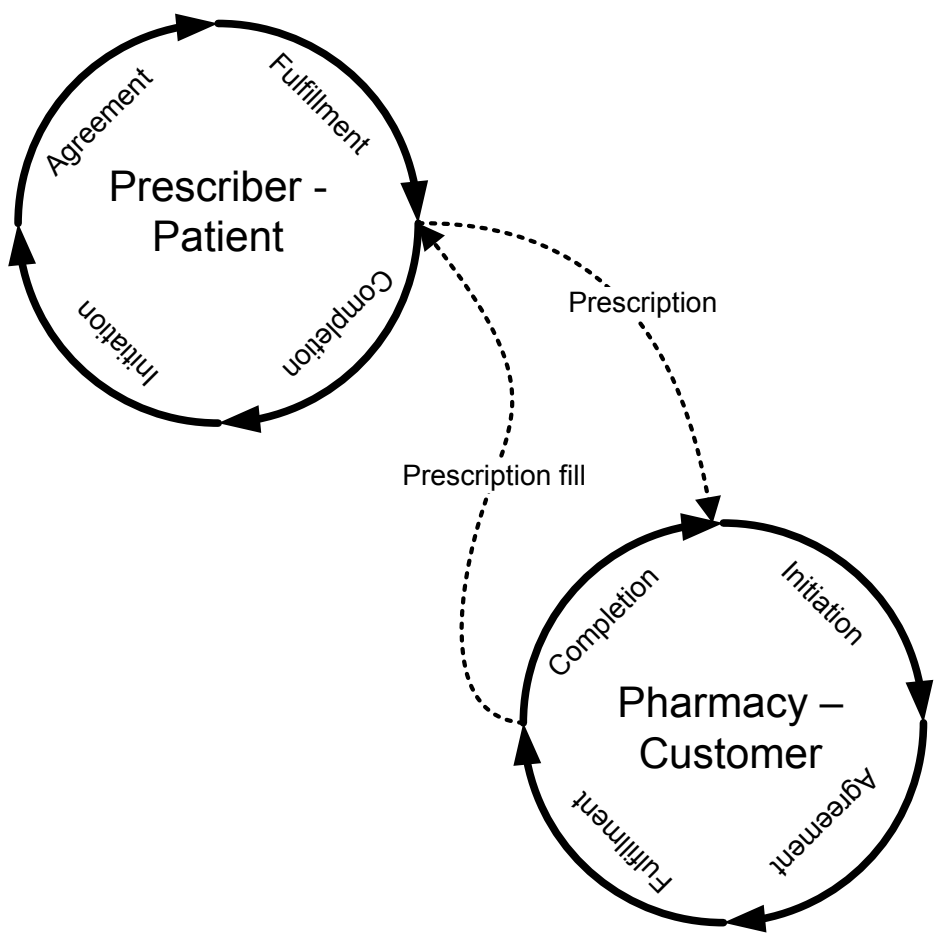

Figure 31 Linked communication loops in ePrescribing (inspired by Action Work Flow approach [71]).

\footnotetext{
${ }^{111}$ Ideally, this assessment would benefit from gathering of additional data surveying the administration of the medical drugs, reading of physiological data, self-assessments by the patient, et cetera. This will be the next step in extending the ePrescribing process.
} 
The link between the different exchanges is the prescription.

The infrastructure for exchange (see Figure 30) involves all the legislation around the prescription document, the policy for reimbursement, the price setting of drugs for the wholesale market, and the end customer market, what drugs are eligible for reimbursed, the legislation on generic substitution, et cetera. In the ePrescribing context, a major part of this infrastructure for exchange is available to the prescriber though infrastructure information services which are made available through the prescribers' EHR-system.

\subsubsection{Pharmacy market - the pharmacy customer exchange}

Any local pharmacy in Sweden can dispense an ePrescription. There are several services supplied to the pharmacy market, mainly providing OTC medical drugs, prescribed medical drugs, and pharmaceutical counseling services. The provision of prescribed medical dugs is completely restricted by the issued prescriptions in the health care market, as there is no right for pharmacists in Sweden ${ }^{112}$ to issue, adapt or renew any prescription. Pharmacist can only make some minor changes to a prescription to correct errors.

On the dyadic level, the initiation phase usually starts with a customer request to buy medical drugs on an ePrescription. The pharmacist retrieves the referred prescription, check for generic substitution and availability, the customer's reimbursement level, and makes a proposal that contains quantity of medical drugs and their net price with reimbursement. The pharmacist also checks the legality of the prescription and makes a pharmacological control of the dosage, checking possible drug interactions et cetera. This phase ends up in a Proposal type of exchange to the customer.

In the next phase, the customer accepts this proposal and commits to pay for the dispensed drugs. The pharmacist prepares the order for dispensing.

The fulfillment phase consists of delivering the drugs and the payment by the customer. The pharmacist makes a technical control of the drugs that are handed out, and gives instructions of use to the customer. The dispensed drugs are registered for the official statistics and reporting to the health care actors what generic substitutions have been made. This event is also registered in the National Pharmacy Register, which can be used later by the prescriber, pharmacist, and the patient as a historical record of dispensed drugs. The completion of this phase creates a record of this transaction which are aggregated during the day and form a basis for an invoice to the health care actors for the reimbursement given by the pharmacy.

${ }^{112}$ In some countries, like Canada, pharmacist can initiate, renew, and adapt prescriptions. [226] 
Finally, the completion phase could consist of a complaint or comment by the customer on the dispensed drug at a later visit to the pharmacy, but also be materialized in a planned counseling event with a pharmacist on the total drug use of the customer.

The pharmacies and the pharmacists are the final gatekeepers working both for the fulfillment of the prescriber's intention with the medical treatment, the authorities' intention for patient safety and the cost effectiveness of the drug use. This makes the dispensing process complex and involves many control mechanisms.

\subsubsection{Model of exchange in ePrescribing - a regulatory perspective}

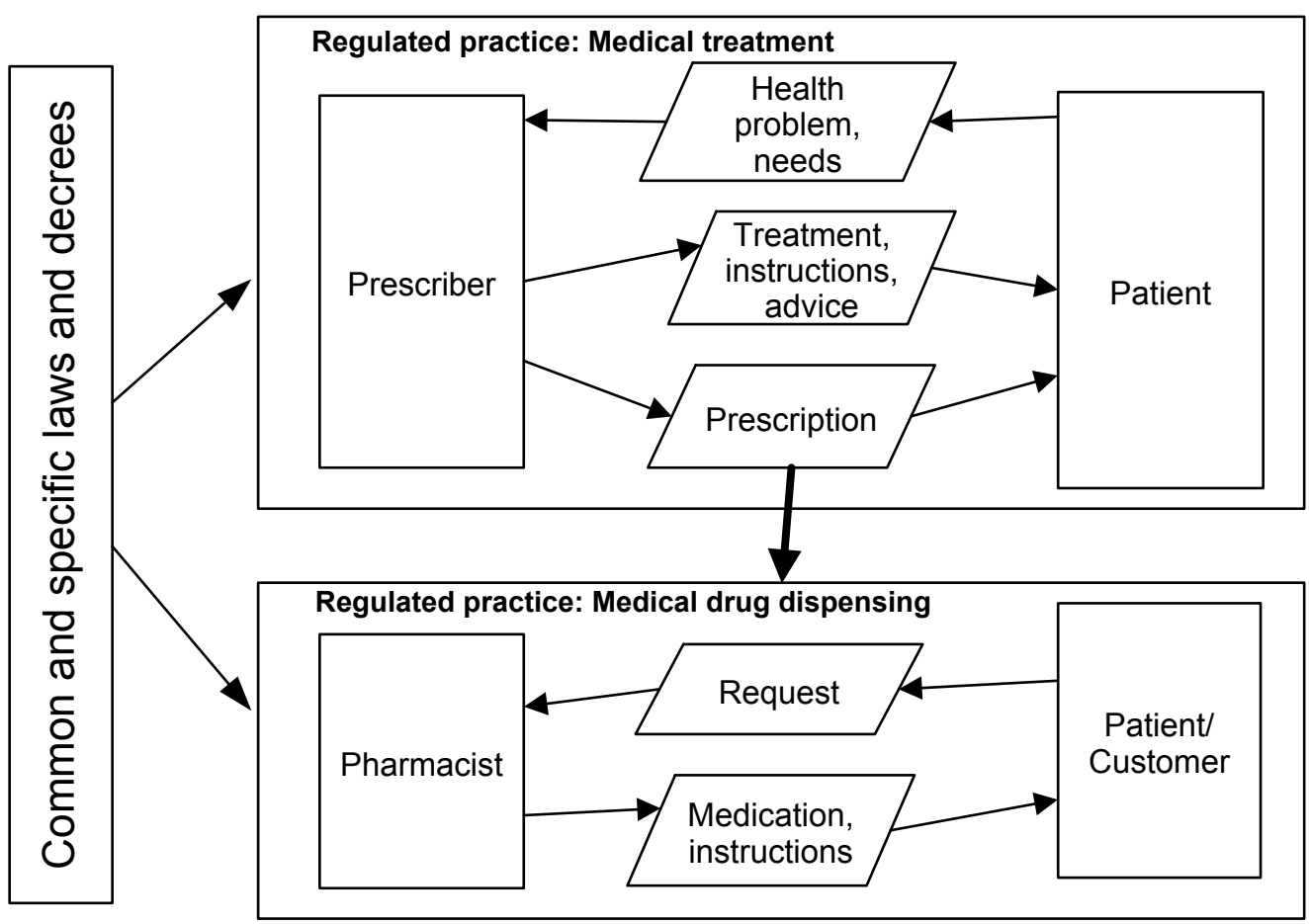

Figure 32 Prescription as a link between the two practices of medical treatment and medical drug dispensing in the health care and pharmacy market respectively.

In Figure 32, the two interacting work practices in Prescribing is illustrated. The first is the medical treatment with the prescriber - patient interaction. The second practice is the medical drug dispensing with the pharmacy - patient/customer interaction. The prescription, which is an outcome of the medical treatment practice, has the role of regulating the pharmacy - patient exchange. It permits the patient to buy the prescribed drug from a pharmacy and, at the same time, it gives the pharmacy the authorization and 
obligation to sell the prescribed drug to the particular customer/patient. Without the prescription, the exchange would not occur ${ }^{113}$.

In terms of the GRM, the medical treatment practice is the regulating practice and the medical drug dispensing practice is the regulated practice. The prescription regulates the transactions in the regulated practice. Both practices are regulated by several laws (for example LVFS 1997:10 [169]).

The described exchanges in Figure 32 have been limited to request - product exchanges. A more comprehensive GEM analysis has been presented in sections 6.4.4 and 6.4.5 above. Figure 32 illustrates a generic model that is valid for both paper prescriptions and ePrescriptions.

However, with the implementation of a national repository of prescriptions, making prescriptions available to all pharmacies, an explicit electronic market place of options ${ }^{114}$ to sell prescribed medical drugs, has been created.

We have now studied ePrescription in its various work practice contexts. It is time to move on to a more detailed analysis of the ePrescription.

\subsection{Socio-pragmatic communication analysis of ePrescribing}

In this section, we will complement the work practice and exchange analysis of ePrescribing (section 6.4 above). The analysis will focus on the ePrescription as a message for communication.

Goldkuhl [216] has developed a socio-pragmatic communication framework. It emphasizes communication as a social action and interaction and conceptualizes various communication functions. This framework has its roots in speech act theory [227, 228]

\footnotetext{
${ }^{113}$ That is why a breakdown in this communication between the different work practices has immediate consequences for both practices.

${ }^{114}$ In the requirement specification work for the National repository of prescriptions and its services towards the re-regulated market from a single pharmacy chain to several competing pharmacy chains, there was an important discussion on how to implement the rules of holding a prescription for a particular pharmacy in order to avoid conflict in updating the repository. Initially, it was decided that a prescription should only be locked for other pharmacies after the customer has confirmed an order to dispense. A fill of a prescription could be revoked if the drugs were not delivered. This discussion erupted because there was a concern to avoid any unfair use by different pharmacy chain. The principle was that it was the customer, which decided when and how a prescription should be filled - by using an eService, telephone, and request either at a pharmacy or by a contract for a subscription or advance order. Later, this design was changed to be a more 'open' model where there was no locking at all of a prescription, but instead at the time of update (completing the fill) there was a version control so that it was not possible to corrupt the repository, i.e. the first to sell wins. Thus, design decisions like these affected the working of the new market for selling of prescribed medical drugs.
} 
and the language action perspective. [159] It is also inspired by several other theories such as semiotics, functional linguistics, and conversation analysis. For background and content of the framework confer Goldkuhl [216]. The socio-pragmatic communication framework is theoretically consistent with the GEM model, since both of them build on the same theoretical basis, socio-instrumental pragmatism. [229]

\subsubsection{Analysis framework: a socio-pragmatic conceptualization of communication}

The analysis framework consists of nine facets of communication called communicative functions, which are described below.

Table 15 The nine communication facets in the socio-pragmatic communication framework (from Goldkuhl [216]).

\begin{tabular}{|c|c|}
\hline Function & Explanation \\
\hline $\begin{array}{l}\text { Trans- } \\
\text { situationally } \\
\text { compliant }\end{array}$ & $\begin{array}{l}\text { The message is in accordance with general institutions and norms and } \\
\text { specific trans-situational grounds, which may be brought into the situation as } \\
\text { the social background to the communication }\end{array}$ \\
\hline $\begin{array}{l}\text { Situationally } \\
\text { responsive }\end{array}$ & $\begin{array}{l}\text { The message may be a response to a prior message in the communication } \\
\text { situation and situational features }\end{array}$ \\
\hline Expressive & $\begin{array}{l}\text { The message is the expression of the locutor's subjectivity (intentions, } \\
\text { desires, skills, emotions, values, understandings, commitments et cetera.) }\end{array}$ \\
\hline Referential & $\begin{array}{l}\text { The message says something about something in the world; objects and } \\
\text { processes talked about }\end{array}$ \\
\hline Accountable & $\begin{array}{l}\text { The message needs to be comprehensible, i.e. it must to some degree be self- } \\
\text { contained and include sufficient self-references and arguments to explain its } \\
\text { role in the communication process }\end{array}$ \\
\hline Directed & $\begin{array}{l}\text { The message is directed towards one or more addressees. There may also be } \\
\text { secondary recipients (an audience) }\end{array}$ \\
\hline Relational & $\begin{array}{l}\text { The message establishes certain action relations (expectations, commitments, } \\
\text { states) between locutor and addressee and sometimes on a socially broader } \\
\text { level }\end{array}$ \\
\hline Projected & The message may be an initiative to further actions \\
\hline Mediational $^{115}$ & $\begin{array}{l}\text { The message is expressed in some medium (channel, carrier) and thus } \\
\text { utilizes the particular features of this medium }\end{array}$ \\
\hline
\end{tabular}

${ }^{115}$ By mediational is here not meant the act of mediating but the form in which the communication is taking place. 


\subsubsection{Analysis of ePrescription communication situations}

In this section, we will make some general remarks before we analyze the two communication situations in ePrescribing: patient - prescriber and customer - pharmacy.

The first step is to clarify who are the locutor and the addressee. The framework assumes a dyadic communication, but it is possible to define secondary addressees if needed.

One result in the analysis using the GEM was that the prescription and its infrastructure for exchange regulated the whole pharmacy market for prescription drugs. The implication is that while the communication at the forum/market level of the health care market mainly takes place between the prescriber and the patient, it is obvious that the pharmacy market is also an addressee of the communication acts, since it is a part in regulating the pharmacies' authorizations to sell drugs to customers.

A pharmacy actor in the model will represent the pharmacy market. Even if the communication between the customer/citizen and the pharmacy exerts an influence on the health care market, this influence is effective after the communication has taken place. This does not contradict the view of ePrescribing as a process that also encompasses the dispensing and consumption of drugs, a view we have taken in the preceding analysis. In this analysis, prescribing and dispensing are separated as two speech acts. They are linked into one overall process via the application of GEM (see the previous section 6.4).

In the dispensing process step at the pharmacy, based on the prescription, the locutor is the customer ${ }^{116}$ and the pharmacy is the addressee.

The two communication situations focus on two important messages, prescription (see section 6.5.3) and prescription order (see section 6.5.4). We have assigned the locutor as the main initiator of the communication. If we look closer at the conversation that actually takes place in these communication situations, we have in some cases an interaction where the addressee takes an initiative in response to acts made by the original locutor. This is particularly the case with the exchange around a prescription order, where the pharmacist creates speech acts in the fulfillment of the order process. As these acts are a direct response to the initial speech acts by the original locutor, we have kept this actor as the locutor in the model, even if in these speech acts the addressee acts as a locutor in those cases. This approach makes it easier to follow the analysis.

${ }^{116}$ Note that the role of the patient has changed from patient to customer in relation to the pharmacy. 


\subsubsection{Analysis of the prescriber - patient communication}

Figure 33 illustrate an application of the framework to the prescriber - patient communication, where the issuing of the prescription is the basic communication act.

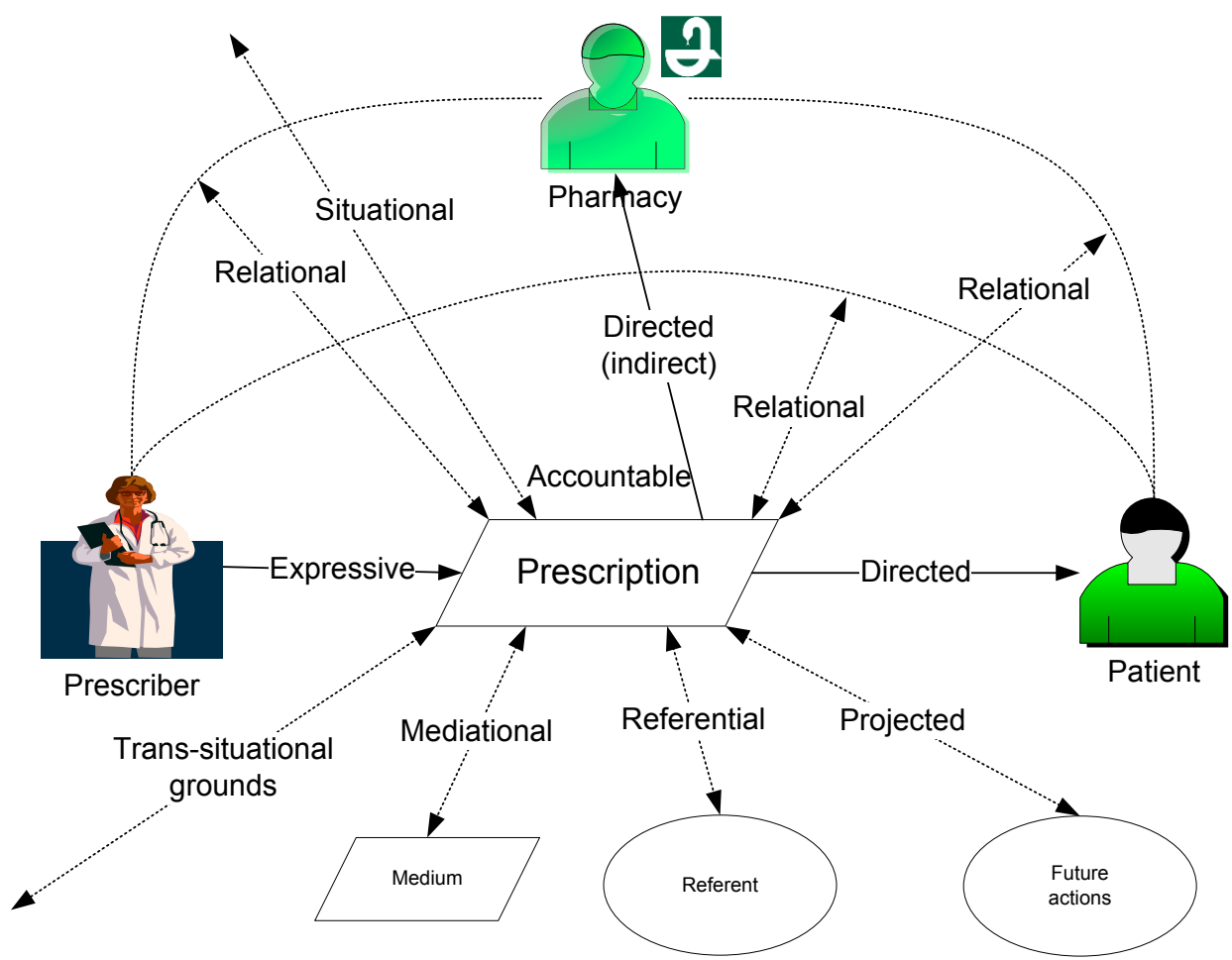

Figure 33 Nine facets of communication - applied to the Prescriber - Patient communication (based on Goldkuhl [216]).

\section{Directed facet}

The directed facet focus on who is the addressee of the communication.

We have two addressees in the action of issuing a prescription: patient and pharmacy, where the pharmacy is indirectly involved in the communication situation. 


\section{Mediational facet}

A prescription could be electronically mediated, issued by phone, sent by fax to the pharmacy, or printed out as a paper prescription handed out to the patient.

\section{Situationally responsive facet}

The communication between the prescriber and the patient can take place in different contexts. One situation is when the prescriber physically meets the patient for consultation either at a hospital or at a care center. It could also be a question of the renewal of a prescription at the request of the patient via telephone or email. In this case, the prescription is a matter of a response to an earlier message. The patient may have a medication history which can be accessible in various ways, either via the patient directly, via an EHR-system or through access to the Swedish National Pharmacy Register [126]. These aspects are covered by the situationally responsive facet.

\section{Expressive facet}

The expressive facet focus on the intention of the prescriber in terms of a medical treatment. The prescriber has the intention to prevent, cure or relieve a condition or a disease through medical treatment. The patient may also have preferences for a certain medication or treatment.

The adequate medical drugs are selected for the treatment together with a specification of the strength, form, dosage, and an instruction of use. This medical directive is an expression of the prescriber's professional medical knowledge. Thus, the intention and knowledge are transcribed into a prescription.

\section{Relational facet}

The issuing of a prescription is part of the relational facet, because it establishes a relation between the patient, prescriber, and indirectly to the pharmacy market. From a speech act point of view [227], this can be considered as a declaration of authorization, and at the same time is the prescription a directive to take a certain amount of medical drugs at a certain interval for certain situations or conditions. The prescriber also makes a commissive action in promising that the regional health care organization will pay the reimbursement for the drug. The prescriber is responsible for these directives in the prescription. Whether or not the addressee will comply with this directive is not given. The patients may never use the ePrescription. [230]

\section{Trans-situationally compliant}

To issue a legally valid prescription, it must be addressed to the patient (as the subject of care) in the form of a document or standardized message according to the norms and rules 
of a prescription, which declare the authorization of the patient to order a drug prescribed in a prescription. The issuing of a prescription must be trans-situationally compliant.

What constitutes a legal prescription is defined in a set of prescription rules issued by the Swedish Medical Products Agency. How these rules are to be applied on electronic prescriptions is then interpreted by the stakeholders.

See $[8,9,42]$ for an explanation how the prescriptions rules are applied in ePrescribing in Sweden. Other regulations concern rules for the reimbursement of the prescribed drug and for the generic substitution.

The conclusion is that the issuing of a prescription takes place in a complex setting, which is one contributing factor to the complexity of the ePrescribing process.

\section{Projected facet}

According to Goldkuhl [216], the projected facet covers some of Searle's speech act functions. [227] One of these speech act functions is the class directive, which we have dealt with earlier in the relation facet. According to Searle, a directive speech act aims at influencing the addressee to take a specific future action. With this in mind, a prescription is an instruction to the patient to take medication according to a dosage scheme for a specified treatment period.

The prescriber can also demand that the drugs should be dispensed several times without further consultation with the prescriber, i.e. a number of iterations can be prescribed. The prescriber can also demand that the prescription should be dispensed on a certain date at the latest.

\section{Referential facet}

The referential facet of the communication is traditionally the major focus in the description of the communication process, particularly when electronically mediated. Most of the effort of analyzing the domain is almost exclusively focused on the referential domain. This facet is a very important part of the communication, because it provides reference to objects in the world. For the ePrescription, there are a number of identifiers that refer to objects in various repositories. One important reference is the prescribed medical product. This reference and its corresponding description are very important for issuing a prescription. Other important identifiers are the prescriber's authorization and workplace code, and the pharmacy and patient identifiers. These identifiers add up to the complexity of the ePrescribing process.

\section{Accountable facet}

The use of the accountable facet refers to the degree of comprehensibility of the speech acts to the addressees. It is important that the patient understands the purpose with the 
medical treatment and is able to understand the medication instructions. This is specially noted in the legislation of prescription rules:

" $23 \S \ldots$ instructions regarding dosage, use, purpose and treatment period shall be written so that the patient or the animal keeper can use the medical drug in a correct manner. ... " (LVFS 1997:10 [169]) (our translation)

The accountability of the message is also important for the pharmacist.

\subsubsection{Analysis of the Customer - Pharmacist Communication}

Figure 34 illustrates an application of the framework to the Customer - Pharmacy communication, where the prescription order is the basic communication act.

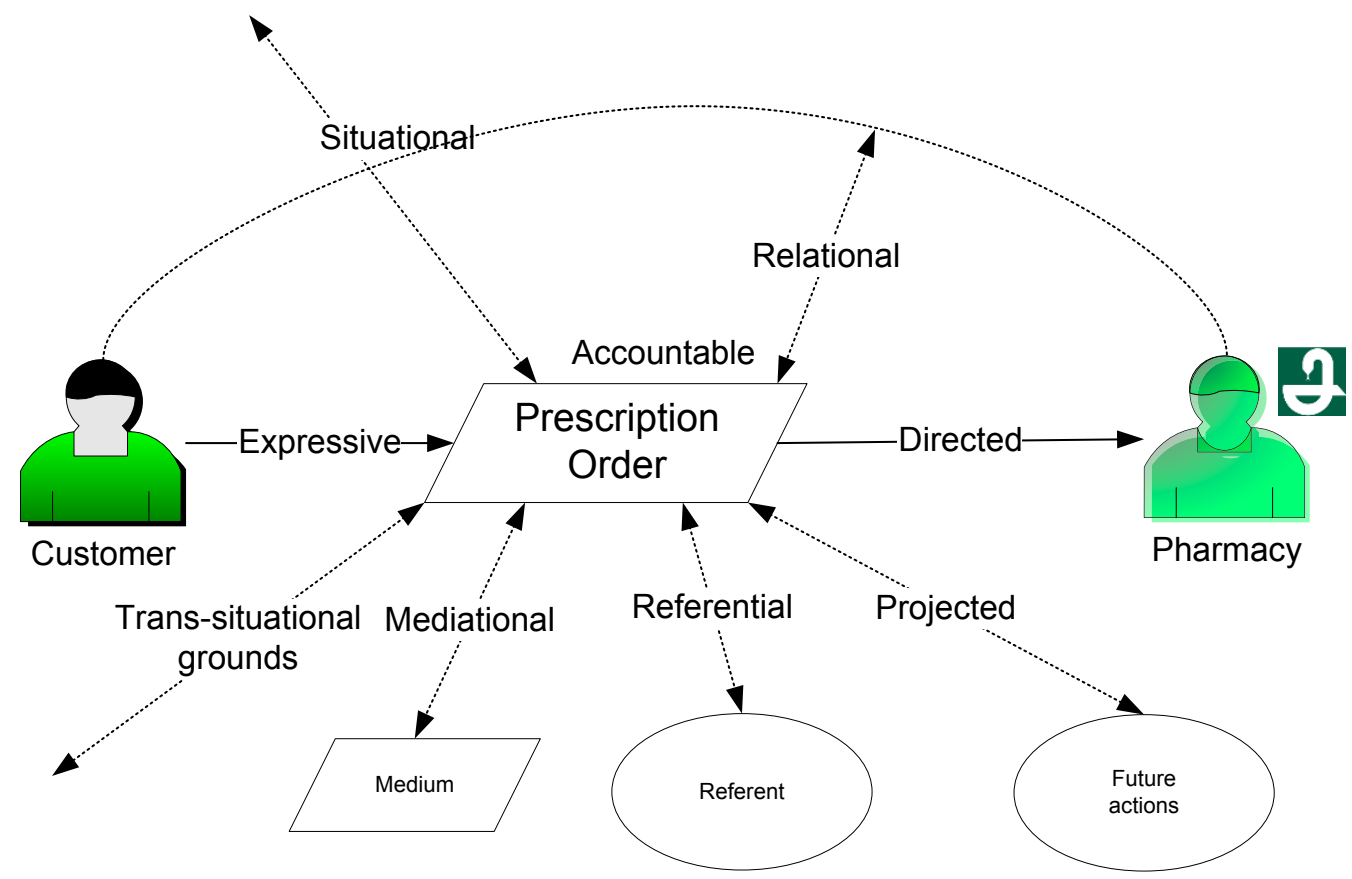

Figure 34 Nine facets of communication - applied to Customer - Pharmacist communication (based on Goldkuhl [216]). 


\section{Directed facet}

From the analysis in section 6.5.3, we conclude that the addressee of the prescription order is the pharmacy. The prescriber is involved later in the process and is therefore not considered as an addressee. For the prescription order, the customer/patient is the locutor.

\section{Situational responsive and mediational facet}

The context in which communication occurs between the customer and the pharmacy can vary. Most of the variation is linked to the mediational facet, which can be internetmediated or telephone-mediated communication, or which is still the most common today, through the medium of oral speech in a physical appearance at a local pharmacy.

The customer makes a speech act of the directive class, whether outspoken or not. The message that is communicated (either face-to-face or mediated through phone or an IS for ordering of medications) is a prescription order which is a request to dispense a prescription drug.

\section{Expressive facet}

The expressive facet expresses the intentions of the customer. A prescription order expresses the customer's intention that the prescription is to be filled under certain conditions.

\section{Relational facet}

The order request by the customer creates action relations with the addressee. The order request is a directive.

The pharmacist's response to this request results in several actions. The pharmacist makes a promise to deliver a certain drug at a certain price, which is a commissive. This promise to deliver a drug at a certain price is based on regulations of the whole pharmacy market regarding pricing, generic substitutions (the cheapest generic drug), and reimbursement rules.

The pharmacist can also create a directive, if the pharmacist has found that a drug in one prescription has a potentially serious interaction with another drug in another prescription, perhaps issued by another prescriber. [231] This directive could aim at urging the customer not to take a certain drug together with another drug or to instruct the customer how to avoid a certain interaction or to avoid the risk of duplicate drugs. Another option for the pharmacist is to contact the prescriber for an alternative drug on the prescription and thereby change the directive on the prescription and the directive of the pharmacist to the patient. 


\section{Accountable facet}

The order by the customer may sometimes be clarified in an interaction between the pharmacist and the customer. It could concern the amount of the medical drug to be dispensed or to clarify together with the customer which prescriptions are to be filled.

In response to the prescription order, the pharmacist contributes to the accountability in making the directive of the prescription more comprehensible by giving additional information and explanation.

Clarification by the pharmacist of the instructions of use and dosage occurs for both paper and ePrescriptions. These clarifications (for example corrections and clarification of non-standardized abbreviations) can be made on the prescription original (whether on paper or electronically) and on the label on the package when delivering the drug. The pharmacist also gives oral instructions when delivering the drugs, for example how to handle an inhaler.

Interview with pharmacists give at hand that many new prescriptions (whether on paper or ePrescriptions) have to be corrected when it regards dosage instructions. In an observational study made at a mail-order pharmacy in Sweden, 38\% of all incoming ePrescriptions were corrected regarding dosage instructions without a need to contact the prescriber. [223]

This indicates that the prescriber does not see the patient as the immediate addressee of the prescription but relies on the pharmacist to correct the dosage instruction to make it readable and comprehensible for the patient.

\section{Trans-situationally compliant}

The regulations regarding dispensing prescribed medical drugs are rather complex. There are legal rules describing what responsibility and rights the pharmacists have in the dispensing process. The pharmacist is responsible for checking that the prescription is valid according to the rules issued by the Swedish Medical Products Agency and that the prescriber has the authorization to prescribe the drug. There are also rules about the substitution of generic drugs that the pharmacist must follow, as well as rules about subvention, the correct workplace code, et cetera.

The pharmacological control is also a very import part of the dispensing process. This means, for example, making a technical check of the medication. This involves also a control that there is no risk of drug-drug interaction among the drugs dispensed, that a correct dosage is used, that the dosage instruction is comprehensible to the patient, that there is no risk of duplicate drug use, and that the drug prescribed is adequate for the indication in the prescription, et cetera.

If errors are found in the prescription, it is possible for the pharmacist to correct it within the norms and rules that are trans-situationally compliant. The pharmacist also approves 
the dispensing with a signature (electronically on the prescription dispensing record and by pencil on the drug package dispensed to the customer).

\section{Referential}

Apart from the information already referred to in the prescription, additional information and status are added. A paper prescription could contain all the history and life cycle of the prescription through hand-written signatures and comments by the pharmacist, together with labels glued on, defining all the dispensing on the prescription. With an electronically stored and maintained prescription, all this is managed in the prescription repository including history and status changes. To electronically manage the life cycle, new referential information has to be gathered and managed.

The process becomes more complex, since it needs to involve management of the whole life cycle of the prescription with many rules regulating subventions and the validity of the prescription.

\section{Projected facet}

The projected facet includes all the advice and instructions that the pharmacist delivers to the customer in order to improve adherence and patient safety. These communication actions are classified as directives and take place when delivering the drug to the customer.

This facet expresses the desire of the pharmacist that the customer should adhere to the directive in the prescription issued by the prescriber.

\subsection{Application of practical theories and elements of a practical theory on ePrescribing}

The purpose of this chapter is twofold:

- to make an empirical grounding of practical theories to assess their utility in analyzing ePrescribing communication;

- to contribute with practical theory on ePrescribing which could guide practitioner in developing and improving ePrescribing.

First, we discuss the utility of the used theories in analyzing ePrescribing, and then, we present some elements of a practical theory on ePrescribing that have emerged in the application of the extant theories to ePrescribing. 


\subsubsection{Utility of practical theories analyzing ePrescribing}

This study contributed with experience in applying three practical theories (GEM, GRM and the socio-pragmatic framework for communication) on ePrescribing.

When applying practical theories in an inquiry into work practices, one important question to ask is whether the usage of the practical theories contributed to a better understanding of the practices analyzed. Did the practical theories contribute to:

- new insights?

- identify problems and opportunities?

- focus the attention on important phenomena?

- a more coherent description?

- situating the various elements in a context?

The inquiry into the ePrescribing practice was an inquiry into a generic ePrescribing practice. It did not analyze a particular local pharmacy or local prescribing practice but the general conditions for these practices.

We think that the analysis presented in this paper demonstrates the ability of the theories used to function as guidance in the analysis and as a contribution of important concepts to describe central phenomena in ePrescribing. It has helped to highlight aspects that were not obvious, and has provided new insights such as:

- the strong regulative role of the prescription for the pharmacy market;

- the strong interdependence between the health care market and the pharmacy market regarding prescribed drugs.

The extant theories contributed also with diagnostic knowledge showing the gaps in the process of current ePrescribing in relation to the identified interdependence. For example, ePrescribing is today still to a high degree a one-way process with little feedback to the medical treatment practice on what is going on in the drug dispensing practice. This oneway character put a high responsibility on the pharmacist for the patient safety and effective drug utilization. Another consequence is poor quality of prescriptions, resulting in that pharmacist frequently corrects prescriptions before they can dispense prescribed drugs to the customer.

The notion of accountability (comprehensible and self-contained) and the importance of identification of the various addresses for the prescription message were important concepts in highlighting the quality of prescriptions. Introducing ePrescriptions will not solve all quality issues.

The understanding of the strong interdependence between the practices can contribute to find new opportunities to improve drug utilization using information technology as an instrument. The theories used have made various contributions in providing important 
concepts for analyzing phenomena and their relationships. The GEM model contributed largely to highlight the interdependence of the practices, particularly with its concept of a forum/market level distinct from the dyadic communication one.

It was important to view the communication settings as part of a shared process, spanning over different market/forum levels, from the act of issuing a prescription to the consumption of medical drugs by the patient. Viewing ePrescribing this way makes it possible to better understand the multi-functionality of the ePrescription message and its role in various phases of the communication.

The notion of exchange phases points towards the need to make a decision about the scope of the process. This guided the analysis of the link between the different forum/market levels with questions like; what do we complete in the completion phase, or what kind of the assessments are made?

The GRM model contributed with the overall insight that ePrescribing encompasses both regulating and regulated practices and to show the specific regulative role of the prescription on the dispensing practice and the pharmacy market.

The socio-pragmatic framework contributed particularly to analyze the multiple functions of the ePrescription message in ePrescribing.

The three models complemented each other. The GEM and GRM model's focus is to get an overall understanding of the exchange (actors, phases, objects, activities) between parties and how exchange is regulated. The socio-pragmatic framework contributes with guidance on the various social acts that are linked to the communication act, i.e. the multifunctionality of the message.

The models also overlap each other, particularly when it comes to analyzing the context of the communication. There is no clear separation of the kind of phenomena that are captured in the models. Instead, they give guidance in viewing various aspects of the same phenomenon.

We think that the usage of the three models in the domain of ePrescribing also contributes to the empirical grounding of these theories and their usefulness in analyzing and modeling such a complex domain as ePrescribing.

A general conclusion is that this kind of analysis sheds light on those social acts hidden behind the systems and documents in the process.

\subsubsection{Elements of a practical theory on ePrescribing}

In this section, we will summarize the most important elements of a practical theory on ePrescribing. For a detailed description, see respective section in this chapter. 
ePrescribing - prescription as a regulating act

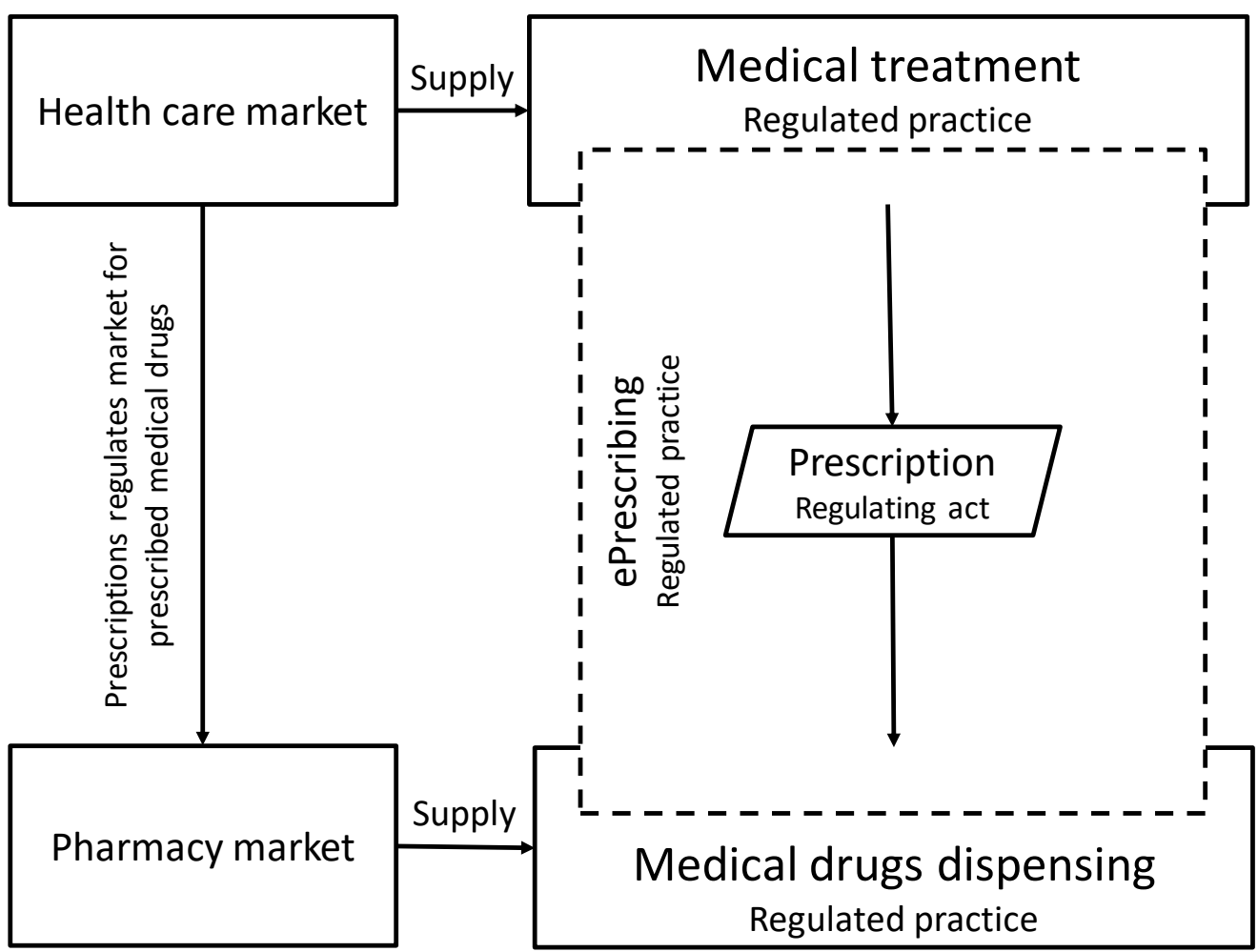

Figure 35 Prescription as a regulating act on the pharmacy market.

ePrescribing (see Figure 35) is a shared work practice with an exchange between work practices in two different markets, the prescribing as part of a medical treatment in the health care market, and the medical drug dispensing in the pharmacy market. These markets contain each of them separate work practices linked to various services supplied. These work practices are highly regulated through legislation and business rules. 


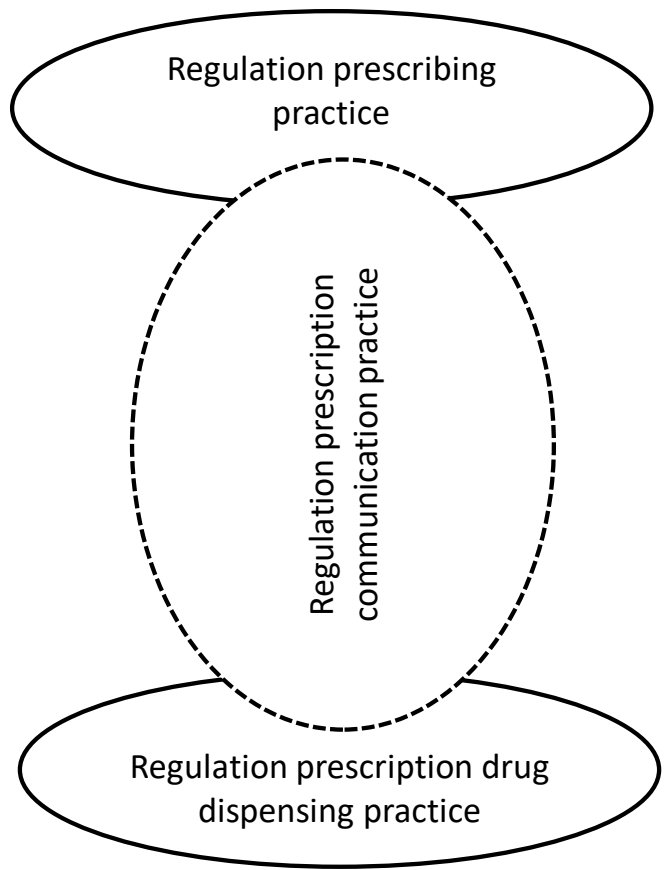

Figure 36 Regulation of different practices in the shared work practice of ePrescribing.

One shared work practice is ePrescribing. This shared work practice is regulated by a combination of legislation and business rules (see Figure 36). There are regulations of the following:

a. the practice of prescribing in the health care market regulating prescribers and patient rights and duties;

b. the relation between the pharmacies and the prescribers communicating prescription (for ePrescribing, fax prescriptions, and paper prescription forms);

c. the prescription drug dispensing practice regulating the rights and duties of the pharmacist and the patient in the pharmacy market.

These regulations in total are the regulation of the shared work practice of ePrescribing. These regulations are to be found in various (and many) legal and business documents. The regulation of the communication of prescriptions (b) is regulated in various ways. There are legal directives that there must exist a contract regulating a secure and reliable communication between a prescriber agent and a pharmacy agent when using ePrescriptions. The legal directives do not regulate the details of the contract. When using fax prescription (faxing a copy of a paper prescription to a pharmacy), there must also be a contract between the communicating parties. Interestingly, regarding paper prescription, and in a sense, it is natural, there is no regulation of the communication of the prescription 
per $\mathrm{se}^{117}$, but there are detailed rules on the prescription form layout in the legal directives. The communication is not involving a direct communication between the prescriber and the pharmacy as the patient is the carrier of the prescription and the communication act. Thus, in this case, the communication act towards the pharmacy market and the pharmacies is implicit.

From a macro point of view, the prescription issued from the health care market in the ePrescribing work practice is a regulating act of all the acts in the pharmacy market regarding prescribed medical drugs. In this sense, the prescription regulates the potential sales volumes of prescription drugs, the specific prescription drug to de sold (taking in account of generic exchange rules), and its cost for the patient and pharmaceutical benefits. One can view a prescription as a call option (right of the patient to buy and duty of the pharmacy to sell) on prescribed medical drugs in the pharmacy market issued by prescribers in the health care market.

\section{ePrescribing - interdependence between Health care and Pharmacy}

ePrescribing (Figure 37) consists of four generic phases of provision and usage: initiation, agreement, fulfillment, and completion (for a description of these phases applied to ePrescribing see 6.4.4 and 6.4.5).

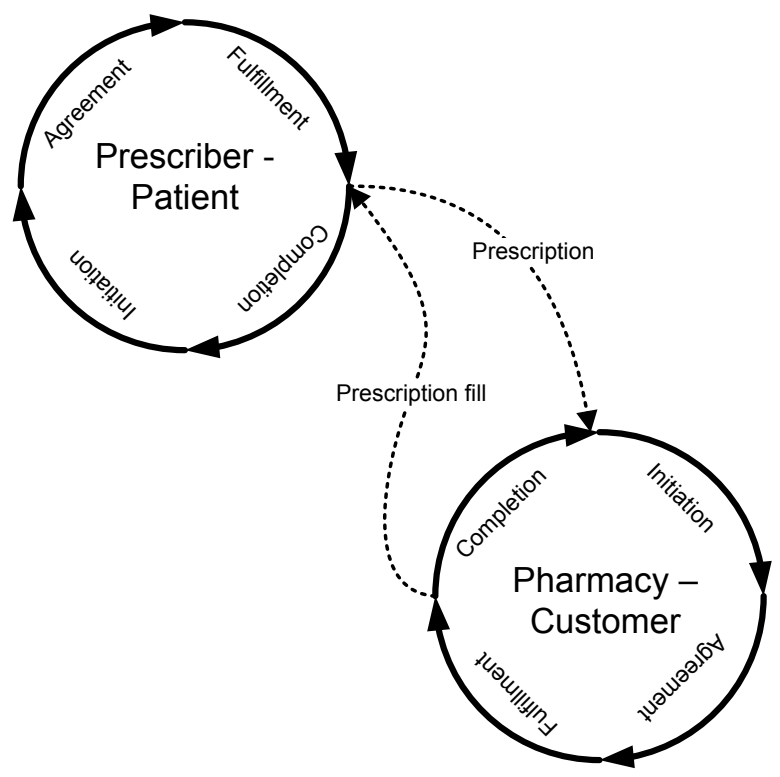

Figure 37 Generic phases in ePrescribing and their interdependence (inspired by Action Work Flow approach [71]).

${ }^{117}$ Only implicitly that the pharmacy is required to use the paper prescription original. 
These phases exist between the prescriber and patient (medical treatment) in the health care market, and between the pharmacy and customer (pharmacy dispensing) in the pharmacy market. The work practices in the different markets are interconnected with prescription and prescription fills. Thus, prescription and prescription fills have an additional role of interrelating the work practices, both in initiation and completion of the work practices.

\section{ePrescription is a social act between prescriber, patient, and pharmacist}

A prescription, and likewise an ePrescription ${ }^{118}$ today, is a complex social act between prescriber, patient, and pharmacist. This complex social act is summarized in four aspects of a prescription:

- media, a form and mode of communication;

- medical content and context;

- legal authorizations;

- economic commissions.

A prescription has thus multiple functions.
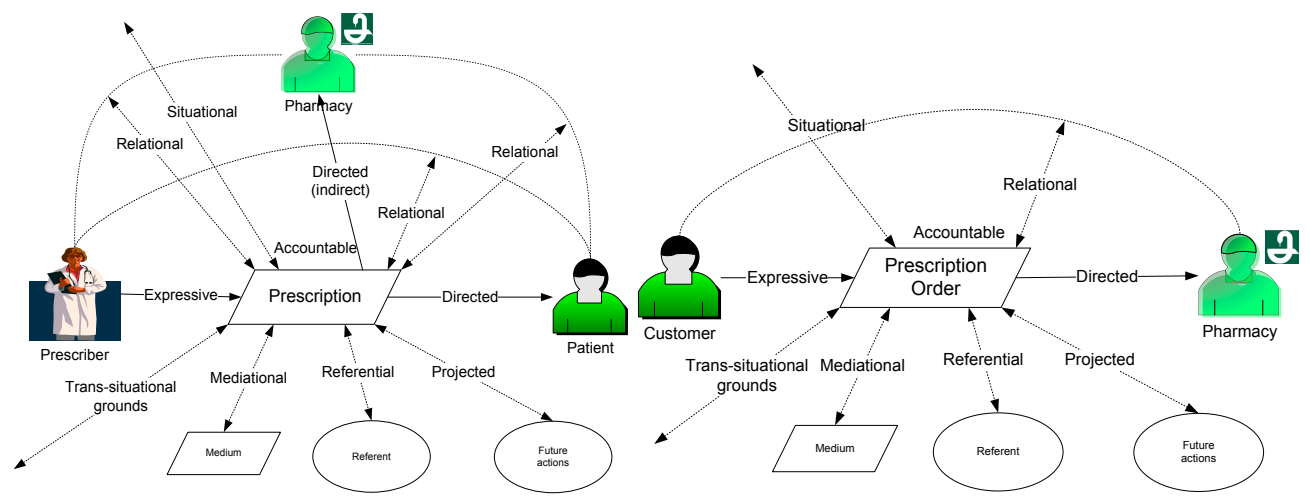

Figure 38 Facets of ePrescription communication.

Figure 38 illustrates the application of the socio-pragmatic communication analysis made in this chapter. It contains different facets of the communication function in a prescription communication act (see below) and a definition of different addresses such as locutor and addressee. There are three actor settings in ePrescribing:

- prescriber as the locutor and the patient as direct addressee;

\footnotetext{
118 ePrescriptions are not merely an electronic transfer mode today but also the original artifact. The difference to a paper/fax of phone prescription is its media form.
} 
- pharmacy or a pharmacy agent is an indirect addressee of the prescription. This relation between the prescriber and the pharmacy is explicitly regulated in ePrescribing using contracts between the parties. Other forms of media and how they should be addressed to the pharmacy is also regulated but not to the same degree ${ }^{119}$ as in ePrescribing;

- customer (patient in relation to the prescriber) ${ }^{120}$ as the locutor and the pharmacy as the direct addressee. In this case, the communication is resulting in a prescription order based on the prescription.

For a detailed description of the various communication situations and the multiple communication functions see 6.5.3 and 6.5.4.

From the socio-pragmatic analysis of ePrescription (or of prescription in general for that matter), we can summarize different functions of the ePrescription communication in a table (see Table 16).

\footnotetext{
${ }^{119}$ Paper prescriptions are regulated in the prescription rules with explicit directives for the printed page layout of the prescription form; fax and phone prescriptions are also regulated in the prescription rules.

${ }^{120}$ A customer at a pharmacy is sometimes referred to as a patient to denote that the dispensing is part of a medical treatment even if the person in not actually a patient in relation to the pharmacy.
} 
Table 16 Summary of ePrescription communication functions.

\section{Function Examples applied to ePrescribing}

Trans-situationally A prescription is a highly-regulated communication act that is compliant defined in prescription, pharmaceutical benefits and work practice rules. The ePrescription exchange is further regulated in eCommunication contracts (see 5.1.1)

Situationally Prescriptions are issued in a context of a medical treatment of a responsive patient in outpatient care

Expressive The prescription is an expression of the knowledge and intent of the prescriber for a medical treatment of a patient

Referential The prescription contains references to prescribed medical drugs and the actors involved such as the workplace, prescriber, patient, and pharmacy/pharmacy agent

Accountable A valid prescription is comprehensible for the patient and the pharmacist in order to make it useful in ordering, dispensing, and consumption of the prescribed medical drug

Directed The prescription contains references to actors, who directly or indirectly relates to the prescription, such as the patient, prescriber, and pharmacy agent or pharmacy

Relational The prescription contains and establishes a number of social relations between the actors, such as directives, commissions, and declarations of authorization

Projected

The prescription projects dispensing and the usage of the drug in a medical treatment in time (short or long-term treatment)

Mediational A prescription can be in various media forms: paper, phone, fax, and ePrescriptions

\section{Main functions of prescription in ePrescribing}

We have seen from this summary of the main elements of a practical theory on ePrescribing that the prescription is a focal point in ePrescribing and has the following main functions:

- a regulating act that on the:

- transaction level regulates each dispensing transaction of prescribed medical drugs in the pharmacy dispensing practice; 
- infrastructure level regulates the health care market, with a similar function as of a call option which is issued by a prescriber towards the whole pharmacy market regulating the sales of prescribed medical drugs. It does also influence the cost of pharmaceutical benefits;

- an interdependent link that connects two different work practice from initiation to its completion as part of the overall shared process of ePrescribing;

- a social act between the prescriber, patient, and pharmacist which have medical, legal and economic consequences.

\subsubsection{Conclusion}

This inquiry contributes with a practical theory on ePrescribing which can be utilized in further inquiries by practitioners, developers, and policymakers, when developing new functions, major changes or making improvements of the ePrescribing practice.

The practical theory on ePrescribing, first presented in 2008 [42], has shown to be robust to changes even if the pharmacy market in Sweden has gone through its biggest change in 30 years. One criterion developed by Cronen [133] for evaluating the reliability of practical theories is the ability to include and assimilate new data. The ability of the practical theory to assimilate the reality of the new re-regulated pharmacy market demonstrates its ability to include new facts without changing its fundamental properties.

A practical theory should be useful for practitioners to better understand their practice in order to change it. In order to improve its utility and to test its validity, the practical theory has to be used and developed in new inquiries. For Dewey knowledge was always end-in view and needed to be tested and refined in new inquiries.

The practical theory on ePrescribing is empirically grounded in ePrescribing in Sweden. Thus, it is first of all a generalization of ePrescribing in Sweden. However, it aims to be a general practical theory of ePrescribing possible to generalize to other countries. See for example a reflection made on ePrescribing in US in light of ePrescribing in Sweden in section 8.4.1 Network governance in ePrescribing - comparison US - Sweden. A future research would be to evaluate the practical theory on ePrescribing in other countries as well as evaluate it in relation to the present evolution and possible changes of ePrescribing in Sweden.

The application of practical theories like GRM, GEM and socio-pragmatic communication analysis have given further support for the suggestion that they are useful in analyzing interoperation between work practices, particularly between different organizations and in highly regulated and interconnected markets. 


\section{Context of interoperation and interoperability}

In section 2.1, we have made a review of interoperability concepts and frameworks and in chapter 4, 5, and 6 , we have described our experience and research in improving interoperability of ePrescribing in Sweden.

To better understand what interoperability is about, we think it is necessary to analyze the context of interoperation. We view interoperability as a quality of interoperation. Thus, if we do not understand interoperation and its context, we will have difficulties to define and understand interoperability.

This chapter aims at theorizing about interoperation and interoperability with a focus on the context of interoperation in order to arrive at a new definition of interoperability that integrates this context. We will use and further elaborate this definition in chapter $9 \mathrm{~A}$ practical theory on interoperation and interoperability.

Information systems are used in interoperation to perform and coordinate actions between actors within and between work practices and organizations. This implies that it is important to understand the role of information systems and how they affect interoperability.

However, information systems are usually associated with applications inside an organization, while interoperation typically is taking place between organizations. Thus, information systems need to be able to support the interaction between organizations. To do so they need to share an infrastructure for communication and institutional objects (se section 2.2.3 Features of information infrastructure). The concept of an information infrastructure ${ }^{121}$ highlights the need and role of infrastructure in inter-organizational interoperation.

${ }^{121}$ See also section 2.1.8 From technical to a broader view on interoperability. 
Interoperation involves communication between agents in separate organizations. Thus, there is a need for mutual understanding of this communication. Different views on how to achieve this mutual understanding will affect how to view interoperability.

Another issue is how to understand the role of messages in this type of communication. Interoperation is not only about mutual understanding; it is also about coordinating actions. Furthermore, we need to analyze the role of a common ground for understanding and action, and the context of communication and interoperation when using an information infrastructure as a mediator compared to a face-to-face communication.

This chapter aims at addressing these questions.

The chapter is structured as follows.

In section 7.1 Interoperation and interoperability - initial analysis, we make an initial analysis and definition of the relation between interoperability and interoperation. The aim is to provide an initial definition of interoperation and interoperability and its context. In the next sections, this context will be further elaborated.

In section 7.2 Information systems and information infrastructure, we define our use of the concepts information system and information infrastructure and describe how these relates to interoperation.

In section 7.3 Theories of meaning and views on interoperation and interoperability, we deal with theories of language and meaning and how they influence the conception of interoperability.

In section 7.4 Messages in the context of interoperation, we analyze how messages are used in interoperation.

In section 7.5 Communication and coordination in a work practice, we analyze the coordinating function of messages and other coordination mechanisms used in work practices.

In order to have a successful communication and to be able to coordinate actions in interoperation, it is necessary to have a common ground between the participants. This notion is defined in section 7.6 Common ground for interoperation.

Interoperation using an information infrastructure implies a mediated communication setting which is different from face-to-face communication. How this setting will influence the means and mode of communication for interoperation are analyzed in section 7.8 Communication settings for interoperation.

Quality of communication is essential for interoperability. In section 7.9 Actability of information systems for interoperation and communication quality, communication quality criteria for communicative action and ability to act using information systems are described. 
The concept of interoperability is elaborated and defined in section 7.10 Definition of interoperability. These definitions are basic concepts used in the theory on interoperation and interoperability presented in chapter 9.

\subsection{Interoperation and interoperability - initial analysis}

In this section, we will make an initial analysis of interoperation and its context. This context will be further developed in the coming sections and finally be synthesized into a definition of interoperability in section 7.10 Definition of interoperability.

\section{Concept of interoperation}

A linguistic analysis [13] of the concept interoperability gives that interoperability is a noun derived from the verb 'interoperate' and the adjective 'interoperable'. Interoperability is here viewed as a capability to interoperate.

Collins English Dictionary [232] defines "inter" with two meanings: between and together, mutual/reciprocal. "Operate" comes from the Latin word 'operāri' which means 'to work'. Collins English Dictionary has mainly two meanings of operate: perform or control work. From this, we suggest that:

"to interoperate is to mutually perform and control work between actors"

Here, we assumed that work is made by actors "interworking".

Interoperate can be seen as part of a work practice. A 'practice' in social theory is defined as:

“... embodied, materially mediated arrays of human activity centrally organized around shared practical understanding." [67] (our emphasis)

In work practice theory, which focuses on work and not just any social practice, actions by producers for a client are central. Thus, work is about actions, both material and communication actions. [233]

Thus, to interoperate means that actors mutually perform and control actions within a practice which is organized around a shared practical understanding.

To "mutually ... control actions" is very similar to a definition of coordination:

"Coordination is managing dependencies between activities." [234]

On coordination, see further subsection 7.5 Communication and coordination in a work practice. 
Thus, we can reformulate our definition as:

"to interoperate means that actors mutually perform and coordinate actions within a work practice which is organized around a shared practical understanding."

It is possible to view 'interoperate' as an ad-hoc activity, done for the moment, occasionally. Here, we focus on interoperation in a planned and controlled context. [57].

Interoperation is a noun that denotes a controlled and repeated sequence of actions over time. Interoperation is a process of controlled and repeated sequence of mutual actions.

Interoperation is here assumed to take place in a communicative setting that is mediated, prescriptive and non-personal. See further section 7.8 Communication settings for interoperation for a definition of this setting.

Interoperation is using an information infrastructure (see section 2.1.8 From technical to a broader view on interoperability for a definition) as an instrument for communication.

In the following sections, we will elaborate further on the various aspects of this context of interoperation.

\subsection{Information systems and information infrastructure}

In this thesis, information systems are viewed as vehicles for communication and social action. Information systems are formal linguistic systems used to communicate between people to support their actions.

Goldkuhl and Ågerfalk define an information system as:

"a technically implemented social system consisting of an action potential (a repertoire of actions and a vocabulary), a memory of earlier actions and action prerequisites, and actions performed interactively by the user and the system and/or automatically by the system." [235]

This definition and the view that an information system's fundamental function is to be an instrument for communication and action, we think is the most appropriate to understand the role of information systems in interoperation.

Particularly, we note (see further 7.9) that the notion of actability of information systems suited well our view that information systems were essentially an instrument for communication and action between actors. Goldkuhl defined information systems actability as:

“... an information system's ability to perform actions, and to permit, promote and facilitate the performance of actions by users, both through the system and based on information from the system, in some business context." [236] 
However, information systems have traditionally been considered as mainly intraorganizational systems, as applications within organizations. This can be illustrated by a quotation from Frisco (Framework of Information System Concepts) ${ }^{122}$ :

"Information systems exist exclusively within organizations, to support their work, and to fulfill their information and communication requirements. To understand information systems, we therefore need to understand organizations, what they are, how they work, what their components are, and what their structure and behavior is. Thus, we will borrow from organization science. Organizations can be viewed as systems, organizational systems. In this view, information systems are specific sub-systems of organizational systems." [237] (our emphasis)

This traditional intra-organizational perspective on information systems, labeled organizational informatics by Beynon-Davies et al [238], is different from the context of interoperation between organizations.

Thus, the use of the term information system may vary depending on the context. In this chapter, we use it in a generic sense when analyzing what an information system is in relation to actors in a business context with an inter-organizational focus.

The generic use of the term information system is useful when we want to talk about the phenomena in a general sense and analyze for example how actors use and relate to an information system and how it is related to a social system like a work practice or business. In using the concept of information system in a generic sense, we can benefit from general theories about information systems to understand the phenomena we are studying.

Traditionally, information systems are often viewed as applications [60] to support a specific business function, such as payroll, inventory, or supply chain system. Thus, it has a certain function for a specific community of users.

In the section 2.1.8 From technical to a broader view on interoperability, we introduced the notion of an information infrastructure as an essential infrastructure for interoperation. We referred to a definition by Hanseth and Lyytinen of an information infrastructure as:

“... a shared, open (and unbounded), heterogeneous and evolving socio-technical system (which we call installed base) consisting of a set of IT capabilities and their user, operations and design communities." [60]

Hanseth and Lyytinen makes a distinction between information systems viewed traditionally as a kind of application with a certain business function and information infrastructure that does not have a specific function, at least does not serve specific organizational tasks.

${ }^{122}$ FRISCO was an initiative from International Federation for Information Processing (IFIP) to standardize the concepts used in the subject field of Information Systems. 
The aim of Hanseth and Lyytinen is to contrast a traditional view of information systems as controlled applications with clear organizational tasks with an information infrastructure that is much more open, evolving, and heterogeneous crossing organizational borders.

While we recognize these contrasts, we prefer to see it as a continuum. At one end, we have a universal information infrastructure such as internet and, at the other end, we have applications within an organization with their own internal information infrastructure. In fact, there is no medium or large enterprise today that do not have an internal information infrastructure that are connected to the outside world in many complex ways. This is in line with the classification of infrastructure made by Hanseth and Lyytinen: Universal, Business sector, and Corporate infrastructure.

Another argument to view information systems as a continuum is that complex information infrastructures evolve from the need to share work and therefore interconnect and share information system resources, often among a limited community of actors. This was the case with the evolution of internet and it is confirmed by the experience of the evolution of an information infrastructure in implementing ePrescribing in Sweden (see case study 4 Implementing ePrescribing in Sweden - case study). Initially, there evolved certain so called inter-organizational information systems ${ }^{123}$ that focused on the interoperation of a specific process, in the beginning, the transfer of ePrescriptions from the local prescriber to the local pharmacy. This process had specific business functions that were shared between the actors. However, with the evolution of other resources and processes linked to this process, a whole infrastructure for ePrescribing linking the medical and pharmaceutical care evolved. Thus, the scope, objective, community, and practice evolved over time, from a simple end-to-end transfer of prescriptions, to become a more general-purpose information infrastructure within and between business sectors.

In the definition above by Hanseth and Lyytinen, the installed base "consist of a set of IT-capabilities and their user, operations and design communities". A set of IT capabilities are viewed as applications with a certain purpose, a view close to what traditionally have been named information systems, or applications. Hanseth and Lyytinen define IT capabilities as "the possibility and/or right of the user or a user community to perform a set of actions on a computational object or process" [82].

Thus, within an information infrastructure there exist traditional information systems or applications that are part of the shared resources in a community. The information infrastructure continuously evolves in planned or unexpected ways; it is heterogeneous in the sense that it contains various types of components such as technical, organizational,

\footnotetext{
${ }^{123}$ Already in 1982, Barret and Konsynski [239] forecasted that new networking technologies and system development techniques would change the internal focus to more frequently involve the external interface. They defined Inter-Organizational Information Sharing System as a "general term referring to systems that involve resources shared between two or more organizations."
} 
and institutional components. They are, to various degrees, open in the sense that they are based on standards (vertical and/or horizontal) enabling different actors to be integrated.

We use the term information infrastructure to refer to a context of use of information systems. This context of use is characterized by sharing and interconnection of systems and practices in complex ways, among organizations, within or between private/public sectors or in the society at large. Furthermore, an information infrastructure evolves out of the needs to share and interconnect information systems for interoperation. Thus, this notion suits well our studied phenomena which is interoperation between organizations, within or between sectors, using shared information systems interconnected in a complex pattern and which evolve over time.

With this notion, we are able to integrate and discuss research studying the evolution of information infrastructures in order to better understand how they evolve and conditions for their evolution. See section 2.1.8 for a description of the relation between information infrastructure and interoperability.

We have also used the term information infrastructure to better understand its evolution for ePrescribing over time. The evolution of an information infrastructure is essential for the evolution of interoperation and interoperability.

\subsection{Theories of meaning and views on interoperation and interoperability}

Semantic interoperability is considered an important research field in order to achieve interoperability in eGovernment and Health care [5, 14, 240]. With this background, one would expect a vivid discussion on basic theoretical issues regarding meaning theories and the context of communication. However, this is seldom the case. Underlying theories or assumptions are instead implicit or not argued in scientific papers.

We have earlier stated that to understand interoperability, we must first define the context of interoperation. In our view, interoperation is made in a work practice context of interworking among actors of different organizations using information infrastructures. Thus, theories on semantic interoperability must deal with communication between systems and people. Theories about communication and meaning theories are therefore of prime importance, if one is going to understand the context of interoperation and thus of interoperability.

Another observation is that an implicit assumption of a theory of communication or meaning is likely to influence how to view interoperation and interoperability problems.

This section aims at describing how theories on meaning influence how to view interoperation and interoperability. We conclude the section by discussing their influence on the use of terminologies and semantic interoperability. 


\subsubsection{Approaches to theories on meaning}

To grasp different approaches in such an extensive research area as theories on meaning, we have chosen to depart from a characterization made by a well-known theoretician on human communication. In an essay from 1988 [241], Habermas discusses three different approaches in a theory on meaning: Formal semantics, Intentionalism, and Use theories of meaning.

As a reference point to discuss these approaches he refer to Bühler [242] and his organon model of language. In Bühler's model, language has three semantic functions:

- expressing the intention of the speaker;

- representing objects and state of affairs;

- establishing relations between the sender and receiver.

\section{Objects and states of affairs}

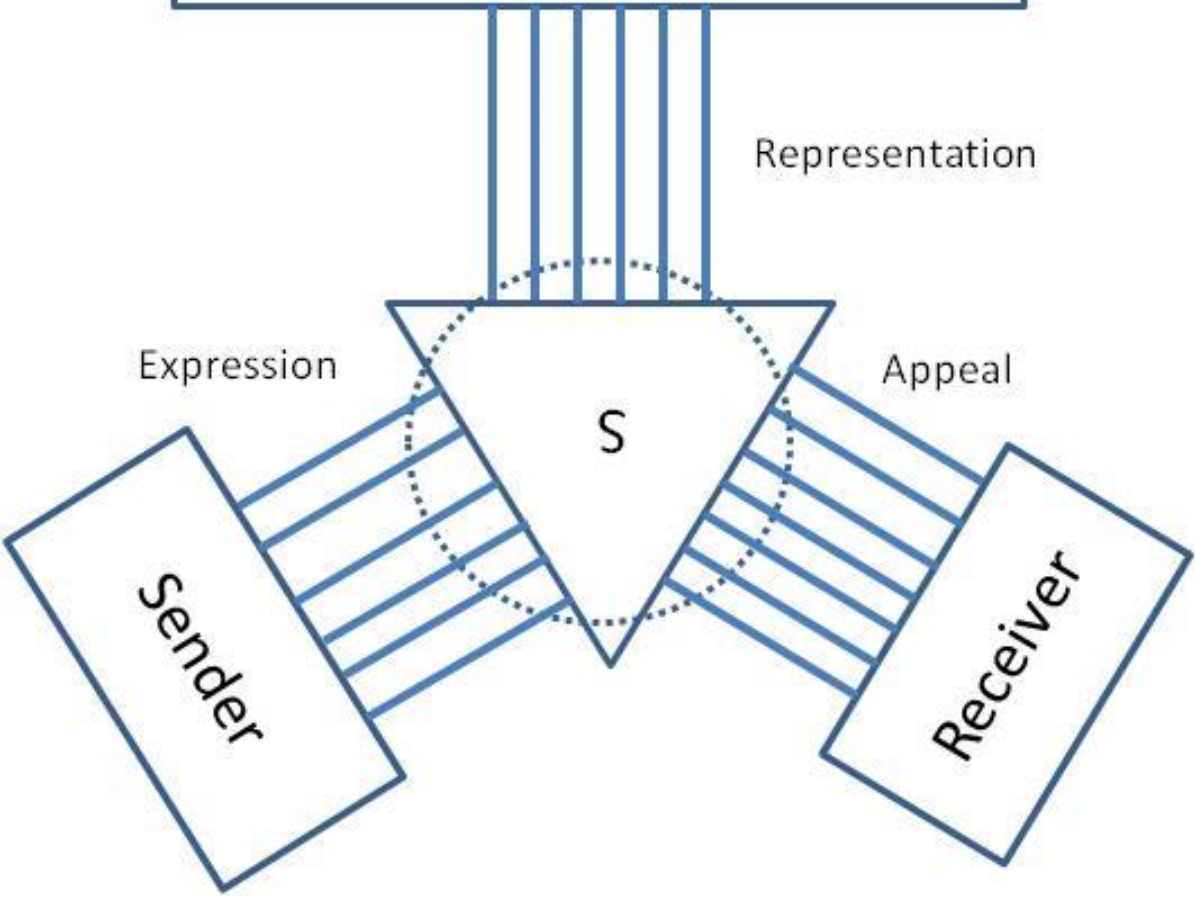

Figure 39 Bühler's schema of semantic functions of language (Re-drawn based on the original figure in [242]). 
In the models (Figure 39 and Figure 40), the Sign (S) have three functions:

- symbol in its coordination to objects and state of affairs (representation);

- symptom on its role to express inner states of the sender (expression);

- signal in its role of making an appeal to the hearer "whose inner and outer behavior it directs ..." [242] (appeal).

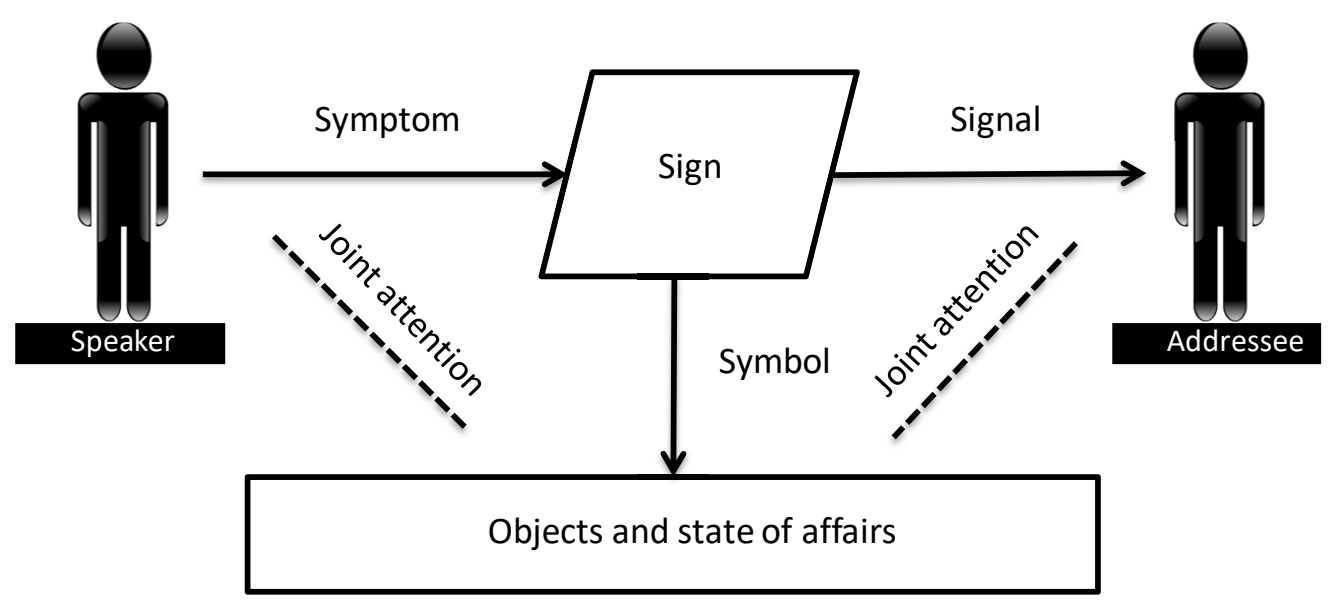

Figure 40 Various functions of the complex Sign according to Bühler with additions of dotted lines to emphasize the joint attention of the actors in the communication. We added the dotted lines of joint attention proposed by Sinha [243].

Joint attention, which is added in Figure 40 (as dotted lines) is basic in all human communication, and is important in establishing a shared reference in a communicative situation. Joint attention is an interaction between at least two individuals coordinating their attention to an object of mutual interest [244].

For Bühler meaning emerged from an integration of symbolic and encyclopedic knowledge [245], foregoing the idea in cognitive linguistics [203] [243] [245] [246] that knowledge of language is not a specific faculty of mind but is part of the overall cognitive abilities of man, pre-figuring the critique of Chomsky's view that knowledge of language is autonomous from other cognitive functions.

After presenting Bühler's model, Habermas [241] describes how the different theories' of meaning have evolved with a focus primarily on one semantic function of the language while largely ignoring the other aspects:

Formal semantics focus on the grammatical form of a linguistic expression. Language is seen as independent of speaking subjects. The intentions and cognition of the language actors or actual language use are of secondary importance. A theory of meaning is based on a correspondence between the linguistics expression and the external world independent of the actors. Meaning is based on conventions by language users. 
Intentionalism uses signs as a vehicle (tool) for communicating the belief or intention of the speaker to the addressee.

Use theories of meaning focus on the action character of meaning, which is in the use of language, not something defined outside of language use and the actors.

Habermas concludes that each of the three theories favors one aspect of the process of reaching an understanding:

"They seek to explain the meaning of a linguistic expression from the perspective of what is meant (as intended meaning), or from the perspective what is said (as literal meaning), or from the perspective of use (as utterance meaning)."[241]

Then, Habermas presents a forth approach using speech acts that take into consideration the three functions of language in Bühler's model. We will not deal with this here further. See Eriksson [247] for comparison of Searle's and Habermas' versions of speech act theory and a presentation of a generic communication model. It is clear that Habermas sees language as a means to represent, communicate, and act.

The three approaches to meaning presented by Habermas will be one reference point when discussing approaches to meaning that follows.

\section{Selection of meaning theories}

There are many meaning theories. Here, we give some reasons why we have chosen some of them for discussion on different approaches to meaning.

An old tradition which explicitly dealt with meaning is semiotics with origins in the history of philosophy. Semiotics is the study of the role of signs and symbols in human communication. Umberto Eco [248] claims that it has ancient roots in philosophy as far back as Aristotle and Plato. At the turn of the 19th century, it became a discipline of its own with the advance by for example Pierce's more elaborated analysis of the sign. We will review some representatives of semiotics that are well known in teaching on informatics such as Ogden \& Richards and some views on semiotics from the tradition of the pragmatism philosophy, which have an influence on information systems research. This will be presented under the heading of Semiotics.

The other main influence to meaning theories in the 20th century comes from the philosophy of language.

One tradition is what Recanati [249] call ideal language philosophy with prominent figures such as Frege, Russell, and Carnap. First of all, they were concerned with formal languages and not directly concerned with natural languages. Later in the 1960s, there were efforts in this tradition to use formal languages to study natural languages. With Montague, there was a breakthrough for what would later have become formal semantics. Another important figure close to formal semantics is Chomsky which in the end of 1950s focused on the formal study of grammar in contrast to the prevailing descriptive approach. 
This tradition of formal treatment of natural language and semantics is still dominant within linguistics and in the research field of interoperability, particularly in computer science. This tradition will be presented under the heading of Formal semantics and its critics. As the title indicate, many of those working with formal semantics in the $60 \mathrm{~s}$ also began to criticize the foundation of formal semantics and the generative grammar of Chomsky. This have been coined 'The Linguistic War" by Harris [250] which essentially was a "war" within this tradition about the relation between syntax and semantics. Later, Lakoff and others have formed new research branches such as cognitive linguistics, breaking with the tradition of formal semantics inspired by psychological and other philosophy of languages theories.

Another important tradition within philosophy of language is the ordinary language philosophy. This tradition was a reaction to the ideal language philosophy, which approach they thought hide important features of natural language. They proposed to focus on the ordinary use of language. Prominent figures in this tradition are the late Wittgenstein, Austin, and later in the 60s, Searle. This tradition has an importance influence in linguistics and psychology as well as in informatics, through the Language Action Perspective on information systems. This stream of thought will be dealt with under the heading Doing things with words - speech acts.

\section{Semiotics}

Semiotics is an important field when discussing semantic theories of language. According to Peirce semiotics is "the analytical study of the essential condition to which all sign are subject," (Quoted in [251]).

We will present and discuss briefly views on meaning by Ogden and Richards, and of Pierce, Dewey, and Morris, and particularly the latter's separation of semantics and pragmatics, which have had great influence within linguistics, but also on theoretical underpinnings of theories on semantic interoperability.

\section{The Meaning of Meaning - Ogden/Richards}

Ogden and Richards published in 1923 their famous work The Meaning of Meaning (MM). [252] They introduced three concepts, Thought, Referent, and Symbol and analyzed their relations in a diagram which has been called the 'Semiotic triangle', which is taught in any course in information systems (see below).

Ogden and Richards studied first of all language and symbols in their role of influence on thought, as an instrument for the communication of thoughts and ideas. [252]

They warn against the common belief that word means anything by themselves and empathizes the role of words as instruments and it is only,

“... when a thinker makes use of them that they stand for anything, or, in one sense, have 'meaning'. They are instruments." [252] 
The study of meaning by Ogden and Richards is focused on the referential aspect of meaning.

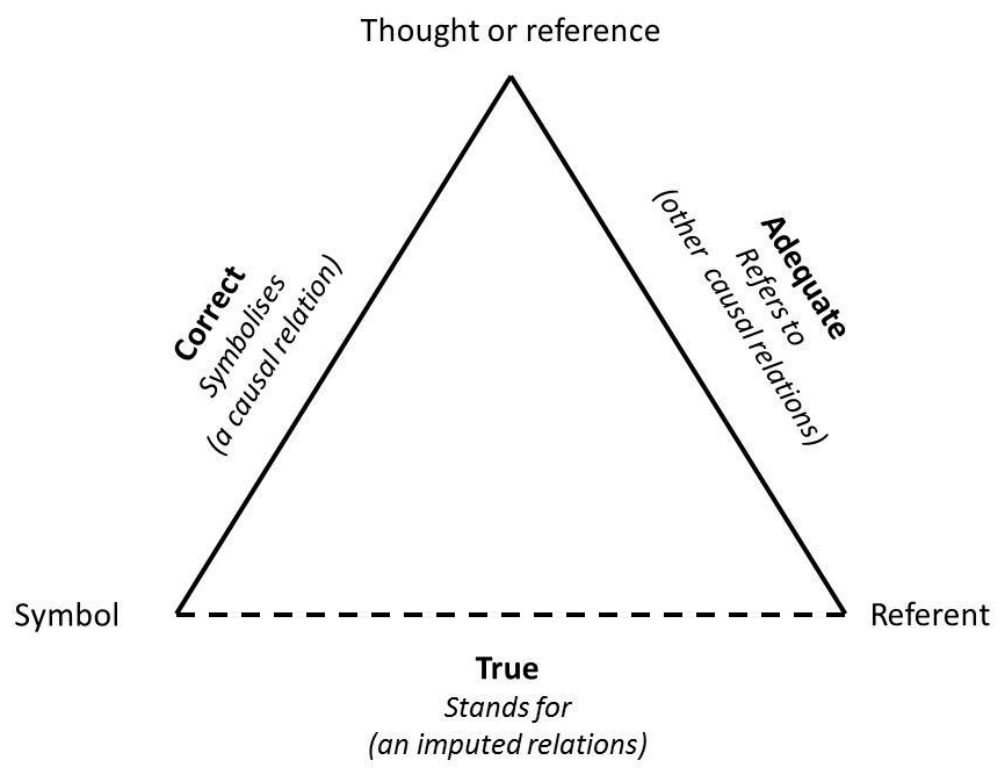

Figure 41 Ogden's and Richards semiotic triangle redrawn from MM [252].

Between Thought and the Referent, there are several relations with are linked both to what a statement refers to in terms what the speaker has in mind and potentially what the hearer has in mind when interpreting the statement. This relation by Ogden and Richards can be viewed as a sign of an intentionalism point of view, focus on 'meaning in the head'.

Between Symbol and Referent, there exists no direct relation, "which consist in its being used by someone to stand for a referent." (our emphasis [252])

The relation between Symbol and Referent is obviously an assignment of a social nature, not something objective outside the relation between the speaker and the hearer. This is close to Bühler's semantic function of the sign as a symbol in reference to objects and state of affairs, its referential function.

Finally, the relation between Thought and Symbol, the statement symbolizes in a correct way the thought or reference of the speaker. Thus, it is close to Bühler's semantic function of the sign as a symptom expressing the intention of the speaker.

The communication process is implicit in the triangle, as opposed to Bühler's model of three semantic functions of language, where sender and receiver are explicit. Their main focus with using the triangle as an instrument for analysis is to analyze the representational aspect of language. The triangle is presented in the chapter called 'Thoughts, Words and Things'. 
It is clear, if one reads the explanation of the triangle by Ogden and Richard, that it does not imply static dyadic relations between the three corners in triangle of thought, symbol and referent, but rather dynamic interdependent relations between them in relation to a statement or utterance of a speaker to a hearer, using language to communicate thought and ideas. [252]

In the same vein as the 'cognitivist' approaches, one can say that the approach of Ogden $\&$ Richard, in their focus on communication of thoughts, is close to the intentionalism approach described by Habermas above.

\section{Meaning and pragmatism}

C. S. Peirce is considered as the founder of semiotics [251] as well one of the founders of the philosophical school of pragmatism together with William James. Peirce theory of signs influenced Ogden and Richards in their work to publish MM, in which they published a comprehensible account of Peirce work as an appendix (appendix D §6).

Pierces theory of sign is rather complex ${ }^{124}$. We will here only describe in brief some basic tenets of his theory of signs. We will then critically, basing ourselves on Dewey, discuss a famous interpretation by Charles William Morris in his Foundations of the Theory of signs, in which Morris makes a distinction between semantics and pragmatics, claiming that he builds on Peirce semiotics.

A sign according to Peirce has not just a relation to what it represents or refers to but also a relation to an interpretant or a system of interpretants.

We can briefly summarize the triadic relation of Sign, Object (or designatum), and Interpretant in a diagram.

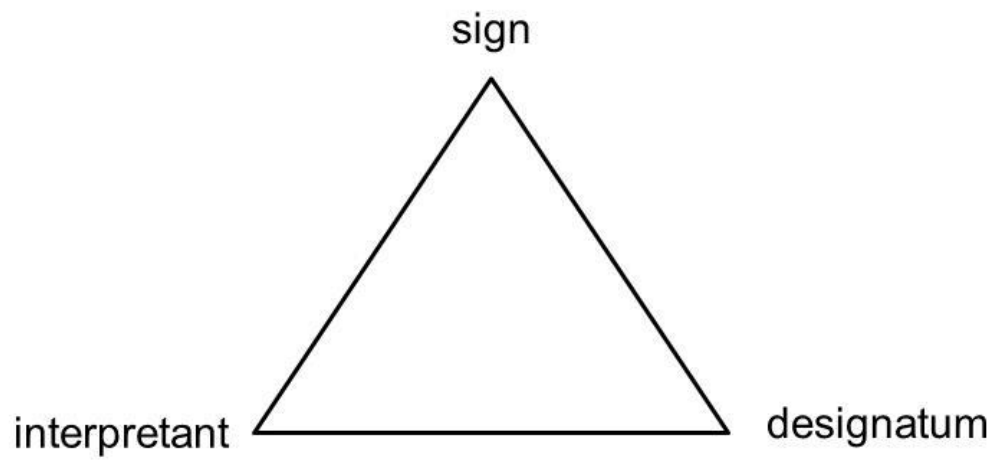

Figure 42 Pierce triadic relation of sign, designatum and interpretant.

A sign refers to a designatum and produces an effect in the interpreter which is the interpretant.

\footnotetext{
${ }^{124}$ In appendix D of MM, Ogden \& Richards writes: "Unfortunately his terminology was so formidable that few have been willing to devote time to its mastery, and the work was never completed."
} 
“... the relation among sign, object and interpretant is triadic and cannot be reduced to a set of combination of dyadic ones." [251]

Thus, meaning is not a static or a dyadic relation, where a sign map to an existing meaning but is something that emerges out of interplay between sign, interpretant and designatum, which is a similar view as held by Ogden and Richard (see above).

In Morris version of Peirce semiotic triangle, the interpretant is replaced with an interpreter. Then the triadic relation is parceled out in three dyadic dimensions, semantic, the relation between the sign and designatum, syntactic is the relation of signs to one another, and pragmatic is the relation of the sign and the interpreter.

Already in 1946 Dewey [253] - another important figure of the philosophy of pragmatism - could see what would be the result of Morris substitution of the interpretant with the interpreter. Dewey criticizes Morris to tear apart the integrated solution provided by Peirce, arguing that Morris reduces semantics to one dyadic relation. [205]

The separation of semantics and pragmatics have influenced linguistics and semiotics to a large extent. One of them is that the formal analysis of language became separated from the empirical knowledge how language actually was learnt and used and also from any notion of cognition. The separation of pragmatics and semantics and where to draw the boundary is debated $[254,255]$ and questioned by scholars. [256]

The social aspect of meaning is more elaborated by for example Dewey, Mead and the late Wittgenstein.

For Dewey, language is used as an instrument for a concerted action for a given end. Language is seen as a function of human association, where communication through language is part of establishing cooperation between actors in an activity. Understanding involves to anticipate together, making joint references and partake in action. Failure to understand means a failure to agree in action and to misunderstand is to do actions which have cross purposes. [257]

This view by Dewey has relevance for interoperability. Interoperation is not first of all for understanding each other, to communicate thought and ideas in themselves, but to communicate in order to act. For Dewey meaning and understanding is intimately linked to action and semantics cannot be separated from action, and thus semantics cannot be singled out from its use by the participants in a communication situation.

\section{Formal semantics and its critics}

Among researches and policymakers on interoperability and particularly regarding the term semantic interoperability, there is a dominant view of semantics close to formal semantics (c.f. ISO [51], HL7 [52]). This view sees semantics as something more or less detached from sender and the receiver. Meanings is formal, objective and is based on truth 
conditional semantics which view the meaning of a sentence as the conditions under which it is true.

Ordinary language philosophers did not accept that the meaning of a word could exist in a vacuum, out of the context of use. Although, there are not many explicitly defending the position today, that meaning can be studied outside of context of use, it still prevails in the separation in linguistics between semantics as the formal study of meaning and truth conditions and pragmatics as the study of language in use. This can also be found in the assumed contrast and separation between literal meaning and speakers meaning [249]. See also above on the separation made by Morris in the subsection Semiotics.

Another implication of formal semantics is that human thought could be studied by analyzing natural language using formal languages. There is little need for empirical studies of how human learns and acquires a language, how concepts are formed and used, and how ordinary language is actually used. Introspection and formal analysis of language with focus on syntax tend to be the dominant method of analysis [112] [258]. This has led to a separation between a formal study of language and an empirical study of language use and acquisition.

\section{Doing things with words - speech acts}

Another influential line of thought which have bearing on meaning in human communication is the theory of speech acts which emphasizes that language is not only about describing the world or of communicating ideas, but also about doing things with words. This school of thought emanates from the philosophy of language and the work by the late Wittgenstein and the school of 'Ordinary- Language Philosophy” at Oxford (Ryle, Austin, Grice).

In his first lectures in his famous 'How to do things with words', Austin declares:

"It was for too long the assumption of philosophers that the business of a 'statement' can only be to 'describe' some state of affairs, or to 'state some fact', which it must do either truly or falsely." [259]

He first shows that there are utterances, what he calls performative utterances that are neither true nor false but rather 'happy' and 'unhappy', i.e. they succeed or do not succeed. This was a critique of the dominant standpoint that meaning is the condition under which it is true.

However, the most fundamental contribution Austin makes is that when one speaks, one is always doing something, when uttering, we are always doing speech acts. Austin distinguished between locutionary act, i.e. "uttering a certain sentence, with a certain sense and reference", illocutionary acts, "which have a certain (conventional) force", and perlocutionary acts, "what we bring about or achieve by saying something”. [259]

Searle [227] develop the ideas of Austin. The illocutionary act is the unit of meaning in communication. When making an utterance, the speaker has an intention to utter, and a 
communication intention. Searle makes a distinction between speaker's meaning and sentence or word meaning, where sentence meaning is conventional intentions of words and sentences and speakers meaning are the intention speakers put into the words and sentences used in a particular speech situation. For Searle, the speaker's intention and meaning is the primary form of linguistic meaning. Meaning for Searle is derived intentionality. Meaningful utterances in the form of words, sentences, and symbols have thus a derived intentionality of speakers thought. [260]

The communication intention of the speaker towards the hearer is to make the hearer understand what the speaker is stating. Understanding is thus grasping meaning, recognizing speaker's intentions. Understanding is not considered a perlocutionary act, which is the effect and consequences it has for the hearer, such as doing something, get convinced, et cetera. Understanding the utterance is called illocutionary effect [227]. Clark [261] makes a critique of Searle, by not emphasizing the role of the hearer and its importance in shaping meaning. This aspect will be discussed in the coming section.

\subsubsection{What is intended, said and its use - summing up on perspectives on meaning}

In this section, we summarize our brief review of language and semantic theories. We will return to our initial starting point using Habermas' categorization and suggest how you can position theories within these categories.

Above we referred to Habermas [241] who categorized different approaches to meaning as:

- intentional - meaning is primarily a matter of speaker's meaning and intention;

- formal semantics - meaning can be studied separate from speaker and hearer, by studying the formal structure of sentences. Meaning is seen a truth condition between word and world;

- meaning is in the use - meaning can only be understood by studying the use of language by the participants in communication.

Briefly, one can say that the intentional approach is close to a psychological view of meaning, where meaning first of all is individual. Meaning is not something objective in the sense of true or false. Meaning cannot be studied by studying the language per se, but must also include the process of sensation, perception and conceptualization.

Although the research field cognitive linguistics does not have a one-sided view of meaning as only a cognitive process, a relation between world and mental structures (or rather between language and mental structures); their point of departure tends to be "cognitivistic" as Peter Gärdenfors [262] puts it. See also the view of Sinha [263] and others within cognitive linguistics who warn against this "cognitivistic" one-sidedness of meaning and promote to also view meaning from a social and action perspective. 
The new "turn" in linguistics like cognitive linguistics and neuro linguistics contribute with new insights about meaning construction which before had been passed to the background in linguistics and philosophy of language. Its empirical approach, to study actual language use and acquisition in contrast to the approach of formal semantics, have given new insights into the use of language. Thus, there are attempts to bridge the gap between a cognitive view on meaning and meaning as intersubjective and part of social action.

Formal semantics, which is an important research field within linguistics, has developed its approach to language, incorporating methods to cope with more complex formal language structures. The benefits of formal semantics are its insistence to stretch as much as possible the formal treatment of language. However, its focus on truth conditional semantics and reference to "object in the world" detached from the performed speech acts and its social context, limits its capability to handle the actual communication situation. The formal treatment of language and representation of conceptual structures makes important contributions to understand conditions for interoperability. However, it is too limited to understand the real complexity of the communication situation in the interoperation between human actors using information infrastructures.

The meaning as use approach is associated with the late Wittgenstein as the most prominent figure. Wittgenstein developed his approach in critique of his earlier approach in formal semantics. This may have influenced him put to the background the question of reference. His notion such as family resemblance and language games have important consequences also for a seemingly distant field as interoperability by showing the difficulty of creating exact definition of concepts and the limits of the applicability of vocabularies, limited to different language games. The empirical study of actual language use, inspired by Wittgenstein and others, on concept formation such as prototype theory, base level categories, et cetera. [264] have made important contributions.

In meaning as use approach one can also include Dewey, Mead and Symbolic interactionism by Blumer, inspired by Mead's "social psychology". For Dewey, language and meaning is inconceivable outside a social context. For Mead, the construction of the "self" is a social process and therefore is "individual meaning" at the same time social meaning. For Blumer meaning arises in the process of interaction between people. It is clear that the social aspect and particularly the primacy of common action is the starting point for pragmatism and symbolic interactionism.

One implication of this is that it is important to avoid an 'objectivist' approach to meaning as something outside the participants or a 'subjectivist" approach seeing meaning as individual, subjective and only in the "head", and a pure 'contextualist' approach which see meaning as only dependent on the context.

Thus, our approach is to view meaning as a joint construction involving both cognitive and social processes, as well as conventional and institutional meaning and common knowledge, which determine and influence each other. 


\subsubsection{Meaning theories and their implications on interoperability}

We have argued for the need to consider the context of interoperation to better understand interoperability. Consequently, we think it is necessary to consider the context of shaping meaning as essential in understanding interoperation and interoperability.

One can contrast two views on meaning, one 'objective' and outside the communication situation minimizing the influence of the context and the other emphasizing the context for meaning construction. The first view is what Recanati [265] calls 'literalism' and the second 'contextualism'.

In this section, we will contrast these views on meaning and discuss their influence on how to view interoperability.

We will first discuss their influence on how to regard semantics of terminologies and then the concept of semantic interoperability.

\section{Semantics of terminologies}

Agreeing on the terminology to be used in the communication between different parties is considered an important part of the capability to interoperate. Thus, we will here discuss the implication of semantic theories on the semantics of terminologies. See also section 2.3.3 and the subsection on standardized vocabularies, which discuss different approaches in terminology research.

The first line of thought (see above), seeing meaning as something objective outside the context of the communication situation, tend to emphasize that is the task of experts to define the meaning of a vocabulary, defining dictionaries, domain ontologies, instructions, et cetera. After this work of standardization, the defined meaning of words is ready to be used. This is what Gärdenfors [113] calls an oligarchical linguistic power structure for social meaning. This approach focus on 'literal' or 'linguistic' meaning separated from the use and user of the terminology. The use of terminology in a particular situation for a particular purpose is in this view regarded as 'pragmatics' and has nothing or little to do with meaning or semantics. From this point of view, it is also feasible to use the defined vocabularies and make them machine readable for computation and translation of vocabularies between different systems and applications. This tends to see semantics as contained in defined vocabularies for a domain or in the mapping between domains, encoded in a formal language.

Thus, the problem of semantic interoperability can be approached as a problem of translating or 'transporting' meaning from one expression to another, using rules for 
mapping data and some domain concepts that represent 'true statements' of a Universe of Discourse (UoD).

The second line of thought leads to another approach. Although, it does not exclude the use of expert definitions of vocabularies and formal languages, its emphasis is much more on the use, establishment and understanding of terminologies. Vocabularies and formal languages are instruments in the meaning construction, not containers of meaning. From this follows an understanding of the limits of lexicons, the difficulty of definitions, and the limits of the scope of applicability. Within terminology research there is an increased concern about how terms are actually used in various social and communicative contexts. $[22,110]$ The fact that meaning is changing and not fixed once for all implies that, with the use of information systems, meaning will change over time. Thus, meaning should also be studied from a diachronic (historical) point of view. [24] Consequently, the meaning in interoperation has to be established, maintained, and developed.

\section{Semantic interoperability}

We have in section 2.1 Interoperability concepts and frameworks discussed the concept of semantic interoperability. We will briefly return to this concept with a focus on different approaches to meaning and how it influences how to view interoperability.

ISO makes a definition of semantic interoperability:

"Semantic interoperability: the ability for information shared by systems to be understood at the level of formally defined domain concepts." [51]

This definition of semantics implies that there is a method to "understand" shared information by using formally defined domain concepts. This assumes that meaning could be expressed and "contained" in a formal language.

In a similar way, HL7 Interoperability Work Group defines semantic interoperability as follows:

"Semantic interoperability ensures that system A and system B understand the data in the same way. It allows computers to understand, interpret, and use data without ambiguity. This is specific to domain and context and usually involves the use of codes and identifiers." [52].

On the other hand, other frameworks like the EIF (European Interoperability Framework) view semantic interoperability as 'meaning' and 'understanding' by the 'communicating parties'.

Viewing semantic interoperability as ISO and HL7 implies to equate semantics with some variety of formal semantics using formal models to define domain concepts and the mapping between different domains. Usually, the underlying theoretical assumptions on 'semantics' in semantic interoperability are taken for granted. Largely, the formal 
approach to semantic interoperability is seen as the overriding approach to achieve interoperability.

In this thesis, while we acknowledge the crucial role and importance of using standards, shared vocabularies, conceptual models for describing the terms and their relationships in a domain, and the use of formal languages to define the agreed exchange of data, we see these as instruments in shaping meaning. These formal models do not embody meaning in themselves. Rather, we focus on the use of formal languages as instruments for communication and action within a social context of a shared work practice. Thus, language, whether formal or natural, does not contain meaning separated from use and the participants, but get their meaning when used by participants for communication and action.

\section{Semantic interoperability and action in a work practice}

The formal approaches contribute with methods how to bridge different representations between systems. However, they do not address other aspects of interoperability such as the actual use of the information infrastructures and - most importantly - the context of interoperation in terms of a shared work practice and how to establish a shared common ground necessary for communication. The idea that it is possible to separate meaning from use and the context in which interoperation takes place tend to limit the view of interoperability problems to more formal and technical issues.

\subsection{Messages in the context of interoperation}

Messages created, transferred, transformed, and interpreted are essential in interoperation using information infrastructures. In fact, interoperation is orchestrated through communication acts in the form of messages. In this section, we analyze the role of messages in interoperation basing ourselves on section 7.3 Theories of meaning and views on interoperation and interoperability.

We will start with placing messages into an overall context of information systems viewed as systems for actions. Then, we will discuss the relation between information and messages referring to Langefors' insight that information is not contained in the message but is the product of an interpretation producing knowledge based on the life experience of the interpreter. We extend this insight, claiming that interoperation needs to be based on the shared knowledge and beliefs of the participants. Furthermore, in interoperation there are actions performed and coordinated. We support the claim of Goldkuhl and others that messages are not only about information and knowledge of facts but also about actions. 


\subsubsection{Messages and information systems - and overview}

Within a language action perspective of information systems, a message can be viewed as an outcome of action but also an action in itself.

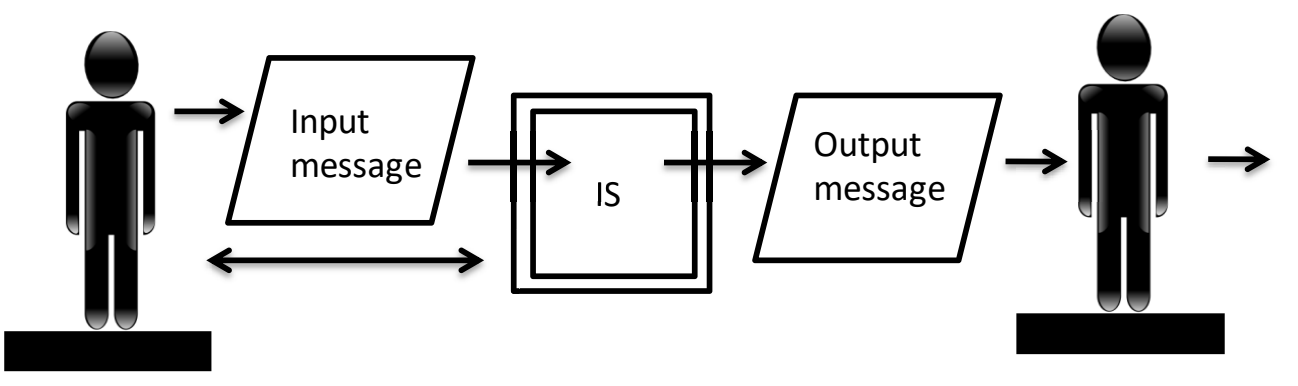

Interactive action Automatic action Consequential action

Figure 43 Actions in relation to an information system from Goldkuhl [235].

An actor (see Figure 43) performs a communication act which result in a message in the information system according to the action repertoire of the information system. The actor is involved in an interactive action with the information system. The information system then performs automatic actions predefined in the information system based on the current state of affair in the information system and predefined processing rules. The automatic actions can be a response to an interactive action or an internal action of the information system. It can also be a transferring or making available a message to other actors, changing the state of affairs in the information system, or translating the message to another format. It can process and send a message to another information system in another organization, et cetera.

The consequential actions are those actions taken by actors interpreting the message. To perceive and interpret a message is an action in itself. The consequential actions can be new action outside the system or action towards an information system.

\subsubsection{Information is not contained in the messages or data}

In traditional information systems theory, messages are viewed as conveying information or containing information. Langefors, a pioneer in information systems research in Scandinavia, disputes the view held by most of the scholars at the time and even today, 
that messages contain ${ }^{125}$ information based on his earlier experience in the $1960 \mathrm{~s}$, investigating data in information systems:

"The first problem - the fundamental infological problem - amounted to the question of how data in a system can contain the right information? The answer was quite shocking data do not contain information at all". [267]

Langefors developed his infological equation to express this insight:

$$
I=i(D, S, t)
$$

$I$ denote information or knowledge produced in the user from the data $D$ and preknowledge $S$, by an interpretation process $i$, during the time $t^{126}$.

$S$ denote the total life-experience of the interpreter and from this Langefors makes the conclusion that it is impossible that every individual gains the same knowledge from the data.

This view of information was a great advance at the time, when data processing was naturally the main focus, because it was situating the information system within the organization and relating to its users. This view of information systems however, mostly emphasized the role of information to make informed actions, to perform tasks in the organization or to make correct decision based on the information obtained. In relation to the figure above (Figure 43), these informed actions can be viewed as consequential action.

Goldkuhl finds the stress in the infological equation on informed users asymmetric [269] as there is no explicit mentioning of the producer of the information.

Based on this understanding, we propose to expand Langefors' insight and add the role of a producer. In addition, we assume that in order to make the communication successful there must be not only a sharing of knowledge and beliefs, but also of communication intention $^{127}$ with the communication act. Likewise, the intention of the interpreter is also

\footnotetext{
${ }^{125}$ Michael Reddy [266] showed how this erroneous view of communication is deeply embedded in the English language. See also Lakoff \& Johnson, 'Metaphors we live by' [114] and Sinha's critique of the 'conduit' metaphor. [263]

${ }^{126}$ From Essays of Infology [267]. $S$ is sometimes called receiving structure or semantic background in Theoretical Analysis of Information Systems [268] from 1966, where this equation first was published.

127 With communication intention, we follow Searle: "Communication intention is the intention to produce in the hearer the knowledge of my meaning by getting him to recognize my intention to produce in him that knowledge." [260] p. 145. Searle distinguish between individual and collective intentionality. Collective intentionality is according to Searle necessary when people are cooperating: "Whenever you have people cooperating, you have collective intentionality." [260] p. 120. Collective intentionality is not the sum of individual intentionality but a shared intentionality necessary for cooperation.
} 
an essential factor in interpreting the communication act. Furthermore, it should include an expressing phase as well as an interpretation phase.

We propose a modified infological equation as follows:

$$
\text { e-message } \text { shared }=\mathrm{e}\left(\mathrm{D}, \mathrm{S}_{\text {producer }}, \mathrm{I}_{\text {producer }}, \mathrm{t}_{1}\right) \cap \mathrm{i}\left(\mathrm{D}, \mathrm{S}_{\text {user }}, \mathrm{I}_{\mathrm{user},}, \mathrm{t}_{2}\right)
$$

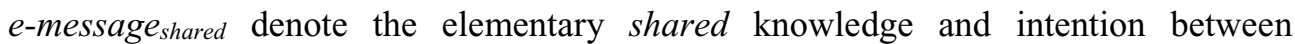
communicating parties as a function of $e$ expressing the knowledge and belief $S_{\text {producer }}$ of

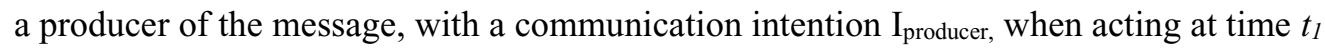
which results in a message $D$ and the intersection with the function of $i$ which is the user interpreting the message $D$ with the user knowledge and beliefs $S_{\text {user }}$, with a communication intention $\mathrm{I}_{\text {producer }}$ at time $t_{2}$ of interpretation.

From this equation, meant for illustration, it is clear that if e-messageshared should not be an empty set, there must be a sharing of knowledge, belief and intentions which are relevant for understanding $D$, i.e. $S_{\text {producer }}$ intersection $S_{\text {user }}$ should not be empty for understanding or expressing $D: S_{\text {producer }} \cap S_{\text {user } \neq} \varnothing$. Also, I Iroducer intersection Iuser should not be empty for understanding or expressing $D: I_{\text {producer }} \cap I_{\text {user } \neq} \emptyset$. With intersection, we here mean not a one to one overlap or correspondence but the degree to which the actors share knowledge and beliefs (S) and communication intention (I) enabling a mutual understanding of D.

Note also that the equation implies that $t_{1}<=t_{2}$, and most likely $t_{1}<t_{2}$, in an asynchronous setting which is the typical case in interoperation between organizations. This is also complicated by the fact that the initial data often have been produced with another intention before mapped to a message which is communicated outside the organization, which means that there are additional pre-processes before producing D. For more on the common ground necessary for communication and various communication settings see section 7.6 and 7.8 respectively.

\subsubsection{Communicating messages is also action and institutional facts}

Goldkuhl argues further that it is necessary to expand the e-message (or information element), which Langefors [267] defined as the knowledge of something elementary or simple about an identified object, with an action component.

Thus, messages as instrument for understanding and action in interoperation.

We have to take into account that a message also implies establishment of social relations. The type of actions linked to messages mediated by an information infrastructure can be analyzed using theories from Austin [259], Searle [208], Goldkuhl [269], Eriksson [247, 270], Ågerfalk [140], or Habermas [241, 271]. 


\subsection{Communication and coordination in a work practice}

We have earlier in this thesis (see 2.2.2) used the notion of work practice as the context for interoperation. A work practice is a habitual recurring pattern of action to produce a certain result for a client. The aspects of interaction within and between work practices are of particular importance to understand interoperation. One important aspect of interaction is the coordination of activities. This coordination is made using communication acts. In this section, we will briefly describe how coordination can be viewed from a language action perspective, how coordination theory defines coordination, and how coordination and coordination mechanisms are viewed in organizational theory.

\subsubsection{Coordination through communication acts}

Weigand et al [272] develops on the relation between communication and coordination within the Language Action Perspective (LAP). Communicative acts and language within LAP is seen as a coordination device. Referring to Habermas' theory of communicative acts, they claim that there can be two kinds of communicative acts: conversational act that aim at creating a shared understanding and consensual acts that are instrumental actions.

Conversational acts are formal or informal acts to create a shared understanding which is the basis for the consensual acts. Conversational act does not need a specific aim for a specific future action. Weigand et al [272] link this type of action as part of creating and maintaining the common ground (see 7.6 Common ground for interoperation). In this view, conversational acts support the development of a mutual understanding that is needed for the interpretation of the communicative acts. Consensual acts are seen as a "short-cut" version of communicative acts, where the shared understanding is already given. The two levels of communicative acts, the shared understanding (the 'life world' in Habermas' terms) and the operational use of regulative language act are intertwined. What makes this distinction interesting is that it highlights the shared understanding that is the basis for communicative acts. In interoperation between organizations, it is essential to understand that this shared understanding is not something given but needs to be created and will evolve with changing circumstances.

\subsubsection{Coordination and coordination mechanisms in a work practice}

If communicative acts are a coordination device how should we define coordination in a work practice context?

Weigand et al [272] make two observation about coordination: 
"(a) the rationale behind coordination is the existence of dependencies between activities or entities, and (b) the goal of coordination is to manage these dependencies in such a way that the activities become parts of a purposeful whole ..."

A similar definition of coordination is made by Malone and Crowston [273] :

"the act of managing interdependencies between activities performed to achieve a goal."

These definitions focus on coordination of activities to achieve a goal, presumably in a context of work within or between organizations.

Weigand et al [272] make a review of coordination theory. From organizational theory, they identify a number of coordination mechanisms, which can be summarized as:

- standardization of processes, outputs, and skills;

- organized management of processes for situations which fall outside the standardized procedures;

- mutual adjustments as a kind of horizontal coordination that complement both standardization and organized management of processes. It is informal and can be innovative, based on mutual understanding.

Standardization is a means to control the behavior of different actors in terms of standardized procedures, outputs, and skills. It is a way to minimize the unstructured communication and lower the transaction cost [274] in communication. A strong standardization will provide efficiency in coordination but also decrease flexibility. This standardization of processes, outputs, and skills ${ }^{128}$ can be inscribed in the behavior of the information systems and the information infrastructure to various degrees (weak or strong) with a balance of automated or manual inscriptions. Standardization of output is a primary coordination mechanism in inter-organizational communication or in diversified organizations.

Mintzberg describes the evolution of coordination mechanism:

"As organizational work becomes more complicated, the favored means of coordination seems to shift, ... from mutual adjustment to direct supervision to standardization, preferably of work processes, otherwise of outputs, or else of skills, finally reverting back to mutual adjustment." [275]

Many of the coordination mechanisms described here can be viewed as governance mechanisms and will be part of infrastructural condition in a shared work practice for interoperation. See 9.3.1 Shared work practice how this is integrated in the theory on interoperation and interoperability. See also 8.2 on governance mechanisms.

\footnotetext{
${ }^{128}$ Skills can be inscribed in the sense of demanding a certain level of professional authorization in order to do certain acts in the information system or work practice.
} 


\subsubsection{Communication acts and coordination mechanism}

To conclude this section, we make the observation that communication acts have a role to coordinate actions in a work practice. The prerequisite for this role is an established shared understanding between the participants in interoperation. Part of this shared understanding can be codified in coordination mechanisms of the work practice that can be invoked to coordinate actions. Part of it resides in memory and habits of the participants.

\subsection{Common ground for interoperation}

For successful communication and common actions, there need to be a common ground. According to Clark [261], a common ground is the sum of mutual and common beliefs, knowledge, and suppositions. The ability to share a common ground is fundamental for communication using language.

In view of that, to interoperate, one is engaged in a joint activity with shared goals, beliefs, and suppositions. To interoperate with information systems means to use information systems as instruments for this joint activity.

A common ground is something that is developed and accumulated. Clark distinguishes two types: communal common ground and personal common ground.

Communal common ground is developed within a limited cultural community. Personal common ground is the shared experience of personal interactions. A professional community with a shared expertise may be regarded as a cultural community from a work practice perspective. Such communities know what is considered central information, and which information is mutually assumed to be shared in a community. In interoperation, we usually have an intersection of various professional communities that communicate in a shared a work practice.

The ePrescribing process has mainly two kind of professional communities:

- prescribers who are professionals (nurses, dentists and doctors) who work within the health care as care givers;

- pharmacists who work at one end of the care giving process of outpatient care, delivering medical drugs for medical treatments.

In this context, a shared common ground is knowledge about medical drugs, their composition, effects, and administration.

Prescribers may be specialists or general practitioners; most pharmacists have general knowledge about medical drugs. Prescribers have knowledge of the diagnosis and treatments while pharmacist have general knowledge of medical drugs and their administration, compliance, drug-drug interaction (which usually span over specialties), delivery, and manufacturing. 
Another shared knowledge between pharmacists and prescribers is about the prescription rules. They have also a partially shared experience of meeting the patient/customer although from different perspectives.

One example of a recent discussion in the community of ePrescribing in Sweden, which relates to the evolution of common ground, is the use of 'Obs!' (similar to N.B.) in the prescription to notify the pharmacist that the prescribed dosage differs from standard daily dose and that is considered by the prescriber to be acceptable in the specific case. Now, the Medical Products Agency proposes to use 'Obs!' for all 'off label' prescriptions which have led to a debate in the journal, 'Läkartidningen' [276] of the Swedish Medical Association.

One important communal common ground is the language community. First, the language spoken, whether native or foreign ${ }^{129}$, then the specialist language in a particular professional community.

Another important part of common ground are shared procedures for joint action, from more simple ones for greetings, shaking hands, et cetera, to more complex script/schemas of behavior how to act in a restaurant, visiting a doctor at a hospital, or going to a pharmacy. These scripts/schemas are activated to simplify our daily activities, and are assumed to be shared by people in a community. We can assume that these types of scripts are also present in an organization using information systems. These shared procedures could be inscribed in the information infrastructure either as formalized and automatic behavior patterns or as weak inscription allowing a certain part to be manually encoded in work practice routines. See section 2.2.3 Features of information infrastructure.

Departing from Clark's view on common ground, Kecskes [278] put forward different properties of common ground in his socio-cognitive [279] view of communication. He distinguishes between core common ground and emergent common ground. The core common ground is the more static and general common knowledge in a certain speech community. This core common ground is established in earlier interactions and experiences. The emergent common ground is the more dynamic, actualized, and particularized knowledge that is constructed in the course of communication. Emergent common ground is not only new shared knowledge in the communication situation, it is also the use and modification of shared prior knowledge. Emergent common ground can contribute to core common ground and core common ground can contribute to (what is relevant and possible in the actual situation) the forming of the emergent common ground. Kecskes et al [280] underlines, in a critique of a static and taken for granted view of common ground, that it is a dynamic construct that is mutually constructed in the communicative process and that core and emergent properties of the common ground are interconnected and inseparable part of the same phenomena.

${ }^{129}$ See the issues that the project epSOS is facing regarding translation of prescription into different languages to make them interoperable within the Europe. [277] 
Kecskes [279] makes a critique of what he called the ideal abstraction of verbal communication, where communication is seen as an intention directed practice based on cooperation, represented by Clark [261] and others. Kecskes does not deny these aspects but think that they do not give an adequate account of the reality of communication. $\mathrm{He}$ underlines the chaotic nature of communication due to "egocentrism" which he claims is not antagonistic to cooperation. The pragmatic theories that have evolved inspired by Grice assume or emphasize according to Kecskes the role of a priori intentions. Instead meaning construction is seen by Kecskes as more of a trial and error process, where intentions not necessarily are there a priori, but a result of the communicative process. [281]

In any case, there must be some a priori assumption of intentions, particularly in a structured and repeated communication situation. Thus, for our purpose, in the context of structured interoperation between organizations this critique is not a major objection. Instead, it emphasizes the need to work more with a priori intentions and core common ground, and pinpoints to problems in interoperation that occurs when intentions are not clearly stated and need to be worked out in practice. Thus, from a design and implementation perspective on interoperation, this indicate the need to establish common intentions and objectives to avoid or minimize these problems. In structured interoperation, there are few possibilities to use a trial and error process, even if this may characterize how things are initially done in practice before efforts are made to improve interoperability.

Consequently, discrepancy of intentions and common ground due to the fact that communication is made by individuals with their own agenda and "egocentrism" can be viewed as a source of interoperability problems. Kecskes, referring to cognitive psychological experiments, claims that there is an overestimation by the speaker of the hearer's ability to understand the speaker's intentions. This can lead to an underestimation by the participants of the need to establish a common ground. What is evident by individuals in one organization is not at all evident in another organization using the same data, particularly when there are few efforts to establish a common ground.

Thus, one of the merits of Kecskes' socio-cognitive approach is that it focusses on aspects of the more negative side of communication such as breakdowns and misunderstandings and therefore in understanding why interoperability error occurs.

For this reason, we think it is useful to adopt these properties of the common ground proposed by Kecskes in our model. These properties of the common ground show the complexity of communication in interoperation. One important challenge is then to establish the core common ground and make it effective in the whole community. This is so because each single communication act is carried out by individuals that has to produce and interpret communication acts so that they correctly lead to the intended actions. With a new phenomenon, such as ePrescription in the beginning of 2000 is was justified and wise to have an implementation model that engaged local prescribers and pharmacists. See chapter 4 Implementing ePrescribing in Sweden - case study. See also section 9.3.2 and 
subsection Generic practice and local instance of practice, where this concern is included in our theory or shared work practices for interoperation.

\subsection{Communication acts and common ground}

In this section, we will outline a model of communication based on the theories described earlier in this chapter. The aim with this model is to illustrate various aspects of the communication process.

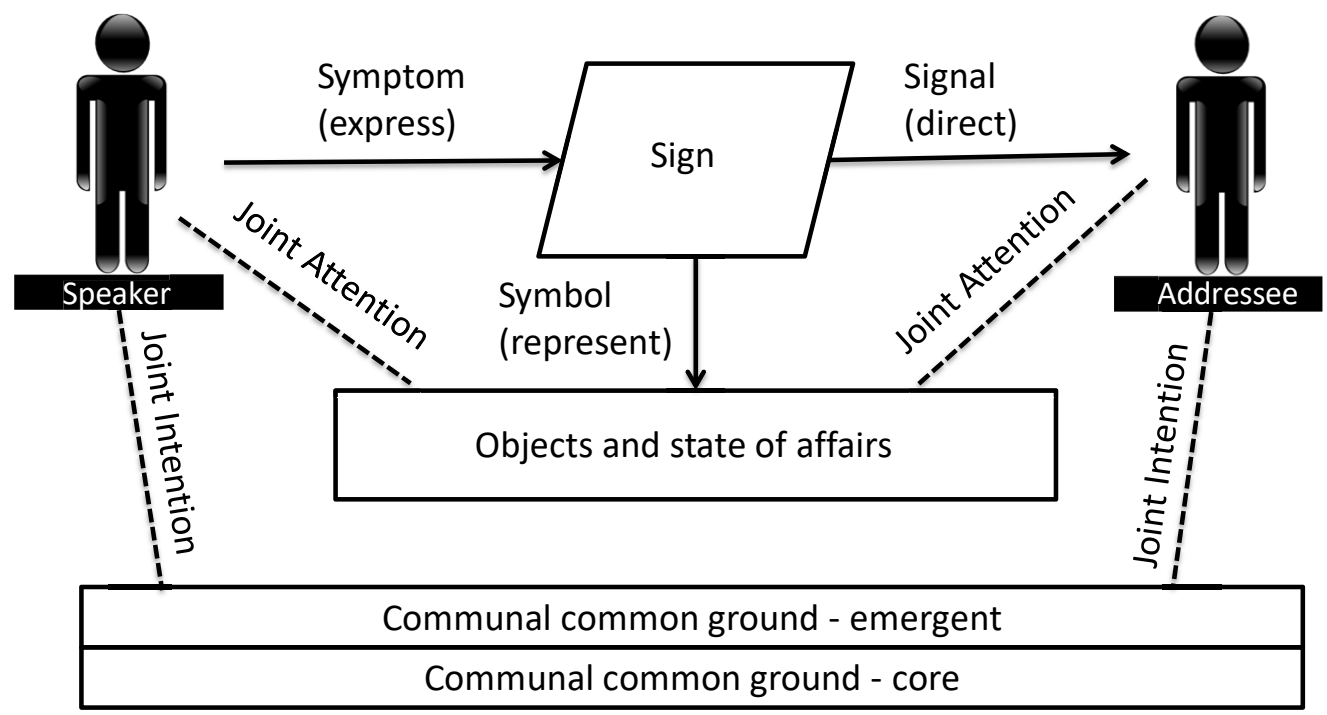

Figure 44 Sign communication and communal common ground.

In Figure 44, we have integrated Bühler's [242] view on sign communication, with Sinha's [263] view of joint intention and attention, and with Clark's [261] and Kecskes' [279] notion of common ground.

For Bühler, a sign has three semantic functions: it is a symptom expressing the speaker's inner states, a symbol with represents ${ }^{130}$ objects and state of affairs and a signal in the quality of its appeal to the hearer for the direction of its inner thoughts and behavior ${ }^{131}$.

${ }^{130}$ Bühler uses coordination instead of the now usual term represent. We have not investigated what Buhler possibly could have meant by this term coordination, which at a first glance give the impression of including an activity, not a mere passive correspondence.

${ }^{131}$ Note that in this model Bühler does not make explicit that the signaling in itself is a social act. The model illustrates the semantic functions according of Bühler, for whom a speech act is an act of speech - 
The model shows a link between sign (here viewed as a communication act) in its representing function towards object and state of affairs. These objects and state of affairs could be represented in an information infrastructure, for example a state of a drug register, or a prescription register. Important part of these objects and state of affairs is the institutional objects in the shared information infrastructure. These objects and state of affairs have (for successful communication) a joint attention in the communication, for example, a specific prescription or a specific drug.

In Figure 44, we have also integrated the notion of joint intention ${ }^{132}$. According to Tomasello et al [282] " ... intention is a plan of action the organism chooses and commits itself to in the pursuit of a goal".

Thus, intentions are both means and goals. In our context, joint intention is the sharing or means (plan of action) to achieve a common goal. Joint intention helps to direct attention to relevant object and state of affairs. Joint attention and joint intention are essential in human communication and can be observed in empirical research of face to face communication. How these essential elements in human communication are expressed in another communicative setting which is not face to face, but mediated and asynchronous will be dealt in section 7.8 Communication settings for interoperation.

The common ground in the model is the background on which the communication takes place. [278]

The core communal common ground - is the common beliefs, knowledge and presuppositions in a community that have been build up historically (following Clark [261]) based on earlier interactions and experience.

The emergent (following Kecskes [280]) communal common ground is the common ground that emerges for the actual communication, in the utterance situation, the situational context of the communication.

This emergent common ground could for example be constructed using the assumption made by the pharmacist in interpretation of the ePrescription based on the core common ground and assumption about the intention by the prescriber based on the content of the ePrescription.

The joint intention (whether assumed or communicated in the communication act) towards the communal common ground gives the situational context of the communication act.

not in the sense of what later Austin [259] and Searle [227] would put is as a social act in itself. We have integrated this latter meaning of the speech act as a social act in itself in the model.

${ }^{132}$ Joint intention is similar to Searle's notion of collective intentionally which he thinks is the basis for all social activity. [260] 
The communal common ground must be established, will evolve over time, and is dynamic in relation to each communication situation.

\subsection{Communication settings for interoperation}

In this work, interoperation and interoperability are essentially seen as communication and capability to communicate using an information infrastructure for shared action in a work practice setting. Therefore, it is useful to analyze different settings for communication in order to situate interoperation.

\subsubsection{Basic settings of communication}

In Herbert H. Clark's book 'Using language' [261], some features of a setting for human communication, which he calls a basic setting, are presented. He argues that this basic setting has to be based on a face-to-face conversation, which is basic for all human communication (whether unspoken, spoken, or written), and from which all other settings derive, such as writing and in our case, we will argue for using information systems as an instrument and media for human linguistic communication. Thus, it is important to analyze in what ways deviations from this basic setting will influence conditions for communication.

In Table 17 we describe the basic features of face-to face conversation. 
Table 17 Features of face-to-face conversation from 'Using Language' [261].

\section{Feature Face-to-face communication}

Co-presence The participants share the same physical environment

Visibility The participants can see each other

Audibility The participants can hear each other

Instantaneity The participants perceive each other's actions at no perceptible delay

Evanescence The medium is evanescent - it fades quickly

Recordlessness The participants action leaves no record or artifact

Simultaneity The participants can produce and receive at once and simultaneously

Extemporaneity The participants formulate and execute their actions extemporaneously, in real time

Self-determination The participants determine for themselves what action to take when

Self-expression The participants take actions as themselves

\subsubsection{Interoperation in a mediated, non-personal, prescriptive setting}

What we consider next is a setting, where participants are using an information infrastructure (II) for structured, repeated communication, often asynchronous, and the language used is a formalized and restricted language, with a predefined repertoire of actions and messages, what Clark would call a prescriptive setting [261]. See also Ågerfalk [140] for referring to the prescriptive setting as adequate for information systems aimed for business action and communication. 
Table 18 Interoperation using information systems for structured, repeatable and organizational communication. ${ }^{133}$

\begin{tabular}{|c|c|c|}
\hline Feature & $\begin{array}{l}\text { Interoperation using an II } 134 \text { in a structured, } \\
\text { repeatable organizational communication }\end{array}$ & $\begin{array}{l}\text { Feature } \\
\text { Category }\end{array}$ \\
\hline Co-presence & Separate physical environment for communication & immediacy \\
\hline Visibility & The participants cannot see each other & \\
\hline Audibility & The participants cannot hear each other & \\
\hline Instantaneity & There is always some delay in communication & \\
\hline Evanescence & The medium is persistent & medium \\
\hline Recordlessness & $\begin{array}{l}\text { The participant's action always leaves records or } \\
\text { artifacts }\end{array}$ & \\
\hline Simultaneity & $\begin{array}{l}\text { Actions by participants are not made at the same } \\
\text { time }\end{array}$ & \\
\hline Extemporaneity & $\begin{array}{l}\text { Communications is not made in real time and more } \\
\text { often asynchronous than synchronous }\end{array}$ & control \\
\hline Self-determination & $\begin{array}{l}\text { Actions can only be taken from a set of predefined } \\
\text { actions, following the affordance of the information } \\
\text { infrastructure }\end{array}$ & \\
\hline Self-expression & $\begin{array}{l}\text { Participants often act representing an organization } \\
\text { or a role within that organization. Often a non- } \\
\text { personal setting. }\end{array}$ & \\
\hline
\end{tabular}

We have added three feature categories, immediacy, medium, and control, borrowed from Clark in Table 18.

In the setting, there is no immediacy in the communication, there are no co-presence, visibility, audibility ${ }^{135}$, and there is always some delay in the communication.

The medium is persistent; an action leaves records, and there are sequence of actions and no simultaneity of communication.

\footnotetext{
${ }^{133}$ This table coincided to be very similar to an analysis of Ågerfalk. [140]

${ }^{134}$ Information infrastructure

${ }^{135}$ We do not include voice or audio communication in the standard mode of communication in this setting. Usually, these modes of communication are used when there is a breakdown in communication that has to be solved, or when structured and formalized communication is not appropriate.
} 
The communication is most often more or less asynchronous. There is a set of predefined action that are allowed to be taken, afforded by the information infrastructure. The actors do not represent themselves but act with roles representing an organization, i.e. there is no interpersonal communication in the standard mode of communication.

\section{ePrescribing in a mediated, non-personal, and prescriptive setting}

We will here consider the process of ePrescribing from the point of view of the basic setting for communication.

ePrescribing is a highly-regulated work practice where a prescriber as a representative of a care giver organization authorizes a pharmacist at a pharmacy to dispense a medical drug to a patient at the patient request. The message that is communicated is the electronic prescription which is created in the prescriber information system (EHR - Electronic Health Record system) and finally accessible for the pharmacist in the pharmacist dispensing system (through intermediary information services). See chapter 6 A practical theory on ePrescribing for a detailed account of the ePrescribing process.

The prescriber is not addressing any particular pharmacist; the prescriber does not even need to address a particular pharmacy or a pharmacy chain. The prescription is usually addressed to the whole pharmacy market. This is termed non-personal setting by Clark in contrast to personal settings, which are typical for face-to-face conversation. [261]

Regarding the feature category medium for communication there is a major difference from face to face communication, in that the medium is persistent and the actions always leave a record and that there is always a delay and thus order of actions presumed given certain preconditions. Thus, there is no immediacy of the communication.

Regarding the feature category of control, there is a general technological trend from slow asynchronous towards more synchronous communication. But so far, not between the speaker and the addressee directly (even if this is desirable in the long term), but between the act of sending a message from the prescriber's information system and receiving a message from the pharmacy information system in the process of acceptance and validation of ePrescription messages.

The level of self-determination by the prescriber and the pharmacist is regulated by laws and by the rules and affordances given by the information infrastructure.

Clark (ibid) also discuss what he called a mediated setting in which there is an intermediate process from the initial creation of a message to its final expression, including for example editing, translation, and publication.

This is the case with using information infrastructure for interoperation. The original message is viewed in one way in the prescriber's system when creating a prescription and is subsequently modified, processed and mapped into intermediate formats and then 
presented to the addressee at the request of the non-personal addressee (having the permission to), which could be a selected and modified view and presented in another way compared how it was originally created.

This fact introduces both flexibility in different uses and presentations, but also a source of communication errors if translation or presentation in some way alters or corrupts the original message or content, or is used in a non-intended way.

To conclude, ePrescribing has a communicative setting that is mediated, non-personal and prescriptive.

\subsection{Actability of information systems for interoperation and communication quality}

In this section, we summarize two research contributions on communication quality criteria that have relevance for interoperability.

The first contribution from Goldkuhl [206] is about quality criteria for actable information systems based on the Information Systems Actability Theory (ISAT).

The second contribution is from Eriksson [283] which develops a theory of general communication quality criteria in the context of business interaction using information systems.

The aim with this section is to provide examples of quality criteria that can be used to improve and evaluate interoperability.

\subsubsection{Actability of information systems}

In this section, we briefly describe Information Systems Actability Theory (ISAT) [206] which we think useful in understanding quality of interoperation using information systems.

ISAT considers an information system to comprise an instrument for technologymediated work communication.

Goldkuhl define information systems actability:

“... as an information system's ability to perform actions, and to permit, promote and facilitate the performance of actions by users, both through the system and based on information from the system, in some business context." [236]

Based on ISAT Goldkuhl has developed a number of quality criteria for actable information systems. These quality criteria are described using a layered model of interaction, communication, and process qualities. 


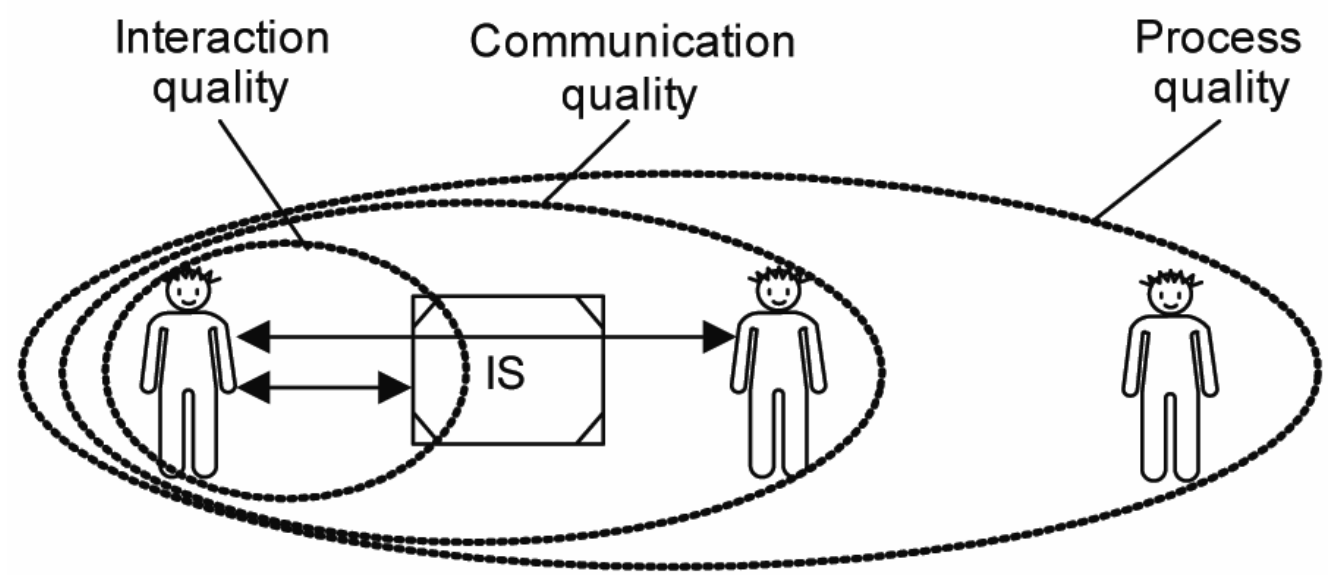

Figure 45 Layers of quality according to the Information Systems Actability Theory [206].

A sender interacts with an information system to communicate something to a receiver, which in turn interacts with an information system to read and interpret a message.

Interaction quality criteria is about what the users are doing with the system. These interaction criteria are important to consider to improve interoperability: clear action repertoire, intelligible vocabulary, action transparency, clear feedback, amenability, and conceptual consistency.

Communication quality ${ }^{136}$ criteria refer to the formulation and communication of messages by a sender, as well as the accessing and interpreting of messages by a receiver. The pragmatic duality of using information systems means that when interacting with an IT artifact, we are at the same time interacting with others [284].

For the formulating phase, all of the defined criteria are highly relevant: satisfying communication needs, relevant communication demands, work practice memory addition, addressee relevant communication and addressee adapted communication. For the accessing and interpreting by the addressee, the criteria of clear and accessible work practice memory, information accuracy, actor clarity, and intention clarity are particularly relevant.

\footnotetext{
${ }^{136}$ Note that Communication quality criteria here is referring to criteria for the information systems that "permit, promote, and facilitate" communication acts, which will contribute to the quality of communication between the participant's. We can call the first type of criteria information systems communication quality criteria. For communication quality criteria in a more general sense we refer to the next section 7.9.2.
} 
Process quality is concerned with how the use of the information system affects the work practice. Process quality criteria refer to the requirement that the output from the system should be useful on behalf of its users.

Actability of information systems can be expanded to encompass an information infrastructure used for interoperation. Thus, besides the actability of information systems within an organization we also consider the actability of the information infrastructure. Figure 46 illustrates this situation. Communication quality is dependent on interaction quality of several separate but interdependent information systems and on the quality of intermediate communication and support infrastructures.

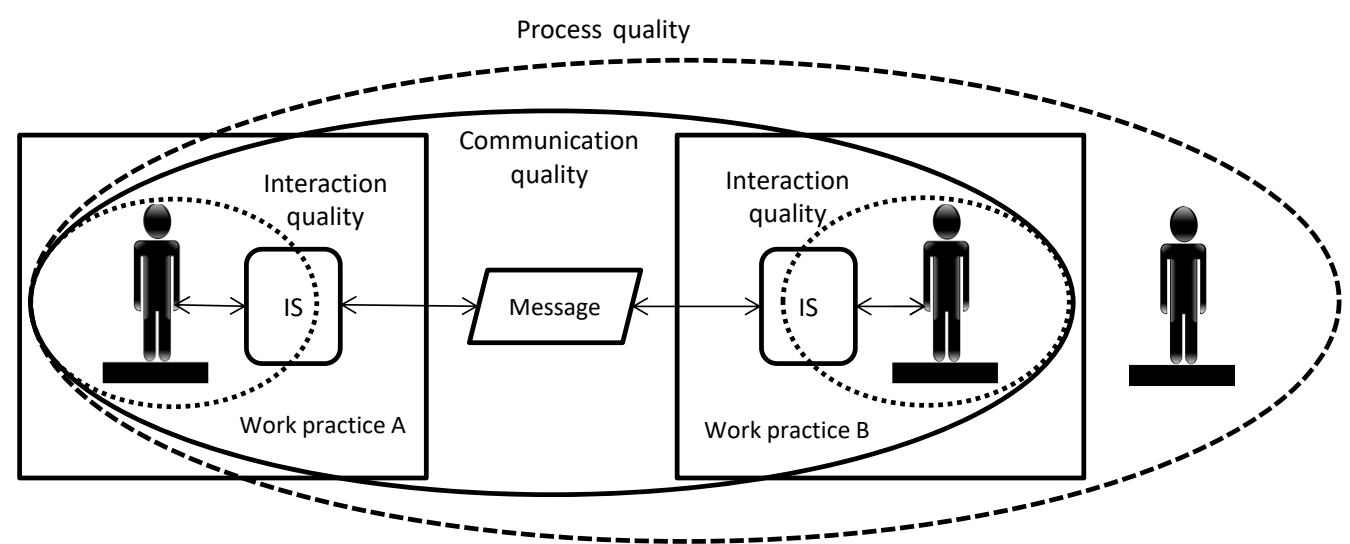

Figure 46 Actability of information systems in the context of inter-organizational interoperation.

The conclusion is that the actability of information infrastructure will have an influence on the quality of communication in interoperation. The actability criteria described contributes with guidance how to evaluate and design information infrastructures for interoperation that facilitate quality of communication between participants in interoperation.

In the next section, we will describe a contribution on what characterizes good quality of communication in a business process setting using information systems.

\subsubsection{Communication quality}

Eriksson [283] develops on the importance of communication quality in the context of business processes and information systems. The basic idea is that communication quality depends on validity and mutual understanding based on social rules and convention. The concept of communication quality is theoretically grounded in speech act theory, Habermas' theory of communicative action and in business action theory. This makes the contribution on communication quality criteria particularly interesting for interoperation using information systems.

Communication quality can be summed up as follows: 
- communicative actions are characterized by being:

- comprehensible communication dependent on:

- relevant and comprehensible information content;

- relevant and understandable action aspect;

○ trustworthy communication dependent on:

- comprehensible communication acts;

- accountable communication acts (can be controlled and criticized);

- context of communication is characterized by:

- empathy: actors are respectful and receptive in their communication;

- reliability: actors fulfill their commitments in a reliable and correct way;

- trustworthiness/security is about knowledge, conduct and ability of the actors to create trustworthy guaranties to maintain safety and trust.

Thus, communication quality is dependent on the quality of the communicative actions and on the context of communication. Notably, these communication quality criteria put forward social aspects such as trustworthiness, reliability, and empathy and their importance for communication quality. For example, in ePrescribing it is essential that the prescriber can rely on the pharmacies and the pharmacist to handle the prescription in a correct way and do what is expected and required in the ePrescribing process. For the pharmacist, it is essential that they can trust that a legitimate prescriber issued the prescription. Furthermore, the pharmacist must rely on the prescriber to have issued a prescription in a professional way with concern for the patient, to with confidence distribute a medical drug while regarding the wellbeing and safety of the patient. Empathy by the prescriber is to show respect for the pharmacist and the patient in making a comprehensible and error free prescription.

\subsection{Definition of interoperability}

In this section, we will use elements from the previous sections in this chapter and from chapter 2 to make a definition of interoperability. This definition is later integrated in the theory on interoperation and interoperability presented in chapter 9 A practical theory on interoperation and interoperability.

\subsubsection{Interoperability as exercised capability to interoperate}

The definition of interoperability aims at synthesizing and give attention to those factors in the context of interoperation that condition and influence interoperability. An additional aim with this definition is to support efforts to define goal, criteria and metrics for 
measuring and improving interoperability. See 7.10.2 Defining goals, criteria, and metrics for interoperability.

First, we recall our definition of interoperation from section 7.1, subsection concept of interoperation:

"to interoperate means that actors mutually perform and coordinate actions within a work practice which is organized around a shared practical understanding."

Following this definition of interoperation, we define interoperability:

Interoperability is the exercised capability of organizations through their agents to interoperate in a work practice in an effective, efficient, and satisfactory manner based on a common ground in a mediated, prescriptive, and non-personal communicative setting using an information infrastructure for mediating interoperation.

Interoperation is taking place between organizations through their agents in a shared work practice.

Interoperability is a capability to interoperate that can be evaluated and measured given defined goals, criteria, and measurement regarding its:

- effectiveness: that the interoperation is exercised in such a manner that it fulfills the purpose and objectives with the shared work practice and interrelated work practices;

- efficiency: that the interoperation is performed in such a manner that it uses well the assigned and consumed resources of the shared work practice and related work practices;

- satisfaction: that the actors and their clients have positive attitudes towards and trust in the interoperation.

Common ground is the sum of the mutual and common beliefs, knowledge and suppositions of the agents in interoperation. It is a shared basis for communication and joint action in interoperation.

With mediated, prescriptive, and non-personal communicative setting, we mean that the participants are using an information infrastructure for structured, repeated communication, often asynchronous (mediated), and the language used is a formalized and restricted language, which a predefined repertoire of actions and messages (prescriptive) and is not directed towards a particular individual ${ }^{137}$ (non-personal).

\footnotetext{
${ }^{137}$ In some cases, as with ePrescribing one of the addressee (as an implied recipient) can be an individual, the patient, who the prescription concerns. However, this does not change the communication situation to be a dyadic personal communication.
} 
The use of an information infrastructure as an instrument for mediating interoperation means that it is both a media for communication but also an active agent in the process of interoperation.

\subsubsection{Defining goals, criteria, and metrics for interoperability}

One aim with the definition of interoperability was to provide guidance on how to define interoperability goals, criteria and metrics for design and evaluation. Interoperability goals can be specified in criteria for assessing these goals. These criteria can be measured using interoperability metrics.

\section{Defining goals for interoperation}

In using the terms effectiveness, efficiency, and satisfaction, we adopted the approach of Ågefalk and Eriksson [285], to include both an instrumental and social orientation in defining interoperability goals.

An instrumental orientation on goals for interoperation means to focus on means in order to achieve a given end.

A social orientation on goals for interoperation means to focus on goals expressed in terms of social values, rules, norms and mutual understanding.

Table 19 illustrates with examples from ePrescribing, goals with both an instrumental and social orientation. 
Table 19 Conceived examples from ePrescribing illustrating different of orientation of goals.

\begin{tabular}{l|l}
\hline $\begin{array}{l}\text { Goals of } \\
\text { interoperation }\end{array}$ & $\begin{array}{l}\text { Conceived example from ePrescribing } \\
\text { Effectiveness }\end{array}$ \\
- & $\begin{array}{l}\text { To prescribe, communicate and dispense ePrescriptions } \\
\text { ePrescribing should be the standard mode of prescribing } \\
\text { covering more than } 90 \% \text { of all prescriptions. }\end{array}$ \\
- & $\begin{array}{l}\text { Prescriptions should be created, communicated, and filled in } \\
\text { accordance with regulations. }\end{array}$ \\
- & $\begin{array}{l}\text { Prescriptions should express the intention of the prescriber, } \\
\text { support mutual understanding of the prescription by the } \\
\text { prescriber, pharmacist, and patient, and the purpose with the } \\
\text { medical treatment, in a safe way for the patient. }\end{array}$ \\
\hline Efficiency & $\begin{array}{l}\text { Prescriptions are created, communicated and filled with few } \\
\text { errors and disturbances to avoid unnecessary use of limited } \\
\text { resources. } \\
\text { The use of resources by different actors in ePrescribing is } \\
\text { acceptable by the actors. }\end{array}$ \\
\hline Satisfactory & $\begin{array}{l}\text { There is positive attitude towards ePrescribing by the } \\
\text { prescribers and the pharmacists in terms of ease of use and } \\
\text { satisfaction with services provided. } \\
\text { ePrescribing is considered trustworthy and reliable by } \\
\text { prescribers, patients and pharmacists. }\end{array}$ \\
\hline
\end{tabular}

These goals for interoperation can be further operationalized if desirable, in quantitative and qualitative metrics ${ }^{138}$.

\section{Relation between goals, criteria, and metrics}

While the definition of interoperability gave some general guidelines for defining interoperability goals, they did not provide a more detailed guide how to evaluate

\footnotetext{
${ }^{138}$ See further chapter: 4 Implementing ePrescribing in Sweden - case study, for examples how the criteria for satisfaction with ePrescribing by different actors and the trust in the interoperation influenced the evolution of ePrescribing in Sweden; 5 Improving interoperability in ePrescribing - a field study, for examples of criteria regarding effectiveness and efficiency that can be considered in design, implementation and operation.
} 
interoperability. We will here briefly provide some guidelines how to define and evaluate goals, criteria, and metrics for interoperability.

Criteria are related to goals to improve interoperability, i.e. target quality criteria to be achieved in the short or long term. These quality criteria could then influence the design of work practices, information infrastructures and their governance mechanism, et cetera, in order to meet these criteria. These criteria could also be used to improve and evaluate interoperability of an existing interoperation. Criteria can be used to formulate metrics to evaluate and follow up interoperability.

One approach to formulate these metrics is goal-oriented metrics, like in The Goal Question Metrics approach developed by Victor Basili and others. [286] This means to translate overall goals with a process, product or resource into questions ${ }^{139}$ and finally metrics. These metrics are then used in a continuous improvement process.

Goals are here considered as statement of a desired future state [287] of an object (process, product or resource). Criteria are here used to describe the characteristics of an object in a certain state. Metrics are methods to assess the criteria in a situation.

Quality is a term that has been used in many different ways. Reeves and Bednar [288] make a historical review of the use of quality as excellence, as value, as conformance to specifications and as meeting/exceeding customer's expectations. They discuss strong and weak point using different definitions of quality.

In this thesis, we regard quality as conformance to specifications and of meeting the expectations of the actors. Conformance to specification ${ }^{140}$ is useful when evaluating the designed artifacts, but it is also necessary to consider their fitness of use to meet the actor's needs and expectation. Interoperation is developed for and implemented in a shared work practice with its transactional and infrastructural conditions. How this shared work practice is designed and implemented will also influence interoperability.

Interoperability can also be regarded as quality of "use" of the information infrastructure in a shared work practice context. All designed and implemented artefacts will influence interoperability and what finally counts is the quality of interoperation using these artefacts.

\footnotetext{
${ }^{139}$ Questions are used to characterize the way to assess or achieve a specific goal. The questions focus on certain quality issues from a certain viewpoint. [286] Thus, questions are a way to arrive at criteria for a goal which then could be defined in metrics to assess the criteria.
}

${ }^{140}$ Specification should be made with a focus on the actor's needs and expectations. 


\section{Interoperability and process metrics}

Interoperability as an exercised capability can be viewed as a process quality. Process quality $^{141}$ can be measured in various ways. A popular approach to measuring processes is Key Process Indicators, KPIs. Walsh [289] develops this concept further in making a distinction between Key Process Drivers (KPD) and Key Process Outcomes (KPO). KPDs are measurement of drivers (also called in-process criteria) that influence outcomes, while KPOs are measurements of outcomes (also called result criteria) that are related to the overall objectives of the process. KPDs are used to operate the process in a certain direction to achieve certain outcomes. KPOs are measurements to follow up.

Without KPDs it will be difficult to know what to change to achieve a certain outcome. In order to identify and understand the role of Key Process Drivers, it is necessary to open up the 'black box' and analyze the process of interoperation and what drives certain outcomes. For example, the resources you put into testing, the quality and understanding of specification of exchanged messages, could be seen as drivers that influence the outcome in terms of number of errors in communicated messages. Other Key Process Drivers are the development of the information infrastructure and implementation of governance mechanism for interoperation.

The field experimental study in improving interoperability in ePrescribing (see chapter 5 ) is an example of measuring Key Process Outcomes in terms of errors in the communicated ePrescriptions and of analyzing Key Process Drivers. It is also an example of an experimentation (change of Key Process Drivers) and of measuring outcome before and after the change. This provides material to learn how process outcomes are influenced by changes of the process drivers.

One important part of improving interoperability is about learning the process, in which experimentation [124] is an important activity. Confer also the concept of an "Experience Factory" by Basili and McArry, in which experimentation is an important part of learning the process. [290]

Measurement of interoperability, particularly continuous operational measurement, like in the ePrescribing work practice, is useful for the control and governance of the operational process.

${ }^{141}$ With process quality, we mean here both how the use and design of information systems influence the quality of the actions and results in the work practice (see Goldkuhl above) and of the quality of actions and results in the work practice influences by other factors. 


\section{Interoperation, governance, and collective action}

In chapter 7 , we made a theoretical analysis of interoperation, its context, and made a definition of interoperability. We described the crucial role of information infrastructures, the context of work practices and the conditions for communication in interoperation.

In this chapter, we focus on organizational and governance issues regarding the evolution of an information infrastructure for interoperation.

The chapter is organized as follows.

The section 8.1 Governance of ePrescribing in Sweden - some elements recall some factors that made ePrescribing evolve in Sweden. The aim is to relate definitions of governing, governance, and collective action, to an empirical context.

Definitions of governing, governance, and collective action are made in section 8.2 Network governing, governance, and collective action.

In section 8.3 New National ePrescription Format - Vertical Information Systems standardization effort as collective action, we use the example of introducing the new ePrescription format in Sweden in order to illustrate a collective action for the implementation of a vertical standard.

There are few studies on governance of networks where several organizations interoperate using information systems. IT Governance and IT service management approaches have a locus on the enterprise and governance of IT within the enterprise. Nevertheless, we think it is fruitful to give some examples of research and work in this field that can contribute to the understanding of governance of networks of organizations that interoperate. In section 8.4 Network governance, IT governance, and IT service management in the context of interoperation, we first describe a framework for IT 
Governance (Weill \& Ross) within and enterprise and then discuss a widespread framework for IT service management, ITIL ${ }^{142}$.

The definitions of governing, governance, governance mechanism, and collective action are integrated in a theory on interoperation and interoperability in chapter 9 , in sections $9.3,9.5,9.6$.

\subsection{Governance of ePrescribing in Sweden - some elements}

The evolution of an information infrastructure for ePrescribing in Sweden was a long-term process from the pioneering years in the 1980s to the mature information infrastructure in the beginning of second decade of 2000 . The evolution of this infrastructure still goes on with new challenges.

The evolution of the information infrastructure was not the result of one design or one implementation project. It was the result of a whole range of activities and decisions made by stakeholders that created the conditions for its further development. These actions were sometimes coordinated and linked, sometimes coinciding and contributing to new possibilities. These actions and decisions ranged from change of legislation, choice of standards, to setting up of new organizational bodies, and a shared operational governance. They provided conditions and structures for governing of joint projects and initiatives.

We will here summarize some of these actions reported in the case study (chapter 4) and the field experimental study (chapter 5). The aim is to give examples of actions that contributed to the governance of ePrescribing in different phases, and to give a concrete illustration of governing, governance, and collective action defined in the next section.

The examples are gathered under the following headings: organizational, legal, economical, standards and technologies, stakeholder's interest and incentives, and social interaction and culture.

\subsubsection{Organizational}

In the early beginnings of the first decade of 2000, there were strategic decisions made by the executive board of the National Pharmacy Corporation (NPC) and at the regional county council in Stockholm to promote and develop ePrescriptions. These organizations initiated internal projects to promote and implement ePrescription and started to cooperate. Several organisms for cooperation around the use of IT in health care sector, which included the NPC, were created, like ELAK and Carelink. The NPC had the main responsibility as a leading organization to administer the ePrescription network (see the

${ }^{142}$ ITIL stands for IT Infrastructure Library. ITIL was developed by a government agency in Great Britain in the end of the 80ties. See http://www.itgovernance.co.uk/itil.aspx 
following section on forms of network governing). Later through the development and implementation of the new National ePrescription Format (NEF) there was an engagement of a wider network of participants, including all the major regional county councils and later all county councils.

Through the NEF project, a number of new shared governance mechanisms were introduced to govern the operational ePrescribing flow. The reregulation of the pharmacy market involved the transfer of the information infrastructure developed by the NPC for ePrescribing services to a state owed network organization which later became a state authority in 2014. A wide variety of organizational forms was used in developing, implementing, and operating ePrescribing, and promoting the evolution of the ePrescribing infrastructure. These organizational forms dealt with the issues that came to the fore such as legal, economic, standards and technologies, stakeholder's interest and incentives, and culture of cooperation. Below, examples of dealing with some of these issues will follow.

\subsubsection{Legal}

Changes in legislation were crucial for evolution of the information infrastructure for ePrescribing in Sweden. In the beginning, an ePrescription was considered as a prescription only transferred electronically. This meant that an ePrescription had to be printed on paper if there were refills after first dispensing. Soon, there were efforts by stakeholders to influence legislation to allow for storing the prescription during its lifetime and to accept the ePrescription as the "original" to which rules and rights were linked.

The changes in legislation granted the same legal status for ePrescription as a paper prescription. Other changes in legislation facilitated the development of the information infrastructure, such as the law on the pharmacy register that mandated that all sales at the pharmacies of prescribed medical drug should be registered and the information made available to the prescriber and the patient.

\subsubsection{Economical}

It was agreed that all the actors should take their own cost for developing their part of the infrastructure. This was not a major problem as the actors were relatively equal in size, with the exception of the major county councils and the NPC. The county councils used their own network for communication (Sjunet). Participants took their own costs for the VAN services. The transfer of the information infrastructure to a state-owned network organization, implied a need to finance this administration and organization. This was regulated by legislation which demanded a fee from the pharmacies based on transactions of sold medical drugs. The costs for testing and approval of new actors and applications 
or new revised versions of existing application were to be paid by the applicant organization.

\subsubsection{Standards and technologies}

The first standardized ePrescription format used EDIFACT based on a UN standard (MEDPRE). Later, through the support of SIS (Sweden's Standards Institute), an implementation guide for an ePrescription in the XML format using the pre-standard ENV13607 was developed. Thus, in the beginning of the first decade of 2000, there were two standards implemented for ePrescriptions in Sweden. After the NEF project, the EDIFACT format was phased out.

The standard for communication was in the beginning X.400 and later web services were used. The latter provided a shorter response time and improved throughput, and the synchronous mode of communication enabled interaction. This change came about in a cooperation with a major county council and NPC and was later adopted by other county councils.

\subsubsection{Stakeholders' interests and incentives}

The major stakeholders had an interest in promoting ePrescriptions. The first identified benefit for the pharmacies was to decrease cost and time for transcribing paper prescriptions into the dispensing system. Later, it became obvious for the prescribers' organizations that they could benefit from a greater control of what was prescribed and the prescribers could save time for prescribing using their electronic health record systems.

The regional county councils in the north of Sweden were early adopters of ePrescription, probably due to the long distance to a doctor. Through ePrescription, a prescription could easily be renewed and sent to a pharmacy after a telephone consultation. In the larger cities, there was a demand to be able to go to any pharmacy to fill a prescription. This was an incentive for a national prescription repository. Another incentive was to limit the number of falsification of prescriptions that were made on paper, often using stolen preprinted prescription note pads.

\subsubsection{Social interaction and culture}

The major stakeholders involved in implementing ePrescribing in Sweden considered the evolution of a culture of cooperation very important. The forums for cooperation within health care created opportunities to meet, and supported strivings towards reaching agreements on goals and how to implement ePrescribing. The question of trust was considered a very important factor. Trust not only between the actors in the network but 
also a focus on working together to maintain and develop trust of the prescribers, pharmacists, and the public in ePrescribing.

\subsection{Network governing, governance, and collective action}

This section aims at defining some central concepts such as governing, governance, governance mechanism, and collective action in the context of achieving and managing interoperation.

Interoperation among a network of actors, demands a different form of governance compared to a market or a traditional hierarchical command structure within an organization. We will start this section by illustrating research on forms of network governing with examples from ePrescribing in Sweden.

\subsubsection{Forms of network governing}

Interoperation is taking place in an inter-organizational setting (not limited to a dyadic relationship). As we have showed with the case study on the evolution of ePrescribing in Sweden, there were many stakeholders and organizations involved. This setting can be viewed as a network of legally autonomous organizations that are engaged in a cooperative endeavor.

In such a network, it is necessary that there exists some governance to regulate common actions, the responsibility of each actor, and solving of conflicts. [291]. By an organization, we mean a legal autonomous organization such as private or public corporation, state or local authority, regional county council, et cetera.

The governing of such a network cannot use traditional hierarchical or market mechanisms. This type of governing, named network governance, is characterized by a coordination of an informal social system in contrast to a traditional bureaucracy within an organization or the regulation by contracts between organizations. [292]

Raab defines networks as "consciously created groups of three of more autonomous but interdependent organizations that strive to achieve common goal and jointly produce an output." [293]

Provan and Kenis [291] ${ }^{143}$ identify three forms of network governing: Participantgoverned, Lead organization, and Network administrative organization (NAO).

Participants-governed networks are governed by the members in the network themselves without any separate governance entity. They can have various degrees of formality and

${ }^{143}$ See also Markus Bui [294] for a comparison of Provan and Kenis approach to other approaches analyzing to governance of 'Interorganizational Coordination Hubs'. 
centralization. One example of participant-governed network was the initial network for making a new national ePrescription format in Sweden (see chapter 5).

In Lead organization governed networks, key activities and decisions are coordinated by one of the participating member, which acts as a lead organization. This organization facilitates and administers the activities and decisions of the network.

Before the initiative to develop a new ePrescription format in Sweden, the NPC was de facto Lead organization via bilateral contract with the regional county councils, regulating the ePrescription flow. The NPC was responsible for administering the format and request for changes.

The early attempt to implement a new ePrescription format evolved into a network governance that made it possible for the NPC to leave its role as Lead organization and engage some of the major regional county councils. Later the network organization Carelink representing the network members took the role of coordinating the work to cope with the complexity of engaging all the regional county councils in Sweden.

Network administrative organization (NAO) forms of governing occurs when there is a separate administrative entity governing the network. This entity is not a participating member as in a Lead organization governed network. An example of a Network administrative organization is the state authority the Swedish eHealth Agency that administers the information infrastructure. This organization was a product of the reregulation of the pharmacy market in Sweden from a state monopoly to private pharmacy chains. It emerged (in its earlier form) in order to transfer and administer the ePrescribing infrastructure developed by the NPC, and make it available to the new pharmacy chains.

\subsubsection{Governing, governance and governance mechanisms}

Governance and governing are commonly used terms within organizational research, within corporations and in the public sector. The terms are often used rather loosely as synonyms, deepening on the context of use. One way to differentiate their use is to pose questions like, 1) who is governing or 2) what kind of IT governance do you have in this company, or 3) is there any governance of this process?

The first question is answered with who does the actual steering, for example CEO and the members of the executive board. The second question may be answered with a description how (structure and rules) various decisions are made in the company regarding IT investment, IT strategies et cetera. The third question may be a bit rhetoric in questioning, if there is any structure in the governing of the process.

Thus, governance in this thesis focus on "system of governing", i.e. the conditions for governing, or to use the words from Oliver E. Williamson's speech at the Nobel Banquet, 
in 10th December 2009 “ ... governance is the means by which to infuse order, thereby to mitigate conflict and realize mutual gains ...".

Without governance, there is no structure or rules for governing.

Governing is the actual steering by actors of activities, resources and people.

Governing can be made with different time perspectives and a scope of application:

- strategic governing has a long-term time perspective for a future general application;

- tactical governing has a medium-term time perspective for a future specific application;

- operational governing has a short-term time perspective for an existing application.

Governance mechanisms are used when we talk about concrete means "to infuse order". Thus, governance mechanisms are instruments to implement governance.

Hoetker and Mellewigt [295] compare two types of governance mechanism when they study choice and performance of governance mechanism depending on what type of assets are shared in alliances:

- formal governance mechanism does not rely on people and their relationships. They stipulate a certain outcome and behavior. Typical formal governance mechanisms are contracts regulating exchange and shared assets, routines for action and behavior. Formal governance mechanisms regulate and codify mutually agreed acceptable behaviors, which could contribute to coordinate efforts and clarify different roles;

- relational governance mechanisms are based on people and their relationships, where the outcome is not always well defined or predictable. Typical examples are steering groups (which rely very much on the people involved and their relationships), teams, committees, and meetings. Relational governance mechanisms focus on communication and sharing of knowledge, and on developing trust and cooperation.

Governance mechanisms are usually a combination of formal and relational mechanisms. Hoetker and Mellewigt [295] conclude that relational governance mechanisms are more appropriate when exploiting knowledge-based assets in an alliance, while formal governance mechanisms are more appropriate for governance of large amounts of property-based assets.

In ePrescribing, there have been a mix of both formal and relational governance mechanisms. Typically, the governance of assets that have involved a larger investment like the ePrescribing information infrastructure has a number of formal governance mechanisms like eCommunication contracts, service level agreements, financial compensations, routines for change, et cetera. On the other hand, relational governance mechanisms have been widely used to develop the information infrastructure, enhancing open communication, knowledge sharing, and trust. 


\subsubsection{Collective action}

When there are opportunities to develop interoperation between different actors, it is often the case that, even if there is a common good to be achieved that would benefit all potential participants, the benefits for each participant is not high enough to motivate an engagement in a process of cooperation. It can also be the case that the potential benefits are not evenly distributed where important actors have little to gain. This situation is called the Collective action dilemma. It emerges when there is an opportunity to achieve a common good but there is not enough incentive for each individual participant taken separately.

Thus, from a point of view of developing interoperation, to capture the opportunities that exist, collective action by the participants involved is an important concept, which is concerned with how to overcome the Collective action dilemma. [95, 296]

Grandori [297] write about this situation " ... that arise to capture opportunities for joining resources and acting collectively. They share, as a common feature, an underlying problem of governing collective action (Olsen, 1965) rather than a problem of regulating exchanges or transactions (Williamson, 1981)." (Olsen [298]), Williamson [274]).

In this thesis, Collective Action is an action that require two or more entities to coordinate their efforts to achieve a common good. Collective action has a perspective of a development of a future process of interoperation.

The development and implementation of an information infrastructure can be viewed, in line with Markus et al [95], as collective action. In section 8.3, we give an example of collective action to implement a new vertical standard in ePrescribing in Sweden.

\subsubsection{Governing, governance and collective action - summing up}

In this subsection, we sum up our analysis of governing, governance, and collective action. Perspectives of governing are presented in Table 20. 
Table 20 Perspectives of governing

\begin{tabular}{|c|c|c|c|c|c|}
\hline Perspective & $\begin{array}{l}\text { Time } \\
\text { scale }\end{array}$ & Scope & $\begin{array}{l}\text { Type of } \\
\text { action }\end{array}$ & Activities & $\begin{array}{l}\text { Governance } \\
\text { mechanism }\end{array}$ \\
\hline Strategic & Long & Sector & $\begin{array}{l}\text { Collective } \\
\text { action }\end{array}$ & $\begin{array}{l}\text { Develop pre- } \\
\text { conditions for } \\
\text { infrastructure } \\
\text { development }\end{array}$ & $\begin{array}{l}\text { Standards, policies, } \\
\text { long term funding, } \\
\text { institutional bodies, } \\
\text { legislation, et cetera }\end{array}$ \\
\hline Tactical & Medium & $\begin{array}{l}\text { Work } \\
\text { practice } \\
\text { infra- } \\
\text { structure }\end{array}$ & $\begin{array}{l}\text { Collective } \\
\text { action }\end{array}$ & $\begin{array}{l}\text { Develop and } \\
\text { implement of } \\
\text { infrastructure } \\
\text { conditions for } \\
\text { interope- } \\
\text { ration }\end{array}$ & $\begin{array}{l}\text { Joint projects, } \\
\text { steering groups, } \\
\text { maintenance and } \\
\text { support organiza- } \\
\text { tions, contracts, } \\
\text { funding, governance } \\
\text { of work practice } \\
\text { interoperation, et } \\
\text { cetera. }\end{array}$ \\
\hline Operational & Short & $\begin{array}{l}\text { Work } \\
\text { practice } \\
\text { transactions }\end{array}$ & $\begin{array}{l}\text { Inter- } \\
\text { operation }\end{array}$ & $\begin{array}{l}\text { Operational } \\
\text { governing of } \\
\text { inter- } \\
\text { operation }\end{array}$ & $\begin{array}{l}\text { Use of governance } \\
\text { mechanisms for } \\
\text { work practice } \\
\text { interoperation }\end{array}$ \\
\hline
\end{tabular}

A perspective of governing is defined by its time scale and scope. In the table, we have three perspectives: strategic, tactical, and operational. Linked to these perspectives are two types of actions such as collective action for future interoperation and existing action of interoperation. These two types of actions are linked to various types of activities. Collective action includes activities to develop (strategic) preconditions for infrastructure development and to develop and implement an infrastructure for interoperation (tactical). An important result of these activities are governance mechanisms for interoperation. Interoperation is about the operational governing of the process of interoperation using governance mechanisms created in collective action.

The strategic perspective of governing is long-term and aims at a more general application (scope), such as a whole sector, which could involve both public and private sector organizations and companies. In the strategic perspective, activities aim at achieving legal, political, economic, and organizational pre-conditions that facilitate future collective action.

The tactical perspective of governing is medium-term with a scope of work practices and their infrastructure conditions. It is about a development and implementation of a shared work practice and its information infrastructure for interoperation, which have concrete 
parties and users. The activities are about creating governance mechanisms, initiating and governing the development and implementation.

The operational perspective is short-term with a scope of work practice transactions. The type of action is interoperation with activities that are focused on transactions and the operational control of interoperation.

Collective action has both a strategic and tactical perspective because it is about a change of a situation, in the long and medium term. The operational perspective of governing is focused on the immediate interoperation. It has the perspective on the stability and sustainability of the interoperation.

\subsection{New National ePrescription Format - Vertical Information Systems standardization effort as collective action}

In this section, we will give an example of collective action in developing and implementing vertical standards within ePrescribing in Sweden. This is an example of a collective action with a tactical perspective (see Table 20).

To analyze the characteristics of developing and implementing a new national ePrescription format (NEF) in Sweden, we will use Markus et al [95] notion of collective action dilemmas in vertical standardization and suggestions how to overcome them. See chapter 5 for a detailed account of this case.

Vertical Information Systems (VIS) standards are designed to promote coordination and communication among actors in a vertical business sector or cross business sectors. [95] Vertical standardization efforts emerge from the need to promote interoperable business processes, usually between partners that have different roles and structures. In eCommerce, there is often a buyer and supplier relation in which a supplier of some goods could deliver to various business sectors. The business processes that interoperate have different properties.

Thus, vertical standards thus need to be developed in a common action among heterogeneous groups of actors, in contrast to horizontal standards that are often developed by homogenous and rival competing groups. Markus et al (ibid) view developing of vertical standards as collective action. They identify a number of collective action dilemmas in development and diffusion of vertical standards. Generally, there is the socalled free rider problem, which means that everybody is waiting for others to be the first to engage in developing and adoption of a standard. Other dilemmas are heterogeneity in interest and distribution of resources that will influence actor's engagements in developing standards and their ability to implement developed standards. Based on a case study in the 
residential mortgage industry in US, Markus et al [95] make some suggestions how to overcome the collective action dilemmas in vertical standardization. They suggest that:

A. participation of all structurally different groups is necessary in order to meet the needs and demands of the interoperating processes;

B. key players in diffusing the VIS standards should be part of the standardization work;

C. it is important to deploy successful tactics regarding engagement, participation, governance, agreements, and scope in developing and diffusion of VIS standards;

D. simple solution promotes diffusion better than a technically complicated one.

We can view the development and implementation of the new ePrescription format in Sweden as a collective action for a vertical standard within a business sector, or rather in the intersection of two different business sectors - the health care and pharmacy market.

The participants in this collective action had a different interest in the development and diffusion of the standard. Resources and their governance were different: on the one hand, there were many regional county councils with a high degree of local decision and funding, and on the other hand, a centralized state owned company at the pharmacy side.

In the following, we will use the suggestions made by Markus et al (ibid) to overcome the collective actions dilemmas in order to compare with lessons learned from the development and implementation of the new ePrescription format in Sweden.

\section{A. Participation of all structurally different groups}

Early in the initiation of the project, two major regional county councils and a county council in the north were engaged together with the NPC in making the first suggestion and design of the new format. The request for participation was open, but most of the county councils did not feel the need to participate early in the process. Soon, the third largest regional county councils in Sweden were also engaged in the project. Thus, relatively early the three major regional county councils were engaged. When the first version of the new format was designed, a new phase of diffusion started, engaging a network organization (Carelink) for cooperation between the county councils. In this phase, the group of regional county councils engaged was extended through various activities. The new design suggestion was remitted to include viewpoints from all the software vendors of the EHR-systems.

\section{B. Key players in diffusion is engaged in standardization work}

The engagement of all the regional county councils that procured and used the EHRsystem that had to be changed to implement the new format was important to for the diffusion of the standard. Also, the early engagement of the three major county councils in the project, was important in facilitating the diffusion. The county councils had to order and finance the changes of the EHR-system themselves, and thus, it was important to have 
the three major county councils as part of the project as well as to have a smaller county council involved to ensure a certain structural and geographical diversity. The software vendors were not primarily involved; their role was to implement the changes needed on the request of the county councils. The NPC played an important role, not only as a centralized organization of the pharmacies, but also, as a consistent promoter over time. The state authorities concerned were supporting the initiative but they were not engaged in the project, although invited.

\section{Deploy successful tactics regarding engagement, participation, governance, agreements, and scope}

One important tactic in engagement and participation was the long-term cooperation between the major county councils and the NPC. This was a continuation of the cooperation in the diffusion of ePrescriptions in Sweden ${ }^{144}$. A key role was also the engagement of the network organization Carelink who could host and govern the work with design, testing, approval and diffusion, as a neutral partner and engage a major part of the county councils. There was no common financing except the participation of the network organization. All development, test and implementation costs were to be financed by each county council and the NPC. There was a common interest among the county councils to the keep the cost down for the change of the EHR-system. A common and nationally accepted standard could distribute the cost among the county councils when they had the same EHR-system. Another successful tactic in the diffusion was making public the progress report of each county council, a tactics that was learned from the implementation of ePrescriptions. This created a kind of competition between the county councils. There was also a constant pressure from the major county councils and the NPC to implement the new format with setting up of deadlines, although they had to be postponed on occasions, they helped to push the implementation forward.

\section{Simple solution promotes diffusion}

In the design phase of the project, there was early a concern from the NPC and the county councils that the design should be as simple as possible to implement. On the other hand, if there were very few changes, there were less interest in making the change. This dilemma was present in the design phase, when there was a balancing of different needs and requirements in relation to its affect on the diffusion. Starting with the idea and metaphor of a 'base line', it was possible to focus on improving the quality first and only implement those functional changes that were considered necessary. From the beginning, the project focused on quality of content and patient safety. This helped to keep the design

\footnotetext{
${ }^{144}$ Reimers et al [299] refer to the term colony by Porra. [300] "Colonies are voluntary collections of individuals that share a common history, common methods for realizing both stability and radical change, and a common local context." [299]
} 
simple and more easily accepted. To 'keep it simple' seems to be a success factor also in this case.

\subsection{Network governance, IT governance, and IT service management in the context of interoperation}

There is a lack of theory on and models for setting up network governance mechanisms in relation to the use of information infrastructures. [301] There are many challenges facing network governance, such as sharing knowledge, resources, governance, and information plus the heterogeneity regarding IT infrastructure and IT governance compared to a single enterprise. In section 8.2.1 Forms of network governing, we described research about network governance forms coming from organizational research.

This section will develop further on how forms of network governance can influence design, implementation, and adoption of interoperation. The second aim is to relate network governance to existing models of governance in enterprises for IT and IT service management, and discuss their limitations and contributions to network governance for interoperation.

The first section (8.4.1) will make a comparison of implementing ePrescribing in US and Sweden. The aim is to highlight the ramifications of the operating model of ePrescribing on incentives and roles of the actors, and the role of network organizations and network governance. These ramifications may in turn affect the adoption and growth of the share of ePrescriptions.

We will then in section 8.4 .2 and 8.4 .3 briefly describe some enterprise IT governance concepts and then a widespread IT service management framework, ITIL. Going beyond their context of an enterprise, we will discuss some potential contributions from these governance models to network governance of interoperation. We will exemplify from ePrescribing in Sweden and compare some of their concepts with those we have developed in section 8.2 Network governing, governance, and collective action.

\subsubsection{Network governance in ePrescribing - comparison US - Sweden}

Electronic prescribing has been an important part of US health policy since 2003 with the passage of Medicare Prescription Drug, Improvement, and Modernization Act (MMA). [302] MMA intended to foster ePrescribing through creation of standards for exchange and removals of rules that could block the development of ePrescribing. [303] However, the increase in the share of ePrescriptions remained modest. In 2008 , only about $4 \%$ of all 
new and renewals of prescriptions were ePrescriptions. [304] After the Medicare Improvements for Patients and Providers Act (MIPPA) from 2008, and which included financial incentives to facilitate the use of ePrescribing, there was a more important increase in the share of ePrescriptions. In 2014, 67\% of all new and renewals of prescription were ePrescriptions in US. [305] ${ }^{145}$ It was promising for further growth that the share of community pharmacies that could accept ePrescription increased from $76 \%$ in 2008 to $96 \%$ in 2014. [304]

Although this is a dramatic increase, it does not match the level of growth of ePrescribing in Sweden between 2000 and onwards (see chapter 4). In 2015 (Swedish eHealth Agency), $98 \%$ of all prescription in Sweden were ePrescriptions. There are several explanations of the reason why the pharmacies uptake in US is higher than the health care providers. One explanation ${ }^{146}$ for the difference is that physicians' time spent issuing a prescription has increased with ePrescriptions. [306] Another explanation is the cost for the physicians to invest in ePrescribing. [302]

Nelson King [301] describes in their paper how the operating model ${ }^{147}$ of ePrescribing in US influences the role of and relationships between actors in the network. Here, an operating model is viewed as a blueprint of actions and exchange between actors in a network to achieve a certain goal, i.e. a network-operating model ${ }^{148}$. Nelson King claim that the design and implementation of the operating model might explain some of the obstacles to and the incentives in increasing the share of ePrescriptions.

Subventions of medical drugs is different in US compared to Sweden. In US, there are both national and state programs (Medicare prescription drug plans (Part D), Medicaid) and private insurances to pay for cost of medical drugs. In Sweden, the county councils pay all medical drug benefits. The pharmacies and the Swedish eHealth Agency administers the economic transactions. The number of prescribers, pharmacies, and IT providers are much higher in US and of course, the population and the number of prescriptions issued each year. This makes the implementation of ePrescribing in US more complex. See [304] for some details.

Even if there are differences between US and Sweden, we think it is interesting to analyze what Nelson King [301] calls the "operating model" of ePrescribing and how it influences

${ }^{145}$ Surescripts reports that in 2014 67\% of all new prescriptions were ePrescriptions (1.2 billion). [305]

146 The most populated states have a lower share of ePrescriptions than other states. When these states share's increase there will be a more dramatic increase.

${ }^{147}$ Nelson King use the term influenced by Ross [307]. Ross stressed the importance that the enterprise define an operating model because it influence which strategies should be supported. An operating model gives a more action oriented and concrete view of the enterprise and give inputs on the relation between workflow and strategy. [301]

${ }^{148}$ This is in line with our definition of a work practice. See earlier sections 2.2.2, and 7.1 and section 9.3.1 where we develop our notion of a shared work practice. 
the roles and relationship of the actors in ePrescribing and its effect on the incentives of the stakeholders to adopt ePrescribing.

Nelson King compares the operating model of paper prescriptions and the implementation of ePrescribing in US. By using paper prescriptions, the patient had a choice to decide to fill the prescription or not and to choose pharmacy. The pharmacies made all the controls related to the medical benefits. This is very similar to the situation with paper prescriptions in Sweden. The implementation of ePrescribing in US changed this operating model. There were two major changes. Through ePrescribing the prescriber has to check the eligibility of the patient to Medicare and the formulary of the Medicare drug plan, previously made by the pharmacies. This means that the prescriber's relation to the patient has changed in the sense that the prescriber has to take into account cost when selecting a particular medical drug. The prescriber also had to make a choice to which pharmacy to send the prescription. This meant that ePrescription changed to become a point-to-point communication between prescriber and pharmacies, and that the patient no longer could choose a pharmacy independently.

This operating model is similar to the early operating model of ePrescribing in Sweden. However, in Sweden, fairly soon this operating model changed towards a more "pull" oriented model, with a national ePrescription mailbox and later the national ePrescription repository. This meant that the patient could choose pharmacy, as before with the paper prescription. This change was demanded by the major county councils of the major cities where there were many pharmacies to choose between. This change of the operating model increased the acceptance of ePrescribing by both the prescriber and the patients. Another difference of the operating models in US and Sweden was that the issuing of a prescription did not mean any extra work for the prescriber. Moreover, the use of EHR systems was more common in Sweden than in US in the beginning of 2000. In 2009, there was almost a 100\% adoption of EHR systems in Sweden. [308]

The "push" metaphor for the operating model of ePrescribing mimics an electronic transfer of messages which was the dominating mode of communication in the 80- and 90 s particularly for inter-organizational communication. Thus, it is fairly natural that such a metaphor for communication has an influence on the choice of operating model. It was also a way to advance the implementation of ePrescribing. Moreover, storing of ePrescriptions in a repository was not legally settled in Sweden. In the beginning of 2000, new technologies and standards for the provision of services, crossing organizational borders also made it possible to imagine other operating models.

Another aspect related to the "push" metaphor is the mistake to view a prescription as an "order" "149. Both in the US and Sweden, it is not always the case that the patient actual goes

${ }^{149}$ With paper prescription, the act of the patient/customer to bring the prescription to the pharmacy implicitly became an order and a relation between the (now) customer and the pharmacy to fill the prescription. This analogy with paper prescription where the "transport" of prescription coincided with an 
to a pharmacy to get the prescription filled. In the beginning of 2000, some pharmacies in Sweden interpreted the prescription as an order and prepared the prescription in advance ${ }^{150}$. However, while some patient never showed up and with the new legislation on generic drug exchange, it lost its meaning. Nevertheless, there were still discussions at the NPC with the introduction of the national mailbox and later the repository for prescriptions, whether to accept an ePrescription as an order or not in some cases, as it was possible to address a local pharmacy for specific reasons. This was of interest for a part of the organization that worked with mail order pharmacy ${ }^{151}$. The implementation was that even if a prescription was addressed to a local pharmacy, it was still managed centrally and "pulled" at the request of the customer (case by case or by subscription).

Nelson King [301] writes that the impetus of cost reduction expected from ePrescribing has primarily been from third party payers such as state and federal governments and insurance companies. The expectations were that an increase of prescriber's choice of generic drugs would benefits these stakeholders. This may explain the choice to make the prescribers to take an increasing role in the cost of medical drug, which was not the case with papers prescriptions. In Sweden, this was not an issue. A law demanded the pharmacies to choose the cheapest generic drug when dispensing a prescription. The initiative in Sweden to develop ePrescribing came not first from third party payers ${ }^{152}$ of medical benefits but from the pharmacies and prescribers. The state authorities were not taking the lead. This may also explain the choices made in the operating model in US.

Nelson King [301] identify a mismatch between the implemented operating model of ePrescribing and the work flow expectations of the network members in ePrescribing. For example, prescribers support ePrescribing but want compensation for extra time spent. Nelson King [301] notes that policy makers and system designers did not seem to take into account various stakeholders reaction and incentives when implementing ePrescribing. This mismatch between the implemented model and the actors in the ePrescribing may have influenced the rate of uptake of ePrescribing in US.

One interesting aspect that may have influenced the choice of operating model of ePrescribing in US and Sweden is the fact that in Sweden there was an organization that

order may have influenced to see the electronic "transport" of a prescription to a pharmacy as an order. However, the mistake is that the order relation is not between the prescriber and the pharmacy but between the customer/patient and the pharmacy. In addition, the prescription is an institutional object in itself issued by an eligible prescriber giving directions and rights to the patient and the pharmacy regulating the dispensing of prescription drugs. See chapter 6 A practical theory on ePrescribing for an analysis of the role of an ePrescription in ePrescribing.

${ }^{150}$ See section 4.8.1.

${ }^{151}$ This view would not be tenable in a reregulated pharmacy market with several pharmacy chains.

${ }^{152}$ In Sweden, the county councils have a double role of prescribing and paying the medical benefits, but they take no active role in reducing the cost of drugs by choosing generic drug, which is managed by the pharmacies. 
took a central role in ePrescribing, the NPC. The NPC was very active in creating an internal information infrastructure to rationalize the dispensing of prescriptions. Early, it was mandated a role by the state authorities to carry out tasks such as reimbursement administration, generic drug change, administration of medical drug register, national pharmacy register [161], and sales statistics. It may be more difficult, but not impossible, to take such a role by other organizations or by creating such an organization as in the case of the Swedish eHealth Agency, which is responsible for the central information infrastructure for ePrescribing in Sweden. In US, important actors were federal and state government institutions, insurance companies, and the so-called network integration infomediaries for example Surescripts that relays ePrescriptions to the pharmacies. With an existing organization at hand that already had a central role in the ePrescribing infrastructure, it seems to be easier to establish an operating model with greater flexibility for the actors based on services rather than on point-to-point communication in communicating ePrescriptions.

From this comparison between the implementation of ePrescribing in Sweden and US, we can conclude the following:

- the work practice ${ }^{153}$ implemented has an influence on stakeholder's incentive and willingness to adopt;

- it is important to make an analysis of the work practice and its ramifications for various stakeholders;

- the legal and economic aspects have an important influence on the design and implementation of the work practice;

- the existence of network organizations and governance will influence the design and implementation of the work practice.

In section 8.2.4 Governing, governance and collective action - summing up, we described three perspectives on governing of interoperation: strategic, tactical, and operational. We can see these aspects also in the case of the evolution of ePrescribing in US. We have the strategic perspective illustrated by government initiatives such as removing of legal obstacles, the use and establishment of organizational bodies for governance, creating economic incentives, and promoting development and use of standards. The tactical perspective is illustrated by the development, design, and implementation of the "operating model" and its governance. The operational governance has not been in focus in this section.

${ }^{153}$ We use here the notion of a work practice instead of operating model in order to link the analysis to our theory. 


\subsubsection{IT governance for enterprises and governance of interoperation}

Weill \& Ross at MIT have made extensive research on IT governance in enterprises in US, Europe, and Asia/Pacific. [309, 310] Weill \& Ross view IT governance as a structure for making decisions on IT in an enterprise [311]. They identify five major decision domains [309]:

- IT principles, which comprise decisions about the strategic role of IT for the business;

- IT architecture which is about technical choices;

- IT infrastructure which comprise decisions about the centrally controlled IT services of an enterprise;

- Business application needs which are the business requirements for IT applications;

- IT investments, which comprise the prioritization and investments decisions.

These decision domains may still be relevant in an inter-organizational setting. In Table 21 we use examples from ePrescribing (see chapter 4 and 5) to illustrate how joint decisions can be made in the different decision domains. 
Table 21 Decision domains and examples of decision from ePrescribing in Sweden.

\begin{tabular}{|c|c|}
\hline Decision domain & Example from ePrescribing \\
\hline IT Principles & $\begin{array}{l}\text { Both major county councils and NPC made early } \\
\text { strategic decisions to promote ePrescribing, as did the } \\
\text { network organizations like Carelink. The policy of the } \\
\text { state was also supporting the effort in the direction of } \\
\text { developing ePrescribing. The promotion of } \\
\text { ePrescribing was a strategic initiative within the health } \\
\text { care sector. }\end{array}$ \\
\hline IT Architecture & $\begin{array}{l}\text { There were joint decisions made regarding identity } \\
\text { management (SITHS), security (S/MIME), system to } \\
\text { system services (Web services), et cetera. }\end{array}$ \\
\hline IT Infrastructure & $\begin{array}{l}\text { The development of the ePrescribing services were a } \\
\text { cooperation between NPC and the county councils, } \\
\text { particularly during the development and } \\
\text { implementation of the new ePrescription format. }\end{array}$ \\
\hline $\begin{array}{l}\text { Business Application } \\
\text { Needs }\end{array}$ & $\begin{array}{l}\text { During the development and implementation of the } \\
\text { new ePrescription format, business requirements from } \\
\text { the stakeholders were considered and approved. }\end{array}$ \\
\hline IT Investments & $\begin{array}{l}\text { Each actor made IT investments themselves although } \\
\text { there was funding of certain common projects. Later, } \\
\text { when the information infrastructure for ePrescribing } \\
\text { was hosted in a separate organization with the } \\
\text { reregulation of the pharmacy market in Sweden, a } \\
\text { financing model of the information infrastructure was } \\
\text { constructed (and decreed by the state). The pharmacy } \\
\text { chains contributed to finance this infrastructure } \\
\text { through fees based on transactions using this } \\
\text { information infrastructure. }\end{array}$ \\
\hline
\end{tabular}

From these examples, we can conclude that the IT decisions domain for IT governance in an enterprise identified by Weill \& Ross are useful to identify decision areas regarding information infrastructures for inter-organizational interoperation.

According to Weill \& Ross [309], a company must design and implement governance mechanisms to guide managers day to day work with governing IT. They define three kinds of governance mechanisms: 
- decision making structures - definition of organizational structures, their roles and locations in decision making;

- alignment processes - i.e. processes how to make decision, and to gain desired involvement in decisions;

- formal communications - how to communicate governance processes in order to make them understood and implemented as desired in the enterprise.

Within a network governance setting, these governance mechanisms are relevant, although governance styles for interoperation in a network are different.

Weill \& Ross focus is not on the operational aspect of IT governance but rather on governing of IT on a strategic and tactical level. IT governance is about making decisions on IT in general (investments, strategies, choices, policies, et cetera.) rather than governance on how IT services should be developed, implemented and operated. In the next section, we will deal with governance of IT services.

\subsubsection{IT service management and interoperation}

A widely recognizes framework for IT service management is ITIL [312].

ITIL defines IT service management as:

"The implementation and management of quality IT services that meet the needs of the business." [313]

In addition, an IT service as:

"A service provided by an IT service provider. An IT service is made up of a combination of information technology, people and processes...." [313]

ITIL is a guide for service providers for the provision of IT services [314].

ITIL contain a description of processes, functions and capabilities to support the delivery of IT services. Although, the scope is limited to governing the delivery of IT services by a service provider, the approach is well developed and has interesting parallels to our analysis on governance and interoperation. With this limitation in mind, we will here shortly describe the main component of ITIL and make some reflections on its relation to the perspective on governing outlined in this chapter.

ITIL [314] is based on five stages of the service life cycle:

- service strategy

- service management seen as a strategic asset and not just as a business capability. Describes the basis for the practice of service management for developing policies, guidelines, and processes;

- service design 
- guidance for design and development of service and service management practices. Includes also change and improvement of existing services over its life cycle;

- service transition

$\circ$ guidance for the development and improvement of capabilities to introduce new and changed services. Describes best practice in transition planning, support and change management, asset and configuration management, release and deployment, validation, and testing;

- service operation

- guidance how to maintain stability in service operation, allowing for changes in design, scale, scope, and service levels. Include processes such as event, incident, problem and access management, service desk, et cetera;

- continuous service improvement

○ guidance how to improve strategy for design, transition and operation of services, and how to improve service quality, efficiency in operation and the continuity of business.

ITIL use a hub-and spoke metaphor when presenting theses phases, in which the service strategy is the 'hub' around which service design, transition and operation revolves as the 'spokes' (see Figure 47). This metaphor highlights that design, transition, and interoperation are instances of processes and projects to design and delivers services or version of services.

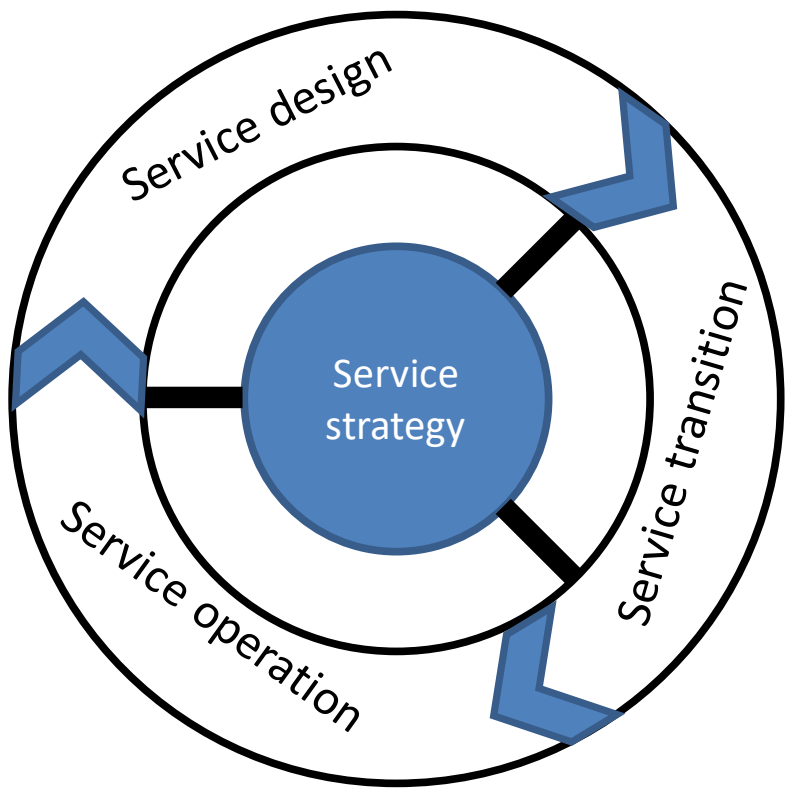

Figure 47 Hub-and-spoke model of ITIL. 
When comparing this framework with our analysis of governing perspectives, we see many similarities.

Service strategy has a strategic perspective, while service design and transition are part of the tactical perspective and service operation has an operational perspective (see Table 22). Continuous improvement concerns all perspective and stages in ITIL.

Table 22 Comparison of ITIL governance mechanisms for different phases and perspectives of governing (Table 20).

\begin{tabular}{lllll}
\hline Perspective & $\begin{array}{l}\text { Time } \\
\text { scale }\end{array}$ & Scope & $\begin{array}{l}\text { Type of } \\
\text { action } \\
\text { (Network } \\
\text { governing) }\end{array}$ & $\begin{array}{l}\text { ITIL } \\
\text { Governance } \\
\text { mechanism }\end{array}$ \\
\hline Strategic & Long & Sector & $\begin{array}{l}\text { Collective } \\
\text { action }\end{array}$ & Service strategy \\
\hline Tactical & Medium & $\begin{array}{l}\text { Work practice } \\
\text { infrastructure }\end{array}$ & $\begin{array}{l}\text { Collective } \\
\text { action }\end{array}$ & $\begin{array}{l}\text { Service design } \\
\text { Service transition }\end{array}$ \\
\hline Operational & Short & $\begin{array}{l}\text { Work practice } \\
\text { transactions }\end{array}$ & Interoperation & Service operation \\
& & & & \\
\hline
\end{tabular}

In Table 22 we have included 'Type of action' from Table 20 on perspectives of governing in a previous section to indicate that it should be possible to include, or at least consider, some of ITILs governance mechanism to be used in collective actions in a network environment. In section 9.6 Interoperation and governance of shared information infrastructure and work practice, we have used ITILs governance mechanisms for operation in order to exemplify our theory and to show that it is possible to apply ITIL governance mechanisms for interoperation.

The conclusion of this comparison of different perspective on governing and the life cycle stages of ITIL is that there are many similarities. Thus, on a more general level the ITIL model of governance supports the perspectives, we have put forward in section 8.2.4 and Table 20.

ITIL is a developed and detailed guidance for IT service management for a service provider. What differs is the scope of application. ITIL is limited to one service provider providing IT services to customers, while interoperation involves at least two separate organizations that share an information infrastructure to interoperate. These organizations, each separately, can use some IT service provider for their share of interoperation and their own IT services.

Governance models for interoperation, similar to ITIL, should be possible to develop, taking into consideration the specific conditions and circumstances that exist for 
Interoperation, governance, and collective action

governance of interoperation which involve several organizations. In any case, a governance model for interoperation need to interact with governance models for IT service management which are used for managing IT services in each organization.

The ITIL framework focuses on IT services and not on the work practices in which the IT services are used. Despite this, frameworks like ITIL for IT service management would surely be an important contribution to a framework for the governance of interoperation. 


$$
292
$$




\section{A practical theory on interoperation and interoperability}

One aim with this thesis (se chapter 1 ) is to contribute with a practical theory on interoperation and interoperability which is empirically grounded in the practice of improving interoperability in ePrescribing and theoretically grounded in theories about information systems, information infrastructures, work practices, network organizations and communication.

This chapter presents a practical theory on interoperation and interoperability. The theory is a generalization of experiences and findings in implementing ePrescribing in Sweden and improving interoperability presented in chapter 4 and 5 . It is theoretically grounded based on chapter $2,6,78$, and $8^{154}$.

In section 9.1, we describe the objective with the theory, and in 9.2, we present an overview of the main components of the theory to guide the reader. The main concepts of the theory are presented in the sections thereafter.

\subsection{Objectives}

In section 1.3, we identified some knowledge gaps for achieving and improving interoperability. In chapter 2 we analyzed some weaknesses of existing definitions and frameworks on interoperability. We can summarize these gaps and weaknesses as follows:

- weak scientific basis for interoperability;

- underlying theoretical assumptions often not problematized and reflected upon;

- few studies evaluating approaches and methods to achieve, maintain and improve interoperability;

\footnotetext{
${ }^{154}$ See further section 10.3 and chapter 3 .
} 
- fragmented views on interoperation and interoperability regarding technical, semantical, organizational, and legal perspectives;

- lack of analysis of the context of interoperation and interoperability, particularly regarding the shared work practice.

This situation is unsatisfactory from research and practitioners point of view. Research cannot be accumulated and compared, if there is a weak conceptual and theoretical basis for classifying and comparing research results. Practitioners will have less guidance in governance, design and implementation of interoperation, and of improving interoperability, if the context of interoperation is not clarified. Practical lessons are more difficult to share and compare.

In short, the diverging concepts and frameworks will hamper the growth of knowledge in the field. In order to reduce this divergence and ambiguity, we propose a practical theory on interoperation and interoperability with the following objectives to:

- conceptualize the notion of interoperation and interoperability in order to improve their conceptual coherence and contribute to a better understanding;

- analyze the context of interoperation and the factors that influence interoperability;

- provide a theory that is empirically grounded in the shared work practice of ePrescribing;

- provide a theory that is grounded in relevant explicit theories, which can be contested and thus contribute to the growth of scientific knowledge;

- provide a theory that can guide practitioners in design and implementation of interoperation and to improve interoperability.

The practical theory is targeting practitioners, providing conceptualizations, patterns of action, and criteria, to develop and implement interoperation and improve interoperability. Another target audience is the research community, informing about relevant research areas, theoretical refinements and possible further situational inquiries.

The theory is not a ready guide or handbook for practitioner to apply. However, such guidance could be developed based on the theory and the content in this thesis.

\subsection{Overall guide to the theory}

This section is a guide to the different theory components of the practical theory.

A practical theory (see section 3.3.3) may consist of the following components:

- conceptualizations: the existing phenomena, their properties and relations in the practice, are generalized. Conceptualizations delimit and define the scope and context of the theory; it directs attention to certain phenomena in a situation. Conceptualizations are used to explain the basic concepts of the theory and make it understandable and useful for organizing empirical material; 
- patterns: how things may and may not work. Patterns are used to explain how a practice works, and what makes sense to do in a situation. Patterns also describe actors and their intentions, actions and context of action and outcome of actions in a practice. Patterns direct attention to essential patterns of action in a practice;

- normative criteria: goodness of things. Normative criteria can be used to evaluate and design a practice;

- design principles: descriptions of ways to create good things, i.e. way to achieve goals and normative criteria of a practice;

- models: illustrative crystallizations of a practical theory.

A practical theory need not have all these components. A minimum requirement of a theory is that it should have Conceptualizations.

The practical theory on interoperation and interoperability has the following components:

- conceptualizations of interoperation, interoperability, shared work practice, collective action, and governance, that delimit and define the scope and context of the theory;

- patterns explain the interdependency of interoperation in a shared work practice and the collective action to achieve interoperation, the relationship between shared work practices, different aspects of interoperation and collective action;

- normative criteria in terms of concepts and definitions for defining and evaluating the capability to interoperate;

- models illustrating conceptualizations, patterns, and normative criteria.

\section{Conceptualizations of the theory on interoperation and interoperability}

In this section, we focus on the central concepts of the theory. Figure 48 illustrates the most important concepts of the presented theory on interoperation and interoperability. The intention with the conceptual map is to guide the reader and make the theory more comprehensible. 


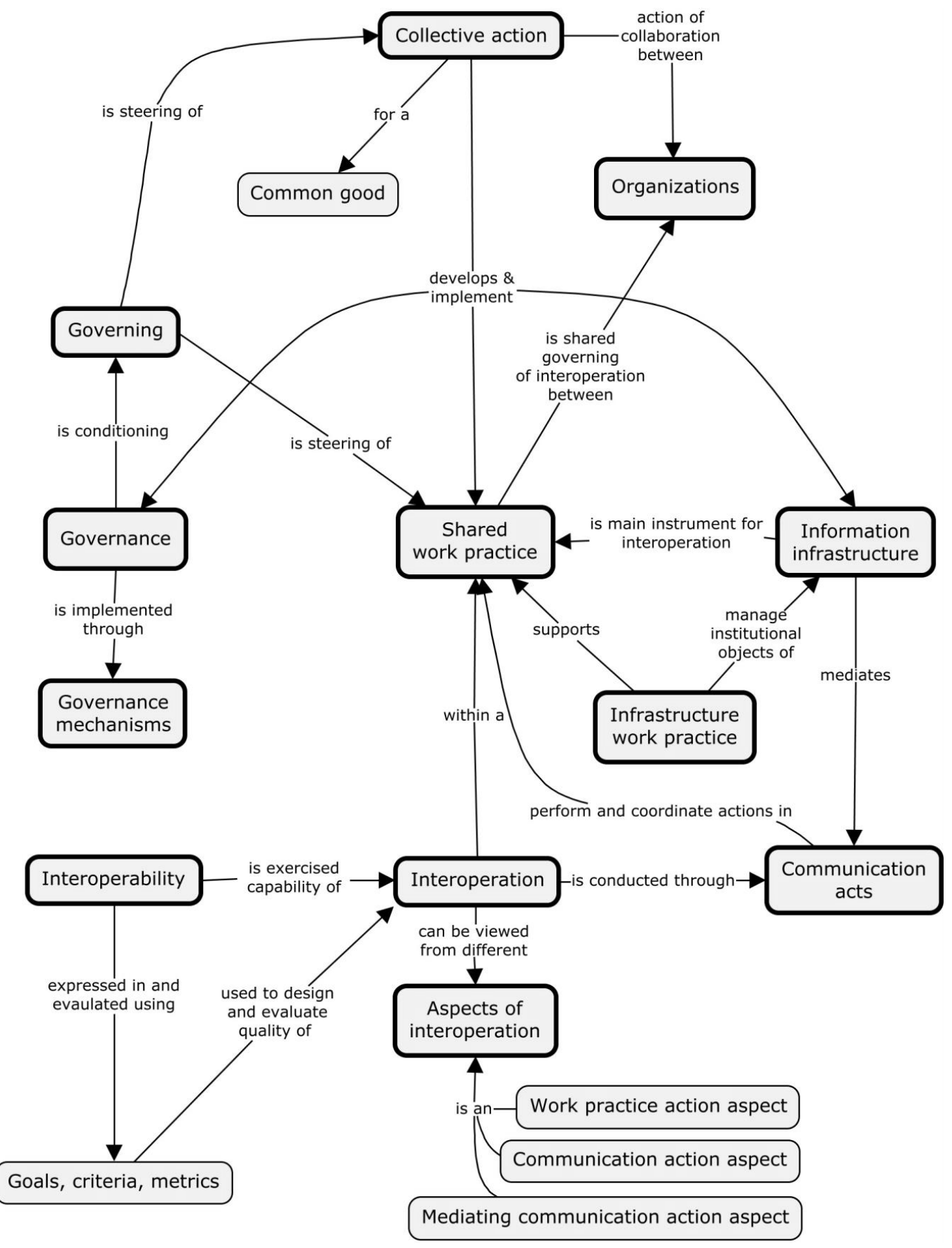

Figure 48 Conceptual map of concepts in the theory on interoperation and interoperability (the central concepts highlighted). 
The core concept of the theory is the definition of interoperation and its context (see previous sections 7.1 and 7.10). The concept of a shared work practice is defined and elaborated in section 9.3 Interoperation and interoperability in a shared work practice.

The role of information infrastructure in interoperation is summarized in section 9.3.2.

In 9.3.2 Interoperation, interoperability, and the role of the information infrastructure, the definition of interoperation and interoperability from chapter 7 is recalled and elaborated to include the notion of a shared work practice.

Earlier, we have analyzed three perspectives (strategic, tactical, and operational) on governing. Governing, governance, governance mechanisms, and collective action are defined in section 8.2 Network governing, governance, and collective action.

The concepts of collective action and interoperation, and their relationships constitute two basic elements of the theory. We briefly formulate them as follows:

- collective action is a collaborative action between organizations for a common good for the development and implementation of interoperation within a shared work practice. Collective action creates conditions for interoperation and for further collective actions;

- interoperation is conducted through communication acts to perform and coordinate actions (material and communication acts) within a shared work practice mediated by an information infrastructure.

Collective action and interoperation and their relationship is further elaborated in sections 9.4, 9.5 and 9.6.

In section 9.7 Aspects of interoperation, three aspects of interoperation are described: work practice action aspect, communication action aspect, and mediating communication action aspect.

\section{Patterns of action in implementing and improving interoperability in ePrescribing and its influence on the theory on interoperation and interoperability}

Patterns of action explain how a practice works, the actors and their intentions, the context and outcome of actions. In this section, we will briefly describe how observed patterns of action in the situational inquiry in ePrescribing, feed the generalization of patterns of action in the theory on interoperation and interoperability.

One important finding in the situational inquiry was that interoperability in ePrescribing could not be improved only by considering the exchange of messages in the actual interoperation. Interoperability was closely linked to implementation of the information infrastructure that mediated the communication acts and the implementation of the shared work practice, which formed the context for interoperation. 
In the situational inquiry in ePrescribing, interoperability was found to be the result of a whole range of actions and decisions made in the successive evolution of ePrescribing in Sweden, and particularly the successive implementation of a complex information infrastructure. These actions taken together contributed to improve interoperability in ePrescribing (see the case study in chapter 4 Implementing ePrescribing in Sweden-case $s t u d y$ ). In addition, the introduction of a new ePrescription format expressed this pattern, with the improved interoperability as the result of a range of actions, decisions, and creation of new institutional bodies and other governance mechanisms.

The conclusion is that interoperability has to be considered in relation to the development and implementation of an information infrastructure, shared work practices, and governance mechanisms for interoperation. Consequently, a theory on interoperation and interoperability has to take into account all these patterns of action in order to fully understand and explain the notion of interoperability. These patterns of action are explained in sections 9.4, 9.5, and 9.6, using the conceptualization described above.

Another pattern that emerged from the situational inquiry in ePrescribing (see chapter 4 and 5) was that, in the early phases, there was a focus mainly on technical aspects of interoperation. Furthermore, in theories on interoperability, many research papers proposed formal methods, focusing on technical and/or formal semantic aspects, not considering the work practice context. Therefore, there was a need to explain different aspects of interoperation in more detail. How these aspects interrelate are described in section 9.7 Aspects of interoperation

Furthermore, the case study revealed how dependent ePrescribing was on various registers. These registers are continuously managed by a number of supporting work practices which we name Infrastructure work practices. In section 9.3.1 and the subsection Infrastructure work practices, we explain how the shared work practice uses and depends on these registers of shared institutional objects, and how the shared work practices relate to the Infrastructure work practices and how they emerge.

\section{Normative criteria for quality of interoperation}

Normative criteria are criteria for evaluating and designing the goodness of a thing or phenomena. The central phenomena in this thesis are interoperation and interoperability. In the theory, we provide general criteria and concepts to design for and evaluate interoperability.

In the section 9.3.2, we provide a definition of interoperability that contain the concept of effective, efficient, and satisfactory manner of interoperation, which can be used to define explicit goals, criteria, and metrics for evaluating and designing ability to interoperate. In section 9.7 Aspects of interoperation, we focus on various aspects of interoperation, which could be used to guide formulation of quality criteria or assumptions about key process drivers to improve interoperability. 


\section{Models of conceptualizations, patterns, and normative criteria}

Models, here meaning visual representations of theoretical concepts, patters of actions and their relations, are used to crystallize and illustrate different components and their relations in the theory on interoperation and interoperability.

Table 23 contains a list of the most important models with a short description what they intend to illustrate in the theory on interoperation and interoperability.

Table 23 List of models to illustrate the theory on interoperation and interoperability.

\section{Model \\ Figure 48 Conceptual map of concepts in the theory on interoperation and interoperability (the central concepts highlighted)}

Figure 49 The context of interoperation

Figure 50 Illustration of a shared work practice emerging out of interoperation between work practices

Table 20 Perspectives of governing

Figure 55 Relations between collective action, shared work practice, and interoperation

Figure 56 The context of communication acts in interoperation

Figure 57 Aspects of interoperation in a shared work practice

\section{Illustrates}

The most important concepts in the theory on interoperation and interoperability and their relation to other concepts are illustrated in a conceptual map.

The context of interoperation including the shared work practice.

The emerging shard work practice out of the needs to interoperate between different work practices.

The relationship between different perspectives on governing regarding time scale, scope of practice, type of action, activities, and governance mechanism.

The relationship between collective action, providing shared work practice, governance mechanism, and an information infrastructure for interoperation.

The context of the communication act illustrated to explain the selection of different aspects of interoperation.

Aspects of interoperation such as work practice action, communication action, and mediating action. 


\subsection{Interoperation and interoperability in a shared work practice}

This section develops further the analysis of the context of interoperation with a focus on the shared work practice. The concept of the shared work practice is then integrated in our definition of interoperability.

Figure 49 illustrates the context of interoperation including the shared work practice.

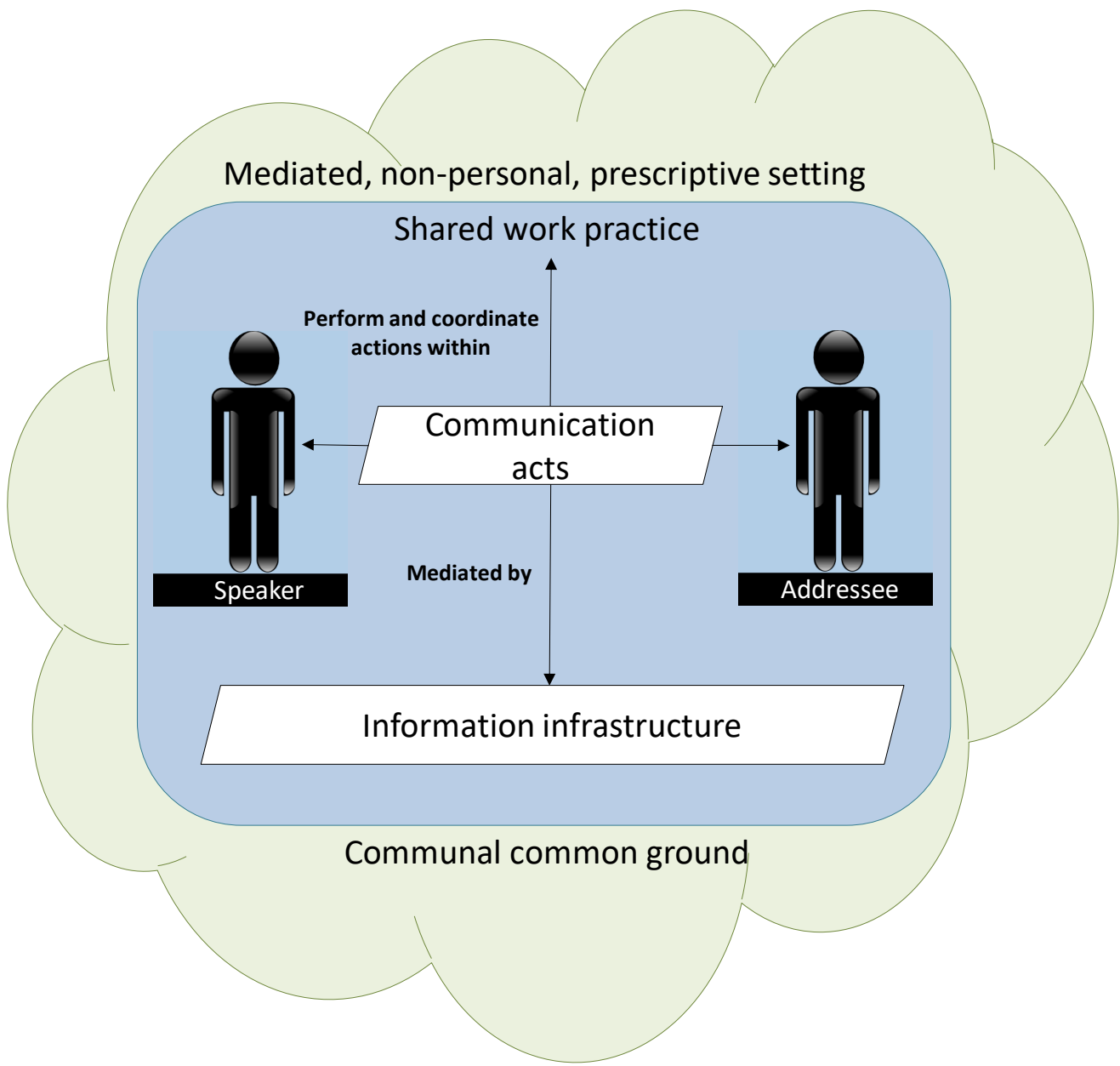

Figure 49 The context of interoperation.

Interoperation ${ }^{155}$ is actor's use of communication acts, mediated by an information infrastructure, to perform and coordinate actions in a shared work practice. Interoperation

${ }^{155}$ See also section 7.1 and 7.10. 
is based on a communal common ground [261], which is the sum of mutual and common beliefs, knowledge, and suppositions in the community of the shared work practice.

The communication acts in interoperation are taking place within a practice setting, which is different from basic face-face communication. This setting can be summarized as mediated, non-personal, and prescriptive ${ }^{156}$.

In the following, we will define what we mean by a shared work practice, how and why it emerges out of a need by the actors in interoperation. We develop on the infrastructural and transactional conditions of the shared work practice and the need for governance mechanism to manage the interoperation.

Moreover, we discuss the following aspect of the shared work practice:

- boundaries of the shared work practice and its relation to other work practices;

- relations of the clients to the shared work practice;

- exchange in a shared work practice;

- aspects of sharing;

- governance mechanisms in a shared work practice;

- interdependence of generic and local practices;

- distribution of time and place of actions in a shared work practice;

- infrastructure work practices;

- use of information infrastructure as the main instrument for mediating interoperation.

Finally, we recall (from 7.10) and refine our definition of interoperability.

\subsubsection{Shared work practice}

Following and extending the definition of a work practice by Goldkuhl and Röstlinger [63], we define a shared work practice as follows:

A shared work practice means that actors from at least two interrelated work practices mutually make something in favor of other actors, this acting is initiated by assignments from some actors, and is performed in distributed time and place and in some manner, and is based on shared material, immaterial and financial conditions of transactional and infrastructural character, and a shared work practice capability, which is mutually established and continuously changed.

${ }^{156}$ See 7.8 for a more in depth description of this setting. 


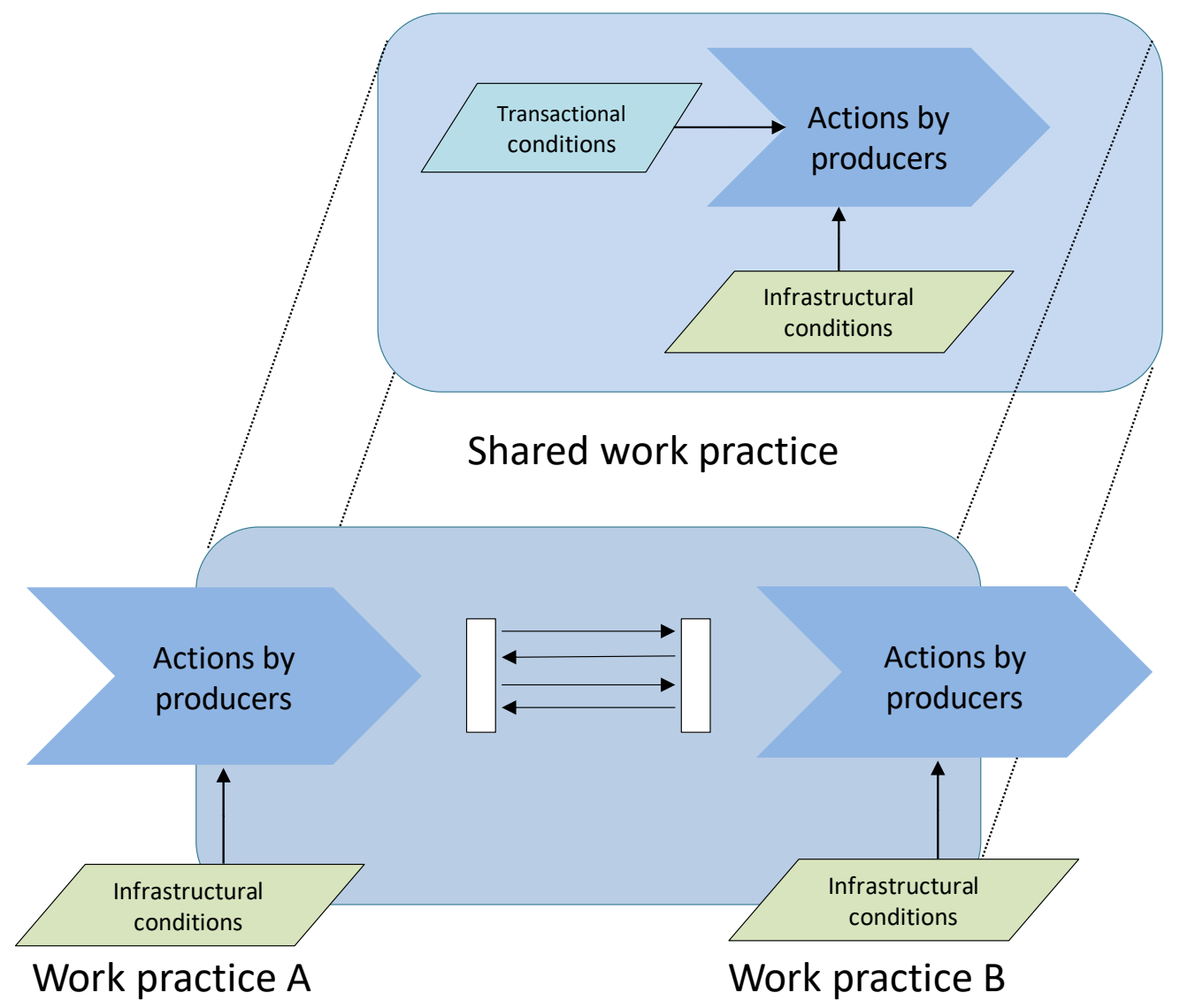

Figure 50 Illustration of a shared work practice emerging out of interoperation between work practices

\section{The need and emerging of shared work practices}

A shared work practice is more than an addition of individual practices or habits. The shared work practice emerge out of the needs of the actors to interoperate and are an accomplishment of the members in the interrelated work practices that interoperate through the shared work practice [68] (see Figure 50). Reimers et al [299] proposed a somewhat similar view of on what they call a "constellations of practices" in the framework they propose for what they name Inter Organizational Information Systems (IOIS):

"This framework view IOIS as constellations of practices that are linked through specific boundary structures such as common data formats." [299]

Confer also Reimers and Johnston [315] discussing persistence and resilience of IOIS applying practice and structuration theory. They claim that an IOIS is not only structure 
but also use, and therefore there is a need for encounters ${ }^{157}$ and brokering in order to make the process survive and adapt in front of environmental changes that are bound to happen. These activities tend to become work practices in themselves over time and become boundary practices.

This need to make the interoperation survive and adapt (in short and long term) is one important basis for a shared work practice.

The evolution of ePrescribing in Sweden illustrates the emerging of a new interdependency and information infrastructure from what initially was merely seen as sending an electronic message from the health care agents to the pharmacies. This became more obvious when the electronic prescription increased in importance from small pioneering experiments to become the major method and even the role model for prescribing medical drugs in outpatient care. This pointed early to the need to create a governance of this interdependency, i.e. creating and defining transactional and infrastructural conditions for the shared work practice of ePrescribing.

\section{Transactional and infrastructural conditions for shared work practices}

The actors in a shared work practice share some transactional and infrastructural conditions ${ }^{158}$. In the following, we use the definition made by Goldkuhl and Röstlinger [63] of work practice conditions, applying them to the context of interoperation in a shared work practice using information infrastructures.

\footnotetext{
${ }^{157}$ Encounters involve representatives from different connected practices to negotiate meanings, norms and coordination of actions. These encounters could lead to modified behavior and a better alignment of the practices. Brokering is an activity to bring knowledge and understanding from one practice to another. It can be done by members that cross the boundary of practices or develop an understanding of other practices due to frequent encounters.

${ }^{158}$ For a definition of these conditions see 2.2.2 Work practices, information systems, and information infrastructures.
} 


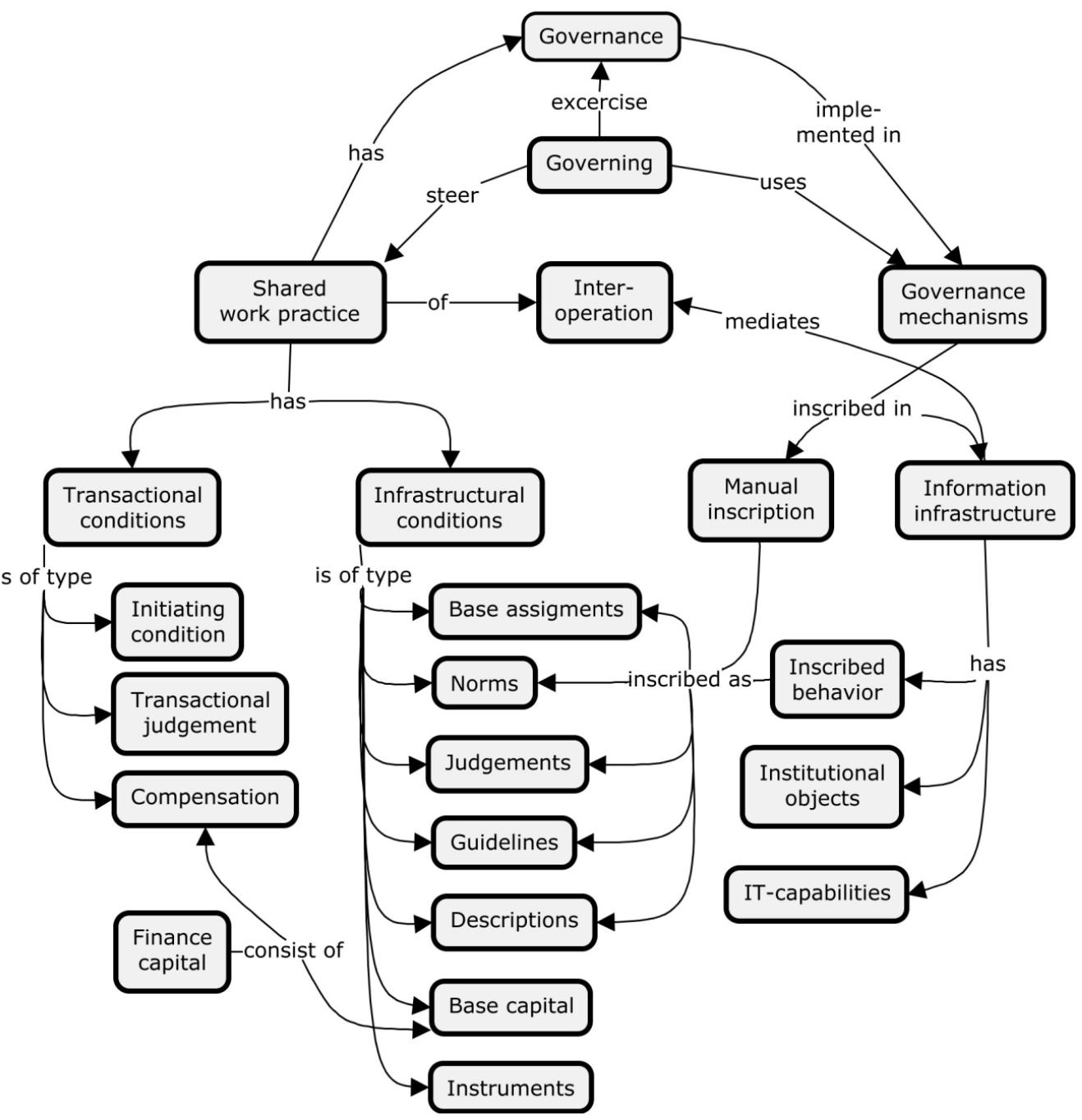

Figure 51 Conceptual map of the relation between governance mechanisms and transactional and infrastructure conditions for a shared work practice of interoperation.

See Figure 51 for a conceptual map that focus on important concepts related to infrastructure and transactional conditions for interoperation,

Infrastructural conditions are of various types such as base assignments, base capital, norms, guidelines, instruments, descriptions, and practice judgments. Infrastructure conditions are used to support and manage recurrent work practice transactions. 
The main instrument ${ }^{159}$ for mediating interoperation is the information infrastructure. It is not only a passive tool because it can itself provide infrastructural conditions, expressed in inscribed behavior of the information infrastructure. The inscribed behavior of the information infrastructure could provide infrastructure conditions such as:

- base assignments in the form of role and resource assignment, and product repertoire;

- guidelines in the form of automatic actions or suggestions for action;

- description of objects used to make decisions for action;

- norms in the form of explicit quality criteria for transactions and the shared work practice;

- judgments of the work practice and transactions in the form of evaluations or warnings.

Base assignments, norms, guidelines, descriptions, and judgments, that are not inscribed behavior of the information infrastructure, are manually inscribed in the infrastructural conditions of the work practice.

Transactional condition (see section 2.2.2 and [63]) consists of product assignments, substances (material/descriptive), judgments, and compensations. A product assignment is what initiates or conditions ${ }^{160}$ a transaction in a work practice. In our context of interoperation, we view it as the communication act that initiates or conditions a transaction in the work practice. The communication act produces a substance (descriptive), in our context a message, which expresses the communication act. Thus, product assignment and substance are initiating conditions (Figure 51). Judgments from a transactional perspective are judgments made about a specific transaction. Compensations are possible financial compensation related to a transaction. In the following, we will make an analysis of boundaries of a shared work practice and their link to initiating conditions.

\section{Boundary action and boundary objects of a shared work practice}

Earlier, we have defined that a shared work practice emerges when at least two interrelated work practices mutually make something in favor of other actors. A question that arises is what actions are shared in the work practice and what actions are (more or less)

\footnotetext{
${ }^{159}$ Information systems and information infrastructures are not merely general tools but are embedded in and part of the work practices.

${ }^{160}$ A product assignment may not always immediately initiate a transaction with has a direct effect on the actors like in a chain of events. It can also initiate a transaction (in our case issuing a prescription) that constitutes a condition for future actions. Thus, a transactional condition may create conditions for other transaction to be initiated.
} 
independent actions in the related work practices, i.e. what are the action boundaries of the shared work practice?

Defining boundaries of a shared work practice is not a trivial task as they reach over organizational and work practice borders. The boundaries are often implicit and can change over time. When we discuss boundaries of a work practice, we focus first on the coordination of actions, not on the production of value for clients. The latter is of course a very important normative aspect for the work practice. However, it is not the point of departure in defining the boundaries of a shared work practices. The reason for this is that we are primarily interested in interoperability, not primarily factors that influence the efficiency in producing value for clients although interoperability is important in order to achieve this.

Boundaries are linked to transactional conditions in the shared work practice. When we refer to product assignment as one transactional condition in the work practice theory, we focus on the communication aspects. We view them as the communication act that initiates a transaction in a shared work practice.

We think it is important to focus not only on the boundary object, i.e. the outcome of an action, but also on the communication act that produces it and its context. If we only focus on the outcome, we will miss all those factors that influences the final content and thus the quality of communication acts ${ }^{161}$. This is essential for interoperability.

Thus, we make a distinction between boundary objects ${ }^{162}$ which are outcome of actions and boundary actions which are the communication acts initiating transactions in a shared work practice. Boundary actions can be difficult to identify, as they may not refer to a visible object or an overt action. Nevertheless, they are important to identify. One way to do this is to analyze under which conditions the boundary objects are produced.

Goldkuhl [316] develops a model of action which has three stages: (1) pre-assessment, where the actor is confronting a situation and perceives the environment and different possibilities for action, (2) intervention is the action directed towards the outside world. After the intervention, the actor makes an assessment of the results and effects of the intervention, which is the (3) post-assessment stage.

Goldkuhl discusses [316] whether these stages are part of one action or if there is a need to make a distinction of different phases as actions in themselves. This depends on the nature of the phases and the granularity of the analysis. For example, whether preassessment is closer to an inquiry and not instantaneous. It also depends on the motives for the analysis of the action. We agree with this, with the consequence that there is no strict objective way to define the boundary actions of a shared work practice.

\footnotetext{
${ }^{161}$ See section 6.4 for an analysis of exchanges in an ePrescribing work practice and 6.5 for an analysis of the context of communication.

${ }^{162}$ See section 2.2.3 for explanation of the notion of a boundary object.
} 
Regarding the completion of the shared work practice, we regard reception and interpretation of communication acts as acts in themselves. From this, we can analyze those boundary actions that conclude a shared work practice.

Below, we will give an example from ePrescribing how one can define boundary actions in a work practice.

In ePrescribing, what initiates the shared work practice can be analyzed as the act of a treatment decision involving a specific medical drug (for outpatient care), by the prescriber in cooperation with the patient. This decision is based on a patient inquiry. Thus, we view these as distinct actions: patient inquiry and decision on treatment. The outcome of the decision is a treatment involving a medical drug. The treatment decision involves a new pre-assessment of possible medical drugs, dosage, and effect on the patient. The prescriber communicates this decision or proposal for treatment with the patient. The next step is to formulate a prescription. Thus, there is a chain of actions that prelude the formulation of a prescription. Whether they are included in the analysis depends on the motive of the analysis. In this case, we want to analyze those factors that may influence the quality of the prescription content and thus influence the interoperability of the shared work practice. We decide that the boundary action will be the decision to initiate a medical treatment with a specific medical drug.

Next step is the formulation of a prescription to be issued and available to the pharmacies in the pharmacy market. When formulating the content of the prescription, the prescriber has to consider all guidelines how to prescribe, norms such as prescription rules in alignment with legislation, and recommended pharmaceuticals, professional judgment, descriptions of medical facts. The prescriber has to use the shared information infrastructure (the IT-artifacts at hand, i.e. the Application Infrastructure) in order to formulate and issue the prescription. The outcome of this first phase of ePrescribing is an accepted (if valid) and issued ePrescription, which authorizes the pharmacies to dispense this prescription at the request of the patient. Thus, ePrescribing is a constellation of work practices that have become a work practice of its own. See Figure 52. 


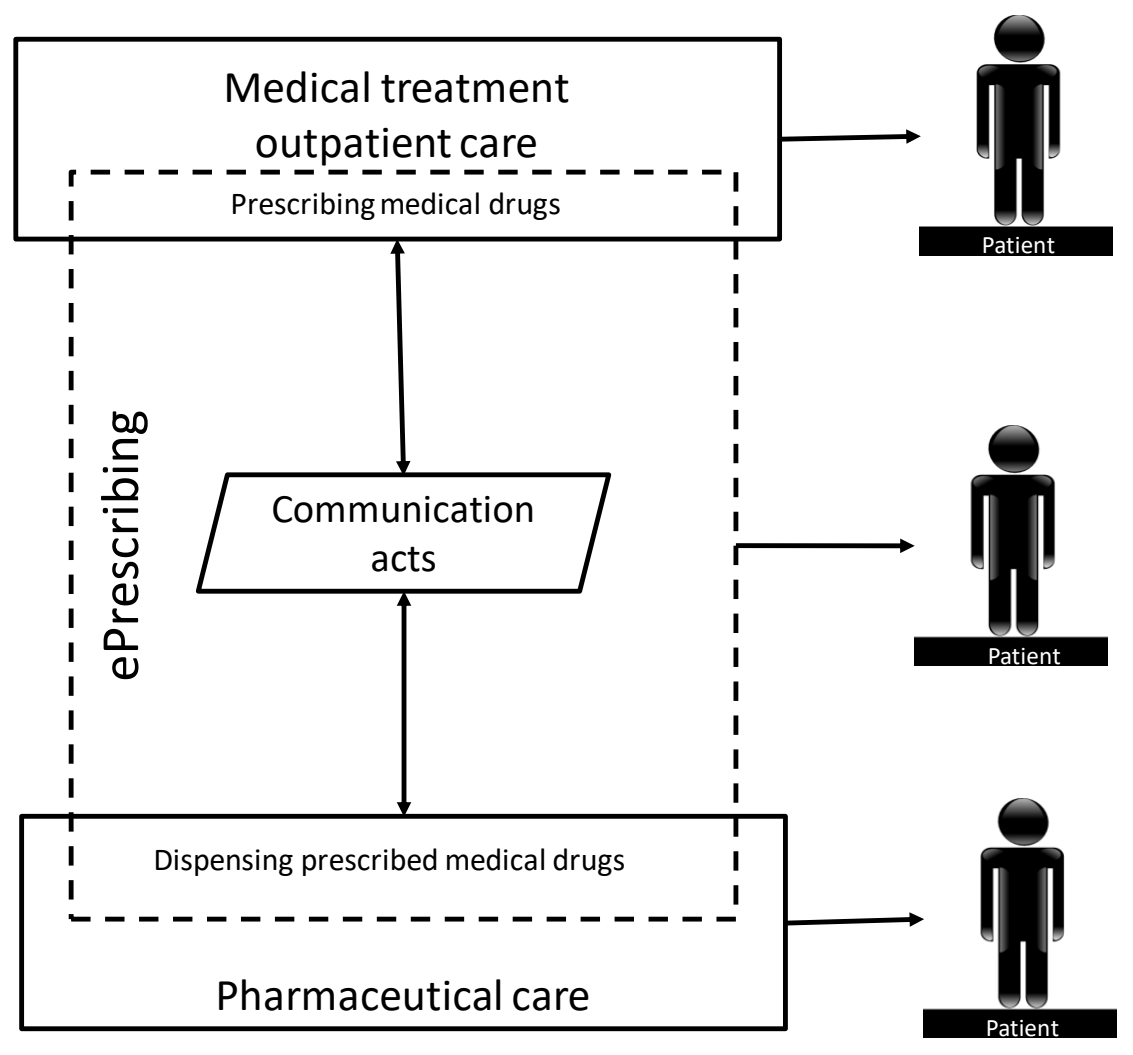

Figure 52 Shared work practice of ePrescribing as a constellation of work practices, each of them having a relation to the patient/customer.

\section{Serving of clients and relations in a shared work practice}

The definition of work practice by Goldkuhl and Röstlinger states that actors make something in favor of other actors. These other actors are clients for the work practice. The goal for a work practice is to produce some results for a client. In the definition above, we stated that this is also valid for a shared work practice. Thus, the reason for a shared work practice is to produce results for clients, whether directly related to the shared work practice or indirectly to the interrelated work practices that uses results from the shared work practice, see Figure 53. Interoperation is not an end in itself, it exists to achieve something for someone.

Thus, a shared work practice can serve clients in other related work practices and common clients of the shared work practices. This is the case with the ePrescribing work practice (Figure 52). The patient, i.e. the client in the work practice Medical treatment outpatient care, has a relation with the prescriber. The patient, i.e. the client in work 
practice Pharmaceutical Care ${ }^{163}$, has a relation to the pharmacist, offering dispensing of medical drugs (prescribed or Over-The-Counter (OTC)), counseling, and other services.

The patient is the ultimate client of the shared work practice. Apart from getting benefits of medical treatment and pharmaceutical care, ePrescribing is issuing a prescription, which is an option for the patient to use on her will and request. The prescription can also contain a promise to pay medical benefits. Thus, the shared work practice creates a value for the patient (see 6.6.2 Elements of a practical theory on ePrescribing).

Summarizing: The ePrescribing work practice gives the patient some rights and opportunities depending on the design of the shared work practice. It gives the right to the patient to get a prescription filled in various ways. May it be by making a prescription order on the issued prescription at a legal internet pharmacy chain and get it delivered at home, or by going to any local pharmacy to get the prescription filled there. In Sweden, the patient can get access to the pharmacy register (via the internet or at the pharmacy), which register all dispensing of prescriptions to get a complete list of dispensed medications. The patient can also give permission to a prescriber to access the pharmacy register.

\section{Generalization of ePrescribing work practice}

In Figure 53, we have made a generalization of ePrescribing from Figure 52.

\footnotetext{
${ }^{163}$ Helper and Strand [317] define (an extract) Pharmaceutical care as: “... the responsible provision of drug therapy for the purpose of achieving definite outcomes that improve a patient's quality of life. ... Pharmaceutical care involves the process through which a pharmacist cooperates with a patient and other professionals in designing, implementing, and monitoring a therapeutic plan that will produce specific therapeutic outcomes for the patient. This in turn involves three major functions: (1) identifying potential and actual drug-related problems, (2) resolving actual drug-related problems, and (3) preventing drugrelated problems. Pharmaceutical care is a necessary element of health care and should be integrated with other elements. Pharmaceutical care is, however, provided for the direct benefit of the patient, and the pharmacist is responsible directly to the patient for the quality of that care."
} 


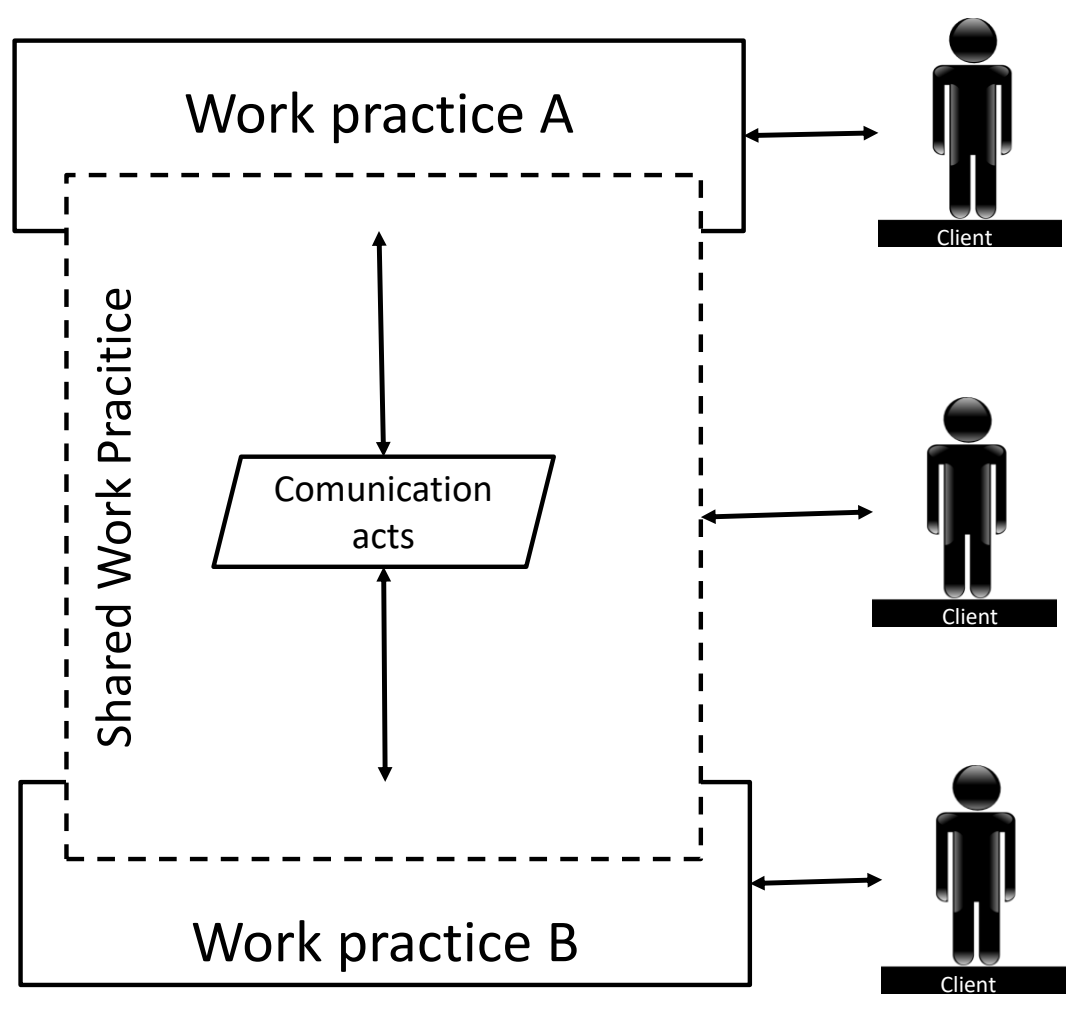

Figure 53 Shared work practice and the interrelated work practices serve different or common clients, which have their own relation to each work practice.

Work practice A (Figure 53) is linked to Medical treatment in outpatient care (Figure 52). The ePrescribing work practice is a subset of work practice $A$ communicating with another work practice $B$ that is about Pharmaceutical care. ePrescribing is the shared work practice between work practice $A$ and $B$.

\section{Exchange in a shared work practice}

From this generalization of ePrescribing into a shared work practice, we can continue to analyze the exchange within this work practice. We propose to combine the Generic Exchange Model (GEM) ${ }^{164}$ and the Action workflow approach [71] to analyze the business exchange from initiation to completion as interconnected loops. This type of model is useful when several clients are involved or when there are different producerclient relationships involved for the completion of the work practice. This is the case with

\footnotetext{
${ }^{164}$ See further section 6.4 .4 for an analysis of the ePrescribing work practice using a Generic Exchange Model (GEM) and how the exchanges in the different work practices are linked.
} 
ePrescribing where we have three pairs of relationships: Prescriber - Patient, Pharmacy Customer (patient or representative), and Prescriber - Pharmacy.

See Figure 54 for an illustration of the model, which contains both general elements and specific elements from ePrescribing.

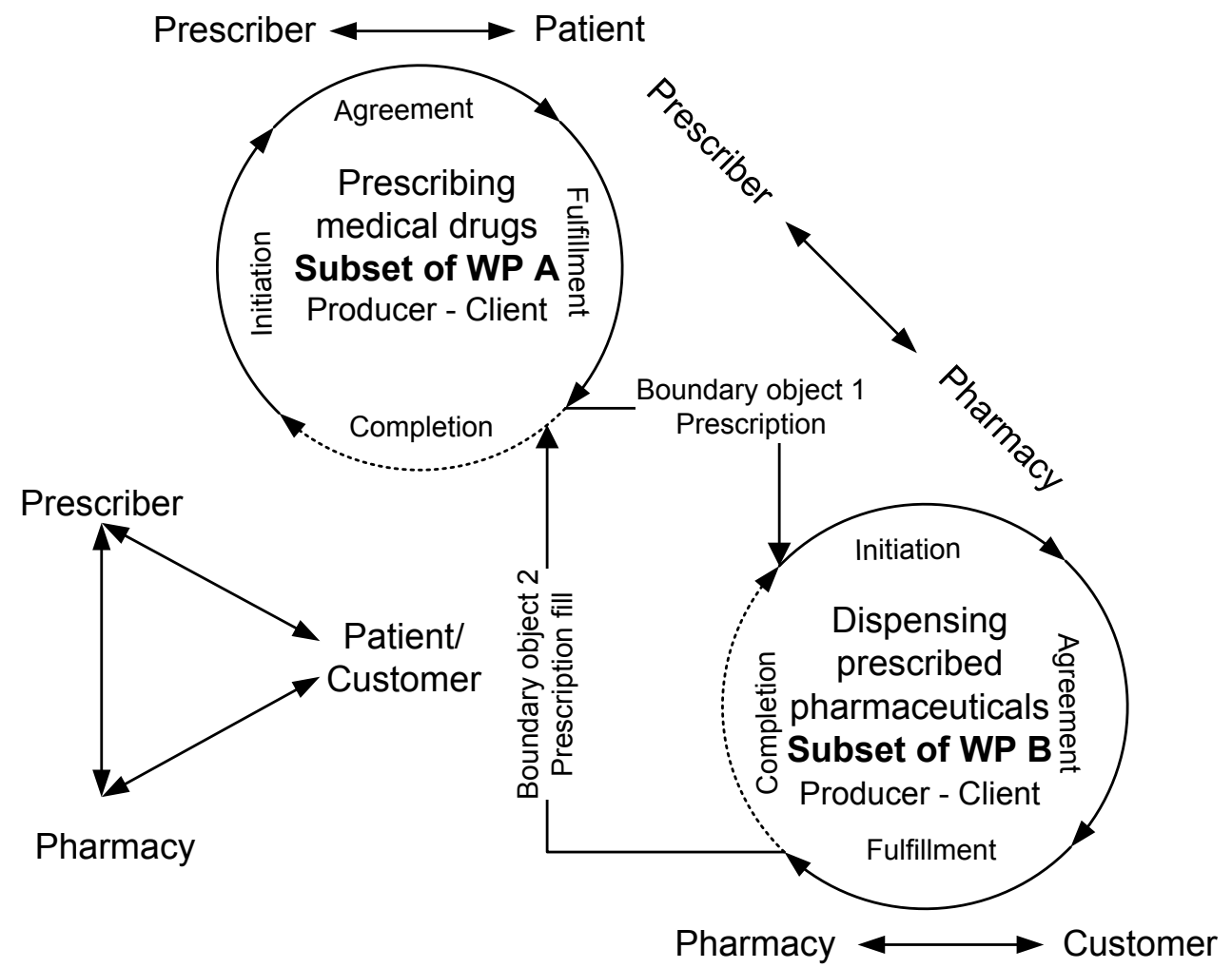

Figure 54 Model of exchange between work practices using a Generic Exchange Model $[73,74]$ and concepts from Action Work flow by Winograd, Flores et al [71].

The model in Figure 54 has an initiation phase in the subset of work practice $A$ (Subset of WP A) with actions that relate to prescribing of medical drugs. The initiation phase of this subset work practice is also the initiation of the shared ePrescribing work practice. In Figure 54, all the phases with unbroken lines belong to the shared work practice. The reason why the completion phases are not included in the shared work practice is that these phases are about assessments of the delivered service or product. From the Prescriber Patient point of view it is about evaluation of the effects of the patient's medical treatment. The Pharmacy - Customer relation is about evaluation of delivered medical drug and accompanying information and services. In the future, it can very well be that the shared work practice will widen to encompass also the consumption of the medical drugs and its effects on the patient with integration of medical devices into the shared information 
infrastructure ${ }^{165}$. This can lead either to a redefinition of the ePrescribing work practice or to a new shared work practice, where the pharmacies are much more involved in the medical treatment of the patient. It could also involve other producers like home care by the municipality or private caregivers.

The completion phase of the shared work practice is the incorporation and recognition of the 'Boundary object 2/Prescription fill', which completes the actions in the shared work practice.

A shared work practice starts with initiating actions producing boundary objects and completes with immediate consequential actions upon the reception of boundary objects. These initiating and completing actions of the work practice is the boundary of the shared work practice in terms of boundary actions.

Figure 54 also illustrates that in the case of ePrescribing, the shared work practice has a triadic relationship among producer - client - producer (in work practice $A$ and $B$ ), i.e. the shared work practice serves in this case a common client. In a shared work practice, there can be a clear producer - client relationships, but also like in ePrescribing more of a give and take situation serving each other, like the relation between the prescriber and the pharmacist at the pharmacy, which is a producer - producer relation, with the patient as the ultimate client.

\section{Aspects of sharing in a work practice}

A shared work practice emerges out of a need to make interoperation survive and adapt in the short and long term. In the preceding section, we have analyzed boundary actions and objects, in other words what actions and objects are shared in the work practice. We gave some suggestions how to conduct such an analysis.

Recalling the definition of a shared work practice, there are also other types of sharing in interoperation, such as sharing of:

- resources (financial, human) and information infrastructure services:

- may be shared to various degrees, from each participant in the network financing resources themselves to commonly financed and governed resources;

- objectives and benefits:

$\circ$ objectives and expected benefits may to various degrees be shared;

- knowledge and communal common ground;

- governance of the shared work practice.

\footnotetext{
${ }^{165}$ With the development of cheaper sensors to register physiological data, serialization of medical packages to enable tracking, DNA marking of single pills and "smartphones", all integrated to an information infrastructure of "Internet of Things" will enable to stretch the boundaries of the shared work practice and pose new challenges to interoperability.
} 
Sharing can either be explicitly recognized or understood by the actors or be implicit and less well understood. If implicit, sharing may come to the fore when interoperation is malfunctioning.

The degree of interdependence in interoperation influences what is shared.

A low complexity interdependence is at hand for example when interoperation use simple (single function) and well-defined communication acts. In this case, there is less need for sharing of clients, objectives, knowledge, or resources.

One example of a low complexity interdependence is in a less regulated market where there are few commitments between the actors or few restrictions and little control by authorities.

A high complexity interdependence is at hand in a highly-regulated market and when communication acts are more intertwined, multifunctional and dependent, and there are common clients, sharing of resources, and knowledge.

In more regulated markets, like the pharmacy and health care market, interoperation has to a higher degree take into account legislation, agreements, controls, sharing of clients, and objectives, et cetera.

When interoperation is based on more developed shared knowledge and beliefs it implies the need to work more consciously and actively in establishing and developing the communal common ground for interoperation (see 7.6 Common ground for interoperation).

When interoperation has a certain volume, and is critical for the delivery of service to clients, shared governance of the work practice becomes a more urgent need.

\section{Governance mechanism in a shared work practice}

In the context of interoperation in a shared work practice, governance mechanisms ${ }^{166}$ are an important dimension of infrastructural conditions. Thus, we complement the work practice theory with governance mechanisms as one important dimension ${ }^{167}$ of infrastructure conditions. Governance mechanisms are means to control and direct the work practice ${ }^{168}$.

Tengblad [318] describes two main philosophies in management theories: rational and normative management philosophy. The rational view, focus on rational decision making,

166 Goldkuhl and Röstlinger do not explicitly focus in their work practice theory on governance mechanisms as a dimension of infrastructure conditions. The focus is more on resources, knowledge and instruments, although elements of governance mechanism can be found in their theory.

${ }^{167}$ Other dimensions of infrastructure are knowledge, experiences and resources.

${ }^{168}$ Here we deal with the operational governance of the work practice. There are other perspectives on governance that is important. See section 8.2. 
planning and governance by rules and routines. The normative view, focus on governance through common norms and values. According to Tengblad [318], these management philosophies are not diametrically opposed but are different aspects of governance. Work practice governance is a combination of elements from both philosophies. Using these views on governance, rational and normative, we have ordered relevant infrastructural conditions of the work practice theory in two categories of governance mechanisms:

- rationally oriented governance mechanisms:

$\circ$ prescriptive guidelines for actions;

- base assignments such as resources and role assignments and assignment of a product repertoire;

- descriptions of facts used in making decisions for action;

- normatively oriented governance mechanisms:

- norms that define values and goals to be reached;

○ judgments on how to evaluate goals and actions.

Intra-organizational work practices usually have governance mechanisms of a more traditional, hierarchical nature ${ }^{169}$. These governance mechanisms are not applicable in an inter-organizational setting and have to be complemented with governance mechanisms that are based on building networks, relations, and trust [319-321]. Thus, governance mechanisms for interoperation are a result of social interaction and agreements between the actors. This suggests that a normative view on governance is useful as well as a rational focus on rules and routines. These norms and other governance mechanisms (guidelines, assignments, et cetera.) has to be established and codified as agreement or contracts, not as directives, rules or goals communicated from above by already established institutional bodies of an organization. See further section 8.2.

\section{Generic practice and local instance of practice}

A generic work practice could be valid for a whole region or national state, regulated by legislation and common practices. However, interoperation is always taking place in a local instance of a practice. This means that the generic practice is interpreted and implemented by agents in the local context. This increases the complexity in implementing and sustaining a generic practice ${ }^{170}$.

\section{Distribution of time and place}

Compared to a local practice within an organization, where actions usually are made in a relative proximity in time and place, shared work practices usually have actions that are

\footnotetext{
${ }^{169}$ See for example Weill \& Ross [309] notion of governance archetypes in IT governance of a typical hierarchical kind: Business monarchy and IT monarchy.

${ }^{170}$ In chapter 4 Implementing ePrescribing in Sweden - case study, we described how the actors used an implementation model to work locally to implement ePrescribing.
} 
separated in time and place. This is what we mean by actions distributed in time and place. See further section 7.8.2 for a definition of a mediated, non-personal and prescriptive communication setting for in interoperation.

\section{Shared work practice capability}

Actors in a work practice are assumed to share their experience and capabilities and form in this sense a community of practice. [80,322] A work practice relies on an established capability to achieve its goals. One important aspect ${ }^{171}$ of work practice capability is the accumulation of the actors' individual knowledge and the institutionalized knowledge of the work practice. The establishment and evolution of this capability through learning and experience is challenging in a shared work practice which is distributed cross organizations and professional communities. [69]

Capability could be a potential capability, which could for example could mean that the ePrescribing work practice has the potential capability through its information infrastructure and other infrastructural conditions, to formulate, transfer, and create ePrescriptions aimed for the pharmacies in the pharmacy market, and being accessible to all pharmacies to be used for dispensing prescribed medical drugs to the patients.

Exercised capability refers to demonstrated qualities of this capability in terms of values such as fast, safe, correct, reliable, transparent, readable, et cetera. Thus, a shared work practice potential capability for interoperation will influence the quality of this interoperation - interoperability. The potential capability to interoperate can be viewed as key process drivers influencing the quality of interoperation. (See further section 7.10.2)

\section{Infrastructure work practices}

A work practice can also produce a common good that is in favor of a whole community or society. This is the case with infrastructure work practices that provide and manage an information infrastructure that can be used by many other work practices.

One important infrastructure work practice for the whole health care sector is the administration of the medical drug repository by authorities and the pharmaceutical industry and its communication by the Swedish eHealth Agency. The Swedish eHealth Agency administers together with other stakeholders a number of registers that are absolutely essential for other work practices like the ePrescribing work practice.

Thus, we are facing a situation where there are complex structures of different work practices that serve other work practices. This illustrates the interdependence between different work practices in a network of shared work practices.

One important type of infrastructure work practice is those that manage shared institutional objects. A typical infrastructure work practice is the management of various

${ }^{171}$ Other aspects are resources and financial conditions. 
repositories such as medical drug, pharmacies, prescribers, work place, mandate and population register. These registers are managed by authorities or other shared organizational resources. These infrastructure work practices can be rather complex and are necessary for other shared work practices that are more oriented towards producing results for clients. In this sense, the infrastructural work practice has a supporting function (see Porters value chain [323]). The infrastructural work practice interacts and coordinates its work with other work practices and in this sense, there emerges a shared infrastructure work practice.

\subsubsection{Interoperation, interoperability, and the role of the information infrastructure}

In the previous section, we developed our concept of a shared work practice which emerges out of the need to cooperate and coordinate action in interoperation. We add this aspect in our definition of interoperability in the following way:

Interoperability is the exercised capability of organizations through their agents to interoperate in a shared work practice in an effective, efficient and satisfactory manner based on a common ground in a mediated, prescriptive and non-personal communicative setting using an information infrastructure for mediating interoperation.

By the mediating role of an information infrastructure, we mean that it serves as an intermediate agent (for formulating, evaluating, transferring, storing, converting, performing, presenting, et cetera.) of the communication acts between actors in interoperation.

The mediating role implies that the information infrastructure is not only a passive media for interoperation but it is also an active agent performing communication acts on behalf of an actor so that they take effect. An information infrastructure completes the communication acts on behalf of an institutional agent, for example of a bank statement or of issuing an ePrescription, without which it will not exist or have an effect in the world. The information infrastructure has also an active role in the formulation and presentation of the communication acts. Thus, with mediation, we do not merely mean passively relaying a message, but an active agent that is involved in many aspects of the communication acts.

\subsection{Collective action and interoperation}

Based on the preceding sections on interoperation and interoperability in a shared work practice, and on the elaboration of governance and collective action concepts made in 
chapter 8 , we aim in this section to integrate these concepts into one model illustrating their relations (see Figure 55).

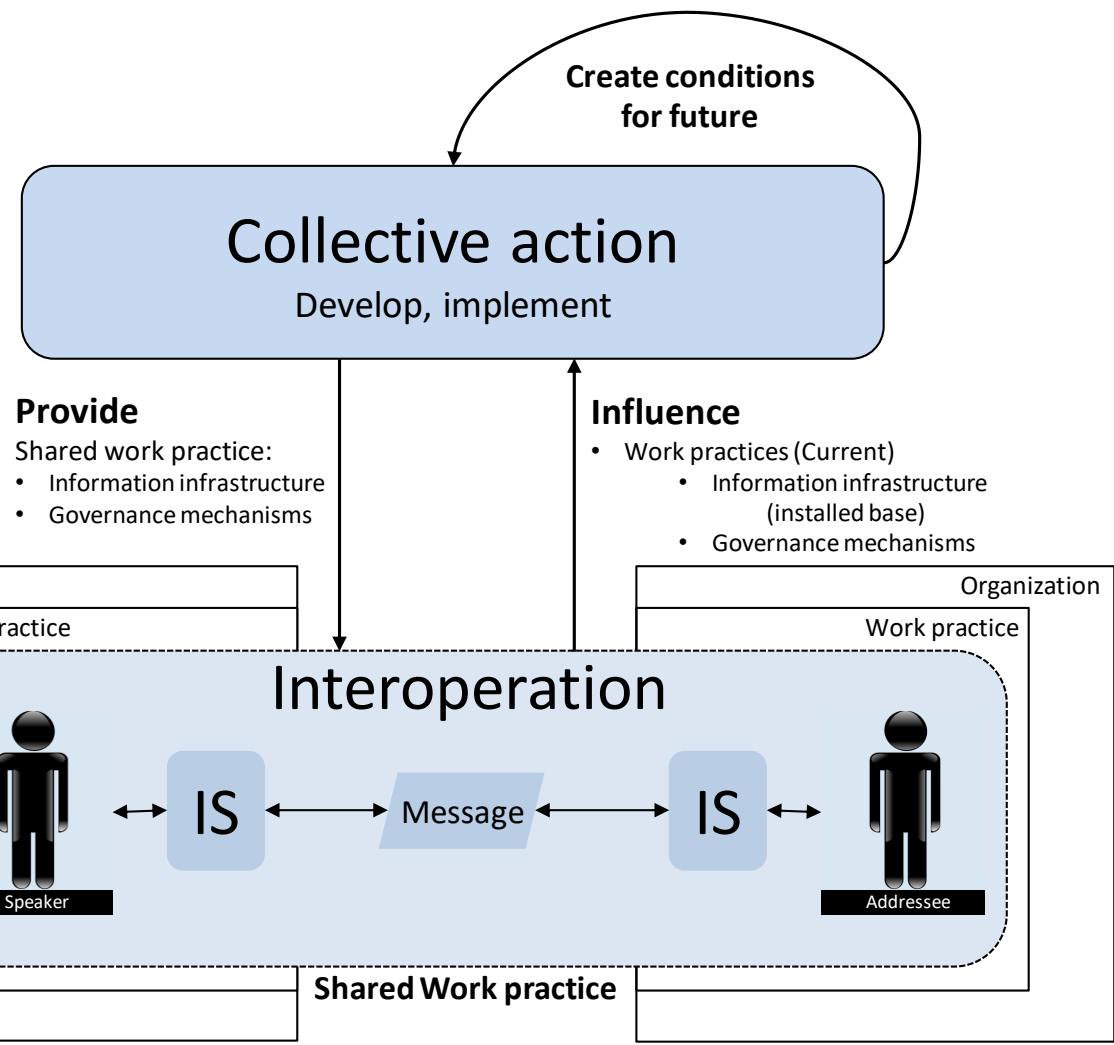

Figure 55 Relations between collective action, shared work practice, and interoperation.

The model contains two parts: interoperation and collective action.

Interoperation is actors use of communication acts, mediated by an information infrastructure, to perform and coordinate actions in a shared work practice.

Collective action is the development and implementation of interoperation.

In our definition of interoperability, we used the term exercised capability to emphasize that interoperability is an operational quality. This capability does not come about by itself but are influenced by many factors. We have in section 7.10.2 Defining goals, criteria, and metrics for interoperability showed how one can set goals, choose criteria, and metrics for design and evaluation of interoperability.

Thus, capability can be viewed either as planned, potential, or exercised capability to interoperate. A planned capability to interoperate is something to be achieved, an objective. Potential capability is something that is implemented and ready to be used. Exercised capability is the actual demonstrated capability. Exercised capability can be measured in relations to expected outcomes, to specifications and actors' expectations. 
This view gives two perspectives on interoperation: existing interoperation and planned future interoperation.

To achieve a planned capability to interoperate in the future between different organizations and communities, it is necessary to engage in a collective action. [95, 298] We have defined collective action (see 8.2.3) as an action that requires two or more entities to coordinate their efforts to achieve a common good. In this thesis, collective action is about development of a future process of interoperation and can have a strategic and tactical perspective. The activities in the collective action are about developing and implementing a shared work practice (and also creating conditions for further collective action) with a particular focus on the information infrastructure and governance mechanisms for interoperation with a targeted planned capability to interoperate.

Development is a collective action of design and maintenance of all ${ }^{172}$ the necessary components of a working information infrastructure and governance mechanisms for the shared work practice. This includes such activities as to prepare change of existing work practices, all preparatory work needed for implementation from a technical and work practice point of view, and the design of all necessary governance mechanisms.

Implementation is a collective action for planning, staffing, and organizing the transition of information infrastructure functionally, including all additional components needed for operation, into operational use and the establishment of shared work practices, including governance mechanisms.

The exercised capability to interoperate (interoperability) in a shared work practice is the capability to support real time communication acts (from its initiation to its completion) between the participants in an effective, efficient and satisfactory manner.

To summarize:

- collective action is a collaborative action between organizations for the development and implementation of a shared work practice with a particular focus on information infrastructures and governance mechanisms with the following perspectives:

○ strategic:

- develop strategies and conditions for further collective action;

○ tactical:

\footnotetext{
172 This is inspired by concepts like Concurrent Engineering: "Concurrent Engineering is a systematic approach to the integrated, concurrent design of products and their related processes, including, manufacturing, and support. This approach is intended to cause the developers from the very outset to consider all elements of the product life cycle, from conception to disposal, including quality, cost, schedule, and user requirements." [324] see also [115]
} 
- develop, implement a shared work practice with essential infrastructure conditions such as:

0 information infrastructure as main instrument for interoperation;

$\circ$ governance mechanisms for interoperation and collective action for future maintenance of interoperation;

- interoperation is conducted through actors use of communication acts, mediated by an information infrastructure, to perform and coordinate actions in a shared work practice.

Collective action provides the infrastructure conditions for interoperation.

\subsection{Collective action and governance}

In this section, we will give some examples of actions and governance linked to collective action at strategic and tactical level to concretize the elements of the theory. For concrete examples from ePrescribing in Sweden, we refer to chapter 4 and 5 and section 8.1 and 8.3. Confer also section 8.2.4 for perspectives on governing, governance and collective action.

\subsubsection{Strategic actions and governance}

Here follow some examples of activities and related governance mechanisms linked to the strategic perspective.

\section{Develop, implement, and maintain vertical standards}

To develop, maintain and agree on vertical standards defining the content and process of the exchange or if standards are not used, industry or vertical agreements for exchange are an important example of collective action. (See section 8.3)

These collective actions are usually made in liaison with third party organizations, which could be a representative for a standard in a country or a region and commonly a representative for the community of parties in a business sector using an implementation of a standard.

Working and reference groups are often used for this work, which usually are made up of experts in the standard for exchange and expert practitioners who have knowledge of the business process involved ${ }^{173}$.

${ }^{173}$ See further section 2.3 Standards for a description on the difference between development and diffusion of horizontal and vertical standards and the need for collective action in vertical standards development and diffusion. 
The implemented standards or other type of agreements - on different levels such as international, regional, national, communal, multilateral - results in agreements between the involved parties. These agreements on the use of vertical standards and the organizational bodies and communities involved are important governing mechanisms.

\section{Participate in and follow development of standards}

To participate in or follow the development of various standards (horizontal and vertical), policies and legislation are likely to have an influence on future interoperation and information infrastructure. This can be carried through by each organization separately of by third party organizations representing the interest of a community.

\section{Common policies on technical standards}

To agree on common policies of application of technical (typically horizontal) standards or methods used in the exchange is important actions. This could include plans for migration, for example from EDIFACT to XML, or X.400 to Web services, to achieve common goals in agreed policies. The resulting agreements, plans, and policies are important governance mechanisms.

\section{Governance mechanisms for future collective action}

Creating governance mechanisms to support and continue the development and growth of the information infrastructure in the long term is important. Example of governance mechanisms can be network organizations (see section 8.2.1) that have the task to coordinate efforts, needs and interest of a community, or long-term funding that could facilitate growth of interoperation and information infrastructure.

\section{Develop information infrastructures that are useful for a sector or part of the society}

General information infrastructures that can be used in a sector or part of the society are an essential part of creating pre-conditions for collective action to implement shared work practices for interoperation. Of particular importance is the development of identifiers and registers of important institutional objects such as actors, products, resources, locations, and agreements - which are useful and essential in a shared work practice. The development of such information infrastructures is a long-term process. The accumulation of such infrastructures over time could together facilitate new opportunities for collective actions. 


\section{Legal, political, and socio-cultural conditions for collective action}

Legal, economic, political, and socio-cultural issues influence the ability for collective action and are part of a strategic perspective on interoperation.

\subsubsection{Tactical actions and governance}

Development and implementation in the medium term (tactical perspective) involve various actions and governance. This section provides some examples.

\section{Joint projects to develop, improve and implement interoperation}

Joint projects within a sector, must deal with issues to achieve interoperation between parties (see below). Previous results from strategic collective actions can be used in these activities, such as policies and approaches to implementation of standards or agreements, as well as existing network organizations, change of legislation, funding principles, et cetera. Joint projects to achieve interoperation are challenging particularly when there are few experiences and good examples in a sector. Experience and a culture that support cooperation and trust are important. The existence of networks or other organizational bodies are also important to initiate and promote joint projects.

\section{Governance mechanisms for change and maintenance of interoperation}

Maintenance and change of interoperation are parts of a continuous improvement of an existing process of interoperation.

In order to measure interoperability ${ }^{174}$ it is necessary to set up some quality criteria and metrics. Measurements could be collected in validation and control of messages in the production flow, as well as from reports of shared event, incident and problem management processes, and from inside each participant organization. They could also be collected making other evaluations such as evaluation of user interfaces, measurement of quality of content that cannot be made using computational methods, measurement of attitudes toward the interoperation, et cetera. These metrics are dependent on the objectives set up for the interoperation to measure effectiveness, efficiency, and stakeholder's satisfaction. See 7.10.2 Defining goals, criteria, and metrics for interoperability.

\footnotetext{
${ }^{174}$ See chapter 5 Improving interoperability in ePrescribing - a field study for an example how one can measure the quality of interoperation.
} 
Another aspect of the maintenance of interoperation is the implementation of changes in the information infrastructure, shared work practice, and related work practices, which could be the results of continuous improvement but also due to request for new functionality. This could be implementation of new or modified exchanges of standardized messages, changes in specifications, testing of interoperation for new systems or parties, new routines for support, and new shared work practice rules, et cetera.

\section{Design and implementation of governance mechanisms for interoperation}

In order to handle interoperability errors in the operational environment, there must exist a process for trouble shooting, taking actions, communicate information, and activation of emergence routines et cetera. This process is both an "in-house" process and a shared process for operational governing of interoperation. Usually there are special teams engaged, which have knowledge of the shared process. See below in section 9.6 Interoperation and governance for more developed examples of operational governance. It is important that operational governance is designed and implemented alongside with the design and implementation of the information infrastructure.

\section{Joint management of agreements}

The shared processes agreed upon in interoperation results in a number of documented agreements. These agreements have to be managed to include changes and renegotiations, in order to be up to date. Typical agreements are:

- communication agreements, such as EDI-agreements;

- business and validation rules related to the exchange, such as how to handle invalid content, for example orders with delivery date to far ahead, rules for control (accept/reject) of the exchange;

- framework-agreements regulating business conditions for the interoperation. 


\subsection{Interoperation and governance of shared information infrastructure and work practice}

We have highlighted the role of governance mechanisms of the shared work practice and particularly of the information infrastructure as one of the most important dimension of infrastructure conditions for interoperation. In this section, we will describe some important governance mechanisms for interoperation within a shared work practice.

It is common that governance mechanisms for interoperation are viewed as each actor's responsibility. It is thus important to acknowledge the need for a shared governance of interoperation.

We will first focus on governance of the information infrastructure from a technical point of view, and then on governance of the shared work practice.

\subsubsection{IT service operation in a shared work practice}

For the management of the delivery of IT services, there are practices developed for each organization to adopt (see 8.4 Network governance, IT governance, and IT service management).

The Information Technology Infrastructure Library (ITIL) framework is a wide spread practice for IT service management within an organization.

ITIL's IT service management contains several process (see 8.4), where the process service operation [314] is defined as the one that carries out operational tasks. Table 24 gather some processes in the ITIL process service operation and give examples how it could be expanded for shared governance, which supports sustainable interoperation on a technical level.

Application management is not part of the IT service operation process. It is included here because one part of the life cycle of application management is about qualifying and deploying changed or new application functionality into operation, directly or indirectly affecting the interoperation. In the ITIL vocabulary, it is part of the service transition process. This aspect is very important for maintaining the quality of interoperation, to have governance mechanism for transition of IT-applications and their support infrastructures to be part of the production environment of the information infrastructure for interoperation.

Note that we here assume the IT service operation as a shared process between organizations and within each organization. 
Table 24 Illustration of IT service operation (ITIL) expanded to the scope of managing interoperation in a shared work practice.

\begin{tabular}{|c|c|c|}
\hline Process & Description & $\begin{array}{l}\text { Example of shared } \\
\text { governance mechanisms }\end{array}$ \\
\hline Event management & $\begin{array}{l}\text { Monitor critical events in } \\
\text { IT-services to alert for } \\
\text { actions. }\end{array}$ & $\begin{array}{l}\text { Shared event management on how } \\
\text { to monitor, act on and } \\
\text { communicate alerts. Shared and } \\
\text { agreed alert limits among the } \\
\text { participants, such as response } \\
\text { time, transaction throughput, down } \\
\text { time. }\end{array}$ \\
\hline Incident management & $\begin{array}{l}\text { Manage all incidents } \\
\text { through logging, } \\
\text { categorization, escalation, } \\
\text { and resolution. }\end{array}$ & $\begin{array}{l}\text { Shared incident management } \\
\text { process through coordinated } \\
\text { escalation routines and resolution } \\
\text { of incidents within and between } \\
\text { organizations. }\end{array}$ \\
\hline Problem management & $\begin{array}{l}\text { Manage improvement of } \\
\text { availability of services by } \\
\text { identifying problems in a } \\
\text { proactive way in order to } \\
\text { prevent incidents or } \\
\text { minimize their impact. }\end{array}$ & $\begin{array}{l}\text { Shared proactive problem } \\
\text { management through sharing of } \\
\text { process data and evaluation. Not } \\
\text { limited to technical problems but } \\
\text { also for work practice related } \\
\text { problems. }\end{array}$ \\
\hline IT operation control & $\begin{array}{l}\text { Monitor and control the IT } \\
\text { services and their } \\
\text { underlying infrastructure. }\end{array}$ & $\begin{array}{l}\text { Shared operational control with } \\
\text { agreed routines and schedules for } \\
\text { backup, restore and routine } \\
\text { maintenance to minimize } \\
\text { influence on the performance of } \\
\text { interoperation. }\end{array}$ \\
\hline $\begin{array}{l}\text { Application management } \\
\text { (deployment) }\end{array}$ & $\begin{array}{l}\text { Managing applications } \\
\text { through-out their lifecycle. } \\
\text { Here deployment and } \\
\text { qualification of applications } \\
\text { that effects operational } \\
\text { interoperability is relevant. }\end{array}$ & $\begin{array}{l}\text { Shared deployment and } \\
\text { qualification process with agreed } \\
\text { plans and routines for deployment } \\
\text { of new versions of applications or } \\
\text { the support infrastructure that } \\
\text { could affect the interoperation. } \\
\text { This could include planned } \\
\text { deployment and functional } \\
\text { qualification tests, coordinated IT } \\
\text { service teams, operational } \\
\text { approvals for new IS to connect. } \\
\text { Application of new work practice } \\
\text { routines that affect interoperation. }\end{array}$ \\
\hline
\end{tabular}


The ITIL framework focus on management of the delivery of IT services within an organization. Our expanded scope has included the delivery of IT services for shared interoperation. Furthermore, interoperation is taking place within a shared work practice, which implies a need also for governance mechanisms for the shared work practice.

\subsubsection{Governance of shared work practice issues}

Apart from reducing errors in the delivery of the IT services (interruption errors, response time delay, data corruption, duplicates, conversion or mapping errors, et cetera.), the most important factor in improving interoperability is the ability of the actors to communicate and agree on the intended meaning of the communication acts and do the corresponding actions to achieve the shared goals in their shared interoperational work practice. These aspects are dealt with in section 9.7 Aspects of interoperation

Interoperation is as mentioned highly dependent on an information infrastructure. Thus, it is not uncommon that incidents and potential problems detected in this environment are caused by factors outside the control of the delivery of IT services.

Incidents detected in IT services could be caused by erroneous, unexpected or unauthorized use of the information infrastructure. Thus, even if incidents are collected in the incident management process for the IT services, the cause of the error may many times be due to user errors, lack of education of users, misunderstandings, deviations from work practice guidelines and rules, and unforeseen situations, et cetera. Thus, there is a need to have a governance of the shared work practice and related issues.

In fact, the governance of the shared work practice should take precedence over the government of the IT services. Without a governance of the shared work practice, governance of IT services will take place in a void. A shared work practice will impose a need for governance of the information infrastructure.

Clear and well understood implementation of governance mechanisms of the shared work practice is likely to have a positive effect to decrease the number of issues and thus their consequences on interoperation, both in the shared work practice and in the governance of the IT services.

Handbooks and guidelines how to interpret communication acts and institutional objects used are important governance mechanisms. Also, rules for state changes of objects, life cycle of objects, repertoire of actions allowed, work practices, and process descriptions, et cetera, are important governance mechanisms for the interoperation in a shared work practice context. Not to forget, a shared definition of goals and benefits of the work practice will guide evaluation and improvement of the quality of interoperation.

These governance mechanisms are part of the work practice infrastructure condition for interoperation. 
Even so, incidents and problems will occur. Thus, it is important to develop and implement routines for escalating and identifying incidents and application of methods to evaluate risks and consequences that possibly could mean harm to critical resources and people, to the operation of IT services, and to the integrity and quality of information.

In a similar fashion, like the ITIL framework has been inspired by Total Quality Management, the governance of work practice related issues could be seen as part of process improvement with the aim to better control the process of interoperation to avoid "frictions" and disturbances. Thus, for work practice issues, it should also be useful to adopt - analogous to IT service management - event, incident and problem management, or some other quality management approach.

Organizational learning (in our context shared work practice learning) is also an important part of process improvement. [325]

\subsection{Aspects of interoperation}

In this section, we will elaborate and define our notion of aspects of interoperation.

In section 9.7.1, we will problematize the dominant trend within practice and research on interoperability to divide interoperability into different levels.

Then, we briefly recall our previous analysis of interoperation and its context to explain our choice of different aspect of interoperation, which are defined in section 9.7.2. We then deepen the aspects and give examples from ePrescribing in Sweden.

\subsection{1 "Levels" of interoperability tend to separate interdependent aspects of interoperation}

We have previously emphasized the need to distinguish between the notion of interoperation and interoperability. Without this distinction, definition of interoperability and its possible "levels" will be blurred. However, we think it is useful to analyze different aspects of interoperation, which can be used to focus on different factors that influence interoperability. This concern is probably one reason behind the efforts made to divide interoperability into different levels ${ }^{175}$ (see section 2.1 Interoperability concepts and frameworks).

\footnotetext{
${ }^{175}$ And presumably of interoperation even if this is not explicitly mentioned in the proposed frameworks.
} 
However, the notion of levels of interoperability can mislead to separate into distinct more or less independent levels, or to view interoperation as a hierarchical decomposable structure starting with a lower technical level and building up more complex levels ${ }^{176}$.

Furthermore, interoperation using an information infrastructure to mediate communication acts, boundary objects are expressed in a formal language using some kind of messaging method. The fact that formal languages are used to communicate relate to another influential metaphor borrowed from linguistics, where there are at least three levels or subject areas analyzing different functions of the sign:

- syntactic (which is about signs relation to other signs);

- semantic (which is about the signs relation to what it refers to);

- pragmatic (which is the relation of the sign towards an interpreter).

This separation of syntax, semantics, and pragmatics ${ }^{177}$ is often used in definitions of interoperability levels. Following Pierce, Dewey and speech act theory (Austin, Searle and Habermas), our approach is that these aspects are interdependent and that communication acts should be analyzed taking the different aspects and their interdependency in mind.

Though it is important to deal with the grammatical, referential, and interpretative aspects of the sign, it is our view that meaning cannot be reduced to one of these aspects alone.[251]

In this chapter, we will propose an alternative view on interoperation and interoperability that attempts to avoid the separation into different levels. We will first define what we mean by aspects of interoperation and then develop each aspect in more detail. For examples of various aspects confer chapter 4 Implementing ePrescribing in Sweden - case study and 5 Improving interoperability in ePrescribing - a field study.

\subsubsection{Aspects of interoperation and its characteristics}

We will use the term aspects of interoperation to highlight the fact that interoperation can be viewed from various angels, focusing certain characteristics of interoperation that will influence interoperability. We will first recall our definition of interoperation (see section

\footnotetext{
176 This level metaphor may be influenced by the Open Systems Interconnection (OSI) model in the data communication field.

${ }^{177}$ A common critic is that there is no strict separation between the levels, but that communication must be seen in its social context. See chapter 7 Context of interoperation and interoperability for an account of this critique and an analysis of the context of communication.
} 
7.10 Definition of interoperability) and its context in order to explain our choice and definition of the aspects of interoperation.

\section{Communication acts are mechanisms for conducting actions}

The initial assumption is that communication acts (as developed by Searle, Habermas, Eriksson, and Goldkuhl, et al), are an essential mechanism for conducting ${ }^{178}$ interoperation. Conduct is here used in two ways, both as doing something, i.e. perform an action and/or organize this doing, i.e. coordinate dependencies of actions. Thus, a communication act is doing something (being performed) and has a role of coordinating other actions (material act or other communication acts) according to constitutive and regulative rules ${ }^{179}$. Communication acts are expressed in a forma ${ }^{180}$ language in the form of messages, which are seen as utterances of sentences. These messages are viewed as part of speech acts formulated, transferred and interpreted by actors using an information infrastructure as instrument.

\footnotetext{
${ }^{178}$ See one definition in Oxford Advanced Learner's Dictionary - conduct something: "to organize and/or do a particular activity."

${ }^{179}$ See 5.7 for application of Searle's account of these two types of rules on prescription rules.

${ }^{180}$ With formal, we mean and cite a text book in mathematical logic: "It is used when referring to a situation where symbols are being used and where the behavior and properties of symbols are determined completely by a given set of rules. In a formal system, the symbols have no meanings, and in dealing with them, we must be careful to assume nothing about their properties other than what is specified in the system.” [326]
} 


\section{Interoperation in a shared work practice using information infrastructure}

The second assumption is that this interoperation is taking place in a shared work practice using a shared information infrastructure to mediate communication acts between actors.

\section{Communication in a mediated, non-personal and prescriptive communication setting}

The third assumption is that the communication acts are made in a mediated, non-personal and prescriptive setting, using an information infrastructure.

- mediated setting means that actors use an information infrastructure for structured, repeated communication, over time and space, using a supporting and application infrastructure;

- non-personal setting means that the addressee of the communication is not a specific person per se, but directed towards actors in another work practice, with a certain function or role in the work practice, rather than a specific person;

- prescriptive setting means that the language used for communication is a formalized and restricted language, with a predefined repertoire of actions and messages.

(See further chapter 7 for a deepening of these concepts.)

\section{Communal common ground for interoperation}

The forth assumption is that there must exist a communal common ground for successful communication. The communal common ground is the sum of common beliefs, knowledge and presuppositions in a community, that have been build up historically based on earlier interactions and experience and what emerges in the actual communication situation.

Figure 56 illustrates and summarizes the context of using communication acts in interoperation. 


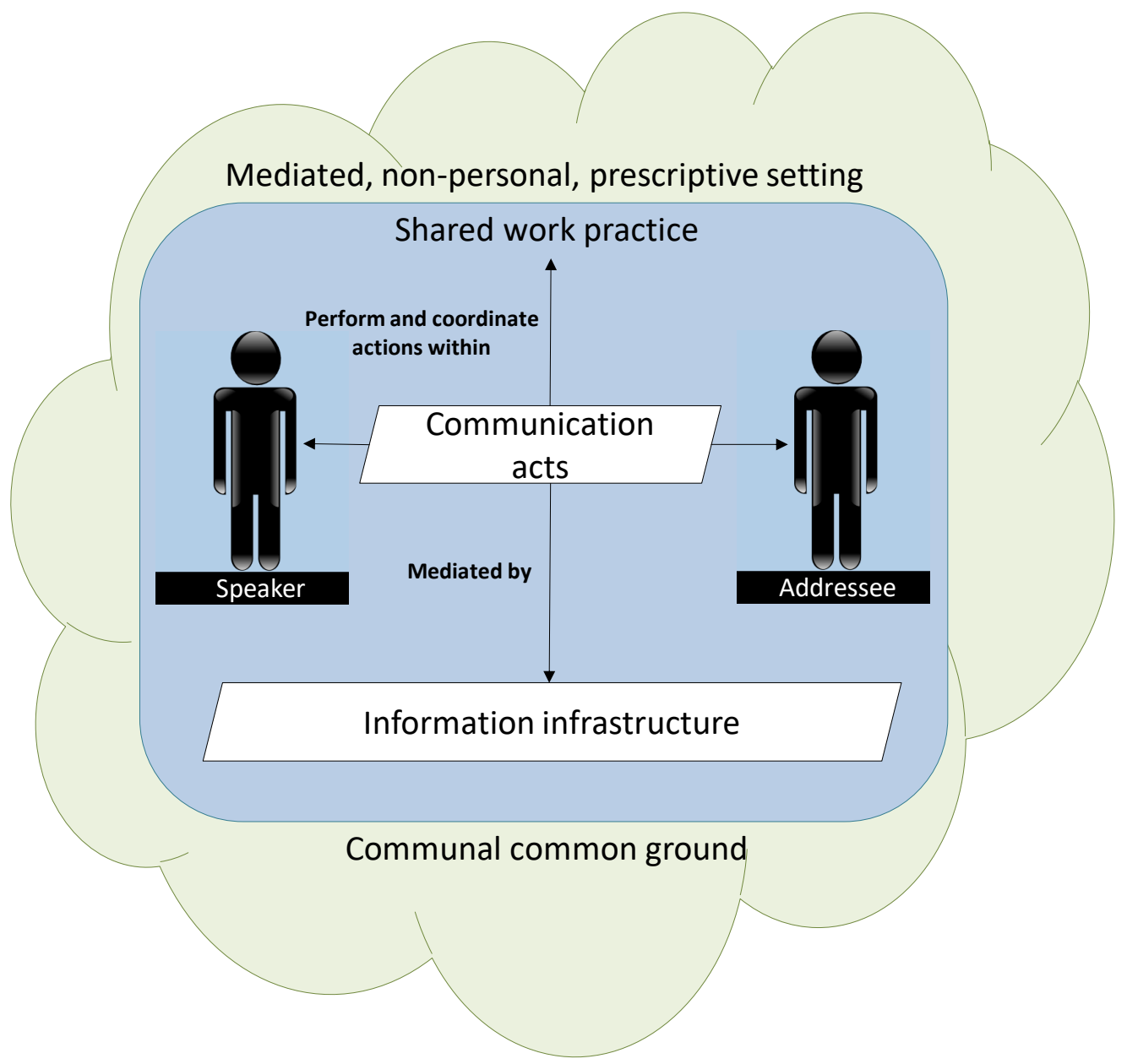

Figure 56 The context of communication acts in interoperation.

From this context, we outline three aspects of interoperation. These aspects originate from different roles of the communications acts as actions within the work practice, as communication acts between actors, and as acts mediated by an information infrastructure.

Thus, we define three aspect of interoperation:

- work practice action aspect focus on the logic of actions from the perspective of the work practice and its conditions (transactional and infrastructural) for the interoperation;

- communication action aspect focus on the shared understanding of the communication acts by the actors; 
- mediating communication action aspects focus on the use of an information infrastructure for mediating communication acts, expressed in messages ${ }^{181}$ between actors. ${ }^{182}$

Figure 57 gives an additional illustration of the different aspects of interoperation put in the context of inter-organizational interoperation with related work practices.

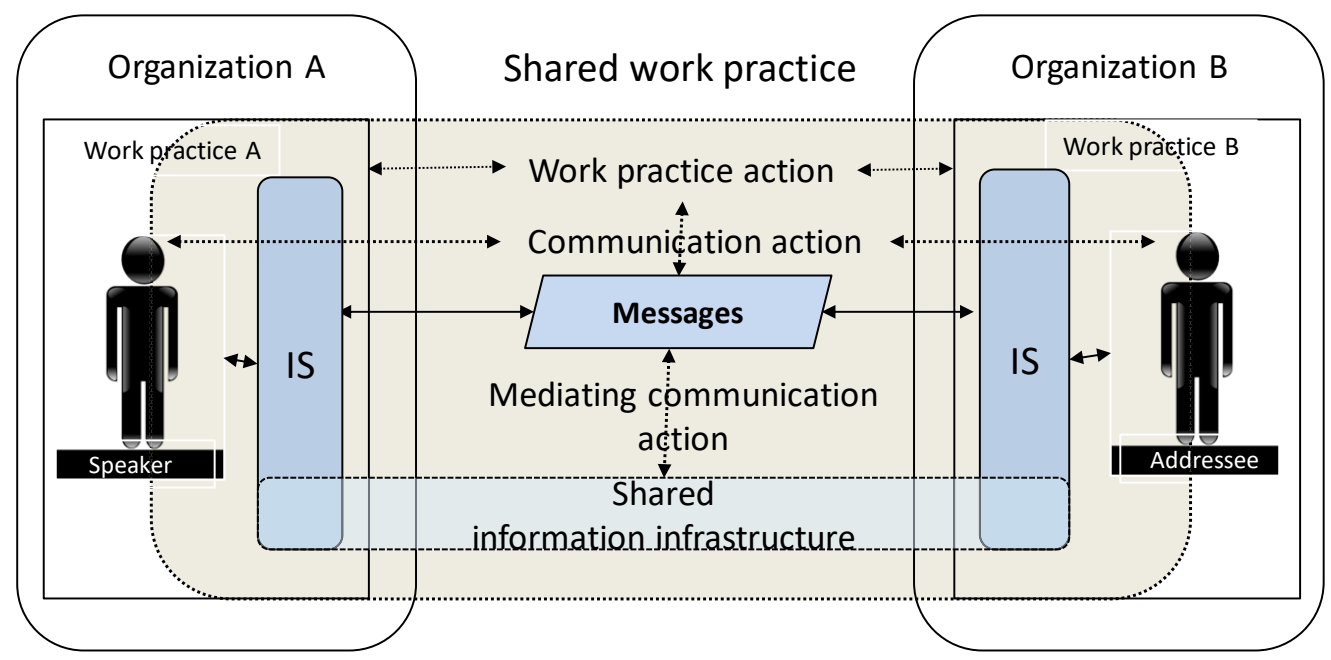

Figure 57 Aspects of interoperation in a shared work practice between different organizations.

All these aspects of interoperation are closely linked. Communication acts are used to coordinate and perform actions in the work practice and is part of its logic of actions. These actions expressed in messages are mediated using an information infrastructure. Some of the actions are carried through by human actors using and interacting with the information infrastructure and some actions are carried through as automatic actions within the information infrastructure.

Below, we provide a short description of what is in focus in the different aspect of interoperation and interoperability.

Work practice action aspect focuses on issues such as:

- goals and expected benefits of the shared work practice;

- repertoire of actions, their order and dependencies to other actions;

${ }^{181}$ Messages are here used as a generic term and are not linked to a certain mode of communication, like messaging technologies, system-to-system services, or stored procedures, intelligent agent et cetera. A message is thus not only a passive informational component but contains also an action component. See $[140,235,269]$

${ }^{182}$ The information infrastructure can also perform automatic communicative actions as a response to a state change or to a communicate action from another actor. 
- actor's roles, competence, knowledge, and authority to act in a shared work practice;

- governance mechanisms for work practice interoperation;

- actors use of information infrastructure and how it relates to the work practice;

- communal common ground ${ }^{183}$ about procedures and context of action in the work practice. These could be inscribed governance mechanisms or implicitly assumed.

Communication action aspect focuses on issues such as:

- the understanding and agreement of the communication acts in the interoperation:

$\circ$ understanding and agreement by the actors of the shared objects and their relationships;

- rules for creating and changing the status of objects;

- agreed vocabularies of terms used or referred to in the interaction;

0 understanding and definition of the function of the boundary object in the interoperation, i.e. the type of communication acts they represent, such as assertion, order, request, commitment, directive et cetera;

- communal common ground, which are the basis for successful communication and shared understanding.

Mediating communication action aspect focuses on how communication acts are formulated, represented, transferred, presented, and performed, and on providing the information infrastructure for this in the shared work practice and related work practices with issues such as:

- representation of the exchanged boundary objects and rules for creating and changing institutional object of the information infrastructure;

- functionality of the applications to support interoperation:

- means for communication such as system-to system services and gateways;

- network management;

- technical standards;

- identity management;

- information infrastructures governance.

\subsubsection{Work practice action aspect}

Work practice action aspect has a focus on the logic of actions and its conditions in a shared work practice. This section starts with the role of formulating goals and expected benefits of the work practice and how it will influence the content and logic of actions and the conditions in which it takes place. Next, we will analyze how these goals and benefits

\footnotetext{
${ }^{183}$ See section 7.7 for a deepening on common ground.
} 
are related to how actions are conducted and their conditions. Finally, we give some examples from ePrescribing how work practice aspects have been considered.

\section{Goals and benefits of the shared work practice}

Participants in a shared work practice share in some sense common goals, although they may have different goals and incentives to engage in a process of interoperation. One of these common goals is related to the reason for interoperation with a focus on the task to be carried out.

The overall goal of a shared work practice is often implicit or regarded self-evident and thus seldom explicitly formulated. However, the goal of a shared work practice (formulated or not) will influence the view of the actors and their roles and in turn influence the direction of the future of the work practice. The goal will also evolve over time with the emergence of new opportunities with the implementation of new technology. See the evolution of ePrescribing in Sweden in chapter 4.

Another aspect on what to be achieved is the expected yields or benefits for different actors. In ePrescribing, there are both aspects of patient safety, quality of the prescription, and other expected yields such a cost reduction and efficiency of the work practice. A more general concern is how to improve drug utilization in the society from a medical, social, and economic point of view. [162] ePrescribing shows the potential of digitalization which could benefit drug utilization in the sense of providing up to date information on prescriptions, providing better control of active prescriptions, information on filled prescriptions, et cetera.

Thus, it is important to be clear on the different goals and the incentives of the actors involved or affected by the shared work practice, because they will influence how interoperation is implemented ${ }^{184}$ and maintained and will influence the work with improving interoperability.

\section{Work practice action logic and infrastructural conditions}

With a formulated (at best) goal and expected benefits of the shared work practice, on why and what is to be achieved and expected, another essential question is how this is to be achieved. This means a shift of focus towards actions of the work practice with questions such as:

- What actions are to be coordinated and what are the pre- and post-actions agreed upon in exchange?

- What are the roles of the actors in the shared work practice and their responsibility and authority?

${ }^{184}$ See section 8.4.1 Network governance in ePrescribing - comparison US - Sweden on the influence of expected benefits and incentives on the implementation of ePrescribing in US. 
- What kinds of boundary objects are exchanged and what are their functions in the work practice?

- What are the rules for creation and change of status of boundary objects?

- What are the transactional and infrastructural conditions for the shared work practice?

- What are the organizational, economical and legal prerequisites?

- What governance mechanisms should be used in the shared work practice?

- How are the existing work practices in the organizations influenced by the demands from the shared work practices?

- Are there any implicit assumptions regarding actions and procedures in the work practice that have to be regulated and communicated?

These questions (and others) regarding work practice change should be addressed in designing and implementing interoperation.

In order to have a good quality of work practice interoperation, there are at least two areas to establish and develop:

- a common understanding among the participants about the shared work practice objectives, benefits, roles, responsibilities, skills and logic of actions. Knowledge and understanding of the "others" "related work practices is important. This is part of a common ground for interoperation and is very important in order to handle situations that fall outside of foreseen interaction and is not explicitly regulated;

- shared governance mechanisms for the work practice.

It is important to find the right balance between standardization of work practices using governance mechanism and mutual understanding, common knowledge and skills in the community. The latter make it possible to mutually adjust behavior to handle a wider range of situations. It is neither desirable nor possible to formalize all the implicit and explicit knowledge and beliefs that are held in a community. Such formalization will only lead to a lack of flexibility and to a very tight integration of the actions in each organization making evolution very difficult and costly.

Governance mechanisms is important to establish in the form of mutual agreements and contracts between the interoperating parties.

These agreements can be of various types such as agreement on:

- business related procedures such as how to handle residues, invoices, fees, delivery conditions, responsibilities, authorizations, and staffing;

- operational governance in term of incident, event and problem management on the work practice level (regarding the operational governance of the information infrastructure see the aspect of mediating communicative actions, below);

- the logic of actions and the function of boundary objects in the work practice actions and related work practices; 
- actor's roles, responsibility and authorization for action in the shared work practice and related work practices;

- the exchange of infrastructural information necessary for the work practice such as register data, product catalogs, information about actors, and statistics (boundary objects of the type repository).

\subsubsection{Communication action aspect}

In this section, we put to the foreground communication acts between actors and factors influencing their quality. The quality of the communication acts depends on the degree of mutual understanding and agreements between the communicating actors. In chapter 7 , we analyzed the context and conditions for mutual understanding of communication acts.

\section{Common ground for communication}

One important condition for successful communication is the common ground that exists in the community of interoperation.

We briefly recall one figure from section 7.7 Communication acts and common ground, see Figure 58.

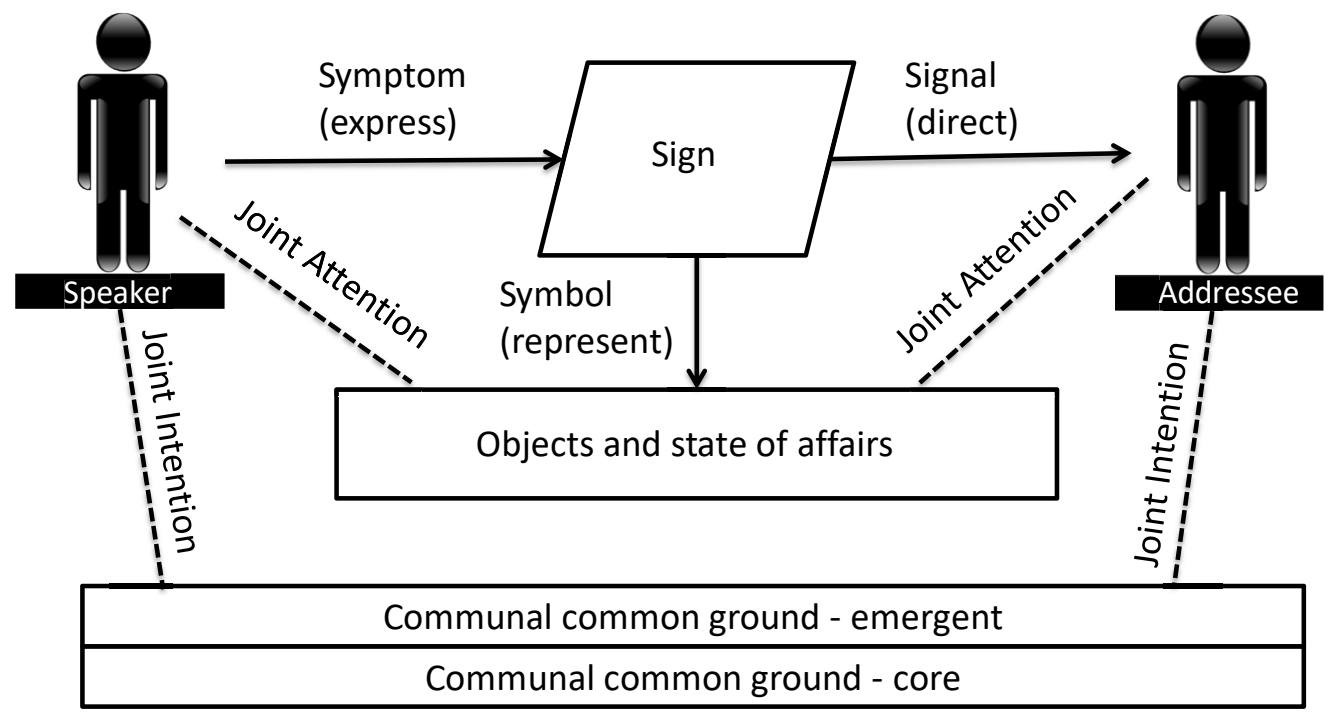

Figure 58 Common ground for communication acts.

In Figure 58 the sign in the communication act have three semantic functions: to express (symptom), direct (signal) and represent (symbol). To communicate, there need to be joint attention to the objects and state of affairs. Joint intention is about plans of action to achieve a goal. Joint intention helps to direct attention to relevant object and state of affairs. Joint intention is part of the communal common ground. 
The communal common ground is the background to the communication.

The communal common ground core - is the common beliefs, knowledge and presuppositions in a community that have been built up historically based on earlier interactions and experience.

The emergent communal common ground is the common ground that emerges for the actual communication, in the utterance situation of the communication.

The joint intention (whether assumed or communicated in the communication act) towards the communal common ground gives the situational context of the communication act.

Thus, understanding and agreement on the meaning of the communicated messages used in the work practice and in the professional domains are very much dependent on the established communal common ground. An important instrument for promoting mutual understanding and agreement in action is the use of specialist language and vocabularies. The messages used to express the communication acts are also important sources to clarify the meaning of communication acts. Careful and common work of defining the messages and their agreed meaning will influence the quality of the communication acts.

\section{Communication setting and communication strategies}

Communication acts using an information infrastructure have a setting that is mediated, non-personal and prescriptive. This will further stress the need to work more seriously with defining the meaning of messages and their use in interoperation as one cannot rely on mutual adjustments, signal acknowledges, and on the fly corrections, which is done in a face to face communication. To explicitly communicate what the communication is about, so called meta-communication will be more important. However, standardization and formalization of messages and routines is not enough to cope with all kinds of situations. There is also a drawback with excessive standardization which could lead to lack of flexibility. Thus, it is also necessary to facilitate mutual learning and adaptation to the different work practice situations in respective organization and professional groups.

Clark \& Brennan [327] show how different communicative settings influence the communication strategies used for successful communication. It is not the place in this thesis to analyses the implication of a mediated, prescriptive and non-personal setting on communication strategies, but it is surely a very important topic to understand.

\section{Analysis of communication acts and the role of boundary objects}

Boundary objects are a common denominator and at the same time adaptable to each actor's use in their work practice. This property of boundary objects makes them very 
useful in interoperation. They can have different meanings in different work practice contexts but at the same time function as a 'glue' in interoperation.

Boundary objects can be further analyzed into basically ${ }^{185}$ two types: object that are used in the transaction, which are termed 'standardized form' and boundary object which are more stable in nature and are objects of reference. This later type of boundary objects, called 'repositories' are an important part of institutional objects in the information infrastructure. Identifiers [84] of these boundary objects are essential in facilitating interoperation.

Thus, these boundary objects have multiple functions and different meanings in each work practice context and needs to be agreed upon for a well-functioning interoperation. In making a conceptual analysis agreed upon by the participants it is important to understand that meaning can only be understood as part of actions in the context of a shared work practice and their relation to the participants own work practice. See Erikson and Ågerfalk [84, 328] for examples of conceptual modeling approaches for analyzing institutional and boundary objects.

\subsubsection{Mediating communication action aspect}

The mediating communication actions aspects involve the acts of formulating, transferring, transforming, performing, making accessible, and presenting communications acts. See section 9.3.2 Interoperation, interoperability, and the role of the information infrastructure for a definition of the mediating role of an information infrastructure.

One important part of this mediating role is the mediation of communication acts between actors expressed in messages. An important task is to define formal syntax and rules for these messages and how they are handled by the applications in terms of actions. Another aspect that will influence interoperability is the actability the information infrastructure, i.e. how well it will permit, promote, and facilitate actions in the work practice. See section 7.9.1 Actability of information systems.

Some communication acts are inscribed in the behavior of the information infrastructure as automatic actions often in response to communication acts by users. These automatic actions influence the actions of humans in the work practice. They are standardized and programmed actions of the work practice, which is assumed or even a precondition for other actions, but not always visible or explicit for the actors in the work practice. Thus, acts by the information infrastructure forms a part of the work practice actions.

Institutional objects are essential for the shared work practice to function. They are usually in the background and supported by specific work practices here named

\footnotetext{
${ }^{185}$ See chapter 2.2.3 Features of information infrastructure for a description of other types of boundary objects analyzed by Star and Griesemer.
} 
infrastructure work practices. These objects can be used by several work practices and thus have multiple functions. These repositories of institutional objects have their own life cycle and are managed by different actors. Their life cycle is not always coordinated with the life cycle of the shared work practice.

Thus, an important aspect of the information infrastructure is the regulation of the life cycle of its institutional objects - how, when, and by whom they are created and get their status changed.

The communication acts mediated have to be communicated using gateways or system to systems services. These have to be designed and managed as shared services.

Other aspects linked to services for communication is the question of a shared information security regulating such issues as identification, authentication, and authorization of users in respective information system in the shared work practice.

\section{Information infrastructure governance}

The shared information infrastructure has to have an operational governance, such as agreements on shared service levels, continuity plans, rules for storage and logging of messages and traffic events, deployment windows, incident, problem and event management, test and approval procedures of new or changed applications. 


\section{Conclusion, contributions, generalizability, and future research}

The aim with this chapter is to summarize conclusions and contributions made in this thesis and relate them to the research aims. Furthermore, we will discuss the empirical and theoretical grounding of the theory of interoperation and interoperability, the plausibility of generalizing the theory towards the health care sector, and the utility of the theory for practitioners.

This chapter is organized as follows:

- 10.1 Conclusion makes a summary of the conclusions made in the thesis and relate to them to the research aims;

- 10.2 Contributions and their practical and theoretical implications, contain a summary of the contribution made in this thesis;

- 10.3 Grounding, summarizes our sources of empirical and theoretical grounding of the theory on interoperation and interoperability presented in chapter 9;

- 10.4 Generalizability of research findings, analyze the plausibility of generalizing the theory on interoperation and interoperability towards the health care sector;

- 10.6 Utility of the theory on interoperation and interoperability for practitioners discuss the utility of the theory on interoperation and interoperability for practitioners.

Finally, we conclude this chapter with suggestions for future research in section 10.7. 


\subsection{Conclusion}

Interoperability has become an important issue within health care and the public sector. Now, there is a general understanding that interoperation and interoperability do not only concern the use of technology, but also involves issues related to work practices, governance, evolution, and development of information infrastructures, organizational cooperation, strategies, and legal issues.

One aim of this thesis is to contribute with practical and theoretical knowledge in achieving and improving interoperability. The contribution is based on an inquiry into ePrescribing practice in Sweden.

Three studies of the ePrescribing practice were presented:

1. case study of the evolution of ePrescribing in Sweden from the pioneering years in 1980s to the growth phase in the early 2000 and the consolidation phase in the second half of the first decade of 2000 ;

2. field experimental study of improving interoperability in ePrescribing with the introduction of a new national ePrescription format (NEF);

3. in-depth analysis of the ePrescribing work practice, which resulted in a practical theory on ePrescribing.

The current status of ePrescribing in Sweden is the result of an evolution since the beginning of the 1980s. To better understand this evolution, a case study was made into the history of ePrescribing in Sweden (1). This case study shows, among other things, the evolution of a complex information infrastructure for ePrescribing, with a shift from pointto-point local communication to the evolution of an information infrastructure that dealt with the whole life cycle of the prescription. The experience from the case study highlights certain factors for achieving interoperability, such as trust, cooperation, long term commitment, and strategic perspective among the stakeholders, but also the evolution of new governance mechanisms for development, maintenance and implementation of ePrescribing.

Another part of this work is to contribute with experience of improving interoperability. This was done through a field experimental study of an improvement project in ePrescribing (2). The field experimental study was designed to measure the quality of the ePrescription message before and after an intervention to improve quality of the communicated message. The findings in the field experimental study showed a dramatic increase of the quality of ePrescription message. These findings were analyzed using theories and frameworks. IS actability theory and actability criteria for design and evaluation were used to relate the findings to aspects of interaction, communication, and process quality. The role of the stakeholders in providing shared information services for the ePrescribing process was described. The European Interoperability Framework (EIF) was used in order to analyze the improvements. The characteristics of the joint intervention 
of NEF were analyzed and put in a historical context of implementing ePrescribing in Sweden.

This field experimental study illustrates that improving interoperability is a complex endeavor, which includes political, legal, economical, organizational, cultural, semantical, and technical issues. These aspects concern the communicated messages, related intraorganizational information systems, information infrastructure, interoperating work practices, and their context.

An early part of the inquiry into ePrescribing in Sweden was an in-depth analysis of the ePrescribing work practice (3). This analysis was triggered by the need to understand the underlying complexity in the ePrescribing communication with its multiple functions.

These three studies point to the need for a theoretical framework that can sort out the complexity in order to accumulate experiences and research results, and be a guide to practitioners working with achieving and improving interoperability.

Thus, another aim with this thesis is to address the lack of theoretical grounding of interoperability concepts and frameworks. The thesis aims at contributing with an empirically and theoretically grounded practical theory on interoperation and interoperability.

The intention with the theory is to conceptualize perspectives on interoperation and interoperability, and to provide a theory grounded in explicit theories that can contribute to the growth of scientific knowledge on interoperability. The theory is empirically grounded in experiences of achieving and improving interoperability in ePrescribing in Sweden. The theory is also intended to be used as a guide for practitioners in conducting their work on interoperability.

The theory on interoperation and interoperability makes a distinction between 1) collective action, which is the development and implementation of a shared work practice with governance mechanisms and information infrastructure for interoperation, and 2) interoperation, which is actor's use of communications acts mediated by an information infrastructure, in order to conduct actions in a shared work practice.

The exercised capability to interoperate - interoperability - is further detailed in three aspects: work practice, communication, and mediating communication action.

The notion of a shared work practice for interoperation and the relation to other work practices such as infrastructure work practices, which contribute with institutional object necessary for the interoperation, were defined and elaborated. 


\subsection{Contributions and their practical and theoretical implications}

In this section, we will briefly summarize the major contributions in this thesis and their practical and theoretical implications. See section 3.7.3 Contributions and theory components for a more detailed account of the results in terms of knowledge categories and theory components. We will also describe the implications of these contributions in terms of their practical implications for the practice and their theoretical implications for research.

Contributions aim at different communities and situations. We distinguish between contributions to the local practice, general practice, and research (see chapter 3 Methods of inquiry for a definition of these types of contributions). The contributions have also implication in different communities.

\subsubsection{Local practice contributions and implications}

Local practice contributions have been made in the operational and developmental work to improve interoperability in ePrescribing. Examples of such contributions are the specification of a new national ePrescription format (NEF), requirements specifications of the information infrastructure for ePrescribing, and handbooks on ePrescriptions and the pharmacy ePrescribing process.

In addition, the documented contributions and the participation in operational and development work have practical implications for the local practice in the long term.

First, the work has been part of the growth and consolidation of the ePrescribing practice in Sweden. The improvement of interoperability in ePrescribing, a substantially improved quality of the ePrescription message, has contributed to the consolidation of the ePrescribing practice in terms of a better control and regulation of the communication in the shared work practice. It was also a prerequisite for the growth of volume without an increase of quality deficiencies, which would drive cost, creating disturbances, and discomfort. This could have endangered the trust and acceptance by the stakeholders that has been built up during years. This consolidation was an enabling factor in the deregulation of the pharmacy market in Sweden, when transferring the complex information infrastructure of ePrescribing from the NPC to a network administrative organization (se 8.2.1) - later a state authority - was a major challenge.

Moreover, the practices developed in improving interoperability in ePrescribing have had an influence on the present practice in ePrescribing in Sweden. This regards the practice of a more formal and stricter control of messages and services with validations of the quality of data, the improved procedures for test and certification of systems to allow access to different IT services, and the further development of handbooks to link the use of IT services to work practices. 


\subsubsection{General practice contributions and implications}

General practice contributions have been made in a case study on implementing ePrescribing in Sweden (see 4 Implementing ePrescribing in Sweden - case study) in a conceptualization of factors influencing the evolution of ePrescribing in Sweden and its information infrastructure. The case study reported and analyzed success factors in implementing ePrescribing in Sweden, which could be a useful example for other similar practices. It showed the importance of strategic, tactical, and operational governance for the evolution of a complex infrastructure.

The field experimental study (see 5 Improving interoperability in ePrescribing - a field $s t u d y$ ) measured interoperability errors before and after an intervention in order to improve interoperability. This unique study contributed with experiences from a set of actions to improve interoperability and demonstrated their effect in a dramatic increase in the quality of the communicated message. The work has practical implications for the general practice of ePrescribing in Sweden but also as examples for other practices how to improve interoperability. Thus, this study gave examples of effective actions to improve interoperability and provided a method how to evaluate the effects of an intervention.

This study contributed to highlight the operational aspect of interoperation in the theory on interoperation and interoperability.

The practice of ePrescribing was analyzed using practical theories. The result was a contribution to a general practice theory on ePrescribing. See $6 \mathrm{~A}$ practical theory on ePrescribing. The practical implication is that it is important to have a good understanding of the shared work practice when designing and developing the information infrastructure. A vague or unreflected view of the shared practice can lead to infrastructure designs that are at odds with the practice and thereby impair the conditions for development of interoperation and growth of the information infrastructure. See experience from ePrescribing implementation in US in section 8.4.1 Network governance in ePrescribing - comparison US - Sweden.

\subsubsection{Research contributions and their implications}

In this section, we will briefly summarize the research contributions made in this thesis and their implications. In section 3.7.3, we focused on characterizing the results. In this section, we will focus on the implications for research. The section starts with the 
interoperability research area and then implications for other areas within information systems research.

The theory on interoperation and interoperability is a contribution to the interoperability research area ${ }^{186}$. In this thesis, the focus is on interoperation between organizations and their agents using information infrastructures and is otherwise not tied to a particular domain. The interoperability research area is considered part of the information systems research discipline.

\section{Interoperability research}

\section{Theory on interoperation and interoperability}

A practical theory on interoperation and interoperability has been presented in this thesis.

The theory is targeting the research community to inform about relevant research areas, theoretical refinements and further situational inquiries. In addition, the theory aims at contributing to the general practitioner a model and language in order to analyze and guide work to achieve and improve interoperability.

The theory on interoperation and interoperability contributes to the quest of consistent theories on interoperability, which are based on explicit theoretical grounds and empirically grounded in extensive inquiries into the evolution of a complex information infrastructure for interoperation.

To the field of research on interoperability, we have contributed with the following:

- defining interoperation as the basis for defining interoperability;

- defining interoperability as the exercised capability to interoperate in the context of a shared work practice using information infrastructures;

- conceptualized the context of interoperation with concepts such as:

○ shared work practice;

○ boundary objects;

- context of communication in interoperation:

- communication as action and shared understanding based on communal common ground;

- settings of communication as prescriptive, non-personal, and mediated;

- work practice, communication, and mediating aspects of interoperation;

$\circ$ information infrastructure as the main instrument for interoperation;

\footnotetext{
${ }^{186}$ Interoperability research can also include the governance of material and human resources as for example in the military domain, see section 2.1.1. Thus, interoperability is a research area that has different application domains such as health care, public governance, military, and public safety, et cetera.
} 
- highlighted the importance of network governance of interoperation from strategic, tactical and operational perspective;

- highlighted the importance of collective action to overcome obstacles for interoperation.

In order to increase the utility of the theory for practitioner, it is necessary to present the theory in another form with examples and guidelines. See section 10.6 Utility of the theory on interoperation and interoperability for practitioners.

\section{Information systems research}

The theory on interoperation and interoperability has integrated external theories from the information systems research field. To some of these theories, we have made some specific contributions.

\section{Information systems development research}

To information systems development research, we have contributed with:

- highlighting the need to view information systems not as isolated applications in homogeneous work contexts, but rather as information infrastructures that enable interoperation between heterogeneous work contexts. While this is more obvious in an inter-organizational setting, medium and large enterprises/organizations have both an internal and external complexity with the regard to interoperation in heterogeneous work contexts.

\section{Information infrastructure research}

To information infrastructure research, we have contributed with:

- an integration of the concept of a shared work practice and its role in interoperation;

- the identification of infrastructure work practices and their crucial role in an information infrastructure;

- showing the importance of identifiers of actors and institutional objects for the evolution of information infrastructures;

- a longitudinal empirical study of a successful case of evolution of a complex information infrastructure. This study confirms the evolutionary character of information infrastructure evolution but shows also the importance of human agency in collective action and the use of strategic, tactical, and operational governance of the information infrastructure as key factors in the success.

\section{Work practice research}

To work practice research, we have contributed with:

- the concept of a shared work practice that extends the application of the work practice concept, which implicitly have been viewed as inside organizations, to a relation of interoperation between work practices within or between organizations; 
- integrating the concept of information infrastructure as the main instrument of the shared work practice;

- identification of infrastructure work practices that provide and support the shared information infrastructure.

\section{Standardization research}

To the research field on information systems standardization, we have contributed with:

- a suggestion ${ }^{187}$, applying the theory on interoperation and interoperability to standardization, to focus on standardization of shared work practices and boundary objects exchanged. Such an approach might overcome some of the complexity issues in standardization. Here, the empirical finding in ePrescribing gives a successful example in standardization of the ePrescribing shared work practice and the boundary objects involved. Thus, we have given an alternative strategy for standardization to avoid reflexivity in standardization. This strategy should be useful to apply in the health care sector.

\subsection{Grounding}

The theoretical grounding is based on:

- analysis of frameworks on interoperability, work practice and information infrastructure theory, and definitions and categorization of different types of standards and standardization (see chapter 2 Interoperability, information infrastructures, work practices, and standards);

- Information Systems Actability Theory (ISAT), theories on meaning and language, an analysis of communication settings for interoperation, and a conceptual analysis of interoperation and interoperability. See chapter 7 Context of interoperation and interoperability;

- theories about network governance, collective action, inter-firm interdependencies, IT governance, and IT service management in 8 Interoperation, governance, and collective action.

The empirical grounding of the theory on interoperation and interoperability is based on the empirical findings presented in chapters:

- 4 Implementing ePrescribing in Sweden - case study;

- 5 Improving interoperability in ePrescribing - a field study.

The theory on interoperation and interoperability is also grounded in the practical theory on ePrescribing presented in chapter 6 A practical theory on ePrescribing. See Figure 59

\footnotetext{
${ }^{187}$ See section 2.3.3 in the subsection on reflexive standardization.
} 
for an illustration of the theoretical and empirical grounding of the theory on interoperation and interoperability.

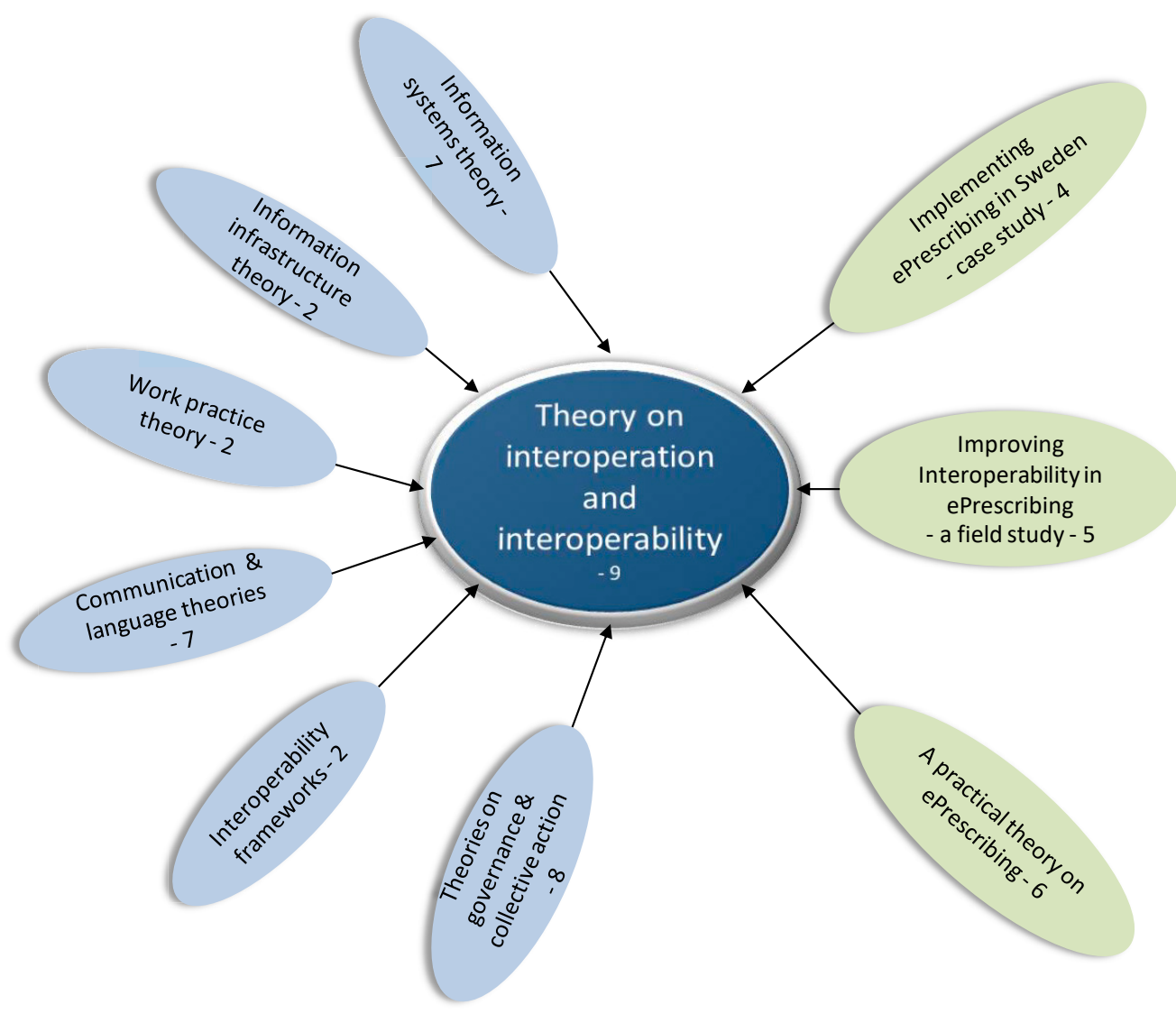

Figure 59 Illustration of theoretical and empirical grounding in different chapters of the thesis.

\subsection{Generalizability of research findings}

The theory on interoperation and interoperability is grounded in the domain of ePrescribing. The theory is not bound to the ePrescribing practice, but attempts to describe interoperability in general terms in order to be a vehicle to examine other similar situations (see Figure 60). 


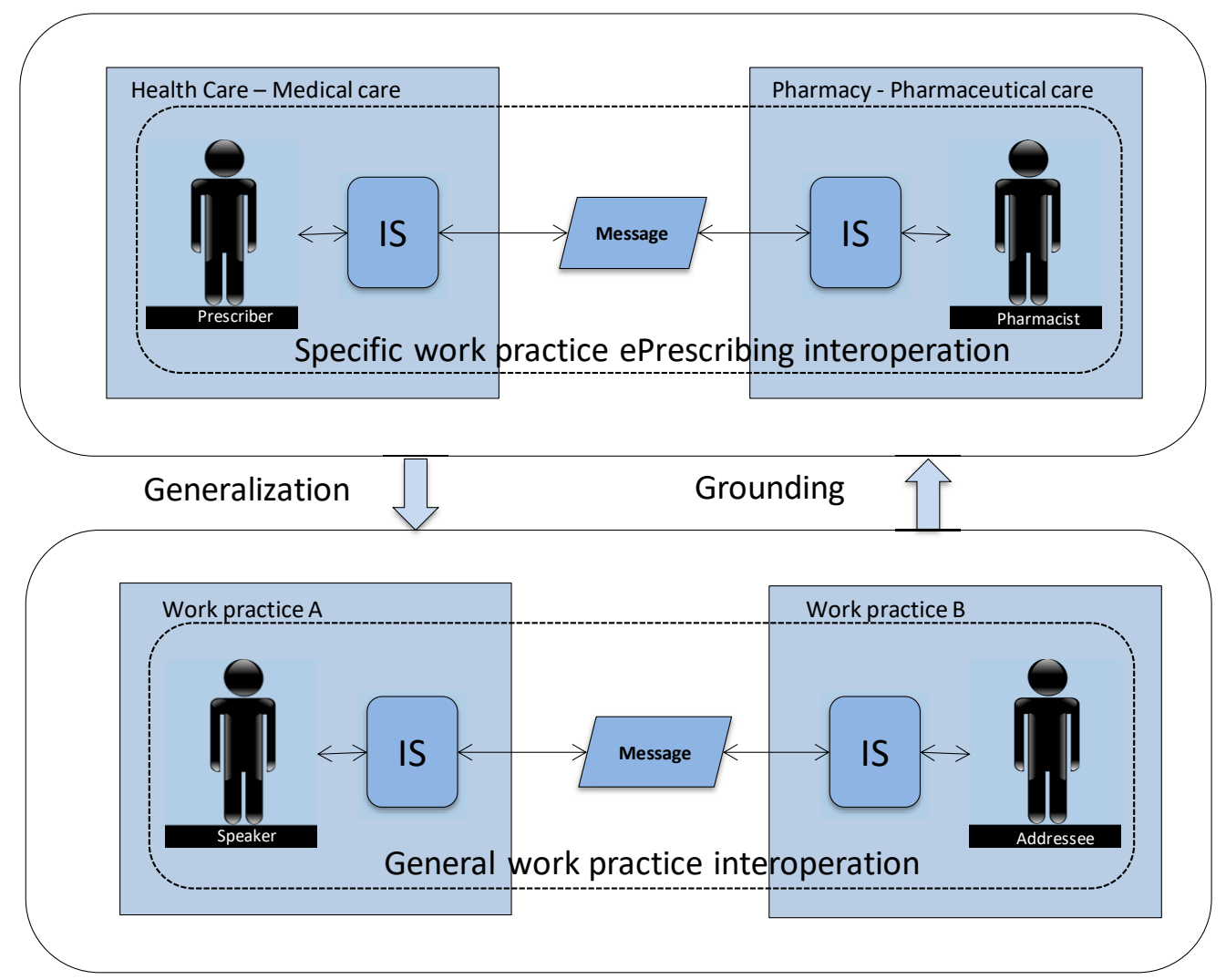

Figure 60 Grounding in and generalization from ePrescribing work practice of the theory on interoperation and interoperability.

In this section, we will discuss the generalizability of the presented theory on interoperation and interoperability. For a more in depth discussion on generalizability in information systems and qualitative research, see section 3.5 Generalizability in information systems and qualitative research.

We will present our assumptions about generalizability and use a framework to reason about the generalizability of research findings. Then, we will analyze the plausibility of generalizing to the health care sector. We will compare the characteristics of the health care sector with ePrescribing. In this section, we also analyze the support for the theory on interoperation and interoperability in the original domain of ePrescribing. 


\subsubsection{Assumptions about generalizability}

Given the account about generalizability in information systems and qualitative research presented in section 3.5, we will here present some assumptions we make before discussing generalizability of the theory on interoperation and interoperability to other practices.

According to Lee \& Baskerville [152] it is not acceptable to generalize a theory based on one case or setting to another case or setting, without making an empirical test of the theory in the new case. Other scholar's claim that is possible to generalize beyond the case where findings or theory have been generated. [154, 156]. These differences could be ascribed to a difference how to view induction and inductive reasoning. For Lee and Baskerville induction is seen as an abstraction from particular to general notions, for others induction and inductive reasoning is inference from matters of facts that have been observed to those that have not yet been observed [154].

The position in this thesis is that induction is ampliative: "Induction can amplify and generalize our experience, broaden and deepen our empirical knowledge." (C S Peirce, quoted in [154]). Induction is not about absolute true or false statements but about justification of beliefs based on evidence available. Here, the approach is to combine thoughts from Tsang \& Williams [154] and Smaling [156] in order to discuss the generalizability of a theory to other cases or setting in which it has not been tested or asserted.

If we agree with Tsang \& Williams that it is possible to generalize findings from a case or sample to another population with regard to similarities and differences in context and time, then we should be able to reason about the generalizability of a theory grounded in a sample or case to other cases or samples that have not yet been investigated. Smaling provides this link in discussing the plausibility of generalizing a theory to another setting not yet tested. Smaling uses for this purpose analogical reasoning and propose a number of quality criteria to improve this analogical reasoning.

In the next subsection, we will reason about the plausibility that the theory on interoperation and interoperability will hold in other settings than ePrescribing, which is the practice on which the theory on interoperation and interoperability is empirically grounded. 


\subsubsection{Generalization of the theory on interoperation and interoperability to the health care sector}

We will limit our discussion on the plausibility that the theory on interoperation and interoperability will hold for other practices to the health care sector.

We will compare characteristics of ePrescribing and the health care sector using three ${ }^{188}$ of Smalling's six quality criteria for analogical reasoning (see 3.5 Generalizability in information systems and qualitative research):

- relative degree of similarity;

- relevance for the conclusion;

- relative plausibility of the conclusion on its own.

The first criterion, relative degree of similarity, states that if there are more similarities than differences in the settings, analogical generalization is more plausible. The second criterion, relevance for the conclusion, states that if similarities in the settings are relevant for the conclusion, it is more plausible that it will hold in another setting. The third criterion, relative plausibility of the conclusion on its own, states that if a theory or finding has a strong support in its original domain, it is more acceptable to use analogical reasoning.

\section{Comparing health care sector in general and ePrescribing}

The health care sector can be defined in a number of different ways. One definition of the scope of practice of health care is: "Health and sick care - actions to medically prevent, investigate, and treat diseases and injuries." 189

This is a very general notion that does not define boundaries for the health care activities. Statistical definitions usually have stricter boundaries defined. Thus International Standards Industrial Classification (ISIC) [329] defines Human health activities as consisting of hospital activities, medical and dental practice activities, and other human health activities. This definition comprises many different professions and activities pursued at hospitals or outside hospitals in various facilities.

In these definitions, dispensing of prescribed medical drugs by pharmacies in outpatient care is not explicitly mentioned. In the ISIC definition on health care activities in hospitals, pharmacy services are mentioned. In this thesis, ePrescribing is defined as an intersection, a continuous workflow for a medical treatment of a patient in outpatient care, between the

\footnotetext{
${ }^{188}$ The other criteria are related to support from other cases and to the empirical and theoretical support of the degree of similarity of settings and their relevance. As these criteria are not applicable for the moment they are not discussed further but should be part of future research.

${ }^{189}$ Our translation from Swedish, Socialstyrelsens Termbank 2007 - the Swedish National Board of Health and Welfare - Terminology.
} 
health care market and the pharmacy market. Thus, from the point of view of ePrescribing the dispensing of prescribed medical drugs by the pharmacies is part of health care activities. The ISIC definition of health care activities also includes laboratory services, blood and transplant organs banks, ambulance transport et cetera. The pharmacy market in general is classified as belonging to "Retail sale of pharmaceutical and medical goods, cosmetic and toilet articles in specialized stores." [329] Thus, pharmacies are both linked to health care activities and retail activities. Consequently, it is natural to view ePrescribing as one particular practice within health care with characteristics of health care practices in general.

We have selected a number of characteristics of ePrescribing, which we think have relevance for the applicability of the theory on interoperation and interoperability, and then compared them with practices within health care (Table 25). We have not made a case study of the characteristics in health care. The comparison is based on our general knowledge of the situation and consultation with medical practitioners.

Table 25 Comparing characteristics in ePrescribing and health care that have relevance for the applicability of the theory on interoperation and interoperability in the health care sector.

\begin{tabular}{lll}
\hline Characteristics & ePrescribing & Health care \\
\hline Multi-professional cooperation & Yes & Yes \\
Highly regulated practices & Yes & Yes \\
$\begin{array}{l}\text { Interorganizational communication } \\
\text { Knowledge intensive communication }\end{array}$ & Yes & Yes \\
$\begin{array}{l}\text { Mediated, non-personal, and } \\
\text { prescriptive setting }\end{array}$ & Yes & Yes \\
$\begin{array}{l}\text { High demands on client safety and } \\
\text { privacy }\end{array}$ & Yes & Yes, for some \\
$\begin{array}{l}\text { Need for complex information } \\
\text { infrastructure }\end{array}$ & Yes & practices \\
$\begin{array}{l}\text { Complex interdependencies of work } \\
\text { practices }\end{array}$ & Yes & Yes \\
$\begin{array}{l}\text { Many stakeholders involved } \\
\begin{array}{l}\text { Demand for health care record of } \\
\text { patient care }\end{array}\end{array}$ & Yes & Yes \\
\hline
\end{tabular}

\footnotetext{
190 This criterion was proposed by a medical doctor in response to the proposed criteria.

${ }^{191}$ At least not in Sweden, except for keeping record of the dispensing history.
} 
Multi-professional cooperation: ePrescribing practice is a multi-professional cooperation, between cooperating prescriber professions and pharmacists. This multiprofessional cooperation is even more the case in health care, particularly at hospitals with various professions and specialists. A medical examination can involve X-ray and laboratory services, consultations by specialists, et cetera. The care involves nurses, and clinical pharmacists and use of pharmacy services such as making extemporaneous production, et cetera.

Highly regulated practices: health care practices are like ePrescribing highly regulated practices.

Inter-organizational communication: ePrescribing is always an inter-organizational communication. This is not always the case for health care practices, which often are made in hospitals with face-to-face communication between health professionals and patients. However, there are many cases of interdepartmental communication within the same hospital organization that is similar to inter-organizational communication. There are also often external communications, which are inter-organizational, like remittance and transferring of patients to other care facilities outside the hospital. Many times, laboratory services involved are inter-organizational communication.

Knowledge intensive communication: many practices in health care as well as in ePrescribing involve highly educated professionals communicating about complex health conditions.

Mediated, non-personal, and prescriptive setting: many practices in health care rely on direct, personal face-to-face communication. There are also practices that partly or completly rely on a mediated, non-personal communication, and regulated (prescriptive) communication setting, such as using EHR systems ${ }^{192}$ to request for consultation, remittance, et cetera. There is also communication with other stakeholders that are not directly involved in the health care that are non-personal, prescriptive, and mediated by some media, such as eProcurement of medical drugs from pharmaceutical distributors other medical equipment's and utilities.

High demands on client safety and privacy: both ePrescribing and health care practices demand a high degree of concern for patient safety and privacy.

Need for complex information infrastructure: both ePrescribing and health care practices need complex information infrastructures which is due to the highly complex nature of the practices and the knowledge involved. The multi-professional cooperation also demands a highly-developed information infrastructure for communication.

\footnotetext{
192 The EHR systems can be seen as instrument for communication between health care professional and now also with the patient.
} 
Complex interdependencies of work practices: many practices are involved in the treatment of a patient both in ePrescribing and in other health care practices.

Many stakeholders involved: like in ePrescribing, there are many stakeholders which are not immediately engaged in health care actives, but which are involved in regulating, inspecting, and requesting information, et cetera.

Demand for health care record of patient care: the demand for documenting patent care is more demanding on the prescribers in health care compared to the demand on the pharmacist to document dispensing history. In ePrescribing, this demand already exists for the prescribers, and that is probably the reason for the preference of using EHR-systems for prescribing in order to facilitate the documentation of the prescription as part of the entire health care record documentation.

\section{Conclusion}

The conclusion from this comparison of the characteristics in ePrescribing and health care practices is that, given the relevance of the criteria selected, that it is plausible that the theory on interoperation and interoperability presented in this thesis could be applied to other settings in health care. Health care practices that have similar characteristics as in ePrescribing are more likely to fit the theory on interoperation and interoperability.

\subsection{Support for the theory on interoperation interoperability in the original domain}

The theory on interoperation and interoperability has been empirically grounded in ePrescribing in Sweden. Thus, the theory is a result of a generalization of the case of ePrescribing and of using extant theories in the theory construction. These extant theories have been used to organize and interpret the empirical material, and they have been used in forming the theoretical constructs in the form of conceptualizations, patterns, and normative criteria of the theory on interoperation and interoperability. The theory has been internally grounded in the sense of making an effort to minimize ambiguities and inconsistencies in definition of theoretical concepts. An effort has also been made to present the theory as clearly as possible to make it comprehensible for both practitioners and researchers.

The empirical findings have been presented in a case study on the evolution of ePrescribing in Sweden, in an analysis of ePrescribing practice to arrive at a general practice theory on ePrescribing, and in a description of a field experimental study in improving interoperability in ePrescribing. The empirical findings are presented in depth, as "thick descriptions", presenting findings in their context. The findings have also been analyzed using extant theories to further analyze the empirical material. This organization 
and generalization of the empirical material was the basis for a further generalization into a theory on interoperation and interoperability using the extant theories as input for the theory building. The theory has been explicitly grounded in a number of extant theories and has been exemplified by referring to the empirical material in order to concretize the theoretical concepts.

In section 3.4.2 Reliability, validity, and evaluation of research, we described some criteria to evaluate the validity of qualitative research, both the validity of its conclusions in relation to the empirical material on which they are based and the validity of the conclusions in relation to other situations. In Table 26, we present a comparison of different criteria for assessing validity in qualitative research from Venkatesh [146] and how they can be applied for this study.

Table 26 Different types of validity in qualitative research from Venkatesh [146] and how they can be used to evaluate the validity of the research in this thesis.

\section{Type of Description Evaluation in this thesis validity in qualitative research}

\begin{tabular}{|c|c|c|}
\hline Descriptive & $\begin{array}{l}\text { The accuracy of what is } \\
\text { reported. }\end{array}$ & $\begin{array}{l}\text { The empirical findings have been } \\
\text { based on many different sources } \\
\text { using a mixed method approach } \\
\text { using both qualitative and } \\
\text { quantitative methods for } \\
\text { acquisition of data. Corroboration } \\
\text { of data from various sources has } \\
\text { been done when possible. }\end{array}$ \\
\hline
\end{tabular}

Credibility Results are believable from the point of view of the participants in the research and that alternative explanations are ruled out.

\author{
An inside researcher, making an \\ inquiry during a long period, \\ having close access to data and the \\ evolution of the situation \\ examined, and a deep pre- \\ understanding of the situation \\ should increase the credibility. The \\ risks of being close to the situation \\ are considered and accounted for. \\ Interaction with other researcher \\ not engaged in the situation made \\ it possible to probe alternative \\ explanations.
}




\begin{tabular}{|c|c|c|}
\hline Transferability & $\begin{array}{l}\text { Degree to which the results are } \\
\text { applicable or possible to } \\
\text { generalize to other context of } \\
\text { settings. }\end{array}$ & $\begin{array}{l}\text { See our discussion in this and } \\
\text { previous section on } \\
\text { generalizability. }\end{array}$ \\
\hline Theoretical & $\begin{array}{l}\text { Degree to which the theory fits } \\
\text { the data. }\end{array}$ & $\begin{array}{l}\text { The theory on interoperation and } \\
\text { interoperability is a generalization } \\
\text { of the empirical findings and of } \\
\text { using extant theories. The theory is } \\
\text { accompanied with examples from } \\
\text { the situational inquiry of } \\
\text { ePrescribing. The thick description } \\
\text { of the findings and with extensive } \\
\text { references between the theoretical } \\
\text { components and the findings } \\
\text { provides a rich material to evaluate } \\
\text { how the theory fits the data. }\end{array}$ \\
\hline Dependability & $\begin{array}{l}\text { How the changes in the setting } \\
\text { affected the way the researcher } \\
\text { approached the study. }\end{array}$ & $\begin{array}{l}\text { The research process has been } \\
\text { described in detail concerning how } \\
\text { the research interest developed and } \\
\text { research questions were posed and } \\
\text { evolved. }\end{array}$ \\
\hline Consistency & $\begin{array}{l}\text { Process of analysis from raw } \\
\text { data to findings. }\end{array}$ & $\begin{array}{l}\text { In the field experimental study, the } \\
\text { process from raw data to findings } \\
\text { is made explicit. The qualitative } \\
\text { data analysis of findings is made } \\
\text { explicit in the thick description } \\
\text { giving both the facts and their } \\
\text { context. When using extant } \\
\text { theories to analyze the data this is } \\
\text { described. }\end{array}$ \\
\hline Interpretive & $\begin{array}{l}\text { Degree of accuracy of the } \\
\text { interpretation of the beliefs, } \\
\text { views, thoughts, feelings, } \\
\text { intentions of the participants by } \\
\text { the researcher. }\end{array}$ & $\begin{array}{l}\text { When findings were based on } \\
\text { interpretation of interviews and of } \\
\text { informant's beliefs, as in the case } \\
\text { study, the informant was given the } \\
\text { opportunity to comments and } \\
\text { correct draft of the case study } \\
\text { report. Two of the informants in } \\
\text { the case study made this. }\end{array}$ \\
\hline
\end{tabular}




\begin{tabular}{lll}
\hline Confirmability & $\begin{array}{l}\text { Degree to which the results } \\
\text { could be confirmed or } \\
\text { corroborated by others. }\end{array}$ & $\begin{array}{l}\text { Two informants (see above) } \\
\text { confirmed the findings in the case } \\
\text { study based on the interviews. } \\
\text { Writing papers together with a } \\
\text { colleague involved in the situation } \\
\text { and with a medical practitioner } \\
\text { contributes to confirmability of } \\
\text { results. }\end{array}$
\end{tabular}

The empirical findings in the situational inquiry in ePrescribing in Sweden have given a rich empirical material for generalizing into a theory on interoperation and interoperability. This theory, which is also influenced by the extant theories chosen and the experience as an inside researcher, is one possible generalization into a theory on interoperation and interoperability. Other extant theories and researchers would probably give other results with other emphasis or views, not necessarily in contradiction with the results presented here, but based on slightly other research interests. The presentation of the thesis has aimed to make as transparent as possible the research process to make it possible for other researchers and practitioner to evaluate the validity, utility and transferability (or generalizability as used here) of the theory.

Furthermore, while the theory on interoperation and interoperability is empirically grounded in ePrescribing in Sweden, it is theoretically grounded in theories on communication and information systems that are not bound to a particular domain. This does also support the plausibility that it is potential to hold in the health care setting as well as potentially in other domains. However, it is necessary to have in mind that the theory has to be applied in a new specific practice context.

\subsection{Utility of the theory on interoperation and interoperability for practitioners}

One intention with the theory on interoperation and interoperability was to provide a theory that is useful for practitioners how to diagnose, design, implement, improve, and maintain interoperation and interoperability. In an academic work like this, it is not appropriate to develop detailed guidelines or handbooks. However, there have been efforts made to increase the utility ${ }^{193}$ of the theory for practitioners:

- the research questions are rooted in real world problems encounter by a practitioner;

- the research object, ePrescribing, have been described in detail from various angels, in 'thick descriptions';

${ }^{193}$ See section 3.5 for a brief discussion on qualities of research that increase the utility value. 
- examples are given from ePrescribing in order to concretize the concepts the theory;

- the author has as a practitioner written handbooks and guidelines which includes some of the components of the generalized theory which show that it is possible to concretize the concepts of the theory in future handbooks and guidelines.

Finally, it is up to the reader to evaluate the usefulness of the theory and its transferability to other domains.

\subsection{Future research}

This research, in the spirit of Dewey, is both an end of an inquiry and input to further inquiries. Here, we will give examples of lines of research that could follow:

- evaluate the utility of the developed theory on interoperation and interoperability with practitioners from various professional roles such as business and requirements analyst, project managers, policy makers, CIOs, CFOs, CEOs, architects, judicial expertise, developers, et cetera;

- evaluate the transferability of the theory on interoperation and interoperability to be used in other domains than ePrescribing, such as the health care and public sector;

- evaluate the transferability of the practical theory on ePrescribing to be used in other countries outside Sweden;

- compare the findings on the evolution of the information infrastructure in ePrescribing with:

- ePrescribing in other Nordic countries (Denmark, Norway, Finland, Iceland);

- ePrescribing in other countries and regions such as Europe, America and Australia;

- compare the evolution of information infrastructure for interoperability in the public sector in Sweden and Europe. 


\section{References}

1. IEEE Standard Computer Dictionary: A Compilation of IEEE Standard Computer Glossaries. 1990, Institute of Electrical and Electronics Engineers: New York.

2. DoD Directive 4630.5: Interoperability and Supportability of IT and National Security Systems (NSS) U.S.A. Department of Defense, Editor. 2004.

3. European Interoperability Framework for Pan-European eGovernment Services version 1.0. 2004.

4. European Interoperability Framework (EIF) for European public services - Annex 2 to the Communication from the Commission to the European Parliment, the Council, the European Economic and Social Committee and the Committee of Regions 'Towards interoperability for European public services'. 2010, European Commission: Bruxelles.

5. Kalra, D., et al., Semantic Interoperability for Better Health and Safer Healthcare Research and Deployment Roadmap for Europe, in SemanticHEALTH Report, V.N. Stroetmann, Editor. 2009, European Commission.

6. EPrescribing and Electronic Transfer of Prescriptions: an International Review. 2012, Health Information and Quality Authority: Dublin, Ireland.

7. The National Progress Report on E-Prescribing and Interoperable Health Care - Years 2011. 2012, Surescripts.

8. Öhlund, S.-E., B. Åstrand, and G. Petersson, Improving Interoperability in ePrescribing. Interactive Journal of Medical Research, 2012. 1(2): p. e17.

9. Öhlund, S.-E., B. Åstrand, and G. Petersson, Interoperability in action - the case of electronic prescribing, in 15th International Symposium of Health Information Management Research - ISHIMR 2011, P.A. Bath, et al., Editors. 2011, University of Zurich: Zurich, Switzerland.

10. Kierkegaard, P., E-Prescription across Europe. Health and Technology, 2012: p. 1-15.

11. Linking up Europe: the Importance of Interoperability for eGovernment Services. 2003, European Commision.

12. Den osynliga infrastrukturen - om förbättrad samordning av offentlig ITstandardisering, in Statens offentliga utredningar. 2007.

13. Goldkuhl, G., The challenges of Interoperability in E-government: Towards a conceptual refinement, in pre-ICIS 2008 SIG eGovernment Workshop. 2008: Paris.

14. Dixon, B.E., D.J. Vreeman, and S.J. Grannis, The long road to semantic interoperability in support of public health: Experiences from two states. Journal of Biomedical Informatics, 2014. 49: p. 3-8.

15. Hagman, A., The Knowledge and Adoption Level of Standards for Technical Interoperability among Providers of Healthcare Information Systems, in KTH, School of Technology and Health (STH). 2016, KTH. Master Thesis.

16. Andersson, M., et al., Gemensamt ramverk av standarder för interoperabilitet och förändringsledning - Slutrapport projekt StandIN. 2016, Medtech4Health.

17. Schneiderman, R., Bluetooth's slow dawn. IEEE Spectrum, 2000. 37(11): p. 61-65.

18. Deavours, D.D., M. Elangovan, and J.E. Dawkins, User-Perceived Interoperability of Bluetooth Devices. 2004, Information and Telecommunication Technology Center, The University of Kansas. 
19. Andrews, J.E., et al., Comparing heterogeneous SNOMED CT coding of clinical research concepts by examining normalized expressions. J. of Biomedical Informatics, 2008. 41(6): p. 1062-1069.

20. Andrews, J.E., R.L. Richesson, and J. Krischer, Variation of SNOMED CT Coding of Clinical Research Concepts among Coding Experts. Journal of the American Medical Informatics Association, 2007. 14(4): p. 497-506.

21. Lewis, G., et al. Why Standards Are Not Enough to Guarantee End-to-End Interoperability. in The Seventh International Conference on Composition-Based Software Systems (ICCBSS 2008). 2008. IEEE Computer Society Press.

22. Temmerman, R., Towards New Ways of Terminology Description. The sociocognitiveapproach. 2000, Philadelphia, PA, USA John Benjamins Publishing Company

23. Temmerman, R., From Principles of Standardisation to a Scientific Study of Terminology, in Towards New Ways of Terminology Description. Sociocognitiveapproach. 2000, John Benjamins Publishing Company: Philadelphia, PA, USA

24. Temmerman, R., Sociocultural situatedness of terminology in the life sciences: The history of splicing, in Body, Language and Mind. Vol II. Interrelations between Biology, Linguistics and Culture, R. Frank, et al., Editors. 2006 Springer Verlag: Tübingen.

25. Brownsword, L.L., et al., Current Perspectives on Interoperability. 2004, Carnegie Mellon University, Software Engineering Insitute: Pittsburgh.

26. Brooks, F.P., No Silver Bullet: Essence and Accidents of Software Engineering IEEE Computer. IEEE Computer, April 1987. 20(4): p. 10-19.

27. Ebel, T., et al., Strength in unity: The promise of global standards in healthcare. 2012, McKinsey\&Company.

28. Edwards, P.N., et al., Understanding Infrastructure: Dynamics, Tensions, and Design, in History and Theory of Infrastructure: Lessons for New Scientific Cyberinfrastructures. Workshop September 28 - October 1, 2006. 2007: Ann Arbor.

29. Williams, T., Interorganisational information systems: issues affecting interorganisational cooperation. Journal of Strategic Information Systems, 1997. 6(3): p. 231-250.

30. Robey, D., I. Ghiyoung, and J.D. Wareham, Theoretical Foundations of Empirical Research on Interorganizational Systems: Assessing Past Contributions and Guiding Future Directions. Journal of the Association for Information Systems, 2008. 9(9): p. 497-518.

31. Thomas C. Ford, et al. A Survey on Interoperability Measurement. in Twelfth International Command and Control Research and Technology Symposium (12th ICCRTS). 2007. Newport, RI.

32. Jardim-Goncalves, R., et al., Systematisation of Interoperability Body of Knowledge: the foundation for Enterprise Interoperability as a science. Enterprise Information Systems, 2012. 7(1): p. 7-32.

33. Lampathaki, F., et al., Infusing scientific foundations into Enterprise Interoperability. Computers in Industry, 2012. 63: p. 858-866.

34. Taxén, L., Sustainable enterprise interoperability from the Activity Domain Theory perspective. Computers in Industry, 2012. 63(8): p. 835-843.

35. Loukis, E. and Y. Charalabidis, Efficiency and Innovation Oriented Business Value of Enterprise Systems Interoperability -- An Empirical Investigation. 2013 46th Hawaii International Conference on System Sciences, 2013: p. 4065.

36. European, C., et al., Unleashing the potential of the European knowledge economy: Value proposition for enterprise interoperability : final version (version 4.0). 2008. 
37. Loukis, E.N. and Y.K. Charalabidis, An empirical investigation of information systems interoperability business value in European firms. Computers in Industry, 2013. 64: p. 412-420.

38. Enterprise Interoperability Research Roadmap. 2008, Information Society and Media Directorate-General, European Comission.

39. Aanestad, M. and T.B. Jensen, Building nation-wide information infrastructures in healthcare through modular implementation strategies. Journal of Strategic Information Systems, 2011. 20: p. 161-176.

40. Hanseth, 0. and E. Monteiro. Changing irreversible networks: Institutionalisation and infrastructure. in ECIS. 1998. Provence, France.

41. Hanseth, O., E. Monteiro, and M. Hatling, Developing Information Infrastructure: The Tension Between Standardization and Flexibility. Science, Technology \& Human Values, 1996. 21(4): p. 407-426.

42. Öhlund, S.-E. and G. Goldkuhl, Towards a socio-pragmatic understanding of ePrescribing, in 5th Intl Conference on Action in Language, Organisations and Information Systems (ALOIS-2008). 2008: Venice.

43. Gibbons, P., et al., Coming to Terms: Scoping Interoperability for Health Care. 2007, Health Level Seven EHR Interoperability Work Group.

44. Robert I. Desourdis, Peter J. Rosamilia, and C.P. Jacobson, Achieving Interoperability in Critical IT and Communication Systems. 2009: Artech House, Inc. 330.

45. Tolk, A., Beyond Technical Interoperability - Introducing a Reference Model for Measures of Merit for Coalition Interoperability, in 8th CCRTS, National Defense University. 2003: Washington, D.C.

46. Chen, D. and G. Doumeingts, European initiatives to develop interoperability of enterprise applications - basic concepts, framework and roadmap. Annual Reviews in Control, 2003. 27(2): p. 153-162.

47. Draft for public comments - as basis for EIF 2.0. 2008, European Commission.

48. Chen, D., G. Doumeingts, and F. Vernadat, Architectures for enterprise integration and interoperability: Past, present and future. Computers in Industry, 2008. 59: p. 647659.

49. ISO, ISO/TR 16056-1:2004 Health informatics -- Interoperability of telehealth systems and networks -- Part 1: Introduction and definitions. 2004.

50. CEN/ISSS, Current and future standardization issues in the eHealth domain: Achieving interoperability. 2005, CEN/ISSS eHealth Standardization Focus Group.

51. ISO, ISO TS 18308:2003 Health informatics - Requirements for an electronic health record architecture. 2003, ISO.

52. Benson, T., Principles of Health Interoperability HL7 and SNOMED. 2010, London: Springer-Verlag.

53. David Chen, Guy Doumeingts, and F. Vernadat, Architectures for enterprise integration and interoperability: Past, present and future. Computers in Industry, 2008.

54. IEC, IEC TC65/290/DC. (2002, June 28). Device profile guideline, TC65: Industrial process measurement and control. 2002.

55. Bob Miller, et al., Towards a Framework for Managing the Information Environment. Information - Knowledge - Systems Management, 2001(2): p. 359-384.

56. Mulley, C. and J.D. Nelson, Interoperability and transport policy: the impediments to interoperability in the organisation of trans-European transport systems. Journal of Transport Geography, 1999. 7(2): p. 93-104.

57. D Carney, et al., Some Current Approaches to Interoperability. 2005, Software Engineering Institute. 
58. D4.1: Structured account of approaches on interoperability, J. Backhouse, Editor. 2005, Future of Identity in the Information Society.

59. Shannon, C.E., A Mathematical Theory of Communication. The Bell System Technical Journal, 1948. 27: p. 379-423,623-656.

60. Hanseth, 0. and K. Lyytinen, Theorizing about Design of Information Infrastructures: Design Kernel Theories and Principles. SPROUTS: Working Papers on Information Systems, 2004.

61. OASIS, Introduction to UDDI: Important Features and Functional Concepts. 2004, Organization for the Advancement of Structured Information Standards.

62. Goldkuhl, G., Workpractice Theory: What It Is and Why We Need It, in Third International Conference on Action in Language, Organisations and Information Systems (ALOIS*2005), P.J. Ågerfalk, L. Bannon, and B. Fitzgerald, Editors. 2005, University of Limerick: Limerik, Ireland.

63. Goldkuhl, G. and A. Röstlinger, Context in Focus: Transaction and Infrastructure in Workpractices, in Action in Language, Organisations and Information Systems (ALOIS). 2006: Aarhus, Denmark.

64. Orlikowski, W.J., Using Technology and Constituting Structures: A Practice Lens for Studying Technology in Organizations. 2000, Institute for Operations Research and the Management Sciences. p. 404.

65. Feldman, M.S. and W.J. Orlikowski, Theorizing practice and practicing theory. Organization Science, 2011. 22(5): p. 1240-1253.

66. Schatzki, T.R., K. Knorr-Cetina, and E.v. Savigny, The practice turn in contemporary theory [electronic resource] / edited by Theodore R. Schatzki, Karin Knorr Cetina, and Eike von Savigny. 2001: New York : Routledge, 2001.

67. Schatzki, T.R., Introduction: Practice Theory, in The practice turn in comtemporary theory, T.R. Schatzki, K. Knorr-Cetina, and E. Savigny, Editors. 2001, Routledge: Florence, KY, USA.

68. Barnes, B., Practice as collective action, in Practice Turn in Contemporary Theory, T.R. Schatzki, K. Knorr-Cetina, and E. Savigny, Editors. 2001, Routledge: Florence, KY, USA. p. 33-34.

69. Orlikowski, W.J., Knowing in Practice: Enacting a Collective Capability in Distributed Organizing. Organization Science, 2002. 13(3): p. 249-273.

70. Hanseth, 0. and E. Monteiro, Inscribing behaviour in information infrastructure standards. Accounting, Management and Information Technologies, 1997. 7(4): p. 183-211.

71. Medina-Mora, R., et al., The action workflow approach to workflow management technology, in Proceedings of the 1992 ACM conference on Computer-supported cooperative work. 1992, ACM: Toronto, Ontario, Canada. p. 281-288.

72. Axelsson, K., U. Melin, and G. Goldkuhl, Understanding B2B interaction - a model to accentuate inter-organisational systems design issues, in 10th European Conference on Information Systems (ECIS2002), W. S, Editor. 2002: Gdansk, Poland. p. 541-550.

73. Goldkuhl, G. and A. Röstlinger. Clarifying government - citizen interaction: from business action to generic exchange in 4th Scandinavian Workshop on eGovernment. 2007. Örebro, Sweden.

74. Goldkuhl, G., Generic regulation model - the evolution of a practical theory for egovernment. Transforming Government: People, Process and Policy, Emerald Group Publishing Limited, 2011.5(3): p. 249-267.

75. Goldkuhl, G. The evolution of a generic regulation model for e-government development. in Scandinavian Workshop on E-government (SWEG-2008). 2008. Copenhagen: Copenhagen Business School. 
76. Edwards, P.N., et al., Introduction: An Agenda for Infrastructure Studies. Journal of the Association for Information Systems, 2009. 10(5): p. 364-374.

77. Pipek, V. and V. Wulf, Infrastructuring: Toward an Integrated Perspective on the Design and Use of Information Technology. Journal of the Association for Information Systems, 2009. 10(5): p. 447-473.

78. Hanseth, O. and N. Lundberg, Designing work oriented infrastructures. Computer Supported Cooperative Work: The Journal of Collaborative Computing, 2001. 10(3): p. 347-372.

79. Bowker, G.C. and S.L. Star, Sorting Things Out: Classification and Its Consequences. 1999: MIT Press.

80. Wenger, E.C. and W.M. Snyder, Communities of practice: The organizational frontier. Harvard Business Review, 2000. 78(1).

81. Star, S.L. and K. Ruhleder, Steps Toward an Ecology of Infrastructure: Design and Access for Large Information Spaces. Info. Sys. Research, 1996. 7(1): p. 111-134.

82. Hanseth, $\mathrm{O}$. and K. Lyytinen, Design theory for dynamic complexity in information infrastructures: the case of building internet. Journal of Information Technology, 2010(25): p. 1-19.

83. Trist, E., The sociotechnical perspective: The evolution of sociotechnical systems as a conceptual framework and an action research program, in Perspectives on Organizational Design and Behavior, A. Van De Ven and W. Joyce, Editors. 1981, John Wiles \& Sons: New York.

84. Eriksson, 0. and P. Ågerfalk, Rethinking the Meaning of Identifiers in Information Infrastructures. Journal of the Association for Information Systems, 2010. 11(8).

85. Bowker, G.C. and S.L. Star, Sorting things out: Classification and its consequences. 1999, Cambridge MA: MIT Press.

86. Star, S.L. and J.R. Griesemer, Institutional Ecology, 'Translations' and Boundary Objects: Amateurs and Professionals in Berkeley's Museum of Vertebrate Zoology, 1907-39. Social Studies of Science, 1989. 19(3): p. 387-420.

87. Cooper, R., In praise of the prescription: The symbolic and boundary object value of the traditional prescription in the electronic age. Health Sociology Review, 2011. 20(4): p. 462-474.

88. Star, S.L., This is not a boundary object: Reflections on the origin of a concept. Science Technology and Human Values, 2010. 35(5): p. 601-617.

89. GS1, GLN in Healthcare - Implementation Guide 2012.

90. Anderson, P. and M.L. Tushman, Technological Discontinuities and Dominant Designs: A Cyclical Model of Technological Change. Administrative Science Quarterly, 1990. 35(4): p. 604-633.

91. Eriksson, O. and G. Goldkuhl, Preconditions for public sector e-infrastructure development. Information and Organization, 2013(3): p. 149.

92. Nielsen, P., A Conceptual Framework of Information Infrastructure Building: A Case Study of the Development of a Content Service for Mobile Phones in Norway, in Faculty of Mathematics and Natural Sciences. 2006, University of Oslo: Oslo, Norway. PhD Thesis.

93. Aanestad, M., Cultivating Networks: Implementing Surgical Telemedicin, in Department of Informatics, Faculty of Mathematics and Natural sciences. 2002, University of Olso: Oslo. Doctor Scientarium Thesis.

94. ITU, E-health Standards and Interoperability, in ITU-T Technology Watch Report. 2012. 
95. Markus, M.L., et al., Industry-wide information systems standardization as collective action: the case of the U.S. residential mortgage industry. MIS Q., 2006. 30(1): p. 439465.

96. Zhao, K., S.S. Khan, and M. Xia, Sustainability of Vertical Standards Consortia as Communities of Practice: A Multilevel Framework. International Journal of Electronic Commerce, 2011. 16(1): p. 11-40.

97. Guijarro, L., Interoperability frameworks and enterprise architectures in e-government initiatives in Europe and the United States. Government Information Quarterly, 2007. 24(1): p. 89-101.

98. Bowker, G.C., The history of information infrastructures: the case of the international classification of diseases. Information Processesing \& Management, 1996. 32(1): p. 49-61.

99. Libicki, M., Information Technology Standards: Quest for the Common Byte. 1995: Elsevier Science \& Technology Books.

100. J Damsgaard and D. Truex, Binary trading relations and the limits of EDI standards: the Procrustean bed of standards. European Journal of Information Systems, 2000. 9: p. 173-188.

101. Lyytinen, K. and J. Damsgaard, What's Wrong with the Diffusion of Innovation Theory?, in Diffusing Software Product and Process Innovations, M. Ardis and B. Marcolin, Editors. 2001, Springer US. p. 173-190.

102. West, J., What are open standards? Implications for adoption, competition and policy, in Standards and Public Policy Conference. 2004: Federal Reserve Bank of Chicago.

103. Group, N.W., Architectural Principles of the Internet. 1996, IETF.

104. Hanseth, O., et al., Reflexive Standardization: Side Effects and Complexity of Standard Making. MIS Quarterly, 2006. 30: p. 563-581.

105. Burns, F. Information for Health. 1998; Available from: http://webarchive.nationalarchives.gov.uk/20130107105354/http:/www.dh.gov.u k/prod consum dh/groups/dh digitalassets/@dh/@en/documents/digitalasset/d $\underline{\mathrm{h} \text { 4014469.pdf. }}$.

106. de Vries, H.J., Standardization: A Business Approach to the Role of National Standardization Organizations. 2013: Springer US.

107. Aanestad, M., et al., Infrastructuring Work: Building a State-Wide Hospital Information Infrastructure in India. Information Systems Research, 2014. 25(4): p. 834-845.

108. Hugoson, M.-Å., T. Magoulas, and K. Pessi, Interoperability Strategies for Business Agility, in Advances in Enterprise Engineering I, J.G. Dietz, A. Albani, and J. Barjis, Editors. 2008, Springer Berlin Heidelberg. p. 108-121.

109. IHTSDO. About SNOMED CT. 2012; Available from: http://www.ihtsdo.org/snomedct/snomed-ct0/.

110. Faber Benítez, P., The cognitive shift in terminology and specialized translation. MonTI. Monografías de Traducción e Interpretación, 2009(1).

111. Wittgenstein, L., Philosophical Investigations. 1953: Basil Blackwell Ltd.

112. Lakoff, G., Women, fire and dangerous things. 1987, Chicago: The University of Chicago Press.

113. Gärdenfors, P., The Emergence of Meaning. Linguistics and philosophy : an international journal, 1993. 16(3): p. 285-309.

114. Lakoff, G. and M. Johnson, Metaphors we live by. 1980, Chicago: The University of Chicago.

115. Öhlund, S.-E., Utveckling av ett utvärderingsinstrument - Prodevo, in Department of Computer and Systems Sciences. 1997, Stockholm University/Royal Institute of Technology: Stockholm. p. 112. Ph.Lic. Thesis. 
116. Dybå, T. and T. Dingsøyr, Empirical studies of agile software development: A systematic review. Information and Software Technology, 2008. 50(9-10): p. 833-859.

117. Gorschek, T., E. Tempero, and L. Angelis, On the use of software design models in software development practice: An empirical investigation. Journal of Systems and Software, 2014. 95: p. 176-193.

118. Bødker, K., F. Kensing, and J. Simonsen, Participatory IT design : designing for business and workplace realities / Keld Bødker, Finn Kensing, Jesper Simonsen. 2004: Place : MIT Press, cop. 2004.

119. Daneva, M., et al., Empirical research methodologies and studies in Requirements Engineering: How far did we come? The Journal of Systems \& Software, 2014. 95: p. $1-9$.

120. Gummesson, E., Qualitive Methods in Management Research. 2000: Sage Publications Inc.

121. Ribes, D. and T.A. Finholt, The Long Now of Technology Infrastructure: Articulating Tensions in Development. Journal of the Association for Information Systems, 2009. 10(5): p. 375-398.

122. Brannick, T. and D. Coghlan, In defense of being - "Native" the case for insider academic research. Organizational Research Methods, 2007. 10(1): p. 59-74.

123. Goldkuhl, G., The research practice of practice research: theorizing and situational inquiry. Systems, Signs \& Actions, 2011. 5(1): p. 7-29.

124. Schön, D., The Reflective Practitioner. 1983, London: Basic Books.

125. Holgersson, S., Yrke: POLIS - Yrkeskunskap, motivation, IT-system och andra förutsättningar för polisarbete, in Institutionen för datavetenskap. 2005, Linköping University: Linköping. PhD Thesis.

126. Åstrand, B., et al., The Swedish National Pharmacy Register, in MEDINFO 2007, K.A. Kuhn, J.R. Warren, and T.-Y. Leong, Editors. 2007, IOS Press: Brisbane, Australia.

127. Baskerville, R. and M.D. Myers, Special Issue on Action Research in Information Systems: Making IS Research Relevant to Practice: Foreword. MIS Quarterly, 2004(3): p. 329.

128. Goldkuhl, G., From Action Research to Practice Research. Australasian Journal of Information Systems, 2012.17(2): p. 57-78.

129. Argyris, C. and D.A. Schön, Theory in practice : increasing professional effectiveness / Chris Argyris, Donald A. Schön. Theory in practice ed. The Jossey-Bass series in higher education. 1975: San Francisco : Jossey-Bass, 1975.

130. Argyris, C., Single-Loop and Double-Loop Models in Research on Decision Making. Administrative Science Quarterly, 1976. 21(3): p. 363-375.

131. Tosey, P., M. Visser, and M.N. Saunders, The origins and conceptualizations of 'tripleloop' learning: A critical review. Management Learning, 2012. 43(3): p. 291-307.

132. Dewey, J., Logic: The Theory of inquiry. 1938, New York: Henry Holt.

133. Cronen, V.E., Practical theory, practical art, and the pragmatic-systemic account of inquiry. Communication theory, 2001. 11(1): p. 14-35.

134. Goldkuhl, G., Kunskapande. 2011, Linköping University.

135. Cronen, V.E., Practical theory and the tasks ahead for social approaches to communication, in Social approaches to communication, L. W, Editor. 1995, Guildford Press: New York.

136. Molander, B., Kunskap i handling. 1996, Göteborg: Daidalos.

137. Goldkuhl, G., What Does it Mean to Serve the Citizen in E-Services? - Towards a Practical Theory Founded in Socio-Instrumental Pragmatism. International Journal of Public Information Systems, 2007. 2007(3): p. 135-159. 
138. Goldkuhl, G. and S. Cronholm, Adding Theoretical Grounding to Gounded Theory: Towards Multi-Gounded Theory. International Journal of Qualitative Methods, 2010. 9(2): p. 187-205.

139. Golafshani, N., Understanding reliability and validity in qualitative research.(Report). The Qualitative Report, 2003(4): p. 597.

140. Ågerfalk, P.J., Information Systems Actability - Understanding Information Technonolgy as a tool for Business Action and Communication, in Department of Computer and Information Science Linköping University. 2003, Linköping University: Linköping. PhD Thesis.

141. Onwuegbuzie, A.J. and R.B. Johnson, The validity issue in mixed research. Research in the Schools, 2006. 13(1): p. 48-63.

142. Johnson, R.B. and A.J. Onwuegbuzie, Mixed Methods Research: A Research Paradigm Whose Time Has Come. Educational Researcher, 2004(7).

143. Hall, J.N., Pragmatism, Evidence, and Mixed Methods Evaluation. New Directions for Evaluation, 2013. 2013(138): p. 15-26.

144. Abowitz, D.A. and T.M. Toole, Mixed method research: fundamental issues of design, validity, and reliability in construction research. Journal of Construction Engineering and Management, 2010(1): p. 108.

145. Ågerfalk, P.J., Embracing diversity through mixed methods research. European Journal of Information Systems, 2013. 22(3): p. 251-256.

146. Venkatesh, V., S.A. Brown, and H. Bala, Bridging the qualitative-quantitative divide: guidelines for conducting mixed methods research in information systems. MIS Quarterly, 2013(1): p. 21.

147. Basic Measurement - International Handbooks of Quantitative Applications in the Social Sciences;; Vol 4, ed. M.S. Lewis-Beck. Vol. 4. 1994: SAGE Pucblications.

148. Beth Dawson and R.G. Trapp, Basic \& Clinical Biostatistics. forth ed. Lange Medical Book. 2004, New York: McGraw-Hill.

149. Newton, P.E. and S.D. Shaw, Standards for talking and thinking about validity. Psychological Methods, 2013. 18(3): p. 301-319.

150. Glaser, B.G. and A.L. Strauss, The discovery of grounded theory : strategies for qualitative research. 1967, Chicago.

151. Goldkuhl, G., Pragmatism vs interpretivism in qualitative information systems research. European Journal of Information Systems, 2012. 21(2): p. 135-146.

152. Lee, A.S. and R.L. Baskerville, Generalizing Generalizability in Information Systems Research. Information Systems Research, 2003(3): p. 221.

153. Yin, R.K., Case study research: design and methods. 4th ed. 2009: SAGE.

154. Tsang, E.W.K. and J.N. Williams, Generalization and Induction: Misconceptions, Clarifications, and a Classification of Induction. MIS Quarterly, 2012. 36(3): p. 729748.

155. Vickers, J., The Problem of Induction, in The Stanford Encyclopedia of Philosophy, E.N. Zalta, Editor. 2013.

156. Smaling, A., Inductive, analogical and communicative generalization. International Journal of Qualitative Methods, 2003. 2(1).

157. Öhlund, S.-E. and R. Wohed, Regelmodellering i praktiken - erfarenheter och resultat från Tempora och modellbaserad kunskapsinhämtning, in TRIAD Modelleringshandboken. 1993, SISU - Svenska Institutet för Systemutveckling.

158. Öhlund, S.-E. ePrescribing implementation in Sweden. in ePrescribing \& Medication Management - International EHTEL Conference 2006. Ljubljana, Slovenia.

159. Winograd, T. and F. Flores, Understanding Computer and Cognition. 1986, Noorwod, NJ: Addison-Wesley. 
160. Stamper, R., et al., Understanding the roles of signs and norms in organization-a semiotic approach to information systems design. Behaviour \& Information Technology, 2000.19(1): p. 15-27.

161. Åstrand, B., et al., The Swedish National Pharmacy Register. Studies in Health Technology and Informatics, 2007. 129: p. 345-349.

162. Åstrand, B., ePrescribing - Studies in Pharmacoinformatics, in School of Pure and Applied Natural Sciences. 2007, University of Kalmar: Kalmar, Sweden. PhD Thesis.

163. Åstrand, B. and B. Hovstadius, Elektronisk recepthantering [Electronic Prescription Management], in Läkemedelsboken 2009-210. 2009, Apoteket AB.

164. Bridell, G. and M. Nordling, Elektronisk recepthantering [Electronic Prescription Management], in Läkemedelsboken 2011-2012. 2011, Läkemedelsverket [Medical Products Agency - Sweden].

165. Nilsson, S., et al., Computer terminal in the physician's office to assist drug prescription. Läkartidningen, 1982. 79(9): p. 760.

166. Nilsson, S., et al. A computer in the physician's consultancy. in MEDINFO 83 Proceedings of the Fourth World Conference on Medical Informatics. 1983. IFIP-IMIA North-Holland Pub.Co., Amsterdam, the Netherlands

167. Åstrand, B. Doctor's use of VDUs for medical prescriptions. in Human-Computer Communications in Health Care, IFIP-IMIA Second Stockholm Conference on Communication in Health Care. 1985. Stockholm: IFIP-IMIA Elsevier Science Publishers B.V. .

168. Anderberg, G., B. Dahlin, and B. Åstrand, Swede*star - ett läkemedelssystem vid Gråbo vårdcentral, in Svensk Farmacevtisk Tidskrift. 1987. p. 20-23.

169. LVFS 1997:10, Läkemedelsverkets föreskrifter om förordnande och utlämnande av läkemedel m.m. (Prescription rules) [In Swedish], in LVFS 1997:10, Medical Products Agency in Sweden, Editor. 1997.

170. Veronin, M., Packaging and Labeling of Pharmaceutical Products Obtained from the Internet. J Med Internet Res, 2011. 13(1): p. e22.

171. Kajbjer, K., R. Nordberg, and G. Klein, Electronic Health Records in Sweden: From Administrative Management to Clinical Decision Support, in History of Nordic Computing 3, J. Impagliazzo, P. Lundin, and B. Wangler, Editors. 2011, Springer Berlin Heidelberg. p. 74-82.

172. Annual Repport 2008. 2008, The Nordic Working Committee for The Assigment of Article Numbers to Pharmaceuticals.

173. CEN, Health informatics - Messages for the exchange of information on medicine prescriptions. ENV 13607. 2000, CEN.

174. Lag (1996:1156) om receptregister, in SFS 1996:1156, S. Riksdag, Editor. 1996, Svensk författningssamling.

175. Uhlin, Å., Brevlåda för e-recept öppnar i dag. Dagens Medicin, 2003.

176. Apoteket; and Stockholm County Council, Sweden - eRecept, an ePrescribing application in eHealth is Worth it -The economic benefits of implemented eHealth solutions at ten European sites, K.A. Stroetmann, et al., Editors. 2006, European Comission - Informations Society and Media: Luxembourg.

177. Lag om ändring i lagen (1996:1156) om receptregister, in SFS 2005:259, S. Riksdag, Editor. 2005, Svensk författningssamling.

178. UN/EDIFACT, MEDPRE 2000 Medical prescription message. 2000, UN/EDIFACT.

179. LVFS 1994:11 Läkemedelsverkets föreskrifter och allmänna råd om läkemedelsförpackningar och märkning av läkemedel, M.P.A.-. Sweden, Editor. 1994. p. 20. 
180. Fallmark, M., NPL - National Repository for Medicinal Products instructions for reviewing and verifying details in the NPL. 2011. p. 30.

181. Lag om läkemedelsförmåner m.m., in SFS 2002:160, S. Riksdag, Editor. 2002, Svensk författningsamling.

182. Lithman, T. and B. Nygren, Rätt organiserat så fungerar recept och förskrivarregistret bra, in Läkartidningen. 1998.

183. Quensel, M., Blir det någon vinst med recept- och förskrivarregister?, in Läkartidningen. 1998.

184. Classon, C. and N. Rehnqvist, Recept på papper snart borta, in Läkartidningen. 1998.

185. Lag (1996:1150) om högkostnadsskydd vid köp av läkemedel m.m., in SFS 1996:1150, S. riksdag, Editor. 1996, Svensk författningssamling.

186. Hammar, T., et al., Patients satisfied with e-prescribing in Sweden: a survey of a nationwide implementation. Journal of Pharmaceutical Health Services Research, 2011. 2(2): p. 97-105.

187. Hammar, T., et al., Swedish pharmacists value ePrescribing: a survey of a nationwide implementation. Journal of Pharmaceutical Health Services Research, 2010. 1(1): p. 23-32.

188. Hellstrom, L., et al., Physicians' attitudes towards ePrescribing - evaluation of a Swedish full-scale implementation. BMC Medical Informatics and Decision Making, 2009. 9.

189. Ohlin, E., Trög start för datateknik vid förskrivning - Läkarna nobbar e-recept trots apotekens beredskap, in Läkartidningen. 2002.

190. Schultz, C.V., Norrbotten bäst på elektroniska recept, in NyTeknik. 2004.

191. Bohlin, C., Enorm ökning när storstäderna går över till e-recept, in Dagens Medicin. 2003.

192. Apoteket AB and Stockholm County Council, Summary of studies of the ETP service (electronically transmitted prescription service) in the county of Stockholm 2005.

193. Bohlin, C., Många läkare vill använda e-recept, in Dagens Medicin. 2003.

194. Söderström, E., N. Eriksson, and R.-M. Åhlfeldt, Managing healthcare information: analyzing trust. International Journal Of Health Care Quality Assurance, 2016. 29(7): p. 786-800.

195. Braa, K. and R. Vidgen, Interpretation, intervention, and reduction in the organizational laboratory: a framework for in-context information system research. Accounting, Management and Information Technologies, 1999. 9: p. 25-47.

196. NEF, Nationellt E-receptformat [In Swedish]. 2007, Apotekens Service AB.

197. SIS, Hälso- och sjukvårdsinformatik - Meddelanden för utbyte av information om läkemedel Guide för svensk implementering av ENV 13607 i XML gällande: Recept/rekvisition - Atterkallande av recept/rekvisition - Information om expedierade läkemedel - Återkallande av information om expedierade läkemedel. 2002, SIS.

198. GS1, EANCOM® 2002 S4 - APERAK Application error and acknowledgement message Edition 2014. 2014, GS1.

199. Remiss: Konsekvensutredning e-recept på läkemedel ska skickas med NPL-identiteter 2013, Apotekens Service.

200. Åstrand, B., et al., Assessment of ePrescription quality: an observational study at three mail-order pharmacies. BMC Med Inform Decis Mak, 2009. 9: p. 8.

201. Ekedahl, A., Problem prescriptions in Sweden necessitating contact with the prescriber before dispensing. Research in Social and Administrative Pharmacy, 2010. 6(3): p. 174-184. 
202. Devine, E.B., et al., The impact of computerized provider order entry on medication errors in a multispecialty group practice. Journal of the American Medical Informatics Association, 2010.17(1): p. 78-84.

203. Wiliam Croft and D.A. Cruse, Cognitive Linguistics. 2004, Cambridge, UK: Cambridge University Press.

204. Langacker, R.W., Cognitive Grammar: A basic Introduction. 2008, Oxford: Oxford University Press.

205. John Dewey and A.F. Bentley, Knowing and the known. 1949.

206. Goldkuhl, G., Actability Criteria for Design and Evaluation: Pragmatic Qualities of Information Systems. International Journal of Information Systems and Social Change, 2011. 2(3): p. 1-15.

207. Searle, J.R., Meaning, communication, and representation. Philosophical grounds of rationality: Intentions, categories, ends, 1986: p. 209-26.

208. Searle, J.R., The Construction of Social Reality. 1995, New York: Free Press.

209. Hindriks, F., Constitutive Rules, Language, and Ontology. Erkenntnis, 2009. 71(2): p. 253-275.

210. Adherence to long-term therapies: evidence for action. 2003, World Health Organization.

211. Ny myndighet för infrastrukturfrågor för vård och apotek, Socialdepartementet, Editor. 2012, Regeringskansliet: Stockholm.

212. Ny myndighet för hälso- och vårdinfrastruktur. Prop. 2012/13:128, Socialdepartementet, Editor. 2013, Regeringskansliet: Stockholm.

213. Ammenwerth, E., et al., The Effect of Electronic Prescribing on Medication Errors and Adverse Drug Events: A Systematic Review. Journal of the American Medical Informatics Association, 2008. 15(5): p. 585-600.

214. Schedlbauer, A., et al., What Evidence Supports the Use of Computerized Alerts and Prompts to Improve Clinicians' Prescribing Behavior? Journal of the American Medical Informatics Association, 2009. 16(4): p. 531-538.

215. Spina, J.R., et al., Potential Safety Gaps in Order Entry and Automated Drug Alerts: A Nationwide Survey of VA Physician Self-Reported Practices With Computerized Order Entry. Medical Care, 2011(10): p. 904.

216. Goldkuhl, G., The many facets of communication - a socio-pragmatic conceptualisation for information systems studies, In Proceedings of the International Workshop on Communication and Coordination in Business Processes, in International Workshop on Communication and Coordination in Business Processes. 2005: Kiruna, Sweden.

217. Goldkuhl, G. and K. Lyytinen. A Language action view of Information Systems. in Third International Conference on Information Systems (ICIS'82). 1982. Ann Arbor, MI, US.

218. Lyytinen, K.J., Implications of Theories of Language for Information Systems. MIS Quarterly, 1985. 9(1): p. 61-74.

219. Nationellt E-receptFormat [In Swedish]. 2007; Available from: http://www.webcitation.org/6E124KFgm.

220. Act (2002:160) on Pharmaceutical Benefits, etc. (Translation). 2002; Available from: http://www.webcitation.org/6MocET3oB.

221. Läkemedelsverket - Medical Products Agency, Vägledning till Läkemedelsverkets föreskrifter (LVFS 2009:13) om förordnande och utlämnande av läkemedel och teknisk sprit 2009.

222. Fass (Boken) - Historik.

2013; $\quad$ Available

from:

http://www.webcitation.org/6Mz3AjRbw. 
223. Törngren, S. and T. Palo, Prescription interventions on the mail-order pharmacy in Boden - an observational study during three weeks, [In Swedish], in Instituionen för Hälsovetenskap. 2006, Luleå Tekniska Högskola: Luleå. BSc Pharm Thesis.

224. Läkemedel - statistik för år 2012 (Pharmaceuticals - statistics for 2012), in Statistik Hälso- och sjukvård. 2013, National Board of Health and Welfare.

225. 2011 Sanningen om läkemedelskostnaderna. 2012, LIF.

226. Law, M.R., et al., Independent Pharmacist Prescribing in Canada. Canadian Pharmacists Journal / Revue des Pharmaciens du Canada, 2012. 145(1): p. 17-23.e1.

227. Searle, J.R., Speech acts. 1969, New York: Cambridge University Press.

228. Habermas, J., The Theory of Communicative Action. 1984, London: Heinemann.

229. Goldkuhl, G., Socio-Instrumental Pragmatism: A Theoretical Synthesis for Pragmatic Conceptualisation in Information Systems, in ALOIS*2005, P. Ågerfalk, L. Bannon, and B. Fitzgerald, Editors. 2005: Limerick, Ireland.

230. Ekedahl, A. and N. Mansson, Unclaimed prescriptions after automated prescription transmittals to pharmacies. Pharmacy World \& Science, 2004. 26(1): p. 26-31.

231. Åstrand, B., et al., Detection of potential drug interactions - a model for a national pharmacy register. European Journal of Clinical Pharmacology, 2006. 62(9): p. 749756.

232. Collins English Dictionary - Complete \& Unabridged 10th Edition. 2017.

233. Goldkuhl, G. and A. Röstlinger, Expanding the scope: From language action to generic practice, in 4th International Workshop on the Language Action Perspective on Communication modelling (LAP'99). 1999: Copenhagen

234. Malone, T.W. and K. Crowston, The Interdisciplinary Study of Coordination. ACM Computing Surveys, 1994. 26(1): p. 87-120.

235. Goldkuhl, G. and P.J. Ågerfalk, Actability: A way to understand information systems pragmatics, in Coordination and Communication Using Signs: Studies in Organisational Semiotics. 2002, Kluwer Academic Publishers: Boston.

236. Goldkuhl, G. and P.J. Ågerfalk, Actability: A way to understand information systems pragmatics, in 3rd International Workshop on organisational semiotics. 2000: Staffordshire University.

237. Falkenberg, E.D., et al., FRISCO - A Framework of Information System Concepts. 1998.

238. Beynon-Davies, P., R. Galliers, and C. Sauer, Business information systems / Paul Beynon-Davies ; consultants: Bob Galliers, Chris Sauer. 2013: New York : Palgrave Macmillan, 2013 2. ed.

239. Barrett, S. and B. Konsynski, Inter-Organization Information Sharing Systems. MIS Quarterly, 1982.6(4): p. 93-105.

240. Martínez-Costa, C., M. Menárguez-Tortosa, and J.T. Fernández-Breis, An approach for the semantic interoperability of ISO EN 13606 and OpenEHR archetypes. Journal of Biomedical Informatics, 2010. 43: p. 736-746.

241. Habermas, J., Towards a Crique of the Theory of Meaning (1988), in On the Pragmatism of Communication. 1998, MIT Press: Cambridge, MA.

242. Bühler, K., Theory of language : the representational function of language. 2011, Amsterdam: John Benjamins Pub. Co.

243. Sinha, C., Cognitive linguistics, psychology and cognitive science. The Oxford handbook of cognitive linguistics, 2005: p. 1-35.

244. Bakeman, R. and L.B. Adamson, Coordinating Attention to People and Objects in Mother-Infant and Peer-Infant Interaction. 1984, University of Chicago Press. p. 1278.

245. Birgitte Nerlich and D.D. Clarke, Cognitive Linguistics and the history of linguistics, in The Oxford Handbook of Cognitive Linguistics, Dirk Geeraerts and H. Cuyckens, Editors. 2007, Oxford University Press: Oxford. p. 589-607. 
246. Fauconnier, G., Pragmatics and Cognitive Linguistics, in The handbook of pragmatics, Laurence R. Horn and G. Ward, Editors. 2004, Blackwell Publishing Ltd.

247. Eriksson, O., A Generic Communication Model based on Habermas and Searles versions of Speech Act Theory, in Proceedings of the fourth International Workshop on the Language Action Perspective on Communication Modelling. 1999: Copenhagen. p. 4358.

248. Eco, U., Semiotics and the philosophy of language. Advances in Semiotics, ed. T.A. Sebeok. 1984.

249. Recanati, F., Literal Meaning. 2004: Cambridge University Press.

250. Harris, R.A., The Linguistics Wars. 1993, New York: Oxford University Press.

251. Jannes Jakob Liszka, Edwin Battistella, and M. Haley, Linguistcis and semiotics II: C.S. Peirce's influence on 20th-century linguistics, in Geschichte der Sprachwissenschaften - History of the Language Sciences, Volume 3 : An International Handbook on the Evolution of the Study of Language from the Beginnings to the Present. 2006, Mouton de Gruyter: Berlin. p. 2589-2599.

252. Ogden, C.K. and I.A. Richards, The Meaning of Meaning. A Study of The Influence of Language upon Thought and of The Science of Symbolism. Sixth ed. 1944, London: Kegan Paul, Trench, Trubner \& CO. LTD.

253. Dewey, J., Peirce's Theory of Linguistic Signs, Thought, and Meaning. The Journal of Philosophy, 1946. 43(4): p. 85-89.

254. Recanati, F., Pragmatics and Semantics, in The handbook of Pragmatics, Laurence R. Horn and G. Ward, Editors. 2004, Blackwell Publishing Ltd: Oxford, UK. p. 442-462.

255. García-Carpintero, M., Recanati on the Semantics/pragmatics Distinction (Recanati sobre la distinción entre semántica y pragmática). 2006, Instituto de Investigaciones Filosóficas, Universidad Nacional Autónoma de México. p. 35.

256. Allwood, J., On the Distinctions between Semantics and Pragmatics. In: Klein. W. \& Levelt, W. "Crossing the Boundaries in Linguistics"; Dordrecht: Reidel Publ. Co., 1981: p. 177.

257. Dewey, J., Experience and nature. 1929, New York: Dover Publications.

258. Lakoff, G. and M. Johnson, Philosophy in the flesh: the embodied mind and its challenges to western thought. 1999, New York: Basic Books.

259. Austin, J.L., How to do things with words. Second Edition ed. 1962, Cambridge, Massachusetts.

260. Searle, J.R., Mind, language and society. 1998, New York: Basic Books.

261. Clark, H.H., Using Language. 1996: Cambridge University Press.

262. Gärdenfors, P., Some Tenets of Cognitive Semantics, in Cognitive Semantcis. 1999, John Benjamins Publishing Company: Philadelphia, USA.

263. Sinha, C., Grounding, Mapping and Acts of Meaning, in Cognitive Linguistics: Foundations, Scope and Methodology, T. Janssen and G. Redeker, Editors. 1999, Mouton de Gruyter: Berlin \& New York. p. 223-255.

264. Gabora, L., E. Rosch, and D. Aerts, Toward an ecological theory of concepts. Ecological Psychology, 2008. 20(1): p. 84-116.

265. Recanati, F., Literalism and Contextualism: Some Varieties, in Contextualism, P. Gerhard, Editor. 2003, Oxford University Press.

266. Michael, R., The Conduit Metaphor: a Case of Frame Conflict in our Language about Language, in Metaphor and Thought, A. Ortony, Editor. 1979, Cambridge University Press: Cambridge.

267. Langefors, B., Essays on Infology, ed. B. Dahlbom. 1995, Lund: Studentlitteratur.

268. Langefors, B., Theoretical analysis of Information Systems. 1966, Lund: Studentlitteratur. 
269. Goldkuhl, G., Information as action and communication, in The Infological equation. Essays in honour of Börje Langefors, B. Dahlbom, Editor. 1995, Gothenburg Studies of Informations Systems, Göteborg University: Gothenburg.

270. Eriksson, 0., The Pragmatic Language Functionality of Information Systems, in Promote IT 2002. 2002: Skövde, Sweden

271. Habermas, J., Truth and Justification. 2003, Cambridge, Massachusetts: MIT Press.

272. Weigand, H., F. van der Poll, and A. de Moor, Coordination through Communication, in 8th International Working Conference on the Language-Action Perspective on Communication Modelling (LAP 2003), H. Weigand, G. Goldkuhl, and A. de Moor, Editors. 2003: Tilburg, The Netherlands, .

273. Malone, T.W. and K. Crowston. What is Coordination Theory and How Can It Help Design Cooperative Work Systems. in Conference on Computer Supported Cooperative Work. 1990. Los Angeles.

274. Williamson, O.E., The Economics of Organization: The Transaction Cost Approach. American Journal of Sociology, 1981. 87(3): p. 548.

275. Mintzberg, H., The Structuring of Organizations. 1979, Engelwood Cliffs: Prentice Hall.

276. Ylva, B., et al. Ompröva föreskriften om 'obs' vid off label-förskrivning. Läkartidningen, 2015.

277. epSOS: Home. 2013; Available from: http://www.webcitation.org/6ECVgbvXt.

278. Kecskes, I. and F. Zhang, On the Dynamic Relations Between Common Ground and Presupposition, in Perspectives on Linguistic Pragmatics, A. Capone, F. Lo Piparo, and M. Carapezza, Editors. 2013, Springer International Publishing. p. 375-395.

279. Kecskes, I., The paradox of communication: Socio-cognitive approach to pragmatics. Pragmatics and Society, 2010. 1(1): p. 50-73.

280. Kecskes, I. and F. Zhang, Activating, seeking, and creating common ground: A sociocognitive approach. Pragmatics \&amp; Cognition, 2009. 17(2): p. 331-355.

281. Kecskes, I., Dueling contexts: A dynamic model of meaning. Journal of Pragmatics, 2008. 40(3): p. 385-406.

282. Tomasello, M., et al., Understanding and sharing intentions: the orgins of cultural cognition. Beahvioral and Brain Sciences, 2005(28): p. 675-735.

283. Eriksson, 0., Kommunikationskvalitet hos informationssystem och affärsprocesser, in Institutionen för datavetenskap. 2000, Linköpings universitet: Linköping. PhD Thesis.

284. Sjöström, J. and G. Goldkuhl, The semiotics of user interfaces - a socio-pragmatic perspective, in 6th International Workshop on Organisational Semiotics. 2003: Reading

285. Ågerfalk, P. and O. Eriksson, Socio-Instrumental Usability: IT Is All About Social Action. Information Technology, 2006. 21.

286. Basili, V., G. Caldiera, and H.D. Rombach, Goal Question Metric Paradigm, in Encyclopedia of Software Engineering. 1994, John Wiley \& Sons, Inc. p. 528-532.

287. Wangler, B., R. Wohed, and S.-E. Ohlund, Business Modelling and Rule Capture in a CASE Environment, in 4th European workshop on the Next Generation of CASE-Tools. 1993: Paris.

288. Reeves, C.A. and D.A. Bednar, Defining Quality: Alternatives and Implications. Academy of Management Review, 1994. 19(3): p. 419-445.

289. Walsh, P., Finding key performance drivers: Some new tools. Total Quality Management, 1996. 7(5): p. 509-519.

290. Basili, V. and F. McGarry, The experience factory. Proceedings of the 19th International Conference: Software Engineering, 1997: p. 643. 
291. Provan, K.G. and P. Kenis, Modes of Network Governance: Structure, Management, and Effectiveness. Journal of Public Administration Research \& Theory, 2008. 18(2): p. 229-252.

292. Jones, C., W.S. Hesterly, and S.P. Borgatti, A general theory of network governance: Exchange conditions and social mechanisms. Academy of Management Review, 1997. 22(4): p. 911-945.

293. Raab, J., Heading toward a society of networks: Empirical developments and theoretical challenges. 2009, 2009.

294. Markus, M.L. and Q.N. Bui, Going Concerns: The Governance of Interorganizational Coordination Hubs. Journal of Management Information Systems, 2012. 28(4): p. 163.

295. Hoetker, G. and T. Mellewigt, Choice and performance of governance mechanisms: matching alliance governance to asset type. Strategic Management Journal, 2009. 30(10): p. 1025-1044.

296. Brito, J., Sending Out an S.O.S.: Public Safety Communications Interoperability as a Collective Action Problem. Federal Communications Law Journal, 2007. 59(3): p. 457492.

297. Grandori, A., An Organizational Assessment of Interfirm Coordination Modes. Organization Studies (Walter de Gruyter GmbH \& Co. KG.), 1997. 18(6): p. 897.

298. Olson, M., The logic of collective action: public goods and the theory of groups. Harvard economic studies: 124. 1965: Harvard University Press.

299. Reimers, K., R.B. Johnston, and S. Klein, An empirical evaluation of existing IS change theories for the case of IOIS evolution. Eur J Inf Syst, 2013.

300. Porra, J., Colonial Systems. Information Systems Research, 1999. 10(1): p. 38-69.

301. King, N., Exploring the impact of operating model choice on the governance of interorganizational workflow: the U.S. e-prescribing network. European Journal of Information Systems, 2013. 22(5): p. 548-568.

302. Friedman, M.A., A. Schueth, and D.S. Bell, Interoperable electronic prescribing in the United States: a progress report. Health Affairs (Project Hope), 2009. 28(2): p. 393403.

303. Bell, D.S. and M.A. Friedman, E-Prescribing And The Medicare Modernization Act Of 2003. Health Affairs, 2005. 24(5): p. 1159-1169.

304. Gabriel, M. and M. Swain, E-Prescribing Trends in the United States, in ONC Data Brief. 2014, Office of the National Coordinator for Health Information Technology: Washington DC.

305. Surescripts, 2014 National Progress Report. 2015.

306. Gabriel, M.E., M.F. Furukawa, and V. Vaidya, Emerging and encouraging trends in eprescribing adoption among providers and pharmacies. Am J Manag Care, 2013. 19(9): p. 760-4.

307. Ross, J.W., P. Weill, and D.C. Robertson, Enterprise architecture as strategy. creating a foundation for business execution. 2006: Boston, Mass. : Harvard Business School, 2006.

308. Jerlvall, L. and T. Pehrsson, eHälsa i Landstingen Oktober 2010. 2010, Inera.

309. Weill, P. and J. Ross, A matrixed approach to designing IT governance. MIT Sloan Management Review, 2005. 46(2): p. 26-34.

310. Weill, P. and J.W. Ross, IT governance : how top performers manage IT decision rights for superior results. 2004: Boston, Mass. : Harvard Business School, 2004.

311. Hendrickx, H., Governance in IT and Architecture: Recommendation for TOGAF. 2010, The Open Group: San Francisco.

312. Official ITIL® website. 2014; Available from: http://www.itil-officialsite.com/.

313. ITIL ${ }^{\circledR}$ Glossary of Terms English v.1.0, A.L. 2011, Editor. 2011. 
314. Steinberg, R., et al., ITIL Service Operation. 2011, TSO: UK.

315. Reimers, K. and R.B. Johnston, Explaining Persistence and Resilience of Interorganisational Information Systems: Theoretical and Methodological Considerations, in 16th European Conference on Information Systems. 2008: Galway, Ireland.

316. Goldkuhl, G., The socio-pragmatics of organisational knowledge: An inquiry of managing eldercare knowledge, in First Scandinavian Workshop on e-Government. 2004: Örebro University, Sweden.

317. Hepler, C.D. and L.M. Strand, Opportunities and responsibilities in pharmaceutical care. American Journal Of Hospital Pharmacy, 1990. 47(3): p. 533-543.

318. Tengblad, S., Om managementteori. 2000. p. 36.

319. Rhodes, R.A.W., The new governance: Governing without government. Political Studies, 1996. 44(4): p. 652-667.

320. Ring, P.S. and A.H. van de Ven, Structuring cooperative relationships between organizations. Strategic Management Journal, 1992. 13(7): p. 483-498.

321. Meier, J., The importance of relationship management in establishing successful interorganizational systems. The Journal of Strategic Information Systems, 1995. $4(2)$ : p. 135-148.

322. Wenger, E., Communities of Pratice. Learning as a Social System. Systems Thinker, 1998.

323. Porter, M.E., Competitive advantage : creating and sustaining superior performance / Michael E. Porter. 2004: New York; London : Free Press, 2004 New ed.

324. Winner, R., et al., The role of concurrent engineering in weapons system acquisition. 1988, Institute for Defense Analysis.

325. Forsberg, T., Process orientation and measurements, in Department of Mechanical Engineering. 1998, Linköping university: Linköping. Licentiate Thesis.

326. Hamilton, A.G., Logic for Mathematicians. 1978, Cambridge: Cambridge University Press.

327. Clark, H.H. and S.E. Brennan, Grounding in communication, in Perspectives on socially shared cognition., L.B. Resnick, J.M. Levine, and S.D. Teasley, Editors. 1991, American Psychological Association: Washington, DC US. p. 127-149.

328. Ågerfalk, P.J. and O. Eriksson. Pragmatisation of Conceptual Modelling. in Information Systems and the future of the Digital Economy, Xth Europan Conference of Information Systems (ECIS 2002). 2002. Gdansk, Poland.

329. United Nations, International Standard Industrial Classification of All Economic Activities, Rev.4. 2008. 